Kalle A. Piirainen (ed.), Kimmo Halme, Tomas Åström, Neil Brown, Martin Wain, Kalle Nielsen, Xavier Potau, Helka Lamminkoski, Vesa Salminen, Janne Huovari, Henri Lahtinen, Hanna Koskela

Erik Arnold, Patries Boekholt, Helene Urth

\title{
How can the EU Framework Programme for Research and Innovation increase the economic and societal impact of RDI funding in Finland?
}

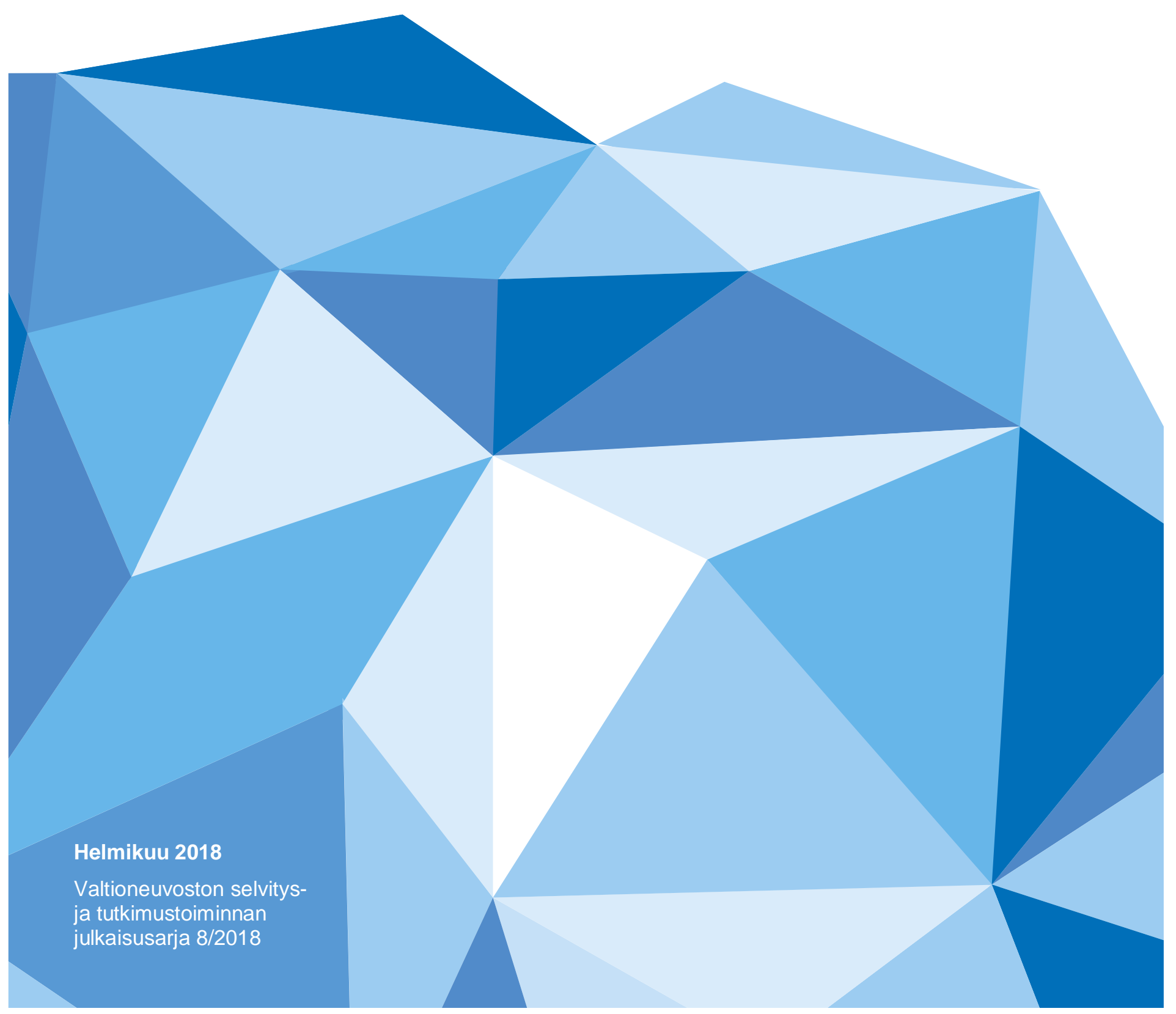




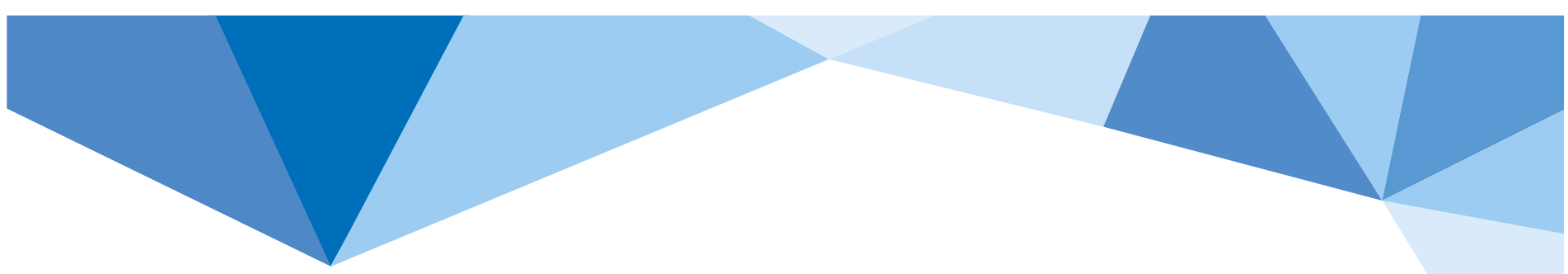

\section{KUVAILULEHTI}

\begin{tabular}{ll}
\hline Julkaisija ja julkaisuaika & Valtioneuvoston kanslia, 15.2.2018 \\
\hline Tekijät & $\begin{array}{l}\text { Kalle A. Piirainen (editor), Kimmo Halme, Tomas Åström, Neil Brown, } \\
\text { Martin Wain, Kalle Nielsen, Xavier Potau, Helka Lamminkoski, Vesa } \\
\text { Salminen, Janne Huovari, Anti Kekäläinen, Henri Lahtinen, Hanna } \\
\text { Koskela, Erik Arnold, Patries Boekholt, Helene Urth }\end{array}$ \\
\hline Julkaisun nimi & $\begin{array}{l}\text { EU:n tutkimuksen ja innovoinnin puiteohjelman vaikuttavuus } \\
\text { Suomessa }\end{array}$ \\
\hline $\begin{array}{l}\text { Julkaisusarjan nimi ja } \\
\text { numero }\end{array}$ & $\begin{array}{l}\text { Valtioneuvoston selvitys- ja tutkimustoiminnan julkaisusarja 8/2018 } \\
\text { Asiasanat }\end{array}$ \\
$\begin{array}{l}\text { Tutkimus, kehitys ja innovaatiotoiminta, TKI-politikka, Euroopan } \\
\text { Unioni, Tutkimuksen ja innovoinnin puiteohjelma, Horisontti 2020 }\end{array}$ \\
$\begin{array}{l}\text { Julkaisun osat/ } \\
\text { muut tuotetut versiot }\end{array}$ \\
$\begin{array}{l}\text { for Research and Innovation increase the economic and societal } \\
\text { impact of RDI funding in Finland?, 8/2018 Key Results }\end{array}$ \\
\hline \begin{tabular}{l} 
Julkaisuaika \\
\hline
\end{tabular}
\end{tabular}

\section{Tiivistelmä}

Tämä selvitys käsittelee Euroopan Unionin Tutkimuksen ja innovoinnin puiteohjelman tuottamaa lisäarvoa ja tapoja, joilla puiteohjelman vaikuttavuutta Suomessa voidaan parantaa.

Hanketasolla puiteohjelmista saadulla rahoituksella on selkeä lisäarvo osallistujille, ja rahoitusta saaneet osallistujat ovat hyvin tyytyväisiä kokemuksiinsa ja hankkeiden tuloksiin. Keskimäärin puiteohjelmista rahoitetut hankkeet ovat tuottaneet uutta tietoa ja uusia taitoja sekä tukeneet kansainvälisten verkostojen syntymistä ja uuden teknologian kehittämistä.

Yleistasolla, Suomen rahoituksen saanto puiteohjelmasta ylittää laskennallisen maksuosuuden, mutta haasteena on, että suomalaisten hakemusten hyväksymisprosentti on suhteellisen alhainen muihin Pohjois-Euroopan pieniin tietotalouksiin verrattuna. Keskeiset suositukset arvioinnin perusteella ovat:

1. Työtä jatkettava EU-puiteohjelmayhteistyön kansallisten painopistealueiden ja tavoitteiden kirkastamiseksi

2. Analysoidaan suomalaisen hakumenestyksen juurisyyt

3. Tuki- ja tehostamistoimia hakemusten laadun ja relevanssin vahvistamiseen

4. Hakemus- ja hankeosaamisen tehokkaampi hyödyntäminen

Tämä julkaisu on toteutettu osana valtioneuvoston vuoden 2017 selvitys- ja tutkimussuunnitelman toimeenpanoa (tietokayttoon.fi).

Julkaisun sisällöstä vastaavat tiedon tuottajat, eikä tekstisisältö välttämättä edusta valtioneuvoston näkemystä. 


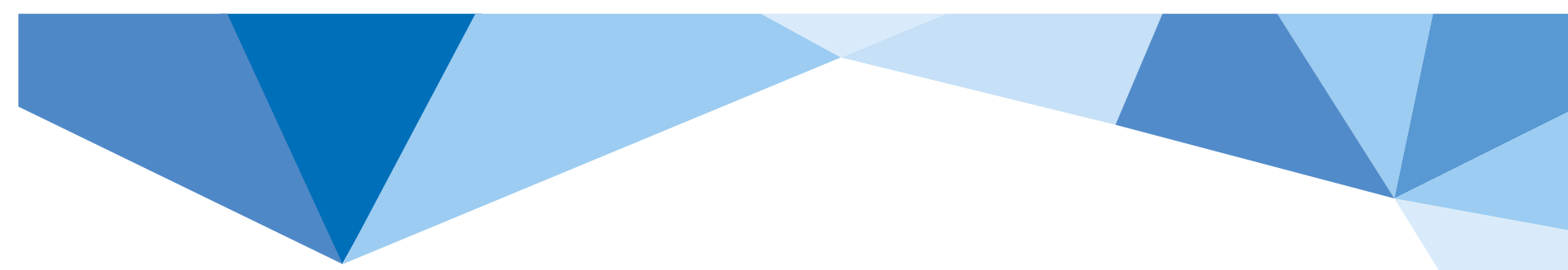

\section{PRESENTATIONSBLAD}

\begin{tabular}{ll}
\hline Utgivare \& utgivningsdatum & Statsrådets kansli, 15.2.2018 \\
\hline Författare & $\begin{array}{l}\text { Kalle A. Piirainen (editor), Kimmo Halme, Tomas Åström, Neil Brown, } \\
\text { Martin Wain, Kalle Nielsen, Xavier Potau, Helka Lamminkoski, Vesa } \\
\text { Salminen, Janne Huovari, Anti Kekäläinen, Henri Lahtinen, Hanna } \\
\text { Koskela, Erik Arnold, Patries Boekholt, Helene Urth }\end{array}$ \\
\hline Publikationens namn & $\begin{array}{l}\text { Hvor kan EU:s ramprogram for forskning og innovation ge mervärde till } \\
\text { Finsk innovationspolitk? }\end{array}$ \\
\hline $\begin{array}{ll}\text { Publikationsseriens namn } \\
\text { och nummer }\end{array}$ & $\begin{array}{l}\text { Publikationsserie för statsrådets utrednings- och forskningsverksamnet } \\
8 / 2018\end{array}$ \\
\hline Nyckelord & $\begin{array}{l}\text { Forskning, innovation, Europeisk Unioninen, Ramprogram för } \\
\text { forskning og innovation, Horizon 2020 }\end{array}$ \\
\hline $\begin{array}{l}\text { Publikationens delar /andra } \\
\text { producerade versioner }\end{array}$ & $\begin{array}{l}\text { 8/2018 Policy Brief, 8/2018 How can the EU Framework Programme } \\
\text { for Research and Innovation increase the economic and societal } \\
\text { impact of RDI funding in Finland?, 8/2018 Key Results }\end{array}$ \\
\hline Utgivningsdatum & 15.2.2018 Sidantal 216 \\
\hline
\end{tabular}

\section{Sammandrag}

Denna studie undersöker vilka slags förmåner som har erhållits från EU:s ramprogram och hur Finlands deltagande kan understödjas ytterligare. Överlag ger ramprogrammet ett tydligt mervärde till de finländska deltagarna och de är generellt mycket nöjda med sina erfarenheter och resultatet av sin medverkan. I de flesta fall har fördelarna av deltagandet överskridit den gjorda investeringen. Projekten har bidragit till att generera ny kunskap, kompetens, internationella nätverk och teknisk utveckling.

Utvärderingen föreslår:

1. En tydlig nationell FUI-strategi gentemot EU och ramprogrammen

2. Analys av grundorsaken till den låga godkännandegraden

3. Starkare stödåtgärder för medverkan i ramprogram

4. Erkännande av spetskompetens och spridning av bästa praxis

Den här publikation är en del i genomförandet av statsrådets utrednings- och forskningsplan för 2017 (tietokayttoon.fi/sv).

De som producerar informationen ansvarar för innehållet i publikationen. Textinnehållet återspeglar inte nödvändigtvis statsrådets ståndpunkt 


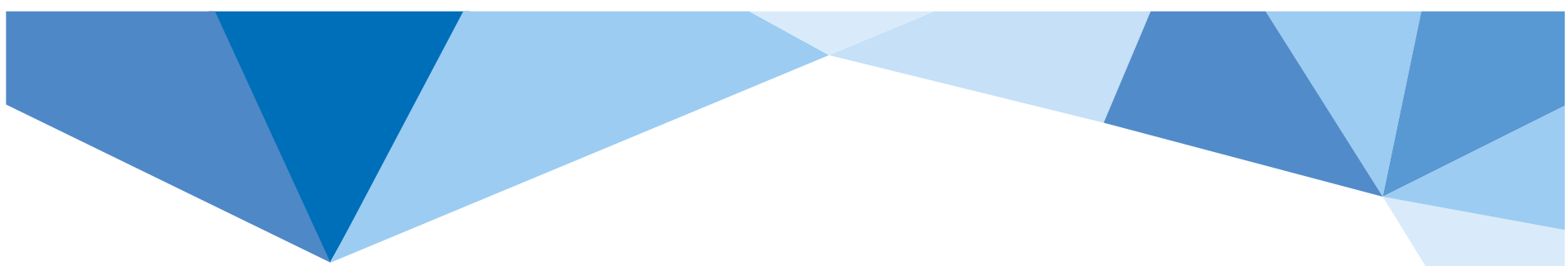

\section{DESCRIPTION}

\begin{tabular}{ll}
\hline Publisher and release date & Prime Minister's Office, 15.2.2018 \\
\hline Authors & Kalle A. Piirainen (editor), Kimmo Halme, Tomas Åström, Neil Brown, \\
& Martin Wain, Kalle Nielsen, Xavier Potau, Helka Lamminkoski, Vesa \\
& Salminen, Janne Huovari, Anti Kekäläinen, Henri Lahtinen, Hanna \\
& Koskela, Erik Arnold, Patries Boekholt, Helene Urth
\end{tabular}

Title of publication

How can the EU Framework Programme for Research and Innovation increase the economic and societal impact of RDI funding in Finland?

Name of series and number of publication

Publications of the Government's analysis, assessment and research activities 8/2018

Keywords

Research, development and innovation, innovation policy, European Union, Framework Programme for Research and Innovation, Horizon 2020

Other parts of publication/ other produced versions

8/2018 Policy Brief, 8/2018 How can the EU Framework Programme for Research and Innovation increase the economic and societal impact of RDI funding in Finland?, 8/2018 Key Results

\begin{tabular}{llll}
\hline Release date & 15.2.2018 Pages $216 \quad$ Language EN
\end{tabular}

\section{Abstract}

Long-term objectives of Finnish research and innovation policy. One objective of the current government is to improve the quality and effectiveness of research and innovation. This study examines what kinds of benefits have been obtained from EU Framework Programmes and how Finnish participation can be further supported.

Overall, the FP provides clear added value for Finnish participants, and they are generally very satisfied with their experience and the results of participation. The projects have contributed to generating new knowledge, skills, international networks and technology development.

Finland's share of the total funding drawdown is larger than the calculated share of payments towards the FP, but the challenge is that Finnish proposal acceptance rate is relatively weak compared to other Northern European small advanced economies. The evaluation proposes:

1. A clear national RDI strategy towards the EU and FPs

2. Analysis of the root cause of low application success rate

3. Strengthening the support measures for FP participation

4. Leverage best practices in FP application and participation

This publication is part of the implementation of the Government Plan for Analysis, Assessment and Research for 2017 ( tietokayttoon.fi/en).

The content is the responsibility of the producers of the information and does not necessarily represent the view of the Government. 


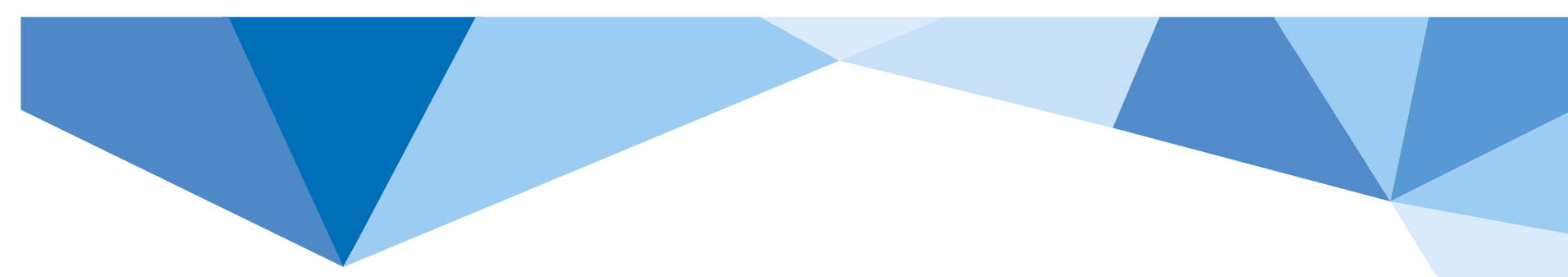

\section{TABLE OF CONTENTS}

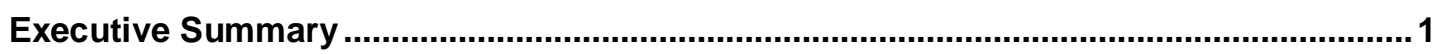

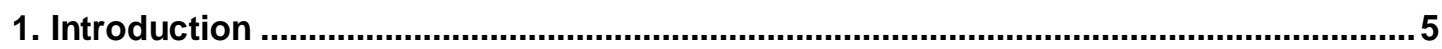

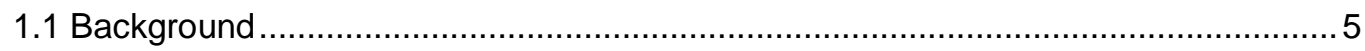

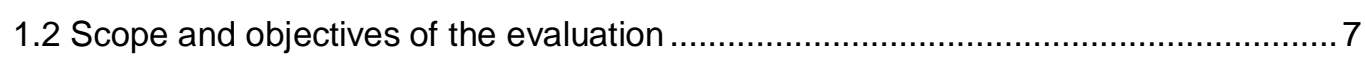

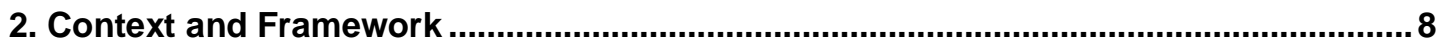

2.1 European research and innovation policy and the role of Horizon 2020 .................. 8

2.2 Previous evaluations European Framework Programmes and Horizon 2020 ......... 12

2.3 Previous national evaluations of FPs .............................................................. 16

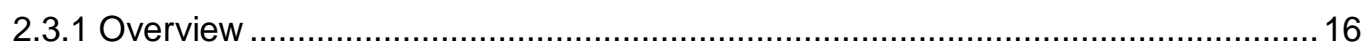

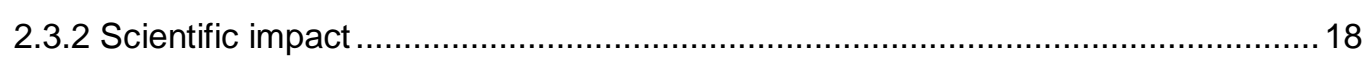

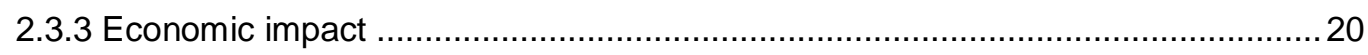

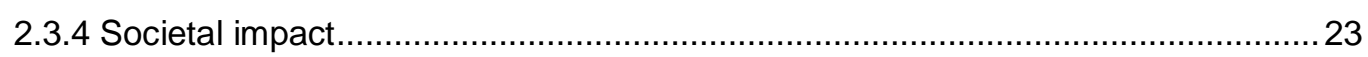

2.4 Status of Finnish participation in Horizon 2020 ................................................... 24

2.5 A framework for evaluating the impact of Horizon 2020 in Finland ..........................25

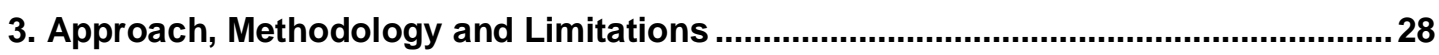

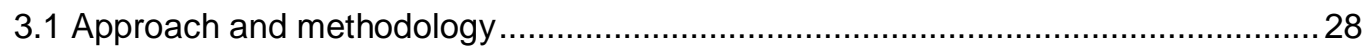

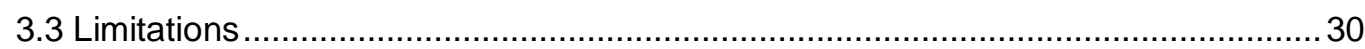

4. Assessment of Finnish Participation in EU Framework Programmes........................32

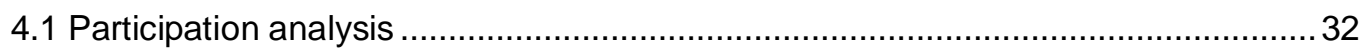

4.1.1 Overview to participation and success of Finnish applicants ............................... 32

4.1.2 Participation in projects and proposal success rate ............................................. 35

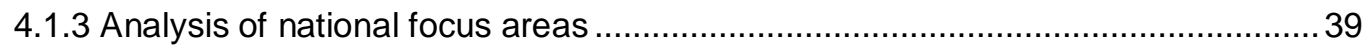

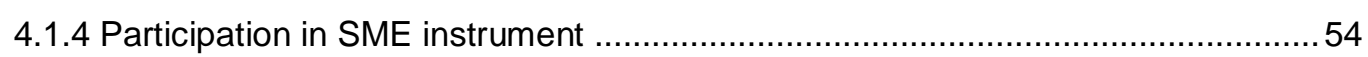

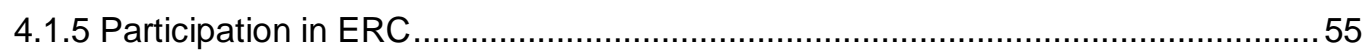

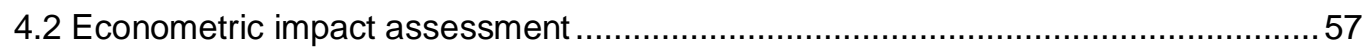

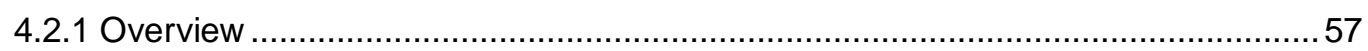

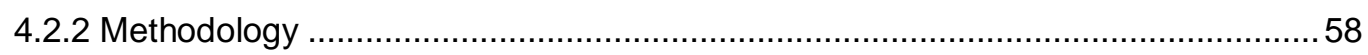

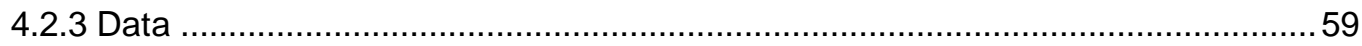

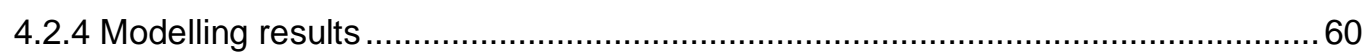




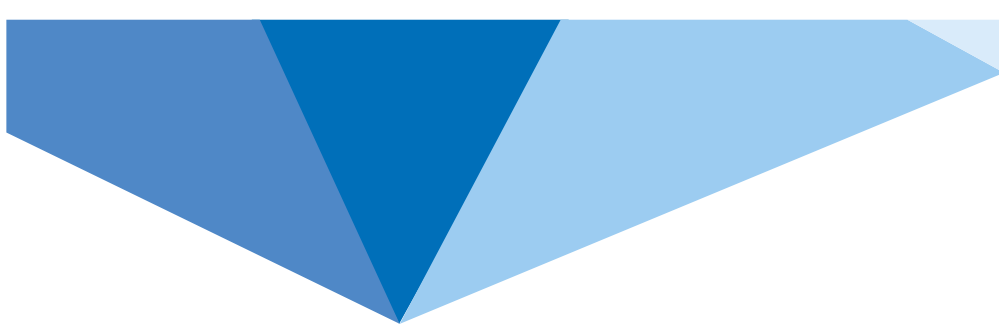

4.2.5 Findings

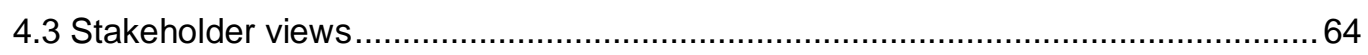

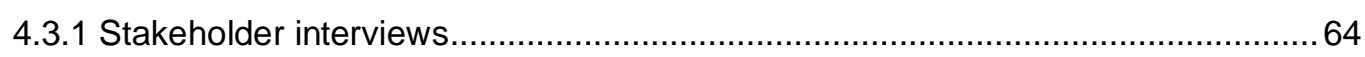

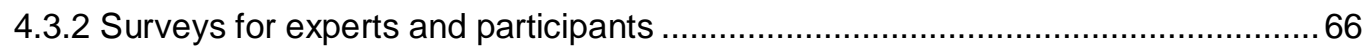

4.4 Finnish ecosystems in Horizon 2020 - case studies........................................ 71

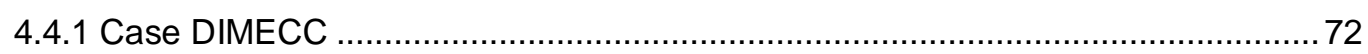

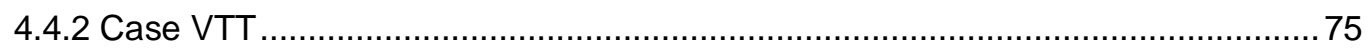

4.4.3 Case Inverse Problems Centre of Excellence ................................................ 81

4.5 Support measures for Horizon 2020 participation .................................................... 85

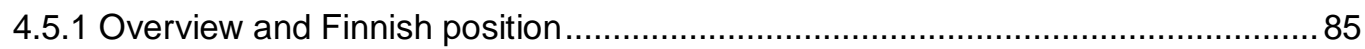

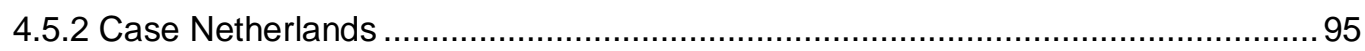

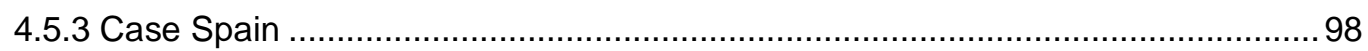

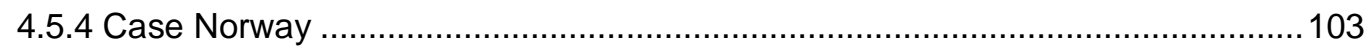

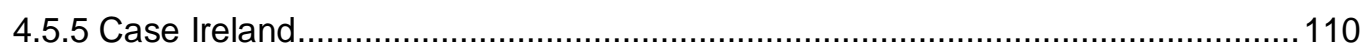

4.5.6 Best practices for supporting FP participation - lessons for the Finnish context 117

5. Conclusion and Recommendations ........................................................................121

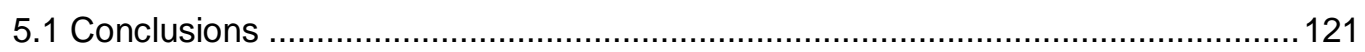

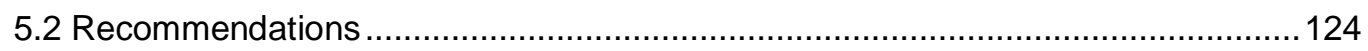

References .............................................................................................................. 127

Appendix A: Detailed Participation Analysis ..............................................................130

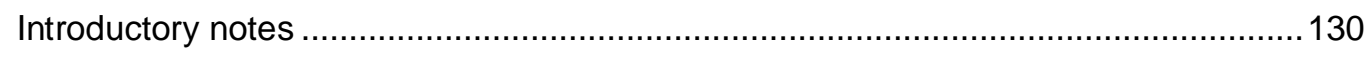

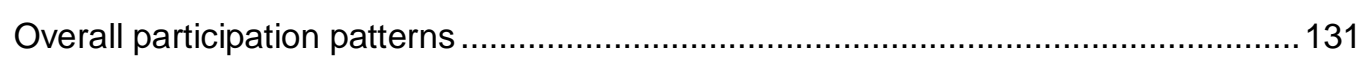

Participation in proposals......................................................................... 131

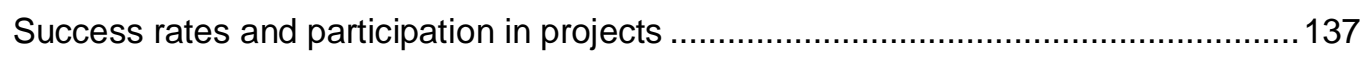

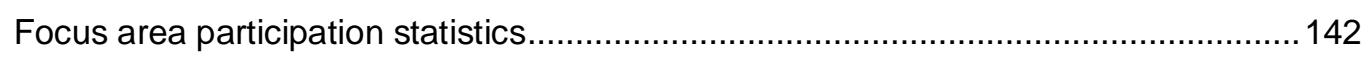

Finnish participation in the area of Health \& Wellbeing within FP7 and Horizon 2020146

Success rates and participation in Health \& Wellbeing projects ............................... 149

Finnish participation in the area of Cleantech, Bioeconomy and Circular economy

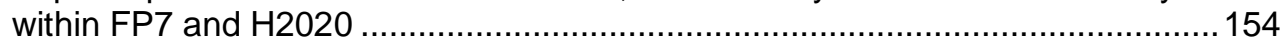

Success rates and participation in CBC projects ............................................ 157

Finnish participation in area of Digitalisation within FP7 and H2020 ....................... 161

Success rates and participation in Digitalisation projects .................................... 165

Longitudinal analysis of participation and success rates......................................... 169

Rates of participation and success over time - overall ......................................... 169 


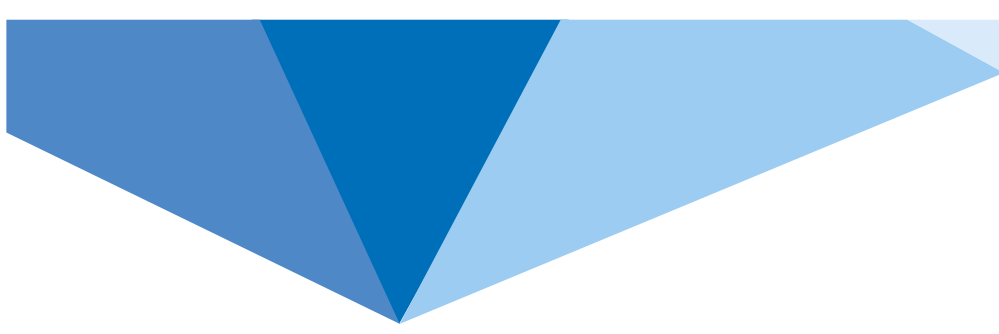

Rates of participation and success over time - in the H\&W area 171

Rates of participation and success over time - in the CBC area .............................173

Rates of participation and success over time - in the Digitalisation area ...................175

Participation in the SME instrument ..................................................................... 177

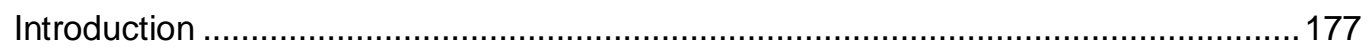

Overall participation in H2020 SME Instrument .................................................... 178

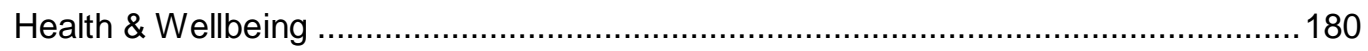

Cleantech, Bioeconomy and Circular Economy ….............................................. 182

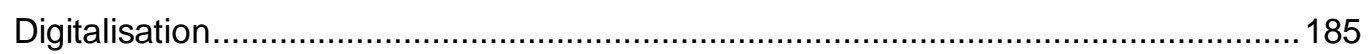

Participation in European Research Council (ERC) activities ....................................187

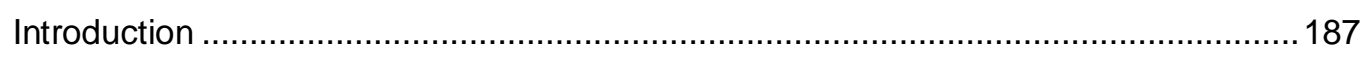

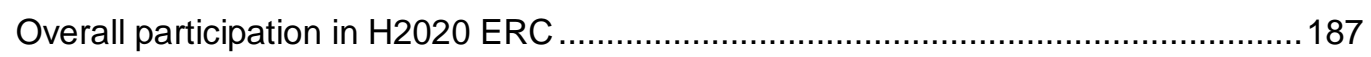

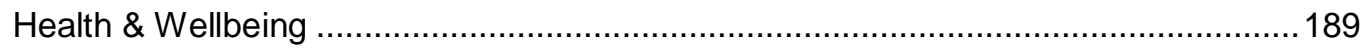

Cleantech, Bioeconomy and Circular Economy ….............................................. 190

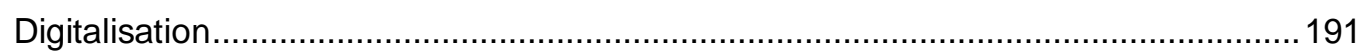

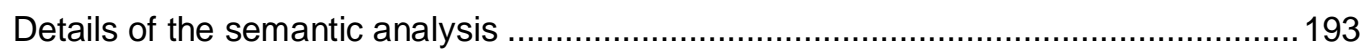

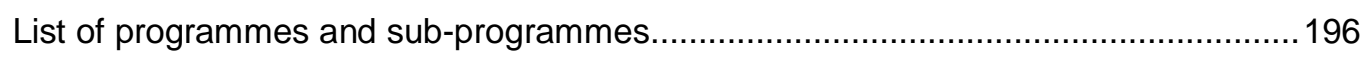

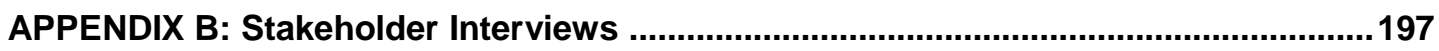

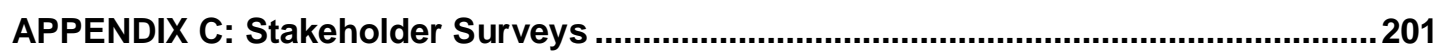

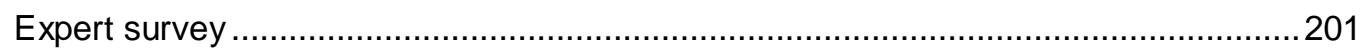

The added value of framework programmes........................................................201

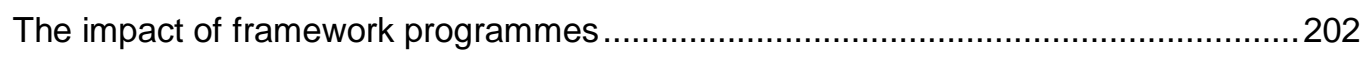

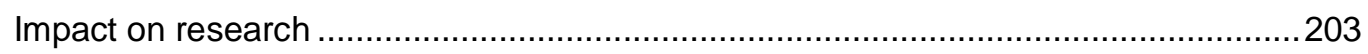

Impact on private sector and international competitiveness ...................................204

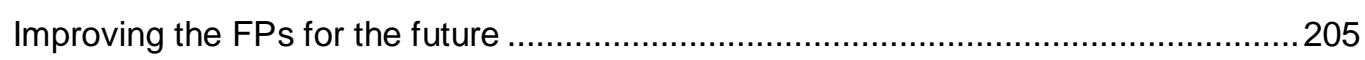

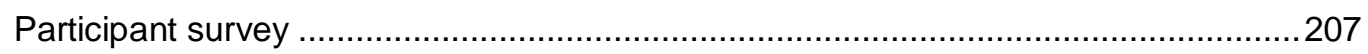

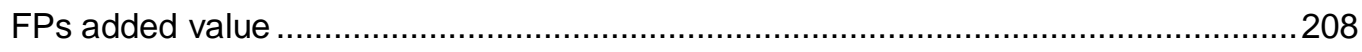

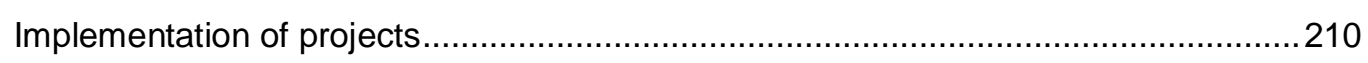

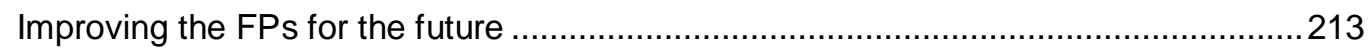

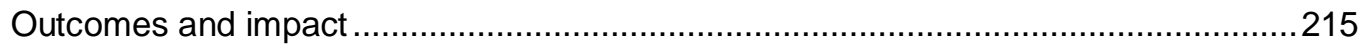




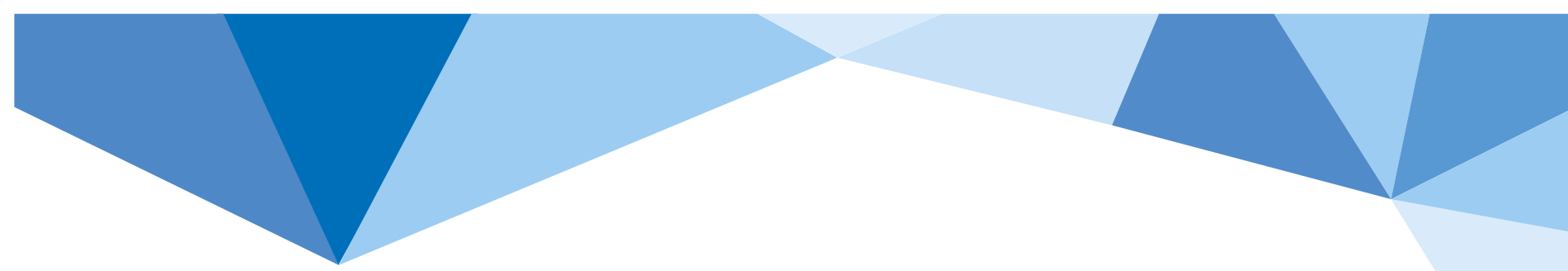

\section{ACRONYMS AND ABBREVIATIONS}

$\begin{array}{ll}\text { CBC } & \text { Cleantech, Bio-economy and Circular Economy } \\ \text { CDTI } & \text { Centro para el Desarrollo Tecnológico Industrial } \\ \text { CIP } & \text { Competitiveness and Innovation Framework Programme } \\ \text { DIMECC } & \text { Digital, Internet, Materials \& Engineering Co-Creation } \\ \text { EC } & \text { European Commission } \\ \text { EIB } & \text { European Investment Bank } \\ \text { EIC } & \text { European Innovation Council } \\ \text { EIF } & \text { European Investment Fund } \\ \text { EIT } & \text { European Institute of Innovation and Technology } \\ \text { EU } & \text { European Union } \\ \text { ERA } & \text { European Research Area } \\ \text { ERAC } & \text { European Research Area Committee } \\ \text { ERC } & \text { European Research Council } \\ \text { ERDF } & \text { European Regional Development Fund } \\ \text { EFSI } & \text { European Fund for Strategic Investments } \\ \text { FET } & \text { Future and Emerging Technologies } \\ \text { FiCEIP } & \text { Finnish Centre of Excellence for Inverse Problems Research } \\ \text { FP } & \text { Framework Programme } \\ \text { FP7 } & \text { the 7th Framework Programme for research and Innovation } \\ \text { GDP } & \text { Gross Domestic Product } \\ \text { H2O20 } & \text { Horizon 2020 - The EU Framework Programme for Research and Innovation } \\ \text { HES } & \text { Higher or Secondary Education } \\ \text { H\&W } & \text { Health and Wellbeing } \\ \text { ICT } & \text { Information and Communication Technology } \\ \text { IN } & \text { Innovation Norway } \\ \text { JTI } & \text { Joint Technology Initiative } \\ \text { KIC } & \text { Knowledge and Innovation Communities } \\ \text { NCP } & \text { National Contact Point } \\ \text { OECD } & \text { Organisation for Economic Co-operation and Development } \\ \text { OTH } & \text { Others } \\ \text { PPI } & \text { Public Procurement of Innovative solutions } \\ \text { PPP } & \text { Public-Private Partnership } \\ \text { PRC } & \text { Private Corporation/Enterprise } \\ \text { PUB } & \text { Public Body } \\ \text { RCN } & \text { Research Council of Norway } \\ \text { SME } & \text { small and medium-sized enterprise } \\ \text { SMEI } & \text { SME instrument } \\ \text { RDI } & \text { Research, Development, and Innovation } \\ \text { REC } & \text { Research Organisation } \\ \text { R\&D } & \text { Research and Development } \\ \text { R\&I } & \text { Research and Innovation } \\ \text { RVO } & \text { Rijksdienst voor Ondernemend Nederland } \\ \text { SFI } & \text { Science Foundation Ireland } \\ \text { VTT } & \text { The Technical Research Centre of Finland } \\ \text { WP } & \text { Work Package } \\ & \end{array}$




\section{EXECUTIVE SUMMARY}

\section{Background and objectives}

One objective of the current government is to improve the quality and effectiveness of research and innovation. At the same time, the competition over domestic funding, particularly among universities and research institutions, has increased. Partially to address this issue the Research and Innovation Council - an advisory body to the Government - has set an objective for Horizon 2020 to increase $50 \%$ the funding received under the $7^{\text {th }}$ Framework Programme for research and Innovation (FP7).

The purpose of this evaluation is to assess the national added value of EU Framework Programmes. This is being addressed with the following research questions:

1. What kinds of benefits have been obtained to date particularly from the Horizon 2020 programme?

2. What parts of the programme and forms of activity are best for a small economy like Finland, also in relation to National priorities?

3. What kind of social, economic or environmental impacts are perceptible/achievable with the programme or with Finnish projects funded from it?

4. What has been the financial performance of businesses that received funding from EU framework programmes?

5. What kind of innovation effects have arisen from projects of research institutes and universities that received funding from EU framework programmes?

6. How should, for example, EU preparatory and co-funding and the role of national funding organisations be further developed?

What kind of conclusions relating to effectiveness are available from comparable countries?

\section{The Role of FPs and Finnish participation}

Determined investment into research and innovation are at the core of EU policies for sustainable growth and competitiveness, and the EU Framework Programmes (FPs) for research and innovation are the main delivery mechanisms of those policies. The FP is seen as a tool for the renewal of industry and society, and a booster for economic growth at the European level, which is well aligned with Finnish Research Development and Innovation policy.

Over time, every new FP has brought an increase in the volume of available EU funding and a variety of instruments for research and innovation. Horizon 2020 has taken particularly large steps in this direction. The budget has been increased to nearly $€ 80$ billion, and its objectives are more directly linked to EU's societal and industrial challenges. It also made a significant attempt to better address the needs of SMEs (through the new SME instrument) and the highest standard academic research (ERC).

With its considerably larger budget and new instruments, the Horizon 2020 has become increasingly attractive to all kinds of research organisations. When at the same time most European countries have faced a series of cuts in national RDI budgets, the popularity of Horizon 2020 has further increased. This has in turn resulted in higher application volumes for Horizon 2020, and consequently lower average success rates than in previous FPs. 
Finnish organisations have been among the more active ones to apply for Horizon 2020. By the end of May 2017, there had been nearly 7,000 proposals with Finnish participations. This equates to $5.4 \%$ of all proposals submitted to the programme during this period, and is slightly lower than was in FP7 (6.1\%).

Finnish success rate remains at an average, or even slightly below the average level, when compared to similar types of economies including Sweden, Denmark, Austria, Norway, Ireland and The Netherlands. Due to relatively large application volumes, Finland's total funding drawdown (€579 million) is still larger than its calculated share of payments towards the FP.

However, closer analysis reveals a more nuanced picture. By some measures, such as EC contribution per thousand research personnel and EC contribution compared to Finnish contribution to FPs, Finland fares even better than the comparison group. On the other hand, the weakness in Finland is the success rate of applications, which is consistently at the low end of the comparison group. Finnish actors are active in applying for funding, but total participation trails behind owing to relatively low proposal quality.

\section{Key facts about Finnish participation in Horizon 2020}

\begin{tabular}{|c|c|c|c|c|}
\hline & \multirow[b]{2}{*}{ All } & \multirow[b]{2}{*}{ Multi-partner } & \multicolumn{2}{|c|}{ Single applicant ${ }^{\star}$} \\
\hline & & & $\begin{array}{l}\text { SME Instrument } \\
(1 \& 2)^{\star}\end{array}$ & $\begin{array}{c}\text { ERC } \\
(\text { Pillar I)* }\end{array}$ \\
\hline $\begin{array}{l}\text { Number of } \\
\text { applications }\end{array}$ & $\begin{array}{l}6,986 \\
(5.4 \% \text { of total })\end{array}$ & $\begin{array}{l}4,796 \\
(10.9 \% \text { of total })\end{array}$ & $\begin{array}{l}1,137 \\
(3.1 \% \text { of total })\end{array}$ & $\begin{array}{l}758 \\
(3.2 \% \text { of total })\end{array}$ \\
\hline Number of projects & $\begin{array}{l}893 \\
(6.0 \% \text { of total })\end{array}$ & $\begin{array}{l}711 \\
(13.1 \% \text { of total })\end{array}$ & $\begin{array}{l}83 \\
(3.1 \% \text { of total) }\end{array}$ & $\begin{array}{l}63 \\
(1.9 \% \text { of total })\end{array}$ \\
\hline Success rate & $\begin{array}{l}12.8 \% \\
\text { (8.7\% for coordinators) } \\
(16.2 \% \text { for partners })\end{array}$ & $15 \%$ & $7.1 \%$ & $8.4 \%$ \\
\hline $\begin{array}{l}\text { Number of } \\
\text { Finnishcoordinations }\end{array}$ & $\begin{array}{l}278 \\
(31 \% \text { of FI projects) }\end{array}$ & $\begin{array}{l}96 \\
\text { (14\% of } \mathrm{FI} \text { projects) }\end{array}$ & $\begin{array}{l}79 \\
(95 \% \text { of } \mathrm{FI} \\
\text { projects })\end{array}$ & $\begin{array}{l}62 \\
\text { (98\% of } \mathrm{FI} \\
\text { projects) }\end{array}$ \\
\hline $\begin{array}{l}\text { EC Contribution to } \\
\text { Finnish participants }\end{array}$ & $\begin{array}{l}€ 579 \text { million } \\
\text { (2.2\% of total, } € 450 \mathrm{k} \\
\text { per participation) }\end{array}$ & $\begin{array}{l}€ 410 \text { million } \\
\text { ( } 2.1 \% \text { of total, } € 371 \mathrm{k} \text { per } \\
\text { participation) }\end{array}$ & $\begin{array}{l}€ 56 \text { million } \\
(5.1 \% \text { of total, } \\
€ 670 \mathrm{k} \text { per } \\
\text { participation }\end{array}$ & $\begin{array}{l}€ 103 \text { million } \\
(2.0 \% \text { of total, } \\
€ 1.6 \mathrm{~m} \text { per } \\
\text { participation })\end{array}$ \\
\hline
\end{tabular}

* Technically SMEI and ERC are not single-partner, but most projects involve a single participant, who is thereby a coordinator

Overall, the FPs provide clear added value for Finnish participants, and they are generally very satisfied with their experience and the results of participation. In most cases the benefits of participation have exceeded the investment. The projects have contributed to generating new knowledge, skills, international networks and technology development.

The direct economic impact is tentatively positive, although the margin of error in the analysis is large. FP funding in isolation has a similar economic impact to national RDI funding. According to the survey, for most participants the economic benefits from the projects are greater than the sums invested. Among the chief benefits are increased knowledge and development of new technologies. These are followed by new products and services. In terms of social impacts participants have found a noticeable or strong contribution to employment and an even stronger contribution towards solving social challenges.

In a broader perspective, greater benefits have been reaped through national ecosystems, which spread the knowledge generated and acquired in FP projects within the national 
framework. The ecosystem cases demonstrate how consistent investment in particular technology areas by different types of actors creates new research and business opportunities, and also supports renewal of incumbent enterprises.

\section{Recommendation 1: Continue to elaborate a clear national RDI strategy towards the EU and FPs}

The stakeholders strongly suggested that a clear national FP strategy be elaborated. It is therefore recommended that further work is done to clarify the national focus areas in relation to present and future FPs, and to enable the stakeholders to position themselves towards the national goals. The strategy work should further clarify the vision, priorities and targets for FP participation, including what are the specific goals for the participation in terms of science, industry and society, and what is the ambition level in terms of drawdown and application success. A well-communicated and participatory strategy process would increase the awareness of, and commitment to national priorities amongst various stakeholders, and hence facilitate for more synchronised and effective implementation. Lastly, it is important that the implementation of the strategy is regularly monitored with participation statistics, etc., to ensure its effectiveness.

\section{Recommendation 2: Analyse the root cause of low application success rate}

One of the key findings of the evaluation is that the Finnish application success rate is lower than expected, and therefore further work is needed to address the exact cause before design of new instruments or actions. Systematic analysis of evaluation feedback, applications and consortia is needed to form a complete picture what is the general quality level of applications and distribution of scores, and reasons for low and high scores. For example, whether the framework programme is able to attract internationally most competent researchers and research organisations, what are the compositions of typical consortia with Finnish participants, and what is the technical and substance quality of applications, in order to identify the strengths and weaknesses of the Finnish applications.

There are several suggested and conceivable reasons why Finnish application success is lower than expected. These hypotheses include, among others, the lack of skills in application writing, lack of appropriate partners, and lack of substance/competence. One level deeper, lack of potential partners may be, again, because of lack of international orientation, because Finnish actors may not be viewed as potential partners, lack European added value, and so on. Understanding which of these or other factors are significant in affecting evaluation of Finnish applications is a key for finding the right problem to address and subsequently the right instruments when trying to raise application success rate.

\section{Recommendation 3: Strengthen the support measures for FP participation}

The present NCP activity is very well-rated; however, the challenge is its lack of resources to fully commit to the work. In some of the comparison countries NCPs engage in finding potential applicants especially in the national focus areas, consortium building and application development, and track down near misses for another round of submission. Which is something that would likely help address the Finnish challenges.

In broader view, the path from national funding instruments to FP needs to be further examined. Based on the evidence, the largest benefits come from projects that relate to existing national RDI activity and programming. In the past, some of the best results have been achieved when national instruments have acted as accelerators towards the FP. However, again national funding should not pose a disincentive for applying EU funding. 
There is as much evidence that parallel/concurrent national programmes lower the interest in FPs as there is for the finding that sequential national programmes enable attracting FP funding. Thus, it is recommended to examine the synchronicity between content themes and timing of future national programming and ecosystem policy and the FP to enables growing a mass of potential participants.

Another layer is at the level of individual applicant. There are some suggestions that some actors already try to identify potential future applicants early when actors start using national funding. This should be developed further, so that desk officers in Tekes and Academy routinely assess future European potential of their clients and direct them towards relevant information and experts.

However, the support system should not be an end unto itself. Each type of instrument and action have a specific purpose and impact logic. Thus, it is recommended that the reasons why Finnish applications fail are carefully studied. While at the moment the hypothesis is that the Finnish problem is quality of applications, and the instruments should target consortium building and application writing, this may change in the future and there should be a feedback system to systematically gather information about application volume and acceptance rate and monitor the application quality i.e. evaluation feedback of the application to enable proactive redirection of support activities.

\section{Recommendation 4: Leverage best practices in FP application and participation}

Participation activity and application success in the framework programmes do not spread evenly across all organisations. It is the largest research organisations, top universities and knowledge-intensive companies that take the major share of all Finnish participations and also demonstrate higher success rates with proposals. These organisations often have a long record of professional research, high overall volumes of research and a history of international research collaboration. More importantly, they have accumulated vast amounts of experience and practice from participating in EU framework programmes - understanding how to identify relevant themes and topics, which kind of partners to look for, how to organise proposal preparation, how to write successful proposal, and how to manage and coordinate projects successfully, etc.

In the interest of increasing the overall level of participation success, this accumulated competence and practices should be leveraged as much as possible. Our largest public research organisations, such as VTT, already act as a major FP application hub and project coordinator for many other organisations. Similar trends should be encouraged and expanded to other organisations as well. 


\section{INTRODUCTION}

\subsection{Background}

One objective of the current government is to improve the quality and effectiveness of research and innovation. This is particularly essential in a situation where there have been budget cuts in research, development, and innovation (RDI) funding to balance government budgets.

Finland has a long history of investing into $R \& D$ and education, which is well reflected in our international standing with regard to competitiveness and innovation, among others. There were steady increases in both private and public R\&D investments for several decades, until the early 2000s. Accordingly, Finland has ranked among the top innovative countries in input indicators and framework conditions, such as investment in RDI, education levels, general technology readiness. ${ }^{1}$

Over the past decade however, the R\&D investments have decreased and the Finnish competitiveness has been quickly deteriorating. In 2016 Finland's gross expenditure on R\&D decreased by $€ 145$ million to $2.8 \%$ of GDP, as compared to the peak of $3.8 \%$ in 2009 . The estimate for the year 2017 is $2.7 \%$. The lack of funds has also been reflected in the decreasing number of researchers.

These decreases have been mainly due to the cuts in the private sector, most of which concern specifically the ICT industry as one of the dominant enterprises underwent a major crisis. Despite the decline, the R\&D intensity of Finland remains among the highest in the EU and globally among advanced economies, and outside ICT industry the general trend of private R\&D expenses has been on a slight rise. Within the EU, Finland remains as one of the innovation leaders.

However, looking at some of the innovativeness and competitiveness indicators more closely, e.g. the World Economic Forum indicators; while the overall ranking has stayed high, specifically the indicators that relate to innovation have been declining for some time. ${ }^{2}$ Also in general, Finland is coming back from a decade-long economic regression and stagnation, that was set off by the financial crisis but has perhaps more importantly been driven also changes in the structure of the economy. When looking at outcomes, in terms of industrial productivity Finland compares to other Northern European advanced economies, and Finnish universities perform mostly averagely as found in The Academy of Finland's science panel. ${ }^{3}$

The shortage of private and public $R \& D$ funding has strongly increased the competition for domestic funding, particularly among universities and research institutions whose direct government funding has been cut. In this respect, the availability of increasing amounts of EU framework funding should have offered a welcome alternative for national funding. Accordingly, the Research and Innovation Council (RIC) - an advisory body to the Government - set a goal for Finland to increase funding received from Horizon 2020 - The

${ }^{1}$ World Economic Forum, 2017

2 Pajarinen, Rouvinen and Ylhäinen, 2017

${ }^{3}$ Suomen Akatemia, 2016 
Framework Programme for Research and Innovation 50\% compared with that obtained under the $7^{\text {th }}$ Framework Programme for research and Innovation (FP7). According to the latest figures, Finland is on track to meet this objective of being a net recipient of Framework Programme (FP) funding, although competition is intensifying.

Furthermore, during 2017 there has been a clear upturn in the Finnish economy, and this is likely to be reflected in both private and public investments to research and innovation. After nearly a decade of contraction, in 2017 the economy is growing again. In 2017, the year-onyear growth of GDP has been 2.7-3.0\% and most growth forecasts have been revised upwards. The Bank of Finland forecasts continuing GDP growth also for the coming years.

Current Government's objectives. Despite the overall R\&D budget cuts, the vision of Prime Minister Sipilä's Programme is to improve the quality and effectiveness of research and innovation activity and for education and research to become more international. The Government Programme includes a number of specific 'key projects' linked to these objectives. Key project five states that cooperation between higher education institutions and business life will be strengthened to bring innovations to the market. It also includes a measure, in which "public and private resources will be drawn upon to put in place highimpact strategic projects and promote a national division of duties in RDI efforts by employing the measures outlined in the multiannual process of intensified cooperation between, for example, universities and research institutes as well as the EU's Horizon 2020 research and innovation programme, the European Regional Development Fund (ERDF) and the European Fund for Strategic Investments (ESFI)."

OECD Review on Finnish innovation system. During 2016-2017 OECD carried out a country review of Finnish research and innovation system. The review was released in June 2017. One of the key outcomes and recommendations of the review concerns internationalisation of Finnish business and research. This is not the first time the concern has been raised. In their review, OECD states that "internationalisation of firms and access to global markets is paramount to enhance innovation activity and firm growth". There are few foreign researchers in Finland, as scope for improvement with regard to international research cooperation. The research landscape is fragmented and needs better governance, among others. The government proposal for 2018 budget states that this OECD review sets the guidelines for government R\&I policy for the next few years.

Relevance and timing of this exercise. In respect of the OECD Country Review, among others, there is a need to properly analyse the Finnish participation on the Horizon 2020 (and whether it can be increased) to support the internationalisation of Finnish research overall. Although Finnish participation in Horizon 2020 is at a relatively good level, there is an interest to make the best of the available funding, particularly when national RDI budgets have been on a lowering trend. At the same time, the planning of the next FP - its approach, structures and key themes - has already started and Finland needs a clear mission with sufficient facts and evidence. It is increasingly important to ensure that the next funding programme is built so that expertise arising from national funding as well as financial and societal impact can be leveraged effectively. In addition, it is necessary to identify what has been the value added of RDI activity taking place via framework programmes in terms of the Government Programme's strategic RDI issues important for Finland, as well as from the perspective of the OECD evaluation to be completed. 


\subsection{Scope and objectives of the evaluation}

General relevance. The core actors (Ministry of Economic Affairs and Employment, Ministry of Education and Culture, Academy of Finland and Tekes) of the national Horizon 2020 network, coordinated by the Ministry of Employment and the Economy, conducted a survey for the Horizon 2020 programme's Finnish National Contact Points (NCPs) and committee members in autumn 2016, which analysed Finnish success factors and benefits in the framework programmes and particularly in the Horizon 2020 programme now under way. The survey also considered in an indicative way what should be retained from Horizon 2020 for the next framework programme and what should be changed. This has created a foundation for the consideration of Finland's strategic starting points in the preliminary preparatory phase of the next EU Framework Programme for Research and Innovation. The most important benefits highlighted by the survey relate to the following impacts: extensive networking with international excellence, rapid access to international markets, significant increase in funding for small and medium-sized enterprises (SMEs), creation of new panEuropean lead markets, and forecasting and identifying global challenges and creating innovative solutions for them in collaboration with the best experts.

Based on the survey and a discussion session arranged in December 2016, it has been perceived necessary to deepen the knowledge base on the benefits and effectiveness obtained by Finns from the framework programmes also with the aid of econometric analysis. In addition, it is timely to review and evaluate the Horizon 2020 programme's revised, instruments, processes and their linkage to national RDI activities, other EU funding instruments and the development of the European Research Area (ERA). The study should also review effectiveness and utility assessments of key comparable countries by linking to the ad hoc effectiveness evaluation group operating under the ERAC (European Research Area Committee) and utilising the different forms of effectiveness defined therein, and also to the "ERA in Action" work of the EU's RDI Liaison Offices. Analysis, assessment and impact information like this is important for building a Finnish position for the proposals of the next framework period.

Besides a general review of the Finnish participation in the Horizon 2020 and its impacts, this evaluation has a specific research perspective to assess the complementarity of EU Framework Programmes to the national RDI funding. This is being addressed with the following research questions:

1. What kinds of benefits have been obtained to date particularly from the Horizon 2020 programme?

2. What parts of the programme and forms of activity are best for a small economy like Finland, also in relation to National priorities?

3. What kind of social, economic or environmental impacts are perceptible/achievable with the programme or with Finnish projects funded from it?

4. What has been the financial performance of businesses that received funding from EU framework programmes?

5. What kind of innovation effects have arisen from projects of research institutes and universities that received funding from EU framework programmes?

6. How should, for example, EU preparatory and co-funding and the role of national funding organisations be further developed?

7. What kind of conclusions relating to effectiveness are available from comparable countries? 


\section{CONTEXT AND FRAMEWORK}

\subsection{European research and innovation policy and the role of Horizon 2020}

European research and innovation policy trends. Horizon 2020 has its roots wellconnected to the recent research and innovation policy development of Europe. In 2010 EU adopted its latest strategy framework, the Europe 2020 Strategy, which set the main lines (i.e. Smart Growth, Sustainable Growth and Inclusive Growth) also for research and innovation in Europe. In particular, much higher emphasis was given to strengthening research and innovation both in the Member States, but particularly collaboration at the European level. The major policy shift was the introduction of the European Research Area (ERA) at this juncture. Two years after, in 2012, the reinforced ERA put more emphasis on a number of more specific issues in European research and innovation collaboration, and also introduced the 3\% R\&D target for EU. The Jobs, Growth and Investment Package in 2014 brought the European Digital Single Market, emphasised Energy Union and a forwardlooking climate change policy in Europe.

Introduction of Horizon 2020 in 2014. Horizon 2020 was designed to drive economic growth and create jobs by coupling research and innovation (R\&I), with an emphasis on excellent science, industrial leadership and tackling societal challenges. The general objective was to contribute to the EU's overarching jobs and growth strategy by: helping to build a society and an economy based on knowledge and innovation across the Union; by leveraging additional research, development and innovation funding; and by contributing to attaining R\&I targets, including the target of $3 \%$ of GDP for R\&I across the Union by 2020 .

Horizon 2020, the EU Framework Programme for Research and Innovation (2014-2020), is unique in the world in terms of its scale, duration and scope. It pursues ambitious objectives, including jobs, growth and better lives for Europe's citizens, through stronger science, technological leadership and the tackling of societal challenges. ${ }^{4}$

Within the European policy context, the Europe 2020 strategy for smart, sustainable and inclusive growth, the Innovation Union initiative and the European Research Area (ERA) are responses to the recognised challenges including low growth, insufficient innovation, and a diverse set of environmental and social challenges that Europe faces. Science and innovation are considered as key factors leading Europe towards smart, sustainable, inclusive growth, and towards tackling the pressing societal challenges. Horizon 2020 emerged as a single strategic framework integrating research and innovation (R\&I) activities and became the largest ever EU R\&I programme with almost $€ 80$ billion funding available for 2014-2020. It has three strategic objectives; 1 ) raising and spreading the levels of excellence in the research base, 2) tackling major societal challenges, and 3) maximizing competitiveness impacts of research and innovation. The Horizon 2020 is structured around these three priorities and the selection of programme activities and instruments is also driven by these priorities. ${ }^{5}$

${ }^{4}$ Interim Evaluation of Horizon 2020, European Commission 2017 (introductory statement by Commissioner Carlos Moedas)

5 European Commission (2011). Commission staff working paper. Executive summary of the impact assessment. Brussels, 30.11.2011. SEC(2011) 1428 final. Volume 1.

http://ec.europa.eu/research/horizon2020/pdf/proposals/horizon_2020_impact_assessment_report_executive_summary.pdf\#view=fit\&pagemode=none; 


\section{Structure of Horizon 2020}

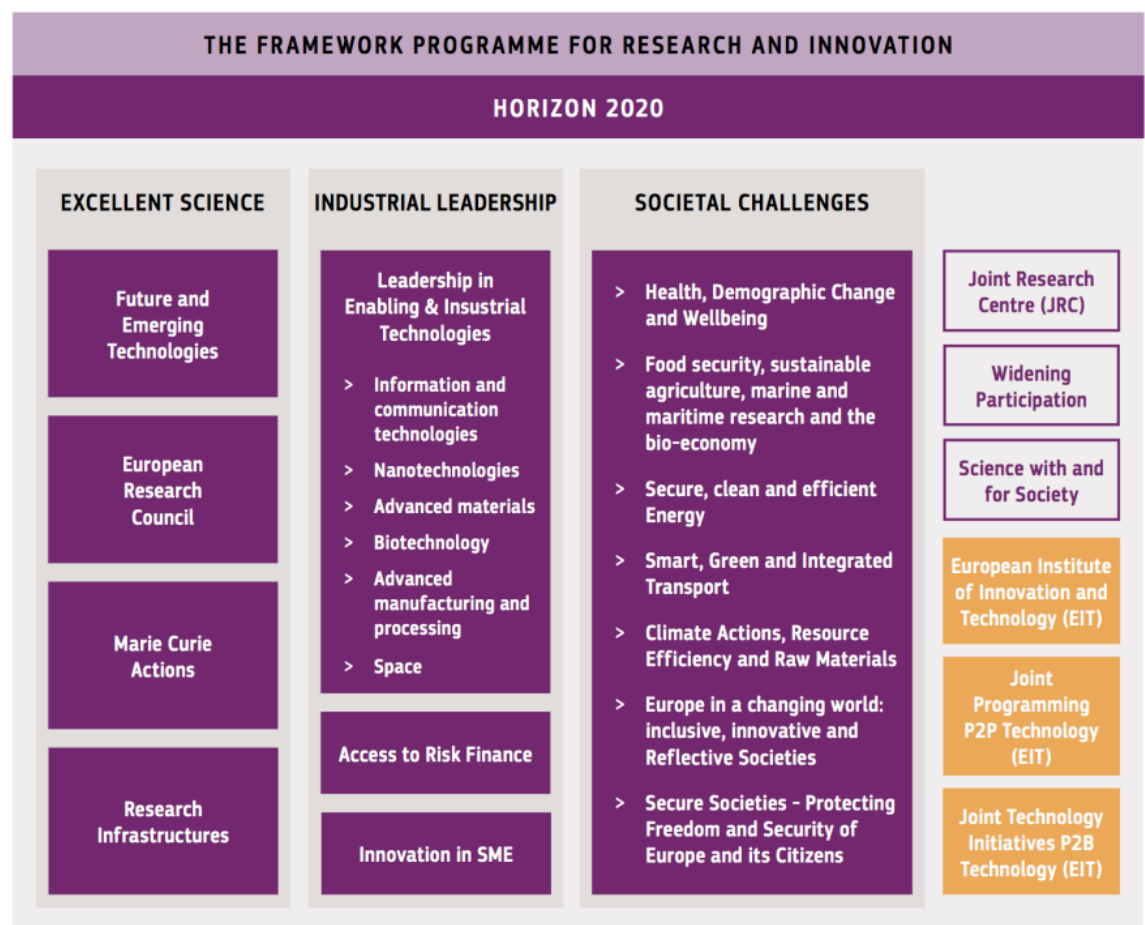

Source: Interim evaluation of Horizon 2020, EC 2017.

Activities of Horizon 2020 are focused on three mutually reinforcing Key Priorities (also called Pillars); 1) Excellent science, 2) Industrial Leadership, 3) Societal Challenges, with two additional priorities 4) Spreading Excellence \& Widening Participation, and 5) Science with and for Society. ${ }^{6}$ In addition, these are complemented by cross-cutting activities related to social sciences and humanities and innovation pilots, as well as direct non-nuclear actions of JRC and activities within the European Institute of Innovation and Technology. These five work programmes are further divided into specific recognised challenges and measures. $^{7}$

Horizon 2020 is open to everyone, but different action types exist defining the expected outcome and for whom specific activities under each work programme are directed; ${ }^{8}$

- Research and innovation actions (RIA) aim to tackle clearly defined challenges with a result of new knowledge or a new technology. Funding is directed to consortia of partners from different countries, industry and academia.

- Innovation actions (IA) are more focused on closer-to-the-market activities, for example through prototyping, testing, demonstrating, piloting, scaling-up etc. Funding for such activities is directed to consortia of partners from different countries, industry and academia.

- $\quad$ Coordination and support actions (CSA) are specifically for the coordination and networking of $R \& I$ projects for which the project funding is covered

European Commission (2014). Horizon 2020 in brief - The EU Framework Programme for Research \& Innovation. ISBN: 978-92-79-33057-5 http://ec.europa.eu/programmes/horizon2020/sites/horizon2020/files/H2020_inBrief_EN_FinalBAT.pdf

${ }^{6}$ European Commission (2011) Horizon 2020 - The Framework Programme for Research and Innovation, Communication from the Commission to the European Parliament, the Council, the European Economic and Social Committee and the Committee of the Regions, COM(2011) 808 final, European Commission 2017 Interim Evaluation of HORIZON 2020, DG-RESEARCH

${ }^{7}$ European Commission (2014)

${ }^{8}$ European Commission (2014); European Commission. Horizon 2020 sections. https://ec.europa.eu/programmes/horizon2020/en/h2020-sections (visited 20171019) 
from another source. This type of funding is to single entities or consortia of partners from different countries, industry and academia.

- $\quad$ Frontier research grants - ERC are for projects that are assessed on the criterion of scientific excellence in any field of research, carried out by a single national or multinational research team led by a so called principal investigator. ERC funding is meant for excellent young and early-career researcher, already independent researchers and senior research leaders with any nationality and field of research.

- $\quad$ Support for training and career development - Marie Skłodowska-Curie Actions (MSCA) are for international research fellowships in the public or private sector, research training and staff exchanges. Funding is directed to both experienced and early stage researchers of any nationality, technical staff, and national/regional research mobility programmes.

- $\quad$ SME instrument (SMEI) aims to develop innovative SMEs growth potential and offers lump sums for feasibility studies, grants for an innovation project's main phases, including demonstration, prototyping, testing and application development, and facilitated access to debt and equity financial instruments to support the commercialisation phase of innovation projects. Funding is available only for SMEs both single and consortia of SMEs established in an EU or associated country. ${ }^{9}$

Fast track to innovation pilot (FTI) is a bottom-up measure that was launched in 2015 to promote trans-disciplinary, cross-sectoral and close-to-themarket innovation activities in any area of technology and to any kind of innovation actor to work together and deliver innovations onto the market and/or into society.

In addition, Public-Private Partnerships (PPP) are supported through joint undertakings called Joint Technology Initiatives (JTIs) that are active in a number of areas of strategic importance for the EU (such as fuel cells and hydrogen, bio-based industries and electronics manufacturing) and through contractual PPPs (such as The Factory of the Future, Green Vehicles, Robotics). Programme co-fund actions supplement individual calls or programmes, such as calls for proposals between national research programmes (ERA-NET co-fund), pre-commercial public procurements or public procurement of innovative solutions (PCP-PPI co-fund) and mobility programmes (Marie Skłodowska-Curie co-fund).

An action of the European Institute of Innovation and Technology (EIT) functions to integrate higher education, research and innovation through the Knowledge and Innovation Communities (KICs), which supports long-term vision based partnerships run by a business logic and results-oriented approach with a focus on achieving economic and social impact. ${ }^{10}$ The Commission has co-financed the establishment of public procurers' networks through the previous framework programme (FP7) and now co-finances public procurers from different European countries through Horizon 2020 and CIP to undertake together PPIs on topics of common interest. ${ }^{11}$ The Future \& Emerging Technologies (FET) programme functioned already within the FP7. It invests in transformative frontier research and innovation with a high potential impact on technology to benefit the economy and Europe-wide society. Within the Horizon 2020 framework the FET forms a part of the 'Excellent science' Pillar. ${ }^{12}$ As a part of the innovation agenda, the Commission has founded

\footnotetext{
${ }^{9}$ As of 1 January 2017, the associated countries are: Iceland, Norway, Albania, Bosnia and Herzegovina, the former Yugoslavian Republic of Macedonia Montenegro, Serbia, Turkey, Israel, Moldova, Switzerland, Faroe Islands, Ukraine, Tunisia, Georgia, Armenia. (European Commission. Associated Countries. http://ec.europa.eu/research/participants/data/ref/h2020/grants manual/hi/3cpart/h2020-hi-list-ac en.pdf )

${ }^{10}$ European Commission (2014).

${ }^{11}$ European Commission (2017). Public Procurement of Innovative Solutions. DG CONECT. 9 May 2017 https://ec.europa.eu/digital-singlemarket/en/public-procurement-innovative-solutions

${ }^{12}$ European Commission (2017). Future \& Emerging Technologies (FET). DG CONNECT. 28 August 2017. https://ec.europa.eu/digital-singlemarket/en/policies/future-and-emerging-technologies (visited 20171019)
} 
European Innovation Council (EIC) for the last period of Horizon 2020 (2018-2020), to pilot joint implementation of SMEI, FTI, and FET-Open ${ }^{13}$.

To enable companies and organisations to gain easier access to risk finance, the InnovFin - EU Finance for Innovators offers financing tools and advisory services covering the entire value chain of research and innovation. InnovFin is a joint initiative launched by the European Investment Bank and the European Commission under the Horizon 2020 pillar for 'Industrial Leadership'. European Investment Bank (EIB) and the European Investment Fund (EIF) have also an important role in implementing financial instruments in partnership with the European Commission by providing loans and guarantees as well as technical assistance and advisory services. ${ }^{14}$ To support the knowledge transfer and exchange of information thematic conferences and events ${ }^{15}$ are organised within the Horizon 2020 framework and advisory groups and independent experts ${ }^{16}$ assist and advice the Commission in connection with the Horizon 2020.

\section{Key changes introduced in Horizon 2020, as compared to FP7 ${ }^{17}$}

- A single programme for all EU-managed R\&I funding, with a single set of participation rules;

- $\quad$ Full integration of innovation in the programme, meaning more support that is closer to market application (e.g. demonstration, support for SMEs, innovation services, venture capital);

- A focus on the major societal challenges facing Europe and the world. This means bringing together different technologies, sectors, scientific disciplines, social sciences and humanities, and innovation actors to find new solutions to these challenges;

- Radically simplified access for participants, including a single web portal for all information and projects, less paperwork to make applications, and fewer controls and audits;

- $\quad$ A more inclusive approach with specific actions to ensure excellent researchers and innovators from all European regions can participate, and reinforced support for partnerships with both the private and public sector to pool resources and build more effective programmes;

- $\quad$ At the same time, successful elements from FP7 are being scaled up, such as the European Research Council (ERC) and transnational collaborative projects.

Anticipations towards the next framework programme. Although Horizon 2020 has legacy features from earlier FPs, it has also introduced number of structural, administrative and thematic changes. The Autumn 2016 Survey of National Contact Points (NCPs) and Program Committee members in Finland highlighted the benefits of extensive networking with international excellence, rapid access to international markets, significant increase in funding for SMEs, creation of new pan-European lead markets, and forecasting and identifying global challenges and creating innovative solutions for them in collaboration with

\footnotetext{
${ }^{13}$ European Commission (2017) European Innovation Council (EIC) pilot DG-RESEARCH https://ec.europa.eu/research/eic/index.cfm

${ }^{14}$ European Commission. Horizon 2020 - Access to risk finance. https://ec.europa.eu/programmes/horizon2020/en/h2020-section/access-risk-finance (visited 20101019)

${ }^{15}$ European Commission. Research \& Innovation - conferences and events. http://ec.europa.eu/research/index.cfm?pg=events\&period=2017\&theme=719491 AD-9C69-558D-B05B8AC79345ED08

${ }^{16}$ European Commission. Experts. http://ec.europa.eu/programmes/horizon2020/en/experts (visited 20171019)

${ }^{17}$ Interim evaluation of Horizon 2020, European Commission 2017
} 
the best experts ${ }^{18}$. This has created one foundation for the consideration of Finland's strategic starting points in the preliminary preparatory phase of the next EU FP.

While Horizon 2020 is only half way through, preparations for the next successive FP ${ }^{19}$ are starting both in terms of its structure and content in the wake of interim evaluation of Horizon 2020. The newly released Horizon 2020 Work Programme for $2018-2020^{20}$ already introduces some of the anticipated changes, such as the grouping of smaller themes into larger missions (low-carbon energy, circular economy, safety, migration, etc.), launching of international flagship projects and supporting open science, and most notably the establishment of the European Innovation Council (EIC) pilot ${ }^{21}$, and the associated grouping of the innovation instruments, the SME instrument with Fast Track to Innovation and FET Open, as well as Horizon competitions under one body.

\subsection{Previous evaluations European Framework Programmes and Horizon 2020}

\section{Typical challenges related to EU Framework Programmes / tradition of Finnish participation and the introduction of Horizon 2020 and the new ambition.}

At the time of this evaluation, the Horizon 2020 has been operating approximately four years (2014-2017). At the time of launching of Horizon 2020, there were several concerns about the ability of Finnish research organisations (and industry) to be able to participate at the level of the previous FPs. To some extent this concern has been overcome, with reasonably good participation rate so far. However, Finland has had a slow start to Horizon 2020; after the first year of Horizon 2020 Finnish success rate and share of return were not yet at the current level. Against the latest information, the share of Finnish SMEs has indeed doubled to around $22 \%$ of received funding, which is a very promising indication. Subsequently, an SME has made it to the top-10 participants list for the first time, while the rest of the list of leading organisations is largely the same as earlier (VTT, largest universities, main research institutions). VTT and other large operators have traditionally played an instrumental role in planning and coordinating towards other Finnish FP participants, but for the Horizon 2020, also other (and private) intermediary organisations have become more active.

The mid-term assessment of Horizon 2020 identified certain issues as discussed below in more detail that will be addressed in planning of the following FP. Additionally the findings in this study will serve highlighting issues from the national perspective.

Findings of the EC Interim Evaluation of Horizon 2020 in May 2017. The interim evaluation of the programme presents a wide range of evidence that Horizon 2020 is in many ways already successful ${ }^{22}$. It is well on track to produce the scientific and technological results and outputs and wider societal impacts needed to effectively achieve its objectives.

It is doing so through actions that are subject to processes and procedures that have been simplified substantially compared to the previous programme and have made the programme much more attractive. More than half of the participants are newcomers, and

\footnotetext{
${ }^{18}$ MEAE, 2016

${ }^{19}$ The current EU Multiannual Financial Framework (MFF) covers years 2014-2020

${ }^{20} \mathrm{http}: / /$ ec.europa.eu/programmes/horizon2020/sites/horizon2020/files/stratprog_overarching_version_for_publication.pdf

${ }^{21} \mathrm{https}: / /$ ec.europa.eu/research/eic/index.cfm

${ }^{22}$ European Commission, 2017
} 
Horizon 2020 receives 65\% more applications per year than FP7 did. Horizon 2020's actions have clear European added value (over $80 \%$ of projects would not have gone ahead without its support) and are managed in a highly cost-efficient manner.

SMEs were expected to benefit in particular from administrative simplification and closer knowledge triangle coordination, especially concerning R\&I finance. Horizon 2020 also integrates a major simplification and standardisation of funding schemes and implementing modalities across all areas. Its far-reaching integration, simplification and harmonisation were expected to reduce costs for both the European Commission and for applicants.

In the interim evaluation, the expected impact of Horizon 2020 was divided into following three categories:

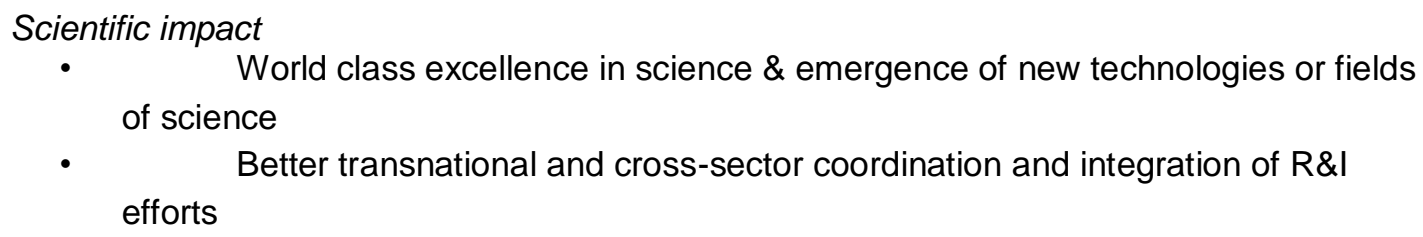

- World class excellence in science \& emergence of new technologies or fields of science

- Better transnational and cross-sector coordination and integration of R\&I efforts

Innovation / economic impact

- $\quad$ Diffusion of innovation in the economy generating jobs, growth and investments, as well as strengthened competitive position of European industry and also better innovation capabilities of EU firms

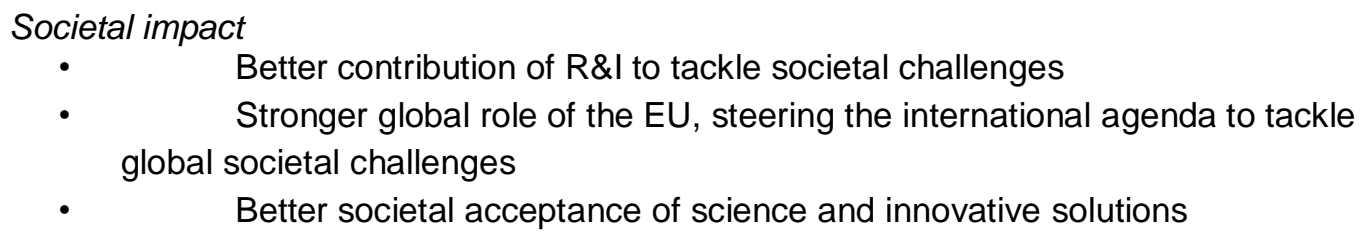

The interim evaluation found that the programme's original rationale for intervention and its objectives and challenges identified at the programme launch are still highly relevant even in light of new political priorities. The EU still spends too little on R\&I (the $3 \%$ expenditure target has not been met) and the innovation gap with key competitors still exists, even though performance is improving. Horizon 2020 supports cutting edge research and technological developments. The relevance of the programme is shown by the sustained interest in its highly competitive calls: more than 30000 proposals were submitted each year, compared to 20000 in FP7. Already now, when half-way through, Horizon 2020 has received more than 100000 eligible proposals, as compared to the 134000 of the total FP7 period. Most impressive has been the $131 \%$ increase in the number of applications from the private sector compared to FP7 (from 20000 to 47000 applications per year). The European Commission has determined that Horizon 2020 has been consequently underfunded by approximately $€ 60$ billion. 
General framework for assessing the impact of Horizon 2020.

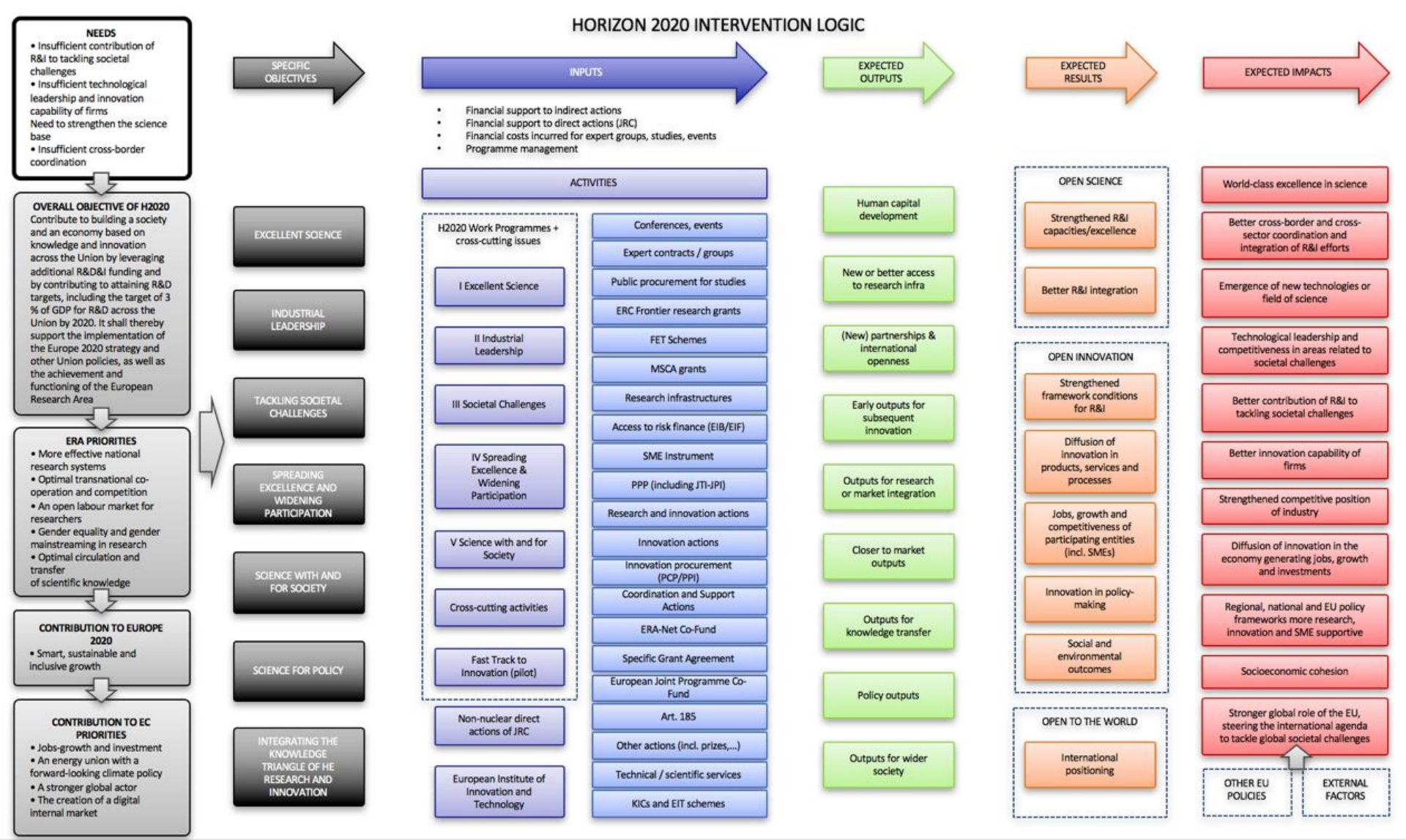

Source: Adapted from (European Commission, 2017) 
The externalisation of the most resource-intensive parts of the programme to Executive Agencies has increased efficiency compared to FP7. It has helped keep the administrative expenditure below the target of $5 \%$ of the budget. Simplification measures have greatly improved operations (time-to-grant). At the same time, the programme's attractiveness has led to very low success rates ( $11.6 \%$ compared to $18.5 \%$ in FP7), leaving some parts strongly underfunded: only 1 in 4 proposals evaluated as being of high-quality were retained, and at the same time, Horizon 2020's focus on excellence leads to a high concentration of funding. The negative consequence of increased private sector interest is its lower success rate; from 23.3\% in FP7 to 13.0\% (-10.3 pps) in Horizon 2020.

With regard to effectiveness, evidence suggests that Horizon 2020 is delivering world class excellence in science. Support to innovation and industrial leadership has been effective with some early results on company growth, additional funding leveraged, and innovations brought to the market. However, the programme falls behind the expenditure target for sustainable development and climate change, although this expenditure represents a considerable increase compared to FP7.

An important aspect is what kind of benefits and added value does Horizon 2020 bring to national and regional support to R\&I in terms of scale, speed and scope. According to the mid-term evaluation, stakeholders state that on average $83 \%$ of projects would not have gone ahead without Horizon 2020 funding.

\section{Status of Horizon 2020 key targets.}

\begin{tabular}{ll}
\hline Horizon 2020 targets & Realised \\
\cline { 2 - 2 } 35\% of EC's financial contribution is climate-related & $27.0 \%$ \\
$60 \%$ of EC's financial contribution is sustainability-related & $53.3 \%$ \\
$20 \%$ of EC's financial contribution is going to SMEs & $23.9 \%$ \\
Source: European Commission, 2017 & $5.6 \%$ \\
\hline
\end{tabular}

\section{Key messages of the High-level Group on maximising the impact of EU R\&I}

\section{programmes. The so called Lamy Report ${ }^{23}$ on the future of European Research was}

published $3^{\text {rd }}$ July 2017 . The report focuses on the guiding principles for designing a post$2020 \mathrm{EU}$ programme for research and innovation. The main message, and vision, is that investing in research and innovation is increasingly crucial for shaping a better European future in a rapidly globalising world, where success depends ever more on the production and conversion of knowledge into innovation. The report gives EU and national stakeholders the following 11 recommendations for planning the future programmes:

1. Prioritise research and innovation in EU and national budgets

2. Build a true EU innovation policy that creates future markets

3. Educate for the future and invest in people who will make the change

4. Design the EU R\&I programme for greater impact

5. Adopt a mission-oriented, impact-focused approach to address global challenges

6. Rationalise the EU funding landscape and achieve synergy with structural funds

7. Simplify further

${ }^{23}$ LAB-FAB-APP, Investing in the European future we want. Report of the independent High-level Group on maximising the impact of EU Research and Innovation Programmes, European Commission 2017. Also known as the 'Lamy Report'. 
8. Mobilise and involve citizens

9. Better align EU and national R\&I investment

10. Make international R\&I cooperation a trademark of EU research and innovation

11. Capture and better communicate impact

It is anticipated that the Lamy Report indicates directions towards which the next EU framework programme will be tuned into.

\subsection{Previous national evaluations of FPs}

This chapter provides a meta-analysis of recent evaluations and studies on the impact of the FPs at national level. Specifically, it looks at six European countries which are comparable to Finland in terms of size and overall research capacity: Austria, Denmark, Ireland, the Netherlands, Norway and Sweden. The analysis focusses on available evidence of ex-post impacts at national level, and does not address EU-level impacts or participation statistics or research near-term outputs systematically.

The chapter is structured in the following way: In the remainder of this section, we provide an overview of the evaluation record from the selected countries, as well as the methods and evidence provided in available evaluations. The following three sub-sections describe scientific, economic, and societal impacts.

\subsubsection{Overview}

The evaluation record contains a variety of types of analyses including monitoring reports, interim and ex-post evaluations. Outcomes and impacts of complex programmes like the FPs are notoriously difficult to determine. Monitoring reports and interim evaluations that focus on participation statistics and support measures are common but, as can be expected, have less to say about the impacts of the EU Framework Programmes at national level.

\section{Participation analyses}

National FP participation is closely scrutinised by national stakeholders and most countries publish regular monitoring reports or interim evaluations with this focus. Austria has been particularly prolific in this area and publishes annual participation overviews with detailed participation analysis down to the regional level (Bundesländer). ${ }^{24}$

One consideration is the 'return on investment' from the nation contribution to the EU budget. This is not least a concern in Norway which, as a non-member of the EU, pays proportionately large amounts into the programme budget in order to secure access for Norwegian participants. The Norwegian FP6 evaluation outlines a number of measures of 'national participation performance' - such as the funding received by national participants compared to GDP or GERD - and concludes that Norway performs "below its national potential" compared to other European countries..$^{25}$ In contrast, an analysis of Swiss participation found that the country had been a net beneficiary of FP6 funding with a financial return of an estimated $152 \%{ }^{26}$

${ }^{24}$ Ehardt-Schmiederer et al., 2014; FFG, 2016, 2017

${ }^{25}$ Langfeldt and Kaloudis, 2009, p. 51

${ }^{26}$ Kern et al., 2014 
More broadly, there is a general assumption in all these studies that increasing the national participation is desirable and should be supported. Nearly all studies use FP programme data (eCORDA) to analyse participation in different programmes, instruments and by types of institutions, as well as the roles played by the national participants, e.g. to what extent they lead projects as coordinators. Some studies also look at motivations and 'drivers' for participation, ${ }^{27}$ the success rates of national applicants ${ }^{28}$ and collaborative patterns between and within countries. ${ }^{29}$

Participation analysis as such does not fall within the scope of this chapter but the impact evaluations reviewed below also tend devote considerable space to this type of analysis and the distinction between the two are often not made clearly in practice.

\section{Ex-post impact assessments}

Impact evaluations are somewhat infrequent and tend to follow the EU programming cycle. A number of national evaluations of the impact of FP6 were published in 2009-2010 and evaluations of national impact of FP7 are now starting to emerge, although they are still few and far between. Whereas all our six countries have had evaluations conducted of FP6, only Denmark and Ireland have published comprehensive analyses of the national impact of FP7 at the time of writing.

Methodologically, most of the studies rely on secondary data analysis - mostly on eCORDA data - and evidence from participant surveys and interviews for the bulk of the analysis.

Many have also used bibliometrics to some extent whereas the use of econometric analysis remains rare. So far, a study from the Danish research and innovation agency is the only example of a fully-fledged econometric analysis, whereas the recent Irish FP7 evaluation found that such an analysis would be too onerous. The following table provides a list of the most recent evaluations and monitoring reports from the six countries included here.

\section{Overview of national ex-post impact evaluations for FP6 and FP7 from selected countries.}

\begin{tabular}{|c|c|c|c|}
\hline Country & Ex-post and impact evaluations & $\begin{array}{l}\text { FPs } \\
\text { covered }\end{array}$ & Methods and evidence \\
\hline AT & $\begin{array}{l}\text { Arnold et al. (2010), Evaluation of Austrian } \\
\text { Support Structures for FP } 7 \text { \& Eureka and } \\
\text { Impact Analysis of EU Research Initiatives on } \\
\text { the Austrian Research \& Innovation System, } \\
\text { Technopolis Group }\end{array}$ & FP6-7 & $\begin{array}{l}\text { Interviews } \\
\text { Focus groups } \\
\text { Participant surveys with control group } \\
\text { Secondary analysis (EU) } \\
\text { Case studies }\end{array}$ \\
\hline DK & $\begin{array}{l}\text { Technopolis Group (2010) Evaluation of } \\
\text { Danish Participation in the } 6^{\text {th }} \text { and } 7^{\text {th }} \\
\text { Framework Programmes, Copenhagen: } \\
\text { DASTI }\end{array}$ & FP6-7 & $\begin{array}{l}\text { Secondary data analysis } \\
\text { Participant surveys } \\
\text { Interviews }\end{array}$ \\
\hline & $\begin{array}{l}\text { DASTI (2015), Effects of participation in EU } \\
\text { framework programmes for research and } \\
\text { technological development, Copenhagen: } \\
\text { DASTI. }\end{array}$ & FP6-7 & $\begin{array}{l}\text { Participant survey with control group } \\
\text { Econometric analysis } \\
\text { Bibliometric analysis }\end{array}$ \\
\hline El & $\begin{array}{l}\text { Technopolis Group (2009). Evaluation of } \\
\text { Framework Programme } 6 \text { in Ireland. Dublin: } \\
\text { Forfás. }\end{array}$ & FP6 & $\begin{array}{l}\text { Secondary data analysis (EU) } \\
\text { Participant surveys (successful, unsuccessful) } \\
\text { Interviews }\end{array}$ \\
\hline & $\begin{array}{l}\text { Rosemberg et al. (2016), Ex-post evaluation of } \\
\text { Ireland's Participation in the 7th EU } \\
\text { Framework Programme, Technopolis Group. }\end{array}$ & FP7 & $\begin{array}{l}\text { Participant survey with control group } \\
\text { Bibliometric analysis }\end{array}$ \\
\hline $\mathrm{NL}$ & $\begin{array}{l}\text { Boekholt et al. (2009), Impact Europese } \\
\text { Kaderprogramma's in Nederland [Impact of } \\
\text { the European Framework Programme in the } \\
\text { Netherlands], Technopolis Group. }\end{array}$ & FP1-6 & $\begin{array}{l}\text { Bibliometric analysis } \\
\text { Interviews }\end{array}$ \\
\hline NO & $\begin{array}{l}\text { Langfeldt, L., \& Kaloudis, A. (2009). In Need of } \\
\text { a Better Framework for Success: An } \\
\text { Evaluation of the Norwegian participation in } \\
\text { the EU 6th Framework Programme (2003- } \\
2006) \text { and the first part of the EU 7th }\end{array}$ & FP6 & $\begin{array}{l}\text { Secondary data analysis (EU, national data) } \\
\text { Participant survey } \\
\text { Interviews } \\
\text { Case studies } \\
\text { Bibliometric analysis }\end{array}$ \\
\hline
\end{tabular}

\footnotetext{
${ }^{27}$ Åström et al., 2012

${ }^{28}$ Rosemberg, Simmonds, et al., 2016

${ }^{29}$ FFG, 2017
} 


\begin{tabular}{|c|c|c|c|}
\hline Country & Ex-post and impact evaluations & $\begin{array}{l}\text { FPs } \\
\text { covered }\end{array}$ & Methods and evidence \\
\hline SE & $\begin{array}{l}\text { Framework Programme (2007-2008). Oslo: } \\
\text { NIFU STEP. } \\
\text { Arnold et al. (2008), Impacts of the Framework } \\
\text { Programme in Sweden, VINNOVA }\end{array}$ & FP3-6 & $\begin{array}{l}\text { Secondary data analysis (national) } \\
\text { Meta-evaluation } \\
\text { Case studies (Institutions and sectors) } \\
\text { Bibliometric analysis }\end{array}$ \\
\hline
\end{tabular}

\subsubsection{Scientific impact}

This section summarises the findings concerning scientific impact, including impacts on public research institutions and universities. There are two main types sources of evidence about scientific impacts: self-reported benefits and impacts by participants collected through surveys and interviews, and evidence from bibliometric analyses. The former is used in all studies included here, whereas bibliometric evidence is less common. These will be discussed in turn below.

\section{Self-reported benefits and impacts}

Most, if not all, of the impact evaluations reviewed here have carried out participant surveys and the following table lists the most important impacts reported by participants.

Networking, cooperation and/or building relationships are consistently ranked as the most important impact. Other highly ranked impacts include increased understand/knowledge, improved research capabilities and enhanced reputation. These main types of impacts will be unpacked below.

\section{Most important benefits or impacts from the EU Framework Programme, as reported in surveys.}

\begin{tabular}{|c|c|c|c|c|c|c|}
\hline Rank & $\begin{array}{l}\text { Austria: } \\
\text { FP6 [1] }\end{array}$ & Denmark: FP6 ${ }^{[2]}$ & $\begin{array}{c}\text { Denmark: FP6/7 } \\
\text { [3] (Universities } \\
\text { and RTOs) }\end{array}$ & $\begin{array}{l}\text { Ireland: } \\
\text { FP6 }{ }^{[4]}\end{array}$ & $\begin{array}{l}\text { Ireland: } \\
\text { FP7 }{ }^{[5]}\end{array}$ & Norway: FP6/7 [6] \\
\hline $1^{\text {st }}$ & $\begin{array}{l}\text { Improved } \\
\text { relationships and } \\
\text { collaboration } \\
\text { with partners } \\
\text { already known }\end{array}$ & $\begin{array}{l}\text { Improved } \\
\text { relationships and } \\
\text { networks }\end{array}$ & $\begin{array}{l}\text { Building new } \\
\text { European } \\
\text { network }\end{array}$ & $\begin{array}{l}\text { Improved } \\
\text { relationships and } \\
\text { networks }\end{array}$ & $\begin{array}{l}\text { Improved our } \\
\text { international } \\
\text { networks }\end{array}$ & $\begin{array}{l}\text { Extended long- } \\
\text { term international } \\
\text { cooperation links }\end{array}$ \\
\hline $2^{\text {nd }}$ & $\begin{array}{l}\text { Improved } \\
\text { relationships and } \\
\text { collaboration } \\
\text { with previously } \\
\text { unknown } \\
\text { partners }\end{array}$ & $\begin{array}{l}\text { Increased } \\
\text { understanding/ } \\
\text { knowledge }\end{array}$ & $\begin{array}{l}\text { Funding of } \\
\text { activities that } \\
\text { otherwise would } \\
\text { not have been } \\
\text { implemented }\end{array}$ & $\begin{array}{l}\text { Increased } \\
\text { understanding } \\
\text { and knowledge }\end{array}$ & $\begin{array}{l}\text { Increased our } \\
\text { understanding } \\
\text { about the } \\
\text { subject }\end{array}$ & $\begin{array}{l}\text { Improved } \\
\text { research } \\
\text { capabilities }\end{array}$ \\
\hline $3^{\text {rd }}$ & $\begin{array}{l}\text { Enhanced } \\
\text { reputation and } \\
\text { image }\end{array}$ & $\begin{array}{l}\text { Increased } \\
\text { scientific } \\
\text { capabilities }\end{array}$ & $\begin{array}{l}\text { Cooperation with } \\
\text { excellent foreign } \\
\text { research- and } \\
\text { foreign } \\
\text { environments }\end{array}$ & $\begin{array}{l}\text { Enhanced } \\
\text { reputation and } \\
\text { image }\end{array}$ & $\begin{array}{l}\text { Increased our } \\
\text { scientific } \\
\text { capacity }\end{array}$ & $\begin{array}{l}\text { Exploration of } \\
\text { new research } \\
\text { areas }\end{array}$ \\
\hline $4^{\text {th }}$ & $\begin{array}{l}\text { Increased } \\
\text { scientific } \\
\text { capabilities and } \\
\text { know-how }\end{array}$ & & $\begin{array}{l}\text { Expansion of } \\
\text { existing } \\
\text { European } \\
\text { network }\end{array}$ & $\begin{array}{l}\text { Increased } \\
\text { scientific } \\
\text { capabilities }\end{array}$ & $\begin{array}{l}\text { Improved our } \\
\text { international } \\
\text { reputation }\end{array}$ & $\begin{array}{l}\text { Improved R\&D } \\
\text { management } \\
\text { skills }\end{array}$ \\
\hline $5^{\text {th }}$ & $\begin{array}{l}\text { Increased } \\
\text { technological } \\
\text { capabilities and } \\
\text { know-how }\end{array}$ & & $\begin{array}{l}\text { International } \\
\text { prestige }\end{array}$ & & $\begin{array}{l}\text { Increased our } \\
\text { ability to access } \\
\text { international } \\
\text { experts }\end{array}$ & $\begin{array}{l}\text { EU projects } \\
\text { contribute to } \\
\text { innovation }\end{array}$ \\
\hline $\begin{array}{l}\text { Note: Co } \\
\text { Sources } \\
\text { [1] "Impa } \\
\text { [2] "Main } \\
\text { [3] "The } \\
\text { [4] "Main } \\
\text { [5] "Bene } \\
\text { [6] "Parti } \\
\text { to propo }\end{array}$ & $\begin{array}{l}\text { ted and colour-coded } \\
\text { of FPs" (Arnold et al. } \\
\text { sitive impacts realise } \\
\text { rage effects from FP } \\
\text { sitive benefits realise } \\
\text { s of participation in FP }\end{array}$ & $\begin{array}{l}\text { the authors. Methodo } \\
\text { 010, p. 83). } \\
\text { y participants" (Techn } \\
\text { P7 perceived by unive } \\
\text { y FP6 participants" ( } \\
\text { all successful respono } \\
\text { ects on research and }\end{array}$ & $\begin{array}{l}\text { olis, 2010, p. 79). } \\
\text { ities and GTS institut } \\
\text { hnopolis, 2009, p. } 20 \\
\text { ts" (Rosemberg et al } \\
\text { covation capacities" ( }\end{array}$ & $\begin{array}{l}\text { (MHES, 2015, p. 36). } \\
016 \text {, p. } 55 \text { ): } \\
\text { gfeldt \& Kaloudis, } 200\end{array}$ & ectly comparable & \\
\hline
\end{tabular}

As shown above, enhanced networking and collaboration is the most commonly reported impact of FP participation. Survey evidence from Norway provides insight into the concrete 
nature of networking and shows that communications between EU project members happen in a variety of ways: E-mails and online tools were preferred for day-to-day communications but most respondents reported meeting face-to-face with project partners at least 1-3 times $^{30} \mathrm{FPs}$ have contributed to making international research partnerships more of an "every-day occurrence" among European researchers(Arnold et al., 2010, p. 81) and has made researcher networks more oriented towards Europe, thereby contributing to the European Research Area (ERA), ${ }^{31}$ as also shown in bibliometric studies discussed below. Perhaps unsurprisingly, it is much less clear whether FP participation enabled networking with researchers from outside of the EU. Although FP often enables new collaborations, many FP networks are built around long-standing core partnerships that have developed over the course of several FPs, ${ }^{32}$ and there appears to be a tendency towards "withinsector-cooperation", i.e. that universities tend to establish partnerships with other universities. ${ }^{33}$

In the academic sector, the main benefits from networking and a closer ERA tend to be described in terms of increased quality of research stemming from early access to the latest knowledge as members of 'invisible colleges' and participation in scientific agenda-setting. ${ }^{34}$ Thus, when many respondents identify increased knowledge/understanding and scientific capabilities as a key impact of FP participation, this appears to be closely linked with interactions within scientific networks.

Different kinds of reputational impacts are also reported by many FP participants. For individual researchers, FP projects can be important 'seal of approval' and proxy for quality within the scientific community ${ }^{35}$ as well as an important reference for winning research contracts. ${ }^{36} \mathrm{FP}$ participation is reported to be a source of prestige for universities ${ }^{37}$ and national reputation as a destination for international researchers. ${ }^{38}$

\section{Bibliometric performance}

In addition to self-reported impacts collected through surveys and interviews, several evaluations have made use of bibliometric methods to assess the scientific impact.

There is little evidence FP participation has a significant impact in terms of the volume and direction of scientific production. Using data from the SESAM Research Performance and Impact Reporting tool (RESPIR), Rosemberg et al. ${ }^{39}$ estimated that the number of Irish publications that can be traced back to FP projects is relatively modest, accounting for about $1 \%$ of all Irish publications. Similarly, findings from Sweden suggest that the subject profile of publications from EU-funded researches was unaffected by the FPs. ${ }^{40}$

The evaluation record contains more evidence of a link between FPs and publications with higher citation impact. Thus, an analysis of Danish publications linked to FP6 and FP7 concluded that "impact levels are generally high, and the impact levels for the FP7 set can

\footnotetext{
${ }^{30}$ Langfeldt and Kaloudis, 2009.

${ }^{31}$ Boekholt et al., 2009, p. viii

${ }^{32}$ Arnold et al., 2010

${ }^{33}$ Langfeldt and Kaloudis, 2009

${ }^{34}$ Arnold et al., 2008, pp. 69-70

${ }^{35}$ Arnold et al., 2008

${ }^{36}$ Arnold et al., 2010

${ }^{37}$ Arnold et al., 2008, p. 65

${ }^{38}$ Rosemberg, Wain, et al., 2016, p. 80

${ }^{39} 2016$, p. 79

${ }^{40}$ Fröberg and Karlsson, 2008
} 
be considered outstanding." ${ }^{41}$ FP-linked publications had substantially higher average citation scores and higher occurrence of highly cited articles than other Danish publications. Publications linked to FP7 also performed better than publications linked to leading national funders (the Danish Council for Independent Research and the Danish National Research Foundation), in large part due to very high impact scores from ERC-funded research. These findings are somewhat surprising in light of survey results showing that participants rank publications among the less important impacts of the FPs. Focussing on the production of EU-funded researchers (rather than individual publications linked to the FP projects), a bibliometric analysis of five Swedish universities found that EU-funded researchers were "more successful in terms of both citation rates and number of collaborations, already before participating in EU-financed projects", suggesting that high impact scores are a prerequisite for obtaining EU-funding rather than an effect of receiving it. ${ }^{42}$

Participation in the FPs can also be seen as a catalyst for internationalisation, which is widely understood to be beneficial for quality and citation impact. Institutional case studies from Austria illustrate this phenomenon(Arnold et al., 2010). In Norway, bibliometric analysis shows a large increase in EU-collaboration (co-authorships) since Norway first entered the FPs in 1994. In the context of a general trend towards more international collaboration, the relative importance of EU collaboration in Norway has increased while the relative share of collaboration with other parts of the world has fallen. This development is, at least in part, attributed to participation in the FPs(Langfeldt and Kaloudis, 2009). In Denmark, FP-related articles were also found to be much more likely to be internationally co-authored than other articles: $70.9 \%$ of FP6-related publications and $67.7 \%$ of FP7-related articles were internationally co-authored, as compared with some $60 \%$ for the two national benchmarks. In fact, it is found that the higher degree of internationalisation largely explains the higher citation scores achieved by FP6-related publications as compared to national benchmarks. For FP7, in contrast, controlling for internationalisation still leaves higher citation performance to be explained by other factors. ${ }^{43}$

\subsubsection{Economic impact}

\section{Self-reported impacts}

Responses from companies in participant surveys tend to point to many of the same impacts as other participants, as shown below. Thus, cooperation and networking are among the most important effects reported by companies, but other impacts such as enhanced knowledge/understanding, capacity building and access to knowledge and expertise are also among top ranked impacts. In industry, the nature of networking might differ, however, from what is seen for academic participants. For example, strategic initiatives like Technology Platforms and Joint Technology Initiatives (JTIs) are seen as important ${ }^{44}$ and long-term involvement in successive FPs is reported to have helped Swedish telecom giant Ericsson position itself in the market through influencing standards and technological direction. ${ }^{45}$

\footnotetext{
${ }^{41}$ MHES, 2015, p. 60

${ }^{42}$ Fröberg and Karlsson, 2008

${ }^{43}$ MHES, 2015

${ }^{44}$ e.g. Technopolis, 2009, p. 22

${ }^{45}$ Arnold et al., 2008
} 


\section{Most important benefits or impacts from the EU Framework Programme for enterprise participants}

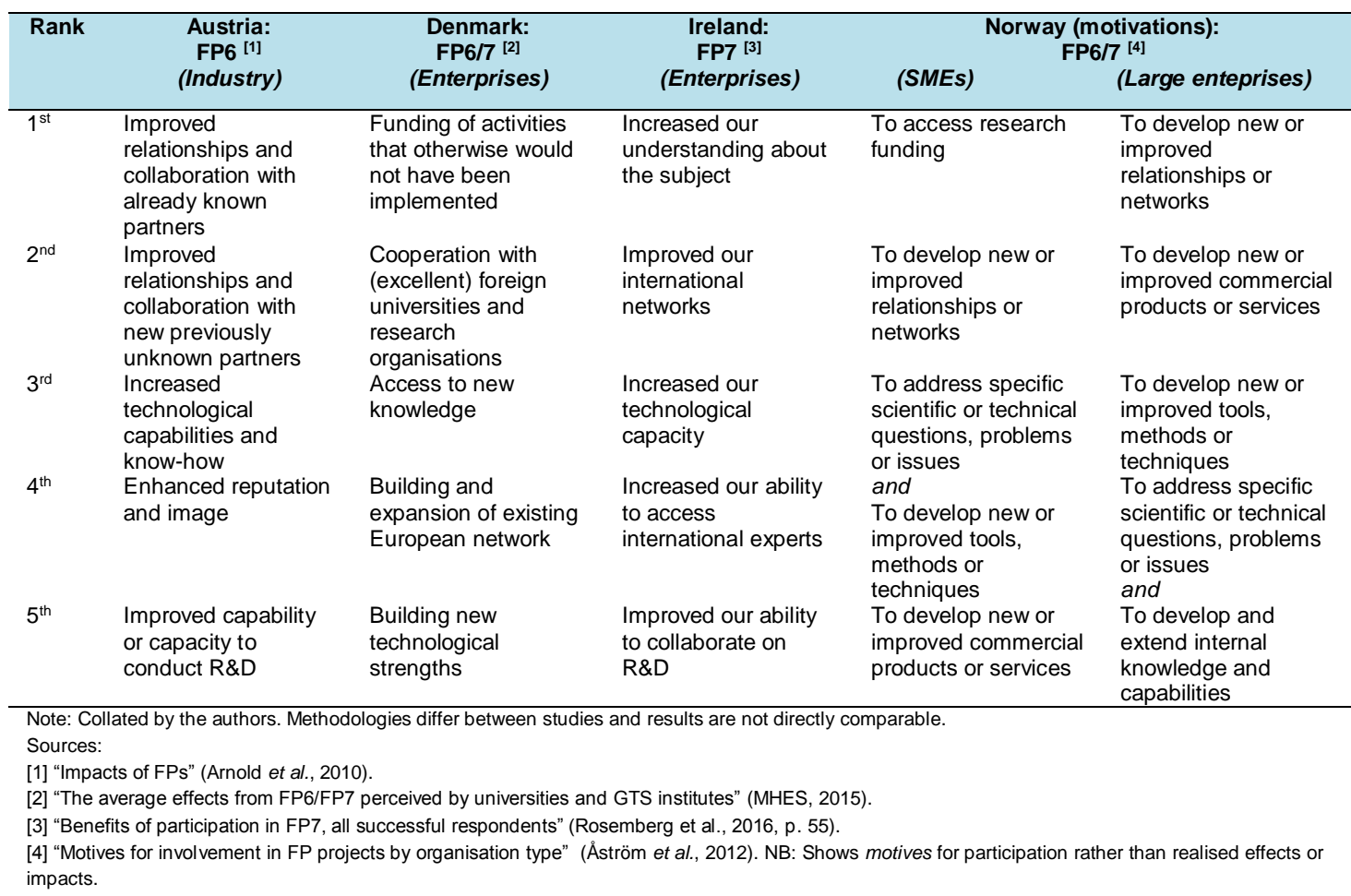

Traditional commercialisation outputs and impacts, such as patents, licensing and spinouts, are not among the most prominent, which can be explained by the pre-competitive nature of the FPs. Both the Danish and Austrian FP6 evaluations found that 'new license agreements' and 'Patents granted' were among the areas that scored the furthest below participant expectations. ${ }^{46}$ Nevertheless, there are examples of such outcomes: For example, a single research group at the University of Lund in Sweden is reported to have produced eight spin-out companies which can be traced back to FP participation, employing a hundred people ${ }^{47}$. A survey of Irish FP7 participants found that FP7 participants had achieved a total of $€ 1$ million income from 21 licensing agreements, and formed 12 spinouts with a combined value of $€ 28$ million and employing 55 people. ${ }^{48}$

Evidence of other economic effects on companies, including new products, increased revenue and employment, is more mixed. Thus, according to a Danish survey, for $49 \%$ of companies, FP participation had led to the introduction of new products or services ${ }^{49}$ and $75 \%$ of Irish companies responded that FP participation had helped improve their portfolio of products and services. The Irish evaluations further found that $73 \%$ reported positive impact on employment, $69 \%$ on turnover, and $64 \%$ on productivity. Similar proportions of company respondents also stated that FP participation had improved their competitive position and commercial opportunities. ${ }^{50}$ In contrast, evidence from Norway suggests a more modest frequency of direct economic impact: only $26.4 \%$ of enterprises expected increase in turnover and $11.5 \%$ expected a reduction in costs for example. Perhaps not surprisingly, it

\footnotetext{
${ }^{46}$ Arnold et al., 2010; Technopolis, 2010, p. 78

${ }^{47}$ Arnold et al., 2008

${ }^{48}$ Rosemberg, Wain, et al., 2016

${ }^{49}$ MHES, 2015, p. 42

${ }^{50}$ Rosemberg, Wain, et al., 2016
} 
was also found that enterprises with a leading responsibility within the FP-funded projects were more likely to expect direct economic benefits than those who were not. ${ }^{51}$

These findings notwithstanding, it is clear that the impact of FP participation depends to a large extent on nature of the company and the industry within which they operate. For example, there are clear differences in the impacts on SMEs and large companies respectively: One study found that SMEs generally attributed higher significance to impacts from FP participation than larger companies ${ }^{52}$ and the Norwegian study of motivations for participating shows the importance of funding for SMEs, whereas large companies prioritise networking ${ }^{53}$ This is also reflected in the relevance attributed to different FP instruments: large companies favour traditional collaborative projects, whereas SMEs prefer special instruments. ${ }^{54}$

Sector-specific factors are illustrated in case studies from Austria and Sweden. In the fields of Pharmaceuticals and Sustainable Energy, it was found that a lack of alignment between national and EU programmes (Austria), as well as fragmentation and a lack of strategic leadership and risk-taking from government and industry led to somewhat fragmented and opportunistic participation without significant strategic influence at EU level (Sweden). In ICT and Automotive industries, both countries found a better alignment between national and EU programmes. In Sweden, the case studies found a crucial role for the FPs in maintaining and strengthening the position and competitiveness of leading industry actors. The long-standing coordination within the automotive industry at European level also played a role in ensuring that FP-funded research was relevant to industry. Overall, themes like the extent of alignment of national and EU programmes (Austria) and strategic leadership from government and industry (Sweden) appear to be important industry-specific factors determining the potential impact of FP participation. ${ }^{55}$

\section{Economic impact analysis}

Participant surveys (some with control group), interviews and case studies remain the most commonly used methods for assessing economic impact and necessarily rely on selfreported impacts from participants. Econometric analysis is not the norm and has only been attempted in a small number of publications. The best example in the countries reviewed here is the of study of Effects of the Framework Programmes published by the Danish Ministry for Higher Education and Science (MHES, 2015).

The section on microeconomic effects of FP participation in the Danish study analyses the intensity level of skilled labour (proportion of MScs and PhDs), export intensity, labour productivity, employment and revenue but ultimately fails to find any statistically significant effect on companies participating in FPs compared to a control group of similar firms. There even appears to have been a negative effect on employment within participating firms. One of the challenges of this type of analysis is finding adequate control groups to construct counterfactuals as companies participating in the FPs tend to be very unusual already before participating: They are concentrated in specific industries (ICT, Manufacturing and Scientific services), employ a much larger share people with Master's and PhD degrees and a larger share of their revenue is derived from exports. Finally, large companies ( $>250$ employees) are significantly overrepresented among FP participants compared to the nonparticipating domestic firms. The authors suggest that a larger sample size and longer time

\footnotetext{
${ }^{51}$ Langfeldt and Kaloudis, 2009

${ }^{52}$ MHES, 2015

${ }^{53}$ Åström et al., 2012

${ }^{54}$ Arnold et al., 2010

${ }^{55}$ Arnold et al., 2008, 2010
} 
frames might provide more robust results, but that both participants and non-participants included in the study are unusually strong economic performers overall. ${ }^{56}$ Rosemberg et al. (2016), for their part, concluded in their study of Irish FP7 participation that econometric analysis based on national business surveys was inappropriate given severe data limitations ${ }^{57}$.

Looking at macroeconomic impacts Rosemberg et al. (2016) provided an estimate on the basis of assumptions from prior studies. Given the total value of FP grants awarded to Ireland, $€ 0.6$ Billion, the following effects were estimated. ${ }^{58}$

- A total investment of $€ 1.1$ billion (i.e. a leverage of $€ 0.46$ billion)

- A total contribution to Ireland's GDP of $€ 6.5$ billion over 21 years (20072028), i.e. equivalent to an annual GDP growth of $\sim € 300$ million.

- $\quad$ A total of $\sim 42,000$ jobs created in Ireland over 21 years (2007-2028), i.e. equivalent to $\sim 2,000$ jobs created per year

These two studies provide examples how econometric analysis of national level impacts can be approached, but also illustrate the challenges inherent in such analysis when it comes to complex interventions such as the FPs.

\subsubsection{Societal impact}

Societal impacts have been close to the top of the European science and innovation policy agenda for nearly a decade, at least since the Lund Declaration stated that "Europe must focus on the Grand Challenges of our time". ${ }^{59}$ Nevertheless, the evidence of societal impact of national participation in the FPs is scarce so far.

The European Commission's own ex-post evaluation of FP7 analyses 'wider societal impacts' in terms of the input (amount of funding and number of projects) from the thematic priorities which address the United Nations' Sustainable Development Goals (SDGs). According to this analysis, FP7 made the biggest contribution to the areas of Sustainable consumption (SDG 12), Access to Energy (SDG 7) and Health Lives (SDG 3). ${ }^{60}$

Within our focus countries, several evaluations address societal impacts but often in a rather brief manner. The Irish FP7 evaluation has taken the most systematic approach and defines societal impact as research that leads to improvements to people's lives, to society as a whole or which strengthens public engagement and science education. With this starting point, 14 FP projects with Irish coordinators were identified and analysed in terms of their activities and potential or expected societal benefits. The approach shows societal impacts in a variety of areas (e.g. to areas such as health, carbon emissions and public engagement with science) emerging from across the different parts of the FP, including thematic areas, ERC and the Science in Society programme. ${ }^{61}$

Regulation and government policy is another potentially important area of societal impact, but the evidence suggests that most participants do not regard this as a priority and/or that

\footnotetext{
${ }^{56}$ MHES, 2015

${ }^{57}$ Rosemberg, Wain, et al., 2016

${ }^{58}$ Rosemberg, Wain, et al., 2016

${ }^{59}$ The Lund Declaration - July 2009, 2009

${ }^{60}$ Fresco, Martinuzzi and Wiman, 2015, pp. 73-75

${ }^{61}$ Rosemberg, Wain, et al., 2016
} 
the actual realisation of such outcomes from FP projects has been modest. In Denmark, only $4 \%$ of survey respondents regarded "New or significantly improved regulations or policies" as important, although $41 \%$ reported that project results had been exploited by Danish policy-makers to some extent. ${ }^{62}$ Similarly, the development of new or improved regulations or policies was the least important motive for Austrian participants to take part in FP6/7 whereas $38 \%$ of respondents felt that this had been realised below expectations, more than any other area. ${ }^{63}$ The Irish FP6 evaluation concludes on this point that "the main impacts of FP6 projects will be on the research community, with the benefits to Irish policy formulation and the business sector being lower in relative terms." ${ }^{4}$

One explanation for the lack of systematic evidence of societal impacts could be that tracing impacts at the project level can be very resource-intensive and therefore not achievable within the parameters of standard FP impact evaluations. This could require detailed qualitative data collective at project level, and impacts may also require longer time-frames to materialise than usually afforded in national impact evaluations. It might also be expected that such evidence will be more systematically available as impact monitoring processes become more embedded at national and EU level, as also recommended in some studies. ${ }^{65}$

\subsection{Status of Finnish participation in Horizon 2020}

As discussed, the early concerns about Finnish participation have at least partially dissipated. By early 2017, there were altogether 893 Horizon 2020 projects with Finnish participants, 278 out of which were coordinated by Finnish partners. In sum, $€ 579$ million funding had been received during this period. These equal to a success rate of $12.8 \%$ on average and a reasonable $2.2 \%$ share of all granted funding.

A particular concern during the FPs has been the sustained low involvement of small and medium-sized enterprises (SMEs) and a serious attempt was made for Horizon 2020 to address this better than earlier FPs. Against the latest information, the share of Finnish SMEs has indeed doubled to around $22 \%$ of received total funding, which is a very promising indication. It is also now the first time an SME has made it to the top-10 participants, while the rest of the list of leading organisations is largely the same as earlier (VTT, largest universities, main research institutions). VTT and other large operators have traditionally played an instrumental role in planning and coordinating towards other Finnish FP participants, but for the Horizon 2020, also other (and private) intermediary organisations have become more active. This is one aspect worth paying a closer look at the study.

\footnotetext{
${ }^{62}$ Technopolis, 2010)

${ }^{63}$ Arnold et al., 2010

${ }^{64}$ Technopolis, 2009

${ }^{65}$ Rosemberg, Wain, et al., 2016
} 
Key facts about Finnish participation in Horizon 2020

\begin{tabular}{|c|c|c|c|c|}
\hline & \multirow[b]{2}{*}{ All } & \multirow[b]{2}{*}{ Multi-partner } & \multicolumn{2}{|c|}{ Single applicant ${ }^{\star}$} \\
\hline & & & $\begin{array}{l}\text { SME Instrument } \\
(1 \& 2)^{\star}\end{array}$ & $\begin{array}{c}\text { ERC } \\
(\text { Pillar I)* }\end{array}$ \\
\hline $\begin{array}{l}\text { Number of } \\
\text { applications }\end{array}$ & $\begin{array}{l}6,986 \\
(5.4 \% \text { of total })\end{array}$ & $\begin{array}{l}4,796 \\
(10.9 \% \text { of total })\end{array}$ & $\begin{array}{l}1,137 \\
(3.1 \% \text { of total })\end{array}$ & $\begin{array}{l}758 \\
(3.2 \% \text { of total) }\end{array}$ \\
\hline Number of projects & $\begin{array}{l}893 \\
(6.0 \% \text { of total })\end{array}$ & $\begin{array}{l}711 \\
(13.1 \% \text { of total })\end{array}$ & $\begin{array}{l}83 \\
(3.1 \% \text { of total })\end{array}$ & $\begin{array}{l}63 \\
(1.9 \% \text { of total })\end{array}$ \\
\hline Success rate & $\begin{array}{l}12.8 \% \\
\text { (8.7\% for coordinators) } \\
(16.2 \% \text { for partners })\end{array}$ & $15 \%$ & $7.1 \%$ & $8.4 \%$ \\
\hline $\begin{array}{l}\text { Number of } \\
\text { Finnishcoordinations }\end{array}$ & $\begin{array}{l}278 \\
(31 \% \text { of } \mathrm{FI} \text { projects })\end{array}$ & $\begin{array}{l}96 \\
(14 \% \text { of FI projects) }\end{array}$ & $\begin{array}{l}79 \\
\text { (95\% of FI } \\
\text { projects) }\end{array}$ & $\begin{array}{l}62 \\
\text { (98\% of FI } \\
\text { projects) }\end{array}$ \\
\hline $\begin{array}{l}\text { EC Contribution to } \\
\text { Finnish participants }\end{array}$ & $\begin{array}{l}€ 579 \text { million } \\
(2.2 \% \text { of total, } € 450 \mathrm{k} \\
\text { per participation })\end{array}$ & $\begin{array}{l}€ 410 \text { million } \\
(2.1 \% \text { of total, } € 371 \mathrm{k} \text { per } \\
\text { participation) }\end{array}$ & $\begin{array}{l}€ 56 \text { million } \\
(5.1 \% \text { of total, } \\
€ 670 \mathrm{k} \text { per } \\
\text { participation }\end{array}$ & $\begin{array}{l}€ 103 \text { million } \\
(2.0 \% \text { of total, } \\
€ 1.6 \mathrm{~m} \text { per } \\
\text { participation) }\end{array}$ \\
\hline
\end{tabular}

* Technically SMEI and ERC are not single-partner, but most projects involve a single participant, who is thereby a coordinator

Source: eCORDA, extracted May 2017

\subsection{A framework for evaluating the impact of Horizon 2020 in Finland}

Towards a common assessment framework for all countries. In 2017, the ERA Council set up an Ad-Hoc Group of Member State experts to elaborate and propose a common framework for measuring the impact of EU framework programmes, ${ }^{66}$ to allow a more systematic assessment of the benefits and impacts of EU funding, as well as to facilitate cross-country comparison and learning. The focus of their analysis is both in the participation itself, as well as its impact to member states. The work of the group is still in progress and official documentation is not yet available, while initial frameworks for assessing the impact have been discussed. The initial dimensions for assessing the impact include following:

Participation structure. The analysis of the structure of national participation in the FPs corresponds to the most common form of monitoring developed by member states. Participation data has the advantage of reflecting the formal information regarding proposal submission and formal project contracts, and therefore it is the data most easily accessible.

Structuring impacts. The assessment of structuring impacts at the national level from the participation in the FPs can be largely framed through the lens of the ERA Roadmap. The priorities that have been considered to delineate the ERA Roadmap reflect the member states view on dimensions that are essential to structure the European Research Area.

Scientific impacts. The European Framework Programmes have been central instruments in the strengthening of the European science and technology knowledge base, which remains as a central objective and

${ }^{66}$ ERAC Ad-Hoc Working Group on Measuring the Impacts at National Level of the participation in EU FPs, preliminary draft, May 2017. 
potential impact at the national level, in addition to the contribution to technological competitiveness.

Innovation impacts. The impact on the innovative capability of the European industry is, arguably, the main objective of the Framework Programmes and ought to be identified here in particular, independently from the wider economic impacts of the national participation.

Economic impacts. Beyond the impacts of the participation in the FPs at the level of national research and innovation systems, as indicated in the impact dimensions identified above, the Framework Programme has within its objectives to promote the competitiveness of the Union's industry and to contribute to the EU2020 Strategy towards smart, sustainable and inclusive growth. It is thus clear that the wider economic impacts are also to be considered when assessing national impacts from participation.

Societal impacts. One particularly important aspect of impact assessment, from the point of view of the wider society, regards the research impact beyond the research community. It should therefore be also considered the societal impacts from the programme, how the research has relevance for the society.

Specific evaluation framework for this study. For the purpose of this study, we have utilised elements of the ERAC Ad-hoc group, and adapted those to the specific objectives of this study. The analytical framework is presented in the following figure.

\section{Analytical framework for assessing the impact of Horizon 2020 on Finnish RDI} funding

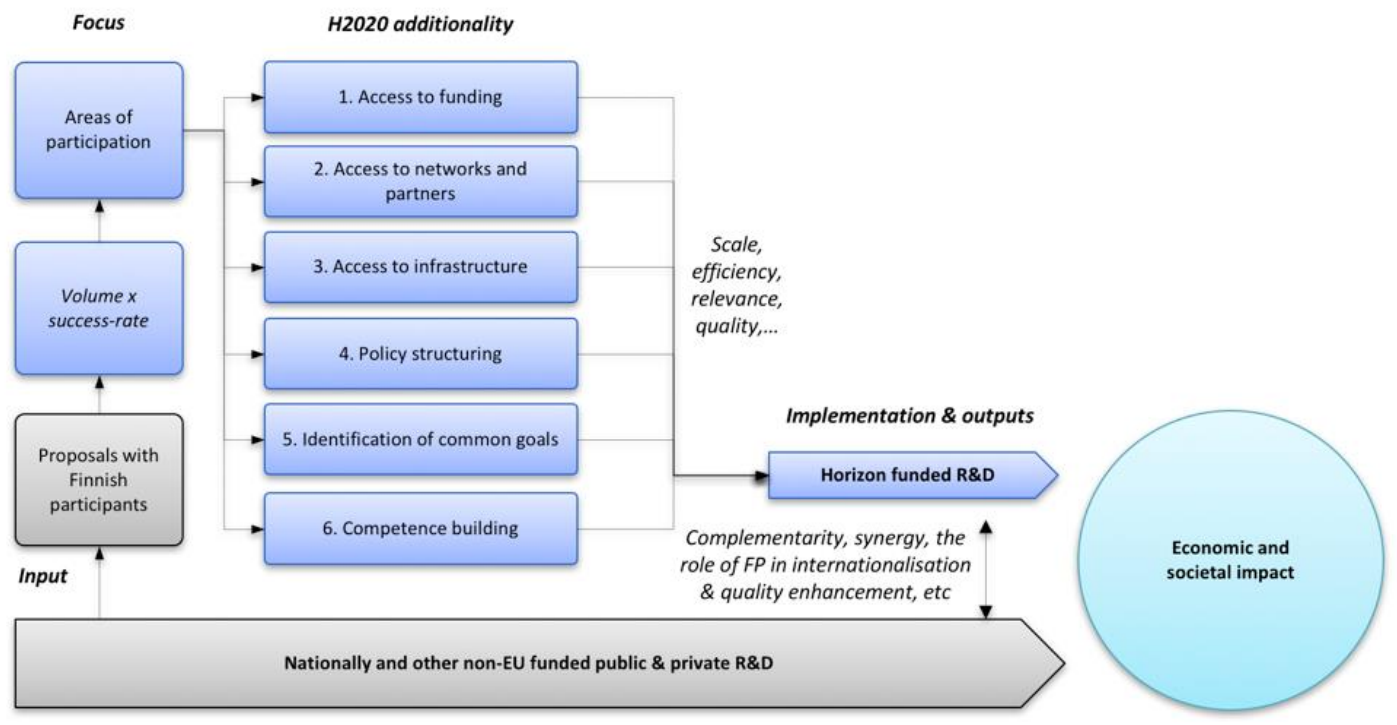

In line with the above, our first analytical dimension is the Finnish participation - from the general application activity to different areas of proposal successes and participation, as well as motives and anticipations behind that.

Further to those, the direct input additionality of Horizon 2020 is analysed. The additionality is assessed from the perspectives of 1) access to increased funding, 2) access to broader collaboration networks and partnering, 3 ) access to (international) research and other 
infrastructures, platforms, etc., 4) Horizon 2020 input to national or local policy structuring (such as complementarity of funding instruments), 5) input to identification of common goals and influence to the direction of research and innovation, as well as 6) input to specific and general competence building among participants. In all these elements, the reflection was done against the option of having conducted (or not conducted) the activities without Horizon 2020 funding and participation, either with or without the help of national RDI funding instruments.

As the Horizon 2020 has been running for four years only, and most of the projects are either at their beginning or at their early phases, it is mostly premature to assess their generated impact. Hence, the impact analysis part of the study focuses on the anticipated economic, scientific, learning and societal impacts of Horizon 2020 participations. Therefore, less weight has been put to the impact assessment part of the study, and subsequently more to the participation structure and the input additionality of Horizon 2020. However, the long-term development of economic impact has been, however assessed from the earlier framework programmes onwards. 


\section{APPROACH, METHODOLOGY AND LIMITATIONS}

\subsection{Approach and methodology}

The following figure illustrates the approach to the project. The work was divided into three work packages (WP). The first (WP1) comprised inception and analysis of context and background. The second (WP2) contained the bulk of data collection and analysis of the impact and contribution of FPs in general and Horizon 2020 in particular. The third WP consisted of overall analysis and synthesis of findings concerning the national added value and contribution of Horizon 2020.

The structure of the project

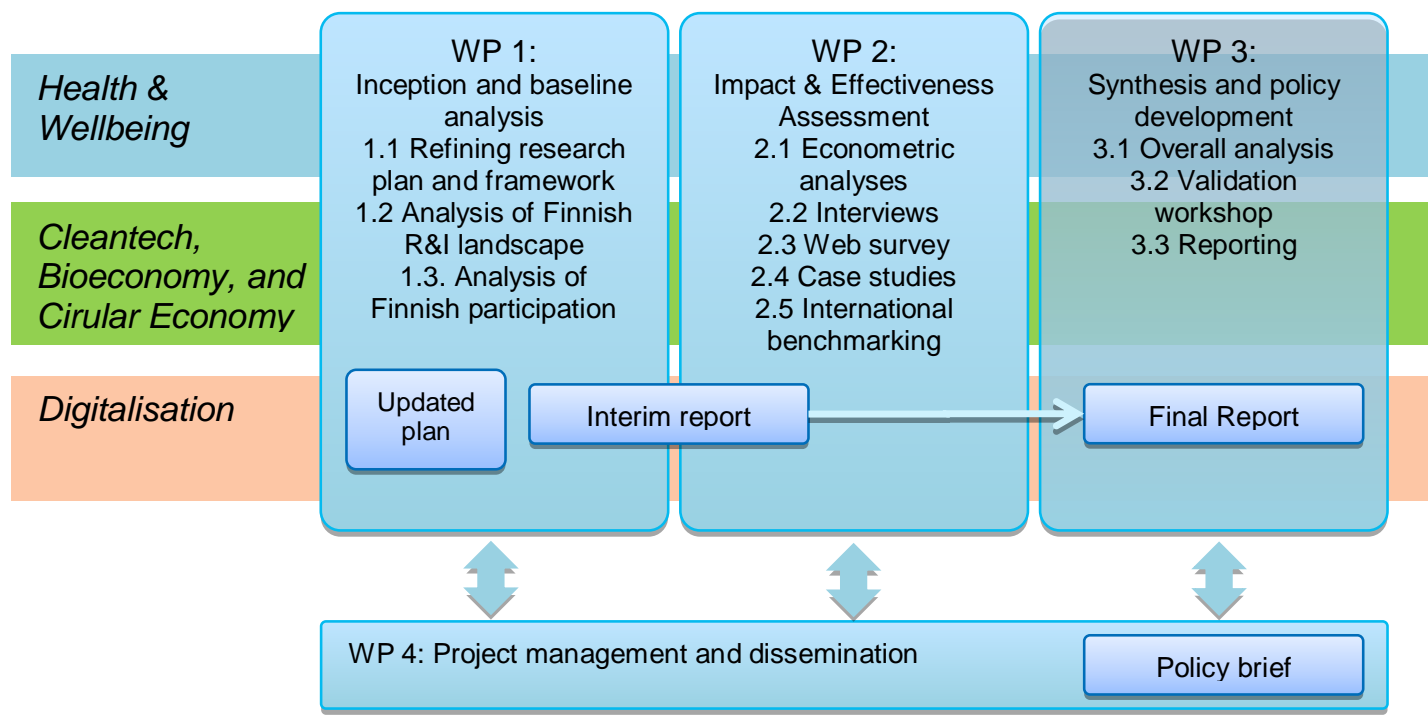

The table below details how the methods mesh with the tasks within the study framework. As laid out in the plan, some tasks imply the method in itself, while others employ multiple. For example, tasks 'Survey' and 'Econometric analysis' mean exactly that, whereas case studies rely on document analysis, interviews, and other relevant data sources.

\section{Study methodology}

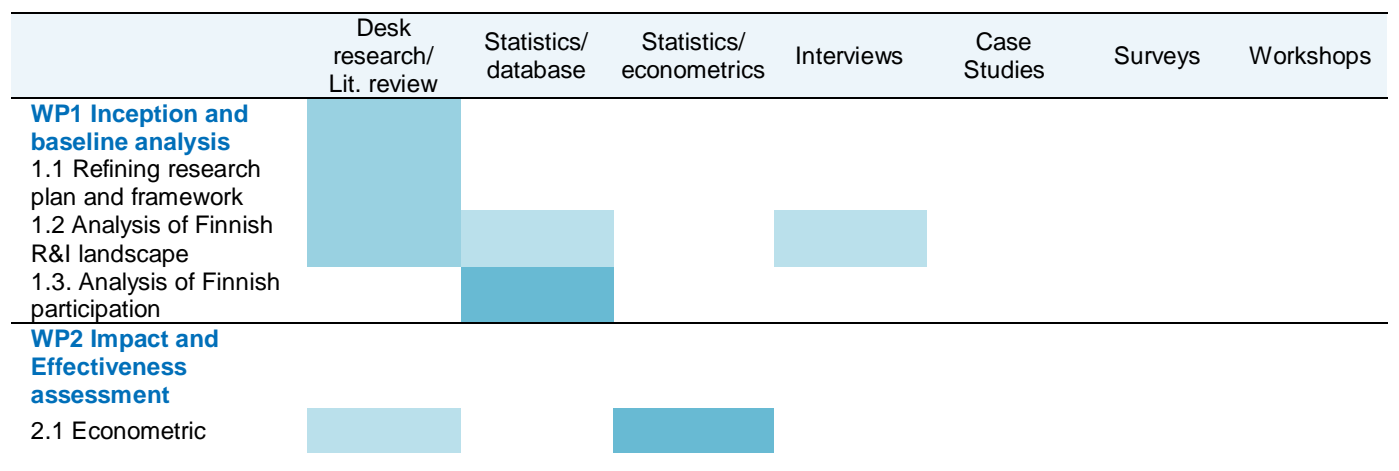




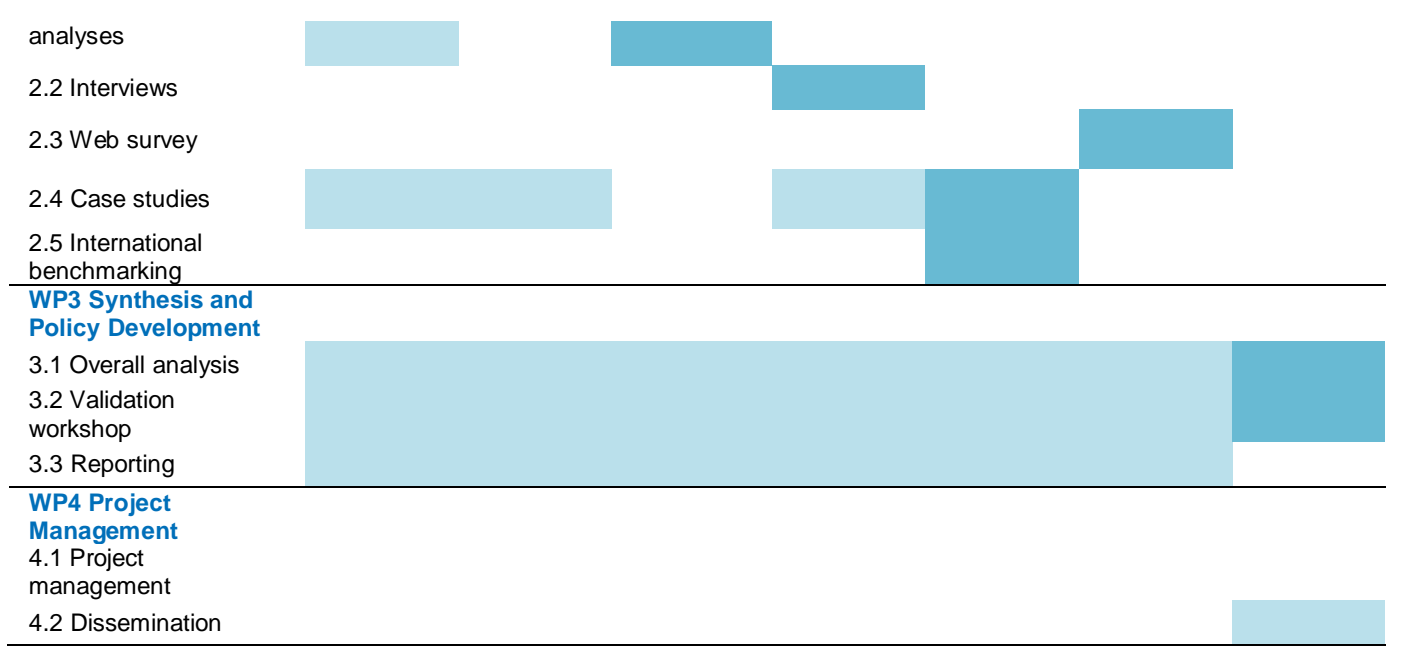

Use of various methods within the project

Between the methods, the statistical and econometric analyses provide quantitative information on how effective FP funding is and how well Finnish participants fare in the program. To complement these findings, the surveys, interviews, and workshops provide more qualitative insight in the circumstances on the effects and added value of FP finding, for a fuller overall picture.

The statistical analysis of participation patterns is based on eCORDA databases of proposals and grants covering the entirety of FP7 and the first three years of Horizon 2020 (data extracted May $31^{\text {st }}$ 2017). Besides overall participation statistics in FP7 and Horizon 2020, the analysis covers participation in three focus areas of Health \& Wellbeing; Cleantech, Bio-economy and Circular Economy (CBC); and Digitalisation.

The study has used semantic analysis to identify areas of FP7 and Horizon 2020 that are of relevance to the three selected focus areas. The identification and tagging were based on concepts contained within the titles and abstracts of proposals. The aim was to identify and tag all FP7/Horizon 2020 projects and proposals that fall with each the three priority areas, regardless of where these are located within the FP7/Horizon 2020 programme structure. This sub-set of proposals and projects could then serve as the basis for analysis of Finnish (and comparator country) participation in each of the priority areas.

The econometric impact assessment focuses on examining the enterprise level effects of FP funding. The approach is to use differences in differences estimation to compare outcomes between the treatment group (FP funding recipients) to the recipients of national funding and untreated control group (-s) with a Differences in Differences method. The data used in this analysis include enterprise level micro statistics including financials and employment, as well as funding decisions between 2003 and early 2017. The econometric method and data are discussed in more detail in section 4.2.)

The interviews have been conducted among stakeholders of the programme both in the inception phase and during the case studies. The sampling logic was purposive, as in informants who have expertise on the Horizon 2020 programme and its contribution or practicalities of funding were explicitly sought. The interviews have been conducted face to face or over the phone. The interviews were semi-structured, based on a template with themes without predetermined answer options. The answers were noted down during the interview. Interviews were conducted until saturation of themes was reached. For the general interviews, the answers were later coded back to the themes following content analysis approach for overall analysis. 
Workshops have been organised both open for the stakeholders and internally. The first workshop was organised June $8^{\text {th }} 2017$ after inception analysis to present initial findings and gather feedback and data. The participants were stakeholders with a relationship to Horizon 2020 either as an administrator or user of funding. The second workshop was organised internally September $6^{\text {th }} 2017$ to review data, develop initial findings and highlight needs for supplementary data collection.

The case studies target innovation (eco-) systems through central organisations within the respective systems. The level of analysis combines organisation in the context of the system. The cases have an exploratory stance, but some propositions as detailed below were developed based on the research questions and inception analysis. The questions and initial hypotheses or propositions for the cases are presented in the following table. The overall objective was to explore how has FP affected formation or development of national innovation networks or ecosystems and interacted with national funding.

\section{Case study framework}

\begin{tabular}{ll}
\hline & \\
\hline Research & What specific benefits are there form using FP? (RQ1) \\
Questions & What has FP funding enabled, in addition to national? (RQ1, 3, \\
& $4-5)$ \\
& What have been the enablers/success factors for this case? \\
& (RQ6) \\
& What is the role of national institutions and funding and their \\
& relation to FP? (RQ6) \\
\hline Propositions & Exploratory case \\
& P1: Clear strategy and aligned activities predict success \\
& P2: Preparation predicts success \\
& P3: Organic competence and/or value based partnership \\
& predicts success \\
& P4: Prior application/funding predicts success \\
& P5: Use of advisors predicts application success \\
\hline
\end{tabular}

The specific questions and propositions set for the case studies.

The cases were chosen to exemplify different types of RDI-ecosystems built around public research institutes, academic networks, and industrial networks, the specific cases are Technical Research Centre of Finland VTT, DIMECC, and Centre of Excellence for Inversion Problems Research.

The main data used in the case studies are documents and interviews. In the case studies, interviews were conducted until saturation and corroborated with secondary sources when possible. Similar setting was applied to case studies on national support systems for FP participation.

\subsection{Limitations}

Limitations are twofold, internal and external. The challenges to internal validity come from limitations of the data and application of methods. All care has been taken to ensure proper implementation of method and quality assurance measures have been employed in terms of feedback from the steering group and internal validation.

Challenges to external validity come from limitations of data when it comes to extrapolation of results. Care has been taken to ensure representative data in each step of the analysis as described below:

Statistical analysis is based on eCORDA repository and analysis of participation figures, and as such the results should be representative. The only possibility of bias is in presentation of 
the results and definitions of the focus areas. In presentation of the results, care has been taken to normalise figures to enable even comparison between contexts. The focus areas have been defined organically through bottom-up analysis, and the definitions are the same between comparisons so the analysis as such is unbiased. However, the analysis is not tailored to fit any particular policy goals and local strengths, which makes it a neutral baseline analysis of relative success in the areas. The same or a similar system could be used in the future as a basis for monitoring progress in these or other focus areas.

Econometric analysis again hinges on the limitations of the data. The largest challenge is that the enterprise population who have received only EU FP programme funding is so small as to weaken statistical power of the results. Thus, comparisons between programmes or instruments in isolation is challenging. Other challenges are survivorship and selection biases, that somewhat affect how accurately the analyses measure the raw effectiveness of subsidies in themselves. Despite the limitations in significance, the results give an indication of relative effectiveness.

Case studies in this context are aimed to describe different nationally significant ecosystems, driven by scientific research, applied technical research, and the industry and explore the contribution of FP in conjunction with national instrument. The cases were chosen as 'critical' as in they were known to be significant in their own areas, and the sampling logic was purposive, as in interviewees were chosen based on their knowledge of the subject. These information from the interviewees was triangulated and confirmed independently through documentation as far as possible. As such the case studies represent themselves, and the generalisation needs to be careful in recognising the pertinent contextual factors. 


\section{ASSESSMENT OF FINNISH PARTICIPATION IN EU FRAMEWORK PROGRAMMES}

In this section, we first present key findings from the various analyses and then provide a synthesis of common findings in the spirit of methodological triangulation. Some details of the data and analyses are presented in Annexes to improve readability of the main document.

\subsection{Participation analysis}

In this participation analysis, we first present the overview and overall statistics. These are based on data extracted from eCORDA and include all funded project from various instruments included therein. ${ }^{67}$ After the overall statistics, we discuss participation in national focus areas. Lastly in this section we take a look at the SME instrument specifically. The following section discusses the most pertinent findings, supplementary statistics about participation are enclose below in the appendixes.

\subsubsection{Overview to participation and success of Finnish applicants}

\section{Participation in proposals}

Finnish actors have contributed to the submission of 6,986 proposals to Horizon 2020 (as of the end of May 2017). This equates to $5.4 \%$ of all proposals submitted to the programme during this period. This is currently slightly lower than the proportion of FP7 proposals involving Finland (6.1\%).

\section{Proposals involving each country}

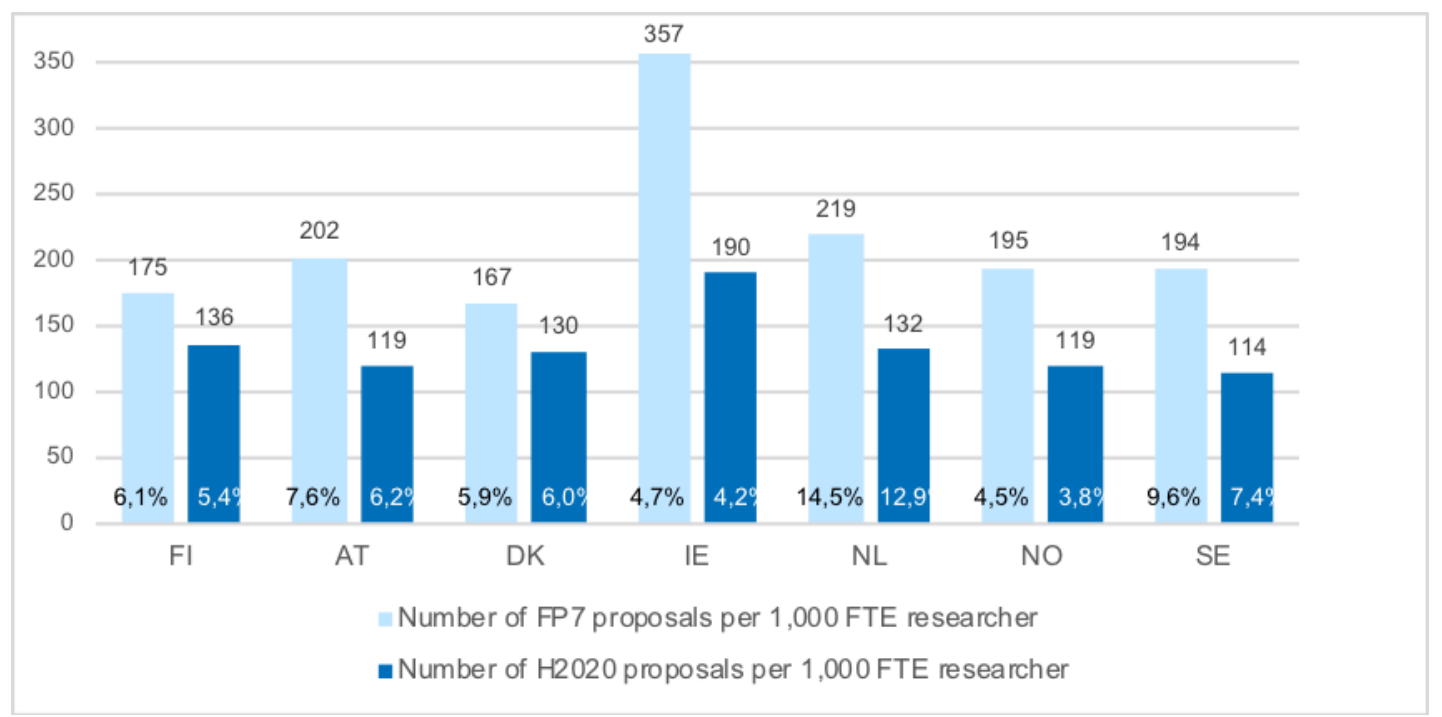

Number of proposal per 1000 research staff and percentage of all FP7 / Horizon 2020 proposals

${ }^{67}$ With some exceptions, also projects under Joint Technology Initiatives are included in eCORDA 
As is shown below, four of the six comparator countries have participated in a greater number and proportion of Horizon 2020 proposals than Finland. However, when taking into account the number of R\&D personnel in each country, the level of Finnish involvement in Horizon 2020 proposals compares more favourably with all-but-one of the comparator countries. This is an improvement from FP7, when Finland's relative involvement in proposals (per researcher) was lower than that of all countries except Denmark.

\section{Number of participations in proposals}

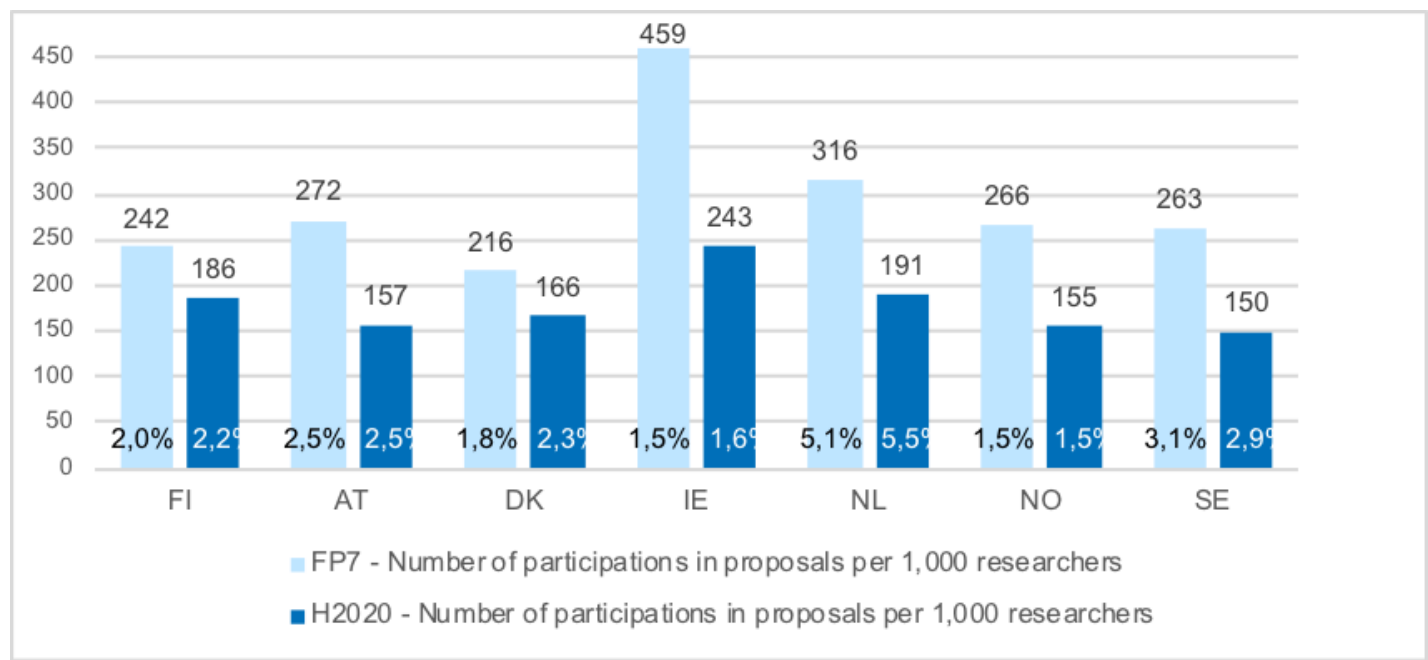

Number of proposal per 1000 research staff and percentage of all FP7 / Horizon 2020 proposals

In 46\% of Horizon 2020 proposals involving Finland, a Finnish actor has held the role of coordinator. This is a higher rate than was seen during FP7, where just $33 \%$ of Finnish proposals were led by a Finnish coordinator. Most comparator countries have seen a similar increase between the two programs, but Finland's rate of proposal coordination in Horizon 2020 is now higher than all comparators. This is a significant improvement on FP7, and as such it is in line with the goal of increasing FP activity in Finland.

Taking account of the relative size of the researcher populations in each country, the number of Horizon 2020 proposal coordinators from Finland is below the rate seen in IE, but above that seen in all other comparators. By comparison, the Finnish rate in FP7 only compared favourably with Denmark.

Many FP proposals (66\% in Horizon 2020) involve just one participant, who is therefore by default also the coordinator. This is particularly the case in some areas of the programme (e.g. nearly all of the 19,000 proposals to the European Research Council involve just one participant). These single-participant proposals can therefore give a misleading picture of true proposal coordination rates. If we repeat the above analysis of proposal coordination, but just for multi-partner proposals (i.e. excluding proposals with only one partner), the data changes significantly.

Finnish actors have participated in 4,796 multi-partner Horizon 2020 proposals, of which it was the coordinator in 995 ( $21 \%$ of) cases. This is a higher rate than any of the comparator countries, other than Ireland, and slightly higher than was achieved by Finland in FP7. The Finnish rate of multi-partner proposal coordination in Horizon 2020, relative to the FTE researcher population (19 coordinators per 1,000 FTE), is also higher than most comparator countries, other than IE and NL. By both these metrics, application activity in Finland has improved relative to most comparator countries between FP7 and Horizon 2020. 
On average, Horizon 2020 proposals involving Finland included 1.4 local (i.e. Finnish) actors each. During FP7, a similar number of Finnish actors (1.4) were involved in each Finnish proposal. In both cases (FP7 and Horizon 2020) the average number is below that of NL, but above all other comparators. Excluding single-partner projects increases the average number slightly (e.g. for $\mathrm{Fl}$ in Horizon 2020, from 1.37 to 1.38 local partners per proposal). However, the overall pattern is similar.

Finnish proposals to Horizon 2020 also included (on average) 10.5 actors from other countries (i.e. beyond Finland). These 48,123 proposal partners came from 133 different countries, but with over half (62\%) located in Germany, the UK, Spain, Italy, France, the Netherlands and Belgium. Other countries accounting for an unusually high proportion of partners (for Finland, compared with overall participation patterns) include Sweden, Norway, Estonia, Austria, Poland, Lithuania, Portugal, and Latvia.

Because of multiple Finnish participations in some proposals, the total number of Finnish participations in Horizon 2020 proposals $(9,551)$ is $37 \%$ higher than the number of unique proposals in which Finland is involved $(6,986)$. Finland accounts for just $2.2 \%$ of all participations in Horizon 2020 proposals, which is lower than NL, SE, AT, and DK, but higher than NO and IE. When taking account of the size of the respective researcher populations, Finland only has a lower number of participations in Horizon 2020 proposals (per 1,000 R\&D personnel) than the Netherlands and Ireland, but a higher participation rate (per 1,000 R\&D personnel) than Sweden, Norway, Austria, and Denmark.

During FP7 proposals involving Finland accounted for on average $2.0 \%$ of all proposals. It was also lower than all the six comparator countries other than Denmark. Nevertheless, because of the longer time-period covered, the participation rate (242 per 1,000 R\&D personnel) was higher than that observed in Horizon 2020. Now during H2020 participation in proposals has grown a few decimals of percentage point. However, looking further at the trend in participation, it seems that Finnish participation is falling slowly behind the comparison. While the figures for 2017 should not be emphasised, it seems that Finnish participation activity is growing, but consistently slower than the comparison. In fact, taking the programme change into account, the trend it is possibly plateauing on the $\sim 2.2 \%$ level.

\section{Proportion of participation in proposals}

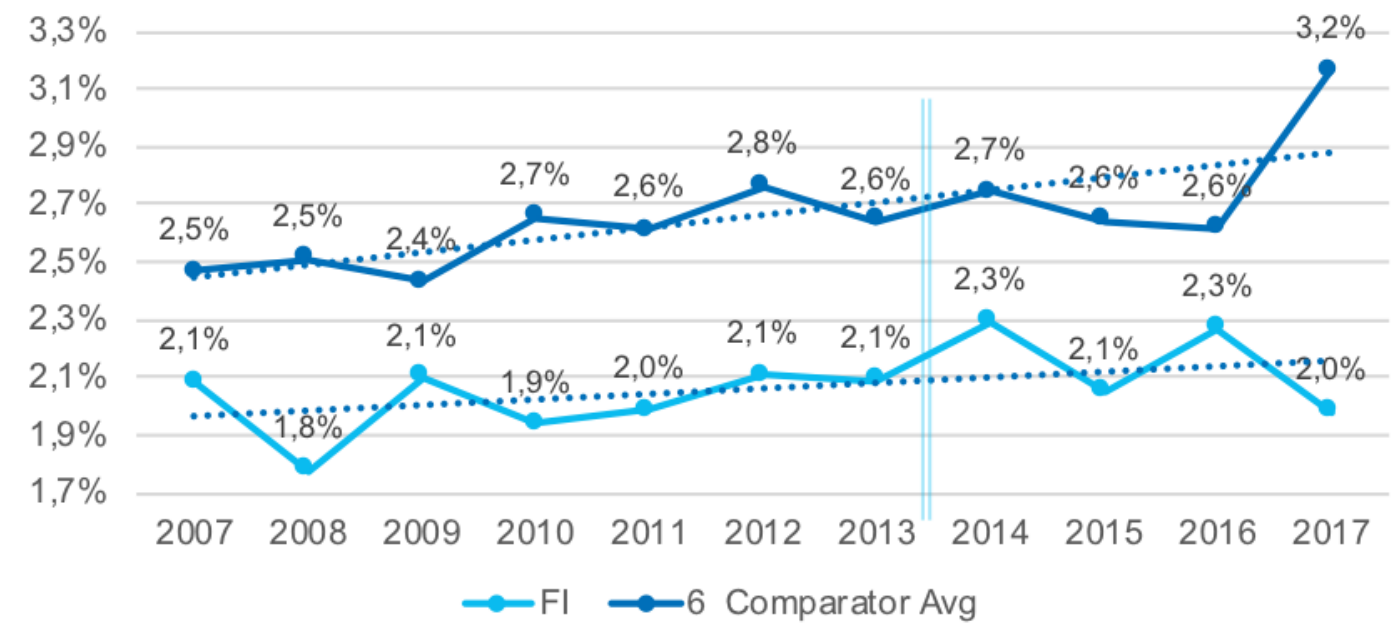

Proportion of Finnish proposals of all compared to average between participants

The distribution of Finnish participations in proposals across the main programme areas of Horizon 2020 is shown in the Appendix, alongside comparable figures for Horizon 2020 
overall and for the comparator countries. While the Finnish distribution largely reflects the overall pattern, it is less active in proposals within the Excellent Science and Science with/for Society programmes, compared with the overall average. Indeed, a smaller proportion of its proposal participations are accounted for by the Excellent Science programme, compared with any of the comparator countries. By comparison, Finland is relatively more active in relation to Industrial Leadership and Euratom programmes, compared with the average. Its proportion of participations accounted for by the Industrial Leadership programme is greater than all comparator countries, while only SE has a greater proportion of participations in the Euratom programme.

\subsubsection{Participation in projects and proposal success rate}

To May 2017, 893 Horizon 2020 grants had been awarded to projects involving Finland. This represents $6 \%$ of all Horizon 2020 projects, which is higher than IE and NO, but lower than the other comparator countries. Finnish actors have been awarded 17 Horizon 2020 projects for every 1,000 R\&D personnel in the country, which is higher than Sweden and on par with Norway. This is an improvement on FP7, when Finland's rate of projects per researcher was below that of all the comparator countries.

\section{Number of awarded FP projects per 1000 research staff}

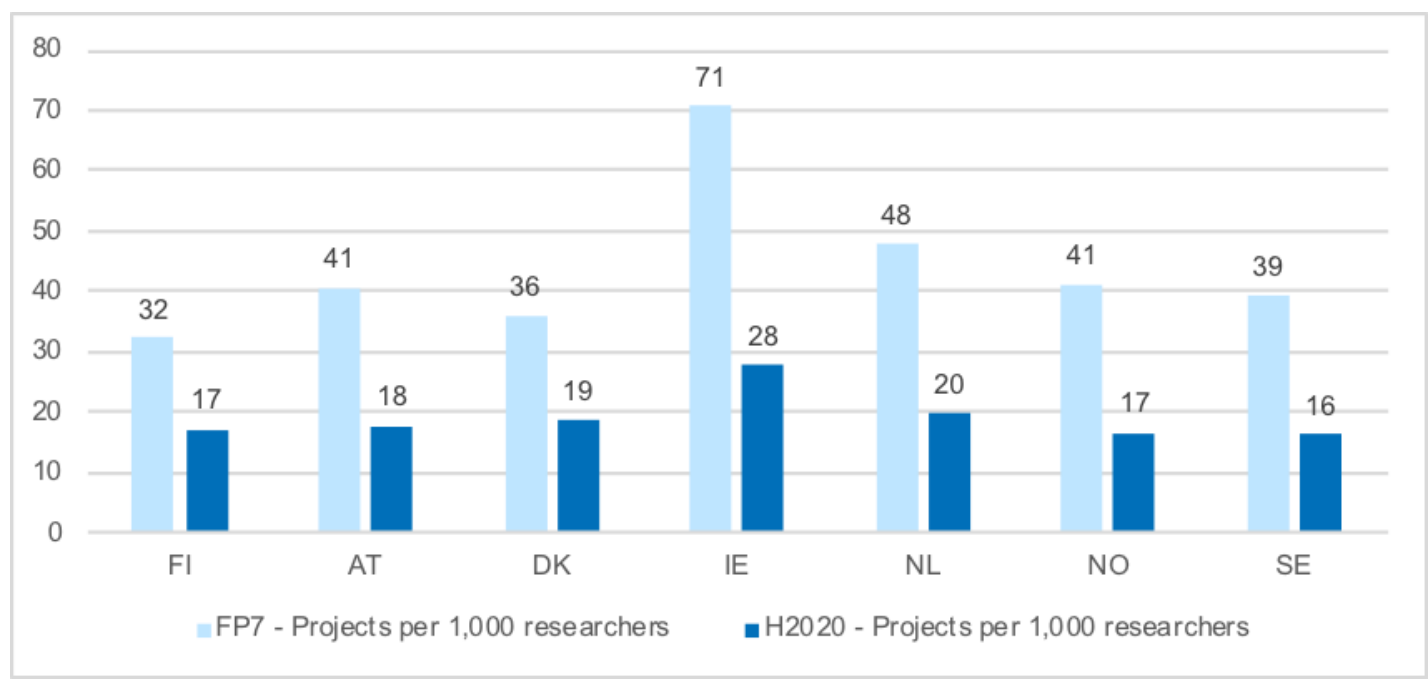

The 893 projects involving Finland came from 6,986 proposals. This equates to a proposal success rate of $12.8 \%$ - which is higher than the overall success rate of Horizon 2020 proposals $(11.5 \%)$, but below the rates achieved in all the comparator countries.

Finnish success rates in FP7 were much higher (18.5\%) than in Horizon 2020, but this partly reflects higher success rates seen in FP7 overall (15.9\%). Finland's FP7 success rate was also slightly below that of all the comparator countries. 


\section{Success rate of proposals}

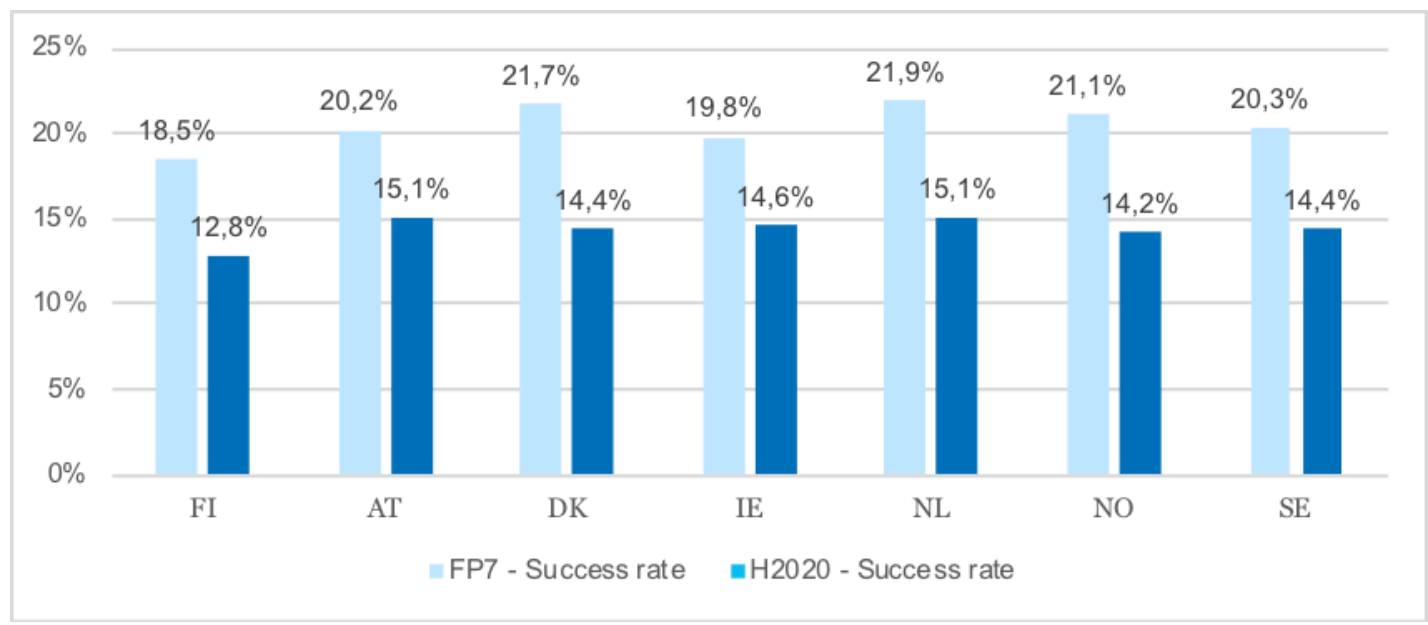

Fraction of approved proposals

Again, looking at broader trends, the success rate of Finnish participations has been stable both during FP7 and Horizon 2020. Spotting trends over the programme periods is not necessarily meaningful, as in general the competition in Horizon 2020 has increased and average success rates have dropped from FP7. However, Finnish success rate is consistently lower than the average of comparator countries most years. Beside the expected level correction between programming periods, Finnish proposal acceptance rate has been stable over time, which is both good and bad as it indicates there is relatively little learning at the system level, but then again there is no catastrophic loss of competitiveness either.

\section{Participation success rate over time}

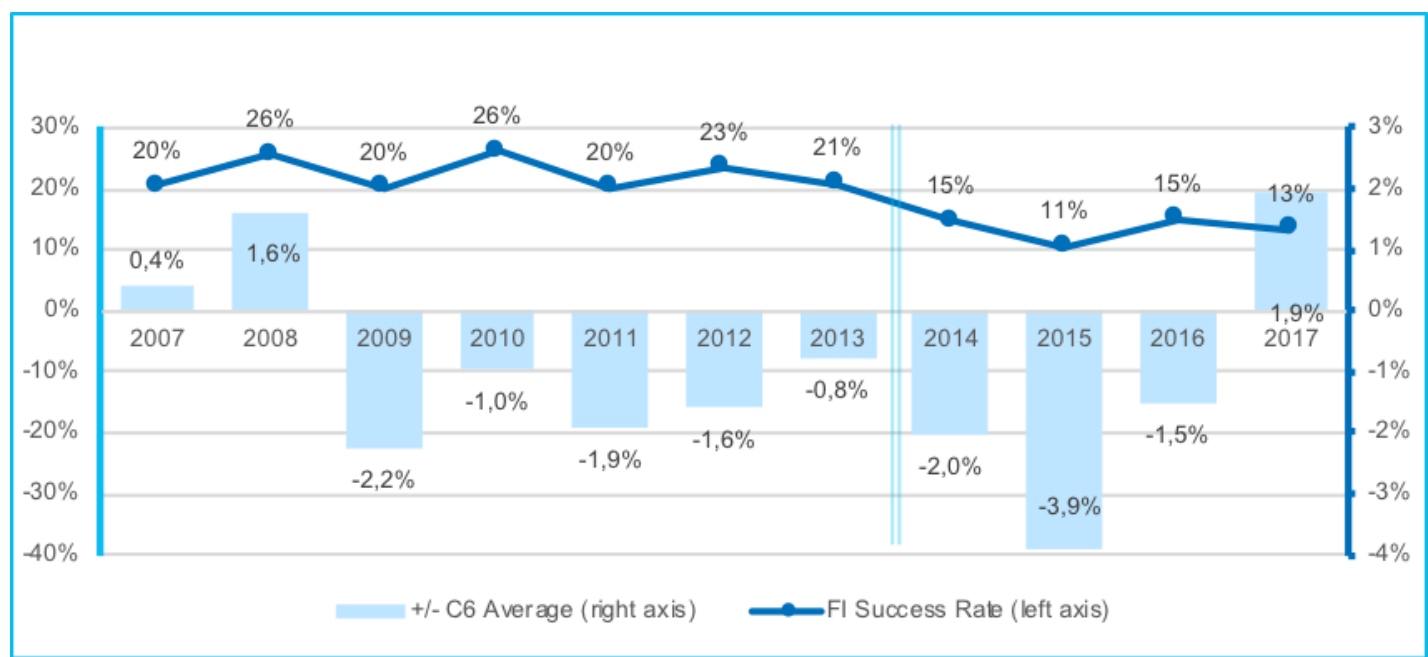

Success rate of proposal with Finnish participants (on the left) by the year and difference to average of comparators (right scale)

Horizon 2020 grants have been awarded to 278 projects with a Finnish coordinator. The role of coordinator is significant, because the coordinator typically has a central role both in defining the project and implementing it, which typically results in a better fit between the project and the coordinators interest and broader benefits from the project. The equates to 5.4 project coordinators for every $1,000 \mathrm{R} \& \mathrm{D}$ personnel in the country. This rate is higher than Sweden, Austria, and Norway, but lower than the other two comparator countries. Finnish coordinator rates in FP7 were slightly higher (at 6.4 coordinators per 1,000 
researchers), but this was below the rates achieved by all comparator countries during this programming period. As such, Finland's performance relative to comparator countries (in terms of coordinator numbers) has tended to improve in the first period of Horizon 2020 compared with the whole of FP7.

The success rate of Finnish-coordinated Horizon 2020 proposals is $8.7 \%$ - which is much lower than the rate of success for proposals where Finland is only a partner $(16.2 \%)$. It is also lower than the overall Horizon 2020 figure (11.5\%), and below the rates of coordinator success achieved in all of the comparator countries. In FP7, Finland's success rate for coordinators was similarly below the overall average and the success rates in all comparator countries.

If we look only at those proposals/projects with multiple participants (i.e. excluding those where the coordinator is the only partner), the success rate for Finnish coordinators increases from $8.7 \%$ to $9.6 \%$ for Horizon 2020 , and from $11.0 \%$ to $16.1 \%$ for FP7. While there is an increase in the success rate overall with this measure, the increase for Finland is more significant than for many of its comparator countries. Nevertheless, the Finnish figures is still lower than in all comparator countries, both for FP7 and Horizon 2020.

The 893 grants awarded to Finland in Horizon 2020 involve 1,288 individual Finnish participations. This represents $2.1 \%$ of all Horizon 2020 participations, which is slightly higher than Denmark, Ireland and Norway, but lower than Austria, Netherlands, and Sweden (each of which accounts for between $2 \%$ and $7 \%$ of all participations). Finland has 25.1 project participations in Horizon 2020 for every 1,000 R\&D personnel in the country, which is higher than DK, NO and SE, but below AT, IE, and NL. This is a slight improvement on Finland's relative position in FP7.

The 1,288 Finnish participations in successful projects, from 9,551 participations in proposals, represents a participation success rate of $13.5 \%$ in Horizon 2020 so far. This is below the overall rate of success for all participations in proposals (14.3\%), and below that for all comparator countries. During FP7, the Finnish participation success rate was slightly above average and above the rate in Ireland, but still lower than in the other comparator countries.

Comparing across different organisation types, Horizon 2020 success rates were highest amongst Finnish participations from public bodies (PUB) (25.1\%). However, rates here were lower than the overall average (26.5\%) and most of the comparator countries. Finnish success rates for private for-profit corporations (excluding education, henceforth PRC) were also high (24\%). This rate of success is greater than the overall average and above the rate in most comparator countries. Specifically for SME-PRC participations, the rate is $10.9 \%$, which is slightly below the Horizon 2020 average, as well as lower than all the comparator countries. Elsewhere in higher or secondary education (HES), public bodies (PUB), and research organisations (REC), Finnish participations achieved success rates lower than the overall average, and below the levels of success seen across most comparator countries.

EC contributions to Finnish participations in Horizon 2020 projects totalled $€ 579$ million, which equates to $2.2 \%$ of all funding to project participations to date. This is below the proportion realised by most of the other comparator countries, but higher than that received by Ireland and Norway. If we 'normalise' contributions by using national GDP figures, then Finland compares favourably with its comparator countries, only being below Netherlands in this measure. The average contribution to each Finnish participation (at $€ 450$ thousand) is also relatively high, with only Netherlands and Norway having a higher rate. 


\section{Proportional contribution from FP}

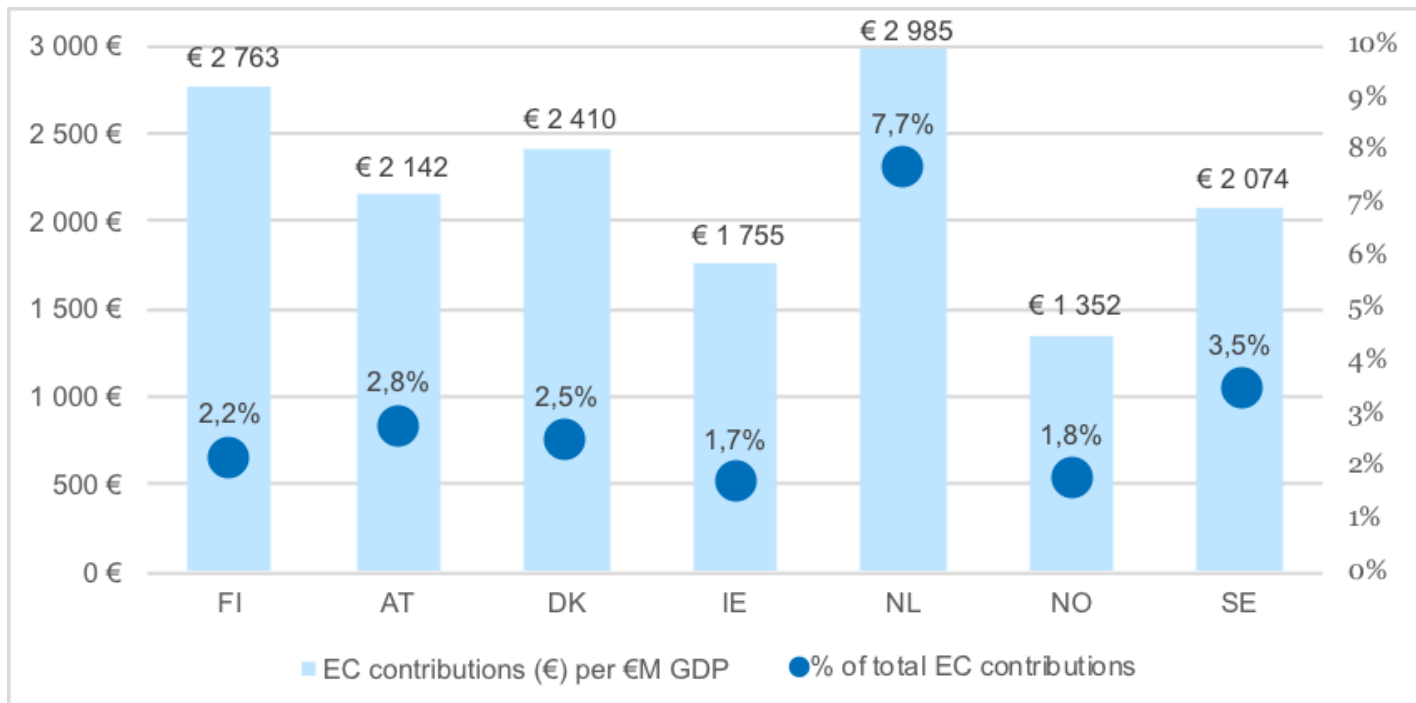

EC contribution per million €of GDP (bars, left axis) and as a fraction of Horizon 2020 programme volume (dots, right axis)

As an overall finding, Finland fares quite well in the light of funding drawdown in absolute numbers and especially in relative contribution per active research staff. The clear weakness in Finland is application success that consistently trails behind.

If we unpack the overall figures, we can see another divergent trend. The average participation rate of the comparators has a very slightly rising trend, whereas Finnish rate of participation has an equal and opposite trend that is consistent both with the diverging trends in applications and stable success rates. While again the trend might be slightly deceiving since the programme change has affected success rates, the divergence may signal that Finnish participation has plateaued, while others are gaining ground still.

Proportion of all participations over time

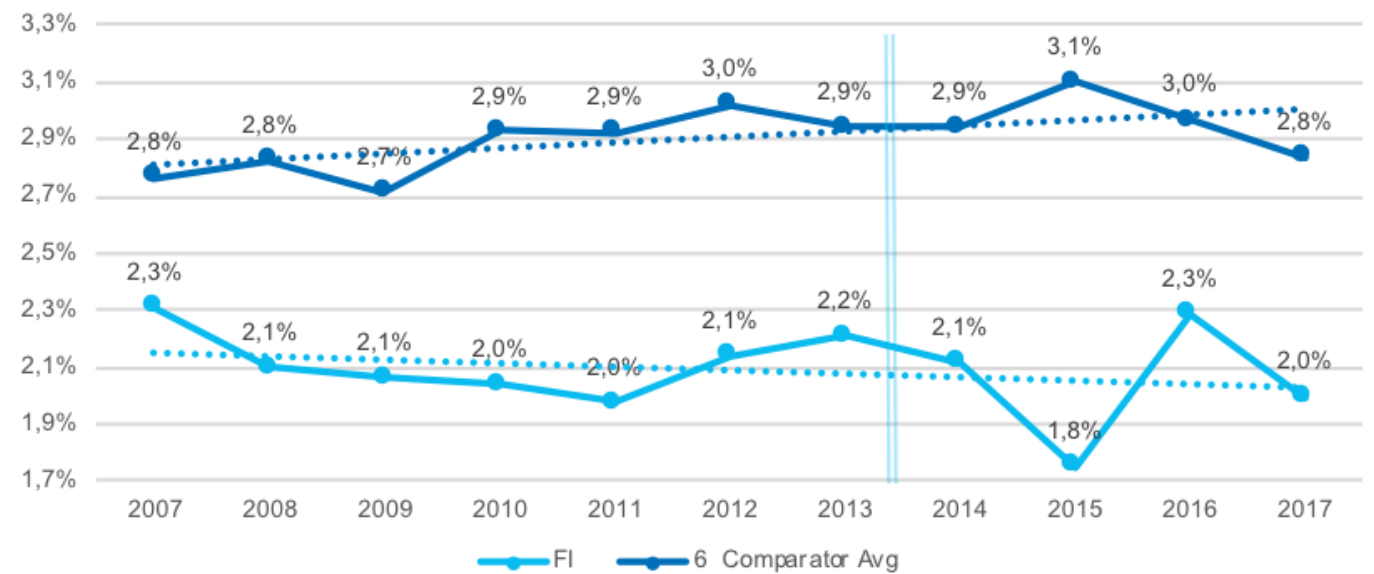

Participations of all projects per year 


\subsubsection{Analysis of national focus areas}

Three specific focus areas were selected based on the longer standing national foci. The list of specific focus areas investigated herein were chosen as a basis for coordinating and developing messages for Horizon 2020 Work Programmes 2016 onwards, based on perceived societal needs and strengths of Finnish innovation system. These are Digitalisation, Health \& Wellbeing $(\mathrm{H} \& W)$, and Cleantech, Bioeconomy and Circular Economy (CBC).

However, it needs to be noted that the foci were selected in 2016 and the data for this analysis were extracted shortly thereafter in 2017, which means that any and all national coordination activities have not much bearing on these findings. As such these data or analyses provide a historical baseline for the national focus areas. Moreover, these areas are chosen as broader policy foci and RDI funding and the FP is only one type of action or instrument implemented to develop these areas.

The individual projects belonging to each focus area were identified through an innovative approach using semantic analysis of project abstracts that enabled populating a list of concepts that were used in searching eCORDA to identify projects that belong conceptually to each of the focus areas (list of keywords in Appendix 1). The keywords were chosen by the researchers through an explorative strategy, and thus the keywords do not reflect the specifics of the Finnish policy foci exactly 1:1 (as discussed also in Section 3). The foci, especially digitalisation and circular or bio-economy are horizontal areas of innovation and technology, which makes narrowing them down and defining them challenging. Therefore, the following results are an indicative comparison between past success in the FPs, not a forecast of future performance.

\section{Digitalisation}

Finnish actors have contributed to the submission of 3,647 Digitalisation proposals in Horizon 2020 (as of May 2017). This equates to $6.1 \%$ of all such proposals submitted to the programme during this period. This is only slightly lower than the proportion of Digitalisation proposals involving Finland in FP7 (6.8\%).

Half of the comparator countries (AT, NL, and SE) have participated in a greater number and proportion of Digitalisation proposals than Finland, in both FP7 and Horizon 2020. However, when taking into account the relative number of R\&D personnel in each country, the number of proposals involving Finland in Horizon 2020 is higher than all comparator countries except Ireland. This is an improvement on FP7, where the Finnish rate of involvement was below that of most comparators. 


\section{Participation in proposals in digitalisation area}

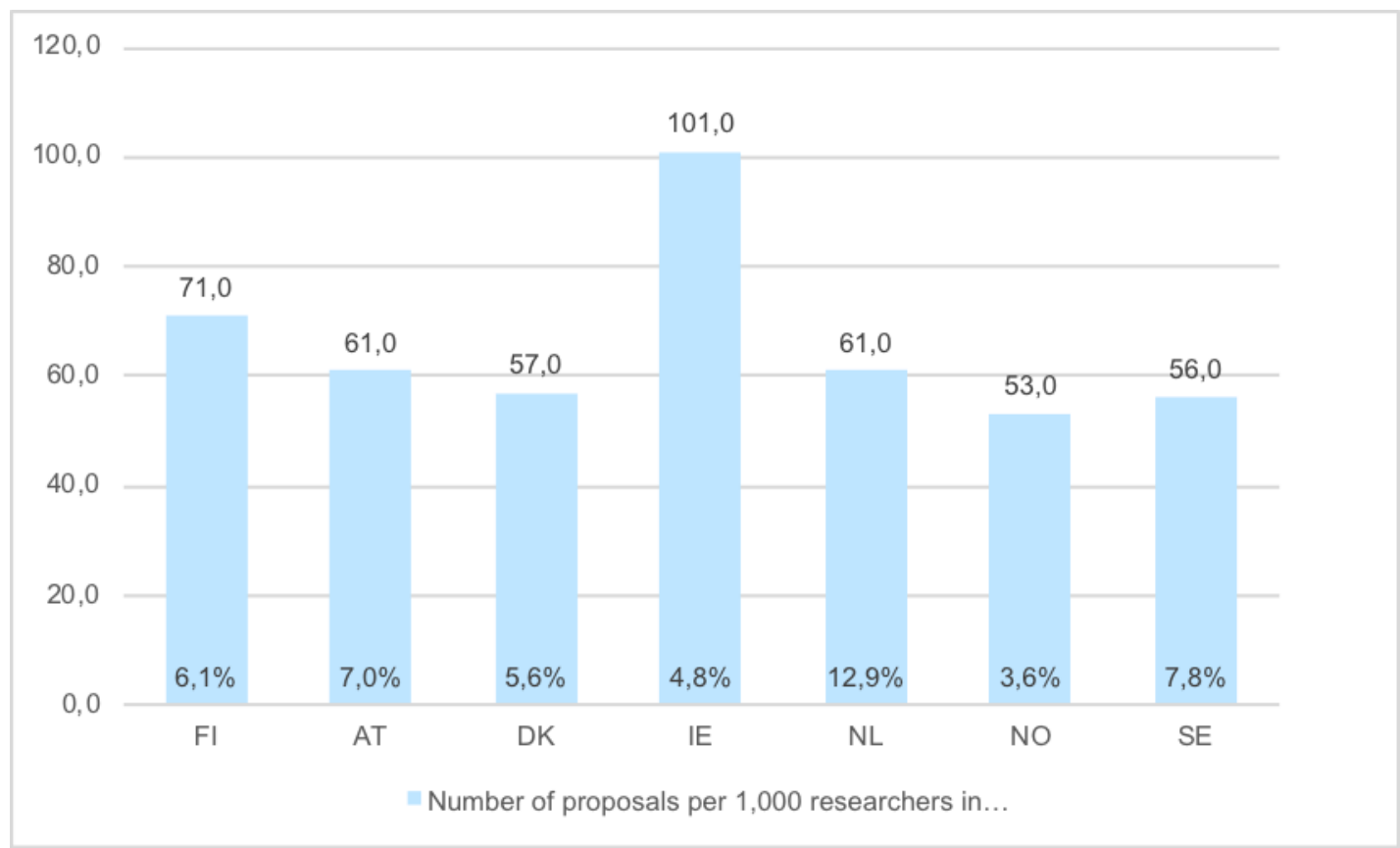

Number of proposal involving country per 1000 researchers and percentage of all proposals

In $43 \%$ of Horizon 2020 Digitalisation proposals involving Finland, a Finnish actor held the role of coordinator. This is much higher than in FP7, where $30 \%$ of Finnish Digitalisation proposals were led by a Finnish coordinator. All comparator countries had a lower rate of coordination than Finland in Horizon 2020, but not in FP7 where IE, NL and SE had a higher rate.

If we consider the relative size of the researcher base in each country, the number of Digitalisation proposal coordinators from Finland (31) in Horizon 2020 is above the rate for all comparator countries except IE. In FP7, the Finnish rate (25 coordinators per 1,000 personnel) was below most of the comparators.

Finnish actors have participated in 2,614 multi-partner Horizon 2020 Digitalisation proposals, of which it has served as the coordinator in $545(21 \%)$. This is a higher rate than all comparator countries except Ireland (22\%). The Finnish rate of Digitalisation proposal coordination in Horizon 2020 relative to the FTE researcher population (10.6), is again higher than all comparator countries expect Ireland. This is a higher rate of activity than in FP7, where Finland had a lower rate of MP coordinators per researcher than nearly all comparators.

Because of multiple participations in some proposals, the total number of Finnish participations in Horizon 2020 Digitalisation proposals $(5,126)$ is higher than the number of unique Digitalisation proposals in which Finland is involved $(3,647)$. These Finnish participations represent just $2.3 \%$ of all participations in Horizon 2020 Digitalisation proposals, which is a lower proportion than AT, NL, and SE. However, when taking account of the size of the respective researcher populations, Finland has a higher number of participations in Horizon 2020 Digitalisation proposals (100 per 1,000 R\&D personnel) than all of the comparator countries except Ireland. 
Finland accounted for a similar proportion (2.1\%) of all participations in Digitalisation proposals in FP7. However, because of the longer time period covered, its participation rate (131 per 1,000 R\&D personnel) was higher than in Horizon 2020.

To May 2017, altogether 427 Horizon 2020 grants had been awarded to Digitalisation projects involving Finland. This represents 6.5\% of all Horizon 2020 Digitalisation projects, which is lower than AT, NL and SE. When one adjusts for the size of the research base in each country, Finland (with 8.3 Horizon 2020 Digitalisation projects for every 1,000 R\&D personnel) sits in the middle of the comparator countries.

The 427 Horizon 2020 Digitalisation projects involving Finland came from 4,533 proposals. This equates to a proposal success rate of $9.4 \%$ - which is lower than the overall success rate of Horizon 2020 Digitalisation proposals (9.9\%), as well as below the rate achieved in all comparator countries. Finnish success rates in FP7 Digitalisation proposals were even higher $(18.1 \%)$ than in Horizon 2020, but this partly reflects higher success rates seen in FP7 overall. Proposal success rates were still below all comparator countries.

\section{Success rate in Digitalisation area}

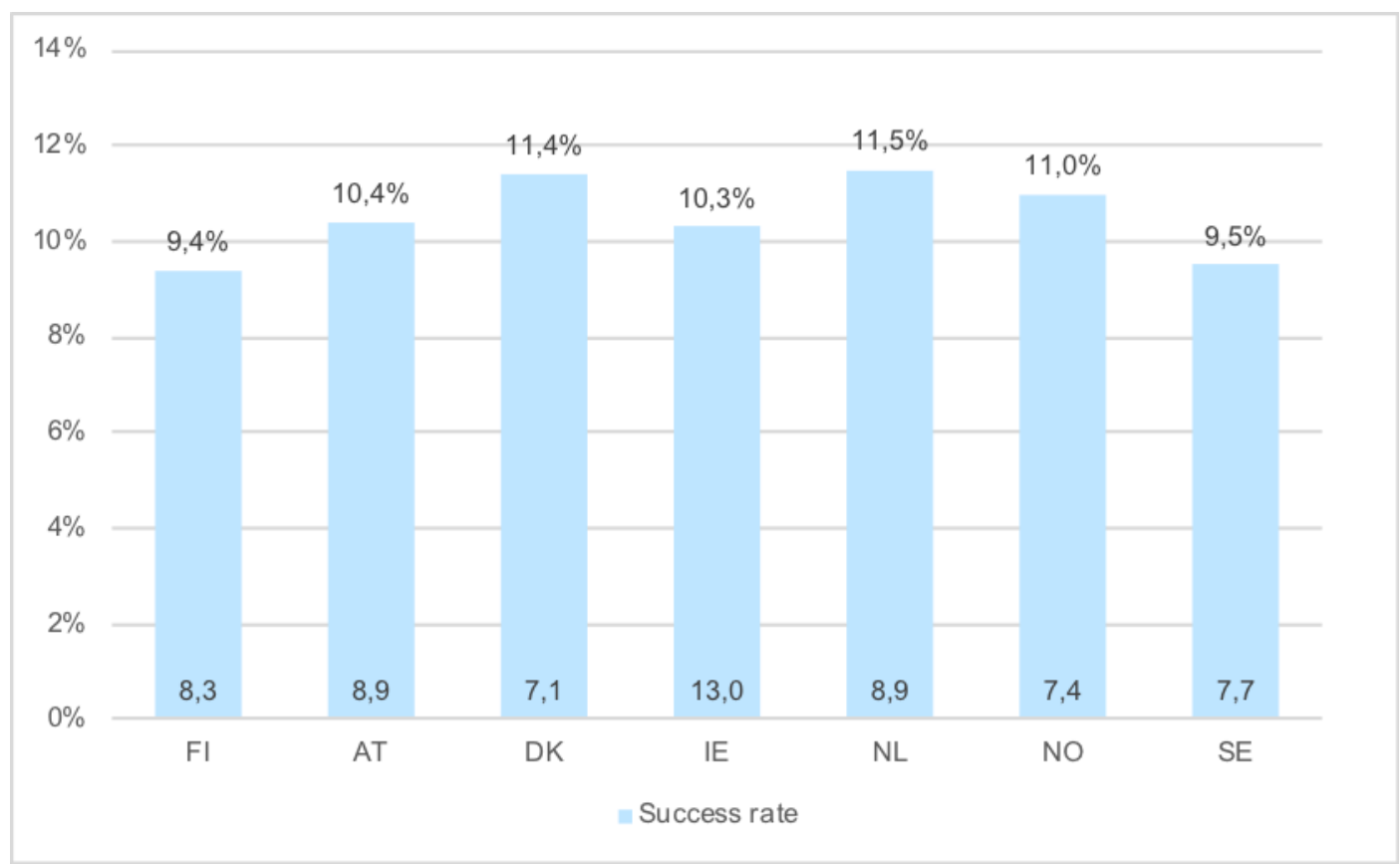

Success rate of projects and number of projects per 1000 research staff

There is a clear break between the programmes which makes spotting a meaningful trend hard. The general level has dropped almost 10 percentage points on average, but from 2014 forward the trend is slightly positive. 


\section{Success rate in Digitalisation area over time}

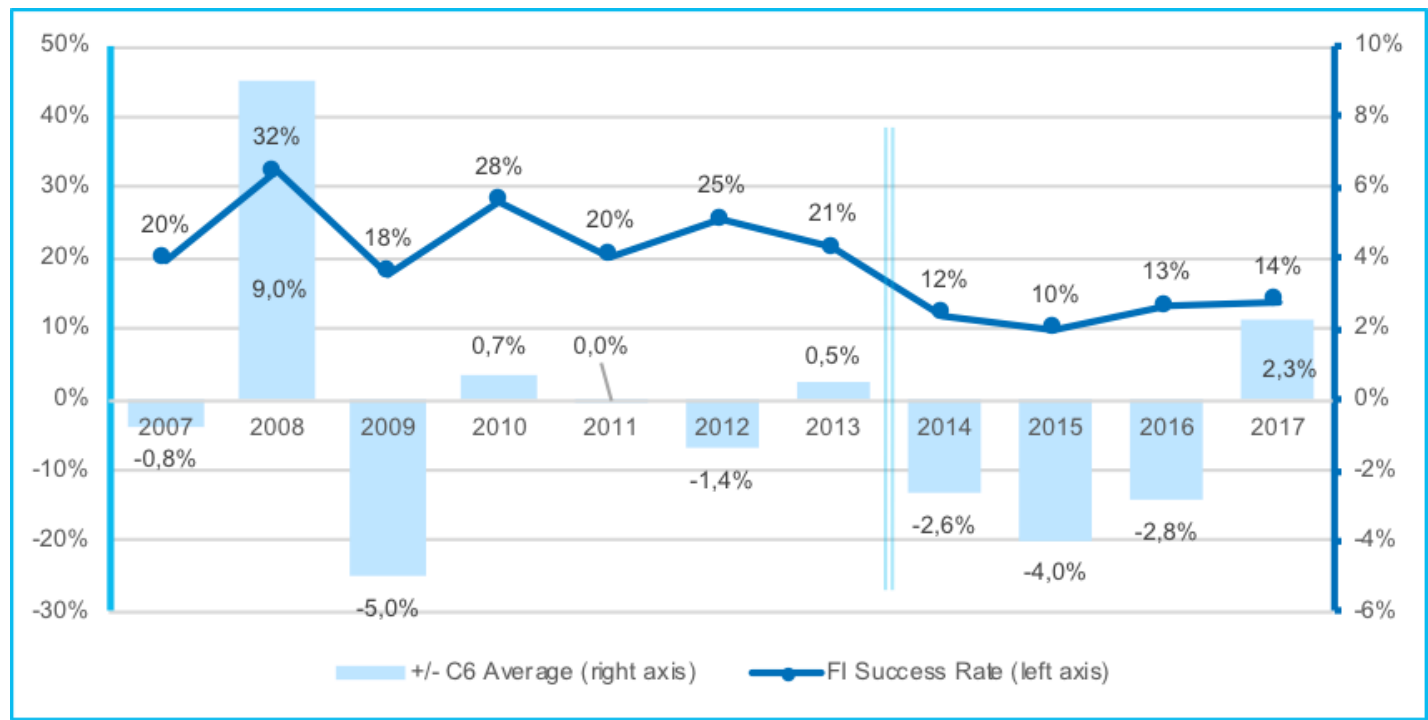

Success rate of Finnish applications per year (left axis), and difference to average of comparison countries (right axis)

Horizon 2020 grants have been awarded to 128 Digitalisation projects with a Finnish coordinator. The equates to 2.5 projects for every $1,000 \mathrm{R} \& \mathrm{D}$ personnel in the country. This rate is below that of all comparator countries apart from Norway and Sweden. The rate (2.7 coordinators per 1,000 personnel) for Finland in FP7 was lower than all comparators except Denmark.

The success rate of Finnish-coordinated Digitalisation proposals in Horizon 2020 is $8.1 \%$. This rate is both lower than the overall Horizon 2020 figure (10.9\%), and lower than the rates of coordinator success achieved in all comparator countries. In FP7, Finland's success rate for coordinators (16.6\%), was above average and greater than in half of the comparator countries.

If we look only at those Horizon 2020 Digitalisation proposals/projects with multiple participants (i.e. excluding those where the coordinator is the only partner), the success rate for Fl coordinators increases from $14.5 \%$ to $19 \%$. However, this is still lower than in all of the comparator countries. 


\section{Success rate of coordinators in Digitalisation area}

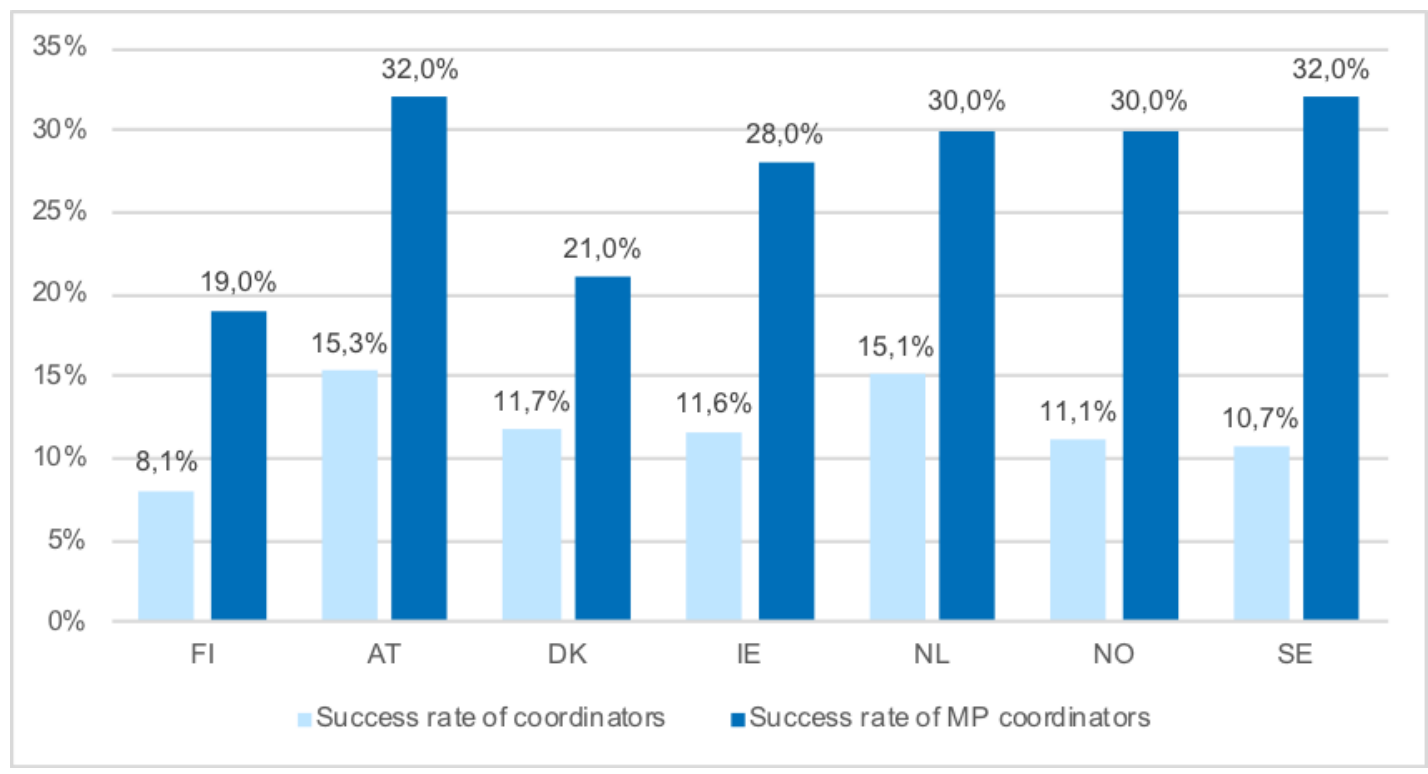

The 427 Digitalisation grants awarded to Finland in Horizon 2020 involve 607 individual Finnish participations. This represents $2 \%$ of all participations in Horizon 2020 Digitalisation projects. When taking account of the size of the researcher base, Finland sits in the middle of the comparator countries. The 11.8 Digitalisation participations per 1,000 R\&D personnel in Finland is below that achieved in $\mathrm{FI}, \mathrm{AT}$ or NL, but above that of DK, NO and SE. A similar pattern can be seen in FP7.

The 607 Finnish participations in successful Horizon 2020 Digitalisation projects, from an original 5,126 participations in proposals, represents a participation success rate of $11.8 \%$ in Horizon 2020 so far. This is below the overall rate of success for all participations in Digitalisation proposals (13.3\%), and below that achieved in all of the comparator countries. The Finnish success rate in FP7 compared more favourably.

Comparing across different organisation types, Finnish success rates for Digitalisation participations were highest amongst PUB and PRC organisations (both 18\%). The PRC success rate was above average and above most comparator countries. Success rates for HES and REC were below average and below all comparators.

EC contributions to Finnish participations in Horizon 2020 Digitalisation projects totalled $€ 294$ million, which equates to $2.3 \%$ of all funding to Digitalisation participations to date. The trend follows the pattern of divergence between Finnish participation and comparison. This is below the proportion realised by Austria, the Netherlands, and Sweden. The average contribution to each Finnish Digitalisation participation (at $€ 484$ thousand) is however above that achieved by all comparator countries apart from the Netherlands. 


\section{Participations in Digitalisation projects over time}

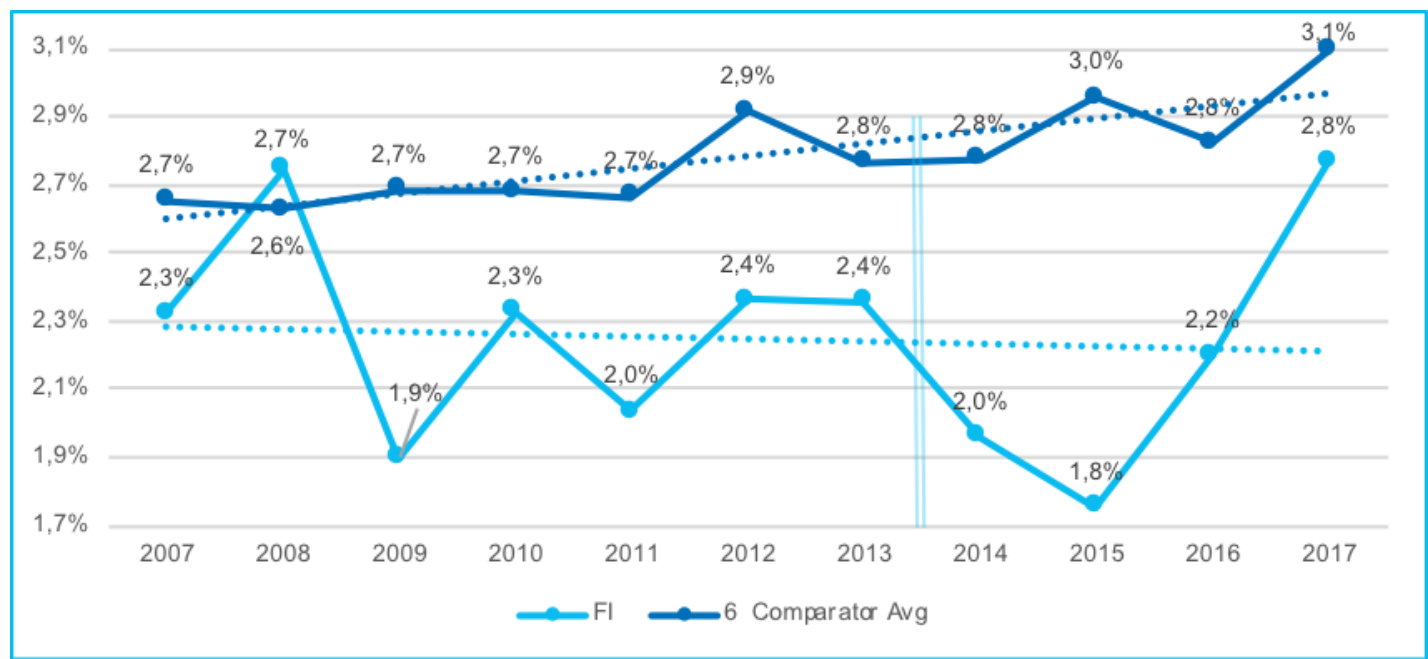

Proportion of all participation per year

\section{Health \& Wellbeing (H\&W)}

Finnish actors have contributed to the submission of 3,051 Health \& Wellbeing proposals in Horizon 2020 (as of May 2017). This equates to $5.3 \%$ of all such proposals submitted to the programme during this period. It is only slightly lower than the proportion of FP7 Health \& Wellbeing proposals involving Finland (5.8\%).

As is shown below, Denmark, Ireland and The Netherlands have all participated in a greater number and proportion of Health \& Wellbeing proposals than Finland, in both FP7 and Horizon 2020. When taking into account the relative number of $R \& D$ personnel in each country, the number of proposals involving Finland compares unfavourably with all comparator countries in FP7 and with half of these countries in Horizon 2020.

\section{Number of H\&W proposals involving country}

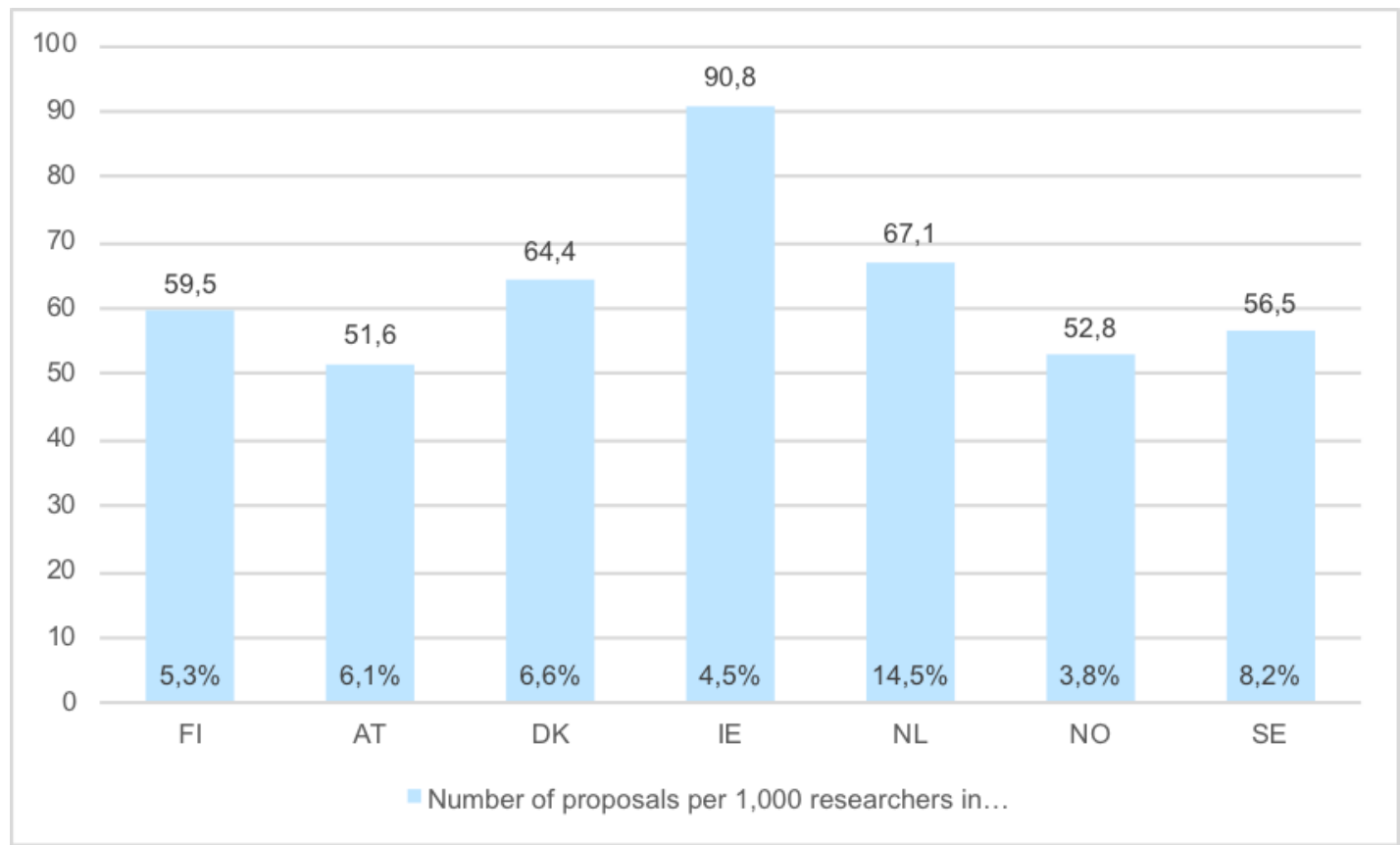

Number of proposals per 1000 research staff and proportion of all participations 
In $45 \%$ of Horizon 2020 Health \& Wellbeing proposals involving Finland, a Finnish actor held the role of coordinator. This is higher than in FP7, where just $36 \%$ of Finnish Health \& Wellbeing proposals were led by a Finnish coordinator. Most comparator countries have seen a similar increase in coordination rates from FP7 to Horizon 2020, although only IE has achieved a higher rate than FI in Horizon 2020.

If we take account of the relative size of the researcher base in each country, the number of Health \& Wellbeing proposal coordinators from Finland in Horizon 2020 (27 per 1,000 researchers) is below the rate seen in half of the comparator countries. This is a slight improvement on FP7 in Finland's relative position.

Finnish actors have participated in 2,114 multi-partner Horizon 2020 Health \& Wellbeing proposals, of which it has served as the coordinator in $426(20.2 \%)$. This is a higher rate than in AT, DK, NO or SE, but below that in IE or NL. It is also higher than Finland achieved in FP7 (16.8\%). The Finnish rate of Health \& Wellbeing proposal coordination in Horizon 2020, relative to the FTE researcher population is lower than most comparator countries, but its relative position has improved slightly from FP7.

Because of multiple Finnish participations in some proposals, the total number of Finnish participations in Horizon 2020 Health \& Wellbeing proposals $(4,102)$ is double than the number of unique Health \& Wellbeing proposals in which Finland is involved $(2,114)$. These Finnish participations represent $2.1 \%$ of all participations in Horizon 2020 Health \& Wellbeing proposals, which is lower than AT, DK, NL and SE, but higher than IE and NO. When taking account of the size of the respective researcher populations, Finland's number of participations in Horizon 2020 Health \& Wellbeing proposals (80 per 1,000 R\&D personnel) puts it in the middle of the group of comparator countries.

Finland accounted for a similar proportion (2.0\%) of all FP7 participations in Health \& Wellbeing proposals. However, because of the longer time-period covered, its participation rate (106.9 per 1,000 R\&D personnel) was higher than observed in Horizon 2020. Despite this, Finland's participation rate in FP7 was lower than all comparator countries.

In Finland, two organisation types (HES and PRC) account for the majority (79\%) of participations in Health \& Wellbeing proposals, with REC accounting for a further $17 \%$. Further, the proportion of SMEs in PRCs is $90 \%$, which is higher than the overall average, and higher than all of the comparators. The distribution of Finnish participations is similar to the overall average, although a slightly above average proportion is accounted for by HES organisations, while a slightly below average proportion is accounted for by PRC and REC organisations.

The average EC funding request per Finnish participation in Horizon 2020 Health \& Wellbeing proposals was around $€ 725$ thousand. This is slightly higher than in most of the comparator countries (except Sweden).

To May 2017, 370 Horizon 2020 grants had been awarded to Health \& Wellbeing projects involving Finland. This represents $5.4 \%$ of all Horizon 2020 projects, which is lower than all the comparator countries other than Ireland and Norway. Finland compares even less favourably when one adjusts for the size of the research base in each country. Finland has been awarded 7.2 Horizon 2020 Health \& Wellbeing projects for every 1,000 R\&D personnel in the country, which is lower than any of the comparator countries.

The 370 Horizon 2020 Health \& Wellbeing projects involving Finland came from 3,051 proposals. This equates to a proposal success rate of $12.1 \%$ - which is slightly above the 
overall success rate of Horizon 2020 Health \& Wellbeing proposals (11.7\%), but below that of all comparator countries. Finnish success rates in FP7 Health \& Wellbeing proposals were higher (19.3\%) than in Horizon 2020, but this partly reflects higher success rates seen in FP7 overall (16.2\%). The Finnish rate in FP7 was still below all comparator countries, except Norway.

\section{Success rate of $\mathrm{H} \& \mathrm{~W}$ proposals}

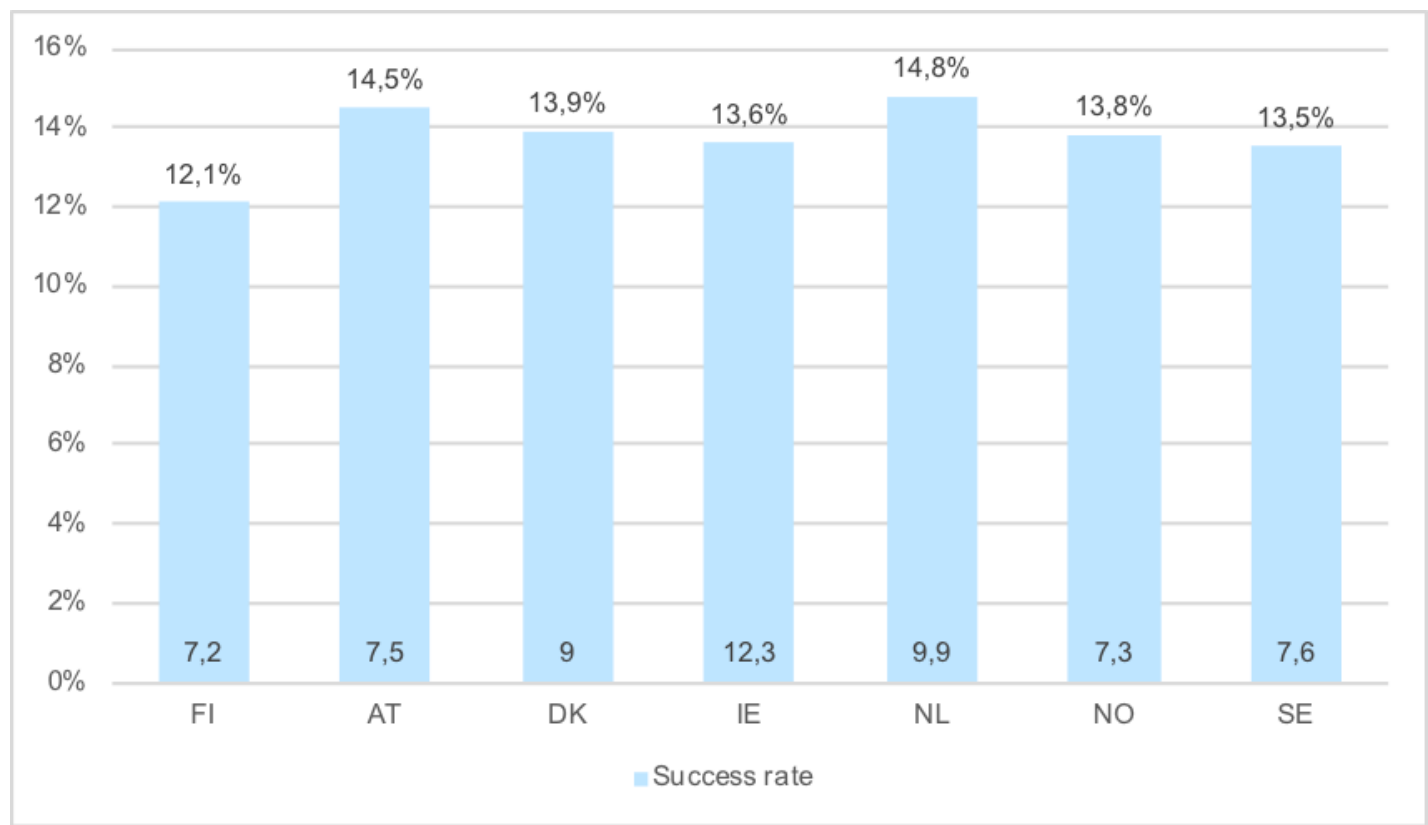

Success rate of projects and number of projects per 1000 research staff

In other parts of the analysis the trend in success rate and participation is slightly muddled by the general level change between the programs, but here the trend is relatively clear and the break came after 2012 after which the success rate of Finnish applications in this has been worse than the previous almost every year except 2016. Further, before 2012 the success rate has been roughly on par with, and after that steadily below the comparison.

\section{Success rate in H\&W over time}

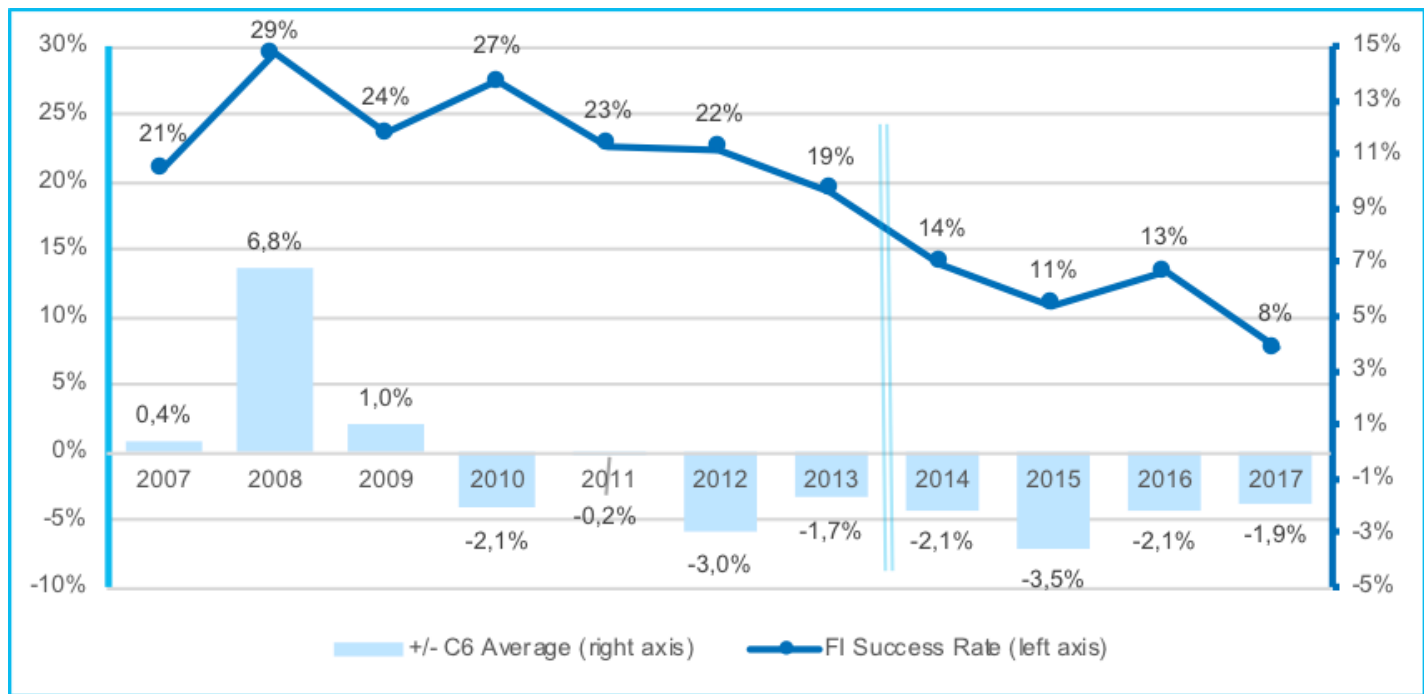

Success rate of Finnish applications per year (left axis), and difference to average of comparison countries (right axis) 
Horizon 2020 grants have been awarded to 107 Health \& Wellbeing projects with a Finnish coordinator. The equates to 2.1 projects for every 1,000 R\&D personnel in the country. This rate is below that of all comparator countries. The rate (coordinators per 1,000 personnel) for Finland in FP7 compared slightly better, but still below that of all comparator countries.

The success rate of Finnish-coordinated Health \& Wellbeing Horizon 2020 proposals is $7.9 \%$ - which is significantly lower than the overall Horizon 2020 figure $(11.7 \%)$, and below the rates of coordinator success achieved in all the comparator countries. In FP7, Finland's success rate for coordinators (19.4\%) was above average (16.2\%), but still below that achieved in most comparator countries (apart from Norway).

If we look only at Horizon 2020 Health \& Wellbeing proposals/projects with multiple participants (i.e. excluding those where the coordinator is the only partner), the success rate for $\mathrm{FI}$ coordinators increases from $12.1 \%$ to $14.1 \%$. This is higher than the overall Horizon 2020 figure $(11.1 \%)$ but below that of four of the comparator countries (AT, NL, NO, \& SE).

\section{Coordinator success rate in $\mathrm{H} \& \mathrm{~W}$ area}

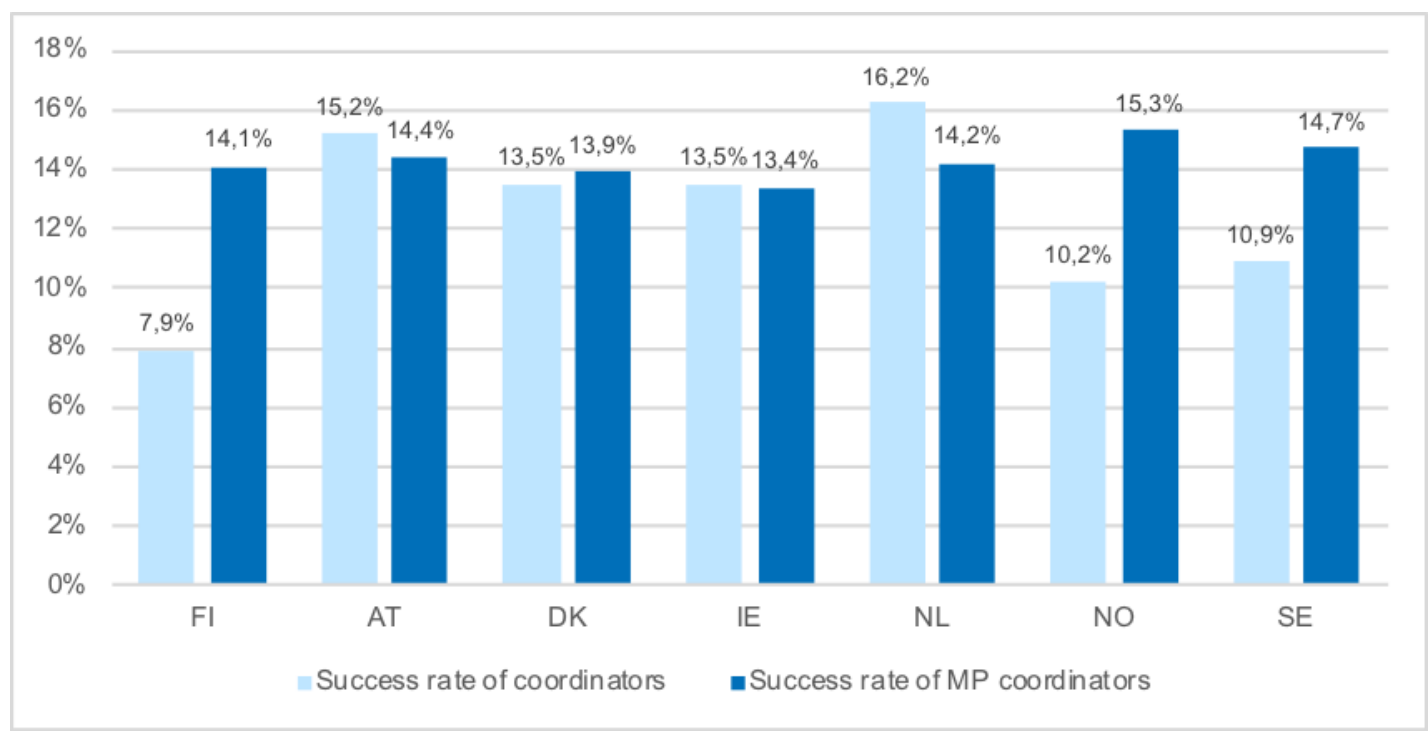

The 299 Health \& Wellbeing grants awarded to Finland in Horizon 2020 involve 506 individual Finnish participations. This represents $2.0 \%$ of all participations in Horizon 2020 projects, which is lower than most of the comparator countries (each of which accounts for between $2 \%$ and $8 \%$ of all participations). Even taking account of the size of the researcher base, Finland does not compare favourably with these countries. The 9.9 Health \& Wellbeing participations per 1,000 R\&D personnel in Finland is below the 10-16 level achieved by most comparators. A similar pattern emerges for FP7.

The 506 Finnish participations in successful Horizon 2020 Health \& Wellbeing projects, from an original 4,102 participations in proposals, represents a participation success rate of $12.3 \%$ in Horizon 2020 so far. This is below the overall rate of success for all participations in Health \& Wellbeing proposals, and also below that achieved in all of the comparator countries. Finland's FP7 participation success rate was also below the overall average, and the rates in all comparator countries.

Comparing across different organisation types, success rates for Health \& Wellbeing participations were highest amongst Finnish public bodies (27\%). Rates here were higher 
than the overall average (23\%), but lower than most of the comparator countries (apart from DK). Finnish participations from PRC organisations performed well against most comparator countries, being higher than all apart from Ireland and the Netherlands.

Elsewhere (HES, REC), Finnish participations achieved success rates that were slightly below the overall average, as well as below that achieved in all comparator countries.

EC contributions to Finnish participations in Horizon 2020 Health \& Wellbeing projects totalled $€ 234$ million, which equates to $2 \%$ of all funding to Health \& Wellbeing participations to date. This is below the proportion realised by most of the other comparator countries, but above that received by Ireland and Norway. The average contribution to each Finnish Health \& Wellbeing participation (at $€ 462$ thousand) is slightly higher than the overall Horizon 2020 Health \& Wellbeing average, but below that realised by all-but-one of the comparator countries (AT).

\section{Participations in H\&W projects over time}

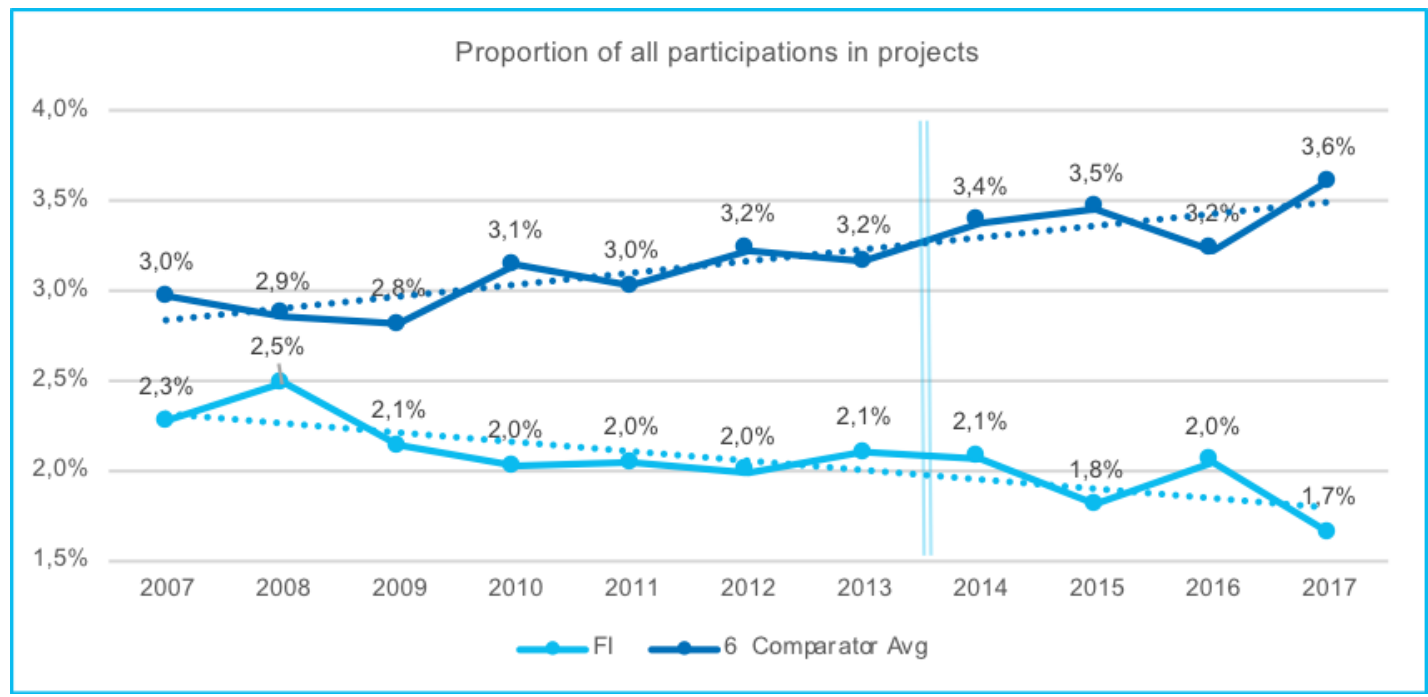

Proportion of all participation per year

\section{Cleantech, Bioeconomy and Circular Economy (CBC)}

Finnish actors have contributed to the submission of 3,798 CBC proposals in Horizon 2020 (as of May 2017). This equates to $5.6 \%$ of all such proposals submitted to the programme during this period. This is slightly lower than the proportion of FP7 CBC proposals involving Finland (6.1\%).

As is shown in the table below, all but two of the comparator countries (IE and NO) have participated in a greater proportion of CBC proposals than Finland, in both FP7 and Horizon 2020. Even when taking into account the relative number of $R \& D$ personnel in each country, the number of proposals involving Finland is lower than all comparator countries in FP7 and lower than three comparators in Horizon 2020.

In $42 \%$ of Horizon 2020 CBC proposals involving Finland, a Finnish actor held the role of coordinator. This is high than in FP7, where $34 \%$ of Finnish CBC proposals were led by a Finnish coordinator. Most comparator countries had a lower or similar rate of coordination in Horizon 2020, while two countries had a slightly higher rate of coordination in FP7 (IE \& NL).

If we take account of the relative size of the researcher base in each country, the number of CBC proposal coordinators from Finland (31.2) in Horizon 2020 is below the rate for all 
comparator countries except DK \& IE. In FP7, the Finnish rate (31.4 coordinators per 1,000 personnel) was below that of all comparators.

Finnish actors have participated in 2,732 multi-partner Horizon 2020 CBC proposals, of which it has served as the coordinator in $532(19 \%)$. This puts it in the middle of the comparator countries. The Finnish rate of CBC proposal coordination in Horizon 2020, relative to the FTE researcher population, is lower than all the comparator countries except Norway and Sweden.

Because of multiple Finnish participations in some proposals, the total number of Finnish participations in Horizon 2020 CBC proposals $(5,290)$ is higher than the number of unique $\mathrm{CBC}$ proposals in which Finland is involved $(3,798)$. These Finnish participations represent just 2.2\% of all participations in Horizon 2020 CBC proposals, which is lower than for each of the comparator countries, except Norway. When taking account of the size of the respective researcher populations, Finland performs comparably better with a higher number of participations in Horizon 2020 CBC proposals (103 per 1,000 R\&D personnel) than all other comparators except Ireland and the Netherlands.

Finland accounted for a similar proportion (2.0\%) of all FP7 participations in CBC proposals. However, because of the longer time period covered, its participation rate (128 per 1,000 R\&D personnel) was higher than in Horizon 2020. However, this was lower than all comparator countries except Denmark.

The table below shows the distribution of Horizon 2020 CBC proposal participations between different types of actor (categorisations as used in eCORDA). For Finland, it shows that two organisation types (HES and PRC combined) accounts for the majority (76\%) of participations in CBC proposals, with REC organisations accounting for a further $19 \%$.

The table also shows the proportion of PRC participations that are SMEs. For Finland, the rate is $86 \%$, which is higher than the overall average, and also higher than all of the comparator countries.

The average EC funding request per Finnish applicant in Horizon 2020 CBC proposals was around $€ 672$ thousand, which is higher than in most of the comparator countries, but slightly lower than the overall average. 


\section{Participation in CBC proposals}

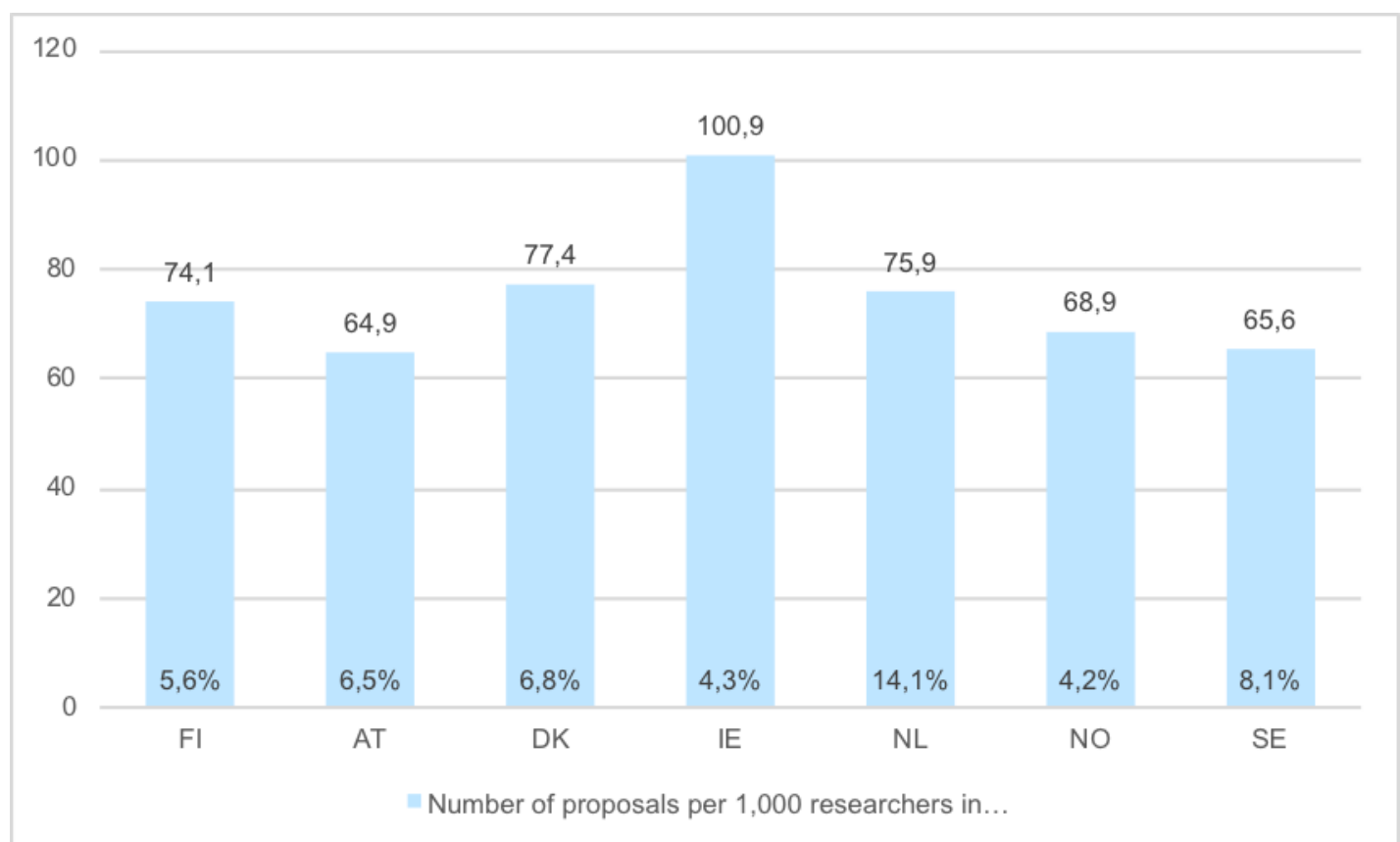

Number of proposal involving country per 1000 researchers and percentage of all proposals

To May 2017, 508 Horizon 2020 grants had been awarded to CBC projects involving Finland. This represents $6.5 \%$ of all Horizon 2020 CBC projects, which is lower than all of the comparator countries except Ireland and Norway. Finland compares little better when one adjusts for the size of the research base in each country. Finland has been awarded 9.9 Horizon $2020 \mathrm{CBC}$ projects for every 1,000 R\&D personnel in the country, which is lower than all of the comparator countries except Norway and Sweden. This is an improvement on FP7, where the Finnish rate $(18$ per 1,000$)$ was lower than all comparators.

The 508 Horizon 2020 CBC projects involving Finland came from 3,798 proposals. This equates to a proposal success rate of $13.4 \%$ - which is above the overall success rate of Horizon 2020 CBC proposals (11.6\%), but below the rate achieved in all of the comparator countries. Finnish success rates in FP7 CBC proposals were higher (19.8\%) than in Horizon 2020 , but this partly reflects higher success rates seen in FP7 overall (16.3\%), and as a result the Finnish success rate was also lower than all comparators in this programme. 


\section{Success rate in CBC area}

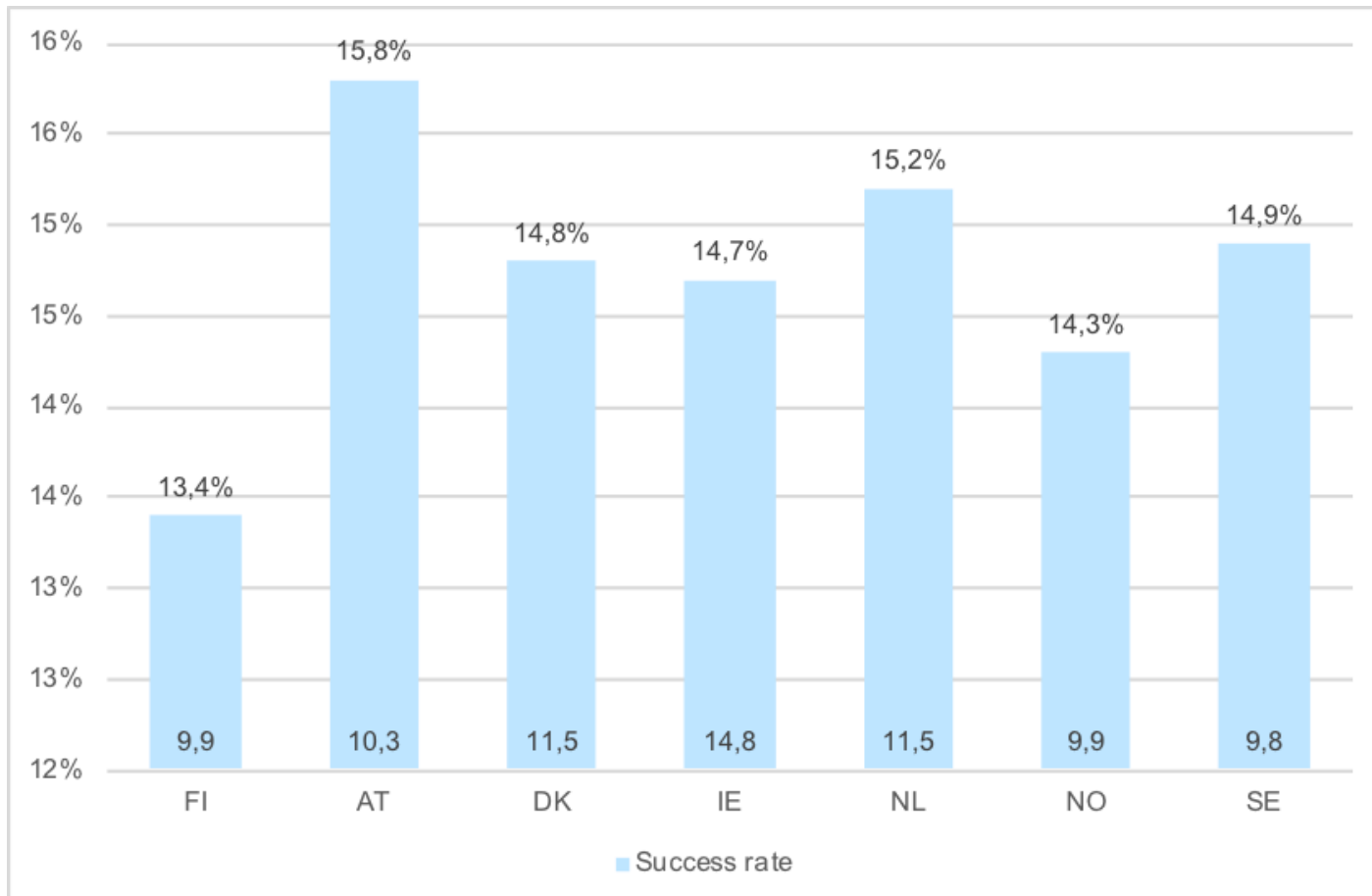

Success rate of projects and number of projects per 1000 research staff

Looking at the Finnish success rate in $\mathrm{CBC}$, it has been stable through FP and during Horizon 2020 as well, although the trend is again slightly downward. The major difference is that pre-2014 the average has been more in par with the comparison.

\section{Success rate in CBC area over time}

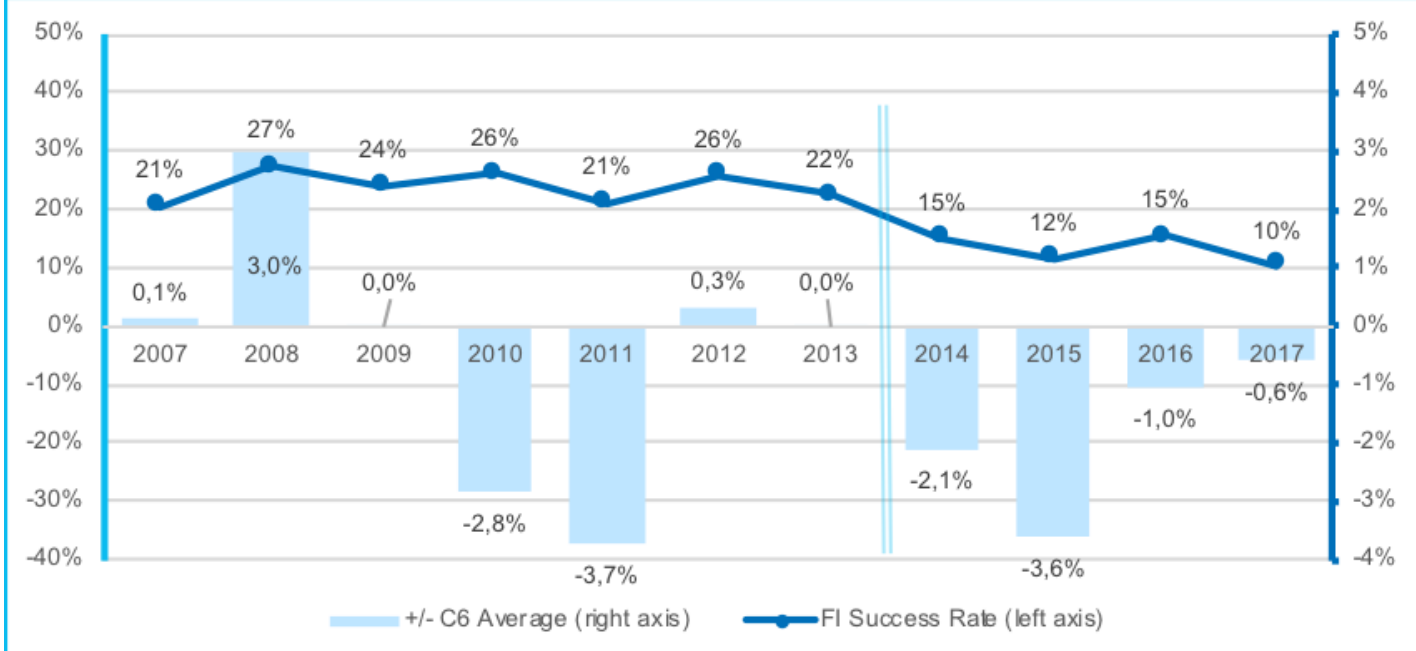

Success rate of Finnish applications per year (left axis), and difference to average of comparison countries (right axis)

Horizon 2020 grants have been awarded to 143 CBC projects with a Finnish coordinator. This equates to 2.8 projects for every 1,000 R\&D personnel in the country. This rate is below that of all comparator countries except SE. The rate (3.3 coordinators per 1,000 personnel) for Finland in FP7 also compared poorly with all comparators. 
The success rate of Finnish-coordinated CBC proposals is $8.9 \%$ in Horizon 2020 - which is lower than the overall average (11.6\%), and below the rates of coordinator success achieved in all comparator countries. In FP7, Finland's success rate for coordinators was slightly better (10.5\%), but this was still lower than all comparator countries.

If we look only at those Horizon $2020 \mathrm{CBC}$ proposals/projects with multiple participants (i.e. excluding those where the coordinator is the only partner), the success rate for $\mathrm{FI}$ coordinators increases from $8.9 \%$ to $9.4 \%$. However, this still compares unfavourably with the overall average and with all comparator countries.

\section{Success rate of coordinators in CBC area}

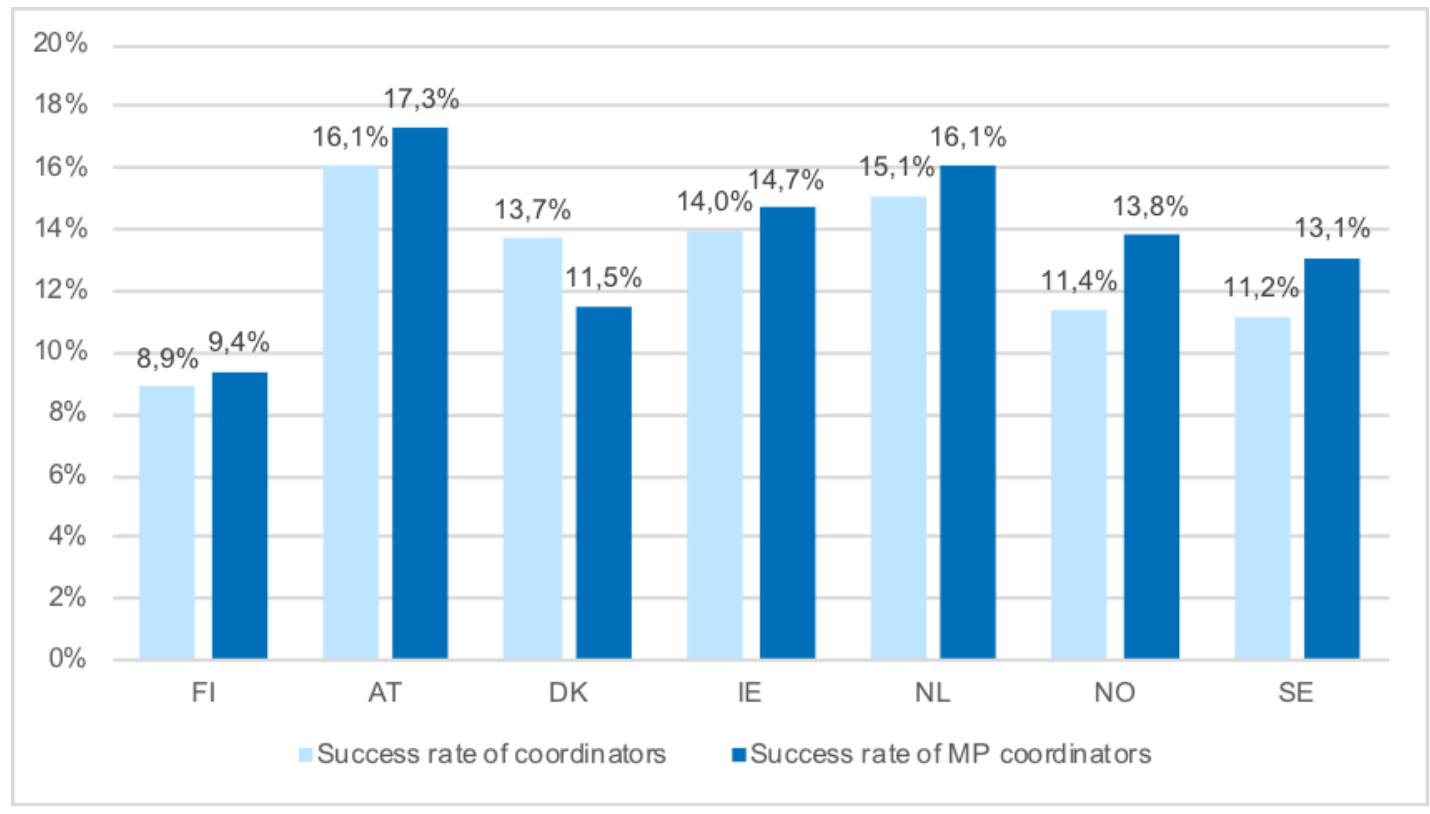

The 508 CBC grants awarded to Finland in Horizon 2020 involve 729 individual Finnish participations. This represents $2.1 \%$ of all participations in Horizon 2020 projects, which is lower than any of the comparator countries, except Ireland and Norway. Even taking account of the size of the researcher base, Finland does not compare favourably with these countries. The 14.2 CBC participations per 1,000 R\&D personnel in Finland is below that achieved elsewhere expect in Norway and Sweden.

Comparing across different organisation types, Finnish success rates for $\mathrm{CBC}$ participations were highest amongst public bodies (29\%). Rates here were higher than the overall average (26\%), but lower than most comparator countries. The success rates of Finnish participations from other organisation types also tend not to compare well with other countries.

The table also shows the success rate of SME-PRC participations in CBC proposals. For Finland, the rate is $12 \%$, which is below the Horizon 2020 average (13\%), as well as below that achieved in all comparator countries except Norway.

EC contributions to Finnish participations in Horizon 2020 CBC projects totalled $€ 335$ million, which equates to $2.3 \%$ of all funding to $\mathrm{CBC}$ participations to date. This is below the proportion realised by each of the other comparator countries except Ireland and Norway. The average contribution to each Finnish CBC participation (at $€ 460$ thousand) is also below that achieved by all comparator countries, although slightly above the all country average. 


\section{Participations in CBC projects over time}

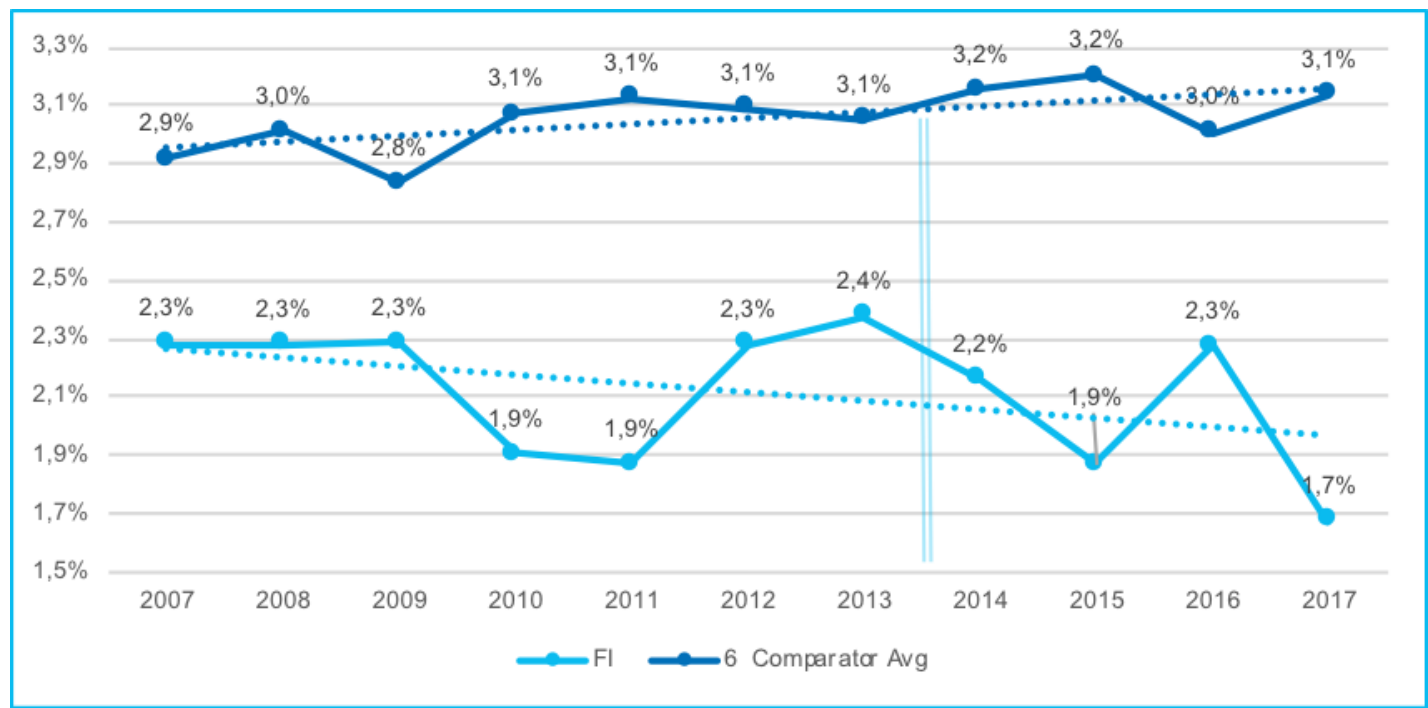

Proportion of all participation per year

\section{Participation in the SME instrument}

Another specific point of interest was participation in the SME instrument (SMEI). The SMEI is a two-phase funding instrument for SMEs with certain conditions, who can propose a small project (maximum grant sum $€ 50$ thousand in SMEI-1) for investigation of a feasibility of a business idea and/or a larger one for demonstration (max. grant sum €2.5 million SMEI2).

Finnish actors level of involvement in SME instrument proposals compares favourably against nearly all comparator countries, for both phases of the instrument. Finns have participated in 604 SME Instrument Phase 1 (SMEI-1) proposals, or $2.3 \%$ of all 26,447 participations so far. This is more than all comparator countries except for NL (3.3\%). Weighting proposal activity by taking account of the size of researcher populations, Finland's rate of participations in SMEI-1 proposals ( 11.8 per 1,000 R\&D personnel) is above all comparators except IE.

Finland has also participated in 573 SMEI-2 proposals, meaning it is relatively more active here (3.9\% of 14,575 participations) than in Phase 1 . However, it still ranks slightly below $\mathrm{NL}$ in terms of absolute levels of involvement. Compared with the size of the researcher population, however, Finland's rate of participations in SMEI-2 proposals (11.2 per 1,000 personnel) is above all comparator countries. 


\subsubsection{Participation in SME instrument}

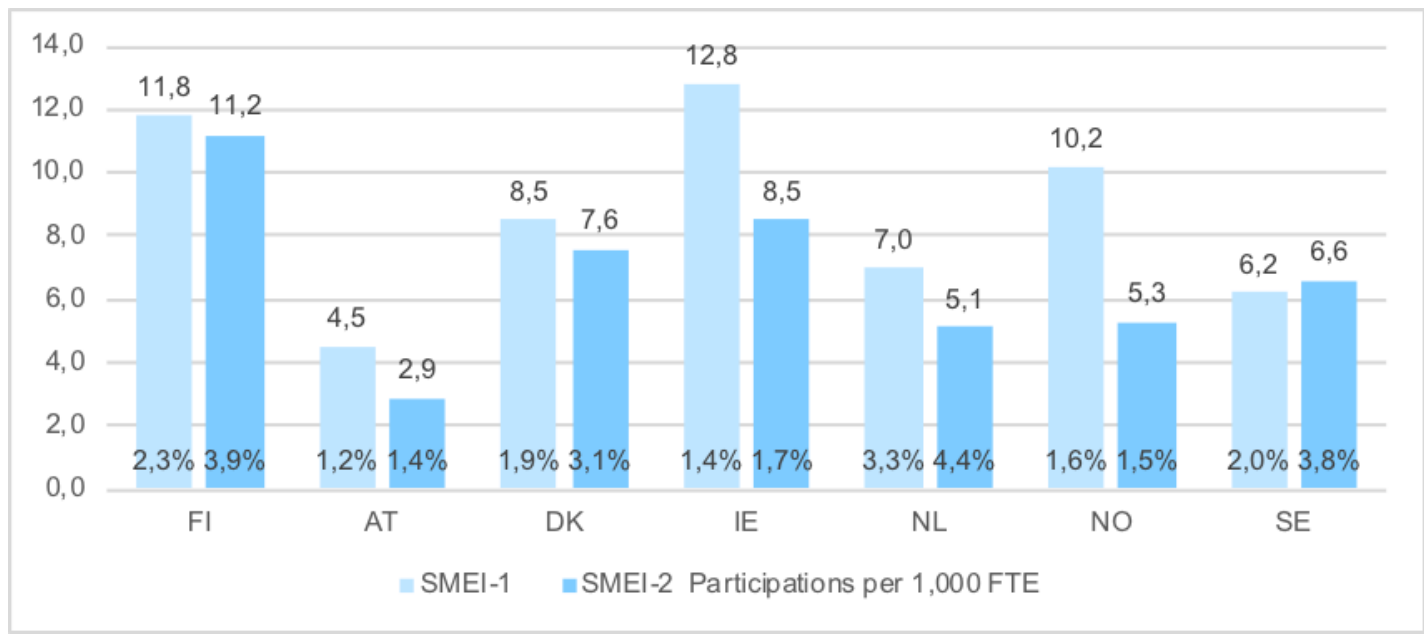

Participation in SMEI-1 and SME-2 as percentages of all participations and as number of project proposals per 1000 research staff

In total, $€ 1.2$ billion of EC funding has been requested through SMEI-1 proposals. Finland accounts for $2.4 \%$ (€28 million) of this total- a higher amount than any of the comparator countries except for NL. On average, Finnish applicants requested $€ 46$ thousand each. This is above the Horizon 2020 average ( $€ 45$ thousand) and places Finland in the middle of the comparators (below SE, DK and SE, but above AT, NL and NO).

The size of phase 2 grants can be much bigger (up to $€ 2.5$ million) than phase 1 ( $€ 50$ thousand). As such, EC funding requests to SMEI-2 total $€ 19.3$ billion. Finland accounts for $5.0 \%$ ( $€ 957$ million) of this total - a higher proportion than any of the comparators except for NL. On average, Finnish participations in SMEI-2 proposals requested $€ 1.7$ million in funding each. This is above the Horizon 2020 average ( $€ 1.3$ million), as well as higher than the average in all of the comparator countries.

Finland's relatively high rate of SMEI proposal activity has not fed through entirely into levels of project activity, particularly for Phase 1. Of the nearly 2,200 Horizon 2020 SMEI-1 grants awarded so far, just 51 have been to Finland. This $2.3 \%$ share of participations places Finland in the middle of the comparator countries (below DK, NL and SE, but above AT, IE and NO). Its rate of participations in SMEI-1 projects (1.0 per 1,000 R\&D personnel) is also below four of the comparator countries (DK, IE, NO and SE).

The country has fared a little better with SMEI-2. Of the 724 grants awarded so far, 33 (or $4.6 \%$ ) have been awarded to Finnish participants. This is fewer than in DK or NL, but more than in the other comparator countries. Compared with the size of the researcher population Finland's rate of participations in SMEI-2 projects ( 0.6 per 1,000 personnel) compares even more favourably, being higher than all comparator countries except for IE (SE also has the same rate as $\mathrm{Fl}$ ).

Based on the data presented above, on participations and funding in proposals / projects, we can calculate success rates within the SME Instrument so far. Finland compares unfavourably with most/all comparators, both in terms of participation success rates and the proportion of requested funding that has been awarded. This explains why the relatively high levels of proposal activity have not fed through into similar levels of SMEI project activity. 
For SMEI-1, just $8.4 \%$ of Finnish participations in proposals have been successful. While this is slightly above the overall average, it is lower than for all of the comparator countries. AT (15.0\%), DK (15.6\%) and SE (16.3\%) in particular achieved success rates that were around double those seen in Finland. The proportion of requested that was awarded follows a similar pattern, although the Finnish rate $(8.2 \%)$ is also slightly below the overall average.

For SMEI-2, Finland has only performed marginally better. Its participation success rate $(5.8 \%)$ is above average and higher than in NL, but still below all other comparators (particularly IE, which achieved a success rate of 11.7\%). Finland's funding success rate $(5.6 \%)$ is also slightly below average and slightly above the NL rate, but below all other comparator countries (again IE stands out among this group with a $13.3 \%$ return).

\section{Participation success rate in SME instrument}

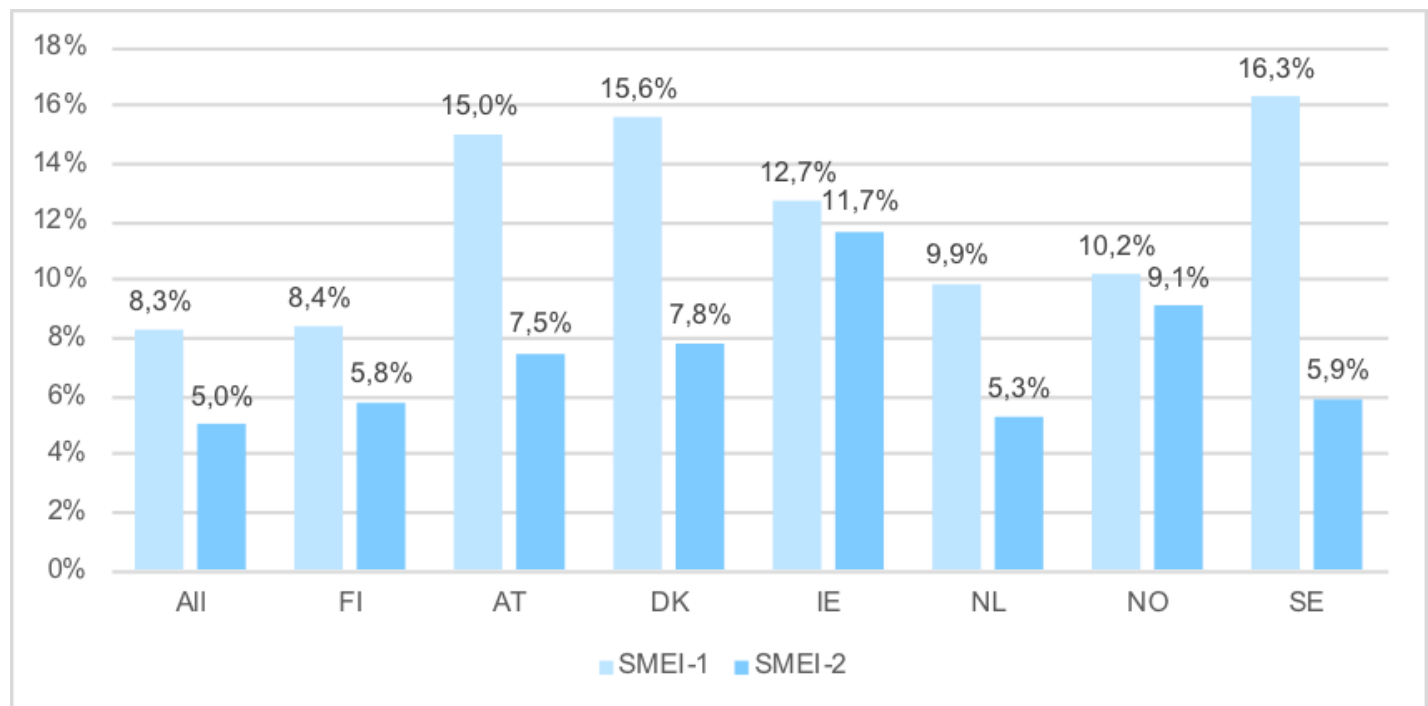

Success rate of applications

\subsubsection{Participation in ERC}

Another specific point of interest was participation in the European Research Council (ERC). Located within the Excellent Science pillar of H2020, ERC provides funding to enable talented and creative individual researchers and their teams to pursue the most promising avenues at the frontiers of science. A total budget of $€ 13,095$ million is available under $\mathrm{H} 2020$ for the implementation of the different ERC funding schemes, with between $€ 150$ thousand (for proof of concept) and $€ 10$ million (for synergy grants) available for individual grants. In nearly all cases, ERC grants are awarded to one researcher at one institution for a single project, with the single selection criteria being scientific excellence.

Finnish actors level of involvement in ERC proposals compares favourably against nearly all comparator countries. Finnish actors have participated 760 times in ERC proposals, or 2.9\% of all 26,407 participations so far. This is more than all comparator countries except for NL (6.4\%) and SE (3.5\%). Weighting proposal activity by taking account of the size of researcher populations, Finland's rate of participations in ERC proposals (14.8 per 1,000 R\&D personnel) is above all comparators. 


\section{Participation in ERC proposals}

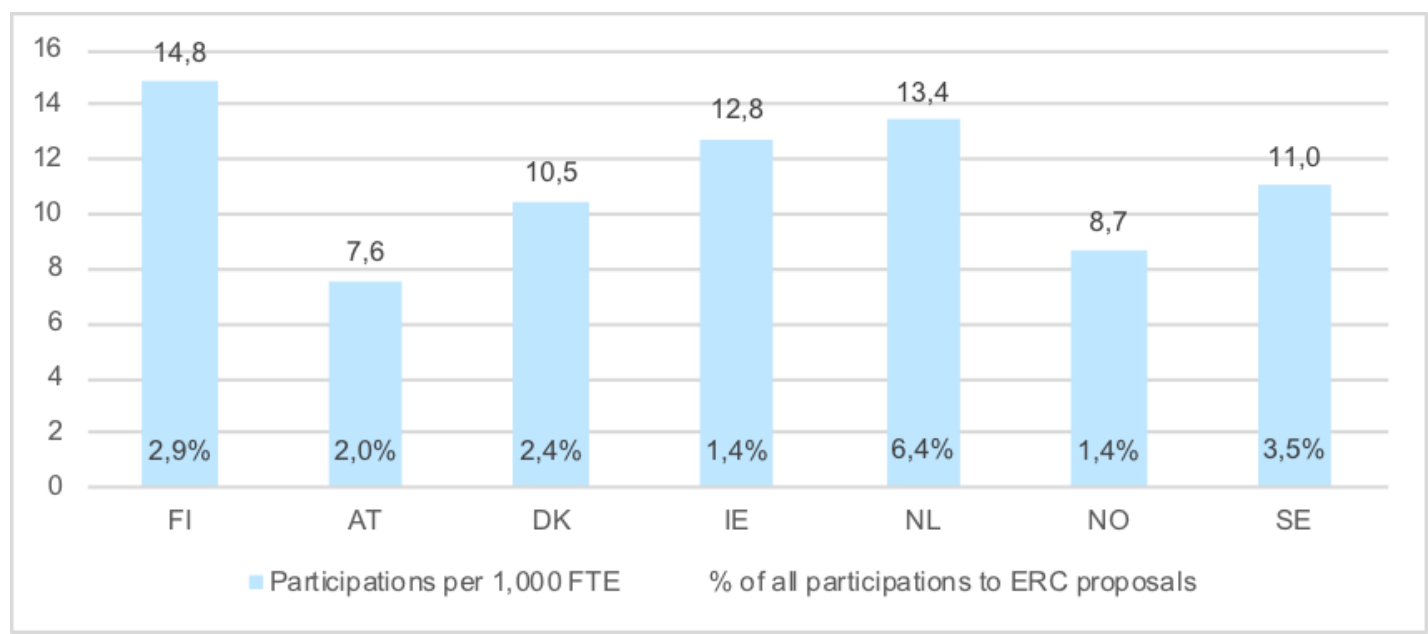

Participation in ERC proposals, as percentages of all participations and as number of proposal participations per 1000 research staff in country

In total, $€ 42$ billion of EC funding has been requested through ERC proposals. Finland accounts for $3.2 \%$ ( $€ 1.3$ billion) of this total- a higher amount than most of the comparator countries (except for NL and SE). On average, Finnish applicants requested $€ 1.8$ million each. This is above the Horizon 2020 average ( $€ 1.6$ million) and places Finland above all the comparators except for NO.

Finnish actors relatively high rate of ERC proposal activity has not fed through entirely into levels of project activity. Of the nearly 3,700 Horizon 2020 ERC grants awarded so far, just 64 have been to Finland. This $1.7 \%$ share of participations places Finland below most comparator countries (only above IE and NO). The rate of participations in ERC projects (1.2 per 1,000 R\&D personnel) is also below all-but-one (NO) of the comparator countries.

Based on the data presented above, on participations and funding in proposals / projects, we can calculate success rates within ERC so far. Finland compares unfavourably with all comparators, both in terms of participation success rates and the proportion of requested funding that has been awarded. This explains why the relatively high levels of proposal activity have not fed through into similar levels of ERC project activity.

Just $8.4 \%$ of Finnish participations in proposals have been successful. This is below the overall average (14\%), as well as below that of all countries except NO. The proportion of requested funding that was awarded follows a similar pattern, although the Finnish rate $(7.7 \%)$ is below that achieved by all of the comparator countries. 
Success rate of ERC applications

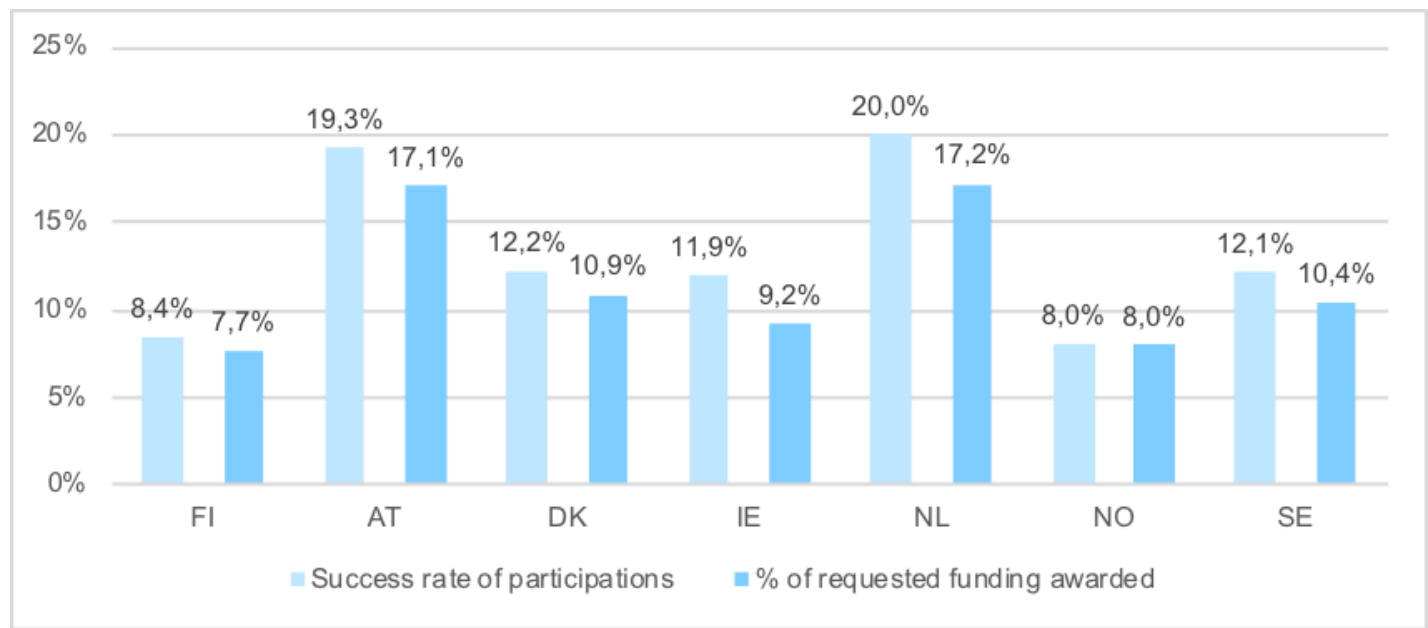

Success rate of applications to ERC and proportion of requested funding awarded

\subsection{Econometric impact assessment}

\subsubsection{Overview}

This chapter presents the econometric analysis of the performance of firms that have received funding from past and present EU framework programmes. As part of a wider evaluation this simple exercise is predominantly prepared to conclude whether the impact of EU funding on chosen outcome variables on the firm level is similar to that of other R\&D subsidies. Impact evaluation of R\&D subsidies is a difficult and laborious task and developing a more nuanced picture would require a more thorough approach for example into externalities. If this is the case, we can draw conclusions regarding the firm level impact from other studies and focus on other aspects of the EU-wide funding programme, as done in other parts of this evaluation.

In the analysis, the impact of funding from framework programmes was analysed from the perspective of firm productivity, turnover, profits, employment, R\&D investments, other investments and exports. The analysis is limited to the firm level. In similar studies with Finnish data no effect on labour productivity has been detected and, on the other hand, even negative productivity growth has been evidenced. ${ }^{68}$ Also, further evidence from Finnish and international studies shows that the impact of R\&D subsidies on firm performance is unclear, even though the impact on $R \& D$ activity seems to be positive. ${ }^{69}$

The impact of R\&D subsidies is a challenging task to study. At the firm level, the impact could take place with a long time-lag, and the outcome is uncertain and its probability distribution highly skewed. Moreover, the impact does not remain within the company that has received the subsidy. In fact, to get a more comprehensive picture of the impact of R\&D subsidies, the spill over effects of $R \& D$ should also be studied. ${ }^{70}$ Therefore, it would be more fruitful to study the effects of $R \& D$ subsidies on overall productivity in the economy.

${ }^{68}$ Viljamaa et al., 2014; Karhunen and Huovari, 2015

${ }^{69}$ Zúñiga-Vicente et al., 2014; Ylhäinen, Rouvinen and Kuusi, 2016

70 for exemple as in Takalo, Tanayama and Toivanen, 2013 
There are also some methodological limitations when studying the effect of $R \& D$ subsides on the firms. Causality of the impact, for example, is a question that needs due attention; to control for the problem of selection bias, the firms that have received subsidies are matched with otherwise similar non-receivers based on some background characteristics to form a comparison group. The selection bias arises if there are some unobservable characteristics that influence the programme participation. The participants and non-participants are likely to differ even in the absence of treatment.

When evaluating the performance of any programme, it is crucial/vital/important to construct a suitable counterfactual that represents the outcome in the absence of the programme. This is complicated since firms self-select to the programme based on the outcome variable that the programme is supposed to affect instead of being exogenously assigned to it. ${ }^{71}$

In addition, the survival bias relates to the fact that attention is only paid to firms that survive, although there are firms that might cease to exist in either treatment or control group during the observation period. The survival bias may lead to overly optimistic evaluations of the impact of a subsidy if the subsidised firms, for example, are more likely to survive due to the subsidy. Regardless, due to pragmatic reasons survival bias is not taken into account in this study.

\subsubsection{Methodology}

The motivation for an impact evaluation is to get evidence if the programme works or not. There is a limited budget for subsidies and we should know whether the programmes work as intended. Based on evidence, we get information on how to modify and design programmes and policies to work better in future.

To assess the impact, we would need to know what would have happened without the programme: whether the programme had been beneficial or harmful, or if it did not have any impact at all. Additionally, we should be able to determine what the outcome was as a result of the programme.

A widely used method for programme evaluation is the difference in differences method (DID from this on). It estimates the effect of treatment, in this case programme funding, comparing differences in outcomes between the treatment group and the comparison group.

The DID requires observation of an outcome variable before and after the treatment. The DID assumes that the outcome variable has a same underlying trend in the treatment and control groups. A difference from that trend after the treatment is considered as caused by the treatment. The major challenge in the DID approach is to find a suitable control group.

In this study, our main control group is firms that have received national RDI funding, in practice Tekes funding, during the same period. In addition, we formed two other control groups: innovative firms based on the innovation survey and R\&D active firms based on R\&D survey.

In addition to selecting specific control groups, we used matching to improve comparability. Treatment group firms were matched to similar firms in control group. We used exact matching to industry classification and nearest neighbourhood matching to firm size.

${ }^{71}$ Heckman and Smith, 1999 
Matching element was included to correct for the selection bias discussed in the introduction. Matching combats the problem related to the confounding variables, or less technically, the variables that affect both independent and dependent variables. Additionally, combining the DID approach to the matching, the unobserved time invariant effects can be controlled for. This is how the comparison group and the treatment group are such that inference can be dubbed causal.

\subsubsection{Data}

To assess the impact of EU RDI funding on Finnish firms, we have combined EU funding data obtained from Tekes with firm level financial and other data from Statistics Finland. Funded firms that we have studied are from three EU framework programmes, FP6, FP7 and Horizon 2020. The data cover funding decisions from 2003 to early 2017. The majority of the funded firms could be matched with firm level data, and we had in total $855 \mathrm{EU}$ funded firms with at least partial data.

There were many more funding decisions since a large part of firms had received funding from several EU programmes within the time period, in total 1389. As some of those funding starts took place during a single year in firms with several funding decisions, we had 1146 individual funding start years in firms to begin with.

\section{Description of data}

\begin{tabular}{lccc}
\hline \multicolumn{1}{c}{ Programme } & Firms & Fundings & Start years \\
\hline FP6 & 218 & 324 & 272 \\
FP7 & 384 & 728 & 589 \\
Horizon 2020 & 253 & 331 & 285 \\
Total & 855 & 1383 & 1146
\end{tabular}

Number of firms, funding decisions and years when one or more funding starts took place in a firm.

Unfortunately, the number of observations we could actually use was lower. To estimate the impact five years after the funding started, we needed data from one year before a funding start to five years after a funding decision took place. So, we could use data only up to the start year 2011 from firms with sufficient years with data before and after a funding start. Another problem was other sources of funding both from the EU and the national funding from Tekes. If firms have several $R \& D$ funding sources within the assessment period, it is difficult to identify the impact of particular funding. Taking together all restrictions, we were left only with 100 observations.

As firm level data contain all sorts of sources of error and randomness, even the original number of 1146 observations would have been rather low. With only 100 observations it is difficult to draw any conclusions. This is evident also from large standard errors of coefficients in the analysis. In the end, we analysed those 100 observations with a clean impact period as well as those observations with other funding sources within the impact period.

The impact of funding was studied on several firm level indicators:

- $\quad$ Personnel 


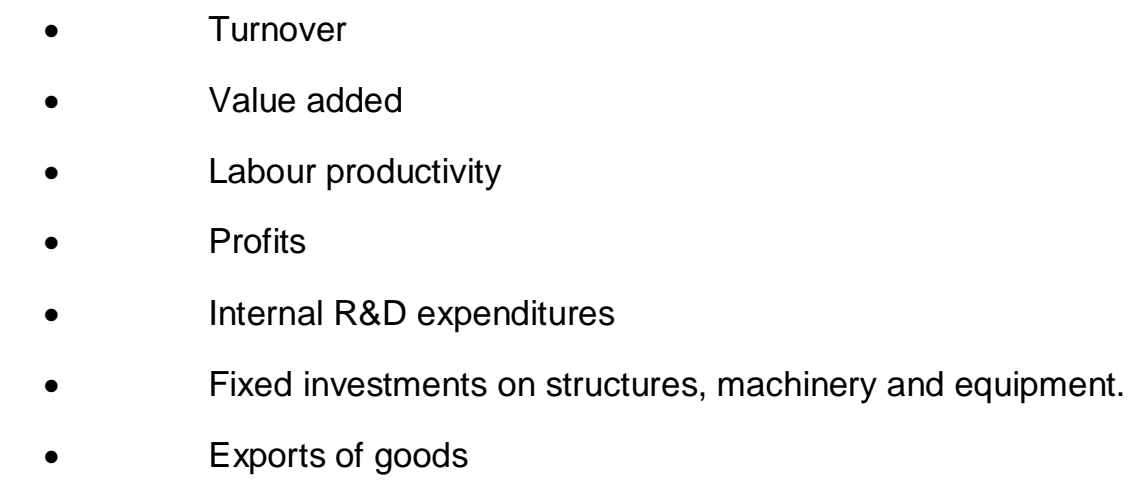

There are three different control groups that are used in the study. Each of the control groups were selected so that the firms in them have either received innovation funding from other sources but not from the EU (namely Tekes funding) or reported innovation or R\&D activity. The control groups are 1) firms that have received Tekes funding but not EU funding, 2) innovative firms based on the innovation survey that have not received either Tekes or EU funding and 3) firms that have reported R\&D activity in the Statistics Finland R\&D survey but have not received either Tekes or EU funding. Control groups:

- $\quad$ Tekes funded (not in EU funding)

- Innovative firms based on innovation survey (not in EU or Tekes funding)

- $\quad$ R\&D active firms based on R\&D survey (not in EU or Tekes funding)

\subsubsection{Modelling results}

The firms that have received EU funding from framework programmes are on average considerably larger than the firms that were a basis for the control groups. This is a result from the fact that the number of EU-funded firms is a lot lower and includes larger share of the biggest manufacturing firms. The median of firm size in groups is more equal, but even with that measure EU-funded firms are clearly larger than the nationally Tekes-funded firms.

Set aside the size, firms in other groups are rather similar to EU-funded firms. However, the EU-funded firms are compared to similar firms in control groups. Within those selected groups, firms are matched based on industry classification and firm size. 


\section{Description of study groups}

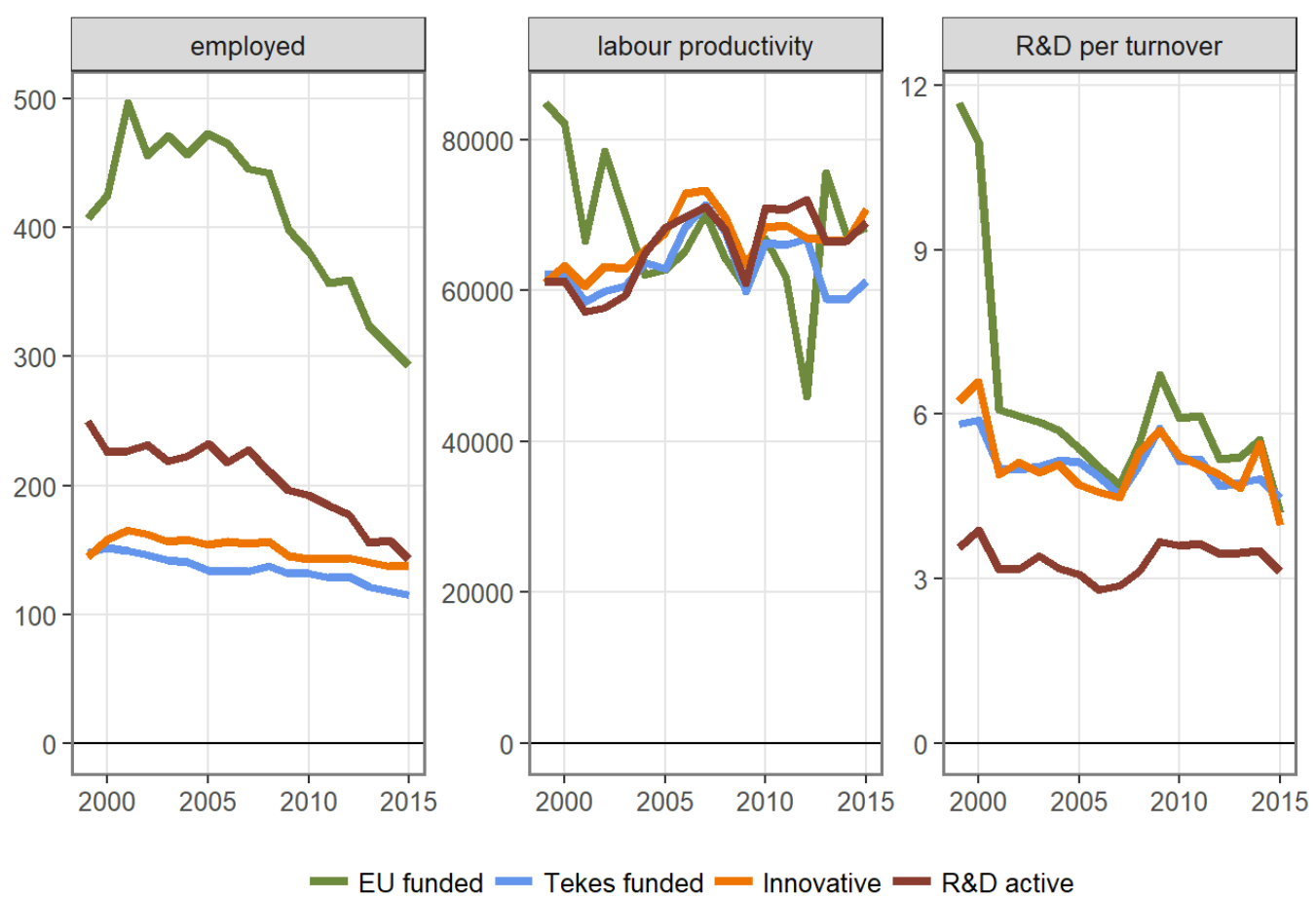

Number of employees, labour productivity ( $€$, value added / employed), and R\&D per turnover (\%) in firms studied years 1999-2015 in firms with more than 5 employees.

Source: Statistics Finland.

\section{FP funding compared to national funding}

First, we compared EU-funded firms with Tekes-funded firms, without matching based on firms' characteristics. EU-funded firms were matched with Tekes-funded firms that had a funding start in the same year. We tried to see whether EU funding differs from national funding on its impact on firms. We did a DID estimation where indicator was regressed with a time dummy-variable, before and (five years) after funding, a treatment dummy-variable, EU funding or Tekes funding, and their interaction (impact), which tells us the impact of EU funding compared to the impact of Tekes funding.

Estimated coefficients for the impact variable give us the estimated difference of EU and Tekes funding. The following figure collects results from estimations for all variables. The point estimates for personnel, turnover and value added gives more positive impact for EU funding, the impact is nearly the same for labour productivity, profits and R\&D expenditures and more negative for investments and exports. However, none of the coefficients is statistically significant as confidence intervals for coefficients are rather large and includes also zero, which means that there is no difference in impact compared to Tekes funding. Based on the result we cannot say that there were any significant differences in impact on firm level between EU and Tekes funding. 


\section{Estimation results for FP funding compared to Tekes funding}
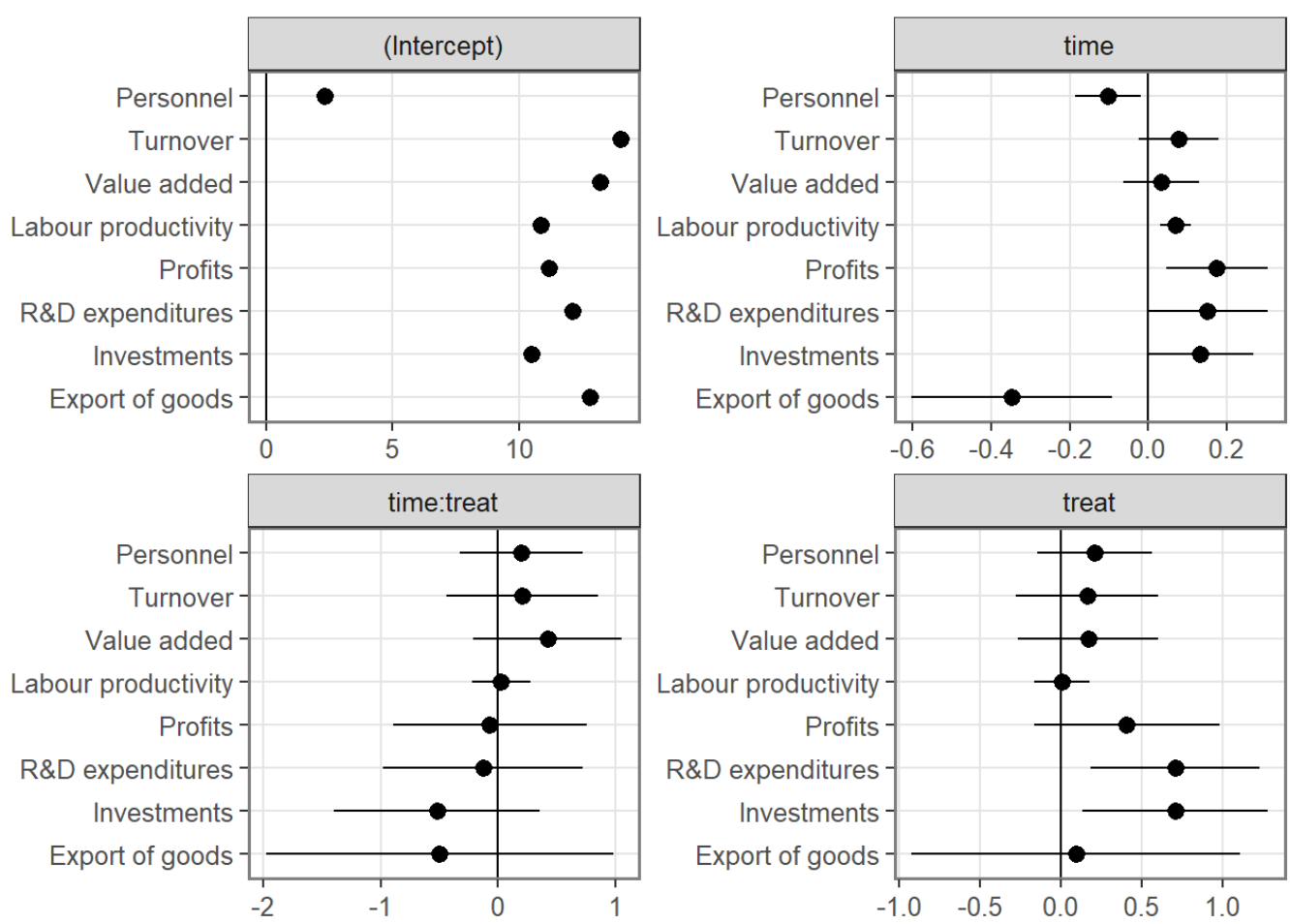

Difference in differences estimation coefficients on clean EU funding compared to clean Tekes funding. Point estimates and confidence intervals (95\%).

\section{Robustness check}

Next, we matched firms based on firm size (personnel) and industry, and compared EUfunded also to other control groups: innovative firms based on innovation survey and R\&D active firms based on R\&D survey. We did a comparison for clean EU FP funding (no other EU or Tekes funding) and all programmes. We used also all programmes because there were so few observations for clean programmes. However, it should be remembered that based on all programmes we cannot draw conclusion on the impact itself.

The results show that none of the coefficients of impact variables is statistically different from zero for clean programmes. It should be noted that confidence intervals are rather large due to low number of observations and large variation in indicators.

Using all EU programme funding, we find that all point estimates of impact are positive, except for exports of goods, and there are even some statistically significant coefficients. Turnover has grown more in EU-funded firms than in Tekes-funded or innovative firms, and also the value added compared to Tekes-funded firms. 


\section{Alternative model intercept terms}

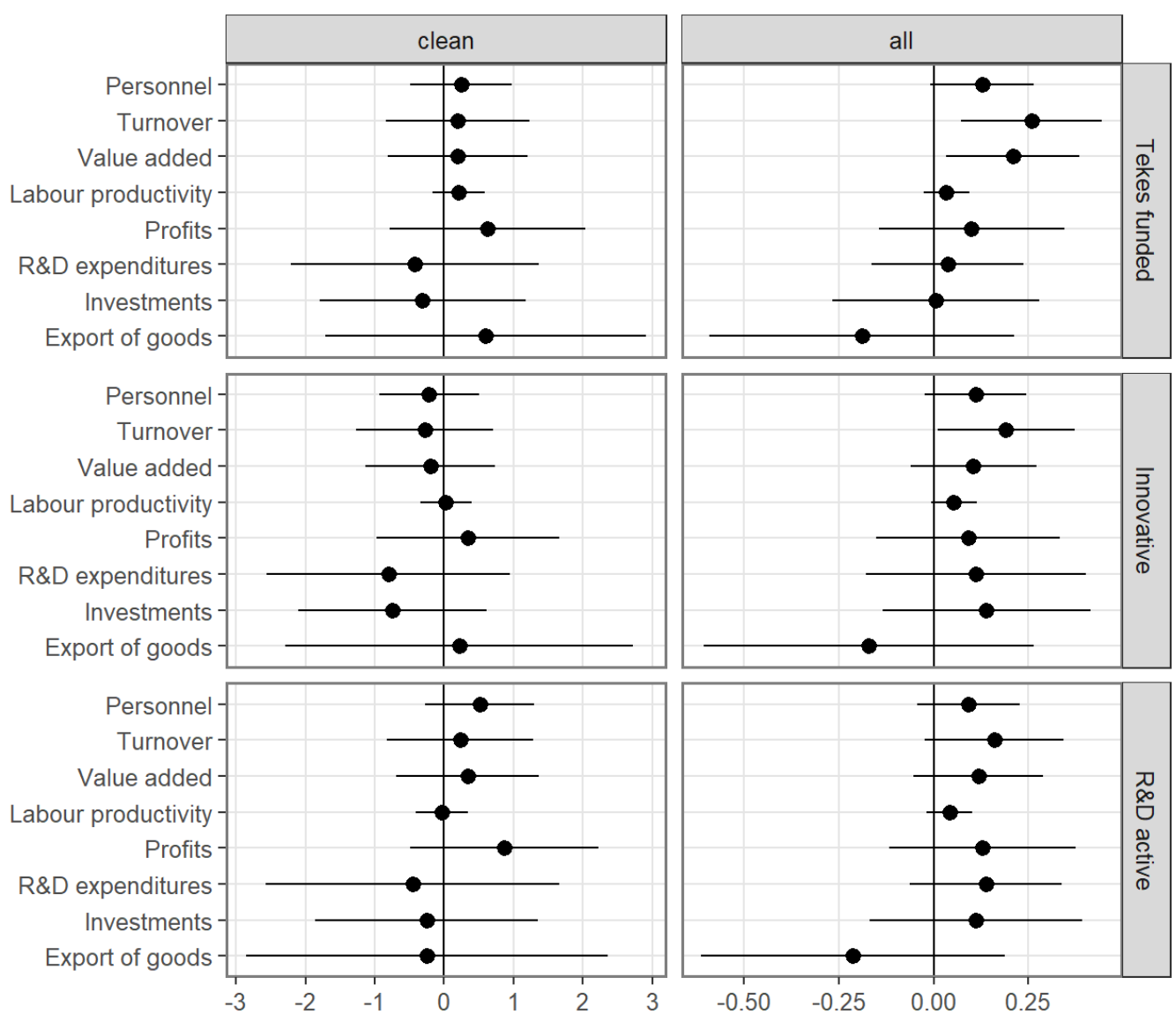

Estimation results of the coefficients of the impact after five years for six models. Compared to control groups of Tekes-funded, innovative and R\&D active firms. Clean and all EU funding. Point estimates and confidence intervals (95\%).

\subsubsection{Findings}

Impact analysis of research and innovation funding is a challenging task. The particular difficulty when analysing EU funding is that the number of receiving firms is rather low, which is reflected in the larger confidences intervals and margin of error. In addition, participating firms in EU funding are larger than average firms and likely have a broader portfolio of activities. A large part of EU-funded firms has received also several other subsidies, from EU or from Tekes. Thus, isolating the impact of an individual funding source is difficult.

With that said, the main result is that the impact of EU RDI funding seems at least as good as that of national Tekes funding. Comparing the impact five years afterwards on EU and Tekes-funded firms that have not received other funding in that period reveals no statistically significant differences. Comparing EU-funded firms with no other funding to other control groups and matching firms to similar control firms does not reveal any statistically significant differences either, largely due to small sample size. 
Comparing all EU-funded firms (that is firms with also other compounded funding) to control groups shows that EU-funded firms seem to have grown faster on average. Growth of turnover is statistically significantly higher compared to Tekes-funded firms and innovative firms. Compared to Tekes-funded firms, value added has grown faster as well. Compared to all three control groups, most of the indicators have had more positive outcomes in the EUfunded firms, even if the difference is not statistically significant in other cases. However, this difference is a product of all the compounded funding, not 'clean' FP funding.

Additionally, the effect of RDI subsidies tends to percolate to commercial gains over a long period of time, for example it has been previously observed in the Finnish context that the productivity gains are reaped more than five years after the intervention. ${ }^{72}$ Another aspect is that some of the benefits of RDI subsidies can dissipate as externalities or spill-overs for various reasons to other enterprises, which means that the net impact in the beneficiary enterprises looks lower while the whole economy benefits. Also, it is not clear whether al FP participants pursue e.g. the added European market knowledge after the FP project. This is to say the modelling possibly underestimates the overall impact of FP at the level of the firm and/or economy. The focus on this analysis is on national impact, but it is likewise possible that the total impact across the EU is larger than any one national assessment estimates.

\subsection{Stakeholder views}

To complement the other data, a number of stakeholders were interviewed face-to-face, and further surveys were sent to the stakeholders and programme participants. The purpose for interviewing stakeholders/experts and direct participants was to gather a broader view to the significance and contribution of Horizon 2020 and previous FPs in Finnish society beside the economic effect.

Stakeholders were selected purposively, including Programme Committee members, National Contact Points, and other civil servants familiar with the FPs, as well as research administrators and representatives of associations and the industry. The participant survey was sent to the contact person/coordinator of each Horizon 2020 and FP7 project that have ended within 5 years.

\subsubsection{Stakeholder interviews}

Starting from the general benefits, the FPs are seen as an opportunity to raise the profile and visibility of Finnish research and industry, and for creating new networks. Also from the pragmatic viewpoint the FPs are gaining importance and interest as national applied research funding has declined. However, the voices from the industry are in somewhat contrast with the public sector view regarding usefulness of FP funding in relation to national RDI funding, likely due to the pragmatic realities of participation bureaucracy and acceptance rates in the FPs in comparison to national RDI programs.

For the specific contribution of the FPs, building institutional and personal-professional networks is one of the main benefits. The networks are tied to benefits in terms of RDI substance, but also the ability to influence the direction of the field and associated standards, tying business contacts and other concrete business benefits. Already the application process has the benefit of forcing forward thinking on the consortium Additionally, receiving EU and particularly ERC grants is a major career achievement for

${ }^{72}$ Viljamaa et al., 2013 
individual researchers, but also their host institutions and that enables building larger and more competent, internationally attractive, and competitive research groups.

As for the negative effects, not many negative externalities were identified. The interviewees answers were mostly related to the tricky parts of the application procedure in the pre-award phase. The most serious suggested negative outcome or externality was that at least in individual cases the standard setting power of FP consortia can act towards sustaining incumbent business models, current dominant designs and other entrenched interests. Another more general theme was the familiar tug-rope between (basic) research and innovation, where the main concerns were pitting research and innovation against each other and that heavily focusing on relatively short-term impact of grants and current issues can direct attention away from solving large complex issues.

When asked about the impact mechanism, judging from the answers, overwhelmingly the most important impact pathway is network formation that is associated with both enriching the RDI substance and formation of new business relationships and access to new value chains and markets. A parallel pathway is pooling of actors and resources in a way that would not happen or would be difficult, which paves the way for better impact.

In reference to relationship with between national funding instruments and the FP, the overall picture is that there is very little harmful overlap of gap. However, some indicated that this apparent coordination between national and EU instruments is more incidental than a result of considered planning and programming. The clearest end deliberate continuum is in the area of Pillar I where national institutions try to identify potential EU applicants early on among their clientele, and nudge and coach them towards the FP. The largest outstanding questions is whether national RDI funding has displaced or crowded-out EU funding, especially during times of plenty. It is difficult to measure, but for example multiple interviewees expressed the view that previously excellent national funding has lessened the pressure to reach towards international cooperation and to some extent taken the incentive to apply for EU funding, and some also expressed doubts if 'the best applicants' in their field were applying for EU funding because they could satisfy their needs with national grants. Particularly SHOK funding was mentioned as an instrument that grabbed the attention of national actors and turned them away from the FP. This question is also related to personnel incentives, both in private and public organisations; it seems incentives are not generally aligned well towards applying FP projects.

The relationship between FP and ERDF/ESF funding was something the interviewees did not bring up much. One factor is that in Finland ERDF/ESF funding is negligible in regions where the largest actors reside. Further, ERDF/ESF funding process and reporting requirements are viewed unfavourable by industry and academia compared to other funding instruments. However, Interviewees from regions with better availability of Cohesion Funds viewed them as important instruments for anchoring innovation to the regions.

Regarding development needs for following FPs, the overwhelmingly most important is further streamlining and simplifying the application, administration and technical reporting, and speeding up the funding process from application to project kick-off. Another related matter is Work Programme content and award criteria, and their relationship to the stated goals of the programme and participation. And third related aspect is evaluation of the applications, some interviewees were concerned about possible different interpretations and vagueness of award criteria and called for more specific criteria and openness in the process. 
Lastly, in relation to national pre-award support measures, the NCP activities and their development were advocated nearly unanimously. Overall the views towards NCP and Tekes EUTI office activities were very positive, the main criticism being that individual NCPs and EUTI have relatively little resources to commit to the activities and thus service availability tends to suffer. In contrast, the interviewees saw pre-award funding for application preparation inefficient and possibly giving altogether wrong incentives, and the present Tekes instruments as sufficient. Multiple research organisations had tried funding application preparation and were not satisfied with the results. Further critical views were expressed again almost unanimously towards lack of common national strategy and coordination within national innovation system in general. The present state of the national innovation system was viewed as lacking clear direction, trust between the actors, and mutual understanding of the goals and means of achieving them. In the context of the FP this was seen as an impediment in proactive positioning towards EU RDI policy and programming. What was called for is a joint broad-based strategy process based on recognition of strengths of the nation-al system.

\subsubsection{Surveys for experts and participants}

In this section, we will review some of the key findings from the surveys to two stakeholder groups, experts and participants. The list of experts is expanded from those who were included in the interviews reported above, including again NCPs, representatives of administrations and agencies in the field of RDI policy, research organisations, and industry associations. The participant group includes contract persons registered for each FP funded project from Horizon 2020 and all FP7 projects ended within the last five years. The full reports are enclosed as an Appendix to this report.

To begin with, the survey was opened in June 2017. The expert survey received 60 answers and the participant survey 146 . In the expert survey, roughly $47 \%$ of respondents were from Ministries and agencies, and further $39 \%$ were from HEls and research organisations. In the participant surveys a full $60 \%$ were from HEls and research organisations, and 31 from enterprises where particularly SMEs were represented. In that, research organisations are somewhat overrepresented compared to historical proportion of participations.

\section{Survey respondent distribution}
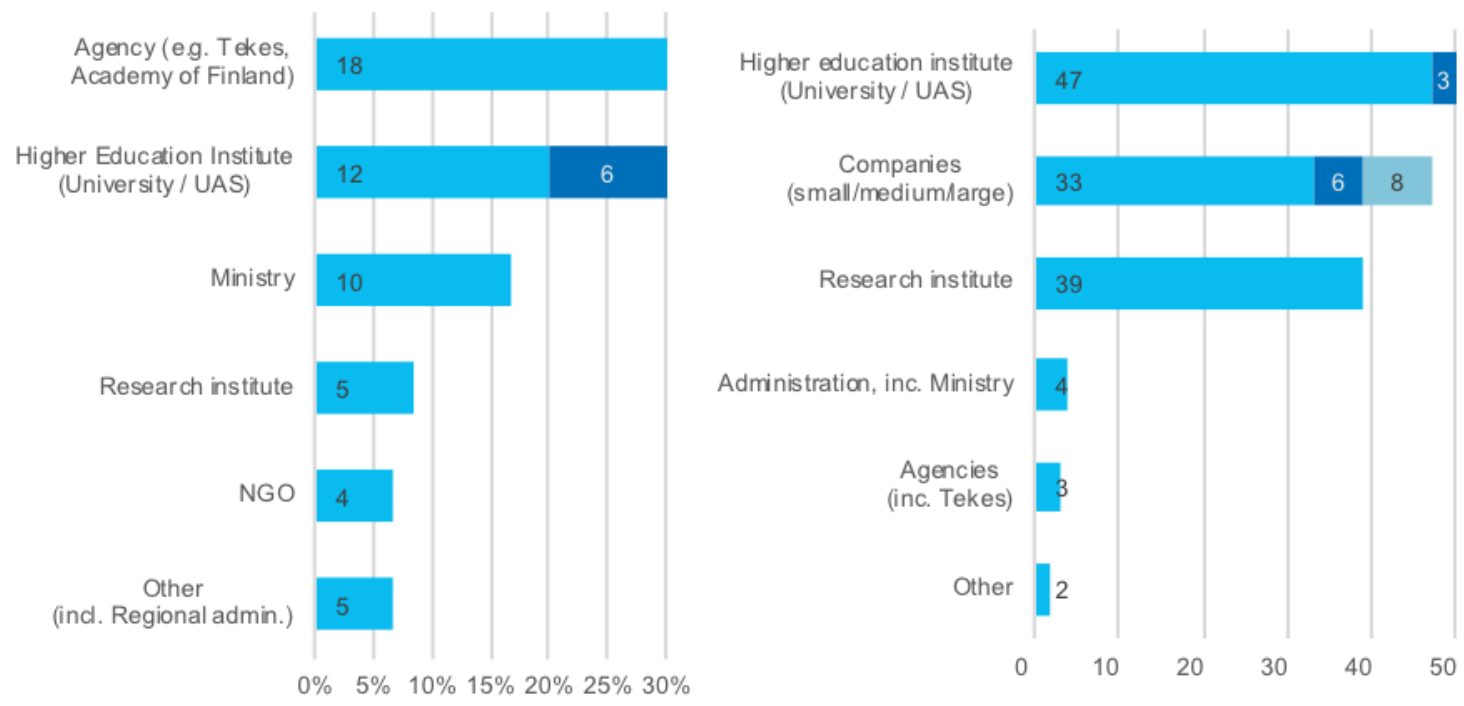
Distribution of survey respondents, $\mathrm{n}=58$ and 148 respectively. Under 'Academia' universities (lighter hue) and colleges/polytechnics (darker hue) are distinguished, in 'Private companies' large, medium, and small are similarly distinguished following EC guidelines.

As the first finding concerning additionality, a stable portion of $70 \%$ of respondent agree that the funded project would not have been carried out without the FP funding. Largest differences to historical figures are in that in the recent FPs the effect on the scale and timing of the work has been smaller (fewer respondents agree that the project was carried out in larger scale or faster with FP funding). Also, significantly fewer agree that the project would have been carried out with other funding or with different objectives. This suggests that in recent times the projects have been more tailored towards the FP and also possibly that the FP and the inherent policy objectives have an increasing effect in steering the direction of RDI activities. In comparison, the Interim Evaluation of Horizon 2020 found that across the Programme $83 \%$ of projects would not have been possible without the FP funding. There are two alternative explanations for the difference, one that relates to relatively strong national RDI base and the primacy of national RDI funding, another is that a portion of the pro-jects could have been nationally funded by the participants estimate, but the partners chose to aim for EU funding because of some perceived benefit e.g. from international collaboration.

\section{Additionality of FP funding}

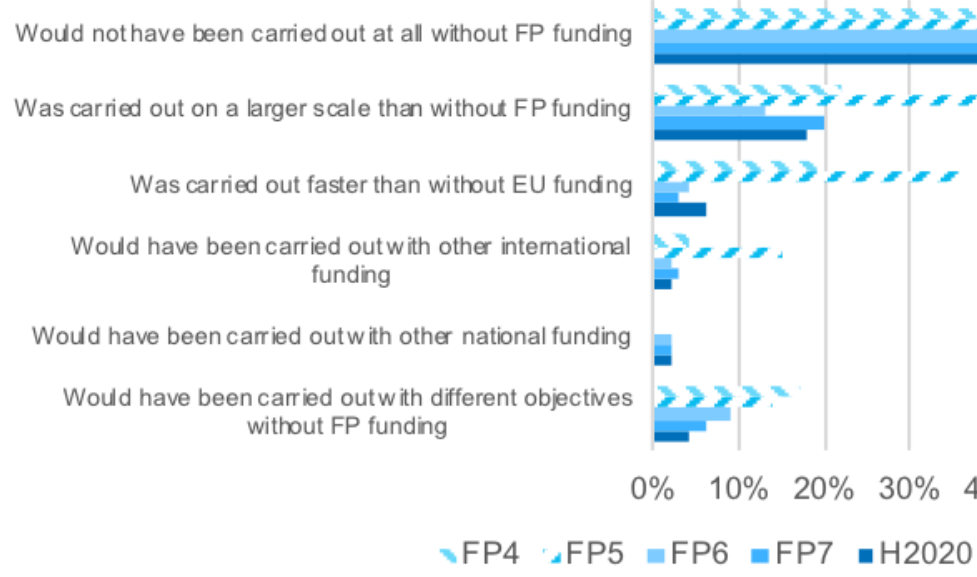

、FP4 $2 \mathrm{FP} 5 \approx \mathrm{FP} 6=\mathrm{FP} 7 \approx \mathrm{H} 2020$

Source: Findings for FP5 and FP4 for scale, from 'Finnish Participation in the EU Fifth Framework Programme and Beyond', 2004, VTT\&TEKES, FP6own survey data

Approaching additionality from the other direction, when asked 'how much of the work carried out in the FP funded projects would have been possible without the FP funding', the largest number of responses is between $10 \%$ and $30 \%$. Put simply, roughly $70 \%$ of the work would have not been carried out without FP funding, reinforcing the finding that FPs have their own unique contribution to the RDI substance. 


\section{Additionality of FP funding}

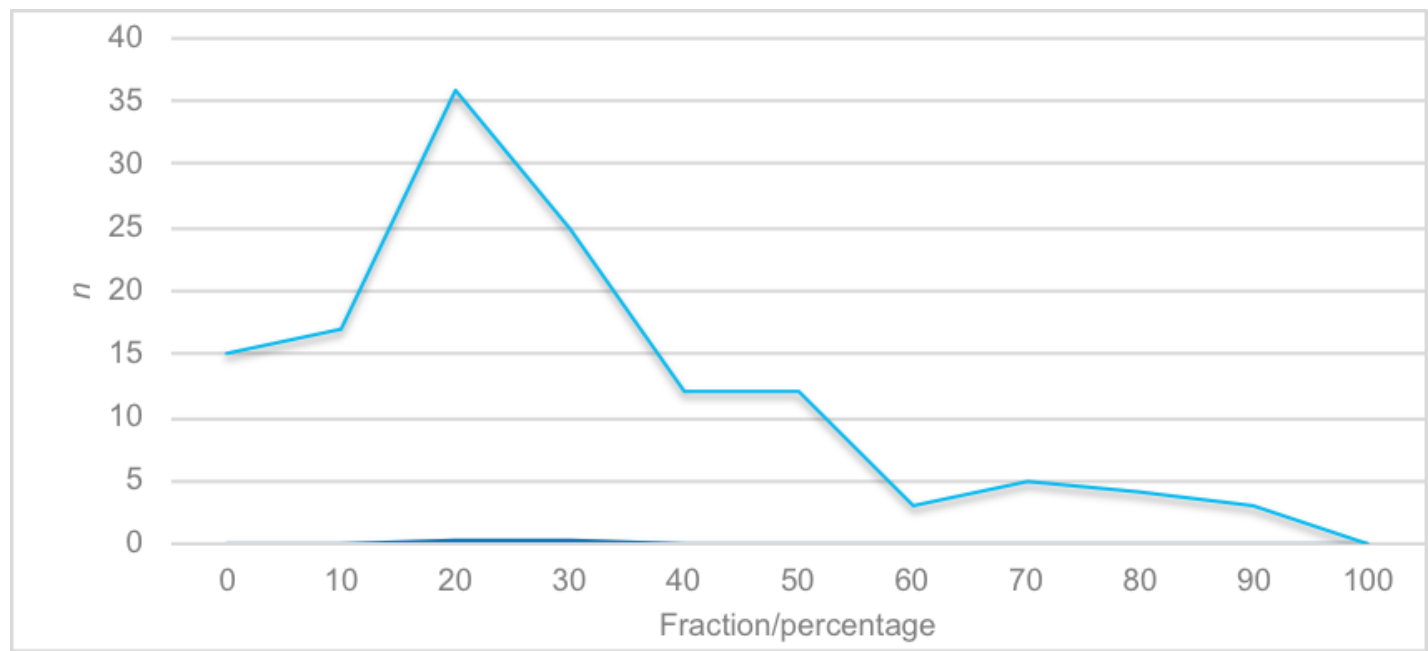

Density plot of number of responses $(n)$ per fraction

Related question is why do Finnish organisations participate in the FPs. The following figure gives the three most important reasons for participation. The three most prevalent \#1 answers are developing new knowledge, new technologies, and the financial leverage afforded by the funding. The most popular \#2 is forming new international networks, which also features as a popular \#3. Then the most popular \#3 has been access to (existing) networks, capabilities and knowledge. This suggests that Finnish participants who have successfully applied for funding have been focused on the substance first and forming networks and gaining access to existing resources second and third.

\section{Top 3 reasons for participating in the FPs}

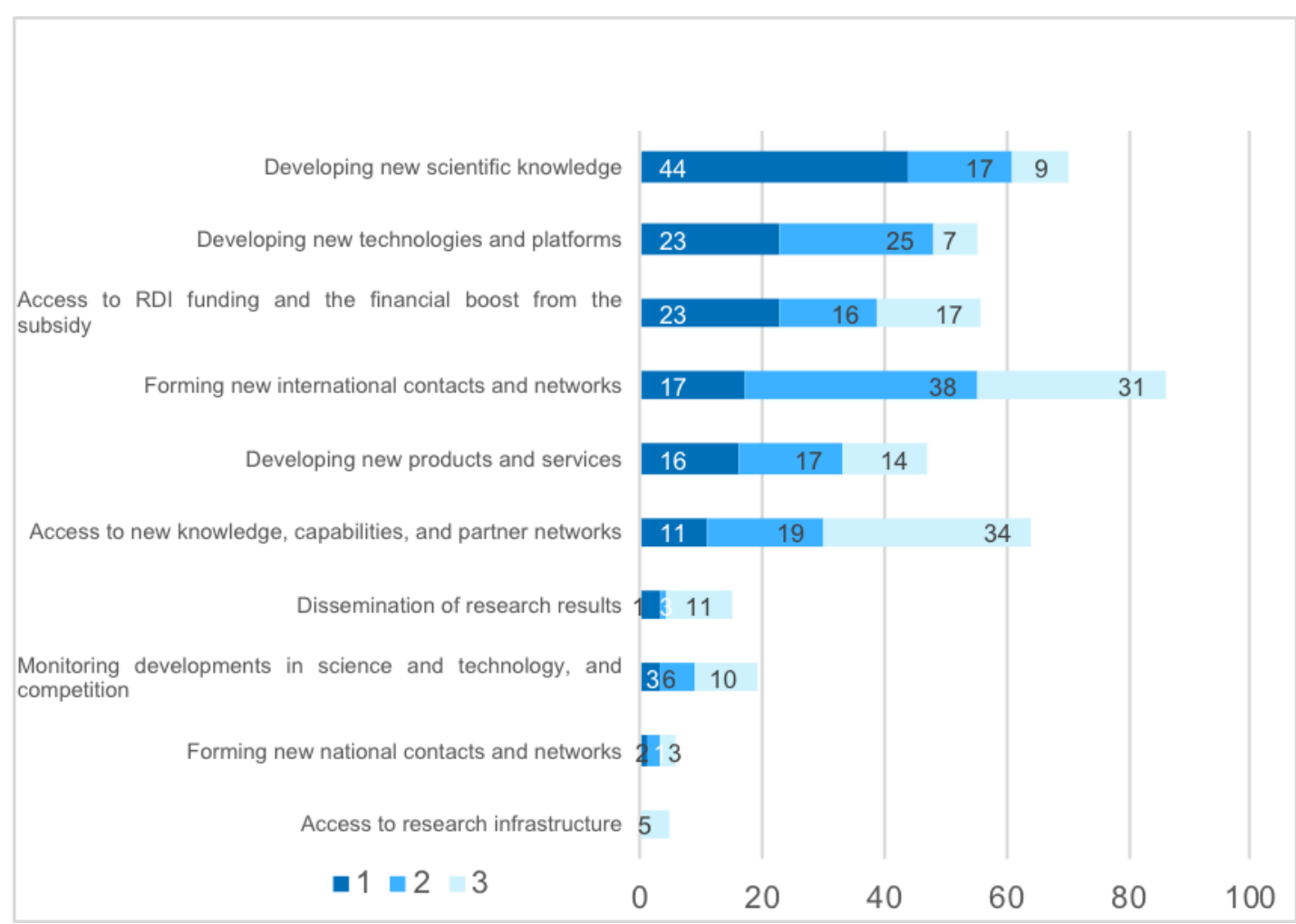

The three most important goals 1-3, numbers of responses per item, scale indicates percentage. 
This finding is closely mirrored in the experts view on the additionality of the FPs. Building international network is seen as by far and away most significant additionality, followed by access to funding. More interestingly, most of the experts view that the FP has had a significant contribution to identification of common challenges and solving societal problems.

\section{Added value of EU FPs according to experts}

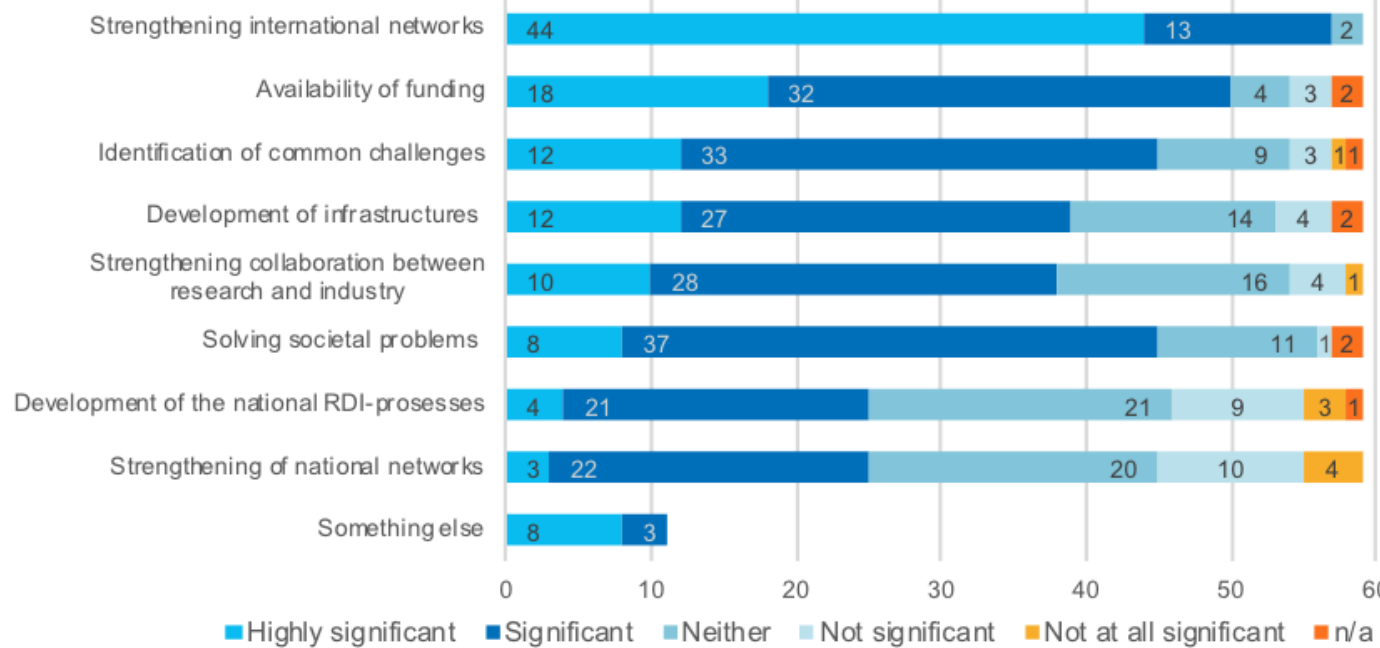

Numbers of respondents and fractions per answer for the items

Again, in a similar fashion, the participants view new partnerships as a major outcome, superseded only by new knowledge. The difference to the preceding figure may be purely due to the difference in point of view between project coordinators and other contact persons and the more of a bird's eye view of the expert group. What is notable though is the fourth outcome, new strategic directions. Another finding is that despite the recent shift in the goals of the FP from research towards innovation, the outcomes are strongest in precommercial end of the spectrum. The most significant contribution is still towards generating new knowledge and competences, networks, and technologies, and to a lesser degree towards new products and services. Regarding direct commercial ventures and registered intellectual property (IPR, including patents, invention disclosures and other IPR), there is a lot of uncertainty and approximately a third of the projects had a no or negligible effect in their own view. While researchers are strongly represented in the respondents, the views on outcomes and impacts are surprisingly consistent between respondent groups as well. The largest differences are between research institutes and the others in terms of new business areas, spin-offs and joint ventures, where research institutes were the most pessimistic and other groups fit within half a point. 


\section{Outcomes of FPs according to all participants}

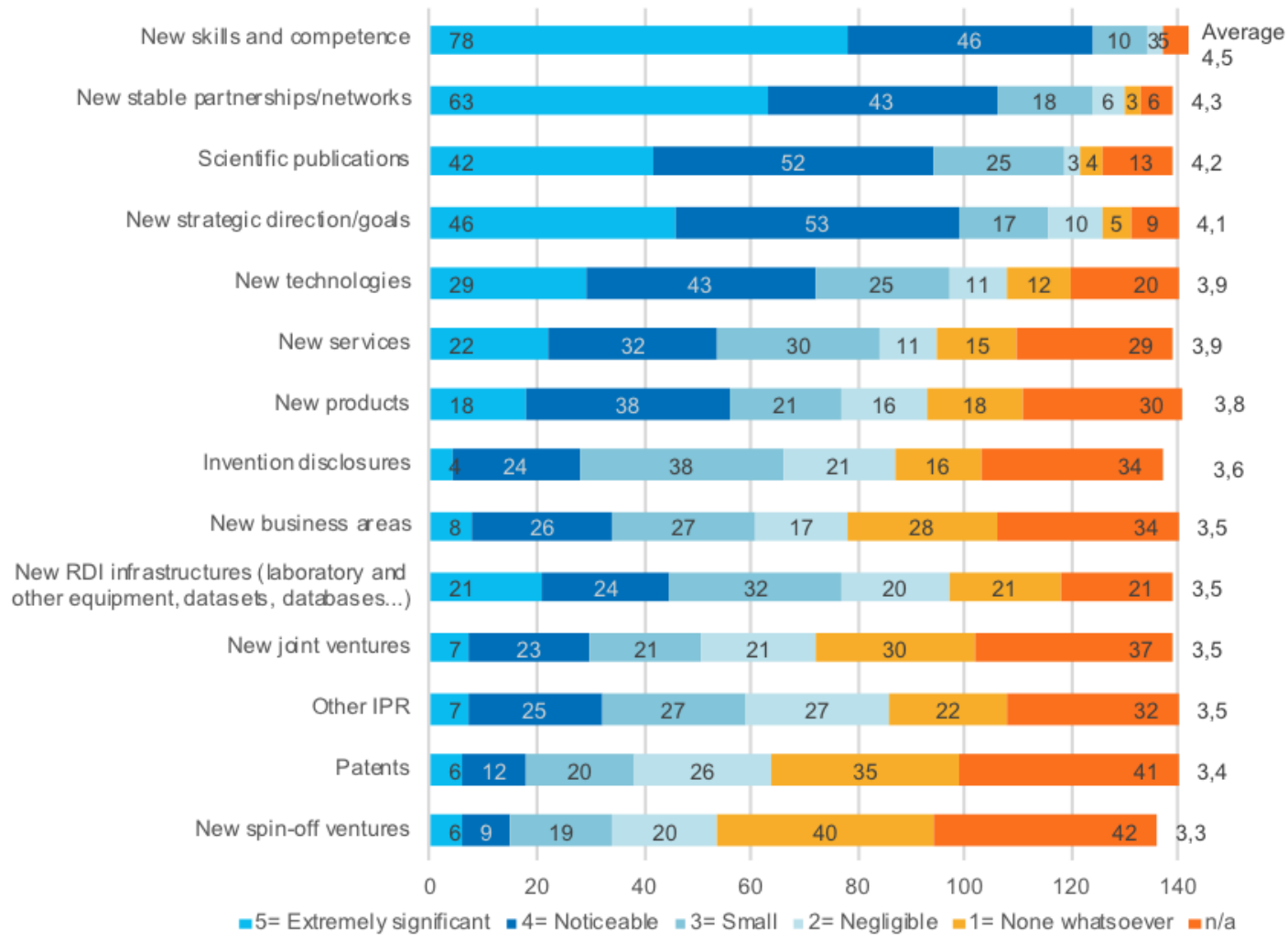

Numbers of respondents per item and average answer

We discussed above that it is possible that Horizon 2020 has had more impact in directions of RDI than before, and this is a relatively direct indication that the policy agendas embedded in the FPs have a direct influence in national RDI at least within the portion funded from the FP.

Going further from the outcome towards impact, the participants are again considerably clearer on the academic impact and noticeable impact it most clear in measures related to academic publishing. However, equally clear is the contribution towards solving societal challenges and employment. In the commercial impact measures uncertainty rises and under a third of the projects has had a noticeable impact in further RDI impact and revenue, in terms of high-quality patents, investments, and exports only around $10 \%$ of all projects has had a positive impact. 


\section{Impact of FPs according to all participants}

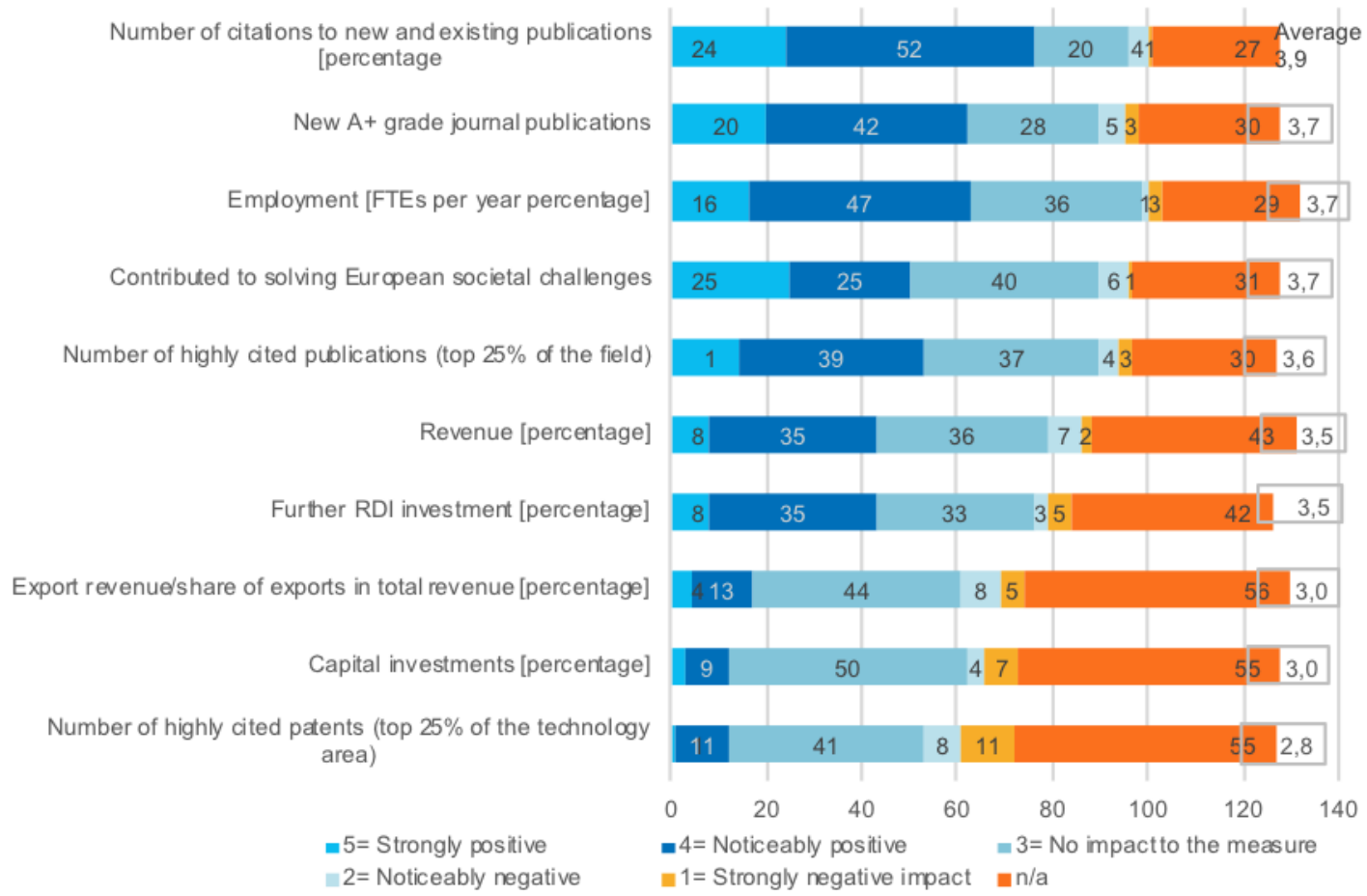

Numbers of respondents per item and average answer

Al in all, it can be said that the FPs contribute to Finnish RDI, but to a large degree the contribution has been focused on pre-commercial capacity building that will hopefully turns into innovation in further development. As such this may not be what has been hoped for in the light of FPs moving from research more towards innovation and solving societal challenges, but taking into account the distribution of participation, and respondents, up to two-thirds of Finnish participants are research organisations whose horizon is naturally more in the pre-commercial research and development end of the spectrum. That said, the answers are relatively consistent between the respondent groups here as well, as is evident in the appendix.

However, it is also reasonably clear that the FPs have had a contribution towards solving societal challenges, which is a new feature and in line with the explicit goals of Horizon 2020. Another and previously unrecorded finding is that the FPs increasingly have role in steering RDI substances also in Finland.

\subsection{Finnish ecosystems in Horizon 2020 - case studies}

The case studies were picked in collaboration with the Project Steering Group. The purpose of the cases, as stated is to illustrate what contribution EU funding has had in Finnish innovation and formation of innovation or ecosystems. The approach was to describe the relevant context to understand the position of FP funding in the outcomes. 


\subsubsection{Case DIMECC}

DIMECC Oy (from Digital, Internet, Materials \& Engineering Co-Creation) has its roots in the Strategic Centres of Excellence (SHOK) programme created in 2006-2007 to create platforms for industrial renewal. The collaboration platform and ecosystem has been formed historically through the SHOK programme that started with the general objective to bridge (basic) research with innovation to support growth and renewal in key areas of industry. (Lähteenmäki-Smith et al., 2013) DIMECC was founded in 2016 (2016 was the first operational year of DIMECC according to Annual report 2016) through a merger between FIMECC (est. 2008) and Digile (est. 2007), which were platforms for machinery and ITindustries respectively. However, the heavy industry cluster in Tampere-Pirkanmaa region dates from early period of industrialisation, and especially the machinery industry in the area grew to significant proportions already in the early $20^{\text {th }}$ century. Thus, the FIMECC and DIMECC ecosystem is built on a base of a long entrenched industrial tradition.

DIMECCs states that their vision is to be "... the leading co-creation platform for digital transformations."

The initial service offering for the SHOKs consisted largely of programme management services. The SHOK organisations focused on facilitating large consortia of enterprises, research performing organisations and other actors in developing RDI programmes and projects, which were proposed mainly for TEKES and to a degree for FP7 (LähteenmäkiSmith et al., 2013). The services of the platform have developed over time, but most of the time they have included elements similar to the present. As of Q4 2017, DIMECC offers the following services:

- $\quad$ Programme and project management: large collaborative RDI projects (10 programmes/projects running, 5 ended)

- $\quad$ Co-creation: smaller industry-driven initiatives and projects (6 projects running)

- $\quad$ Networking services and coordination (4 networks)

While the FIMECC and DIGILE evolved initially separately, the long-standing co-operation around collaborative research and development projects forms the basis for present activities and service portfolio. DIMECC states that their "network consists of $2.000+R \& D \& I$ professionals, $400+$ organisations, 69 shareholders and 10+ co-creation facilitators". DIMECC shareholders include 44 enterprises from industries such as materials and metals processing, machinery, software and IT solutions, instruments and consumer devices, as well as 25 higher education institutions and one research institute. Qualitatively, the network includes the leading Finnish enterprises of their respective industries and leading Finnish research institutions. (DIMECC Oy, no date)

\section{Role and effects of FP funding}

DIMECC plays a large role in national RDI scene as a hub of interest, and cooperative platform for key players particularly in machinery and metals processing, IT and associated service industries, and serves as an example of successful innovation (eco-) system creation in general. After roughly 10 years of operation, the ecosystem has matured into a stable network or ecosystem of internationally established partners. DIMECC has developed an internationally recognised brand and is viewed by some as a progenitor of the Industry 4.0/PPPP (Public-Private-People-Partnership) platform model of recent European vogue. 
The core service in DIMECC is the programme management, which is the single largest activity. The programs are borne from the genuine interests of the platform's constituents with a bottom-up process. The programs set clear goals and matching indicators with thresholds for monitoring progress in the start. The consortiums are open for applications for all interested parties willing to invest, and the applicants are selected based on their track record, with a rule of thumb that $80 \%$ have a solid track record of delivery and meeting or exceeding their goals, and the last $20 \%$ are unknown or less experienced partners that have a chance to prove their capability. This ensures that the consortia have capability to successfully complete the programme with acceptable risk, while allowing new ideas and partners to flow in. During implementation, the set of indicators are monitored on a yearly basis and deviations are corrected. This includes also restructuring the consortia, if partners continually fail to deliver or fall behind mutually set targets. This simple system sets incentives for the participants to act in good faith and do their best.

However, at least on the surface, the role of Horizon 2020 and previous EU FPs in creation and continued work on DIMECC platform is relatively minor. The core funding base for the RDI programmes historically has been national grants particularly from TEKES and service fees from the constituents. As an illustration, according to DIMECC documents published in $2016,47 \%$ of the total funding for DIMECC programmes came from TEKES SHOKinstrument (which is ramping down during 2017), $8 \%$ from research organisations, further $6 \%$ from SMEs and the final 39\% from large enterprises. According to DIMECC, roughly $20 \%$ of total funding for the DIMECC organization comes from the EU in the form of service agreements and grants. To illustrate, EU CORDIS search found two projects where either TIVIT, DIGILE, FIMECC or DIMECC has been a partner: CONCORD for implementing Future Internet PPP (FP7-FI CSA, 2011-2016) and Manufuture 2017 Conference organisation (Horizon 2020-NMBP, 2016-2018). In addition, DIMECC has been in partnership negotiations with EIT Raw Materials KIC in the past and is a listed partner in European Factories of the Future Research Association.

These figures also do not include the FP funding garnered by DIMECC constituents for themselves, some of whom are among the most prolific FP participants, e.g. VTT, Aalto University, Oulu University, Tampere University of Technology, CSC Scientific Computing Centre, ABB, Nokia Solutions and Networks, LM Ericson Ab are found on both lists and together these 8 organisations account for more than 2500 project participations in Horizon 2020. The interviews suggest also that the networks formed around DIMECC have contributed to formation of FP projects. Further, DIMECC have consistently developed collaboration between industry-driven platforms in Europe, examples being OWL Clustermanagement $\mathrm{GmBH}$ and Flanders Make to create a foundation for European collaboration. DIMECC have further been developing services to support FP participation, but due to changes in funding structure has had to postpone launching new services.

Looking at the data for explanations why FP funding has not had a larger role in DIMECC, there are multiple parallel explanations. The overall answer heard in the interviews is that 'the enterprise constituents are not interested' to specifically develop PF projects in DIMECC. To flesh out this overarching answer we can explore two explanations. First, historically national funding with favourable conditions and lean application and administration process has saturated the RDI funding needs. Second, during this period of funding, the constituents have created well-functioning collaborative relationships that are viewed as fruitful, which may have further taken incentive out of international networking. Purely from the narrow viewpoint of participation success in EU FPs they do not necessarily make a large difference. The interviews actually directly proposed that the previous 
generous national funding has displaced international RDI funding especially during the previous European programming period.

Furthermore, especially for the network engines that are already multi-national enterprises, DIMECC programs serve a specific purpose that is related to RDI substance and not internationalisation as an end-goal. DIMECC act as a 'service provider' for their constituents, and have no specific interest or incentive to market any particular funding instrument. Especially for MNEs which have a clear internal RDI agenda, the FP, DIMECC, and any other RDI programme and instrument appear as tools to solve specific problems related to the internal roadmap or agenda, and they choose the tool that is viewed best for a given problem. That is to say enterprises take a specific RDI problem to a programme where they can gather the best consortium to solve it with the least administrative overhead. Another hypothesis previously noted in the SHOK programme was that there is at least a potential incentive problem in bringing core business RDI in joint collaborations and enterprises may prefer their own networks for these development projects, but DIMECC have also addressed this challenge in their programme management.

Relatedly, the interviews brought up a structural issue in building FP projects through national platforms. An interviewee pointed this out in saying that it is difficult even for MNEs to draw Finnish partners to larger European projects, unless they have specific expertise and added value to the specific project. To put this into perspective, looking at the mechanics of FP project applications through participation figures, in successful application there are on average approx. 1.4 Finnish participants, which means on average roughly every other application has two Finnish participants and every other just one. Meaning building national ecosystems, while beneficial in general, in and of themselves do not contribute towards FP participation.

Another way to look at the data, is that there is a complementary relationship between nationally funded RDI and FP funded RDI on the same platform. Information moves in collaborative RDI, and when there is a stable constellation of actors that participate in parallel in FP projects and nationally or privately funded projects, (some part of) the knowledge created in FPs will be distributed through the network. At the same time the international state-of-the-art becomes (more) visible for all partners.

\section{Conclusions and lessons}

The main finding is that on balance of probability, ecosystems like the one around DIMECC have an important part in fostering networks that support the wider impact of EU FPs and national funding as well. There is good evidence that formation of industrial/innovation (eco) systems is beneficial for the economy. In fact, that much has been relatively clear since the early 1990 s industrial clusters literature, which is to say platforms like DIMECC are probably beneficial for the economy in general.

While this sort of impact is hard to measure through conventional indicators or participation success, the interviewees have strongly indicated that collaborations around DIMECC have a contribution. The mechanism is twofold, first collaborations that are built on the platform generate further collaboration, also towards the FP. Second, the platform facilitates knowledge exchange and the results generated in e.g. FPs and the market knowledge spreads through the network to a wider audience than the immediate participants.

DIMECC constituents are generally very satisfied in the platform and collaboration and the ecosystems is viewed as significant for renewal and growth of the industry, and DIMECC is able to show very solid growth and financials for its constituents despite the 'lost decade' in 
the Finnish economy. Particular benefit from DIMECC-type cross-cutting or cross-industry platform is that it offers an opportunity to understand demands for technology, products and services through direct co-creation relationships, and develop new kinds of solutions bundles.

The strength of DIMECCs programme management is openness of the operation model that brings a wide array of stakeholders together in a smart way. The largest factors in DIMECCs success are RDI programming based on the genuine organic interest of the constituents and developed programme management. From the enterprise viewpoint, a 'genuine' functional ecosystem is a tight network of enterprises and other actors that are willing to commit to and invest in mutual interests, to 'have skin in the game'. These collaborations have been fruitful for DIMECC constituents and the economy by extension and DIMECC may serve as a model for ecosystem creation.

\subsubsection{Case VTT}

The Technical Research Centre of Finland - VTT was founded in 1942 and has during its history gained an important position as a centre for applied research, engineering and innovation in Finland. VTT's mission is to support industrial and societal competitiveness. VTT has reported that it has played a part in over a third of Finnish innovations over the course of their history. ${ }^{73}$ VTT has approx. 2100 personnel over six offices in Espoo, Tampere, Oulu, Jyväskylä, Kuopio and Kajaani. The largest centre being the head office in Espoo. ${ }^{74}$

The bulk of VTT activities are jointly-funded collaborative pre-commercial RDI projects with enterprises and universities. Other services include contract research and advice, product development and testing, and VTT's research infrastructures are an integral part of the services. The VTT Group of companies includes VTT Technical Research Centre of Finland Ltd, VTT Expert Services Ltd, VTT Ventures Ltd, VTT Memsfab Ltd, and VTT International Ltd. (Including Korea Branch), and VTT Brazil LTDA.

VTT operates as a government-owned limited liability company, steered by MEAE on behalf of the Government. VTT's turnover (2016) was $€ 270$ million. The group operating income (total €249 million in 2016) comprises $31 \%$ government general budgetary support grant, $16 \%$ domestic private sector revenue, $9 \%$ foreign private sector revenue, $26 \%$ domestic public sector revenue (including 16\% Tekes grants) and 15\% foreign public sector revenue (including 13\% EU grants). According to preliminary estimate, in 2017 revenues from EU have surpassed revenues from TEKES for the first time in VTT history.

\section{Role and effects of FP funding}

Historically VTT have had a role as a mediator between universities and industry who compete among their ranks. Besides the core research activities and associated services, VTT's position as an independent research institute has enabled them to act as a platform for collaborations that would otherwise have been difficult to achieve. This has also meant that VTT have been a nexus for FP projects and has amassed expertise in the process of grants writing and project management. In fact, VTT is one of the largest beneficiaries of EU FPs in Finland.

\footnotetext{
${ }^{73}$ Loikkanen et al., 2013

${ }^{74}$ VTT, 2015; VTT Oy, 2016
} 
VTT have recently launched a new forward looking strategy. VTT strategy is challenge driven and organised around themes called VTT Lighthouses in line with strategic goals of national and EU administrations: ${ }^{75}$

\begin{tabular}{ll} 
- & Climate Action \\
- & Resource Sufficiency \\
- & Good Life \\
- & Safety \& Security \\
\hline & Industrial Renewal
\end{tabular}

The strategy illustrates how VTT proactively adapts to changes in RDI landscape. In this case the new strategy is increasingly oriented towards EU goals, partly steered by the fact that national applied research funding in Finland has declined recently from its past levels. VTT participates actively in different agenda setting forums, both as an organisation and as individuals. VTT works closely with for example EARTO, the European Association of Research and Technology Organisations, and participates in discussion on the European fora. Related to the strategy process, VTT has started a process of specialisation to support regional capabilities and innovation ecosystems. The following three examples illustrate the specialisation effort: Bioruukki in Espoo, SMACC in Tampere and Printed Intelligence Centre Printocent in Oulu.

\section{Bioruukki}

One of smart specialisation goals defined for 2014-2020 in Helsinki-Uusimaa Region was to make the Region the leading European platform for the development of Cleantech solutions, including testing, development and commercialisation of environmental technologies, energy solutions, biomass utilisation, key infrastructure, and service models. ${ }^{76}$

The research organisations in the area, particularly VTT and Aalto University have developed significant expertise in cleantech over time. Especially biomass use and other renewables have been a focus of VTT for several decades, and for example between 20072013 VTT participated in more than 30 FP7 projects related to biomass and renewable energy solutions. The projects developed competences and resulted in a number of proofof-concepts.

As bio- and circular economy was recognised as a strategic priority for Finland, VTT and Aalto University started a collaboration to develop the research infrastructures in the field. VTT has had the main role in Bioruukki piloting centre in Espoo, which was inaugurated 2015. The investment was based on strategic decisions and an agreement to consolidate heavy wet laboratories located in the Otaniemi campus area between VTT and Aalto University. Bioruukki aims to accelerate business in bio- and circular economy by serving a variety of users, from large companies to start-ups and research projects. Bioruukki provides a piloting environment that includes process equipment for a thermochemical conversion platform, a biomass processing platform, energy storage platform and (by 2019) a green chemistry platform and over more than $8,000 \mathrm{~m}^{2}$ plant floor.

Total investment costs of Bioruukki piloting centre are estimated to be $€ 32$ million by 2019 . Financing comprises special grants from national government budgets ( $€ 13$ million), VTT's own capital investments ( $€ 10$ million), real estate owner ( $€ 9$ million paid in-kind).

\footnotetext{
${ }^{75}$ VTT Oy, 2016, no date

${ }^{76}$ Uusimaa-ohjelma: Vision ja Strategia 2040, Strategiset valinnat 2014-2017, 2013
} 
Additionally, the estimated labour cost of building the equipment and ramping up activities is approx. $€ 1$ million. Academy of Finland has funded VTT's new Bioeconomy infrastructure equipment with $€ 2.6$ million and Helsinki Uusimaa Region with $€ 0.5$ million ERDF-funding (specifically for a fibre spinning pilot).

Bioruukki establishment made possible for VTT to offer one-stop-shop, top-level piloting capacity and competences for scale-up and demonstration, process development and custom manufacturing research and services in the field of new biobased chemicals, materials and fuels. Currently revenue from projects is $~ € 20$ million and industrial projects make up around $30 \%$ of operation. From 2013 to 2015 there have been 137 customers, in 186 projects, from 14 countries. Annually SME's share of sales is $7-10 \%$, around $40-60$ companies from 10 different countries. Piloting results are utilised broadly in Finland. The following examples, some of which precede Bioruukki, illustrate the types of RDI that uses the platform:

- $\quad$ Fortum: Joensuu bio-oil plant

- $\quad$ Chemigate: New production plant for starch based paper chemicals in Lapua

- $\quad$ Fazer: Beta-glucan production at Lahden kauramylly

- $\quad$ Metsä Group: Äänekoski bio product mill

- $\quad$ Start-up companies: Spinnova (Jyväskylä), Paptic (Espoo), Infinited Fibre Company (Espoo)

At European level, VTT Bioruukki is already considered a leading forest-based bio- and circular economy open innovation pilot environment and competence centre. From 20142017, VTT Bioruukki have participated in 16 Horizon 2020 projects directly related to bioand circular economy. Specifically related to Bioruukki, VTT have obtained several Coordination and Support Actions in collaboration with other top European pilot centres. These projects are strategic by taking in consideration the needs of diverse users and stakeholders groups, e.g. the projects below:

- $\quad$ Erifore (Horizon 2020 Research Infrastructure programme)

- $\quad$ Smartpilots (Interreg Europe programme)

- $\quad$ EU-Great (Horizon 2020 NMBP programme)

- $\quad$ Pilots4U (Horizon $2020 \mathrm{BBI}$ JU programme)

- $\quad$ BRISK2 (Horizon 2020 Research Infrastructure programme)

Bioruukki have benefited from the grants, besides the infrastructure investments, specifically in terms of developing a sense of state-of-the-art in the field and ability to follow development, refining business models, and building collaborations with similar actors.

\section{Smart Machines and Manufacturing Competence Centre (SMACC)}

Tampere regional strategy has always placed great importance on the renewal of manufacturing industries. This is an obvious consequence of the strong manufacturing history of the region and the presence of strong RDI actors, including research 
organisations VTT, Tampere University of Technology (TUT), Tampere Polytechnic (TAMK), and industrial platform organisation DIMECC, and strategic links to Orgalime (European Engineering Industries Association).

Research activities have developed a strong knowledge base, and only from 2007 to 2013, VTT participated in more than 90 FP7 projects related to machinery, automatization, and digitalisation for manufacturing industries. In Horizon 2020, VTT continued to develop its competences winning 28 projects concerning manufacturing innovation, covering also human-automation cooperation, eco-design, safety and security, ethics and responsible research and innovation themes.

In 2015 VTT, TUT and TAMK established Smart Machines and Manufacturing Competence Centre (SMACC) together in a fashion similar to Bioruukki. SMACC offers a one-stop-shop to the network of research infrastructures and test facilities of the three partners. The SMACC initiative was supported by the City of Tampere and the Tampere Regional Council with the aim of boosting Finnish exports, of increasing the competiveness of the ecosystem, of linking scattered research and development environments, and of building closer collaboration links between research and industry. Currently SMACC-Labs' infrastructures are grouped under 5 themes: Digital Factory, Robotic Village, Digital Systems, Material Insight and Smart Machines. ${ }^{77}$

SMACC strategy has been focused on sharing and creating value out of existing facilities, less on building new infrastructures, although a $€ 4$ million virtual manufacturing laboratory was still added between 2014-2015. Currently the value of SMACC shared research portfolio is about $€ 40$ million per year. In 2015 there were 450 projects involving at least one SME.

VTT SMACC were successful in receiving 4 Digital Innovation Hub (DIH) project grants for maturing SMACC hub services offered to SMEs (3 of the total 4 financed in 2017). The EU Digital Innovation Hubs calls are for large projects aimed at supporting ecosystems to provide services to SMEs and build partnerships between businesses in Europe. SMACC's focus is developing the strategic priority competence areas and networking with other internationally competitive hubs:

- $\quad$ MIDIH (Cyber physical systems and IOT open digital platforms, Horizon 2020, 2017-2020)

- $\quad$ L4MS (Customized logistics automation, Horizon 2020, 2017-2021)

- $\quad$ AMable (Additive manufacturing, Horizon 2020, 2017-2021)

- $\quad$ XS214MS (Networking and support action for digital innovation hubs, Horizon 2020, 2015-2018)

\section{PrintoCent}

PrintoCent is a joint effort of VTT, Oulu University and City of Oulu to co-develop a credible plan for the industrial renewal of Oulu region and replace the declining electronics industry jobs. The vision was to make Oulu a world leader in hybrid, flexible printed intelligence.

${ }^{77}$ Pirkanmaan liitto, no date; SMACC, no date 
The technologies supported by PrintoCent produce integrated antennas, electronics, energy harvesting, and in general thin, transparent, light weight hybrid structures, components or products, which can be mass manufactured with additive Roll-to-Roll -manufacturing methods to enable low cost and high-volume manufacturing of loT sensors, lab-on-chip disposable diagnostics and large area structural electronics solutions.

PrintoCent's development started in the 1990s out of researchers' interests towards flexible and printable electronics. In the early 2000 s collaborative research started in TEKES programs and 2003-2004 brought the first EU programs for flexible displays, and PrintoCent carried out two FP6 projects FP6 ROLLED (VTT coordination) and OLLA (Philips coordination).

The first phase of development can be described as a portfolio of projects on flexible displays and other printed electronics. Until 2006 the bulk of the funding came from VTT's internal budget, TEKES programs and industrial partners, e.g. interested in the development of new materials for OLEDs. In 2006 VTT was forming strategic spearhead programs, and PrintoCent was chosen as one spearhead. The area started growing from 35 employees in 2006 to approx. 100 in 2009.

Between 2006-2013 PrintoCent and related activities were able to attract strong support from EU FP7 and 3 new pilot production lines were established in this period. At least 25 projects $^{78}$ where funded in connection with PrintoCent. The contribution of these projects were development of specific technological advances such as low cost roll-to-roll processes, high resolution nano-printing, as well as establishing strategic international networks with projects like COLAE (FP7, 2011-2014) "Commercialisation Clusters of Organic and Large Area Electronics" and FLEXNET "Network of Excellence for Building up Knowledge for Improved Systems Integration for Flexible Organic and Large Area Electronics (FOLAE) and its exploitation" (FP7, 2010-2012).

PrintoCent's research and innovation activities still receive Horizon 2020 funding ${ }^{79}$ but increasingly revenue is coming from customer projects and PrintoCent industrial ecosystem. Because of the strong ecosystem and track record, PrintoCent was able to secure strategic Horizon 2020 projects like SMARTEES for the establishing of a European Digital Innovation Hub dedicated to OLAE, and to continue expanding the range of printed intelligence technologies to higher TRL with 4 pilot line projects (INscope, ATLASS, NOVUM, PISCALE). Overall, approximately $2 / 3$ of funding for PrintoCent has been international/EU funding.

During the early years it was recognised in that incumbent enterprises were not ready for the technologies being developed. By 2006 it was recognised it was necessary to invest into fostering start-ups that could develop a competitive edge from the extra functionalities and benefits of printed intelligence and who would be more amenable for new potentially disruptive technology development.

In parallel Oulu region has invested ${ }^{80}$ in and supported the start of the industrial ecosystem for the first years. Currently, the industrial cluster activities continued based on a nominal fee for the industrial partners. In the Oulu region, more than 300 experts are available in

\footnotetext{
${ }^{78}$ FACESS, PriMeBits, Opera, PolyMAP, PolyNET, FlexNET, PRODI, GREENBAt, NovaCIGS, POINTS, POLARIC, PRIAM, APPLE, SOPHIA, COLAE, DIGINOVA, FLEXIBILITY, IN-LIGHT, ROTROT, ArtESun, 4M2020, CHEETAH, Graphene flagship, NanoCate, LASSIE

799 H2020 projects: PI-SCALE (VTT EU contribution: $1.5 \mathrm{M} €$ ), LUMENTILE 1M€, ROLL-OUT $1 \mathrm{M} €$, Symbiotic 0.8 M€, ATLASS 0.75M€, TagltSmart $0.6 \mathrm{M} €$, NOVUM 1,5M€, InSCOPE (1,2M€), SMARTEES $(0,3 \mathrm{M} €)$

${ }^{80}$ Projects ERDF 2015- PrintoCent Business Development $0.5 \mathrm{M} €$, Pilot Factory Upgrade 1.3 M€, Disposable Diagnostics $0.6 \mathrm{M}$, Projects ERDF 2007 2014 (altogether >10) PrintoCent Start\&Run 0.5 M€, R2R-PILOT 2.3 M€, Hybrid Pilot Fab 0.8 M€, BioPrint 0.6 M€, Optools 0.4 M€, PritnLab-oamk 0.3 $\mathrm{M} €$, Optical Measurement Methods for QA 0.8 M€, Print ele and BioMaterials $0.3 \mathrm{M} €$
} 
research and in industry. Education, Training and Research initiatives were funded to generate the multidisciplinary experts for the needs of ecosystem growth.

PrintoCent and related activities have had a significant contribution to Oulu's start-up scene through the RDI activities and associated accelerators events (since 2012), Polar Bear pitching competitions, and 'PÄLLl' entrepreneurship trainings (since 2013). The funding to start-up companies has exceeded $€ 40$ million and the turnover of companies in the field is over $€ 25$ million year 2016. Between 2010 and the time of writing 26 start-ups that use printed electronics technology or associated instrumentation have been founded. Out of the 26, 21 have survived to date and have created directly 170 jobs. In the past year, for example Tactotek received $€ 2.5$ million from Horizon 2020 SME instrument (phase 2) and Spectral Engines has won the prestigious Horizon 2020 Innovation Prize with $€ 0.8$ million in prize money.

Printed intelligence is in early industrialisation phase, and there is a need for flexible manufacturing solutions. Manufacturing lines for different markets/products are in the investment phase. Typical Investment level are €2-10 million per enterprise making the total expected investment in the region $€ 50-70$ million in 2016-2020.

Besides regional impact, PrintoCent has effect with its international member companies and partners. Utilisation of PrintoCent pilot lines is at full capacity and fully booked months ahead with a ratio of around $30 \%$ industrial projects. Partners are incubator/accelerator, start-up company, SMEs, midcaps, large enterprises (Nokia, BASF, Merck, DNP, NGS Pilkington, Scanfil)

The timeline illustrates the overall development arch of an industrial innovation ecosystem. PrintoCent was borne out of regional expertise in electronics manufacturing. One of the major factors is commitment of people and consistent investment over the years. The initiation happened at an opportune time under national funding and VTT was ready to participate in European consortia when the first relevant programs were starting. Once the first European project was delivered, it opened several collaborations and enabled continued investment. Overall PrintoCent has enjoyed strong support from VTT as a spearhead technology area, and from the region as well. In the latest development phase, the cumulated expertise has also spun new industrial activity, because of directed efforts, aided by the fact that Nokia's decline after 2008 has been a blow to the electronics industry in the region and has freed up expertise for new start-ups and left existing enterprises amenable for exploring new technologies.

\section{Conclusions and lessons}

VTTs story has two levels, VTT as a national research institution, and VTT as a regional actor. At the national level VTT has shown to be a proactive actor towards the national and EU policy and programming. VTT has in recent years developed a clear strategy based on national and EU policy goals and have actively participated in relevant fora as an organisation and as individual expert in agenda setting discussions. The proactive stance enables VTT to adapt to policy changes and thrive in a competitive environment. Part of VTT's success is the said position as a sort of a neutral arbiter in the innovation system. Another aspect is proactive recognition of (funding) opportunities, and system building based on internal and regional capabilities.

Related to Group level strategy is VTT's smart specialisation effort that relies on VTT's internal competences and regional industrial base. The first two cases Bioruukki and SMACC are relatively new, but PrintoCent illustrates several aspects of organic growth and 
development of industrial ecosystems. One is that the ecosystem is built on existing regional capabilities. Oulu region had an industrial base in electronics and related research capabilities, out of which PrintoCent started growing. The strong growth at the start was partly a question of good timing, as national research programmes enabled early risk-taking and a start to the area, and when the European programs started, VTT had some results to show when entering the European arena. Out of the first European projects, grew a programme of multiple projects. Second fortuitous timing from PrintoCent's point of view was that VTT selected the printed intelligence as a spearhead area in a phase when the research programme was ready to grow. Which leads to the other major factor, that VTT and the individuals have committed to and invested consistently into developing the technology areas that make PrintoCent and have further committed resources into developing related services and commercialisation actions.

From the national standpoint, there are also instances where EU funding has meshed into national landscape bringing added value in terms of research and innovation. The contribution to innovation is most visible in Bioruukki and PrintoCent, where EU funding has contributed to creating new businesses from technical research. However, especially in Oulu region the innovation outcomes are foremost borne out of joint effort and commitment of existing capabilities in the region and smart use of different instruments.

\subsubsection{Case Inverse Problems Centre of Excellence}

The Finnish Centre of Excellence in Inverse Problems (FiCEIP) is internationally recognised as the world's leading unit in the field. It specialises in the theory, implementation and application of inversion methods. The objective is to create fundamentally new, efficient, and theoretically sound solutions to practical inverse problems, especially in following application areas:

- Medical imaging,

- Geophysics and space research,

- $\quad$ Remote sensing and modelling in environmental and climate research.

The director of the Centre is Academy professor Matti Lassas (Univ. of Helsinki) and the vice-director is professor Mikko Kaasalainen (Tampere Univ. of Technology). The Finnish Centre of Excellence in Inverse Problems Research is a network comprising research groups in the following institutions.

The Finnish Centre of Excellence is associated with The Finnish Inverse Problems Society (Suomen inversioseura ry, FIPS). FIPS was founded in December 1997 and officially registered in June 1998. The mission of the society is to promote research activities within the field of inverse problems in Finland and maintain and improve the connections between the various research groups working in this area. The society is interdisciplinary in nature, bringing together the expertise in mathematical, physical and engineering sciences. What is more, the society seeks to build bridges between the academia and industry.

Members of FiCEIP and FIPS in comparison

\begin{tabular}{ll}
\hline \multicolumn{1}{c}{ FiCEIP (2006-) } & \multicolumn{1}{c}{ FIPS (1997-) } \\
\hline University of Helsinki, Department of Mathematics and & University of Helsinki, \\
Statistics, Inverse Problems Group & Department of Mathematics and Statistics \\
\hline University of Eastern Finland, Department of Applied & University of Eastern Finland, \\
Physics, Inverse Problems and Mathematical Modelling & Department of Applied Physics \\
\hline
\end{tabular}




\begin{tabular}{|c|c|}
\hline FiCEIP (2006-) & FIPS (1997-) \\
\hline \multicolumn{2}{|l|}{ group } \\
\hline $\begin{array}{l}\text { University of Jyväskylä, Department of Mathematics and } \\
\text { Statistics, Inverse Problems Group }\end{array}$ & $\begin{array}{l}\text { University of Jyväskylä, Department of Mathematics and } \\
\text { Statistics, Inverse Problems Group }\end{array}$ \\
\hline $\begin{array}{l}\text { Lappeenranta University of Technology, Department of } \\
\text { Mathematics and Physics, Inverse Problems group }\end{array}$ & $\begin{array}{l}\text { Lappeenranta University of Technology, } \\
\text { Laboratory of Mathematics }\end{array}$ \\
\hline $\begin{array}{l}\text { University of Oulu, Department of Mathematical } \\
\text { Sciences, Inverse Problems Group } \\
\text { University of Oulu, Sodankylä Geophysical Observatory }\end{array}$ & $\begin{array}{l}\text { University of Oulu, Department of Mathematical } \\
\text { Sciences, } \\
\text { Sodankylä Geophysical Observatory }\end{array}$ \\
\hline \multirow[t]{2}{*}{$\begin{array}{l}\text { Tampere University of Technology, } \\
\text { Institute of Mathematics, Inverse Problems group }\end{array}$} & $\begin{array}{l}\text { Tampere University of Technology, } \\
\text { Department of Mathematics }\end{array}$ \\
\hline & $\begin{array}{l}\text { Helsinki University Central Hospital, BioMag Laboratory } \\
\text { Aalto University School of Science and Technology, } \\
\text { Institute of Mathematics, Laboratory of Biomedical } \\
\text { Engineering }\end{array}$ \\
\hline
\end{tabular}

Comparison of membership between FiCEIP and FIPS.

Source: Desk research

\section{Role and effects of FP funding}

FiCEIP has been funded by the Academy of Finland from different phases of the CoE programme 2006-08, 2009-2011, 2012-14 and 2015-17(€9 005162 in 4 separate grants). Besides the multiple phases of CoE funding for FiCEIP, overall the Academy of Finland has funded inverse problems research with 114 grants under various programs with altogether $€ 36960$ 687(Inclusive aforementioned CoE) between 2002-2017. Much of the AoF project funding has been granted to researchers in the afore mentioned institutions. According to the data FiCEIP is an internationally recognised top research network. It seems that the mounting funding has enabled creation of critical mass of people and resulted in a world class knowledge network, e.g. interviewees estimate that out of experts with some international renown in the area, a quarter lives in Finland, and that people have chosen to move to Finland to be able to better work with the network.

Besides national funding, the EU CORDIS database there is 184 projects involving inverse problems since the mid-1990s, and 11 of them has a Finnish participant. The first project with a Finnish participant was a COST action between 1993- 1997 with a liberal budget of $€ 20$ million followed by a Summer School and a Conference in 1999. Next the EU contributed a small sum to a project with German coordinator and University of Kuopio 2000-2002 and then another modest sum 2007-2008. The EU funding volume mounted in 2010s with one NMP CP and two ERC and Marie Curie Grants. In some ways, this indicated that Finnish inverse problems research is on one hand on a high international level, but also moving towards more practical solutions with MSCA industrial doctorates and collaborative projects.

Table Summary of FP funding for Inverse Problems research

\begin{tabular}{|c|c|c|c|c|}
\hline $\begin{array}{l}\text { Years, instrument } \\
\text { (PID) }\end{array}$ & Coordinator & Finnish partner & Topic & EU contribution \\
\hline $\begin{array}{l}\text { 1993-1997 } \\
\text { COST Action (2204) }\end{array}$ & CEC, Belgium & VTT & $\begin{array}{l}\text { Develop models giving } \\
\text { a more comprehensive } \\
\text { view and a better } \\
\text { understanding of } \\
\text { phenomena affecting } \\
\text { materials in order to } \\
\text { optimise existing } \\
\text { processes and uses }\end{array}$ & $€ 20$ million \\
\hline $\begin{array}{l}1999 \\
\text { (HPCF-CT-1999- } \\
\text { 00150, HPCF-CT- } \\
\text { 1999-00109) }\end{array}$ & $\begin{array}{l}\text { Helsinki University of } \\
\text { Technology }\end{array}$ & & $\begin{array}{l}\text { Summer School and a } \\
\text { Conference on inverse } \\
\text { problems }\end{array}$ & $\begin{array}{l}€ 0,03+0,06 \\
\text { million }\end{array}$ \\
\hline $\begin{array}{l}2000-2002 \text { (PID } \\
\text { INTAS-1997-00537) }\end{array}$ & TU Bergakademie Freiberg & University of Jyväskylä & $\begin{array}{l}\text { The aim of this project } \\
\text { is to develop methods } \\
\text { for the estimation of } \\
\text { basic parameters of } \\
\text { point and fibre }\end{array}$ & $€ 0,006$ million \\
\hline
\end{tabular}




\begin{tabular}{|c|c|c|c|c|}
\hline $\begin{array}{l}\text { Years, instrument } \\
\text { (PID) }\end{array}$ & Coordinator & Finnish partner & Topic & EU contribution \\
\hline & & & $\begin{array}{l}\text { processes (intensity, } \\
\text { parameters of fibre } \\
\text { orientation and length) } \\
\text { from transformed } \\
\text { realisations }\end{array}$ & \\
\hline $\begin{array}{l}2007-2008 \\
\text { (INTAS 2006- } \\
1000017-8909)\end{array}$ & $\begin{array}{l}\text { Kocaeli University, Izmir, } \\
\text { Turkey }\end{array}$ & University of Kuopio & $\begin{array}{l}\text { Numerical solutions to } \\
\text { inverse and } \\
\text { optimisation problems } \\
\text { for distributed systems. }\end{array}$ & $€ 0,1$ million \\
\hline 2012-2015 & Trinity College Dublin & $\begin{array}{l}\text { Tampere University of } \\
\text { Technology, University }\end{array}$ & $\begin{array}{l}\text { To develop a } \\
\text { quantitative, flexible }\end{array}$ & $\begin{array}{l}€ 3,4 \text { million (out } \\
\text { of total } 4,4\end{array}$ \\
\hline FP7-NMP & & of Jyväskylä & $\begin{array}{l}\text { and fully atomistic } \\
\text { theory of ultrafast } \\
\text { dynamics in real } \\
\text { materials. }\end{array}$ & million) \\
\hline \multicolumn{5}{|l|}{ HUMAN/IDEAS/Pillar I } \\
\hline $\begin{array}{l}\text { 2011-2016 } \\
\text { ERC-AdG (267700) }\end{array}$ & Tallina tehnikaylikool & University of Helsinki & $\begin{array}{l}\text { Mathematical theory } \\
\text { and practical } \\
\text { interpretation of indirect } \\
\text { measurements. }\end{array}$ & $€ 1,8$ million \\
\hline $\begin{array}{l}\text { 2012-2017 } \\
\text { ERC-StG (307023) }\end{array}$ & University of Jyväskylä & & $\begin{array}{l}\text { Inverse Problems in } \\
\text { Partial Differential } \\
\text { Equations and } \\
\text { Geometry. }\end{array}$ & $€ 1,0$ million \\
\hline $\begin{array}{l}2013-2017 \\
\text { MC-ITN }\end{array}$ & Technische Universiteit Delft & $\begin{array}{l}\text { University of Eastern } \\
\text { Finland }\end{array}$ & $\begin{array}{l}\text { The development of } \\
\text { disruptive new optical } \\
\text { design tools. }\end{array}$ & $€ 3,2$ million \\
\hline $\begin{array}{l}2015-2019 \\
\text { MCSA-ITN Industrial } \\
\text { Doctorate }\end{array}$ & Forschungverbund Berlin EV & $\begin{array}{l}\text { University of Oulu, } \\
\text { SSAB Oy, Outokumpu }\end{array}$ & $\begin{array}{l}\text { The research is } \\
\text { focussed on three } \\
\text { major topics - induction } \\
\text { heating, phase } \\
\text { transformations in steel } \\
\text { alloys, ladle stirring. }\end{array}$ & $€ 2,1$ million \\
\hline
\end{tabular}

Source: CORDIS database

The timing of national and EU funding is concurrent, which suggests they are complementary. In fact, FIPS is founded after the first COST Action's completion, and after some gap the CoE funding start concurrently with FP funding. While the funding information gives a certain picture, additionally the interviews reveal that between the CoE, FIPS and enterprises that utilize inverse methods there is a tight professional and personal network of people who are prepared to go out of their way, e.g. volunteer their time across organisational boundaries, to help each other with interesting inverse problems. This is helped by the fact that most researchers in the network have been students of network members, particularly Prof. Matti Lassas and/or Samuli Siltanen at University of Helsinki at some point of their career Thus the impact of publicly funded research extends to enterprises and other stakeholders in ways hidden from view.

Besides high level of academic output, FiCEIP recognises two spin-off companies on their website: Numcore, a measurement and process control systems provider, and Kuava Ltd., a numerical and statistical modelling and optimisation company. Additionally, the research conducted has directly contributed to product development in medical imaging. For example, research in Electric Impedance Tomography ran between 1996 and 2013 in Helsinki University. In 2001 TEKES funded an applied research project related to medical imaging that spurred the development of commercial $\mathrm{x}$-ray volume tomography solutions over the next years.

We explored the contribution of inverse problems research and interplay of national and EU funding further through company cases of Elekta and Eigenor.

Elekta $A B$ is a medical imaging company headquartered in Sweden. Elekta acquired Finnish Neuromag Oy that was a spinoff from Helsinki University of Technology Cold Temperature Laboratory started 1989. Neuromag developed a new science-based high-performance solution for medical imaging, an accurate and efficient MRI solution based on 
superconductive magnet sensory network specifically for cranial MRI. Neuromag was absorbed into the Elektra portfolio around 2009 and continues as a trademark.

Since the merger, the focus of operations in the Finnish unit has changed to solutions development rather than research and technology development, thus the need for RDI funding has changed from research to following research and application of results to software and product development. Neuromag Oy has been involved in 5 EU FP projects since 1998 under the name Neuromag and further 7 as Elekta Neuromag Oy or Elekta $A B / O y$. The latest examples of EU funding reflect this; Elekta has an MCSA funded research stay at the company and a collaborative project 'BREAKBEN' (2016-2018, FETOpen, PID: 686865) According to interviews, Elekta's role in BREAKBEN is development of prototype hardware equipment based on the research and software development at the academic partners. Overall the stance in Elekta towards FP is that unless there is a specific application into software and/or hardware being develop, they stay on the back foot. The interest is following the state-of-the-art in research to keep up with the international competition and absorbing possible new knowledge on the one hand, and on the other 'market study' as in studying the demand for existing possible new imaging solutions. This following can be and is done both through RDI projects, and through existing professional and personal networks, as well as clients.

The other example, Eigenor is a spinoff from Sodankylä Geophysical Observatory (now part of University of Oulu), originally called Invers Oy (registered 1990 and assumed tax liabilities 1995, terminated 2011). Invers was founded to utilise and apply SGeO research results into signals analysis. Invers ran into financial trouble and the IPR was bought by the present consortium, Eigenor, in 2008. Eigenor focus on software that implements inverse mathematics to signals analysis for medical imaging and other volume tomography applications, and radar imaging. Eigenor's added value is possibility to develop more accurate imaging over other signals analysis methods for a given amount of measurements, which adds up to increased accuracy and/or faster imaging.

Eigenor's path is different from Neuromag, in that the present consortium came in with different expectations and organisational culture, preferring to work with private capital and aiming for quick entry to market, which shows in relatively small amount of public funding compared to e.g. Neuromag. Eigenor has relied on a 'lean' model with private funding and commercial partnerships, or partnering in e.g. EU projects as a subcontractor that is to some extent invisible for analysis. Despite the smaller number of collaborative projects, the working relationship with inversion researchers is tight and Eigenor follow relevant research closely. Eigenor's interest in these projects has been technology and software development and demonstration of the product.

Eigenor's challenge at the moment is that they have been able to develop viable software solutions according to their own plan, however as inversion problems is a relatively unknown research area and the solutions are new, the market is not ready to absorb solutions at the expected pace. They are considering entering further projects to demonstrate and validate the technology.

The reason for Eigenor's RDI funding choices are resource constraints on two levels. First, based on their experiences they view project bureaucracy excessive for a small enterprise of few people focused on delivering a product; since the staff is not experienced in grants writing and subsidy administration the learning curve appears to steep and recruiting another person to prepare proposals and administer projects is not possible. Second, the EU funding model with subsidy payments in lumps at long intervals is not a suitable model 
for a liquidity challenged SME in their view. Waiting for periodical reporting for payments is not feasible for them at the moment if the staff can spend their time on projects that can be billed more regularly.

\section{Conclusions and lessons}

According to the data, FiCEIP is a research network on the top level of the field. It seems that the mounting funding has enabled creation of critical mass of people and resulted in a world class knowledge network, e.g. interviewees estimate that out of experts with some international renown in the area of inverse problems, a quarter lives in Finland, and that people have chosen to move to Finland to be able to better work with the network.

The network seems to be very close and beside project activity, there is other collaboration between individuals and organisations. Thus, the impact of publicly funded research extends to enterprises and other stakeholders in ways partially hidden from view.

There is no common scale for judging has an academic research programme resulted in many or few spinoffs or other commercial outputs. However, from FiCEIP there is multiple direct spinoff ventures. Additionally, there are industrial doctorates and researcher in situ arrangements, as well as 'traditional' Collaborative Projects or Innovation Actions. These findings illustrate the pathways of impact through which a rather abstract and esoteric academic programme can have in industry.

The concrete added value in EU funding in these cases has been supporting the creation of a world-class academic research programme and development of commercial applications. The concrete value for enterprises has been different depending on the maturity of the enterprise. Elekta's focus as a more mature enterprise is refining the technology and new solutions or applications, following the technology frontier and learning about the markets. For Eigenor it is development and refinement of software products and demonstration of technology.

\subsection{Support measures for Horizon 2020 participation}

The following section presents four further case studies into support measures for FP participation. The cases were selected based on FP performance and good practices identified through the expert interviews. The selected cases are The Netherlands, Spain, Norway and Ireland.

\subsubsection{Overview and Finnish position}

\section{Framing best practice}

There are many examples of support mechanisms and instruments to support the participation of researchers and businesses in the FPs across the broad range of participating Member States and Associated countries. However, there are few specific evaluations of FP support measures that would allow us to draw on conclusions related to relevance, effectiveness, efficiency, and impact. As such, in order to reach a view of which of the multitude of supports may constitute best practice, we take a two-pronged approach to the search of information: 
We identify top-performing Member States in Horizon 2020 by examining which appear in the top-15 in any two of three categories ${ }^{81}$ in the Horizon 2020 First Results report, published by the European Commission in $2015 .{ }^{82}$ Good performance in the FPs may reflect strong institutions more than best practice in the support system, though we may assume that support systems co-evolve with the research systems in the majority of cases

- We highlight interesting examples from Member States that speak to relevant strategic objectives, and particularly where changes or amendments to the systems of support are observable (i.e. elements that have been introduced, removed or refocused as the support system has been developed between Horizon 2020 and FP7)

To make best use of the resulting information on support measures, we present findings through a typology, which is harmonised with that used elsewhere in this study.

\section{Overview of support mechanisms}

Most Member States offer a diverse range of financial, non-financial and structural support measures to help potential and current applicants to engage with the FP. It is possible to group the types of support offered into a broad typology presented below. It is possible to further extend this typology across a horizontal axis, too, examining supports in terms of their intended audience. Support measures are offered in the main for researchers within higher education institutions and public research organisations, as well as for private sector businesses, though eligibility criteria vary. Few supports other than the National Contact Points appear to be aimed at supporting the participation of government actors in the FPs.

\section{A typology of FP participation support instruments}

\begin{tabular}{ll}
\hline \multicolumn{1}{c}{ Support category } & \multicolumn{1}{c}{ Actions included } \\
\hline $\begin{array}{l}\text { Funding for proactive actions to } \\
\text { influence calls }\end{array}$ & $\begin{array}{l}\text { Influencing EU groups or research agendas / calls via } \\
\text { membership of specific groups or committees }\end{array}$ \\
& $\begin{array}{l}\text { Support to, or coordination of, JPI/co-fund engagement } \\
\text { Alignment of national research funding programmes to EU / } \\
\text { FP priorities }\end{array}$ \\
\hline \multirow{2}{*}{ Funding to find calls and partners } & General awareness of FP nationally or in specific groups \\
& Support for international networking \\
\hline \multirow{3}{*}{ Funding to produce proposals } & Payment of salary costs for authors \\
& Travel costs for partnership meetings / conferences / events \\
& Payment of consultancy costs \\
& Training / capacity-building \\
\hline & Top-up or match funding \\
& 'Buy out' or replacement funding for academics \\
'Second chance' funding, to conduct or further develop non- \\
funded projects
\end{tabular}

${ }^{81}$ The three categories are: i) Application success rates, ii) Share of signed grant agreements, iii) Share of Horizon 2020 funding received. $15 \mathrm{Member}$ States appear in at least two of those categories: Austria, Belgium, Denmark, Finland, France, Germany, Greece, Ireland, Italy, Netherlands, Poland, Portugal, Spain, Sweden, and the UK. In addition, we see that one Associated country - Switzerland - performs particularly well.

82 See: https://ec.europa.eu/programmes/horizon2020/sites/horizon2020/files/horizon_2020_first_results_1.pdf 
The following sub-sections set out a brief synthesis of the FP support measures observed in the sub-set of Member States selected for this review, per each heading of the typology and highlighting pertinent examples throughout.

\section{Advice and guidance}

Central to Member States' support to FP participation are their networks of National Contact Points (NCPs). Though NCP services are generally designed to the standards and guiding principles of the European Commission, ${ }^{83}$ and cover all sub-programmes of Horizon 2020, networks of NCPs are organised differently in different Member States. A review of regional FP support measures found that there are several typologies of NCP network organisation, reflecting their national innovation systems. The review also found that NCP networks may be augmented regionally (e.g. Belgium, ${ }^{84}$ Poland, ${ }^{85} \mathrm{UK}$ - Northern Ireland ${ }^{86}$ ). Poland offers one example of an NCP network that is augmented by regional contact points: The NCP network focuses on specialist issues, while the regional contact points offer more generic support as the first contact for applicants, and refers requests for specific expertise to relevant experts within the NCP network. ${ }^{87}$

1) Inner-ministry NCP system

2) NCP system coordinated by a Ministry, but decentralised operations

3) Public agency based NCP-system

4) Project-based contracted NCP system with a public organisation

5) Project-based contracted NCP system with a private non-profit organisation

6) Federal multi-level NCP-system

Across the support systems reviewed, the visibility of NCPs, and their 'connectedness' with other parts of the support system and target constituents is often stressed as important. For example, the Greek NCP network is well-regarded for its expertise and visibility, as well as its knowledge in managing EU projects and close links with the national public research infrastructure. However, it has been acknowledged that its lack of national co-funding and frequent changes in key staff are limiting factors. The network has also been assessed as having few links to the private sector (and especially with SMEs), and little involvement of regional players. ${ }^{88}$

A number of Member States have specifically prioritised visibility and connectedness. In preparation for Horizon 2020, France formalised the role of its NCPs via the introduction of national standards. ${ }^{89} \mathrm{An}$ intensive promotion campaign was also launched, through which all NCPs were encouraged to establish mutually-supportive relationships with support services acting at regional and local level. The Irish NCP network contains two dedicated NCPs for SMEs that work primarily to raise awareness, build relationships and then provide hands-on

\footnotetext{
${ }^{83}$ See: http://ec.europa.eu/research/participants/data/support/20131125 NCP\%20Minimum\%20standards.pdf

${ }^{84}$ See: http://www.ncpwallonie.be/, https://www.ncpbrussels.be/

${ }^{85}$ Dall, Nyiri and Schuch, "Capacity Building and institutional strengthening of Science and Research in BiH International benchmarking of the NCP systems in Europe", 2010

${ }^{86}$ See : http://h2020ni.com/supportcontacts/

${ }^{87}$ Gulda, Walendowski, Markianidou, Otte, "Peer review of the Polish research and innovation system - Background report", 2017. Available at: https://rio.jrc.ec.europa.eu/sites/default/files/report/Peer\%20review\%20of\%20the\%20Polish\%20research\%20and\%20innovation\%20system\%20\%20Background\%20report.pdf

${ }^{88}$ Sakellariou, "The structure of the NCP System in Greece, strengths and weaknesses, evaluation and potential steps for improvement", presentation, 2009

${ }^{89}$ See: http://www.horizon2020.gouv.fr
} 
support. In addition, Ireland has introduced a special 'industry team' for Horizon 2020. The team is made up of relevant NCPs and National Delegates, and has been introduced to ensure that the relevant expertise can be brought to multi-sectoral and multi-disciplinary projects. In consultation with a member of Ireland's team, the study team was informed of the team's ability to bring in thematic expertise such as ICT - a key area of success for Ireland in the FPs.

Under FP7, the Austrian Research Promotion Agency (FFG) ${ }^{90}$ ran a programme of 'Strategy Talks', targeting leading Austrian firms, universities and research organisations to explore their participation in the FPs, addressing organisations rather than individual researchers. The 2010 evaluation of the support services for FP participation support in Austria found that the 'Strategy Talks' had been very well received. ${ }^{91}$ The 'Strategy Talks' have since been developed into comprehensive consulting services. The FFG Academy now offers in-depth training to applicants to Horizon 2020, including, for example, how to write a competitive ERC bid. The training covers basic principles, tips, how evaluation panel members view and review proposals, and the opportunity to share the experiences of an ERC grant holder. ${ }^{92}$

Several Member States have launched specific support measures that provide help with proposal writing, finding partners and building partnerships, or organising networking events through their NCP system. In some cases, these kinds of functions are fulfilled for businesses through close alignment with the Enterprise Europe Network (EEN).

There are other examples of best practice in advisory support that do not relate specifically NCP networks. Germany's European Liaison Office of the German Research Organisations (KoWi) is a comprehensive service platform for German research organisations, selforganised by its scientific members and co-funded by the federal government. ${ }^{93}$ It offers services across a range of research funding streams and project lifecycle stages, from advice and coaching to specific training on EU proposal writing and project management. ${ }^{94}$ Similarly, the Netherlands Enterprise Agency provides services through its IRIS team (International research and innovation collaboration) such as information days aimed at specific calls, training (for instance on legal and financial terms), international and technological missions, partner search, and liaison between the Netherlands and Brussels.

In some Member States, the national organisation that oversees the NCP network also coordinates the country's representation in the European Technology Platforms (ETPs) and Joint Technology Initiatives (JTIs). This approach is taken by the Portuguese Office for the Promotion of the R\&TD Framework Programme (Gabinete de Promoção do Programa Quadro de I\&DT, GPPQ), whose mission is to bridge the gap between researchers and Portuguese companies, and the activities of Horizon 2020.95 Adopting this type of mutual coordination was discussed as a possible avenue to increase the influence of Ireland in the ETPs and JTIs within the interim evaluation of Ireland's participation in Horizon 2020. ${ }^{96}$

\section{Funding for proactive actions to influence calls}

To achieve maximum synergy, most Member States have drafted their research and innovation strategies and action plans in line with the European research priorities (e.g.

\footnotetext{
${ }^{90} \mathrm{FFG}$ is the lead national agency for H2020, and oversees both the national strategy to increase participation and the NCP network

${ }^{91}$ Arnold, Boekholt, Good, Radauer, Stroyan, Tiefenthaler, Vermeulen, "Evaluation of Austrian Support Structures for FP 7 \& Eureka and Impact Analysis of EU Research Initiatives on the Austrian Research \& Innovation System", 2010

${ }^{92}$ See https://www.ffg.at/europa/veranstaltungen/ffg-akademie 2016-07-07

${ }^{93}$ See: http://www.kowi.de/en/kowi/about-kowi/about-kowi.aspx

${ }^{94}$ See: http://www.kowi.de/en/kowi/services/services.aspx

${ }^{95}$ See: https://rio.jrc.ec.europa.eu/en/organisations/office-support-participation-horizon-2020

${ }^{96}$ Rosemberg Montes, Simmonds, Wain and Nielsen, “Interim evaluation of Ireland's Participation in Horizon 2020", 2016
} 
France Europe 2020, ${ }^{97}$ the Netherlands' 'Top Sectors' policy ${ }^{98}$ ) In addition, a select few have conducted specific national exercises to align national and European research priorities: Ireland's 'National Research Prioritisation Exercise', ${ }^{99}$ for example, sought to ensure that Horizon 2020 participation is aligned with the country's leading economic and research sectors. The priority areas were subsequently refined in its national strategy for research and development, science and technology, Innovation 2020. ${ }^{100}$

The majority of Member States invest in some form of support to influence the Horizon 2020 Work Programmes and calls. These are mostly made up of directly-funded activities rather than grant schemes, though grants are also offered for hosting events in Brussels (e.g. Science Foundation Ireland's Brussels Conference Programme), as well as ways to promote national research strengths, and to provide inputs to national representatives in the Horizon 2020 Programme Committees and Advisory Groups.

Commonly, there is a Brussels presence or office for the Member State, which provides intelligence between the national or regional researchers and the European Commission. A powerful example of this is the Netherlands House for Education and Research (Neth-ER), a collaborative approach between Dutch universities, regional education centres, and national research organisations to develop the positioning of Dutch research within European research and innovation policy. Neth-ER is part-funded by the Dutch Ministry of Education, Culture and Science. ${ }^{101}$

France has sought to increase participation in Advisory Groups and evaluation panels ${ }^{102}$ as part of the broader drive to address falling participation in prior FPs, and to increase the French research community's influence in the European Research Area's decision-making. To do so the country reorganised its representatives. ${ }^{103}$

In some cases, special groups made up of senior officials are put in place to drive the strategic approach to influence calls. For example, Denmark established Strategic Reference Groups in priority programme areas, consisting of National Delegates and core participant organisations within each Horizon 2020 sub-programme, to provide up-to-date information on research developments, strengths and Danish positions to the Programme Committee members. ${ }^{104}$ France, meanwhile, operates a national 'Mirror Group' to support the French representatives in the Joint Programing Initiative (JPI) Governing Boards. ${ }^{105}$ In order to drive the identification and pursuit of opportunities in Horizon 2020, Ireland has established a single High-Level Group for Horizon 2020, chaired by the Chief Scientific Advisor to the Irish Prime Minister, and backed by the Minister for Skills, Research and Innovation. ${ }^{106}$

\section{Funding to find calls and partners}

Most Member States offer some form of grant to support international networking, partner meetings and attendance at relevant events, such as conferences. The grants are usually

\footnotetext{
${ }^{97}$ See: http://www.agence-nationale-recherche.fr/PA2018\&usg=ALkJrhiZuJ0OzF cpnTHH7iftZk-YA28Mw

${ }^{98}$ The Ministry of Economic Affairs and Ministry of Education, Culture and Science, "Global challenges, Dutch solutions", 2014

${ }^{99}$ Research Prioritisation Action Group, "National Research Prioritisation Exercise: First Progress Report June 2014”, 2014

${ }^{100}$ See: https://dbei.gov.ie/en/Publications/Innovation-2020.html

101 See: https://www.neth-er.eu/en/about-neth-er

102 See: http://www.horizon2020.gouv.fr/

103 lbid

${ }^{104}$ Kolar, Hunter, Boekholt, and Teichler, "Mutual Learning Exercise: Alignment and Interoperability of National Research Programmes. National Coordination", 2015

${ }^{105}$ Ibid

${ }^{106}$ See: http://www.horizon2020.ie/minister-damien-english-wants-researchers-to-think-big/
} 
small (in the order of $€ 100-600$ per day), and cover out-of-pocket expenses such as travel, accommodation and subsistence, as well as certain fees, such as registration for conferences. Schemes are mostly targeted at researchers, but may also be available to businesses dependent upon eligibility and strategic orientation.

Some Member States include travel and accommodation funding within their financial support measures for proposal preparation. For example, in Germany, the current support for proposal preparation focuses on collaboration with partners in key strategic geographies (see the next section), and funding covers travel and accommodation for German and foreign researchers and experts.

\section{Funding to produce proposals}

Funding to support applicants to produce proposals is the most common form of support offered among the Member States examined, and usually offers a larger amount of funding than the other categories of support. Many countries continue to offer financial support to universities and research organisations to prepare proposals, and often, larger amounts are available for those applying to coordinate a Horizon 2020 consortium. Where funding is available to a broader set of organisations, the funding is differentiated depending on recipient (i.e. research organisations or commercial entities). Funding to produce proposals generally the costs of preparatory work, including project-related resources, equipment, and personnel costs.

There is an observable trend among more developed Member States to shift financial support away from generic support and toward areas of specific need, or to address specific structural imbalances. These may include addressing perceived under-performance in Horizon 2020 pillars or sub-programmes, or to increasing the participation of a certain subset of organisations.

A rather striking example of this among the Member States examined, Austria ceased provision of direct financial support for Horizon 2020, instead realigning its budgets toward addressing organisations or groups in real need via, for example, advisory support and training. The 2010 evaluation of the Austrian support system suggested that rather than subsidise activities that actors would undertake anyway (or that actors are able to do by themselves), state support should rather aim to create added value and induce learning among applicants. ${ }^{107}$

In France, the programme 'Setting up European or International Scientific Networks' (Montage de réseaux scientifiques européens ou internationaux, MRSEl) has been established for Horizon 2020 as part of a suite of measures to address declining participation observed in prior FPs. The programme aims to facilitate access to European research funding through the formation and coordination of transnational networks. Up to $€ 30$ thousand is available over 18 months across all disciplines for research networks that specifically intend to prepare and submit a collaborative project in response to a large-scale European or international call for proposals with major technological and scientific impact. ${ }^{108}$

Germany's national funding to produce proposals under Horizon 2020 specifically supports collaborative applications to Horizon 2020 with partners from three strategically-important areas: i) Central and South-Eastern Europe, ii) North and South America, and iii) the AsiaPacific Research Area. Funding ranges between $€ 60$ thousand for 12 months, to $€ 150$

${ }^{107}$ Arnold, Boekholt, Good, Radauer, Stroyan, Tiefenthaler, and Vermeulen, "Evaluation of Austrian Support Structures for FP 7 \& Eureka and Impact Analysis of EU Research Initiatives on the Austrian Research \& Innovation System", 2010

108 See: https://uk.ambafrance.org/ANR-Montage-de-reseaux-scientifiques-europeens-ou-internationaux-MRSEI 
thousand for 36 months. The funding variously supports proposals to the three pillars of Societal Challenges, Excellent Science and Industrial Leadership, and is calculated on the type of beneficiary (where commercial entities may be funded for up to $50 \%$ of their eligible costs). Germany also offers a grant of up to $€ 25$ thousand over nine months to support the fachhochschulen, which have been identified as an area for improvement in terms of FP participation.

Ireland's performance in successive FPs suggests significant development in its capacity and capability to engage with the FPs, and its financial support measures have consequently developed: current national financial support is aimed at coordinators, and at researchers applying to the ERC - including researchers in disciplines that are traditionally less-exposed to the FPs. Grants of up to $€ 12.5$ thousand are available to those applying to coordinate a Horizon 2020 project, covering all costs except consultancy, while the remainder of funding in this category is aimed at applicants to the ERC. Funding to ERC applicants includes funding of up to $€ 500$ thousand for those who submitted a proposal that was deemed fundable but did not receive funding due to a lack of available programme budget. Two grant schemes are aimed at supporting researchers from the Arts, Humanities and Social Sciences (AHSS) to access the ERC, including a grant of up to $€ 220$ thousand to develop interdisciplinary projects with research from the Science, Technology, Engineering and Maths (STEM) subjects.

The Polish Ministry of Science and Higher Education (MNiSW) launched a scheme for Horizon 2020 called 'Grants for grants' ('Granty na granty'). The scheme is part of a suite of supports to address low levels of internationalisation, ${ }^{109}$ and provides approximately $€ 7.5$ thousand for research institutions intending to take a coordinator role in a project consortium. ${ }^{110}$ The scheme offers differentiated funding amounts based on beneficiary (research organisations or SMEs, for example). ${ }^{111}$ The grants support the preparation of an application (including consultancy) in the writing and reviewing of the application or the organisation of project consortium. The grant process is flexible, and may be requested ex ante (before preparing and submitting the funding application) or ex post (after the funding application has been submitted and evaluated). In the latter case, costs for preparing the application can be reimbursed, however, only if the application has reached a certain scoring threshold in the evaluation process. Prior consultation suggests that uptake has been rather high, ${ }^{112}$ and the scheme appears to replace an SME-specific grant in place for FP7, which received little uptake. ${ }^{113}$ Poland also launched an incentive scheme to encourage applications from employees of research institutes ('Benefits on the Horizon'). A 'bonus' equivalent to approximately $10 \%$ of the EU funding secured, is available to individual staff members if the organisation is successful and takes a coordination role in the project.

Across Member States, there are few schemes that are dedicated solely to industry or SME participation, though these do exist in a small number of cases, such as in the UK Devolved Administrations. The Scottish Funding Council (SFC) launched a new 'Horizon 2020 SME Engagement Scheme' 114 to encourage greater SME participation. SMEs apply for a voucher of between $€ 1,200$ - $€ 6,000$ to access Scottish higher education expertise and

\footnotetext{
${ }^{109}$ European Commission Joint Research Centre, "Research \& Innovation Observatory Country Report - Poland”, 2016. Available at: https://rio.jrc.ec.europa.eu/en/country-analysis/Poland/country-report

${ }^{110}$ See: http://www.granty-na-badania.com/2016/06/granty-na-granty-2016.html

111111 Gulda, Walendowski, Markianidou, Otte, "Peer review of the Polish research and innovation system - Background report", 2017. Available at: https://rio.jrc.ec.europa.eu/sites/default/files/report/Peer\%20review\%20of\%20the\%20Polish\%20research\%20and\%20innovation\%20system\%20\%20Background\%20report.pdf

${ }^{112}$ Simmonds, Brown, Wain, Rosemberg Montes, Izsak, Roman, "Review of the support mechanisms provided by the Northern Ireland Executive to support delivery of the Executive's target of participants winning €145m from Horizon 2020", 2016

${ }^{113}$ Gulda, Walendowski, Markianidou, Otte, Op. Cit.

${ }^{114}$ See: http://www.gov.scot/Topics/Business-Industry/support/Horizon2020
} 
advice for assistance in the Horizon 2020 application process. A similar scheme was launched by Invest Northern Ireland, though uptake was found to be rather low. ${ }^{115}$ Invest Northern Ireland also offer Project Definition Funding, a grant of up to $€ 15$ thousand for proposal preparation, covering the full range of costs (from travel to legal advice and consultancy) that is available to researchers and businesses that meet Invest Northern Ireland's broader funding eligibility criteria. ${ }^{116}$ The Welsh government offers the ScoRE Cymru (Supporting Collaborative Research and Innovation in Europe) scheme, which provides funding to stimulate Wales-based organisations to participate in European collaborative research such as Horizon 2020. ScoRE Cymru can provide up to approximately $€ 13.5$ thousand for the bid writing costs of applications, and approximately $€ 1$ thousand for travel and meetings. ${ }^{117} 118$ While not strictly a dedicated SME-facing scheme, as of late $2014,72 \%$ of funding awarded through the scheme had been awarded to SMEs.

\section{Co-funding for FP participants}

There are several examples of co-funding for FP participants, each of which aim to mitigate the impact of funding shortfalls and support the successful implementation of projects. For example, the Academy of Finland provides match-funding for non-commercial research organisations with projects under the Horizon 2020 Societal Challenges priority, in order to address funding shortfalls and encourage participation in European projects. Similarly, Science Foundation Ireland provides an additional overhead payment to the Irish host institution of ERC award winners, to assist the successful implementation of ERC-funded research. Science Foundation Ireland also offers additional funding to support Irish host institutions that have recruited an ERC awardee from abroad.

\section{Finnish Position}

Generally Finnish support measures are middle of the pack. The present system of support comprises mainly advisory through National Contact points and two funding instruments. First is Tekes funding for preparation of nationally significant projects, defined as projects where a Finnish applicant has a significant role as a work package leader or coordinator of the project. The funding is granted by application for proposals that have passed the threshold scores in evaluation. Another instrument is overhead cost subsidy granted by Academy of Finland under Strategic Research Council, that is specifically targeted for Pillar III projects. Additionally, it is permitted to use Tekes and Academy funded project time to prepare EU applications that are related to the project topic.

Historically there have been different instruments specifically for funding application preparation both open national funding and internal funding in different research organisations. There are no public evaluations available of those. According to Tekes estimates, the volume has been between $€ 1-2$ million per year with the average contribution being approximately $€ 50$ thousand, which means 20-40 projects or applications have benefitted from the pre-award grant yearly. In general, both of the main funding organisations have concluded that effectiveness of pre-award funding, i.e. proposal stage funding is not high in terms of improving success rates. This same conclusion has been drawn in other national institutions as well. It may however have an effect on the number of proposals, but other data suggest that the quality rather than number of proposals is the limiting factor in Finland.

${ }^{115}$ Simmonds, Brown, Wain, Rosemberg Montes, Izsak, Roman, Op. Cit.

${ }^{116}$ See: http://h2020ni.com/financial-support/

117 See: http://gov.wales/funding/eu-funds/horizon2020/?lang=en

${ }^{118} \mathrm{See}$ https://ec.europa.eu/growth/tools-databases/regional-innovation-monitor/support-measure/score-cymru 
The Finnish NCP activities are distributed within Tekes and Academy of Finland, and the coordination point and official FP information office is Tekes EU Research and Innovation Programmes (EUTI) office. As for stakeholder views on advisory services, the NCP activities are viewed very favourably in terms of quality. The perceived bottle neck is the limited resources of NCPs, who have generally only a part of their time committed specifically for NCP activities while a larger part is committed to other tasks in the host organisations.

As for private advisory services, there is a small cadre of EU consultants that operate in Finland, but hard numbers of the volume of activities do not exist in the public sphere. The stakeholder views on private are ambiguous; on the one hand the services are rated well for the most part, but on the other the use of such services is viewed as a necessary evil and there is wide spread principled opposition for using public subsidies on private contractors for application preparation both in the public and private spheres.

Contrasting with the case countries, the difference between the other countries and Finland is not so much quantity of instruments as how they are implemented. Two of the features in common between the well-performing countries are clear goals and strategy for EU participation with monitoring and extensive proactive NCP services. 


\section{Overview of FP support measures}

\begin{tabular}{|c|c|c|c|c|c|c|c|c|}
\hline & Finland & Sweden & & Denmark & Norway & Spain & Netherlands & Ireland \\
\hline $\begin{array}{l}\text { Non-financial } \\
\text { advisory services }\end{array}$ & \multicolumn{8}{|c|}{ Yes, similar services in all countries (mainly through NCPs and EEN) } \\
\hline $\begin{array}{l}\text { Funding to } \\
\text { influence calls }\end{array}$ & No & Yes & No & & Yes & No & No & Yes \\
\hline $\begin{array}{l}\text { Funding to find } \\
\text { calls and partners }\end{array}$ & No & Yes, travel grants & No & & Yes, travel grants & $\begin{array}{l}\text { Yes, network building } \\
\text { instruments }\end{array}$ & No & Yes, travel grants \\
\hline $\begin{array}{l}\text { Funding to } \\
\text { produce } \\
\text { proposals }\end{array}$ & $\begin{array}{l}\text { Yes, for large projects } \\
\text { with at least two } \\
\text { Finnish participants }\end{array}$ & $\begin{array}{l}\text { Yes, in selected sub- } \\
\text { programmes }\end{array}$ & Yes & & $\begin{array}{l}\text { Yes, very elaborate and } \\
\text { generous. Second- } \\
\text { chance funding for well- } \\
\text { rated, rejected ERC and } \\
\text { SME Instrument phase } 1 \\
\text { proposals }\end{array}$ & $\begin{array}{l}\text { Yes, indirect capacity } \\
\text { building and networking } \\
\text { instruments }\end{array}$ & No & $\begin{array}{l}\text { Yes, for coordinators and } \\
\text { ERC proposers. Second- } \\
\text { chance funding for well- } \\
\text { rated, rejected ERC } \\
\text { proposals }\end{array}$ \\
\hline $\begin{array}{l}\text { National co- } \\
\text { funding }\end{array}$ & $\begin{array}{l}\text { Yes, for projects in } \\
\text { Societal Challenges }\end{array}$ & No & No & & $\begin{array}{l}\text { Yes, mainly for research } \\
\text { institutes, but also for } \\
\text { other actors in selected } \\
\text { sub-programmes }\end{array}$ & No & $\begin{array}{l}\text { Yes, in selected sub- } \\
\text { programmes, as well as for } \\
\text { R\&D providers }\end{array}$ & $\begin{array}{l}\text { Yes, for ERC hosts, and } \\
\text { for those recruiting ERC } \\
\text { winners from overseas }\end{array}$ \\
\hline
\end{tabular}




\subsubsection{Case Netherlands}

This case study describes the Netherlands support measures for participation in Horizon 2020. It illustrates the scarcity of available support measures. In describing the support available, the document also sets out the 'target audience' for the support, whether government, academia, research performing organisations, businesses, or a combination thereof. In addition to setting out the non-financial support for participation in Horizon 2020, the document briefly sets out structural support. The case study then mobilises previous evaluations and interviews with key individuals in-country to discuss the effectiveness of the support available, before concluding with a set of 'lessons learned'.

\section{The Netherlands' participation in Horizon 2020}

The Netherlands has experienced success in Horizon 2020, ranking sixth in each of three main categories at the time of the first results report of Horizon 2020 (European Commission, 2014): application success rates, share of signed grant agreements, and share of Horizon 2020 (Horizon 2020) funding received.

While, like all Member States, the Netherlands' application success rates decreased from FP7 to Horizon 2020 (by approximately 10 percentage points), the Netherlands' reported success rate of $16 \%$ was in line with the overall application success rate for Horizon 2020 at the time of the report. The report shows that there was a slight increase in the share of Dutch participations in signed grant agreements, but a slight decrease in the share of EU contribution from FP7 to Horizon 2020.

\section{Performance of the Netherlands in FP7 and Horizon 2020}

\begin{tabular}{lll}
\multicolumn{1}{c}{ Horizon 2020 performance area } & Rank & Value \\
\hline $\begin{array}{l}\text { Application success rates in Horizon 2020 } \\
\text { Share of participations in signed grant agreements in }\end{array}$ & $\begin{array}{l}6^{\text {th }} \\
6^{\text {th }}\end{array}$ & $\begin{array}{l}16 \%^{*} \\
7 \%^{*}\end{array}$ \\
$\begin{array}{l}\text { Horizon 2020 } \\
\text { Share of Horizon } 2020 \text { funding received in Horizon }\end{array}$ & $6^{\text {th }}$ & $8 \%{ }^{*}$ \\
Performance in specific themes/programmes in FP7 & & $\begin{array}{l}{ }^{*} \text { Under FP7, the Netherlands } \\
\text { performed well under the ERC, } \\
\text { receiving } 9 \% \text { of all ERC grants }\end{array}$ \\
\hline
\end{tabular}

Source: extracted from DG Research and Innovation, (European Commission, 2014; Dorst, Deuten and Horlings, 2016)

\section{Objectives and targets of the current national strategy}

The Netherlands does not have a specific national Horizon 2020 strategy although they have a national research agenda. Therefore, neither quantitative nor qualitative objects have been identified. At the strategic level the mutual governmental aim is to increase the SME participation in Horizon 2020 in the Netherlands. This objective is incorporated in the agendas of central ministries.

The Dutch National Research Agenda (NRA) is in line with the approach of Horizon 2020 when it comes to societal challenges. The Dutch NRA contains several references to Horizon 2020. Overall, a transition towards a mission oriented approach is preferred, as thematic national programming in the Netherlands has been aligned increasingly with Horizon 2020 challenges over the past years.

Societal challenges are also tackled by the Top Sector policy which connects Dutch industry, science and government. The Top Sectors represent nine economic sectors in which the Netherlands has a strong position internationally. Since many of the EU grand 
challenges have close linkages to some of the top sectors, they also provide opportunities the Dutch actors can tap into. Therefore, a clear alignment of the Top Sectors with Horizon 2020 has been called for. Increased cross-sectoral exchanges were seen as additional benefits alongside top-sector participation in EU programmes.

\section{Key organisations involved in supporting FP participation}

The key organisation involved in supporting FP participation in the Netherlands is Netherlands Enterprise Agency (RVO) which has several assignments from various Dutch ministries. Through the assignments it is RVO's role to assist companies and knowledge institutions to receive as much funding from Horizon 2020 as possible. The key ministries responsible for Horizon 2020 at the policy level include the Ministry of Economic Affairs and the Ministry of Education, Culture and Science. The former has a keen interest in the participation of companies while the latter focuses on European Research Council and Marie Skłodowska-Curie fellowships in order to support Dutch researchers and scientists. The Ministry of Economic Affairs and the Ministry of Education, Culture and Science cooperated with other ministries to ensure that in the run-up to Horizon 2020 the research themes and other topics, such as SME participation, were formulated in a way that benefits Dutch parties.

As the operational arm of the Ministry of Economic Affairs, RVO provides information, training, and individual advice on how to participate in Horizon 2020. Additionally, RVO helps the stakeholders to find partners in the Netherlands, and is responsible for three pillars of Horizon 2020. As a part of RVO, Team IRIS (International Research and Innovation Cooperation) is the National Contact Point (NCP) for Horizon 2020 in the Netherlands.

Influencing the future calls in Horizon2020, as well as for the next FP, is a relevant activity carried out by the Ministry of Economic Affairs and the Ministry of Education, Culture and Science. Lobbying is done also by nine sounding boards. The sounding boards are publicprivate-partnerships of 50-100 members cooperating to identify relevant national topics to be enhanced at the European level. RVO acts as the secretariat for the sounding boards.

The Netherlands Organisation for Scientific Research (NWO) does not play a very active role in supporting Horizon 2020 participation in the Netherlands. NWO mainly participates in different ERA-nets. NWO also provides funding through Encouraging European Research instrument to publicly funded knowledge institutions. However, the support is only made available for European projects having already acquired grant within Horizon 2020. Thus, the instrument is not included in this case study.

Besides the aforementioned key organisations, there are several private companies supporting FP participation. Additionally, various universities and larger businesses have their own EU desk or a designated subject matter expert (sometimes based in Brussels) to help their researchers. These desks work closely with a designated section within the Netherlands Enterprise Agency.

\section{Framework Programme support measures}

The list of existing support measures in the Netherlands is short. There is no public funding for proactive actions to influence calls, to find calls and partners, or to produce proposals. The Dutch approach is not to give funding in order to receive funding. Thus, the government of the Netherlands only funds general support to (potential) participants through the set up at RVO. Free of charge support is provided in the form of information, training and advice. 
Special sessions are also organised in cooperation with the ministries, Top Sectors, NWO, universities and other stakeholders.

\section{Summary of FP participation support measures in the Netherlands}

\begin{tabular}{|c|c|c|c|}
\hline Name of measure & Responsible body & Scope, scale and eligibility & $\begin{array}{l}\text { Annual budget } \\
\text { (€Millions) }\end{array}$ \\
\hline $\begin{array}{l}\text { Advisory services } \\
\text { for companies, } \\
\text { universities and } \\
\text { knowledge } \\
\text { institutes }\end{array}$ & $\begin{array}{l}\text { Netherlands } \\
\text { Enterprise Agency }\end{array}$ & $\begin{array}{l}\text { Netherlands Enterprise Agency provides information, training, } \\
\text { and individual advice on how to participate in Horizon 2020. In } \\
\text { addition, the organisation helps to find partners in the } \\
\text { Netherlands } \\
25 \text { NCPs are currently providing these services, focusing } \\
\text { especially on legal and financial matters }\end{array}$ & $\begin{array}{l}\text { Annual budget of } \\
\text { RVO: } € 2,5 \mathrm{~m}\end{array}$ \\
\hline
\end{tabular}

\section{Effectiveness}

Over 1200 Dutch organisations participated in FP7 projects (2007-2013). Their success rate of $23 \%$ (of proposals accepted) was one of the highest in Europe. As demonstrated above, the success rate has decreased in Horizon 2020. Despite the decrease the Netherlands continue to perform at a good European level.

According to the interviewee there are no recent evaluations of Dutch support instruments or participation in FP7 or Horizon 2020. Concrete evidence of the effectiveness of the support delivered does not exist. RVO monitors client satisfaction through surveys. Key performance indicators such as number of services delivered and number of advice offered are also used. According to the interviewee RVO has tried to correlate the funds received with the number of activities NCPs have performed. This exercise has proven to be very difficult.

There have not been any changes in support measures between FP7 and Horizon 2020. The decision not to provide direct funding to receive European funding has been made years ago. Instead all efforts are put in the advice and information given to various stakeholders. According to the interviewee the success ratio is significantly higher when applicants have contacted RVO and received help in proposals from the NCP.

\section{Lessons for the study}

The Netherlands provides an example of approach based on information, training and advice. Such an approach has existed for several years and is not likely to change in the near future. The case of Netherlands demonstrates that positive impact can be generated without financial support instruments. Lack of financial support is compensated by high quality research infrastructure. There are strong research institutions with long tradition in international collaboration (e.g. Delft University of Technology, Eindhoven University of Technology, TNO, VU-VUMC and the University of Amsterdam) in the Netherlands. The interviewee considers that the research infrastructure, large European networks and international mind-set contribute to the Dutch success in FP7 and Horizon 2020.

The Netherlands has long tradition in public-private-partnerships. This is evident in the focus groups that have been established for various parts of Horizon 2020. The focus groups unite government, knowledge institutions, the business community and other stakeholders, including patient associations, for instance, to discuss the position of the Netherlands when shaping the programmes. This takes place on a larger scale and in a more structured way than in previous Framework Programmes. Civil servants representing the Netherlands in European programme committees, and who are responsible for implementing Horizon 2020, 
use the focus groups to establish their position, and they work closely with colleagues from other member states. (Ministry of Economic Affairs, 2014)

Another lesson learned from the case of the Netherlands is centralised, clearly visible NCP activity. The 25 full-time NCPs are providing a centre of excellence for Dutch actors. The NCPs work together, share knowledge and possess also legal and financial expertise covering the different aspects of Horizon 2020. Similar to the long tradition in PPP, the Dutch NCP activity has been centralised for more than 20 years.

\subsubsection{Case Spain}

This case study provides an overview of Spain's participation in Horizon 2020 while taking a peek into past success. This is done in the section assessing Spain effectiveness in supporting FP participation. Additionally, information is provided on objectives set in national strategies, key organisations implementing the strategies as well as the actual support measures in Spain. A few key observations from the case study at presented at the end.

\section{Spain's participation in Horizon 2020}

Spain has experienced success in Horizon 2020, performing in the top 15 of each of three main categories at the time of the first results report of Horizon 2020: application success rates, share of signed grant agreements, and share of Horizon 2020 (Horizon 2020) funding received.

Common with all Member States, Spain's application success rates decreased from FP7 to Horizon 2020. Spain's application success rate reported within the First Results report (approximately 14\%) was slightly lower than the overall success rate at the time of the report (which was approximately 16\%). The report also shows that Spain experienced a slight increase in the share of participations in signed grant agreements and the share of EU contribution from FP7 to Horizon 2020.

Table 1 Performance of Spain in FP7 and Horizon 2020

\begin{tabular}{|c|c|c|}
\hline Horizon 2020 performance area & Rank & Value \\
\hline Application success rates in Horizon 2020 & $15^{\text {th }}$ & $14 \%$ * \\
\hline $\begin{array}{l}\text { Share of participations in signed grant agreements in } \\
\text { Horizon } 2020\end{array}$ & $3^{\text {rd }}$ & $11 \%$ * \\
\hline $\begin{array}{l}\text { Share of Horizon } 2020 \text { funding received in Horizon } \\
2020\end{array}$ & $4^{\text {th }}$ & $9 \%$ * \\
\hline Performance in specific themes/programmes in FP7 & & $\begin{array}{l}\text { ** Thematically, Spain performed particularly well in } \\
\text { FP7 in ICT and NMP (based on amount of funding } \\
\text { secured) and in "Energy" (based on proportional } \\
\text { funding secured). Spain ranked second of all Member } \\
\text { States in proportional funding secured for "Energy" } \\
(13.2 \%) \text {, as well as "Research for the benefit of SMEs" } \\
(14.5 \%) \text {, and "Regions of Knowledge" }(13.0 \%) \text {. }\end{array}$ \\
\hline
\end{tabular}

Source: extracted from DG Research and Innovation, (European Commission, 2014; Dorst, Deuten and Horlings, 2016)

\section{Objectives and targets of the current national strategy}

Spain has formulated an impressive target concerning Horizon 2020 funding. The objective is to receive $9.5 \%$ of all Horizon 2020 funds allocated to Member States (EU28) during the period of 2014-2020. The figure is based on political decision to level the funding Spain is investing in the EU.

Both public and private RDI funding has been a challenge in Spain since 2010. Therefore, increase in RDI funding is one of the key objectives in the current Strategy for Science, Technology and Innovation (2013-2020). The strategy and the related State Plan for 
Technical and Scientific Research and Innovation represent an effort to align the most important strategic documents with Horizon 2020. These two schemes aim to encourage business leadership in research and development as well as tackle the challenges facing European societies. ${ }^{119}$

Spain is also preparing a new national R\&D plan for coming years. The plan is expected to resemble a framework programme. There will, however, be no funding dedicated to the plan. Hence it will be a strategic document which, according to an interviewee, is likely to contain multitude of wishes instead of clear priorities.

\section{Key organisations involved in supporting FP participation}

At the highest political level the Secretary of State for Research, Development and Innovation is the key organisation supporting Spanish participation in Horizon 2020. The Secretary represents the Spanish interest in Europe and positions the country regarding European affairs. Implementation of Horizon 2020 support rests with Oficina Europea (European Office) and Centro para el Desarrollo Tecnológico Industrial (CDTI, The Centre for the Development of Industrial Technology).

Both organisations operate under the Ministry of Economy and Competitiveness as well as State for Research, Development and Innovation as National Contact Points (NCPs). European Office acts as NCP in matters related to European Research Council (ERC), Marie Sklodowska Curie Actions (MSCA), Emerging and Future Technologies (FET), Challenge 6 "Europe in a Changing World: Inclusive, Innovative, Reflective Societies" and "Science with and for Society" (SwafS). ${ }^{120}$

CDTI enhances Spanish companies' competitiveness and internationalisation through innovation. CDTI participates in European programme committees, represents the interests of Spain and promotes Spanish participation in Horizon 2020. ${ }^{121}$ There are 46 NCPs for ten themes in CDTI. The NCP responsibilities are divided amongst European Office and CDTI as follows: the former is responsible for pillar 1 while the latter is in charge of pillars 2 and 3. The distribution of labour derives from history. European Office has traditionally had close contacts with the academia while CDTI has been cooperating with businesses.

Additionally, the Spanish Horizon 2020 support system consists of experts and NCPs from universities, RTO's, regions and other institutions. These experts can be seen as part-time NCPs that raise awareness of Horizon 2020 as well as represent Spain in programme committees. At the regions, they have an important role in identifying new companies that have potential to participate in Horizon 2020 projects in the future. For instance, Instituto de Biomecánica de Valencia (IBV) has been hired by CDTI as a specialised entity to support Spanish companies taking part in Horizon 2020. ${ }^{122}$ IBV and other research institutions collaborate closely with $\mathrm{CDTI}$ across Spanish regions.

\section{Framework Programme support measures}

The range of identified support measures at the national level is not wide. Provided support mainly consists of advice on how to improve the quality of the proposals given by the NCPs. Overall services provided by the NCPs are:

\footnotetext{
${ }^{119}$ See: http://horizon2020projects.com/policy-research/spain-outlines-horizon-2020-innovation-strategy/

${ }^{120}$ See: https://oficinaeuropea.fecyt.es/quienes-somos

${ }^{121}$ See: http://www.cdti.es/index.asp?MP=14\&MS=59\&MN=1; http://www.cdti.es/index.asp?MP=14\&MS=60\&MN=2

${ }^{122}$ See: http://www.biomecanicamente.org/revista/item/302-rb-62-i-pyme-ingles.html
} 
- $\quad$ Advice throughout the life cycle of proposals: analysis and early detection of opportunities, guidance on the calls, proposals screening, partner search, assistance in the negotiation and implementation of projects.

- Promotion of FP: organisation and participation in workshops, seminars, conferences, etc.

- Active dissemination of information

- $\quad$ Training: organisation of specific seminars and courses. Participation in postgraduate courses. Development of guidelines for participation.

- $\quad$ Search for alternative funding at national and European levels

One of the advisory services provided by NCPs are regional information days consisting of systematic proposal reviews. The service is based on agreements CDTI has with all Spanish regions. These agreements represent a framework governing the relations between the regions and CDTI for the promotion for national, European and International RDI programmes managed by CDTI. Due to the agreements, at least one institutional day of generic nature is organised annually. However, no numerical commitment for FP promotion is mentioned in the agreements. Such agreements have been signed since late 1990s and their duration was infinite. Due to recent changes in legislation duration should not exceed four years.

During the regional information days NCPs review proposals prepared by universities, companies and other actors to improve the quality of the proposals and to ensure national success in calls. Prior to information days NCPs communicate with regions in order to identify the biggest demand for advice / review of proposals. Criteria used in the assessment includes for instance Horizon 2020 theme, existing "critical mass" of participants or no, proposals to be reviewed and involvement of regional agency. These events can also be company specific, i.e. selective promotion can be done to a single company which has been identified as a forerunner in an industry and which also has strong potential to benefit from EU funding.

Advisory services are also provided through training. For example, CDTI is investing $€ 120000$ per year for EU project management training. Furthermore, CDTI extends the provision of advisory services through the contract it has with IBV. IBV's portfolio of services consists of giving advice on how to define the business idea or concept, adapting the idea to the call for proposals, searching for partners, writing the proposals and providing management support while preparing and submitting the application.

Horizon 2020 participation of Spanish researchers is supported by the State Research Agency (launched this year). The instrument Redes y Gestores (networks and managers) dates back to the later stage of FP6. Another instrument also managed by the State Research Agency - Europa Investigación (European research) - was launched in 2013. In the call research groups are asked to submit a proposal fulfilling the following criteria 1) consortium should be coordinated by Spanish research institute, 2) at least $35 \%$ of requested EU funding should return to Spain (as work load in the project) and 3) the consortium should involve actors lacking previous experience in Framework Programmes. If the applicant/research group fails to fulfil the criteria, he/she/it must give the money back. The State Research Agency furthermore supports those researchers who got into an 
interview, but failed to receive a grant through Proyectos Europa Excelencia (Europe excellence projects). The measure encourages researchers to try again.

There is neither funding for proactive actions to influence calls, co-funding for FP participants nor funding to find calls and partners as such in Spain. However, CDTI allocates $€ 1-2$ million annually to find potential company participants in Horizon 2020. This is an incentive programme for a network comprised of agents (consultancy firms, universities, RTOs, etc.) having previous experience in FP projects. The objective of the programme is to identify newcomers (especially SMEs) or new project coordinators in Horizon 2020. CDTI has contracted a pool of 50 actors for this task, and funding is provided for these actors instead of supporting the applicants. Funding from CDTI is bound to applicants' success in Horizon 2020.

Financial support has been provided to applicants whose proposals were rejected in the first round through Assistance for proposals preparation (ACP) since 1994. ACP is only available for an SME once in four years. Additionally, CDTI has to assess the SME's participation in Horizon 2020 to be very relevant. CDTI has reserved approximately $€ 1$ million per year for this instrument. Since CDTI is responsible for pillars 2 and 3 of Horizon 2020, the National Agency for Research (AEI) provides funding for research institutions and other public actors in Pillar 1.

Furthermore, a similar measure is also available at the regional level. An SME can only receive financial assistance either from the national or regional level. Therefore, the applicants are required to sign a declaration of statement concerning previous funding. There are strong regions in Spain such as the Basque Country and Catalonia that attract majority of EU funding, and they may also have own structures supporting participation in EU programmes. According to an interviewee the Basque Country has strong support in business R\&D innovation in Horizon 2020 while Catalonia focuses on excellent science. No official data has been discovered on regional support measures in Spain.

\section{Summary of FP participation support measures in Spain}

\begin{tabular}{|c|c|c|c|}
\hline Name of measure & Responsible body & Scope, scale and eligibility & $\begin{array}{c}\text { Annual budget } \\
\text { (€million) }\end{array}$ \\
\hline Advisory services & $\begin{array}{l}\text { National Contact } \\
\text { Points (NCPs) }\end{array}$ & Advice and guidance at proposal stage & - \\
\hline $\begin{array}{l}\text { Assistance for } \\
\text { proposals } \\
\text { preparation }\end{array}$ & CDTI & $\begin{array}{l}\text { Assisting companies (SMEs) to resubmit rejected } \\
\text { proposals }\end{array}$ & $€ 1$ million \\
\hline $\begin{array}{l}\text { Dynamisation } \\
\text { Actions: "Europa } \\
\text { Investigación" }\end{array}$ & $\begin{array}{l}\text { National Agency for } \\
\text { Research (AEI) }\end{array}$ & $\begin{array}{l}\text { to promote and improve Spanish participation in } \\
\text { European initiatives in science and technology in } \\
\text { Horizon 2020; } \\
\text { support can be used to finance expenditures for the } \\
\text { purchase of consumables, supplies and similar } \\
\text { products, consultancy, translation and equivalent } \\
\text { services, travel and subsistence expenses, attendance } \\
\text { at conferences and conferences, consultancy fees and } \\
\text { support for innovation, registration fees for congresses } \\
\text { and technical conferences and subcontracting costs for } \\
\text { assisted activities } \\
\text { eligible for public or private non-profit entities with } \\
\text { proven ability and competence to carry out } R \text { \& } D \\
\text { projects that imply a significant advance of knowledge. }\end{array}$ & $€ 3$ million \\
\hline $\begin{array}{l}\text { Dynamisation } \\
\text { Actions:"Europa } \\
\text { Redes y Gestores" } \\
2014\end{array}$ & $\begin{array}{l}\text { National Agency for } \\
\text { Research (AEI) }\end{array}$ & $\begin{array}{l}\text { purpose of the measure is to finance the cost of } \\
\text { creating or strengthening structures to promote the } \\
\text { participation of research groups in international } \\
\text { projects, in particular Horizon } 2020 \text {, as well as } \\
\text { networking to foster synergies between agents of the } \\
\text { Spanish System of Science Technology and Enterprise. } \\
\text { support can be granted to public research institutions, } \\
\text { public and private universities with proven capacity and } \\
\text { activity in R \& D, public R \& D centres, public bodies } \\
\text { and centres with their own legal personality dependent } \\
\text { or linked to the General State Administration, and those } \\
\text { dependent on or linked to the territorial public } \\
\text { administrations and their bodies, or those mainly in the }\end{array}$ & $€ 5.3$ million \\
\hline
\end{tabular}




\begin{tabular}{|c|c|c|c|}
\hline Name of measure & Responsible body & Scope, scale and eligibility & $\begin{array}{c}\text { Annual budget } \\
(€ \text { million) }\end{array}$ \\
\hline & & $\begin{array}{l}\text { public sector, non-profit public and private health } \\
\text { institutions and institutions, research institutes, public } \\
\text { and private non-profit entities carrying out R \& D } \\
\text { activities. }\end{array}$ & \\
\hline $\begin{array}{l}\text { Dynamisation } \\
\text { Actions: } \\
\text { "Proyectos Europa } \\
\text { Excelencia" }\end{array}$ & $\begin{array}{l}\text { National Agency for } \\
\text { Research (AEI) }\end{array}$ & $\begin{array}{l}\text { the measure aims for promoting the internationalisation } \\
\text { of } R \& D \text { activities, encouraging the participation of } \\
\text { researchers with promising scientific trajectories } \\
\text { support can be used for financing personnel costs, } \\
\text { small equipment, materials and other costs related to } \\
\text { the project objectives } \\
\text { beneficiaries include public or private non-profit entities } \\
\text { with proven ability and competence to carry out } R \& D \\
\text { projects that imply a significant advance of knowledge }\end{array}$ & $750000 €$ \\
\hline $\begin{array}{l}\text { Dynamisation } \\
\text { Actions: "Redes de } \\
\text { Excelencia" }\end{array}$ & $\begin{array}{l}\text { National Agency for } \\
\text { Research (AEI) }\end{array}$ & $\begin{array}{l}\text { creation and development of networks of research } \\
\text { groups aimed at improving the research results } \\
\text { obtained through actions financed in previous calls for } \\
\text { the } 2008-2012 \text { National RDI Plan and the } 2013-2016 \\
\text { RDI State Plan, promote the general coordination of the } \\
\text { networks as well as KICs and ERICs } \\
\text { eligible costs include personnel costs, organisational } \\
\text { costs and assistance to scientific and technical } \\
\text { activities of the network and other costs related to the } \\
\text { development and implementation of the activities for } \\
\text { which they have been granted } \\
\text { beneficiaries: public or private non-profit entities with } \\
\text { proven ability and competence to carry out R \& D } \\
\text { projects that imply a significant advance of knowledge. }\end{array}$ & $€ 2.5$ million \\
\hline $\begin{array}{l}\text { Support for } \\
\text { company } \\
\text { participation in } \\
\text { Horizon } 2020 \\
\text { (Incentive } \\
\text { programme) }\end{array}$ & CDTI & $\begin{array}{l}\text { The objective of the programme is to find newcomers or } \\
\text { new project coordinators in FP and the aim is at } \\
\text { business, especially SMEs }\end{array}$ & $€ 1-2$ million \\
\hline
\end{tabular}

Source: Desk research and consultation

\section{Effectiveness}

Neither desk study nor interviews provided information on publicly available evaluations concerning effectiveness of support in FP / Horizon 2020 participation. Other sources demonstrate Spain's continuous success under the framework programmes. In FP7 the country ranked fifth amongst EU member states in the share of funding awarded and the number of 'participants signed contracts'. Furthermore, according to the Ministry of Economy and Competitiveness, Spain received an estimated $8.3 \%$ of total EU funding, up from 6.5\% under FP6. Based on the first results from Horizon 2020 good performance continues - Spain ranks as high as third in share of participations in signed grant agreements in Horizon 2020 and fourth in share of Horizon 2020 funding received in Horizon 2020. Thus, the likelihood of reaching the ambitious target of $9.5 \%$ funding share of the whole Programme is good.

Activities targeting companies seem to be effective. According to the interviewee CDTl's incentive programme has a leverage of 1 to 7 . CDTI is active in finding the new comers, because it is not typical that same company participates in an EU programme every other year. Furthermore, Spain tops the charts in coordinated projects, ranking 1st in project leadership with $15.2 \%$ (378 coordinators), compared to $10.7 \%$ led by Spain under FP7. Further evidence of effectiveness is return that companies have been obtaining: 2 out of 3 Spanish participants in the Horizon 2020 are companies, and are directly responsible for $38.2 \%$ of the economic return. By sector, Spain is also the first in Europe in projects related to calls for SMEs and environment, and second in nanotechnology, materials and manufacturing (with returns above 14\%). ${ }^{123}$ It can be argued that the presence of strong consultancy companies specialised in supporting various stakeholders in writing and submitting "winning" proposals at least partly explains Spain's success.

\footnotetext{
${ }^{123}$ See: http://www.zabala.eu/en/news/spain-reaches-fourth-position-h2020-returns-investment-\%E2\%82\%AC-19338m
} 
The changes in support measures between FP7 and Horizon 2020 have been minimal, and only concern the volume of financial support. Content or number of support measures has remained the same. The budget for supporting FP participation was higher during 20072010. This was due to government's intention to create a well-working structure for supporting FP participation. Once this investment was done, the budget was downsized. Since financial assistance does not form the core of the public FP support in Spain, universities, research institutions and companies need to be willing to invest their own resources and funding for applying and participating in Horizon 2020 projects.

\section{Lessons for the study}

Spain invests to certain extent in financial support as well as advice in order to increase participation in Horizon 2020. The role of NCPs is important in this regard. A selection system has been created to cover country as large as Spain. The regions interested in having an info day must demonstrate demand for such an event. These events are used for dissemination of information. However, the most important aspect of information days is reviewing of proposals prepared by universities, companies and other actors. This is a user / client friendly approach which emphasises the importance of proactive attitude of the regions. As a consequence, the NCPs visit the regions instead of asking various stakeholders to make the journey to the capital.

The approach is linked to the systematic monitoring of performance and success in Horizon 2020 participation jointly by CDTI and European Office. Information for instance on submitted proposals and signed contracts is gathered to a database. The database is an efficient tool for assessing Spanish participation in Horizon 2020. Information can be extracted on regions, universities, companies or industries allowing NCPs to take corrective action if need arises. These actions include for instance contacting potential businesses in specific industry in order to promote and support their participation in a call. In a similar manner participation and success of researchers / research groups is monitored and not successful, yet promising, applicants are supported in resubmitting an application during the next call.

Furthermore, setting a clear target at the highest political level - in the past for FP7 and currently in Horizon 2020 participation - can be considered an explaining factor in Spain's

success. Progress towards this goal is monitored and supported by dedication of NCPs and representatives. According to an interviewee collaboration between representatives and NCPs is effective and is founded on firm ground. Also, the support system seems to have been rather stable over the years. There are instruments dating back to 1990 s and there have been no drastic changes in the key organisations providing support. For instance, CDTI has experience of over 25 years in promoting Spanish participation in framework programmes.

\subsubsection{Case Norway}

This case study presents an overview of Norway's support measures for participation in Horizon 2020. It outlines the support measures available across five main categories: advisory services, funding for proactive actions to influence calls, funding to find calls and partners, funding to produce proposals, and co-funding for FP participants.

Norway's participation in Horizon 2020 
Norway is among the most successful Associated Countries in Horizon 2020 according to the first results report of Horizon 2020. ${ }^{124}$ Through the first year of Horizon 2020, Norway ranked second among Associated Countries in the two areas presented in that report, 'Share of eligible applications', and 'Share of participations in signed grant agreements' (see below). Norway ranks behind Switzerland in both areas, and, while both countries have experienced a decrease in their respective shares of eligible proposals and of participations in signed grant agreements between FP7 and Horizon 2020, Norway's decrease is smaller. Norway's share of eligible proposals decreased by approximate 0.1 percentage point between FP7 and Horizon 2020, compared to Switzerland's decrease of 1.1 percentage points. Similarly, Norway's share of participations in signed grant agreements decreased by approximately 0.3 percentage points, compared to Switzerland's decrease of approximately 1.3 percentage points.

\section{Performance of Norway in Horizon 2020}

\begin{tabular}{lll}
\hline Horizon 2020 performance area & \multicolumn{1}{c}{ Rank } & \multicolumn{1}{c}{ Value } \\
\hline Share of eligible proposals & $\begin{array}{l}2^{\text {nd }} \text { among Associated } \\
\text { Countries }\end{array}$ & $1.4 \%^{*}$ \\
$\begin{array}{l}\text { Share of participations in signed } \\
\text { grant agreements } \\
\begin{array}{l}\text { Performance in specific } \\
\text { Countries }\end{array}\end{array}$ & $1.6 \%{ }^{*}$ \\
& $\begin{array}{l}\text { Norway is performing particularly well in } \\
\text { biotech (based on proposal success rates) } \\
\text { and Innovation in SME (based on proportion } \\
\text { funding secured) }\end{array}$ \\
\hline
\end{tabular}

\section{Objectives and targets of the current national strategy}

Although not an EU member state, Norway became associated to the FPs through the European Economic Area (EEA) agreement and has participated in the FPs since the beginning of 1994, i.e. in FP4. Norway's financial contribution to the FPs is calculated based on its GDP and it is paid explicitly; the annual cost for participating in Horizon 2020 is around $€ 447$ million. ${ }^{125}$ The fact that the cost is explicit and quite substantial has led to a clear policy focus on making the most of the FP association, and a series of research White Papers and national strategies have therefore focused on the importance of increasing Norwegian participation to gain as much benefit as possible. In 2014, Norway decided to also affiliate itself with Horizon 2020, and shortly thereafter the Government presented its Strategy for research and innovation cooperation with the EU, which announced the Government's ambition that Norwegian organisations should bring back two percent of the competitive funds available in Horizon 2020. The Strategy also set four qualitative objectives, namely to increase quality and competitiveness of Norwegian research and innovation; to increase innovation capacity, value creation and sustainable economic development; to contribute to improved social welfare and sustainable social development; and to develop the research and innovation sector. ${ }^{126}$

The 2014 White Paper Long-term plan for research and higher education (Langtidsplan for forskning og høyere utdanning 2015-2024) emphasised the need to reinforce research and education to meet challenges and seize opportunities in the Norwegian knowledge society in the coming decade. The importance of continued internationalisation was stressed, and the White Paper noted that for the two percent goal to be reached, the scope of Norwegian activities must increase radically. The White Paper concluded that there is an inherent potential to increase the scope of participation in all sectors. In cooperation with the

\footnotetext{
${ }^{124}$ See: https://ec.europa.eu/programmes/horizon2020/sites/horizon2020/files/horizon 2020 first results 1.pdf

${ }^{125}$ See: www.regieringen.no/no/tema/europapolitikk/tema-norge-eu/okonomiske-bidrag/id684932/

${ }^{126}$ Strategi for forsknings- og innovasjonssamarbeidet med EU. Horisont 2020 og ERA, MER, 2014.
} 
Research Council of Norway (RCN), the Government therefore was to develop a set of measures and instruments to respond to the needs of various sectors, taking the Strategy for research and innovation cooperation with the EU as a point of departure. The White Paper emphasised that different sectors have different needs. Research institutes were described as needing support to meet the gap between costs covered by EC funding and actual costs. Since the institutes play an important role in mobilising industry, support to institutes also was seen as a means of increasing company participation. The higher education (HE) sector and the hospital trusts were described as needing information and support for positioning activities, writing proposals, and establishing and conducting projects. Industry's greatest need was said to be funding to mobilise companies to take part, and to assist them in establishing projects. ${ }^{127}$

\section{Key organisations involved in supporting FP participation}

The main agency tasked with facilitating FP participation is RCN, in cooperation with Innovation Norway (IN) and the Norwegian Space Centre (NSC).

\section{Framework Programme support measures}

Norway's range of supports for prospective Horizon 2020 participants is quite comprehensive. The country's support for participation in the FPs has been developed over successive programming periods, and the present support measures are, to a notable degree, an extension to those developed under FP7. For simplicity, the following subsections merely mention "Horizon 2020" and "FP", but most of the measures are not strictly limited to the FPs, but also fund activities to participate in programmes and actions co-funded by Horizon 2020, such as Article 185, ERA-NET Cofund and Joint Technology Initiatives (JTIs).

\section{Advisory services}

The Norwegian network of National Contact Points (NCP) is led by RCN, with the assistance of IN when it comes to the SME Instrument and Access to risk finance, and the Norwegian Space Centre (NSC) for space-related matters. Together these agencies provide elaborate information and advisory services, mainly through NCPs covering all Horizon 2020 sub-programmes. IN hosts the Enterprise Europe Network (EEN) in Norway, which assists SMEs with partnership search, reviews proposal drafts, advices on business-related matters and provides support to innovation. Together, the NCPs and a network of regional EU advisors that IN has throughout Norway provide comprehensive information on FP opportunities and advice regarding FP participation, both in the form of seminars and courses and in individual interaction.

Through a competitive measure, IN also co-funds EU advisors within clusters funded through the Norwegian Innovation Clusters programme (which IN leads together with RCN and the Industrial Development Corporation of Norway (Siva)).

Moreover, RCN's new competence-building initiative for Horizon 2020 proposers, the Path to EU Excellence, provides a comprehensive course offer to researchers, EU advisors and administrators. The objective of Path to EU Excellence is to enable Norwegian proposers to submit more proposals and proposals of higher quality through a combination of courses and support in the proposal development phase. RCN thus offers mentoring in developing Horizon 2020 proposals, including review of proposals. The target groups for these services

${ }^{127}$ St.meld. nr. 7 (2014-2015), Langtidsplan for forskning og høyere utdanning 2015-2024. 
are mainly proposers from industry and the public sector, but also researchers from research institutes and universities with limited internal support capacity. ${ }^{128}$

\section{Funding for proactive actions to influence calls}

The main Norwegian FP support measure, RCN's Project Establishment Support (Prosjektetableringsstotte, PES2020), was launched as PES in 2006 and subsequently greatly expanded during FP7. When it comes to influencing EU-related processes and calls for proposals, PES2020 funds projects with up to NOK1 million for up to three years. ${ }^{129}$

Several of RCN's (national) R\&D programmes provide support for similar proactive activities within their respective remits, including BIOTEK2021, ENERGIX, Transport 2025 and the industry-oriented User-driven Research-based Innovation (Brukerstyrt innovasjonsarena, BIA) programme, as do the seven Regional Research Funds (Regionale Forskningsfondene, RFF). ${ }^{130}$

\section{Funding to find calls and partners}

PES2020 reimburses travel costs to Horizon 2020-relevant events, up to NOK100 thousand. ${ }^{131}$ Moreover, RCN funds a number of national networks that aim to increase Horizon 2020 participation through increasing competence, improving collaboration between key actors, learning and sharing of good practice and development of alliances. ${ }^{132}$

\section{Funding to produce proposals}

While PES2020 funds proactive activities of different kinds, its most important aspect is that it funds proposal production, and this is what consumes most of PES2020's budget (NOK 128.5 million in 2017). PES2020 was modified in May 2017. Until May 2017, companies and research institutes got up to 50 percent of their costs covered. Salary costs were not eligible for public servants, unless replacement staff was hired. Since May 2017, PES2020 support is disbursed as a lump sum and costs need not be reported. Some sample support amounts according the previous and the new rules include: ${ }^{133,134}$

- $\quad$ Coordinators of proposals for Research and Innovation Actions (RIA):

- Until May 2017: NOK 200 thousand, plus NOK 50housand if the proposal reaches the assessment threshold and another NOK 50 thousand if the proposal is funded (maximum amounts)

- Since May 2017: NOK 400 thousand, plus NOK100 thousand if the proposal reaches the threshold (lump sum)

- $\quad$ Proposal participants:

- Until May 2017: NOK40 thousand, plus NOK10 thousand if the proposal reaches the threshold and another NOK10 thousand if the proposal is funded (maximum amounts)

\footnotetext{
${ }^{128}$ See: https://www.forskningsradet.no/prognett-horisont2020/Courses_and_help_with_proposals/1254022852485

${ }^{129}$ Prosjektetableringsstøtte - PES2020, Horisont 2020, RCN, 2016.

${ }^{130}$ See: https://www.forskningsradet.no/prognett-horisont2020/Stotte til vare sokere/1253990570332

${ }^{131}$ Prosjektetableringsstøtte - PES2020, Horisont 2020, RCN, 2016.

132 See: https://www.forskningsradet.no/prognett-horisont2020/Stotte til vare sokere/1253990570332

${ }^{133}$ Prosjektetableringsstøtte - PES2020, Horisont 2020, RCN, 2016.

${ }^{134}$ Prosjektetableringsstøtte - PES2020, Horisont 2020, RCN, 2017.
} 
- Since May 2017: NOK50 thousand, plus NOK10 thousand if the proposal reaches the threshold (lump sum)

- Work package leaders:

- Until May 2017: NOK40-60 thousand, plus NOK10 thousand if the proposal reaches the threshold and another NOK10 thousand if the proposal is funded (maximum amounts)

- Since May 2017: NOK70 thousand, plus NOK10 thousand if the proposal reaches the threshold (lump sum)

All forms of PES2020 support require that a proposal is submitted to RCN, and funding to produce Horizon 2020 proposals is contingent on the proposal being deemed eligible by the Commission. Frequent proposers to Horizon 2020 among higher education institutions (HEIs), research institutes and hospital trusts receive an annual PES2020 grant, the size of which depends on the organisation's request and its past FP performance. In 2017, 17 HEIs, 33 research institutes and four hospital trusts have such annual grants that are internally distributed to the organisation's proposers. ${ }^{135}$ Since 2016, HEls may use the annual grant to strengthen their internal EU support functions (also referred to as grants offices, international offices, EU offices etc.; in most cases, these internal support functions have a broader remit than EU programmes).

The RCN's HELSE-EU measure aims to contribute to i) increased participation from Norwegian health researchers and ii) to additional health-related Horizon 2020 proposals. The measure funds national collaboration on strategic health topics with the aim of producing Horizon 2020 proposals, and also funds proposers who have finished on the Commission's reserve list and that want to submit a revised - or a completely new proposal. The intention with the national collaboration is to share knowledge and good practices, and to develop alliances to make Norwegian health research communities more competitive within Horizon 2020. Support is available to companies, HEls, research institutes, hospital trusts, public sector organisation and user organisations. The measure was introduced in 2016, and its budget for 2018 and 2019 is NOK16 million. ${ }^{136}$

The RCN's FRIPRO research programme funds proposers who have made it to the European Research Council (ERC) stage 2 without being funded and that wish to submit a revised proposal. RCN offers grants up to NOK500 thousand if a new ERC proposal is submitted within two years of the original proposal. ${ }^{137}$

Through the EC's Seal of Excellence scheme, IN provides funding to SMEs whose proposals to phase 1 of Horizon 2020's SME Instrument scored above the quality threshold but did not receive EU funding due to budgetary constraints. Stage 2 projects are not funded by IN.

\section{Co-funding for FP participants}

Another most important financial FP support measure is RCN's STIM-EU, which was established in 2012. Since 2015, STIM-EU provides research institutes with an extra 33 percent in funding in addition to Horizon 2020 funding already awarded. There is no requirement that the support should be used to co-fund the Horizon 2020 project(s) in

${ }^{135}$ Forskningsinstitusjoner med PES2020-rammebevilgning for 2017, RCN.

${ }^{136}$ See: https://www.forskningsradet.no/no/Utlysning/HELSEEU/1254019239883

${ }^{137}$ See: https://www.forskningsradet.no/no/Utlysning/FRIPRO/1254017364454 
question, but most institutes report to RCN that the majority of the STIM EU funding is indeed used for this purpose. The need for this measure is in part motivated by Norwegian research institutes having (very) low base funding compared to their counterparts in most other countries. ${ }^{138}$

Eligible institutes are those that are part of the national research institute base funding system that RCN administers, plus another five institutes outside the base funding system. Support is calculated based on FP funding already received for RIAs, Innovation Actions (IAs), Coordination and Support Actions (CSAs), Marie Skłodowska-Curie Actions (MSCAs) and ERC grants, as are actions that receive part of their funding from Horizon 2020, such as JTIs. The institutes need not apply for STIM-EU funding, since RCN calculates the eligible amounts based on eCORDA data. Institutes that participate together with Norwegian companies, Norwegian public-sector organisations, or that coordinate projects receive extra funding (partnering with Norwegian companies counts for double as much as partnering with public-sector organisations or coordinating). ${ }^{139}$

Several of RCN's R\&D programmes provide additional funding to Norwegian participants in projects in selected Horizon 2020 sub-programmes that lie within the programmes' respective remits. This funding is for additional activities that can increase the impact in Norway of the participation in a Horizon 2020 project. The KLIMAFORSK programme funds such additional activities related to projects within the "Climate action, environment, resource efficiency and raw materials" Societal Challenge. The BION/ER programme does the same in the "Food security, sustainable agriculture and forestry, marine and maritime and inland water research, and the Bioeconomy" Societal Challenge, and the BEDREHELSE programme similarly within the "Health, demographic change and wellbeing" Societal Challenge.

IN provides key account service and 12 days of external expert advisory services to all SMEs that have received EC funding in phase 1 of Horizon 2020's SME Instrument. IN also provides companies with advice on loans through the European Investment Fund (EIF) and the European Investment Bank (EIB).

\section{Effectiveness}

As mentioned above, the present FP support measures are to a notable degree an extension of those honed under FP7. A selection of the FP7 measures, including several that are still - with some modifications - in use under Horizon 2020, were evaluated in 2013. In summary, the evaluation found that: ${ }^{140}$

- $\quad$ Two programme-level measures to fund proactive actions to influence calls (the ENERGIX programme with within energy and the CLIMIT programme within climate) were deemed to be effective through facilitating future Norwegian FP participation, and the evaluation proposed that such measures should be extended to more fields

- $\quad$ The PES measure was found to lead to the most comprehensive results in terms of additional proposals, more competitive proposals and higher financial

${ }^{138}$ T. Åström, C. Rosemberg Montes, T. Fridholm, A. Håkansson and A. Zika-Viktorsson, "Impact analysis of the technical-industrial research institutes in Norway", RCN, 2015.

${ }^{139}$ STIM-EU Tiltak for økt deltakelse av forskningsinstitutter i EUs rammeprogram. Retningslinjer for ordningen, RCN, 2016.

${ }^{140}$ T. Åström, A. Håkansson, G. Melin, P. Stern, P. Boekholt and E. Arnold, “Impact evaluation of the Research Council of Norway's support measures to increase participation in EU-funded research", RCN, 2013 
return. The evaluation proposed that the measure should be continued but be primarily focused on proposers with the greatest needs

- $\quad$ The direct impact of the FRIPRO programme's "second-chance" funding for ERC proposals that were deemed fundable but were not funded for budgetary reasons was found to be limited. However, the measure was assumed likely to enhance the quality of Norwegian research, as well as to lead to defragmentation of Norwegian research environments. The evaluation nevertheless questioned whether it was worthwhile maintaining this measure. Note that this measure, which has been abandoned, is different from the existing FRIPRO measure mentioned above

- $\quad$ The STIM-EU measure was included in the evaluation, but it was at the time so new that it was too early to evaluate its efficiency. However, the measure was assumed to result in additional and more competitive proposals from research institutes, as well as the participation of more Norwegian companies. The evaluation proposed that that the measure should be perpetuated as long as the base grants to research institutes remain low by international standards

- $\quad$ The ENERGIX programme's co-funding of Norwegian HEls and research institutes participating in $\mathrm{FCH}$ JU projects was found to lead to rather comprehensive results in terms of additional proposals, more competitive proposals and higher financial return. The evaluation proposed that such measures should be extended to more JUs

\section{Lessons learned}

The evaluation of RCN's FP7 support measures concluded that PES funding makes proposals from Norwegian HEls and research institutes more competitive and results in more Norwegian coordinators, but that its effect on the number of proposals is probably limited. The Norwegian research institutes' low level of base funding limits their ability to cofund FP projects, for which reason the STIM-EU and FCH JU measures were found to correspond to real needs. It was assumed that the same also held true for the proactive measures, since the revenue that potentially may emerge from such efforts lie so far into the future that they likely would not be carried out to the same extent without explicit support. The evaluation further concluded that PES funding is significantly more important for SMEs than for HEls, research institutes and large companies. ${ }^{141}$

The aforementioned evaluation showed that RCN's FP7 support measures were allencompassing and quite generous. Under Horizon 2020, RCN's portfolio has become even more elaborate and simultaneously IN has implemented additional support measures that primarily focus on the private sector. This development stems from what it considered an unsatisfactory level of Norwegian FP participation, but it is a warranted question why so many and so generous financial support measures are needed to entice Norwegian researchers and organisations to participate in the FPs. The 2013 evaluation argued that the main reason for the relatively low participation of HEls and hospital trusts was that their (national) funding was so generous that they did not have overly compelling reasons to look abroad for funding. In such a situation, additional support measures were assumed to have limited effect. (Recall that another logic applies to Norwegian research institutes due to their 
low level of base funding.) The evaluation suggested that the main reasons for the unsatisfactory level of Norwegian FP participation at the time were: ${ }^{142}$

A lack of determination and strategic approach at several levels. At the organisational level, there was a lack of concrete objectives for EU participation. Ministries could make (part of) the base grants to HEls and regional health authorities (that manage the hospital trusts) conditional on a certain level of FP participation in order to accelerate such a development. Moreover, the evaluation argued that it would be a good idea to create individualised incentive schemes and further develop support functions within organisations to facilitate and professionalise researchers' work with FP proposals and projects.

Norway has a relatively small R\&D capacity in relation to its Gross Domestic Product (which determines the cost of the nation's affiliation with the FPs), meaning that there is a resource limitation. The high cost level of Norwegian organisations means that Norwegian R\&D performers must be better than their competitors in other countries to be competitive

\subsubsection{Case Ireland}

This case study presents an overview of Ireland's support measures for participation in Horizon 2020. It outlines the suite of support available at the national level across five main categories: advisory services, funding for proactive actions to influence calls, funding to find calls and partners, funding to produce proposals, and co-funding for FP participants. In describing the support available, the document also sets out the 'target audience' for the support, whether government, academia, research performing organisations, businesses, or a combination thereof. In addition to setting out the financial and non-financial support for participation in Horizon 2020, the document briefly sets out structural support. The case study then mobilises previous evaluations and interviews with key individuals in-country to discuss the effectiveness of the support available, before concluding with a set of 'lessons learned'.

\section{Ireland's participation in Horizon 2020}

Ireland has experienced success in Horizon 2020, performing in the top 15 of each of three main categories: proposal success rates, share of signed grant agreements, and share of Horizon 2020 funding received at the time of the first results report of Horizon 2020 (see Table 1).

More recently, the interim evaluation of Ireland's participation in Horizon 2020, ${ }^{143}$ using data to March 2016, found that Ireland (when compared with the same period of FP7) was submitting more and larger proposals to Horizon 2020, and had secured notably higher financial return in EC contributions (a 228\% increase on the funding in the first two years of FP7). At the time of the evaluation, there had been high business demand driven by SMEs, and a slightly higher success rate for industry than for higher education institutions over the same period. Company funding accounted for $30 \%$ of funding for the period, and it was estimated that client companies of Ireland's enterprise agencies accounted for $85 \%$ of company funding in the period. Intel Ireland is listed in the Top 50 Horizon 2020 Companies, ${ }^{144}$ and at the time of the evaluation of participation, Ireland ranked top in the SME Instrument, based on proposal success rate.

\footnotetext{
142 Ibid.

${ }^{143}$ C. Rosemberg Montes, P. Simmonds, M. Wain, K. Nielsen, “Interim evaluation of Ireland's Participation in Horizon 2020”, DJEI, 2016

${ }^{144}$ Building Research Relationships with International Industry Partners (February 2015 presentation given by Dr Imelda Lambkin)
} 


\section{Performance of Ireland in Horizon 2020}

\begin{tabular}{lll}
\hline \multicolumn{1}{c}{ Horizon 2020 performance area } & Rank & \multicolumn{1}{c}{ Value } \\
\hline Proposal success rates & $12^{\text {th }}$ & $15 \%^{*}$ \\
Share of signed grant agreements & $14^{\text {th }}$ & $2 \%{ }^{*}$ \\
Share of Horizon 2020 funding received & $13^{\text {th }}$ & $2 \%{ }^{*}$ \\
Performance in specific & & Ireland performs well in ICT (in terms of overall \\
themes/programmes & & funding secured), and ranks top in the SME \\
& & Instrument by proposal success rate ** \\
\hline
\end{tabular}

Source: * extracted from DG Research and Innovation, “Horizon 2020 First Results”, 2015; ** based on eCORDA analysis (March 2016)

\section{Objectives and targets of the current national strategy}

Ireland's current, dedicated Horizon 2020 Strategy, "EU Framework Programme for Research and Innovation (2014-2020): Ireland's Strategy and Target for Participation" was published in 2014 by the Department of Jobs, Enterprise and Innovation (DJEI). ${ }^{145}$ As well as more than doubling the target for financial return when compared to FP7 (from €600 million to $€ 1.25$ billion), the current strategy identifies a strategic objective to build on the success of SME participation in FP7, to further build on the success of Irish coordinators, and to overcome a perceived relative underperformance in securing ERC funding. Specific support mechanisms or schemes are in place for each of these areas. Finally, there is a cross-border strategy for Northern Ireland and Ireland, which sets a target of $€ 175$ million in funding for cross-border projects. ${ }^{146}$ The strategy was published by InterTradelreland, the cross-border trade and business development body.

\section{Key organisations involved in supporting FP participation}

Overall Ministerial responsibility for Horizon 2020 sits with DJEI, who set the remit of the support structures. The 'operational' support structure for Horizon 2020, the National Support Network, is led by Enterprise Ireland, the national agency responsible for supporting Irish businesses in the manufacturing and internationally-traded service sectors. The National Support Network is comprised of two government departments, ${ }^{147}$ two national agencies, ${ }^{148}$ the major national research funding bodies, ${ }^{149}$ a national research institute, ${ }^{150}$ and the Irish Universities Association. The National Support Network has the remit to "optimise Irish participation" in Horizon 2020, ${ }^{151}$ and has been organised broadly in line with the three pillars of Horizon 2020, and the organisations' strengths. ${ }^{152}$

There are several important groups, too. DJEl chairs a High-Level Group for Horizon 2020, which has been established to oversee implementation of the national strategy, and to identify and champion strategic 'big wins' for Ireland in the programme. There is also a working group focused on strategic research proposals, chaired by the Director General of Science Foundation Ireland (and Chief Scientific Advisor to the Irish Prime Minister). The group is backed by the Minister for Skills, Research and Innovation. ${ }^{153}$ Finally, the All-Island Horizon 2020 Steering Group is convened and chaired by InterTradelreland. The Steering Group comprises members from Irish and Northern Irish Government departments and

\footnotetext{
${ }^{145}$ DJEI, “EU Framework Programme for Research and Innovation (2014-2020). Ireland's Strategy and Target for Participation”, 2014

${ }^{146}$ European Commission Joint Research Centre, "Research \& Innovation Observatory Country Report - Ireland", 2015

${ }^{147}$ DJEl and the Department for Agriculture, Food and Marine

${ }^{148}$ The Environmental Protection Agency and the Sustainable Energy Authority of Ireland

${ }^{149}$ The Health Research Board, Higher Education Authority, Irish Research Council, and Science Foundation Ireland

${ }^{150}$ The Marine Institute

${ }^{151}$ Enterprise Ireland, "Strategies to maximise participation in Horizon 2020", 2013

${ }^{152}$ For example, the Industrial Leadership pillar is Iargely covered by Enterprise Ireland, and Excellent Science by Science Foundation Ireland and the Irish Research Council.

${ }^{153}$ See: http://www.horizon2020.ie/minister-damien-english-wants-researchers-to-think-big/
} 
agencies involved in Horizon 2020 support networks, as well as representatives from the North-South Ministerial Council ${ }^{154}$ and the European Commission.

\section{Framework Programme support measures}

Ireland's range of supports for prospective Horizon 2020 participants is fairly comprehensive, with support measures present across each of five major categories. The country's support for participation in the FPs has been developed over successive programming periods since FP5, as national aspirations and targets for participation have also increased sharply. The majority of supports described below are specific to Horizon 2020.

\section{Advisory services}

Each organisation in the National Support Network provides direct support to their stakeholders, from information, advice and guidance, to mock interviews, peer learning, research infrastructure and funding schemes.

The network of National Contact Points (NCPs) is overseen by Enterprise Ireland, and comprises 36 representatives from 10 research and industry agencies. The NCPs cover all sub-programmes of Horizon 2020 and work on an All-Island basis to provide guidance and information, as well as 'hand-holding' support through proposal preparation. The NCP service has been designed in light of the European Commission's recommendation of 'professionalised' support services. ${ }^{155}$ The last couple of years has also seen the development of a special team to support industry engagement and multi-disciplinary research. The team comprises relevant NCPs, National Delegates and agency development advisors to support bringing expertise and businesses into multi-sectoral and multi-disciplinary projects such as ICT (which, as an enabling technology, can apply to projects in energy, manufacturing, and health). The NCPs are available for each type of potential participant, from government, academia, research organisations and businesses, with two dedicated NCPs for SMEs. Enterprise Ireland also host the Enterprise Europe Network (EEN) in Ireland, which provides a range of complementary services, including technology assessments to identify funding opportunities and partner searches. ${ }^{156}$

The Irish Marie Curie Office is funded by the Irish Research Council, and managed by the Irish Universities Association. It exists to support the full range of stakeholders that are eligible for the Marie Skłodowska-Curie Actions (MSCA) in the process of applying for and managing an award. Its resourcing includes the dedicated MSCA NCP, and dedicated staff to deal with immigration issues.

Science Foundation Ireland (SFI) have a dedicated EU support team within their EU Affairs Office. This team is in place to support SFI award holders, whether individual researchers or organisations, ${ }^{157}$ or any of the SFI-funded research centres, ${ }^{158}$ and the wider research community to leverage national funding against European monies.

\section{Funding for proactive actions to influence calls}

\footnotetext{
${ }^{154}$ See: https://www.northsouthministerialcouncil.org/

155 See: http://ec.europa.eu/research/participants/data/support/20131125 NCP\%20Minimum\%20standards.pdf

${ }^{156}$ See: http://www.een-ireland.ie/content/services/access eu funding/

${ }^{157}$ See: http://www.sfi.ie/funding/funding-overview.html

${ }^{158}$ See: http://www.sfi.ie/investments-achievements/sfi-research-centres/
} 
Ireland's support system features both financial and 'soft' supports for proactive actions to influence calls. SFI offers grants of up to $€ 50$ thousand through their Brussels Conference Programme for researchers to host an event in Brussels for the purpose of enhancing Horizon 2020 funding through influencing, promoting activities, and building networks. On the 'softer' side, Enterprise Ireland's Brussels office ${ }^{159}$ is made available for partner meetings and hosting of events in Brussels, for any Irish applicant.

\section{Funding to find calls and partners}

Enterprise Ireland offers funding for academic researchers to meet research partners in other countries. The funding is available for multiple visits, to facilitate participation in Horizon 2020 (excluding COST), and up to $€ 3$ thousand (at $€ 400$ per day) is available for out of pocket expenses such as hotels, meals, taxis, local fares and incidentals.

The cross-border trade body InterTradelreland provides funding for Northern Irish/Irish partnerships to i) travel to meet with each other, and ii) travel for meetings with overseas partners, or to attend relevant events. The funding is available for both academics and industry/other organisations, with up to $€ 550$ available to support cross-border partnerships to travel to meet with each other, and up to $€ 437$ to support cross-border partnerships to travel to Europe.

\section{Funding to produce proposals}

There is a large range of financial support available for those aiming to coordinate a project under Horizon 2020, and/or those applying to the ERC. While most support is available for researchers, it may be possible for Irish companies to avail of financial assistance towards the cost of preparing their Horizon 2020 proposal, via their assigned development advisor. ${ }^{160}$

Enterprise Ireland's Coordination Support Grants are available to facilitate the preparatory work leading to a proposal for the coordination of projects. Two types of support grant are available:

Coordination grants for academic coordinators, for any research project within Horizon 2020 , up to $€ 12,5$ thousand available.

ERC preparation grants for academic researchers applying to the ERC, up to $€ 8$ thousand available for a Starting Grant, Consolidator Grant or Advanced Grant. Up to $€ 5$ thousand is available for applicants to a Proof of Concept Grant.

SFI offers 'second chance' grants to academic ERC applicants. The SFI ERC Development Programme supports researchers based in Ireland that have submitted a proposal to the ERC Starting Grant, Consolidator Grant and Advanced Grant programmes, that were deemed fundable, but were not eventually funded by the ERC due to a lack of available programme budget. The grants are available for up to $50 \%$ of the original ERC proposal, or $€ 500$ thousand, whichever is lower, for a maximum of 24 months.

The Irish Research Council's Basic Research Excellence Award offers between $€ 60$ thousand and $€ 100$ thousand to researchers in the Arts, Humanities and Social Sciences who applied to the ERC and achieved an ' $A$ ' rated outcome but had not received funding. The grant is contingent upon the intention to re-apply to the ERC in the next available call.

\footnotetext{
${ }^{159}$ See: https://enterprise-ireland.com/en/Export-Assistance/International-Office-Network-Services-and-Contacts/Belgium.htm

${ }^{160}$ For example, if the company is a client of one of the Irish enterprise agencies
} 


\section{Co-funding for FP participants}

SFI offers financial support for ERC participants. The SFI ERC Support Programme provides an additional overhead payment to the Host Institution of ERC award winners, which is designed to assist awardees to successfully carry out their ERC-funded research. Awardees who secured ERC funding while at an Irish institution, as well as those subsequently recruited to an Irish institution from overseas are eligible. The amounts differ as follows:

- $\quad$ ERC award (2015 call or later) with an Irish Host Institution: $€ 150$ thousand, regardless of ERC scheme.

- $\quad$ ERC award from a 2014 call with an Irish Host Institution: $20 \%$ of the award stated in the ERC grant agreement, up to a maximum of $€ 300$ thousand, regardless of ERC scheme.

- $\quad$ ERC awardees (from any year) that have been recruited to work in an Irish Host Institution: The award may depend on the time remaining on the ERC award and will depend on the type of ERC award held, as follows: ERC Starting Grant up to $€ 500$ thousand; ERC Consolidator Grant up to $€ 750$ thousand; ERC Advanced Grant up to $€ 1$ million.

Ireland also invests structurally, in the broader research population and infrastructure, to boost participation in the FPs. Through 2016, the Irish Research Council invested approximately $€ 90$ thousand in workshops to support the embedding of interdisciplinary thinking in the Irish research system. ${ }^{161}$ The SFI-funded Research Centres have been set targets for Horizon 2020 funding, ${ }^{162}$ and have been awarded supplementary funding to support dedicated EU Grant Managers within the centres that co-ordinate European activity. There are 13 such posts in the 12 funded centres.

Furthermore, national research funding has been aligned to both national strengths and European priorities. This was first undertaken through the national Research Prioritisation Exercise in 2014, ${ }^{163}$ and was refined in the national strategy Innovation 2020. ${ }^{164}$ Applicants to some national research funding must present a concrete plan for accessing European funding as an eligibility criterion.

\section{Summary of FP participation support measures in Ireland}

\begin{tabular}{|c|c|c|c|c|}
\hline Type of measure & Name of measure & Responsible body & Scope, scale and eligibility & $\begin{array}{l}\text { Funding } \\
\text { available }\end{array}$ \\
\hline \multirow[t]{4}{*}{$\begin{array}{l}\text { Advisory } \\
\text { services }\end{array}$} & $\begin{array}{l}\text { Network of National } \\
\text { Contact Points } \\
\text { (NCPs) }\end{array}$ & Enterprise Ireland & $\begin{array}{l}36 \text { NCPs } \\
\text { All-island basis } \\
\text { Advice and guidance across all } \\
\text { Horizon } 2020 \text { programmes }\end{array}$ & -- \\
\hline & $\begin{array}{l}\text { Enterprise Europe } \\
\text { Network }\end{array}$ & Enterprise Ireland & $\begin{array}{l}\text { Services to SMEs include } \\
\text { technology assessments to identify } \\
\text { funding opportunities and partner } \\
\text { searches. }\end{array}$ & -- \\
\hline & $\begin{array}{l}\text { Irish Marie Curie } \\
\text { Office }\end{array}$ & $\begin{array}{l}\text { Irish Universities } \\
\text { Association }\end{array}$ & $\begin{array}{l}\text { Supports proposal for and } \\
\text { management of MSCA awards }\end{array}$ & -- \\
\hline & $\begin{array}{l}\text { EU support team (EU } \\
\text { Affairs Office) }\end{array}$ & $\begin{array}{l}\text { Science } \\
\text { Foundation Ireland }\end{array}$ & Supports SFI award holders & -- \\
\hline $\begin{array}{l}\text { Funding for } \\
\text { proactive actions } \\
\text { to influence calls }\end{array}$ & $\begin{array}{l}\text { Brussels Conference } \\
\text { Programme }\end{array}$ & $\begin{array}{l}\text { Science } \\
\text { Foundation Ireland }\end{array}$ & $\begin{array}{l}\text { Hosting a Brussels event for } \\
\text { influencing, promoting activities, and } \\
\text { building networks }\end{array}$ & Up to $€ 50,000$ \\
\hline Funding to find & Travel grants for & Enterprise Ireland & Facilitates visits to meet research & Up to $€ 3,000$ \\
\hline
\end{tabular}




\begin{tabular}{|c|c|c|c|c|}
\hline Type of measure & Name of measure & Responsible body & Scope, scale and eligibility & $\begin{array}{l}\text { Funding } \\
\text { available }\end{array}$ \\
\hline \multirow{2}{*}{$\begin{array}{l}\text { calls and } \\
\text { partners }\end{array}$} & academic researchers & & partners in other countries & (€400 per day) \\
\hline & Travel grants & InterTradelreland & $\begin{array}{l}\text { Facilitates Northern Irish/Irish } \\
\text { partnerships to i) travel to meet with } \\
\text { each other, and ii) to travel for } \\
\text { meetings with overseas partners, or } \\
\text { to attend relevant events. Available } \\
\text { for both academics and } \\
\text { industry/other organisations. }\end{array}$ & $\begin{array}{l}\text { Between } € 400 \text { - } \\
€ 550\end{array}$ \\
\hline \multirow[t]{6}{*}{$\begin{array}{l}\text { Funding to } \\
\text { produce } \\
\text { proposals }\end{array}$} & Coordination support & Enterprise Ireland & $\begin{array}{l}\text { A grant to support the preparatory } \\
\text { work for a proposal that will lead to } \\
\text { the coordination of a project under } \\
\text { Horizon } 2020\end{array}$ & \multirow{2}{*}{$\begin{array}{l}\text { Up to } € 12,500 \text { for } \\
\text { academic } \\
\text { coordinators, } \\
\text { Up to } € 3,000 \text { for } \\
\text { a COST action } \\
\text { Up to } € 8,000 \\
\text { Up to } € 5,000 \text { is } \\
\text { available for an } \\
\text { ERC Proof of } \\
\text { Concept Grant }\end{array}$} \\
\hline & ERC preparation & Enterprise Ireland & $\begin{array}{l}\text { For applicants to an ERC Starting } \\
\text { Grant, Consolidator Grant or } \\
\text { Advanced Grant, as well as for ERC } \\
\text { Proof of Concept Grants. }\end{array}$ & \\
\hline & $\begin{array}{l}\text { ERC Development } \\
\text { Programme }\end{array}$ & $\begin{array}{l}\text { Science } \\
\text { Foundation Ireland }\end{array}$ & $\begin{array}{l}\text { Supports academic researchers that } \\
\text { submitted a proposal for an ERC } \\
\text { Starting Grant, Consolidator Grant or } \\
\text { Advanced Grant that was deemed } \\
\text { fundable, but did not receive funding } \\
\text { due to a lack of available programme } \\
\text { budget. }\end{array}$ & $\begin{array}{l}\text { The lower of } \\
€ 500,000 \text { or } 50 \% \\
\text { of the original } \\
\text { ERC proposal, } \\
\text { for up to } 24 \\
\text { months }\end{array}$ \\
\hline & New Horizons & Irish Research & For AHSS researchers: & Up to $€ 100,000$ \\
\hline & & Council & $\begin{array}{l}\text { 15-month 'Starter Grant' to provide } \\
\text { seed funding for an ERC grant in the } \\
\text { medium term } \\
15-24 \text { month 'Interdisciplinary Grant' } \\
\text { for AHSS researchers to collaborate } \\
\text { with STEM researchers on } \\
\text { interdisciplinary projects that would } \\
\text { address societal challenges under } \\
\text { Horizon 2020, or establish consortia } \\
\text { on upcoming topics across the } \\
\text { societal challenge pillar }\end{array}$ & Up to $€ 220,000$ \\
\hline & $\begin{array}{l}\text { Basic Research } \\
\text { Excellence Award }\end{array}$ & $\begin{array}{l}\text { Irish Research } \\
\text { Council }\end{array}$ & $\begin{array}{l}\text { Funding to non-funded AHSS } \\
\text { applicants to an ERC grant that } \\
\text { achieved an ' } A \text { ' rating. The award is } \\
\text { contingent upon intention to re-apply } \\
\text { to the ERC in the next available call. }\end{array}$ & $\begin{array}{l}\text { Between } € 60,000 \\
\text { and } € 100,000\end{array}$ \\
\hline Co-funding for & ERC Support & Science & Provides an additional overhead & \multirow[b]{2}{*}{$\begin{array}{l}€ 150,000 \text { is } \\
\text { offered for ERC } \\
\text { awards from a } \\
2015 \text { call or later, } \\
\text { regardless of } \\
\text { ERC scheme }\end{array}$} \\
\hline FP participants & Programme & Foundation Ireland & $\begin{array}{l}\text { payment to the Irish host institution } \\
\text { of ERC award winners, to assist the } \\
\text { successful implementation of ERC- } \\
\text { funded research. }\end{array}$ & \\
\hline
\end{tabular}

\section{Effectiveness}

In addition to examining Ireland's participation in the programme to date, the 2016 evaluation of Ireland's participation in Horizon $2020^{165}$ examined the relevance, adequacy and effectiveness of the support available to applicants and participants.

The evaluation found that the NCP network was well-regarded by those consulted. A majority of respondents to the survey conducted for the interim evaluation reported that their interaction with the NCP network had helped them to i) improve their understanding of critical success factors, ii) understand which calls to target, and iii) identify a specific opportunity relevant to their organisation. More than a third of respondents agreed that interaction with the NCP network had improved the implementation and impact aspects of their proposal. A comparative analysis between FP7 and Horizon 2020 revealed an increase in positive views of benefits of the different NCP functions, including being alerted to specific opportunities, understanding what calls to target, and making improvements to implementation aspects. The evaluation remarked that Ireland's less-dramatic reversal in success rates between Horizon 2020 and FP7, as compared with the programme overall, may reflect the investment in the support system and the growing experience of Ireland's

${ }^{165}$ C. Rosemberg Montes, P. Simmonds, M. Wain, K. Nielsen, "Interim evaluation of Ireland's Participation in Horizon 2020", DJEI, 2016 
research base. The evaluation also found general satisfaction among respondents with the wide-range of financial support measures that are available, and in particular the coordinator support grant and travel grant available from Enterprise Ireland.

Our interviewee suggested that the effectiveness of the support system lies in two main areas:

- $\quad$ The conscious development of the support structure has been overseen by strong political leadership over the last 10-15 years. Ireland follows an 'all-ofgovernment' (i.e. cross-departmental) approach to supporting Horizon 2020 participation, and publishes ambitious targets for participation. The all-ofgovernment approach to reaching these targets is underpinned by a set of metrics, and it was suggested that these metrics 'focus the mind' and productively bring together the bodies operating in the support structure.

- $\quad$ Taking a proactive approach to which parts of the programme to target and how was presented in two ways. The High-Level Group, chaired by DJEl was discussed in light of the political leadership for participation, focusing on 'bigger picture' aspects of where Ireland Inc. can or should participate. It was suggested that this group has been the proponent of pursuing more and larger-scale projects. In addition, the network of NCPs works proactively to build relationships with researchers and industry, implementing the 'how' of getting people involved. This is also backed by the special multidisciplinary team mentioned in section 0 , and is an extension of the remit of Enterprise Ireland to bring more industry into Horizon 2020 as the lead agency in that funds industry nationally.

\section{Lessons learned}

In addition to setting a significantly higher overall target for secured funding in comparison to FP7, Ireland has sought to increase the number of Irish coordinators, to build on the success of SME participation, and to improve performance in the ERC. The suite of support measures available to applicants and participants is set out rather clearly to support these goals, and depending on eligibility, financial support is available to academics, researchers and businesses.

In the interim evaluation of Ireland's participation in Horizon 2020, all support measures scored well for relevance, suggesting that they are well designed and oriented for the needs of Irish applicants and participants. The financial support for coordinators and travel for academic researchers were particularly well-regarded based on consultation for the evaluation, and scored best of all supports for effectiveness.

Our interviewee stressed the importance of the strong political leadership in driving the development of the system since FP5, setting the focus (i.e. pursuing larger strategic projects), and mobilising all relevant bodies. Ireland has, perhaps as a small system, been able to purposefully structure its network of NCPs and other experts to facilitate bringing both industry partners and national strengths (in, for example, ICT) to proposals.

Finally, the approach to setting Horizon 2020 funding targets for nationally-funded research centres, and making the consideration of European funding an eligibility criterion for some national research funding may prove important to building awareness and capability elsewhere in the research system. 


\subsubsection{Best practices for supporting FP participation - lessons for the Finnish context}

The Research and Innovation Council of Finland's review of the Finnish R\&I landscape for 2015-2020 identifies a low level of internationalisation in the Finnish innovation system as a weakness, and sets out an objective for a $50 \%$ increase in funding secured from Horizon 2020 in comparison to FP7. ${ }^{166}$ In order to reach this objective, the review suggests strengthening the support structures for participation, with a focus on increasing interaction between research and innovation stakeholders, including joint project preparation and the formation of international research consortia. ${ }^{167}$ There is also a significant focus on the internationalisation of Finnish SMEs and businesses.

The examination of support measures for participation in Horizon 2020 across highperforming Member States reveals a general trend away from generic support measures and toward more tailored support that addresses specific deficits, imbalances or areas of need. One Member State in particular (Austria) has ceased financial support to applicants, and realigned its budgets to provide more support and training in areas of need. Others (France, Germany, Ireland) offer financial support to reach specific goals, such as increasing the number of coordinators, or further internationalising the research and industry base. Others still offer examples of practice in supporting the participation of municipal and public sector actors in influencing decisions and research agendas (Denmark, Netherlands, Portugal). Reflecting the findings from the analysis of participation, it seems that Finnish actors are active in applying, but the quality of applications forms a bottle neck to the process. One important finding is that Finland fares rather evenly in Horizon 2020 applications for better or worse. It is clear especially SMEI in and in some of the focus areas that Finns are active in applying for projects, but the amount of applications does not turn into projects because of the mediocre success rate. Similarly looking at the success rates in national focus areas, which also contain JTI-earmarked applications as far they are included in the statistics, ${ }^{168}$ the applications in those areas do not fare particularly well either. A general point regarding the national focus areas is we have not had the data to specifically evaluate how strategic and far reaching the funded projects are in terms of advancing those particular topic areas in Finland or Europe. As such the raw application success is one observation, and due to timing of the analysis it does not inform us about the effectiveness of recent national activities directed towards development of those areas. All of this poses the question whether the problem is in the capability of applicants, finding a competitive consortium, or writing the actual application.

Focusing on the project level, we have no specific data on where do applications involving Finland fall short. There are however indications from the interviews and secondary sources, presented in the following table. The self-perceived strength of Finnish participants and applicants is proficiency in project management and delivery, but many of the stakeholders expressed their concern that Finnish actors lack in European networks and international focus that are a key in writing successful applications, and that it is very difficult for Finnish actors to express the European added value of their proposal. The NCPs have studied application evaluation feedback and concluded that the major discernible weaknesses in the surveyed sample from a couple of dozen applications from a handful of

\footnotetext{
${ }^{166}$ See Finnish Research and Innovation Policy Council, 2014

${ }^{167}$ Funding is available via the Ministry of Education and Culture, Ministry of Employment and the Economy, the Academy of Finland and Tekes to support the formation of international research consortia

${ }^{168}$ According to TEKES, the data quality varies between JITS
} 
organisations were presenting the overall approach and methodology, and the European added value or impact on specific and concrete terms. ${ }^{169}$

\section{FP proposal evaluation criteria and possible Finnish weaknesses}

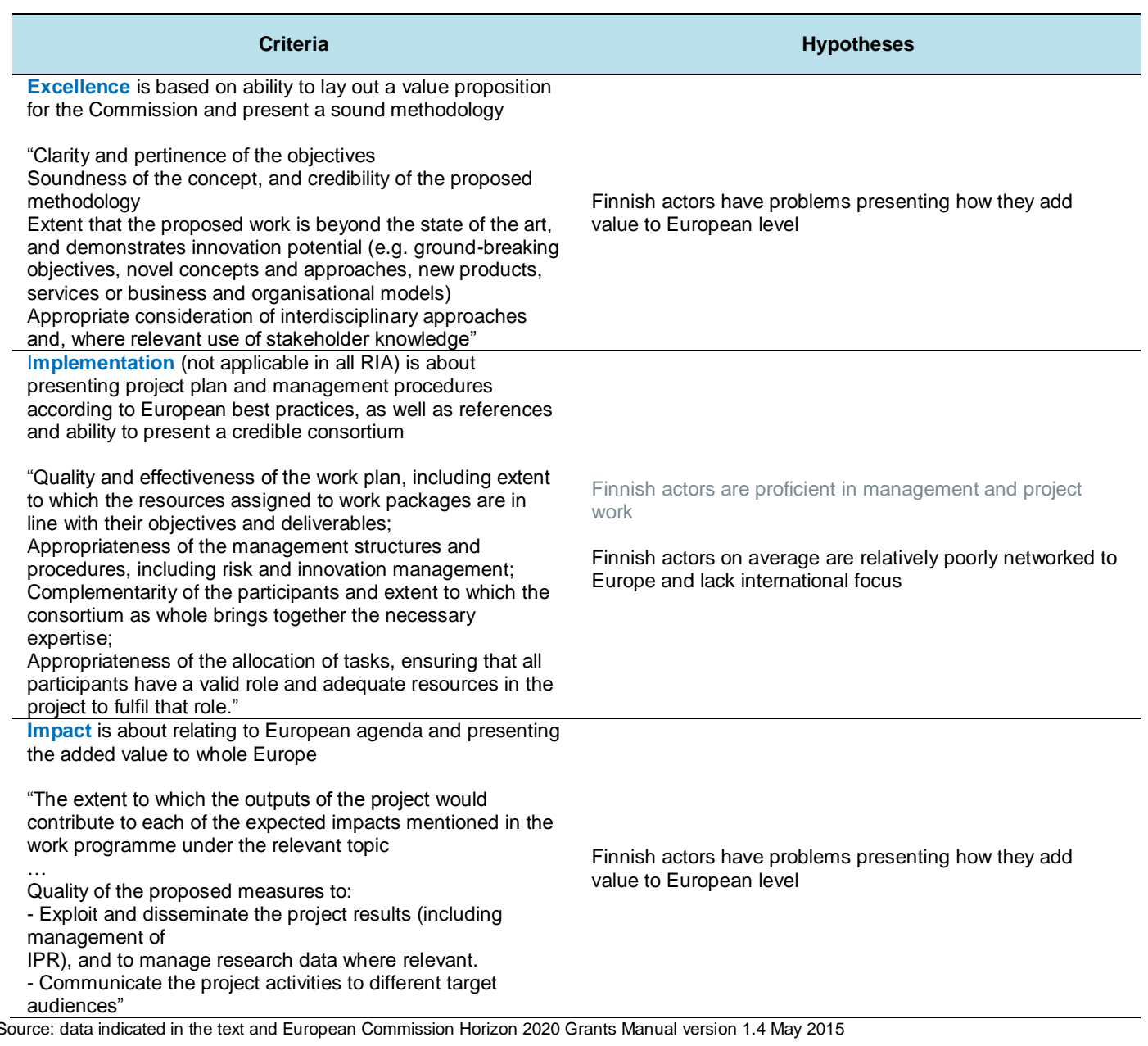

From the perspective of FPs, Finnish actors need to learn how to find partners and prepare high quality applications. A related fundamental question is that are Finnish actors viewed as interesting and capable or credible partners and applicants in Europe. Raising competence and capability nationally does not automatically turn into success in FPs, the capability for the pre-award phase is and likely will be even more important in the future. All of these questions are pertinent to future success of Finnish actors in the FP and innovation in general.

Relatedly, it would be useful to study the paths from national funding towards the EU more closely, especially from the perspective what type of instruments best encourage and build competence towards the FP and what is the optimum level of national RDI funding to gain maximum added value. While in general the continuum from national instruments to EU ones is viewed consistent, there is a question how the recent decrease in national applied research funding is changing the balance. The data both suggest, perhaps paradoxically, that on the one hand there is no harmful overlap and very little gaps between national instruments and the FP, and on the other that generous national funding with favourable conditions has at times acted as a disincentive for FP participation. Likely the reality is not either or, but rather both as different actors have different interests and funding needs which

${ }^{169}$ Holmberg, 2017 
change over time. At the level of an individual $R \& D$ team the rationality is clear, for a given set of goals, the incentive is towards the minimum of administration to raise adequate funds for attaining the specific objectives. If in this situation national funds are available without any conditions towards EU funding, the preference is like relatively strong towards the former and in effect national finding may crowd out EU funding. At the same time however, a lack of national funding and other support to enable building competence leaves some unable to access European funding. Giving an exhaustive answer would entail more study on the

Going further towards the $9^{\text {th }} \mathrm{FP}$, it is anticipated that mission oriented aspects of the programme are strengthened, which would mean more open-ended calls and focus on gathering strong consortia who have a clear value proposition for Europe. It is foreseen that FP9 will launch a small number of Big Missions, projects with high visibility to the general public and a potential for big societal and or economic impact. While it is not yet certain how this will be implemented, stakeholders across Europe will be lobbying to prioritise their specific theme as a potential Big Mission. This requires intensive networking activities, both at policy and participants level, prior to the launch of FP9.

It is also anticipated that in FP9 the activities of the European Innovation Council will be reinforced and even become one of the main pillars of FP9. It is a good sign that Finnish SMEs have done relatively well in the new SME instrument which is likely to be a strong feature in FP9. Finland also has a good position and relative long history in supporting startups, SMEs with a growth ambition and innovation through new business models. This new EU approach could be advantageous for the Finnish SME landscape. Finnish agencies and stakeholders should therefore pay close attention to the EIC pilot that has been launched for the remainder of $\mathrm{H} 2020$ with a budget of $€ 2.7$ billion, as it will set the scene for the EIC approach in FP9.

Further, alongside the traditionally open FP funding with calls for proposals open to all eligible proposers in the EU, an increasing share of the FP funding is taken up by so-called partnership programmes. These could be Public-to-Public Partnership programmes where part of the funding comes from research funders from the EU Member and Associated States as well as Public-Private Partnership programmes, where part of the funding comes from the private sector and the private sector has an important role in the governance of the programme. A recent study that has mapped these instruments on behalf of the Estonian government came to the conclusion that the total budget for these type of instruments is expected to take up $25 \%$ of the entire Horizon 2020 budget. ${ }^{170}$

One of the main conclusions of the report is that there is a lack of transparency on the decision-making processes to launch these instruments and their individual thematic initiatives. Member States do not always have an active role or even the necessary information to assess the potential interest of these instruments, particularly the public private partnership instruments as JTUs and the contractual PPPs.

In the preparation for FP9 the position of these partnerships instruments has become a discussion point between Member States (through the European Council) and the Commission. For Finland, it is important to decide what role it wants to play in these instruments that use a variable geometry principle.

Another large question is how can the acceptance rate of applications be improved, that should be studied before designing new instruments or taking other major action trying to

${ }^{170}$ Boekholt, Romanainen and Madubuko, 2017. 
improve acceptance/success rate. Granted, the FP is competitive and there is some arbitrariness in the process. The findings still beg the question, what are the main bottle necks, the leading questions being is the problem in lack of serious interest for applying EU funding, perceived competence or lack thereof of Finnish partners, lack of international visibility and networks, trouble finding credible partners, or lack of skill in writing. The bottle neck might be any one or a combination of these factors, and effectiveness of actions to raise success rate hinges on finding the right problem.

Taking the above summary points of the Finnish report, we see that there are several lessons to be drawn from best practice that are applicable to Finland:

- $\quad$ Supporting quality of applications. Several Countries have a system for quality assurance and support for application writing. For example, the Spanish NPC network is reachable throughout the country and offers quality assurance and coaching for the applications.

- Increasing interaction between research and innovation stakeholders. Member States are seen to mobilise a combination of financial support and 'softer' support. A number of examples exist of support for joint project preparation and the formation of international research consortia. In particular, the development of an Irish multi-disciplinary industry team exemplifies the role of NCPs as proactively building relationships with and between industry and research partners, with the team particularly working to mobilise expertise from across the system to support such projects

- Internationalisation of SMEs and businesses. Germany's national funding for support to Horizon 2020 applicants is focused entirely around the internationalisation of its research and business base, offering support to applicants to develop collaborative projects with partners in key strategic geographies (Central and South-Eastern Europe, North and South America, and the Asia-Pacific). More generally, many Member States offer differentiated amounts of support for industry partners within their suite of financial support for producing proposals. Dedicated schemes are less common, though there is evidence of the use innovation voucherstyle funding to facilitate SMEs to access academic and research expertise, though uptake appears to be mixed 


\section{CONCLUSION AND RECOMMENDATIONS}

\subsection{Conclusions}

Determined investment into research and innovation are at the core of EU policies for sustainable growth and competitiveness, and the EU framework programmes for research and innovation are the main delivery mechanisms of those policies. The FP is seen as a tool for the renewal of industry and society, and a booster for economic growth at the European level, which is well aligned with Finnish RDI policy.

Over time, every new FP has brought an increase in the volume of available EU funding and variety of instruments for research and innovation. The latest FP, the Horizon 2020, has taken particularly large steps in this direction. The budget has been increased to nearly $€ 80$ billion, and its objectives are more directly linked to EU's societal and industrial challenges. It also made a significant attempt to better address the needs of SMEs (through the SME instrument) and academic research of the highest standard (through ERC).

With its considerably larger budget and new instruments, Horizon 2020 has become increasingly attractive to all kinds of research organisations. When at the same time most European countries have faced a series of cuts in national RDI budgets, the popularity of Horizon 2020 has further increased as an alternative funding source. This has in turn resulted in higher application volumes for Horizon 2020, and consequently lower average success rates than in previous FPs.

Finnish organisations have been active in applying for funding from Horizon 2020. By the end of May 2017, there have been nearly 7,000 proposals with Finnish participants, equal to $5.4 \%$ of all proposals submitted to the programme during this period.

Unfortunately, Finnish success rate remains at an average, or even slightly below the average level, when compared to similar types of economies (SE, DK, AT, NO, IE, NL). However, due to relatively large number of applications, Finland's total funding drawdown ( $€ 579$ million) is still larger than its calculated share of payments towards the FP.

The analysis shows that the FPs have brought a clear added value for Finnish participants, and the participants are generally very satisfied with their experience and results of participation. The projects have contributed towards new knowledge, skills, international networks, and technology development.

The direct economic impact of FP projects to participant companies appears positive, although the margin of error in the analysis is large. FP funding in isolation has a similar economic impact than national RDI funding. According to the survey, for most participants the economic benefits from the projects surpass the invested sums.

The specific conclusions regarding national impact and added value of Horizon 2020 by each specific question posed for the evaluation are as follows: 


\section{Q1. What kinds of benefits have been obtained to date particularly from the Horizon 2020 programme?}

Participants in the FP have been generally very satisfied with their participation and in most cases the benefit from the participation has exceeded the investment.

The most pronounced benefit from the EU FPs have been:

- $\quad$ generation of new knowledge and capabilities, followed by

- $\quad$ international contacts and networks, that in turn enable

- $\quad$ access to new information, capabilities, and markets.

Especially from the industry perspective, collaborative (Research and) Innovation Actions enable working with potential customers and users to develop solutions that are tailored to the target market and also enable learning about preferences and markets.

European programmes also expose national actors to new level of competition scientifically and commercially and raise the bar for participants. Also in doing so, FP projects offer a showroom window to display Finnish capabilities and earn prestige.

\section{Q2. What parts of the programme and forms of activity are best for a small economy like Finland, also in relation to Finnish RDI policy focus areas?}

Finnish strength in applying for FP finding is evenness. There is no specific niche where participation would have been orders of magnitude more successful. The strongest successes have been achieved in those (sub-) programmes where there is a clear concentration of national capability, particularly Energy and ICT. Also the total drawdown from the SME-instrument is substantial, despite the comparatively low acceptance rate of applications. This in fact illustrates the Finnish paradox, almost across the board Finnish application success rate trails behind comparable countries, but due to relatively high volume of activity, drawdown in per researcher or normalized by GDP for example is roughly on par with the comparison.

The analysis of success in national focus areas (Health \& Wellbeing, Digitalisation, and BioCircular Economy) shows these areas fare no better or worse. These areas were chosen late 2016 and the participation data end in early 2017, so the current results form a baseline view of success.

In broader view, greater benefits have been reaped through national ecosystems, which spread the knowledge generated and acquired in FP projects within the national framework. The ecosystem cases (Section 4 above) demonstrate how consistent investment in particular technology areas by different types of actors create new research and business opportunities, and also support renewal of incumbent enterprises.

\section{Q3. What kind of social, economic or environmental impacts are perceptible/achievable with the programme or with Finnish projects funded from it?}

According to the participants' perceptions, among the chief benefits are increase in knowledge and development of new technologies. These are followed by new products and services. In terms of social impacts, participants have found a noticeable or strong 
contribution towards employment and an even stronger contribution towards solving social challenges.

These perceptions are supported by interviews which propose that, broadly speaking, solving societal challenges in built in the programs in terms of specific goals for developing energy saving, environmentally friendlier, and more accessible technologies, services and other solutions. This notion is also consistent with participants finding that the FPs also contribute to finding new strategic directions and goals.

\section{Q4. What has been the financial performance of businesses that received funding from EU framework programmes?}

The econometric analysis assessed the impact of EU funding with a five-year window after funding, with the matching year being the one before. The examined dependent variables were turnover, employment, productivity, investments and exports. The results of analysis were positive, but due to limited sample size not statistically significant. To put the effect into scale, the net economic impact of FP funding in isolation from other instruments is similar to national RDI funding. There is however some uncertainty in making strong conclusion on this point due to limitations in the data.

More significant effect was found for compounded funding, i.e. for those enterprises that have been granted national and various types of EU funding. This finding may be subject to some selection bias, as in applicants of various programmes have more experience in applying for funding by default and they are also a self-selected group that have chosen to apply for subsidies time and again. However, it also suggests that there is synergy between national and EU funding.

\section{Q5. What kind of innovation effects have arisen from projects of research institutes and universities that received funding from EU framework programmes?}

The participants report FP projects have contributed towards new technologies, services and products, and to a lesser degree towards new business ventures and IP. These effects arise in many cases through collaborative effort with enterprises.

However, the ecosystem cases also illustrate another vector through contribution to and even creation of innovative ecosystems. The VTT case and particularly PrintoCent illustrates a development path of an ecosystem based on (partially) EU-funded research and the case of FiCEIP illustrates how basic research also contributes towards creation of innovative spin-offs.

\section{Q6. How should, for example, EU preparatory and co-funding and the role of national funding organisations be further developed?}

Stakeholders are generally very satisfied with the content and professionalism of Finnish NCP services. The main bottle neck in the support system are dearth of resources committed to the NCP activities. The stakeholder views towards private professional support services for application and use of EU-funding colloquially known as 'EU advisors/consultants' are variable.

In terms of international comparison, the portfolio of Finnish FP participation support measures is average among the investigated countries. Contrasting with the best practice cases, the well-performing countries have a clear strategy towards the FP with specific goals and monitoring systems. The NCPs also act proactively through the life-cycle of the 
application to identify potential participants and build consortia, to support preparation of the application, assist in contract negotiation and analyse evaluations to identify potential second round applicants and develop services even further.

As for pre-award funding for proposal preparation, the support is equivocal. Both nationally and in the comparison group, the finding has been that grants for proposal preparation tends to increase number of submitted proposals, but does not correlate as strongly with quality of application and thus the relationship to funded projects is tenuous. Based on the cases, the case is for pre-award grants is best supported if there is a dearth of applications. However, the analysis of participation may suggest, the bottle neck in Finland is not lack of activity in submitted proposals inasmuch acceptance rate. Further, this is contraindicated by the observations that qualitatively the commitment of the applicants and their genuine interest in European collaboration plays a large role in successful applications.

For the last aspect of this question that concerns national funding organisations, the stakeholders uniformly across all respondent groups and levels indicate that a clear national and EU RDI strategy would help coordinate efforts and align RDI efforts and investments towards national and EU profiles. This view is also supported by the best practice cases discussed above, and in the best systems the strategy is coupled with yearly monitoring to enable corrective measures. Going deeper into the stakeholder views, perhaps what is needed is a forum for setting and negotiating directions for RDI strategy and policy, rather than a mere paper that expresses some goals. As of now the stakeholders express worry over lack of direction and ownership or leadership in RDI strategy, which perhaps coincides with the lack of a forum for discussing these matters.

\section{Q7. What kind of conclusions relating to effectiveness are available from comparable countries?}

The main benefits of FPs in terms of international contacts and networks, visibility and prestige, development of market knowledge and so on are very robust and consistent between comparable countries and over time.

The findings and conclusions of this evaluation discussed immediately above are consistent both with earlier findings on contribution of EU FPs and also with earlier research literature on impact of RDI subsidies.

As such the turn of Horizon 2020 to a Framework Programme for Research \& Innovation from the earlier Research and Technology Demonstration has not for the time being had a strong effect on the goals of the participants or the outcome and impact of FP projects; the main goals and outcomes are still in Finland and have been elsewhere quite heavily focused on pre-commercial development and less direct product and service development or other commercial outputs, SME instrument and specific demonstration projects notwithstanding.

\subsection{Recommendations}

\section{Recommendation 1: Continue to elaborate a clear national RDI strategy towards the EU and FPs}

The stakeholders strongly suggested that a clear national EU RDI strategy be elaborated. It is therefore recommended that further work is done to clarify the national focus areas in relation to present and future FPs, and to enable the stakeholders to position themselves towards the national goals. The strategy work should further clarify the vision, priorities and 
targets for FP participation in the future FPs, including what are the specific goals for the participation in terms of science, industry and society, and what is the ambition level in terms of drawdown and application success. A well-communicated and participatory strategy process would increase the awareness of, and commitment to national priorities amongst various stakeholders, and hence facilitate for more synchronised and effective implementation. Lastly, it is important that the implementation of the strategy is regularly monitored with participation statistics, etc., to ensure its effectiveness.

\section{Recommendation 2: Analyse the root cause of low application success rate}

One of the key findings of the evaluation is that the Finnish application success rate is lower than expected, and therefore further work is needed to address the exact cause before design of new instruments or actions. Systematic analysis of evaluation feedback, applications and consortia is needed to form a complete picture what is the general quality level of applications and distribution of scores, and reasons for low and high scores. For example, whether the framework programme is able to attract the internationally most competitive researchers and research organisations, what are the compositions of typical consortia with Finnish participants, and what is the technical and substance quality of applications, in order to identify the strengths and weaknesses of the Finnish applications.

There are several suggested and conceivable reasons why Finnish application success is lower than expected. These hypotheses include, among others, the lack of skills in application writing, lack of appropriate partners, and lack of substance/competence. One level deeper, lack of potential partners may be, again, because of lack of international orientation, because Finnish actors may not be viewed as potential partners, lack European added value, and so on. Understanding which of these or other factors are significant in affecting evaluation of Finnish applications is a key for finding the right problem to address and subsequently the right instruments when trying to raise application success rate.

\section{Recommendation 3: Strengthen the support measures for FP participation}

The present NCP activity is very well-rated; however, the challenge is its lack of resources to fully commit to the work. In some of the comparison countries NCPs engage in finding potential applicants especially in the national focus areas, consortium building and application development, and track down near misses for another round of submission. Which is something that would likely help address the Finnish challenges.

In broader view, the path from national funding instruments to FP needs to be further examined. Based on the evidence, the largest benefits come from projects that relate to existing national RDI activity and programming. In the past, some of the best results have been achieved when national instruments have acted as accelerators towards the FP. However, again national funding should not pose a disincentive for applying EU funding. There is as much evidence that parallel/concurrent national programmes lower the interest in FPs as there is for the finding that sequential national programmes enable attracting FP funding. Thus, it is recommended to examine the synchronicity between content themes and timing of future national programming and ecosystem policy and the FP to enables growing a mass of potential participants.

Another layer is at the level of individual applicant. There are some suggestions that some actors already try to identify potential future applicants early when actors start using national funding. This should be developed further, so that desk officers in Tekes and Academy routinely assess future European potential of their clients and direct them towards relevant information and experts. 
However, the support system should not be an end unto itself. Each type of instrument and action have a specific purpose and impact logic. Thus, it is recommended that the reasons why Finnish applications fail are carefully studied. While at the moment the hypothesis is that the Finnish problem is quality of applications, and the instruments should target consortium building and application writing, this may change in the future and there should be a feedback system to systematically gather information about application volume and acceptance rate and monitor the application quality i.e. evaluation feedback of the application to enable proactive redirection of support activities.

\section{Recommendation 4: Leverage best practices in FP application and participation}

Participation activity and application success in the framework programmes do not spread evenly across all organisations. It is the largest research organisations, top universities and knowledge-intensive companies that take the major share of all Finnish participations and also demonstrate higher success rates with proposals. These organisations often have a long record of professional research, high overall volumes of research and a history of international research collaboration. More importantly, they have accumulated vast amounts of experience and practice from participating in EU framework programmes - understanding how to identify relevant themes and topics, which kind of partners to look for, how to organise proposal preparation, how to write successful proposal, and how to manage and coordinate projects successfully, etc.

In the interest of increasing the overall level of participation success, this accumulated competence and practices should be leveraged as much as possible. Our largest public research organisations, such as VTT, already act as a major FP application hub and project coordinator for many other organisations. Similar trends should be encouraged and expanded to other organisations as well. Thus it is recommended to build on existing strong ecosystems and encourage the formation of new ones. 


\section{REFERENCES}

Arnold, E. et al. (2008) Impacts of the Framework Programme in Sweden, Vinnova, .... Stockholm: VINNOVA (VA 2008:11).

Arnold, E. et al. (2010) 'Evaluation of Austrian Support Structures for FP 7 \& Eureka and Impact Analysis of EU Research Initiatives on the Austrian Research \& Innovation System - Final Report', (November).

Åström, T. et al. (2012) On motives for participation in the Framework Programme. Technopolis Group.

Åström, T. et al. (2016) Reaping Benefits of EU Framework Programmes: Evaluation of Tekes 'Safety and Security and Fuel Cell Programmes. Helsinki, FI. Available at:

https://www.tekes.fi/globalassets/julkaisut/3_2016_reaping-benefits-of-eu-framework-programmes.pdf.

Boekholt, P. et al. (2009) Impact Europese Kaderprogramma's in Nederland. Technopolis Group.

Boekholt, P., Romanainen, J. and Madubuko, T. (2017) Increased coherence and openness of European Union research and innovation partnerships. Tallinn, EE.

DIMECC Oy (no date) DIMECC - Company. Available at: https://www.dimecc.com/company/ (Accessed: 24 October 2017).

Dorst, H., Deuten, J. and Horlings, E. (2016) The Dutch science system in the European Research Area. Available at: https://www.rathenau.nl/en/publication/dutch-science-system-european-researcharea (Accessed: 30 October 2017).

Ehardt-Schmiederer, M. et al. (2014) Entwicklung und Demonstration (2007-2013) - PROVISO-

Bericht. Wien: PROVISO c/o BMWF.

European Commission (2014) Horizon 2020: First Results, Research and innovation. doi: $10.2777 / 420545$.

European Commission (2017) In-Depth Interim Evaluation of Horizon 2020. SWD(2017) 220 final. Brussels, BE. Available at:

https://ec.europa.eu/research/evaluations/pdf/archive/h2020 evaluations/swd(2017)220-in-depthinterim evaluation-h2020. pdf\#view=fit\&pagemode=none.

FFG (2016) Überblicksbericht zu Österreich in Horizon 2020. Wien: Österreichische Forschungsförderungsgesellschaft mbH (FFG).

FFG (2017) Überblicksbericht zu Österreich in Horizon 2020. Wien: Österreichische Forschungsförderungsgesellschaft mbH (FFG).

Fresco, L. O., Martinuzzi, A. and Wiman, A. (2015) COMMITMENT and COHERENCE essential ingredients for success in science and innovation. Ex-Post-Evaluation of the 7th EU Framework Programme (2007-2013).

Fröberg, J. and Karlsson, S. (2008) 'Possible effects of Swedish participation in EU frame programmes 3-6 on bibliometric measures', in Arnold, E. et al. (eds) Impacts of the Framework Programme in Sweden.

Heckman, J. J. and Smith, J. A. (1999) 'The Pre-programme Earnings Dip and the Determinants of Participation in a Social Programme. Implications for Simple Programme Evaluation Strategies', The Economic Journal, 109(457), pp. 313-348.

Holmberg, E. (2017) Älä tule paha hakemus, tule hyvä hakemus. Helsinki. Available at:

https://www.tekes.eu/ajankohtaista/blogit/elina-holmberg-ala-tule-paha-hakemus-tule-hyva-hakemus/ (Accessed: 20 November 2017).

Karhunen, H. and Huovari, J. (2015) 'R\&D subsidies and productivity in SMEs', Small Business 
Economics, 45(4), pp. 805-823. doi: 10.1007/s11187-015-9658-9.

Kern, M. et al. (2014) Impact of Swiss Participation in the Seventh European Framework Programme for Research. State Secretariat for Education Research and Innovation SERI.

Lähteenmäki-Smith, K. et al. (2013) "Licence to SHOK?" - External Evaluation of the Strategic Centres for Science, Technology and Innovation, MEE Publications. Available at:

http://www.tem.fi/julkaisut?C=98033\&xmid=4981.

Langfeldt, L. and Kaloudis, A. (2009) In Need of a Better Framework for Success: An Evaluation of the Norwegian participation in the EU 6th Framework Programme (2003-2006) and the first part of the EU 7th Framework Programme (2007-2008). Oslo: NIFU STEP.

Loikkanen, T. et al. (2013) Roles, effectiveness, and impact of VTT: Towards broad-based impact monitoring of a research and technology organisation. Espoo, Finland.

MEAE (2016) Tekesin ja suomen akatemian komiteajäsenten vastaukset FP9 kannanmuodostuksen pohjaa varten. Helsinki.

MHES (2015) Effects of participation in EU framework programmes for research and technological development - for researchers, institutions and private companies in Denmark. Copenhagen: Ministry of Higher Education and Science.

Ministry of Economic Affairs (2014) Global challenges Dutch Solutions. Available at:

https://www.government.nl/documents/reports/2014/01/21/global-challenges-dutch-solutions

(Accessed: 30 October 2017).

Pajarinen, M., Rouvinen, P. and YIhäinen, I. (2017) Onko IMD:n ja WEF:n kilpailukyky-raporteista politiikanteon tueksi? 51/2017. Helsinki, FI.

Pirkanmaan liitto (no date) Innovaatioekosysteemi. Available at:

http://www.pirkanmaa.fi/innovaatioymparisto/innovaatioalustat/ (Accessed: 24 October 2017).

Rosemberg, C., Wain, M., et al. (2016) Ex-post evaluation of Ireland's Participation in the 7th EU Framework Programme. Technopolis Group.

Rosemberg, C., Simmonds, P., et al. (2016) Interim evaluation of Ireland's Participation in Horizon 2020. Technopolis Group.

SMACC (no date) Home - SMACC. Available at: http://smacc.fi/en/ (Accessed: 24 October 2017).

Suomen Akatemia (2016) Tieteen tila 2016. Helsinki. Available at: http://www.aka.fi/fi/tiedepoliittinentoiminta/tieteen-tila/ajankohtaista/tieteen-tila-2016/ (Accessed: 16 November 2017).

Takalo, T., Tanayama, T. and Toivanen, O. (2013) 'Estimating the benefits of targeted R\&D subsidies', Review of Economics and Statistics, 95(1), pp. 255-272.

Technopolis (2009) Evaluation of Framework Programme 6 in Ireland. Dublin: Forfás.

Technopolis (2010) Evaluation of Danish Participation in the 6th and 7th Framework Programmes. Copenhagen: Danish Agency for Science, Technology and Innovation (DASTI).

The Lund Declaration - July 2009 (2009). se2009.eu.

Uusimaa-ohjelma: Vision ja Strategia 2040, Strategiset valinnat 2014-2017 (2013). Helsinki, FI.

Available at: https://www.uudenmaanliitto.fi/files/12115/Uusimaa-ohjelma A27-

2013 valtuuston hyvaksyma.pdf (Accessed: 24 October 2017).

Viljamaa, K. et al. (2013) 'Impact of Tekes Activities on Productivity and Renewal', p. 83. Available at: http://www.tekes.fi/Global/Nyt/Uutiset/Productivity and renewal

2013.pdf\%5Cnhttp://www.tekes.fi/nyt/uutiset-2013/tuoreita-tutkimuksia-yritystukien-

tuottavuusvaikutuksista1/.

Viljamaa, K. et al. (2014) Impact of Tekes Activities on Productivity and Renewal. 315/2014. Helsinki, FI: Finnish Funding Agency for Technology and Innovation - TEKES. Available at:

http://www.tekes.fi/Global/Nyt/Uutiset/Productivity and renewal 2013.pdf. 
VTT (2015) General Brochure. Available at:

http://www.vttresearch.com/Documents/vtt about us/presentation material/vtt general brochure eng lish.pdf.

VTT Oy (2016) VTT-katsaus 2016, 17 Mar, 2016. Espoo, Finland.

VTT Oy (no date) VTT 2016-2020. Available at: http://www.vtt.fi/tietoa-meistä/strategia (Accessed: 24 October 2017).

World Economic Forum (2017) 'Country/Economy profile Finland', in Global Competitiveness Report 2015-2016. World Economic Forum, pp. 168-169. Available at: http://reports. weforum.org/globalcompetitiveness-report-2015-2016/economies/\#economy=FIN (Accessed: 16 November 2017).

Ylhäinen, I., Rouvinen, P. and Kuusi, T. (2016) Katsaus yksityisen t\&k-toiminnan ja sen julkisen rahoituksen vaikuttavuuteen. 57/2016.

Zúñiga-Vicente, J. Á. et al. (2014) 'Assessing the effect of public subsidies on firm R\&D investment: a survey', Journal of Economic Surveys, 28(1), pp. 36-67.

The Department of Jobs, Enterprise and Innovation, "EU Framework Programme for Research and Innovation (2014-2020). Ireland's Strategy and Target for Participation”, 2014

The Department of Jobs, Enterprise and Innovation, "National Research Prioritisation Exercise: First Progress Report", 2014

The Department of Jobs, Enterprise and Innovation, “Innovation 2020”, 2015

Enterprise Ireland, “Strategies to maximise participation in Horizon 2020”, 2013

European Commission Directorate-General for Research and Innovation, "Horizon 2020 First Results", 2015

European Commission Joint Research Centre, "Research \& Innovation Observatory Country Report Ireland", 2015

Science Foundation Ireland Annual Plan, 2015

C. Rosemberg Montes, P. Simmonds, M. Wain, K. Nielsen, “Interim evaluation of Ireland's

Participation in Horizon 2020", DJEI, 2016

Knowledge Coalition, “Dutch National Research Agenda”, 2016

Ministry of Economic Affairs and Ministry of Education, Culture and Science, "Global Challenges,

Dutch Solutions", 2014

Ministry of Economic Affairs, "Top Sectors in the Netherlands", 2015

OECD, "OECD Reviews of Innovation Policy: Netherlands”, 2014

The Netherlands' position paper on the Interim Evaluation of Horizon 2020

Presentation: CDTI'S support to the participation in European projects, Javier García Serrano CDTI, La Granja, April 2016

Presentation: An approach to stimulate participation in Framework Programs and International Cooperation Programs, Javier García Serrano, CDTI, Warsaw, April 27th 2016

CDTI institutional presentation, Madrid, 20th September 2015 


\section{APPENDIX A: DETAILED PARTICIPATION ANALYSIS}

\section{Introductory notes}

This section presents statistics and analysis of the profile and patterns of Finnish participation in Horizon 2020, including comparisons with performance in FP7 and amongst five selected comparator countries: Austria (AT), Denmark (DK), Ireland (IE), Netherlands (NL), Norway (NO), and Sweden (SE). The analysis presented is based on eCORDA databases of proposals and grants covering the entirety of FP7 and the first three years of Horizon 2020 (data extracted 31st May 2017).

While the initial analysis presented in the section covers FP7/H2020 overall, we then focus on participation in relation to the three study areas of Health \& Wellbeing; Cleantech, Bioeconomy and Circular Economy (CBC); and Digitalisation. That analysis is based on our screening and tagging of proposal titles and abstracts as relevant to each of these thematic areas, as described in Appendix A (semantic analysis).

Throughout this section, we use shading to indicate comparator country figures that are greater than Finland. This helps to quickly visualise the locations of greatest activity / success, as well the extent to which Finland is over- / underperforming in comparison with this wider peer group.

Where we weight participation data by the number of FTE researchers in each country, we use UNESCO Institute of Statistics figures on the total number of R\&D personnel (FTE). For FP7, an average is taken of the years 2007 to 2013, while for Horizon 2020 we take an average for 2014 to 2015 (latest available data).

Table 2 Total R\&D personnel (FTE) per country - used for weighting of participation data

\begin{tabular}{llllllll}
\hline & FI & AT & DK & IE & NL & NO & SE \\
\hline 2007 & 56,243 & 53,252 & 46,897 & 18,157 & 93,788 & 33,635 & 75,318 \\
\hline 2008 & 56,698 & 58,014 & 58,589 & 20,018 & 93,432 & 35,487 & 79,549 \\
\hline 2009 & 56,069 & 56,438 & 55,918 & 19,705 & 87,874 & 36,091 & 77,363 \\
\hline 2010 & 55,897 & 59,923 & 56,623 & 19,722 & 100,544 & 36,121 & 77,418 \\
\hline 2011 & 54,526 & 61,171 & 57,585 & 21,591 & 117,436 & 36,950 & 78,445 \\
\hline 2012 & 54,047 & 64,550 & 57,734 & 22,607 & 122,215 & 37,707 & 81,272 \\
\hline 2013 & 52,972 & 66,186 & 58,246 & 24,129 & 123,206 & 38,536 & 80,957 \\
\hline 2014 & 52,130 & 67,135 & 58,745 & 28,379 & 123,096 & 40,297 & 83,473 \\
\hline 2015 & 50,367 & 69,318 & 60,030 & 29,444 & 128,327 & 42,695 & 84,523 \\
\hline FP7 (2007-2013 average) & 55,207 & 59,933 & 55,942 & 20,847 & 105,499 & 36,361 & 78,617 \\
\hline $\begin{array}{l}\text { Horizon 2020 (2014 \& 2015 } \\
\text { average) }\end{array}$ & 51,249 & 68,227 & 59,388 & 28,912 & 125,712 & 41,496 & 83,998 \\
\hline Source: UNESCO Institute of Statistics & & & & & & &
\end{tabular}

Where we weight financial data by the GDP in each country, we use Eurostat figures on the GDP at market prices. For Horizon 2020 comparisons the figure for 2015 is used (latest available data).

Table 3 Gross Domestic Product per country at market prices, 2015, Emillion

$\begin{array}{lllllll}\text { FI } & \text { AT } & \text { DK } & \text { IE } & \text { NL } & \text { NO } & \text { SE }\end{array}$




\begin{tabular}{|c|c|c|c|c|c|c|c|}
\hline Horizon 2020 (2015 figure) & 209,581 & 339,896 & 271,786 & 262,037 & 683,457 & 348,332 & 447,010 \\
\hline
\end{tabular}

\section{Overall participation patterns}

\section{Participation in proposals}

Finnish actors have contributed to the submission of 6,986 proposals to Horizon 2020 (as of the end of May 2017). This equates to $5.4 \%$ of all proposals submitted to the programme during this period. This is currently slightly lower than the proportion of FP7 proposals involving Finland (6.1\%). As is shown in Table 4, four of the six comparator countries have participated in a greater number and proportion of Horizon 2020 proposals than Finland. However, when taking into account the number of R\&D personnel in each country, the level of Finnish involvement in Horizon 2020 proposals compares more favourably with all-butone of the comparator countries. This is an improvement on FP7, when Finland's relative involvement in proposals (per researcher) was lower than all countries except DK.

Table 4 FP7/Horizon 2020 proposals involving Finland comparator countries

\begin{tabular}{|c|c|c|c|c|c|c|c|c|}
\hline Horizon 2020 & All & $\mathrm{FI}$ & AT & DK & $\mathrm{IE}$ & $\mathrm{NL}$ & NO & SE \\
\hline $\begin{array}{l}\text { Number of proposals } \\
\text { involving... }\end{array}$ & 129,513 & 6,986 & 8,087 & 7,740 & 5,495 & 16,644 & 4,921 & 9,562 \\
\hline $\begin{array}{l}\text { Proportion of all } \\
\text { proposals involving... }\end{array}$ & $100 \%$ & $5.4 \%$ & $6.2 \%$ & $6.0 \%$ & $4.2 \%$ & $12.9 \%$ & $3.8 \%$ & $7.4 \%$ \\
\hline $\begin{array}{l}\text { Number of proposals per } \\
1,000 \text { researchers in... }\end{array}$ & & 136 & 119 & 130 & 190 & 132 & 119 & 114 \\
\hline FP7 & ALL & FI & AT & DK & IE & NL & NO & SE \\
\hline $\begin{array}{l}\text { Number of proposals } \\
\text { involving... }\end{array}$ & 158,609 & 9,671 & 12,104 & 9,323 & 7,440 & 23,076 & 7,081 & 15,274 \\
\hline $\begin{array}{l}\text { Proportion of all } \\
\text { proposals involving... }\end{array}$ & $100 \%$ & $6.1 \%$ & $7.6 \%$ & $5.9 \%$ & $4.7 \%$ & $14.5 \%$ & $4.5 \%$ & $9.6 \%$ \\
\hline $\begin{array}{l}\text { Number of proposals per } \\
1,000 \text { researchers in... }\end{array}$ & & 175 & 202 & 167 & 357 & 219 & 195 & 194 \\
\hline
\end{tabular}

In $46 \%$ of Horizon 2020 proposals involving Finland, a Finnish actor has held the role of coordinator. This is a higher rate than was seen during FP7, where just $33 \%$ of Finnish proposals were led by a Finnish coordinator. Most comparator countries have seen a similar increase between the two programmes, but Finland's rate of proposal coordination in Horizon 2020 is now higher than all comparators. This is a significant improvement on FP7.

Taking account of the relative size of the researcher populations in each country, the number of Horizon 2020 proposal coordinators from Finland is below the rate seen in IE, but above that seen in all other comparators. By comparison, the Finnish rate in FP7 only compared favourably with Denmark.

Table 5 FP7/Horizon 2020 proposals with a 'domestic' coordinator

\begin{tabular}{lllllllll}
\hline Horizon 2020 & All & FI & AT & DK & IE & NL & NO & SE \\
\hline $\begin{array}{l}\text { Number of proposals with } \\
\text { domestic coordinator }\end{array}$ & 129,513 & 3,185 & 2,479 & 3,438 & 2,419 & 6,835 & 2,031 & 3,658 \\
\hline $\begin{array}{l}\% \text { of country's proposals with } \\
\text { domestic coordinator }\end{array}$ & $100 \%$ & $46 \%$ & $31 \%$ & $44 \%$ & $44 \%$ & $41 \%$ & $41 \%$ & $38 \%$ \\
\hline $\begin{array}{l}\text { Coordinators per 1,000 } \\
\text { researchers }\end{array}$ & 62 & 36 & 58 & 84 & 54 & 49 & 44 \\
\hline
\end{tabular}




\begin{tabular}{|c|c|c|c|c|c|c|c|c|}
\hline FP7 & ALL & FI & AT & DK & IE & NL & NO & SE \\
\hline $\begin{array}{l}\text { Number of proposals with } \\
\text { domestic coordinator }\end{array}$ & 158,571 & 3,219 & 3,711 & 3,145 & 2,677 & 8,478 & 2,309 & 5,337 \\
\hline $\begin{array}{l}\% \text { of country's proposals with } \\
\text { domestic coordinator }\end{array}$ & $100 \%$ & $33 \%$ & $31 \%$ & $34 \%$ & $36 \%$ & $37 \%$ & $33 \%$ & $35 \%$ \\
\hline $\begin{array}{l}\text { Coordinators per } 1,000 \\
\text { researchers }\end{array}$ & & 58 & 62 & 56 & 128 & 80 & 64 & 68 \\
\hline
\end{tabular}

Many FP proposals (66\% in Horizon 2020) involve just one participant, who is therefore by default also the coordinator. This is particularly the case in some areas of the programme (e.g. nearly all of the 19,000 proposals to the European Research Council involve just one participant). These single-participant proposals can therefore give a misleading picture of true proposal coordination rates. If we repeat the above analysis of proposal coordination, but just for multi-partner proposals (i.e. excluding proposals with only one partner), the data changes significantly.

Finland has participated in 4,796 multi-partner Horizon 2020 proposals, of which it was the coordinator in 995 ( $21 \%$ of) cases. This is a higher rate than any of the comparator countries, other than Ireland, and slightly higher than was achieved by Finland in FP7. The Finnish rate of multi-partner proposal coordination in Horizon 2020, relative to the FTE researcher population (19 coordinators per 1,000 FTE), is also higher than most comparator countries, other than IE and NL. By both these metrics, Finland has improved relative to most comparator countries between FP7 and Horizon 2020.

Table 6 FP7/Horizon 2020 'multi-partner' (MP) proposals with a 'domestic' coordinator

\begin{tabular}{|c|c|c|c|c|c|c|c|c|}
\hline Horizon 2020 & All & $\mathrm{FI}$ & AT & DK & $\mathrm{IE}$ & $\mathrm{NL}$ & NO & SE \\
\hline $\begin{array}{l}\text { Number of MP proposals } \\
\text { involving... }\end{array}$ & 44,157 & 4,796 & 6,624 & 5,311 & 3,995 & 12,276 & 3,627 & 6,889 \\
\hline $\begin{array}{l}\text { Number of MP proposals } \\
\text { with domestic coordinator }\end{array}$ & 44,157 & 995 & 1016 & 1009 & 919 & 2,467 & 737 & 985 \\
\hline & & $21 \%$ & & & & & & \\
\hline $\begin{array}{l}\% \text { of country's MP proposals } \\
\text { with domestic coordinator }\end{array}$ & $100 \%$ & & $15 \%$ & $19 \%$ & $23 \%$ & $20 \%$ & $20 \%$ & $14 \%$ \\
\hline $\begin{array}{l}\text { Coordinators of MP } \\
\text { proposals per } 1,000 \\
\text { researchers }\end{array}$ & & 19 & 15 & 17 & 32 & 20 & 18 & 12 \\
\hline FP7 & All & FI & AT & DK & IE & NL & NO & SE \\
\hline $\begin{array}{l}\text { Number of MP proposals } \\
\text { involving... }\end{array}$ & 70,809 & 7,841 & 10,319 & 7,436 & 6,080 & 18,083 & 5,962 & 12,081 \\
\hline $\begin{array}{l}\text { Number of MP proposals } \\
\text { with domestic coordinator }\end{array}$ & 70,809 & 1,389 & 1,926 & 1,258 & 1,317 & 3,485 & 1,190 & 2,144 \\
\hline $\begin{array}{l}\text { \% of country's MP proposals } \\
\text { with domestic coordinator }\end{array}$ & $100 \%$ & $18 \%$ & $19 \%$ & $17 \%$ & $22 \%$ & $19 \%$ & $20 \%$ & $18 \%$ \\
\hline $\begin{array}{l}\text { Coordinators of MP } \\
\text { proposals per } 1,000 \\
\text { researchers }\end{array}$ & & 25 & 32 & 22 & 63 & 33 & 33 & 27 \\
\hline
\end{tabular}

On average, Horizon 2020 proposals involving Finland included 1.4 local (i.e. Finnish) actors each. During FP7, a similar number of Finnish actors (1.4) were involved in each Finnish proposal. In both cases (FP7 and Horizon 2020) the average number is below that of NL, but above all other comparators. Excluding single-partner projects increases the average number slightly (e.g. for Fl in Horizon 2020, from 1.37 to 1.38 local partners per proposal). However, the overall pattern is similar. 
Table 7 Average number of 'domestic' actors in each of its FP7/Horizon 2020 proposals

\begin{tabular}{llllllll}
\hline Of proposals involving country... & FI & AT & DK & IE & NL & NO & SE \\
\hline $\begin{array}{l}\text { Horizon 2020 - Average number of local } \\
\text { actors }\end{array}$ & 1.37 & 1.33 & 1.28 & 1.28 & 1.44 & 1.31 & 1.31 \\
\hline FP7 - Average number of local actors & 1.38 & 1.35 & 1.30 & 1.29 & 1.44 & 1.36 & 1.35 \\
\hline Of MP proposals involving country... & FI & AT & DK & IE & NL & NO & SE \\
\hline $\begin{array}{l}\text { Horizon 2020 - Average number of local } \\
\text { actors }\end{array}$ & 1.53 & 1.40 & 1.40 & 1.38 & 1.60 & 1.42 & 1.44 \\
\hline FP7 - Average number of local actors & 1.47 & 1.41 & 1.37 & 1.35 & 1.57 & 1.43 & 1.45 \\
\hline
\end{tabular}

Finnish proposals to Horizon 2020 also included (on average) 10.5 actors from other countries (i.e. beyond Finland). These 48,123 proposal partners came from 133 different countries, but with over half (62\%) located in Germany, the UK, Spain, Italy, France, the Netherlands and Belgium. Other countries accounting for an unusually high proportion of partners (for Finland, compared with overall participation patterns) include Sweden, Norway, Estonia, Austria, Poland, Lithuania, Portugal, and Latvia.

Because of multiple Finnish participations in some proposals, the total number of Finnish participations in Horizon 2020 proposals $(9,551)$ is $37 \%$ higher than the number of unique proposals in which Finland is involved $(6,986)$. Finland accounts for just $2.2 \%$ of all participations in Horizon 2020 proposals, which is lower than NL, SE, AT, and DK, but higher than NO and IE. When taking account of the size of the respective researcher populations, Finland only has a lower number of participations in Horizon 2020 proposals (per 1,000 R\&D personnel) than the Netherlands and Ireland, but higher a higher participation rate (per 1,000 R\&D personnel) than Sweden, Norway, Austria, and Denmark.

Finland accounted for a slightly lower proportion (2.0\%) of all participations in FP7 proposals. However, because of the longer time-period covered, its participation rate (242 per 1,000 R\&D personnel) was higher than that observed in Horizon 2020. It was also lower than all the six comparator countries other than Denmark.

Table 8 Participations in FP7/Horizon 2020 proposals from Finland and comparator countries

\begin{tabular}{|c|c|c|c|c|c|c|c|c|}
\hline Horizon 2020 & All & $\mathrm{FI}$ & AT & DK & $\mathrm{IE}$ & $\mathrm{NL}$ & $\mathrm{NO}$ & SE \\
\hline $\begin{array}{l}\text { Number of participations } \\
\text { in proposals }\end{array}$ & 436,639 & 9,551 & 10,743 & 9,873 & 7,029 & 24,010 & 6,450 & 12,572 \\
\hline $\begin{array}{l}\% \text { of all participations in } \\
\text { proposals }\end{array}$ & $0 \%$ & $2.2 \%$ & $2.5 \%$ & $2.3 \%$ & $1.6 \%$ & $5.5 \%$ & $1.5 \%$ & $2.9 \%$ \\
\hline $\begin{array}{l}\text { Number of participations } \\
\text { in proposals per } 1,000 \\
\text { researchers in... }\end{array}$ & 0 & 186 & 157 & 166 & 243 & 191 & 155 & 150 \\
\hline FP7 & All & FI & AT & DK & $\mathrm{IE}$ & $\mathrm{NL}$ & NO & SE \\
\hline $\begin{array}{l}\text { Number of participations } \\
\text { in proposals }\end{array}$ & 656,713 & 13,335 & 16,322 & 12,077 & 9,575 & 33,305 & 9,661 & 20,685 \\
\hline $\begin{array}{l}\% \text { of all participations in } \\
\text { proposals }\end{array}$ & $100 \%$ & $2.0 \%$ & $2.5 \%$ & $1.8 \%$ & $1.5 \%$ & $5.1 \%$ & $1.5 \%$ & $3.1 \%$ \\
\hline $\begin{array}{l}\text { Number of participations } \\
\text { in proposals per } 1,000 \\
\text { researchers in... }\end{array}$ & 0 & 242 & 272 & 216 & 459 & 316 & 266 & 263 \\
\hline
\end{tabular}

Finnish participations in Horizon 2020 proposals came from 1,761 unique organisations ("participants"), meaning that each of these actors (on average) participated in 5.4 proposals. This is slightly lower rate of proposal participation than the average for Horizon 2020 as a whole, where each organisation (on average) participates in 5.5 proposals each. However, nearly half (46\%) of Finnish proposal participations are accounted for by just 11 
organisations, who have participated in 100 or more proposals each. These are the VTT Technical Research Centre of Finland, the universities of Helsinki, Oulu, Eastern Finland, Turku, Jyväskylä, and Tampere, the universities of technology of Helsinki, Tampere, and Lappeenranta, and the Finnish Meteorological Institute.

Table 9 shows the distribution of Horizon 2020 proposal participations between different types of actor (categorisations as used in eCORDA). For Finland, it shows that two organisation types (HES and PRC) account for the majority (77\%) of participations, with REC accounting for a further $17 \%$. The distribution is similar to the overall average, though with a slightly higher proportion of Finnish participations accounted for by HES and a lower proportion accounted for by PRC and REC organisations.

The table also shows the proportion of PRC participations that are SMEs. For Finland, the rate is $87 \%$, which is higher than the overall average, and also higher than all of the comparator countries.

Table 9 Distribution of participations in Horizon 2020 proposals by organisational type

\begin{tabular}{lllllllll}
\hline Horizon 2020 & All & FI & AT & DK & IE & NL & NO & SE \\
\hline HES - Higher or secondary education & $38 \%$ & $42 \%$ & $36 \%$ & $52 \%$ & $53 \%$ & $45 \%$ & $38 \%$ & $54 \%$ \\
\hline PRC - Private for profit (excl. education) & $37 \%$ & $35 \%$ & $36 \%$ & $32 \%$ & $38 \%$ & $35 \%$ & $33 \%$ & $32 \%$ \\
\hline REC - Research organisations & $18 \%$ & $17 \%$ & $21 \%$ & $8 \%$ & $3 \%$ & $13 \%$ & $25 \%$ & $8 \%$ \\
\hline PUB - Public body (excl. REC/HES) & $3 \%$ & $3 \%$ & $2 \%$ & $5 \%$ & $3 \%$ & $2 \%$ & $3 \%$ & $4 \%$ \\
\hline OTH - Others & $4 \%$ & $3 \%$ & $4 \%$ & $3 \%$ & $2 \%$ & $4 \%$ & $2 \%$ & $2 \%$ \\
\hline Total & 436,63 & 9,551 & 10,743 & 9,873 & 7,029 & 24,010 & 6,450 & 12,572 \\
\hline SMEs as a $\%$ of PRC & $98 \%$ & $87 \%$ & $74 \%$ & $83 \%$ & $79 \%$ & $79 \%$ & $82 \%$ & $75 \%$ \\
\hline
\end{tabular}

The most frequent Finnish proposal participants in each organisational category are shown in the table below. The number of proposal participations they account for is also shown in parenthesis in each case.

Table 10 FI organisations (from each organisational type) that participated most frequently in Horizon 2020

\begin{tabular}{|c|c|}
\hline Organisation type & Most frequent participants in Horizon 2020 proposals (number of participations) \\
\hline $\begin{array}{l}\text { HES - Higher or secondary } \\
\text { education }\end{array}$ & $\begin{array}{l}\text { (854) HELSINGIN YLIOPISTO } \\
\text { (742) AALTO-KORKEAKOULUSAATIO } \\
\text { (435) OULUN YLIOPISTO } \\
\text { (324) TTY-SAATIO } \\
\text { (306) ITA-SUOMEN YLIOPISTO } \\
\text { (305) TURUN YLIOPISTO }\end{array}$ \\
\hline $\begin{array}{l}\text { PRC - Private for profit (excl. } \\
\text { education) }\end{array}$ & $\begin{array}{l}\text { (27) PICOSUN OY** } \\
\text { (27) VAASAETT LTD AB OY** } \\
\text { (26) NOKIA SOLUTIONS AND NETWORKS OY }\end{array}$ \\
\hline [* SMEs] & $\begin{array}{l}\text { (25) OY L M ERICSSON AB } \\
\text { (25) SPINVERSE INNOVATION MANAGEMENT OY** } \\
\text { (23) TIMEGATE INSTRUMENTS OY** } \\
\text { (19) BIOCOMPUTING PLATFORMS LTD OY** } \\
\text { (17) ABB OY }\end{array}$ \\
\hline REC - Research organisations & $\begin{array}{l}\text { (946) TEKNOLOGIAN TUTKIMUSKESKUS VTT } \\
\text { (132) ILMATIETEEN LAITOS } \\
\text { (82) LUONNONVARAKESKUS } \\
\text { (78) TERVEYDEN JA HYVINVOINNIN LAITOS } \\
\text { (60) SUOMEN YMPARISTOKESKUS } \\
\text { (41) EUROPEAN FOREST INSTITUTE } \\
\text { (34) HELSINGIN JA UUDENMAAN SAIRAANHOITOPIIRIN KUNTAYHTYMÃ }\end{array}$ \\
\hline $\begin{array}{l}\text { PUB - Public body (excl. } \\
\text { REC/HES) }\end{array}$ & $\begin{array}{l}\text { (23) HELSINGIN KAUPUNKI } \\
\text { (22) TAMPEREEN KAUPUNKI } \\
\text { (17) SUOMEN AKATEMIA } \\
\text { (12) Four Computing Oy } \\
\text { (12) POLIISIHALLITUS }\end{array}$ \\
\hline OTH - Others & $\begin{array}{l}\text { (47) FORUM VIRIUM HELSINKI OY } \\
\text { (32) CSC-TIETEEN TIETOTEKNIIKAN KESKUS OY } \\
\text { (14) TURKU SCIENCE PARK OY AB }\end{array}$ \\
\hline
\end{tabular}


The average EC funding request per Finnish participation in Horizon 2020 proposals was around $€ 652$ thousand, which is higher than most of the comparator countries, but slightly lower than Norway. The overall average funding request is significantly higher, but this is skewed by a small number of extremely large requests.

Table 11 EC contributions requested in Horizon 2020 proposals

\begin{tabular}{lllllllll}
\hline Horizon 2020 & All & FI & AT & DK & IE & NL & NO & SE \\
\hline $\begin{array}{l}\text { Selected participations in } \\
\text { proposals (with financial } \\
\text { data) }\end{array}$ & 436,639 & 9,551 & 10,743 & 9,873 & 7,029 & 24,010 & 6,450 & 12,572 \\
\hline $\begin{array}{l}\text { Total EC contribution } \\
\text { requested (Emillion) }\end{array}$ & 371,026 & 6,230 & 5,686 & 6,074 & 4,339 & 15,037 & 4,244 & 8,051 \\
\hline $\begin{array}{l}\text { Average contribution } \\
\text { requested per } \\
\text { participation }\end{array}$ & 849,732 & 652,267 & 529,261 & 615,183 & 617,326 & 626,264 & 658,050 & 640,389 \\
\hline
\end{tabular}

The average Finnish funding request is highest amongst HES. Average requests from HES, REC, PUB, OTH and PUB-SMEs organisations in Finland are above that of most comparator countries, while average requests from all PRC organisations tends to be lower than in most of the other countries.

Table 12 EC contributions requested by participant groups

\begin{tabular}{lllllllll}
\hline $\begin{array}{l}\text { Horizon } \\
2020\end{array}$ & All & FI & AT & DK & IE & NL & NO & SE \\
\hline HES & $€ 651,271$ & $€ 782,556$ & $€ 619,986$ & $€ 685,109$ & $€ 698,994$ & $€ 742,018$ & $€ 768,548$ & $€ 706,141$ \\
\hline REC & $€ 643,874$ & $€ 683,080$ & $€ 576,971$ & $€ 509,252$ & $€ 376,632$ & $€ 678,454$ & $€ 729,248$ & $€ 734,137$ \\
\hline PUB & $€ 401,399$ & $€ 404,921$ & $€ 309,421$ & $€ 587,771$ & $€ 318,107$ & $€ 391,520$ & $€ 379,399$ & $€ 521,822$ \\
\hline PRC & $€ 483,969$ & $€ 514,320$ & $€ 455,108$ & $€ 543,394$ & $€ 566,875$ & $€ 510,771$ & $€ 516,161$ & $€ 530,910$ \\
\hline OTH & $€ 9,061,887$ & $€ 442,908$ & $€ 272,671$ & $€ 166,482$ & $€ 335,798$ & $€ 380,655$ & $€ 409,133$ & $€ 437,541$ \\
\hline PRC- & $€ 481,932$ & $€ 602,188$ & $€ 430,652$ & $€ 430,652$ & $€ 586,070$ & $€ 512,057$ & $€ 523,755$ & $€ 632,513$ \\
\hline SMES & & & & & & & & \\
\hline
\end{tabular}

The distribution of Finnish participations in proposals across the main programme areas of Horizon 2020 is shown below, alongside comparable figures for Horizon 2020 overall and for the comparator countries. While the Finnish distribution largely reflects the overall pattern, it is less active in proposals within the Excellent Science and Science with/for Society programmes, compared with the overall average. Indeed, a smaller proportion of its proposal participations are accounted for by the Excellent Science programme, compared with any of the comparator countries. By comparison, Finland is relatively more active in relation to Industrial Leadership and Euratom programmes, compared with the average. Its proportion of participations accounted for by the Industrial Leadership programme is greater than all comparator countries, while only SE has a greater proportion of participations in the Euratom programme.

Table 13 Distribution of participations in Horizon 2020 proposals by programme area (\% of all country's participations)

\begin{tabular}{|c|c|c|c|c|c|c|c|c|}
\hline Horizon 2020 & All & $\mathrm{FI}$ & AT & DK & IE & $\mathrm{NL}$ & NO & SE \\
\hline Societal Challenges & $39.8 \%$ & $40.0 \%$ & $41.4 \%$ & $39.3 \%$ & $37.4 \%$ & $40.2 \%$ & $44.1 \%$ & $38.5 \%$ \\
\hline Industrial Leadership & $22.8 \%$ & $28.1 \%$ & $24.1 \%$ & $16.6 \%$ & $24.7 \%$ & $18.5 \%$ & $20.4 \%$ & \\
\hline Excellent Science & $32.3 \%$ & $27.6 \%$ & $28.5 \%$ & $40.2 \%$ & $32.8 \%$ & $36.8 \%$ & $31.1 \%$ & $36.9 \%$ \\
\hline $\begin{array}{l}\text { Science with and for } \\
\text { Society }\end{array}$ & $1.7 \%$ & $1.4 \%$ & $2.4 \%$ & $1.3 \%$ & $1.9 \%$ & $1.5 \%$ & $1.5 \%$ & $1.2 \%$ \\
\hline Euratom & $0.5 \%$ & $0.8 \%$ & $0.1 \%$ & $0.1 \%$ & $0.0 \%$ & $0.3 \%$ & $0.5 \%$ & $0.9 \%$ \\
\hline $\begin{array}{l}\text { Spreading } \\
\text { excellence and } \\
\text { widening }\end{array}$ & $0.9 \%$ & $0.8 \%$ & $1.2 \%$ & $0.7 \%$ & $0.5 \%$ & $0.7 \%$ & $0.5 \%$ & $0.9 \%$ \\
\hline
\end{tabular}




\begin{tabular}{lllllllll}
\hline participation & & & & & & & & \\
\end{tabular}

This relative concentration of Finnish activity within particular areas of the programme can be seen more clearly if we compare the distribution of proposal participations at the subprogramme level.

While in absolute terms Finland's participation in Horizon 2020 proposals is concentrated in ICT (18\% of all FI participations), Marie Curie Actions (14\%), and Health (11\%) programmes, these are also the biggest programmes in Horizon 2020 more generally. If we weight the data by calculating Finland's share of all proposals participations to a subprogramme, then we find that the country has been (relatively) very active in some areas, and less so in others.

Overall, Finland accounts for $2.2 \%$ of all participations in Horizon 2020 proposals. It accounts for a higher proportion of participations in proposals in the 10 sub-programmes shown below. These are the areas where Finland has been relatively more 'active' and include the EURATOM, RISKFINANCE and ICT programmes (3\%-plus of all participations in proposals).

Table 14 Sub-programmes with a relatively high participation rate of Finland in proposals

\begin{tabular}{|c|c|c|c|c|}
\hline Programme & Sub-programme & & $\begin{array}{l}\text { FI participations in } \\
\text { proposals }\end{array}$ & $\begin{array}{l}\text { As } \% \text { of all } \\
\text { participations in } \\
\text { sub-programme }\end{array}$ \\
\hline Euratom & EURATOM & Euratom & 79 & $4.0 \%$ \\
\hline Industrial Leadership & RISKFINANCE & Access to risk finance & 11 & $3.0 \%$ \\
\hline Industrial Leadership & ICT & $\begin{array}{l}\text { Information and } \\
\text { Communication Technologies }\end{array}$ & 1,722 & $3,0 \%$ \\
\hline Excellent Science & ERC & European Research Council & 762 & $2.9 \%$ \\
\hline Societal Challenges & ENV & $\begin{array}{l}\text { Climate action, environment, } \\
\text { resource efficiency and raw } \\
\text { materials }\end{array}$ & 539 & $2.8 \%$ \\
\hline $\begin{array}{l}\text { Science with and for } \\
\text { Society }\end{array}$ & CAREER & $\begin{array}{l}\text { Make scientific and } \\
\text { technological careers } \\
\text { attractive for young people }\end{array}$ & 75 & $2.6 \%$ \\
\hline Industrial Leadership & ADVMANU & $\begin{array}{l}\text { Advanced manufacturing and } \\
\text { processing }\end{array}$ & 359 & $2.5 \%$ \\
\hline Societal Challenges & HEALTH & $\begin{array}{l}\text { Health, demographic change } \\
\text { and wellbeing }\end{array}$ & 1,019 & $2.5 \%$ \\
\hline Industrial Leadership & NMP & $\begin{array}{l}\text { Nanotechnologies, Advanced } \\
\text { Materials and Production }\end{array}$ & 255 & $2.4 \%$ \\
\hline Excellent science & INFRA & Research infrastructures & 150 & $2.3 \%$ \\
\hline \multicolumn{3}{|c|}{ Horizon 2020 all programmes } & 9,551 & $2.2 \%$ \\
\hline
\end{tabular}

At the same time, Finland has been less 'active' in the 32 other sub-programmes (summarised below).

Table 15 Sub-programmes with a relatively low participation rate of Finland in proposals

\begin{tabular}{ll}
\hline Programme & As \% of all participations in sub-programme \\
\hline ENERGY; ADVMAT & $2.2 \%$ \\
\hline FOOD & $2.1 \%$ \\
\hline SPACE; SOCIETY; TWINING; FET, SME & $2.0 \%$ \\
\hline SECURITY & $1.8 \%$ \\
\hline GOV; WIDESPREAD; TPT; SCIENCE & $1.6 \%$ \\
\hline CROSST; MSCA & $1.5 \%$ \\
\hline INEGSOC; BIOTECH; GENDEREQ & $<1.5 \%$ \\
\hline
\end{tabular}




\section{Success rates and participation in projects}

To May 2017, 893 Horizon 2020 grants had been awarded to projects involving Finland. This represents $6 \%$ of all Horizon 2020 projects, which is higher than IE and NO, but lower than the other comparator countries. Finland has been awarded 16 Horizon 2020 projects for every $1,000 R \& D$ personnel in the country, which is higher than in either SE or NO. This is an improvement on FP7, when Finland's rate of projects per researcher was below that of all the comparator countries.

Table 16 Projects (per 1,000 R\&D personnel) - Finland and comparator countries

\begin{tabular}{lllllllll}
\hline Horizon 2020 & All & FI & AT & DK & IE & NL & NO & SE \\
\hline Projects & 14,875 & 893 & 1,224 & 1,115 & 805 & 2,520 & 698 & 1,381 \\
\hline $\begin{array}{l}\text { Projects per 1,000 } \\
\text { researchers }\end{array}$ & All & FI & AT & DK & IE & NL & NO & SE \\
\hline FP7 & 25,205 & 1,786 & 2,448 & 2,025 & 1,472 & 5,047 & 1,497 & 3,099 \\
\hline Projects & & 32.4 & 40.8 & 36.2 & 70.6 & 47.8 & 41.2 & 39.4 \\
\hline $\begin{array}{l}\text { Projects per 1,000 } \\
\text { researchers }\end{array}$ & & & 17.9 & 18.8 & 27.8 & 20.0 & 16.8 \\
\hline
\end{tabular}

The 893 projects involving Finland came from 6,986 proposals. This equates to a proposal success rate of $12.8 \%$ - which is higher than the overall success rate of Horizon 2020 proposals $(11.5 \%)$, but below the rates achieved in all the comparator countries.

Finnish success rates in FP7 were much higher (18.5\%) than in Horizon 2020, but this partly reflects higher success rates seen in FP7 overall (15.9\%). Finland's FP7 success rate was also slightly below that of all the comparator countries.

Table 17 Success rate of proposals - Finland and comparator countries

\begin{tabular}{lllllllll}
\hline Horizon 2020 & All & FI & AT & DK & IE & NL & NO & SE \\
\hline Proposals & 129,513 & 6,986 & 8,087 & 7,740 & 5,495 & 16,644 & 4,921 & 9,562 \\
\hline Projects & 14,875 & 893 & 1,224 & 1,115 & 805 & 2,520 & 692 & 1,381 \\
\hline Success rate & $11.5 \%$ & $12.8 \%$ & $15.1 \%$ & $14.4 \%$ & $14.6 \%$ & $15.1 \%$ & $14.2 \%$ & $14.4 \%$ \\
\hline FP7 & All & FI & AT & DK & IE & NL & NO & SE \\
\hline Proposals & 158,609 & 9,671 & 12,104 & 9,323 & 7,440 & 23,076 & 7,081 & 15,274 \\
\hline Projects & 25,205 & 1,786 & 2,448 & 2,025 & 1,472 & 5,047 & 1,497 & 3099 \\
\hline Success rate & $15.9 \%$ & $18.5 \%$ & $20.2 \%$ & $21.7 \%$ & $19.8 \%$ & $21.9 \%$ & $21.1 \%$ & $20.3 \%$ \\
\hline
\end{tabular}

Horizon 2020 grants have been awarded to 278 projects with a Finnish coordinator. The equates to 5.4 project coordinators for every 1,000 R\&D personnel in the country. This rate is higher than SE, AT and NO, but lower than the other two comparator countries. Finnish coordinator rates in FP7 were slightly higher (at 6.4 coordinators per 1,000 researchers), but this was below the rates achieved by all comparator countries during this programming period. As such, Finland's performance relative to comparator countries (in terms of coordinator numbers) has tended to improve in the first period of Horizon 2020 compared with the whole of FP7. 
Table 18 Coordinators (per 1,000 R\&D personnel) - Finland and comparator countries

\begin{tabular}{lllllllll}
\hline Horizon 2020 & All & FI & AT & DK & IE & NL & NO & SE \\
\hline Coordinators & 14,875 & 278 & 369 & 462 & 326 & 1033 & 218 & 404 \\
\hline $\begin{array}{l}\text { Coordinators per 1,000 } \\
\text { researchers }\end{array}$ & All & FI & AT & DK & IE & NL & NO & SE \\
\hline FP7 & 25,205 & 353 & 669 & 506 & 445 & 1632 & 350 & 722 \\
\hline Coordinators & & 6.4 & 11.2 & 9.0 & 21.3 & 15.5 & 9.6 & 9.2 \\
\hline $\begin{array}{l}\text { Coordinators per 1,000 } \\
\text { researchers }\end{array}$ & & & & & & 7.8 & & 9.3 \\
\hline
\end{tabular}

The success rate of Finnish-coordinated Horizon 2020 proposals is $8.7 \%$ - which is much lower than the rate of success for proposals where Finland is only a partner (16.2\%). It is also lower than the overall Horizon 2020 figure (11.5\%), and below the rates of coordinator success achieved in all of the comparator countries. In FP7, Finland's success rate for coordinators was similarly below the overall average and the success rates in all comparator countries.

Table 19 Success rate of proposals with/without domestic coordinator - Finland and comparator countries

\begin{tabular}{lllllllll}
\hline Horizon 2020 success rates & All & FI & AT & DK & IE & NL & NO & SE \\
\hline Proposal with domestic coordinator & $11.5 \%$ & $\mathbf{8 . 7} \%$ & $14.9 \%$ & $13.4 \%$ & $13.5 \%$ & $15.1 \%$ & $10.7 \%$ & $11.0 \%$ \\
\hline Proposal without domestic coordinator & & $16.2 \%$ & $15.2 \%$ & $15.2 \%$ & $15.6 \%$ & $15.2 \%$ & $16.6 \%$ & $16.5 \%$ \\
\hline FP7 success rates & All & FI & AT & DK & IE & NL & NO & SE \\
\hline Proposal with domestic coordinator & $15.9 \%$ & $11.0 \%$ & $18.0 \%$ & $16.1 \%$ & $16.6 \%$ & $19.2 \%$ & $15.2 \%$ & $13.5 \%$ \\
\hline Proposal without domestic coordinator & & $\mathbf{2 2 . 2} \%$ & $21.2 \%$ & $24.6 \%$ & $21.6 \%$ & $23.4 \%$ & $24.0 \%$ & $23.9 \%$ \\
\hline
\end{tabular}

If we look only at those proposals/projects with multiple participants (i.e. excluding those where the coordinator is the only partner), the success rate for Finnish coordinators increases from $8.7 \%$ to $9.6 \%$ for Horizon 2020 , and from $11.0 \%$ to $16.1 \%$ for FP7. While there is an increase in the success rate overall with this measure, the increase for Finland is more significant than for many of its comparator countries. Nevertheless, the Finnish figures is still lower than in all comparator countries, both for FP7 and Horizon 2020.

Table 20 Success rate of multi-partner proposals with domestic coordinator

\begin{tabular}{lllllllll}
\hline Horizon 2020-multi partner & All & FI & AT & DK & IE & NL & NO & SE \\
\hline Proposals & 44,157 & 995 & 1,016 & 1,009 & 919 & 2,467 & 737 & 985 \\
\hline Projects & 5,413 & 96 & 169 & 122 & 117 & 377 & 99 & 120 \\
\hline Success rate & $12.3 \%$ & $9.6 \%$ & $16.6 \%$ & $12.1 \%$ & $12.7 \%$ & $15.3 \%$ & $13.4 \%$ & $12.2 \%$ \\
\hline FP7 - multi partner & All & FI & AT & DK & IE & NL & NO & SE \\
\hline Proposals & 70,809 & 1,389 & 1,926 & 1,258 & 1,317 & 3,485 & 1,190 & 2,144 \\
\hline Projects & 12,278 & 223 & 381 & 232 & 250 & 836 & 240 & 362 \\
\hline Success rate & $17.3 \%$ & $16.1 \%$ & $19.8 \%$ & $18.4 \%$ & $19.0 \%$ & $24.0 \%$ & $20.2 \%$ & $16.9 \%$ \\
\hline
\end{tabular}

The 893 grants awarded to Finland in Horizon 2020 involve 1,288 individual Finnish participations. This represents $2.1 \%$ of all Horizon 2020 participations, which is slightly higher than Denmark, Ireland and Norway, but lower than Austria, Netherlands, and Sweden (each of which accounts for between $2 \%$ and $7 \%$ of all participations). Finland has 25.1 project participations in Horizon 2020 for every 1,000 R\&D personnel in the country, which is higher than DK, NO and SE, but below AT, IE, and NL. This is a slight improvement on Finland's relative position in FP7. 
Table 21 Participations (per 1,000 R\&D personnel) - Finland and comparator countries

\begin{tabular}{lllllllll}
\hline Horizon 2020 & All & FI & AT & DK & IE & NL & NO & SE \\
\hline Participations in projects & 62,506 & 1,288 & 1,766 & 1,481 & 1,054 & 3,989 & 959 & 1,963 \\
\hline Participations per 1,000 researchers & & 25.1 & 25.9 & 24.9 & 36.5 & 31.7 & 23.1 & 23.4 \\
\hline FP7 & All & FI & AT & DK & IE & NL & NO & SE \\
\hline Participations in projects & 136,388 & 2,905 & 3,595 & 2,821 & 1,985 & 8,342 & 2,223 & 4,582 \\
\hline Participations per 1,000 researchers & & 52.6 & 60.0 & 50.4 & 95.2 & 79.1 & 61.1 & 58.3 \\
\hline
\end{tabular}

The 1,288 Finnish participations in successful projects, from 9,551 participations in proposals, represents a participation success rate of $13.5 \%$ in Horizon 2020 so far. This is below the overall rate of success for all participations in proposals (14.3\%), and below that for all comparator countries. During FP7, the Finnish participation success rate was slightly above average and above the rate in Ireland, but still lower than in the other comparator countries.

Table 22 Success rate of participations - Finland and comparator countries

\begin{tabular}{lllllllll}
\hline Participation success rate & All & FI & AT & DK & IE & NL & NO & SE \\
\hline Horizon 2020 & $14.3 \%$ & $13.5 \%$ & $16.4 \%$ & $15.0 \%$ & $15.0 \%$ & $16.6 \%$ & $14.9 \%$ & $15.6 \%$ \\
\hline FP7 & $20.8 \%$ & $21.8 \%$ & $22.0 \%$ & $23.4 \%$ & $20.7 \%$ & $25.0 \%$ & $23.0 \%$ & $22.2 \%$ \\
\hline
\end{tabular}

Comparing across different organisation types, Horizon 2020 success rates were highest amongst Finnish participations from public bodies (25.1\%). However, rates here were lower than the overall average (26.5\%), and lower than most of the comparator countries. Finnish success rates for PRC organisations were also high (24\%). This rate of success is greater than the overall average and above the rate in most comparator countries. Elsewhere (HES, PUB, and REC), Finnish participations achieved success rates lower than the overall average, and below the levels of success seen across most comparator countries.

The table also shows the success rate of SME-PRC participations. ${ }^{171}$ For Finland, the rate is $10.9 \%$, which is slightly below the Horizon 2020 average, as well as lower than all the comparator countries.

Table 23 Success rate of participations, by organisation type - Finland and comparator countries (Horizon 2020)

\begin{tabular}{|c|c|c|c|c|c|c|c|c|}
\hline Participation success rate & All & $\mathrm{FI}$ & AT & DK & IE & NL & NO & SE \\
\hline HES - Higher or secondary education & $12.4 \%$ & $10.8 \%$ & $13.2 \%$ & $14.3 \%$ & $13.6 \%$ & $14.7 \%$ & $12.2 \%$ & $13.3 \%$ \\
\hline PRC - Private for profit (excl. education) & $20.0 \%$ & $23.6 \%$ & $20.6 \%$ & $25.8 \%$ & $18.7 \%$ & $20.2 \%$ & $14.6 \%$ & $20.4 \%$ \\
\hline REC - Research organisations & $13.0 \%$ & $12.5 \%$ & $17.2 \%$ & $13.8 \%$ & $14.5 \%$ & $15.4 \%$ & $13.2 \%$ & $16.6 \%$ \\
\hline $\begin{array}{l}\text { PUB - Public body (excl. research and } \\
\text { education) }\end{array}$ & $26.5 \%$ & $25.1 \%$ & $40.6 \%$ & $24.1 \%$ & $31.1 \%$ & $27.1 \%$ & $39.4 \%$ & $32.3 \%$ \\
\hline OTH - Others & $17.4 \%$ & $18.7 \%$ & $17.2 \%$ & $15.3 \%$ & $25.2 \%$ & $23.3 \%$ & $18.1 \%$ & $18.2 \%$ \\
\hline PRC-SMES & $11.6 \%$ & $10.9 \%$ & $14.4 \%$ & $12.9 \%$ & $14.4 \%$ & $14.4 \%$ & $11.6 \%$ & $13.2 \%$ \\
\hline
\end{tabular}

EC contributions to Finnish participations in Horizon 2020 projects totalled $€ 579$ million, which equates to $2.2 \%$ of all funding to project participations to date. This is below the proportion realised by most of the other comparator countries, but higher than that received by Ireland and Norway. If we 'normalise' contributions by using national GDP figures, then Finland compares favourably with its comparator countries, only being below Netherlands in this measure. The average contribution to each Finnish participation (at $€ 450$ thousand) is also relatively high, with only Netherlands and Norway having a higher rate. 
Table 24 EC contributions as a proportion of requested funding - Finland and comparator countries

\begin{tabular}{lllllllll}
\hline Horizon 2020 & All & FI & AT & DK & IE & NL & NO & SE \\
\hline Participations in projects & 62,506 & 1,288 & 1,766 & 1,481 & 1,054 & 3,989 & 959 & 1,963 \\
\hline Total EC contribution (€million) & 26,410 & 579 & 728 & 655 & 460 & 2,040 & 471 & 927 \\
\hline \% of total EC contributions & & $2.2 \%$ & $2.8 \%$ & $2.5 \%$ & $1.7 \%$ & $7.7 \%$ & $1.8 \%$ & $3.5 \%$ \\
\hline $\begin{array}{l}\text { EC contributions }(€) \text { per } € \text { million } \\
\text { GDP }\end{array}$ & & 2,763 & 2,142 & 2,410 & 1,755 & 2,985 & 1,352 & 2,074 \\
\hline $\begin{array}{l}\text { Average EC contribution }(€) \text { per } \\
\text { participation }\end{array}$ & 422,519 & 449,534 & 412,231 & 442,269 & 436,433 & 511,406 & 491,137 & 472,236 \\
\hline
\end{tabular}

Finnish success rates across the main programme areas of Horizon 2020 broadly follow the patterns for Horizon 2020 overall. However, the country has seen slightly above average levels of success in the areas of Euratom and Spreading Excellence. In both, Finland also compares favourably with all / most comparator countries. In the other programme areas, Finland's participation success rate is below average and below that of nearly all comparator countries.

Table 25 Participation success rate by programme area

\begin{tabular}{lcccccccc}
\hline & All & FI & AT & DK & IE & NL & NO & SE \\
\hline Euratom & $44.2 \%$ & $46.8 \%$ & $41.7 \%$ & $50.0 \%$ & $\begin{array}{c}100.0 \\
\%\end{array}$ & $45.2 \%$ & $22.2 \%$ & $33.3 \%$ \\
\hline $\begin{array}{l}\text { Spreading excellence and widening } \\
\text { participation }\end{array}$ & $16.0 \%$ & $17.8 \%$ & $16.3 \%$ & $16.7 \%$ & $13.5 \%$ & $15.7 \%$ & $6.5 \%$ & $13.8 \%$ \\
\hline Societal Challenges & $15.1 \%$ & $14.4 \%$ & $17.7 \%$ & $17.2 \%$ & $16.5 \%$ & $18.2 \%$ & $16.5 \%$ & $18.5 \%$ \\
\hline Industrial Leadership & $15.2 \%$ & $13.0 \%$ & $17.6 \%$ & $15.3 \%$ & $15.1 \%$ & $16.6 \%$ & $18.0 \%$ & $16.4 \%$ \\
\hline Excellent Science & $13.0 \%$ & $12.2 \%$ & $14.7 \%$ & $13.4 \%$ & $14.2 \%$ & $15.3 \%$ & $11.5 \%$ & $12.5 \%$ \\
\hline Science with and for Society & $9.8 \%$ & $9.6 \%$ & $15.8 \%$ & $12.3 \%$ & $8.9 \%$ & $12.0 \%$ & $14.1 \%$ & $7.5 \%$ \\
\hline Cross-Theme & $5.3 \%$ & $3.1 \%$ & $3.6 \%$ & $1.6 \%$ & $5.5 \%$ & $9.6 \%$ & $2.1 \%$ & $5.4 \%$ \\
\hline Horizon 2020 & $\mathbf{1 4 . 3} \%$ & $13.5 \%$ & $\mathbf{1 6 . 4} \%$ & $\mathbf{1 5 . 0} \%$ & $\mathbf{1 5 . 0} \%$ & $\mathbf{1 6 . 6 \%}$ & $\mathbf{1 4 . 9} \%$ & $\mathbf{1 5 . 6} \%$ \\
\hline
\end{tabular}

Looking in more detail, there are 14 sub-programmes where Finnish participations achieved a higher success rate than average.

Table 26 Sub-programmes with relatively high Finnish success rates

\begin{tabular}{|c|c|c|c|c|c|}
\hline Programme & Sub programme & & Overall & $\mathrm{FI}$ & $\begin{array}{l}\% \\
\text { difference }\end{array}$ \\
\hline $\begin{array}{l}\text { Science with and for } \\
\text { Society }\end{array}$ & SCIENCE & $\begin{array}{l}\text { Encourage citizens to engage in } \\
\text { science }\end{array}$ & $2.8 \%$ & $9.1 \%$ & $+227 \%$ \\
\hline $\begin{array}{l}\text { Science with and for } \\
\text { Society }\end{array}$ & GENDEREQ & $\begin{array}{l}\text { Promote gender equality in } \\
\text { research and innovation }\end{array}$ & $12.7 \%$ & $25.0 \%$ & $+97 \%$ \\
\hline $\begin{array}{l}\text { Spreading excellence } \\
\text { and widening } \\
\text { participation }\end{array}$ & WIDESPREAD & $\begin{array}{l}\text { Teaming of excellent research } \\
\text { institutions and low performing RDI } \\
\text { regions }\end{array}$ & $19.2 \%$ & $28.6 \%$ & $+49 \%$ \\
\hline Societal Challenges & SECURITY & $\begin{array}{l}\text { Secure societies - Protecting } \\
\text { freedom and security of Europe and } \\
\text { its citizens }\end{array}$ & $12.0 \%$ & $16.4 \%$ & $+37 \%$ \\
\hline $\begin{array}{l}\text { Science with and for } \\
\text { Society }\end{array}$ & GOV & $\begin{array}{l}\text { Develop the governance for the } \\
\text { advancement of responsible } \\
\text { research and innovation }\end{array}$ & $22.2 \%$ & $28.6 \%$ & $+28 \%$ \\
\hline Excellent Science & INFRA & Research infrastructures & $44.6 \%$ & $54.0 \%$ & $+21 \%$ \\
\hline Industrial Leadership & RISKFINANCE & Access to risk finance & $8.5 \%$ & $9.1 \%$ & $+7 \%$ \\
\hline Euratom & EURATOM & Euratom & $44.2 \%$ & $46.8 \%$ & $+6 \%$ \\
\hline Societal Challenges & FOOD & $\begin{array}{l}\text { Food security, sustainable } \\
\text { agriculture and forestry, marine and } \\
\text { maritime and inland water research }\end{array}$ & $17.6 \%$ & $18.6 \%$ & $+6 \%$ \\
\hline Industrial Leadership & ADVMANU & $\begin{array}{l}\text { Advanced manufacturing and } \\
\text { processing }\end{array}$ & $14.7 \%$ & $15.3 \%$ & $+4 \%$ \\
\hline Excellent Science & FET & Future and Emerging Technologies & $6.2 \%$ & $6.4 \%$ & $+2 \%$ \\
\hline
\end{tabular}

There were also 17 sub-programmes of Horizon 2020 where Finnish participations achieved a lower success rate than average (shown below). In addition, there were 6 subprogrammes were Finland has not yet participated in a proposal and 6 further subprogrammes were no proposals have yet been submitted. 
Table 27 Sub-programmes with relatively low Finnish success rates

\begin{tabular}{|c|c|c|c|c|c|}
\hline Programme & Sub-programme & & Overall & $\mathrm{FI}$ & $\%$ difference \\
\hline Excellent Science & MSCA & Excellent Science & $12.0 \%$ & $11.6 \%$ & $-3.5 \%$ \\
\hline Societal Challenges & ENERGY & Secure, clean and efficient energy & $16.6 \%$ & $15.8 \%$ & $-4.8 \%$ \\
\hline Societal Challenges & SOCIETY & $\begin{array}{l}\text { Europe in a changing world - } \\
\text { inclusive, innovative and reflective } \\
\text { Societies }\end{array}$ & $7.6 \%$ & $7.2 \%$ & $-4.9 \%$ \\
\hline Societal Challenges & ENV & $\begin{array}{l}\text { Climate action, environment, } \\
\text { resource efficiency and raw } \\
\text { materials }\end{array}$ & $18.4 \%$ & $17.4 \%$ & $-5.1 \%$ \\
\hline Industrial Leadership & $\mathrm{ICT}$ & $\begin{array}{l}\text { Information and Communication } \\
\text { Technologies }\end{array}$ & $14.0 \%$ & $13.0 \%$ & $-7.6 \%$ \\
\hline $\begin{array}{l}\text { Spreading excellence } \\
\text { and widening } \\
\text { participation }\end{array}$ & TWINING & Twinning of research institutions & $12.1 \%$ & $11.1 \%$ & $-8.3 \%$ \\
\hline Societal Challenges & HEALTH & $\begin{array}{l}\text { Health, demographic change and } \\
\text { wellbeing }\end{array}$ & $10.9 \%$ & $9.7 \%$ & $-11.2 \%$ \\
\hline Societal Challenges & TPT & $\begin{array}{l}\text { Smart, green and integrated } \\
\text { transport }\end{array}$ & $24.7 \%$ & $21.6 \%$ & $-12.4 \%$ \\
\hline $\begin{array}{l}\text { Science with and for } \\
\text { Society }\end{array}$ & CAREER & $\begin{array}{l}\text { Make scientific and technological } \\
\text { careers attractive for young people }\end{array}$ & $6.3 \%$ & $5.3 \%$ & $-15.7 \%$ \\
\hline Industrial Leadership & ADVMAT & Advanced materials & $18.4 \%$ & $15.2 \%$ & $-17.9 \%$ \\
\hline Industrial Leadership & BIOTECH & Biotechnology & $10.9 \%$ & $8.8 \%$ & $-18.8 \%$ \\
\hline Industrial Leadership & NMP & $\begin{array}{l}\text { Nanotechnologies, Advanced } \\
\text { Materials and Production }\end{array}$ & $10.0 \%$ & $7.8 \%$ & $-21.4 \%$ \\
\hline $\begin{array}{l}\text { Science with and for } \\
\text { Society }\end{array}$ & INEGSOC & $\begin{array}{l}\text { Integrate society in science and } \\
\text { innovation }\end{array}$ & $9.6 \%$ & $7.4 \%$ & $-22.7 \%$ \\
\hline Excellent Science & ERC & European Research Council & $14.0 \%$ & $8.4 \%$ & $-39.9 \%$ \\
\hline Industrial Leadership & SPACE & Space & $19.6 \%$ & $11.7 \%$ & $-40.5 \%$ \\
\hline Cross-theme & CROSST & Cross-theme & $5.3 \%$ & $3.1 \%$ & $-42.7 \%$ \\
\hline Industrial Leadership & SME & Innovation in SMEs & $47.5 \%$ & $23.8 \%$ & $-49.9 \%$ \\
\hline
\end{tabular}

From a funding perspective, Finland has achieved $2.19 \%$ of total EC contributions. There are 12 sub-programmes of Horizon 2020 where EC contributions to Finnish participations account for at least $2.2 \%$ of the total awards made (shown below).

Table 28 Sub-programmes where Finland accounts for the highest proportion of EC contributions awarded

\begin{tabular}{|c|c|c|c|c|c|}
\hline $\begin{array}{l}\text { Horizon } 2020 \\
\text { Programme }\end{array}$ & \multicolumn{2}{|c|}{ Sub-programme } & \multirow{2}{*}{$\begin{array}{l}\text { Total EC } \\
\text { contributions } \\
\text { (€Mio.) }\end{array}$} & \multirow{2}{*}{$\begin{array}{l}\text { EC contributions } \\
\text { to Finland } \\
\text { (€Mio.) } \\
0.1\end{array}$} & \multirow{2}{*}{$\begin{array}{l}\% \\
4.3 \%\end{array}$} \\
\hline $\begin{array}{l}\text { Science with and } \\
\text { for Society }\end{array}$ & SCIENCE & $\begin{array}{l}\text { Encourage citizens to engage in } \\
\text { science }\end{array}$ & & & \\
\hline $\begin{array}{l}\text { Societal } \\
\text { Challenges }\end{array}$ & ENV & $\begin{array}{l}\text { Climate action, environment, } \\
\text { resource efficiency and raw } \\
\text { materials }\end{array}$ & 1133 & 37 & $3.3 \%$ \\
\hline $\begin{array}{l}\text { Industrial } \\
\text { Leadership }\end{array}$ & ADVMANU & $\begin{array}{l}\text { Advanced manufacturing and } \\
\text { processing }\end{array}$ & 857 & 28 & $3.3 \%$ \\
\hline $\begin{array}{l}\text { Science with and } \\
\text { for Society }\end{array}$ & CAREER & $\begin{array}{l}\text { Make scientific and technological } \\
\text { careers attractive for young people }\end{array}$ & 32 & 1 & $3.0 \%$ \\
\hline $\begin{array}{l}\text { Societal } \\
\text { Challenges }\end{array}$ & SECURITY & $\begin{array}{l}\text { Secure societies - Protecting } \\
\text { freedom and security of Europe and } \\
\text { its citizens }\end{array}$ & 595 & 18 & $2.9 \%$ \\
\hline $\begin{array}{l}\text { Societal } \\
\text { Challenges }\end{array}$ & ENERGY & Secure, clean and efficient energy & 2253 & 62 & $2.8 \%$ \\
\hline Excellent Science & INFRA & Research infrastructures & 1026 & 28 & $2.7 \%$ \\
\hline $\begin{array}{l}\text { Industrial } \\
\text { Leadership }\end{array}$ & ICT & $\begin{array}{l}\text { Information and Communication } \\
\text { Technologies }\end{array}$ & 3096 & 83 & $2.7 \%$ \\
\hline $\begin{array}{l}\text { Societal } \\
\text { Challenges }\end{array}$ & SOCIETY & $\begin{array}{l}\text { Europe in a changing world - } \\
\text { inclusive, innovative and reflective } \\
\text { Societies }\end{array}$ & 381 & 9 & $2.4 \%$ \\
\hline $\begin{array}{l}\text { Industrial } \\
\text { Leadership }\end{array}$ & ADVMAT & Advanced materials & 361 & 9 & $2.4 \%$ \\
\hline $\begin{array}{l}\text { Societal } \\
\text { Challenges }\end{array}$ & FOOD & $\begin{array}{l}\text { Food security, sustainable } \\
\text { agriculture and forestry, marine and } \\
\text { maritime and inland water research }\end{array}$ & 1279 & 30 & $2.3 \%$ \\
\hline $\begin{array}{l}\text { Industrial } \\
\text { Leadership }\end{array}$ & BIOTECH & Biotechnology & 153 & 3 & $2.2 \%$ \\
\hline
\end{tabular}


There are then 16 sub-programmes (shown below) where EC contributions to Finnish participations account for less than $2.2 \%$ of all funding to each of these areas of Horizon 2020. In addition, there are other sub-programmes where Finland has not received any funding. These include ERA, INTNET, NCPNET, RESACESS, SEAWP-CROSST and SWAFS-CROSST.

Table 29 Sub-programmes where Finland accounts for the lowest proportion of EC contributions awarded

\begin{tabular}{|c|c|c|c|c|c|}
\hline $\begin{array}{l}\text { Horizon } 2020 \\
\text { Programme }\end{array}$ & Sub-programme & & $\begin{array}{l}\text { Total EC } \\
\text { Contr. (€Mio.) }\end{array}$ & $\begin{array}{l}\text { EC Contr. } \\
\text { to } \mathrm{FI}(€ \text { Mio.) }\end{array}$ & $\%$ \\
\hline Societal Challenges & TPT & $\begin{array}{l}\text { Smart, green and integrated } \\
\text { transport }\end{array}$ & 1,953 & 40 & $2.0 \%$ \\
\hline $\begin{array}{l}\text { Science with and for } \\
\text { Society }\end{array}$ & GENDEREQ & $\begin{array}{l}\text { Promote gender equality in research } \\
\text { and innovation }\end{array}$ & 28 & 1 & $2.0 \%$ \\
\hline Excellent Science & ERC & European Research Council & 5,273 & 104 & $2.0 \%$ \\
\hline Societal Challenges & HEALTH & $\begin{array}{l}\text { Health, demographic change and } \\
\text { wellbeing }\end{array}$ & 2,191 & 43 & $1.9 \%$ \\
\hline Euratom & EURATOM & Euratom & 640 & 12 & $1.9 \%$ \\
\hline $\begin{array}{l}\text { Science with and for } \\
\text { Society }\end{array}$ & INEGSOC & $\begin{array}{l}\text { Integrate society in science and } \\
\text { innovation }\end{array}$ & 40 & 1 & $1.7 \%$ \\
\hline Excellent Science & MSCA & Excellent Science & 2,891 & 45 & $1.6 \%$ \\
\hline Excellent Science & FET & Future and Emerging Technologies & 706 & 11 & $1.5 \%$ \\
\hline $\begin{array}{l}\text { Science with and for } \\
\text { Society }\end{array}$ & GOV & $\begin{array}{l}\text { Develop the governance for the } \\
\text { advancement of responsible } \\
\text { research and innovation }\end{array}$ & 46 & 1 & $1.5 \%$ \\
\hline Industrial Leadership & SPACE & Space & 373 & 5 & $1.4 \%$ \\
\hline $\begin{array}{l}\text { Spreading excellence } \\
\text { and widening } \\
\text { participation }\end{array}$ & TWINING & Twinning of research institutions & 67 & 1 & $1.3 \%$ \\
\hline Industrial Leadership & NMP & $\begin{array}{l}\text { Nanotechnologies, Advanced } \\
\text { Materials and Production }\end{array}$ & 414 & 5 & $1.3 \%$ \\
\hline Cross-theme & CROSST & Cross-theme & 200 & 2 & $1.1 \%$ \\
\hline Industrial Leadership & RISKFINANCE & Access to risk finance & 8 & 0.1 & $1.1 \%$ \\
\hline Industrial Leadership & SME & Innovation in SMEs & 113 & 1 & $0.9 \%$ \\
\hline $\begin{array}{l}\text { Spreading excellence } \\
\text { and widening } \\
\text { participation }\end{array}$ & WIDESPREAD & $\begin{array}{l}\text { Teaming of excellent research } \\
\text { institutions and low performing RDI } \\
\text { regions }\end{array}$ & 166 & 1 & $0.6 \%$ \\
\hline
\end{tabular}

\section{Focus area participation statistics}

In the tables below we profile the locations within FP7/H2020 where we have identified areas of relevance to the three priority topics. These tables show the overall funding provided to each sub-programme of $\mathrm{FP} 7 / \mathrm{H} 2020$, as well as the amount and proportion of this accounted for by projects tagged within each of the three priority areas. This provides an overview of both the distribution and scale of relevant activity (i.e. where across FP programmes has relevant activity taken place and how significant is this within the wider portfolio of projects). Shading has been used to highlight the main concentrations of relevant activity - either in absolute terms, or relative to the overall size of each subprogramme. 
Table 30 EC contributions to FP7 projects (all, Health \& Wellbeing, CBC, Digitalisation) - by sub-programme

\begin{tabular}{|c|c|c|c|c|c|c|c|c|}
\hline & & \multicolumn{4}{|c|}{ EC Contributions (€million) to... } & \multicolumn{3}{|c|}{ \% of EC Contributions to.. } \\
\hline & & All projects & $\begin{array}{c}\text { Health \& Wellbeing } \\
\text { projects }\end{array}$ & $\begin{array}{c}\mathrm{CBC} \\
\text { projects }\end{array}$ & $\begin{array}{c}\text { Digitalisation } \\
\text { projects }\end{array}$ & $\begin{array}{l}\text { Health \& Wellbeing } \\
\text { projects }\end{array}$ & $\begin{array}{c}\text { CBC } \\
\text { projects }\end{array}$ & $\begin{array}{c}\text { Digitalisation } \\
\text { projects }\end{array}$ \\
\hline COOPERATION & & 28,643 & 13,383 & 16,241 & 14,549 & $47 \%$ & $57 \%$ & $51 \%$ \\
\hline HEALTH & Health & 4,786 & 4,706 & 3,765 & 1,139 & $98 \%$ & $79 \%$ & $24 \%$ \\
\hline KBBE & Food, Agriculture, and Biotechnology & 1,851 & 1,374 & 1,634 & 418 & $74 \%$ & $88 \%$ & $23 \%$ \\
\hline ICT & Information and Communication Technologies & 7,874 & 2,781 & 3,208 & 6,563 & $35 \%$ & $41 \%$ & $83 \%$ \\
\hline NMP & $\begin{array}{l}\text { Nanosciences, Nanotechnologies, Materials and } \\
\text { new Production Technologies }\end{array}$ & 3,232 & 1,449 & 2,087 & 2,647 & $45 \%$ & $65 \%$ & $82 \%$ \\
\hline ENERGY & Energy & 1,810 & 372 & 1,285 & 605 & $21 \%$ & $71 \%$ & $33 \%$ \\
\hline ENV & Environment (including Climate Change) & 1,719 & 626 & 1,246 & 421 & $36 \%$ & $72 \%$ & $25 \%$ \\
\hline TPT & Transport (including Aeronautics) & 2,218 & 529 & 1,014 & 877 & $24 \%$ & $46 \%$ & $40 \%$ \\
\hline SSH & Socio-economic sciences and Humanities & 580 & 187 & 230 & 57 & $32 \%$ & $40 \%$ & $10 \%$ \\
\hline SPA & Space & 713 & 85 & 262 & 331 & $12 \%$ & $37 \%$ & $46 \%$ \\
\hline SEC & Security & 1,332 & 265 & 424 & 698 & $20 \%$ & $32 \%$ & $52 \%$ \\
\hline GA & General Activities (Annex IV) & 312 & 14 & 274 & 6 & $4 \%$ & $88 \%$ & $2 \%$ \\
\hline SP1-JTI & Joint Technology Initiatives (Annex IV-SP1) & 2,216 & 995 & 813 & 786 & $45 \%$ & $37 \%$ & $35 \%$ \\
\hline IDEAS & & 7713 & 4207 & 4200 & 2056 & $56 \%$ & & \\
\hline ERC & European Research Council & 7,713 & $\begin{array}{l}4,291 \\
4,297 \\
\end{array}$ & $\begin{array}{r}4,0<0 \\
4,328 \\
\end{array}$ & $\begin{array}{l}3,050 \\
3,056\end{array}$ & $56 \%$ & $56 \%$ & $40 \%$ \\
\hline & & & & & & & & \\
\hline PEOPLE & & $\mathbf{4 , 7 5 4}$ & 2,536 & 2,630 & 1,778 & $53 \%$ & $55 \%$ & $37 \%$ \\
\hline PEOPLE & Marie-Curie Actions & 4,754 & 2,536 & 2,630 & 1,778 & $53 \%$ & $55 \%$ & $37 \%$ \\
\hline & & & & & & & & \\
\hline CAPACITIES & & 3,769 & 1,708 & 2,134 & 1,777 & $45 \%$ & $57 \%$ & $47 \%$ \\
\hline INFRA & Research Infrastructures & 1,528 & 718 & 861 & 755 & $47 \%$ & $56 \%$ & $49 \%$ \\
\hline SME & Research for the benefit of SMEs & 1,245 & 511 & 740 & 642 & $41 \%$ & $59 \%$ & $52 \%$ \\
\hline REGIONS & Regions of Knowledge & 127 & 61 & 89 & 43 & $48 \%$ & $70 \%$ & $34 \%$ \\
\hline REGPOT & Research Potential & 378 & 263 & 250 & 209 & $70 \%$ & $66 \%$ & $55 \%$ \\
\hline Sis & Science in Society & 288 & 93 & 108 & 79 & $32 \%$ & $38 \%$ & $27 \%$ \\
\hline $\mathrm{COH}$ & Coherent development of research policies & 29 & 7 & 1 & 1 & $23 \%$ & $5 \%$ & $3 \%$ \\
\hline INCO & Activities of International Cooperation & 173 & 55 & 84 & 49 & $32 \%$ & $48 \%$ & $28 \%$ \\
\hline Euratom & & 358 & 193 & 220 & 137 & $54 \%$ & $62 \%$ & $38 \%$ \\
\hline Fission & Nuclear Fission and Radiation Protection & 353 & 191 & 218 & 137 & $54 \%$ & $62 \%$ & $39 \%$ \\
\hline Fusion & Fusion Energy & 5 & 2 & 2 & & $40 \%$ & $40 \%$ & $0 \%$ \\
\hline Total & & 45,236 & 22,116 & 25,555 & 21,296 & $49 \%$ & $56 \%$ & $47 \%$ \\
\hline
\end{tabular}


Table 31 EC contributions to H2020 projects (all, Health \& Wellbeing, CBC, Digitalisation) - by sub-programme

\begin{tabular}{|c|c|c|c|c|c|c|c|c|}
\hline & & \multicolumn{4}{|c|}{ EC Contributions (€million) to... } & \multicolumn{3}{|c|}{$\%$ of EC Contributions to... } \\
\hline & & $\begin{array}{l}\text { All } \\
\text { projects }\end{array}$ & $\begin{array}{l}\text { H\&W } \\
\text { projects }\end{array}$ & $\begin{array}{l}\text { CBC } \\
\text { projects }\end{array}$ & $\begin{array}{l}\text { Digit' } \\
\text { projects }\end{array}$ & $\begin{array}{l}\text { H\&W } \\
\text { projects }\end{array}$ & $\begin{array}{l}\text { CBC } \\
\text { projects }\end{array}$ & $\begin{array}{l}\text { Digit } \\
\text { projects }\end{array}$ \\
\hline \multicolumn{2}{|l|}{ Excellent Science } & 9,897 & 5,381 & 5,271 & 4,419 & $54 \%$ & $53 \%$ & $45 \%$ \\
\hline ERC & European Research Council & 5,273 & 2,807 & 2,779 & 2,202 & $53 \%$ & $53 \%$ & $42 \%$ \\
\hline FET & Future and Emerging Technologies & 706 & 346 & 234 & 469 & $49 \%$ & $33 \%$ & $66 \%$ \\
\hline MSCA & Marie Sklodowska-Curie actions & 2,891 & 1,774 & 1,713 & 1,225 & $61 \%$ & $59 \%$ & $42 \%$ \\
\hline INFRA & Research infrastructures & 1,026 & 454 & 545 & 523 & $44 \%$ & $53 \%$ & $51 \%$ \\
\hline \multicolumn{2}{|l|}{ Industrial Leadership } & 5,375 & 1,655 & 2,236 & 4,275 & $31 \%$ & $42 \%$ & $80 \%$ \\
\hline ICT & Information and Communication Technologies & 3,096 & 911 & 868 & 2,762 & $29 \%$ & $28 \%$ & $89 \%$ \\
\hline NMP & Nanotechnologies, Advanced Materials and Production & 414 & 240 & 250 & 356 & $58 \%$ & $60 \%$ & $86 \%$ \\
\hline ADVMAT & Advanced materials & 361 & 105 & 248 & 275 & $29 \%$ & $69 \%$ & $76 \%$ \\
\hline BIOTECH & Biotechnology & 153 & 130 & 143 & 60 & $85 \%$ & $93 \%$ & $39 \%$ \\
\hline ADVMANU & Advanced manufacturing and processing & 857 & 196 & 555 & 586 & $23 \%$ & $65 \%$ & $68 \%$ \\
\hline SPACE & Space & 373 & 35 & 109 & 209 & $9 \%$ & $29 \%$ & $56 \%$ \\
\hline RISKFINANCE & Access to risk finance & 8 & - & 3 & 2 & $0 \%$ & $32 \%$ & $27 \%$ \\
\hline SME & Innovation in SMEs & 113 & 37 & 60 & 24 & $33 \%$ & $54 \%$ & $21 \%$ \\
\hline \multicolumn{2}{|c|}{ Societal Challenges } & 9,784 & 4,302 & 6,804 & 3,867 & $44 \%$ & $70 \%$ & $40 \%$ \\
\hline HEALTH & \multirow{2}{*}{$\begin{array}{l}\text { Health, demographic change and wellbeing } \\
\text { Food security, sustainable agriculture and forestry, marine and maritime and } \\
\text { inland water research }\end{array}$} & 2,191 & 2,141 & 1,453 & 686 & $98 \%$ & $66 \%$ & $31 \%$ \\
\hline FOOD & & 1,279 & 749 & 1,196 & 360 & $59 \%$ & $93 \%$ & $28 \%$ \\
\hline \multirow{5}{*}{$\begin{array}{l}\text { ENERGY } \\
\text { TPT } \\
\text { ENV } \\
\text { SOCIETY } \\
\text { SECURITY }\end{array}$} & Secure, clean and efficient energy & 2,253 & 463 & 1,855 & 863 & $21 \%$ & $82 \%$ & $38 \%$ \\
\hline & Smart, green and integrated transport & 1,953 & 357 & 958 & 940 & $18 \%$ & $49 \%$ & $48 \%$ \\
\hline & Climate action, environment, resource efficiency and raw materials & 1,133 & 346 & 954 & 457 & $31 \%$ & $84 \%$ & $40 \%$ \\
\hline & Europe in a changing world - inclusive, innovative, reflective Societies & 381 & 68 & 161 & 163 & $18 \%$ & $42 \%$ & $43 \%$ \\
\hline \multirow{2}{*}{\multicolumn{2}{|c|}{$\begin{array}{l}\text { SECURIIr } \\
\text { Spreading excellence }\end{array}$}} & 595 & 177 & 227 & 398 & $30 \%$ & $38 \%$ & $67 \%$ \\
\hline & & 361 & 144 & 198 & 99 & $40 \%$ & $55 \%$ & $27 \%$ \\
\hline $\begin{array}{l}\text { SEAWP-CROSST } \\
\text { SE }\end{array}$ & Spreading excellence and widening participation - Cross-theme & 2 & 1 & 2 & & $75 \%$ & $88 \%$ & $0 \%$ \\
\hline WIDESPREAD & Teaming excellent research institutions \& low performing RDI regions & 166 & 76 & 142 & 55 & $46 \%$ & $86 \%$ & $33 \%$ \\
\hline TWINING & $\begin{array}{l}\text { Twinning of research institutions } \\
\text {. }\end{array}$ & 67 & 43 & 35 & 30 & $63 \%$ & $51 \%$ & $44 \%$ \\
\hline ERA & ERA chairs & 34 & 24 & 19 & 15 & $71 \%$ & $57 \%$ & $43 \%$ \\
\hline INTNET & Supporting access to international networks & 90 & - & - & - & $0 \%$ & $0 \%$ & $0 \%$ \\
\hline NCPNET & Transnational networks of National Contact Points & 2 & - & - & - & $0 \%$ & $0 \%$ & $0 \%$ \\
\hline \multicolumn{2}{|c|}{ Science with and for society } & 154 & 40 & 57 & 49 & $26 \%$ & $37 \%$ & $32 \%$ \\
\hline SWAFS-CROSST & Science with and for Society - Cross-theme & 4 & & 1 & 1 & $0 \%$ & $24 \%$ & $19 \%$ \\
\hline CAREER & Make scientific and technological careers attractive for young people & 32 & 6 & 7 & 13 & $18 \%$ & $23 \%$ & $41 \%$ \\
\hline GENDEREQ & Promote gender equality in research and innovation & 28 & 5 & 9 & 2 & $17 \%$ & $31 \%$ & $7 \%$ \\
\hline INEGSOC & Integrate society in science and innovation & 40 & 14 & 20 & 14 & $35 \%$ & $49 \%$ & $34 \%$ \\
\hline SCIENCE & Encourage citizens to engage in science & 3 & - & - & - & $0 \%$ & $0 \%$ & $0 \%$ \\
\hline RESACCESS & Develop the accessibility \& use of results of publicly-funded research & 1 & - & 1 & 1 & $0 \%$ & $100 \%$ & $100 \%$ \\
\hline GOV & Develop the governance for the advancement of RRI & 46 & 15 & 19 & 19 & $33 \%$ & $41 \%$ & $41 \%$ \\
\hline EURATOM & Euratom & 640 & 83 & 111 & 86 & $13 \%$ & $17 \%$ & $13 \%$ \\
\hline
\end{tabular}




\begin{tabular}{|c|c|c|c|c|c|c|c|c|}
\hline & & \multicolumn{4}{|c|}{ EC Contributions (€million) to... } & \multicolumn{3}{|c|}{$\%$ of EC Contributions to... } \\
\hline & & $\begin{array}{l}\text { All } \\
\text { projects }\end{array}$ & $\begin{array}{l}\mathrm{H} \& \mathrm{~W} \\
\text { projects }\end{array}$ & $\begin{array}{l}\text { CBC } \\
\text { projects }\end{array}$ & $\begin{array}{l}\text { Digit' } \\
\text { projects }\end{array}$ & $\begin{array}{l}\mathrm{H} \& \mathrm{~W} \\
\text { projects }\end{array}$ & $\begin{array}{l}\text { CBC } \\
\text { projects }\end{array}$ & $\begin{array}{l}\text { Digit } \\
\text { projects }\end{array}$ \\
\hline CROSST & Cross-theme & 200 & 74 & 131 & 87 & $37 \%$ & $66 \%$ & $43 \%$ \\
\hline Total & & 26,410 & 11,678 & 14,807 & 12,881 & $44 \%$ & $56 \%$ & $49 \%$ \\
\hline
\end{tabular}


Finnish participation in the area of Health \& Wellbeing within FP7 and Horizon 2020

The following analysis is based on our screening and tagging of action lines and proposals as relevant to the field of Health \& Wellbeing, as described in the end of this appendix. When we refer to Health \& Wellbeing proposals or participations this relates to our categorisation, and not to specific programmes within FP7 or Horizon 2020.

Finnish actors have contributed to the submission of 3,051 Health \& Wellbeing proposals in Horizon 2020 (as of May 2017). This equates to $5.3 \%$ of all such proposals submitted to the programme during this period. It is only slightly lower than the proportion of FP7 Health \& Wellbeing proposals involving Finland (5.8\%).

As is shown below, Austria, Denmark, Netherlands, and Sweden have all participated in a greater number and proportion of Health \& Wellbeing proposals than Finland, in both FP7 and Horizon 2020. When taking into account the relative number of $R \& D$ personnel in each country, the number of proposals involving Finland compares unfavourably with all comparator countries in FP7 and with half of these countries in Horizon 2020.

Table 32 FP7/Horizon 2020 Health \& Wellbeing proposals involving Finland and comparator countries

\begin{tabular}{lllllllll}
\hline Horizon 2020 & All & FI & AT & DK & IE & NL & NO & SE \\
\hline Number of proposals involving... & 58,055 & 3,051 & 3,519 & 3,826 & 2,624 & 8,431 & 2,189 & 4,745 \\
\hline Proportion of all proposals involving ... & & $5.3 \%$ & $6.1 \%$ & $6.6 \%$ & $4.5 \%$ & $14.5 \%$ & $3.8 \%$ & $8.2 \%$ \\
\hline Number of proposals per 1,000 researchers in ... & & 59.5 & 51.6 & 64.4 & 90.8 & 67.1 & 52.8 & 56.5 \\
\hline FP7 & All & FI & AT & DK & IE & NL & NO & SE \\
\hline Number of proposals involving ... & 76,165 & 4,380 & 5,129 & 4,801 & 3,525 & 11,379 & 4,096 & 7,633 \\
\hline Proportion of all proposals involving... & & $5.8 \%$ & $6.7 \%$ & $6.3 \%$ & $4.6 \%$ & $14.9 \%$ & $5.4 \%$ & $10.0 \%$ \\
\hline Number of proposals per 1,000 researchers in... & & 79 & 86 & 86 & 169 & 108 & 113 & 97 \\
\hline
\end{tabular}

In $45 \%$ of Horizon 2020 Health \& Wellbeing proposals involving Finland, a Finnish actor held the role of coordinator. This is higher than in FP7, where just $36 \%$ of Finnish Health \& Wellbeing proposals were led by a Finnish coordinator. Most comparator countries have seen a similar increase in coordination rates from FP7 to Horizon 2020, although only IE has achieved a higher rate than Fl in Horizon 2020.

If we take account of the relative size of the researcher base in each country, the number of Health \& Wellbeing proposal coordinators from Finland in Horizon 2020 (27 per 1,000 researchers) is below the rate seen in half of the comparator countries. This is a slight improvement on FP7 in Finland's relative position.

Table 33 FP7/Horizon 2020 Health \& Wellbeing proposals with a 'domestic' coordinator

\begin{tabular}{|c|c|c|c|c|c|c|c|c|}
\hline Horizon 2020 & All & $\mathrm{FI}$ & AT & DK & $\mathrm{IE}$ & $\mathrm{NL}$ & NO & SE \\
\hline Number of proposals with domestic coordinator & 58,055 & 1,363 & 1,085 & 1,673 & 1,191 & 3,577 & 869 & 1,949 \\
\hline $\begin{array}{l}\% \text { of country's proposals with domestic } \\
\text { coordinator }\end{array}$ & & $45 \%$ & $31 \%$ & $44 \%$ & $45 \%$ & $42 \%$ & $40 \%$ & $41 \%$ \\
\hline Coordinators per 1,000 researchers & & 26.6 & 15.9 & 28.2 & 41.2 & 28.5 & 20.9 & 23.2 \\
\hline FP7 & All & FI & AT & DK & IE & NL & NO & SE \\
\hline Number of proposals with domestic coordinator & 76,165 & 1,580 & 1,706 & 1,600 & 1,415 & 4,485 & 1,025 & 3,039 \\
\hline $\begin{array}{l}\% \text { of country's proposals with domestic } \\
\text { coordinator }\end{array}$ & & $36 \%$ & $33 \%$ & $33 \%$ & $40 \%$ & $39 \%$ & $25 \%$ & $40 \%$ \\
\hline Coordinators per 1,000 researchers & & 28.6 & 28.5 & 28.6 & 67.9 & 42.5 & 28.2 & 38.7 \\
\hline
\end{tabular}


Finland has participated in 2,114 multi-partner Horizon 2020 Health \& Wellbeing

proposals, of which it has served as the coordinator in 426 (20.2\%). This is a higher rate than in AT, DK, NO or SE, but below that in IE or NL. It is also higher than Finland achieved in FP7 (16.8\%). The Finnish rate of Health \& Wellbeing proposal coordination in Horizon 2020 , relative to the FTE researcher population is lower than most comparator countries, but its relative position has improved slightly from FP7.

Table 34 FP7/H2020 'multi-partner' (MP) Health \& Wellbeing proposals with a 'domestic' coordinator

\begin{tabular}{|c|c|c|c|c|c|c|c|c|}
\hline $\mathrm{H} 2020$ & All & $\mathrm{FI}$ & AT & DK & IE & NL & NO & SE \\
\hline Number of MP proposals involving... & 19,366 & 2,114 & 2,844 & 2,676 & 1,920 & 6,158 & 1,631 & 3,298 \\
\hline $\begin{array}{l}\text { Number of MP proposals with } \\
\text { domestic coordinator }\end{array}$ & 19,366 & 426 & 410 & 523 & 487 & 1,304 & 311 & 502 \\
\hline $\begin{array}{l}\text { \% of country's MP proposals with } \\
\text { domestic coordinator }\end{array}$ & & $20.2 \%$ & $14.4 \%$ & $19.5 \%$ & $25.4 \%$ & $21.2 \%$ & $19.1 \%$ & $15.2 \%$ \\
\hline $\begin{array}{l}\text { Coordinators of MP proposals per } \\
1,000 \text { researchers }\end{array}$ & & 41.2 & 41.7 & 45.1 & 66.4 & 49.0 & 39.3 & 39.3 \\
\hline FP7 & All & $\mathrm{FI}$ & AT & DK & IE & NL & NO & SE \\
\hline Number of MP proposals involving... & 30,737 & 3,367 & 4,236 & 3,837 & 2,776 & 8,677 & 2,488 & 5,650 \\
\hline $\begin{array}{l}\text { Number of MP proposals with } \\
\text { domestic coordinator }\end{array}$ & 30,737 & 567 & 813 & 636 & 666 & 1,783 & 494 & 1,056 \\
\hline $\begin{array}{l}\text { \% of country's MP proposals with } \\
\text { domestic coordinator }\end{array}$ & & $16.8 \%$ & $19.2 \%$ & $16.6 \%$ & $24.0 \%$ & $20.5 \%$ & $19.9 \%$ & $18.7 \%$ \\
\hline $\begin{array}{l}\text { Coordinators of MP proposals per } \\
1,000 \text { researchers }\end{array}$ & & 10.3 & 13.6 & 11.4 & 31.9 & 16.9 & 13.6 & 13.4 \\
\hline
\end{tabular}

Because of multiple Finnish participations in some proposals, the total number of Finnish participations in $\mathrm{H} 2020$ Health \& Wellbeing proposals $(4,102)$ is double than the number of unique Health \& Wellbeing proposals in which Finland is involved $(2,114)$. These Finnish participations represent $2.1 \%$ of all participations in $\mathrm{H} 2020$ Health \& Wellbeing proposals, which is lower than AT, DK, NL and SE, but higher than IE and NO. When taking account of the size of the respective researcher populations, Finland's number of participations in H2020 Health \& Wellbeing proposals (80 per 1,000 R\&D personnel) puts it in the middle of the group of comparator countries.

Finland accounted for a similar proportion (2.0\%) of all FP7 participations in Health \& Wellbeing proposals. However, because of the longer time-period covered, its participation rate (106.9 per 1,000 R\&D personnel) was higher than observed in H2020. Despite this, Finland's participation rate in FP7 was lower than all comparator countries.

Table 35 Participations in FP7/H2020 Health \& Wellbeing proposals from Finland and comparator countries

\begin{tabular}{|c|c|c|c|c|c|c|c|c|}
\hline $\mathrm{H} 2020$ & All & $\mathrm{FI}$ & AT & DK & IE & NL & NO & SE \\
\hline Number of participations in proposals & 193,821 & 4,102 & 4,608 & 4,863 & 3,363 & 12,436 & 2,805 & 6,112 \\
\hline $\begin{array}{l}\text { Proportion of all participations in } \\
\text { proposals }\end{array}$ & & $2.1 \%$ & $2.4 \%$ & $2.5 \%$ & $1.7 \%$ & $6.4 \%$ & $1.4 \%$ & $3.2 \%$ \\
\hline $\begin{array}{l}\text { Number of participations in proposals } \\
\text { per } 1,000 \text { researchers in... }\end{array}$ & & 80.0 & 67.5 & 81.9 & 116.3 & 98.9 & 67.6 & 72.8 \\
\hline FP7 & All & $\mathrm{FI}$ & AT & DK & IE & NL & NO & SE \\
\hline Number of participations in proposals & 294,228 & 5,904 & 6,881 & 6,199 & 4,613 & 16,789 & 4,096 & 10,194 \\
\hline $\begin{array}{l}\text { Proportion of all participations in } \\
\text { proposals }\end{array}$ & & $2.0 \%$ & $2.3 \%$ & $2.1 \%$ & $1.6 \%$ & $5.7 \%$ & $1.4 \%$ & $3.5 \%$ \\
\hline $\begin{array}{l}\text { Number of participations in proposals } \\
\text { per } 1,000 \text { researchers in... }\end{array}$ & & 106.9 & 114.8 & 110.8 & 221.3 & 159.1 & 112.6 & 129.7 \\
\hline
\end{tabular}

Table 33 shows the distribution of $\mathrm{H} 2020$ Health \& Wellbeing proposal participations between different types of actor (categorisations as used in eCORDA). For Finland, it shows that two organisation types (HES and PRC) account for the majority $(79 \%)$ of participations in Health \& Wellbeing proposals, with REC accounting for a further $17 \%$. The distribution of Finnish participations is similar to the overall average, although a slightly 
above average proportion is accounted for by HES organisations, while a slightly below average proportion is accounted for by PRC and REC organisations.

The table also shows the proportion of PRC participations that are SMEs. For Finland, the rate is $90 \%$, which is higher than the overall average, and higher than all of the comparators.

Table 36 Distribution of participations in H2020 Health \& Wellbeing proposals by organisational type

\begin{tabular}{|c|c|c|c|c|c|c|c|c|}
\hline $\mathrm{H} 2020$ & All & FI & AT & DK & IE & NL & NO & SE \\
\hline HES - Higher or secondary education & $43 \%$ & $49 \%$ & $44 \%$ & $54 \%$ & $59 \%$ & $51 \%$ & $46 \%$ & $62 \%$ \\
\hline PRC - Private for profit (excl. education) & $32 \%$ & $30 \%$ & $31 \%$ & $30 \%$ & $33 \%$ & $32 \%$ & $27 \%$ & $27 \%$ \\
\hline REC - Research organisations & $20 \%$ & $17 \%$ & $20 \%$ & $7 \%$ & $4 \%$ & $12 \%$ & $23 \%$ & $6 \%$ \\
\hline PUB - Public body (excl. REC/HES) & $3 \%$ & $3 \%$ & $2 \%$ & $7 \%$ & $2 \%$ & $2 \%$ & $2 \%$ & $4 \%$ \\
\hline OTH - Others & $3 \%$ & $2 \%$ & $4 \%$ & $2 \%$ & $2 \%$ & $3 \%$ & $1 \%$ & $1 \%$ \\
\hline Total & 193,821 & 4,102 & 4,608 & 4,863 & 3,363 & 12,436 & 2,805 & 6,112 \\
\hline SMEs as a $\%$ of PRC & $81 \%$ & $90 \%$ & $75 \%$ & $81 \%$ & $82 \%$ & $82 \%$ & $84 \%$ & $81 \%$ \\
\hline
\end{tabular}

The average EC funding request per Finnish participation in H2020 Health \& Wellbeing proposals was around $€ 725$ thousand. This is slightly higher than in most of the comparator countries (except Sweden).

Table 37 EC contributions requested in H2020 Health \& Wellbeing proposals

\begin{tabular}{lcccccccc}
\hline H2020 & All & FI & AT & DK & IE & NL & NO & SE \\
\hline $\begin{array}{l}\text { Selected participations in } \\
\text { proposals (those with } \\
\text { financial data) }\end{array}$ & 193,821 & 4,102 & 4,608 & 4,863 & 3,363 & 12,436 & 2,805 & 6,112 \\
\hline $\begin{array}{l}\text { Total EC contribution } \\
\text { requested (€million) }\end{array}$ & 118,426 & 2,973 & 2,758 & 3,204 & 2,351 & 8,596 & 2,021 & 4,460 \\
\hline $\begin{array}{l}\text { Average EC contribution (€) } \\
\text { requested per participation }\end{array}$ & 611,007 & 724,871 & 598,467 & 658,791 & 698,990 & 691,180 & 720,471 & 729,779 \\
\hline
\end{tabular}

Below we compare the distribution of Health \& Wellbeing proposal participations at the subprogramme level (a full list of sub-programme acronyms and titles is provided in the end of this appendix).

Overall, Finland accounts for $2.1 \%$ of all participations in H2020 Health \& Wellbeing proposals.

It is more active (relatively) in 11 sub-programmes, and the CAREER, ICT, ERC and SOCIETY sub-programmes in particular, where it accounts for at least $3 \%$ of all Health \& Wellbeing proposal participations in each case. Only in the CAREER sub-programme is Finland more active than all of the comparator countries.

Table 38 H2O20 sub-programmes with a relatively high participation rate of Finland in Health \& Wellbeing proposals

\begin{tabular}{lcccccccc}
\hline & Overall & FI & AT & DK & IE & NL & NO & SE \\
\hline CAREER & 603 & $3.8 \%$ & $2.3 \%$ & $0.8 \%$ & $3.0 \%$ & $3.6 \%$ & $1.7 \%$ & $2.3 \%$ \\
\hline ICT & 16,321 & $3.0 \%$ & $2.8 \%$ & $1.7 \%$ & $2.2 \%$ & $5.8 \%$ & $1.6 \%$ & $2.5 \%$ \\
\hline ERC & 13,535 & $3.0 \%$ & $1.9 \%$ & $2.3 \%$ & $1.4 \%$ & $7.0 \%$ & $1.1 \%$ & $4.1 \%$ \\
\hline SOCIETY & 3,719 & $3.0 \%$ & $2.3 \%$ & $1.7 \%$ & $1.4 \%$ & $3.1 \%$ & $1.5 \%$ & $2.4 \%$ \\
\hline EURATOM & 575 & $2.8 \%$ & $0.7 \%$ & $0.5 \%$ & $0.2 \%$ & $3.5 \%$ & $0.5 \%$ & $6.3 \%$ \\
\hline SME & 663 & $2.6 \%$ & $3.2 \%$ & $3.9 \%$ & $1.2 \%$ & $5.4 \%$ & $1.7 \%$ & $3.5 \%$ \\
\hline HEALTH & 40,575 & $2.5 \%$ & $2.3 \%$ & $2.6 \%$ & $1.6 \%$ & $7.6 \%$ & $1.4 \%$ & $3.4 \%$ \\
\hline ADVMAT & 1,577 & $2.3 \%$ & $2.4 \%$ & $2.0 \%$ & $2.3 \%$ & $3.5 \%$ & $1.5 \%$ & $3.5 \%$ \\
\hline ENV & 6,107 & $2.3 \%$ & $2.1 \%$ & $1.9 \%$ & $1.1 \%$ & $6.0 \%$ & $1.3 \%$ & $3.4 \%$ \\
\hline NMP & 5,876 & $2.2 \%$ & $2.1 \%$ & $2.1 \%$ & $2.2 \%$ & $4.4 \%$ & $1.2 \%$ & $3.1 \%$ \\
\hline ENERGY & 6,668 & $2.2 \%$ & $2.6 \%$ & $2.8 \%$ & $1.5 \%$ & $5.4 \%$ & $2.0 \%$ & $2.8 \%$ \\
\hline
\end{tabular}




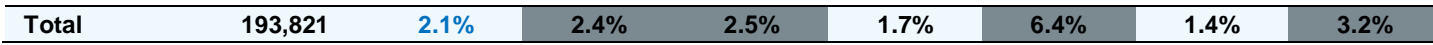

It is relatively less active in Health \& Wellbeing proposals in the remaining 20 subprogrammes (shown below). In particular, there have been no Finnish participations in relevant proposals in the ERA, RISKFINANCE, SEAWP and RESACCESS subprogrammes. Finland also only accounts for $1 \%$ or less of participations in relevant $\mathrm{H} 2020$ proposals in the INEGSOC, SCIENCE, and GENDEREQ sub-programmes.

Table 39 H2020 sub-programmes with a relatively low participation rate of Finland in Health \& Wellbeing proposals

\begin{tabular}{lcccccccc}
\hline & Overall & FI & AT & DK & IE & NL & NO & SE \\
\hline FET & 11,571 & $2.1 \%$ & $2.7 \%$ & $1.9 \%$ & $1.2 \%$ & $5.5 \%$ & $1.0 \%$ & $3.0 \%$ \\
\hline FOOD & 12,074 & $2.0 \%$ & $2.0 \%$ & $2.8 \%$ & $1.9 \%$ & $5.9 \%$ & $2.1 \%$ & $2.2 \%$ \\
\hline INFRA & 3,052 & $2.0 \%$ & $2.6 \%$ & $1.4 \%$ & $1.3 \%$ & $7.9 \%$ & $2.2 \%$ & $3.2 \%$ \\
\hline SPACE & 914 & $1.9 \%$ & $2.2 \%$ & $0.8 \%$ & $1.4 \%$ & $4.3 \%$ & $0.4 \%$ & $1.6 \%$ \\
\hline ADVMANU & 3,836 & $1.8 \%$ & $3.4 \%$ & $1.9 \%$ & $1.4 \%$ & $4.7 \%$ & $1.4 \%$ & $2.5 \%$ \\
\hline TWINING & 1,091 & $1.8 \%$ & $2.7 \%$ & $2.5 \%$ & $1.6 \%$ & $4.5 \%$ & $0.9 \%$ & $3.6 \%$ \\
\hline SECURITY & 3,140 & $1.7 \%$ & $2.7 \%$ & $1.0 \%$ & $2.4 \%$ & $4.1 \%$ & $1.8 \%$ & $1.8 \%$ \\
\hline WIDESPREAD & 902 & $1.7 \%$ & $3.1 \%$ & $0.4 \%$ & $0.4 \%$ & $2.4 \%$ & $0.4 \%$ & $2.1 \%$ \\
\hline TPT & 4,275 & $1.5 \%$ & $3.1 \%$ & $1.7 \%$ & $0.9 \%$ & $5.0 \%$ & $1.2 \%$ & $3.1 \%$ \\
\hline MSCA & 49,769 & $1.4 \%$ & $2.2 \%$ & $3.4 \%$ & $2.0 \%$ & $7.1 \%$ & $1.4 \%$ & $3.5 \%$ \\
\hline CROSST & 3,190 & $1.4 \%$ & $3.1 \%$ & $2.5 \%$ & $2.9 \%$ & $7.7 \%$ & $2.0 \%$ & $2.9 \%$ \\
\hline BIOTECH & 2,363 & $1.4 \%$ & $2.5 \%$ & $3.0 \%$ & $1.9 \%$ & $6.3 \%$ & $2.0 \%$ & $4.0 \%$ \\
\hline GOV & 276 & $1.4 \%$ & $5.8 \%$ & $3.3 \%$ & $0.7 \%$ & $7.2 \%$ & $2.5 \%$ & $1.1 \%$ \\
\hline INEGSOC & 581 & $1.0 \%$ & $4.6 \%$ & $1.0 \%$ & $1.2 \%$ & $3.4 \%$ & $0.3 \%$ & $0.9 \%$ \\
\hline SCIENCE & 222 & $0.9 \%$ & $1.4 \%$ & $2.3 \%$ & $2.3 \%$ & $3.6 \%$ & $1.8 \%$ & $3.2 \%$ \\
\hline GENDEREQ & 238 & $0.4 \%$ & $3.4 \%$ & $0.8 \%$ & $0.8 \%$ & $3.8 \%$ & $2.9 \%$ & $2.1 \%$ \\
\hline ERA & 46 & $0.0 \%$ & $0.0 \%$ & $0.0 \%$ & $0.0 \%$ & $0.0 \%$ & $0.0 \%$ & $0.0 \%$ \\
\hline RISKFINANCE & 36 & $0.0 \%$ & $2.8 \%$ & $5.6 \%$ & $2.8 \%$ & $0.0 \%$ & $0.0 \%$ & $2.8 \%$ \\
\hline SEAWP-CROSST & 16 & $0.0 \%$ & $12.5 \%$ & $0.0 \%$ & $0.0 \%$ & $12.5 \%$ & $0.0 \%$ & $6.3 \%$ \\
\hline RESACCESS & 10 & $0.0 \%$ & $0.0 \%$ & $0.0 \%$ & $0.0 \%$ & $10.0 \%$ & $0.0 \%$ & $0.0 \%$ \\
\hline & & & & & & & & $3.2 \%$ \\
\hline Total & 193,821 & $2.1 \%$ & $2.4 \%$ & $2.5 \%$ & $1.7 \%$ & $6.4 \%$ & $1.4 \%$ & 3 \\
\hline
\end{tabular}

\section{Success rates and participation in Health \& Wellbeing projects}

To May 2017, $370 \mathrm{H} 2020$ grants had been awarded to Health \& Wellbeing projects involving Finland. This represents $5.4 \%$ of all $\mathrm{H} 2020$ projects, which is lower than all the comparator countries other than Ireland and Norway. Finland compares even less favourably when one adjusts for the size of the research base in each country. Finland has been awarded 7.2 H2020 Health \& Wellbeing projects for every 1,000 R\&D personnel in the country, which is lower than any of the comparator countries.

Table 40 Health \& wellbeing Projects (per 1,000 R\&D personnel) - Finland and comparator countries

\begin{tabular}{lcccccccc}
\hline H2020 & All & FI & AT & DK & IE & NL & NO & SE \\
\hline Projects & 6,811 & 370 & 511 & 533 & 357 & 1,249 & 301 & 641 \\
\hline Projects per 1,000 researchers & & 7.2 & 7.5 & 9.0 & 12.3 & 9.9 & 7.3 & 7.6 \\
\hline FP7 & All & FI & AT & DK & IE & NL & NO & SE \\
\hline Projects & 12,330 & 847 & 1,087 & 1,083 & 719 & 2,541 & 550 & 1548 \\
\hline Projects per 1,000 researchers & & 15.3 & 18.1 & 19.4 & 34.5 & 24.1 & 15.1 & 19.7 \\
\hline
\end{tabular}

The $370 \mathrm{H} 2020$ Health \& Wellbeing projects involving Finland came from 3,051 proposals. This equates to a proposal success rate of $12.1 \%$ - which is slightly above the overall success rate of $\mathrm{H} 2020$ Health \& Wellbeing proposals (11.7\%), but below that of all comparator countries. Finnish success rates in FP7 Health \& Wellbeing proposals were 
higher (19.3\%) than in $\mathrm{H} 2020$, but this partly reflects higher success rates seen in FP7 overall (16.2\%). The Finnish rate in FP7 was still below all comparator countries, except Norway.

Table 41 Success rate of Health \& Wellbeing proposals - Finland and comparator countries

\begin{tabular}{lcccccccc}
\hline H2020 & All & FI & AT & DK & IE & NL & NO & SE \\
\hline Proposals & 58,055 & 3,051 & 3,519 & 3,826 & 2,624 & 8,431 & 2,189 & 4,745 \\
\hline Projects & 6,811 & 370 & 511 & 533 & 357 & 1,249 & 301 & 641 \\
\hline Success rate & $11.7 \%$ & $12.1 \%$ & $14.5 \%$ & $13.9 \%$ & $13.6 \%$ & $14.8 \%$ & $13.8 \%$ & $13.5 \%$ \\
\hline FP7 & All & FI & AT & DK & IE & NL & NO & SE \\
\hline Proposals & 76165 & 4380 & 5129 & 4801 & 3525 & 11379 & 4096 & 7633 \\
\hline Projects & 12330 & 847 & 1087 & 1083 & 719 & 2541 & 550 & 1548 \\
\hline Success rate & $16.2 \%$ & $19.3 \%$ & $21.2 \%$ & $22.6 \%$ & $20.4 \%$ & $22.3 \%$ & $13.4 \%$ & $20.3 \%$ \\
\hline
\end{tabular}

H2020 grants have been awarded to 107 Health \& Wellbeing projects with a Finnish coordinator. The equates to 2.1 projects for every 1,000 R\&D personnel in the country. This rate is below that of all comparator countries. The rate (coordinators per 1,000 personnel) for Finland in FP7 compared slightly better, but still below that of all comparator countries.

Table 42 Coordinators of Health \& Wellbeing projects (per 1,000 R\&D personnel) - Finland and comparator countries

\begin{tabular}{lccccccc}
\hline H2020 & All & FI & AT & DK & IE & NL & NO \\
\hline Coordinators & 6,811 & 107 & 165 & 226 & 161 & 578 & 89 \\
\hline Coordinators per 1,000 researchers & & 2.1 & 2.4 & 3.8 & 5.6 & 4.6 & 2.1 \\
\hline FP7 & All & FI & AT & DK & IE & NL & NO \\
\hline Coordinators & 12,409 & 174 & 306 & 262 & 259 & 895 & 141 \\
\hline Coordinators per 1,000 researchers & & 3.2 & 5.1 & 4.7 & 12.4 & 8.5 & 3.9 \\
\hline
\end{tabular}

The success rate of Finnish-coordinated Health \& Wellbeing H2020 proposals is $7.9 \%$ which is significantly lower than the overall $\mathrm{H} 2020$ figure (11.7\%), and below the rates of coordinator success achieved in all the comparator countries. In FP7, Finland's success rate for coordinators $(19.4 \%)$ was above average $(16.2 \%)$, but still below that achieved in most comparator countries (apart from Norway).

Table 43 Success rate of Health \& Wellbeing proposals with/without domestic coordinator - Finland and comparator countries

\begin{tabular}{lcccccccc}
\hline H2020 success rates & All & FI & AT & DK & IE & NL & NO & SE \\
\hline Proposal with domestic coordinator & $11.7 \%$ & $7.9 \%$ & $15.2 \%$ & $13.5 \%$ & $13.5 \%$ & $16.2 \%$ & $10.2 \%$ & $10.9 \%$ \\
\hline Proposal without domestic coordinator & & $\mathbf{1 5 . 6 \%}$ & $14.2 \%$ & $14.3 \%$ & $13.7 \%$ & $13.8 \%$ & $16.1 \%$ & $15.3 \%$ \\
\hline FP7 success rates & All & FI & AT & DK & IE & NL & NO & SE \\
\hline Proposal with domestic coordinator & $16.2 \%$ & $19.4 \%$ & $21.2 \%$ & $22.6 \%$ & $20.6 \%$ & $22.4 \%$ & $15.5 \%$ & $20.3 \%$ \\
\hline Proposal without domestic coordinator & & $\mathbf{2 4 . 1} \%$ & $22.9 \%$ & $25.7 \%$ & $22.1 \%$ & $24.0 \%$ & $16.1 \%$ & $24.3 \%$ \\
\hline
\end{tabular}

If we look only at $\mathrm{H} 2020$ Health \& Wellbeing proposals/projects with multiple participants (i.e. excluding those where the coordinator is the only partner), the success rate for $\mathrm{FI}$ coordinators increases from $12.1 \%$ to $14.1 \%$. This is higher than the overall H2O20 figure (11.1\%) but below that of four of the comparator countries (AT, NL, NO, \& SE).

Table 44 Success rate of multi-partner Health \& Wellbeing proposals with domestic coordinator

\begin{tabular}{lcccccccc}
\hline H2020 - multi partner & All & FI & AT & DK & IE & NL & NO & SE \\
\hline Proposals & 19,366 & 2,114 & 2,844 & 2,676 & 1,920 & 6,158 & 1,631 & 3,298 \\
\hline Projects & 2,156 & 299 & 409 & 372 & 258 & 874 & 250 & 486 \\
\hline
\end{tabular}




\begin{tabular}{lllllllll}
\hline Success rate & $11.1 \%$ & $14.1 \%$ & $14.4 \%$ & $13.9 \%$ & $13.4 \%$ & $14.2 \%$ & $15.3 \%$ & $14.7 \%$ \\
\hline
\end{tabular}

The 299 Health \& Wellbeing grants awarded to Finland in H2020 involve 506 individual Finnish participations. This represents $2.0 \%$ of all participations in $\mathrm{H} 2020$ projects, which is lower than most of the comparator countries (each of which accounts for between $2 \%$ and $8 \%$ of all participations). Even taking account of the size of the researcher base, Finland does not compare favourably with these countries. The 9.9 Health \& Wellbeing participations per 1,000 R\&D personnel in Finland is below the 10-16 achieved by most comparators. A similar pattern emerges for FP7.

Table 45 Participations in Health \& Wellbeing projects (per 1,000 R\&D personnel) - Finland and comparator countries

\begin{tabular}{lcccccccc}
\hline H2020 & All & FI & AT & DK & IE & NL & NO & SE \\
\hline Participations in projects & 25,779 & 506 & 721 & 685 & 463 & 2,055 & 403 & 882 \\
\hline Participations per 1,000 researchers & & 9.9 & 10.6 & 11.5 & 16.0 & 16.3 & 9.7 & 10.5 \\
\hline FP7 & All & FI & AT & DK & IE & NL & NO & SE \\
\hline Participations in projects & 62,658 & 1,339 & 1,596 & 1,480 & 978 & 4,203 & 788 & 2276 \\
\hline Participations per 1,000 researchers & & 24.3 & 26.6 & 26.5 & 46.9 & 39.8 & 21.7 & 29.0 \\
\hline
\end{tabular}

The 506 Finnish participations in successful H2020 Health \& Wellbeing projects, from an original 4,102 participations in proposals, represents a participation success rate of $12.3 \%$ in H2020 so far. This is below the overall rate of success for all participations in Health \& Wellbeing proposals, and also below that achieved in all of the comparator countries. Finland's FP7 participation success rate was also below the overall average, and the rates in all comparator countries.

Table 46 Success rate of Health \& Wellbeing participations - Finland and comparator countries

\begin{tabular}{lcccccccc}
\hline Participation success rate & All & FI & AT & DK & IE & NL & NO & SE \\
\hline H2020 & $13.3 \%$ & $\mathbf{1 2 . 3} \%$ & $15.6 \%$ & $14.1 \%$ & $13.8 \%$ & $16.5 \%$ & $14.4 \%$ & $14.4 \%$ \\
\hline FP7 & $21.3 \%$ & $19.2 \%$ & $22.3 \%$ & $23.9 \%$ & $22.7 \%$ & $23.2 \%$ & $25.0 \%$ & $21.2 \%$ \\
\hline
\end{tabular}

Comparing across different organisation types, success rates for Health \& Wellbeing participations were highest amongst Finnish public bodies (27\%). Rates here were higher than the overall average (23\%), but lower than most of the comparator countries (apart from DK). Finnish participations from PRC organisations performed well against most comparator countries, being higher than all apart from Ireland and the Netherlands. Elsewhere (HES, REC), Finnish participations achieved success rates that were slightly below the overall average, as well as below that achieved in all comparator countries.

The table also shows the success rate of SME-PRC participations in Health \& Wellbeing proposals ${ }^{172}$. For Finnish participations, the rate is $10 \%$, which is slightly below the $\mathrm{H} 2020$ average $(11 \%)$, as well as below that in all comparator countries.

Table 47 Success rate of Health \& Wellbeing participations, by organisation type - Finland and comparator countries (H2020)

\begin{tabular}{lcccccccc}
\hline Participation success rate & All & FI & AT & DK & IE & NL & NO & SE \\
\hline HES - Higher or secondary education & $12 \%$ & $10 \%$ & $13 \%$ & $14 \%$ & $13 \%$ & $15 \%$ & $12 \%$ & $13 \%$ \\
\hline PRC - Private for profit (excl. education) & $18 \%$ & $20 \%$ & $20 \%$ & $16 \%$ & $24 \%$ & $21 \%$ & $18 \%$ & $22 \%$ \\
\hline REC - Research organisations & $12 \%$ & $11 \%$ & $16 \%$ & $12 \%$ & $13 \%$ & $15 \%$ & $13 \%$ & $15 \%$ \\
\hline
\end{tabular}

${ }^{172}$ As mentioned previously, information on whether a PRC participant is an SME or not is only available for $78 \%$ of proposal participations and $80 \%$ of project participations. Success rates are calculated based only on those that are known. 


\begin{tabular}{lllllllll}
\hline PUB - Public body (excl. research and education) & $23 \%$ & $27 \%$ & $40 \%$ & $20 \%$ & $38 \%$ & $30 \%$ & $51 \%$ & $28 \%$ \\
\hline OTH - Others & $16 \%$ & $18 \%$ & $18 \%$ & $14 \%$ & $20 \%$ & $24 \%$ & $17 \%$ & $21 \%$ \\
\hline & & & & & & & \\
\hline PRC-SMES & $11 \%$ & $10 \%$ & $13 \%$ & $12 \%$ & $14 \%$ & $14 \%$ & $13 \%$ & $13 \%$ \\
\hline
\end{tabular}

EC contributions to Finnish participations in $\mathrm{H} 2020$ Health \& Wellbeing projects totalled $€ 234$ million, which equates to $2 \%$ of all funding to Health \& Wellbeing participations to date. This is below the proportion realised by most of the other comparator countries, but above that received by Ireland and Norway. The average contribution to each Finnish Health \& Wellbeing participation (at €462 thousand) is slightly higher than the overall $\mathrm{H} 2020 \mathrm{Health}$ \& Wellbeing average, but below that realised by all-but-one of the comparator countries (AT).

Table 48 EC contributions to Health \& Wellbeing participations as a proportion of requested funding - Finland and comparator countries

\begin{tabular}{|c|c|c|c|c|c|c|c|c|}
\hline $\mathrm{H} 2020$ & All & $\mathrm{FI}$ & AT & DK & IE & NL & NO & SE \\
\hline $\begin{array}{l}\text { Selected participations in } \\
\text { projects (those with } \\
\text { financial data) }\end{array}$ & 25,779 & 506 & 721 & 685 & 463 & 2055 & 403 & 882 \\
\hline $\begin{array}{l}\text { Total EC contribution } \\
(€ \text { million) }\end{array}$ & 11,678 & 234 & 332 & 325 & 224 & 1,100 & 187 & 457 \\
\hline $\begin{array}{l}\% \text { of total EC } \\
\text { contributions }\end{array}$ & & $2 \%$ & $3 \%$ & $3 \%$ & $2 \%$ & $9 \%$ & $2 \%$ & $4 \%$ \\
\hline $\begin{array}{l}\text { Average EC contribution } \\
(€) \text { per participation }\end{array}$ & 453,004 & 462,451 & 460,472 & 474,453 & 483,801 & 535,280 & 464,020 & 518,141 \\
\hline
\end{tabular}

There were 11 sub-programmes of $\mathrm{H} 2020$ where Finnish participation success rates in Health \& Wellbeing proposals were above the overall average. These are shown at the top of the table below and include SECURITY, ADVMAT and FET, where Finnish success rates were at least one-third higher than overall in these sub-programmes. Elsewhere Finnish success rates were below average, or Finland has not yet participated in relevant proposals. The total number of participations in relevant proposals is also shown to give a sense of the scale of opportunity for Health \& Wellbeing activity within each sub-programme.

Table 49 Finnish success rates in H2020 Health \& Wellbeing proposals by sub-programme

\begin{tabular}{|c|c|c|c|c|c|}
\hline Sub-programme & & $\begin{array}{c}\text { All } \\
\text { participations } \\
\text { in proposals }\end{array}$ & $\begin{array}{c}\text { Overall } \\
\text { success } \\
\text { rate }\end{array}$ & $\begin{array}{c}\text { FI } \\
\text { success } \\
\text { rate }\end{array}$ & $\begin{array}{c}\% \\
\text { differe } \\
\text { nce }\end{array}$ \\
\hline SECURITY & $\begin{array}{l}\text { Secure societies - Protecting freedom and } \\
\text { security of Europe and its citizens }\end{array}$ & 3,140 & $15.6 \%$ & $24.1 \%$ & $54.0 \%$ \\
\hline ADVMAT & Advanced materials & 1,577 & $13.5 \%$ & $18.9 \%$ & $40.1 \%$ \\
\hline FET & Future and Emerging Technologies & 11,571 & $5.1 \%$ & $7.0 \%$ & $38.7 \%$ \\
\hline INFRA & Research infrastructures & 3,052 & $42.0 \%$ & $55.7 \%$ & $32.6 \%$ \\
\hline EURATOM & Euratom & 575 & $52.7 \%$ & $68.8 \%$ & $30.5 \%$ \\
\hline SOCIETY & $\begin{array}{l}\text { Europe in a changing world - inclusive, } \\
\text { innovative and reflective Societies }\end{array}$ & 3,719 & $7.9 \%$ & $10.0 \%$ & $26.9 \%$ \\
\hline ADVMANU & Advanced manufacturing and processing & 3,836 & $12.9 \%$ & $15.9 \%$ & $24.0 \%$ \\
\hline WIDESPREAD & $\begin{array}{l}\text { Teaming of excellent research institutions and } \\
\text { low performing RDI regions }\end{array}$ & 902 & $21.7 \%$ & $26.7 \%$ & $22.7 \%$ \\
\hline ENV & $\begin{array}{l}\text { Climate action, environment, resource } \\
\text { efficiency and raw materials }\end{array}$ & 6,107 & $16.9 \%$ & $18.2 \%$ & $7.5 \%$ \\
\hline GOV & $\begin{array}{l}\text { Develop the governance for the advancement } \\
\text { of responsible research and innovation }\end{array}$ & 276 & $24.3 \%$ & $25.0 \%$ & $3.0 \%$ \\
\hline TWINING & Twinning of research institutions & 1,091 & $14.6 \%$ & $15.0 \%$ & $2.9 \%$ \\
\hline SCIENCE & Encourage citizens to engage in science & 222 & $0.0 \%$ & $0.0 \%$ & $\mathrm{n} / \mathrm{a}$ \\
\hline FOOD & $\begin{array}{l}\text { Food security, sustainable agriculture and } \\
\text { forestry, marine and maritime and inland } \\
\text { water research }\end{array}$ & 12,074 & $17.5 \%$ & $17.1 \%$ & $-2.2 \%$ \\
\hline ENERGY & Secure, clean and efficient energy & 6,668 & $16.1 \%$ & $15.6 \%$ & $-2.7 \%$ \\
\hline BIOTECH & Biotechnology & 2,363 & $9.6 \%$ & $9.4 \%$ & $-2.8 \%$ \\
\hline MSCA & Marie Sklodowska-Curie actions & 49,769 & $12.5 \%$ & $11.8 \%$ & $-5.1 \%$ \\
\hline ICT & Information and Communication Technologies & 16,321 & $15.5 \%$ & $14.1 \%$ & $-9.2 \%$ \\
\hline HEALTH & Health, demographic change and wellbeing & 40,575 & $10.9 \%$ & $9.8 \%$ & $-9.6 \%$ \\
\hline CAREER & $\begin{array}{l}\text { Make scientific and technological careers } \\
\text { attractive for young people }\end{array}$ & 603 & $6.8 \%$ & $4.3 \%$ & $-36.1 \%$ \\
\hline NMP & $\begin{array}{l}\text { Nanotechnologies, Advanced Materials and } \\
\text { Production }\end{array}$ & 5,876 & $9.9 \%$ & $6.1 \%$ & $-38.1 \%$ \\
\hline
\end{tabular}




\begin{tabular}{|c|c|c|c|c|c|}
\hline ERC & European Research Council & 13,535 & $14.6 \%$ & $7.4 \%$ & $-48.9 \%$ \\
\hline TPT & Smart, green and integrated transport & 4,275 & $23.1 \%$ & $10.9 \%$ & $-52.6 \%$ \\
\hline CROSST & Cross-theme & 3,190 & $4.9 \%$ & $2.3 \%$ & $-53.2 \%$ \\
\hline SPACE & Space & 914 & $12.9 \%$ & $5.9 \%$ & $-54.4 \%$ \\
\hline SME & Innovation in SMEs & 663 & $22.0 \%$ & $5.9 \%$ & $-73.3 \%$ \\
\hline GENDEREQ & $\begin{array}{l}\text { Promote gender equality in research and } \\
\text { innovation }\end{array}$ & 238 & $8.8 \%$ & $0.0 \%$ & $100.0 \%$ \\
\hline INEGSOC & Integrate society in science and innovation & 581 & $10.2 \%$ & $0.0 \%$ & $100.0 \%$ \\
\hline ERA & ERA chairs & 46 & $21.7 \%$ & $\mathrm{n} / \mathrm{a}$ & $\mathrm{n} / \mathrm{a}$ \\
\hline $\begin{array}{l}\text { SEAWP- } \\
\text { CROSST }\end{array}$ & $\begin{array}{l}\text { Spreading excellence and widening } \\
\text { participation - Cross-theme }\end{array}$ & 16 & $100.0 \%$ & $\mathrm{n} / \mathrm{a}$ & $\mathrm{n} / \mathrm{a}$ \\
\hline RESACCESS & $\begin{array}{l}\text { Develop the accessibility and the use of the } \\
\text { results of publicly-funded research }\end{array}$ & 10 & $0.0 \%$ & $n / a$ & $\mathrm{n} / \mathrm{a}$ \\
\hline RISKFINANCE & Access to risk finance & 36 & $0.0 \%$ & $\mathrm{n} / \mathrm{a}$ & $\mathrm{n} / \mathrm{a}$ \\
\hline Total & & 193,821 & $13.3 \%$ & $12.3 \%$ & $-7.3 \%$ \\
\hline
\end{tabular}

Overall, EC contributions to Finnish participations in H2020 Health \& Wellbeing projects accounted for $2.0 \%$ of total EC contributions to relevant projects. However, there are 9 subprogrammes where Finland achieved a higher proportion of the total - and in particular the SOCIETY, ADVMAT and ENV programmes, where Finland secured over $4 \%$ of the funding awarded to Health \& Wellbeing projects in each case. Elsewhere the proportion of funding awarded to Finland was below $2 \%$. In the three sub-programmes awarding most funding to Health \& Wellbeing projects (HEALTH, ERC and MSCA), Finland's share of contributions was between $1.7 \%$ and $2.0 \%$.

Table 50 EC contributions to Finnish participations in H2O2O Health \& Wellbeing projects, by sub-programme

\begin{tabular}{|c|c|c|c|c|}
\hline Sub-programme & & $\begin{array}{c}\text { Total EC } \\
\text { contributions } \\
\text { (€Mio.) }\end{array}$ & $\begin{array}{c}\text { EC } \\
\text { contributio } \\
\text { ns to FI } \\
\text { (€Mio.) }\end{array}$ & $\%$ \\
\hline SOCIETY & $\begin{array}{l}\text { Europe in a changing world - inclusive, innovative and } \\
\text { reflective Societies }\end{array}$ & 68 & 3 & $4.8 \%$ \\
\hline ADVMAT & Advanced materials & 105 & 5 & $4.7 \%$ \\
\hline ENV & $\begin{array}{l}\text { Climate action, environment, resource efficiency and raw } \\
\text { materials }\end{array}$ & 346 & 14 & $4.2 \%$ \\
\hline EURATOM & Euratom & 83 & 3 & $3.9 \%$ \\
\hline SECURITY & $\begin{array}{l}\text { Secure societies - Protecting freedom and security of } \\
\text { Europe and its citizens }\end{array}$ & 177 & 6 & $3.3 \%$ \\
\hline INFRA & Research infrastructures & 454 & 14 & $3.0 \%$ \\
\hline ADVMANU & Advanced manufacturing and processing & 196 & 6 & $3.0 \%$ \\
\hline BIOTECH & Biotechnology & 130 & 3 & $2.7 \%$ \\
\hline FOOD & $\begin{array}{l}\text { Food security, sustainable agriculture and forestry, marine } \\
\text { and maritime and inland water research }\end{array}$ & 749 & 19 & $2.5 \%$ \\
\hline HEALTH & Health, demographic change and wellbeing & 2,141 & 42 & $2.0 \%$ \\
\hline ERC & European Research Council & 2,807 & 52 & $1.9 \%$ \\
\hline ICT & Information and Communication Technologies & 911 & 17 & $1.9 \%$ \\
\hline FET & Future and Emerging Technologies & 346 & 6 & $1.8 \%$ \\
\hline ENERGY & Secure, clean and efficient energy & 463 & 8 & $1.7 \%$ \\
\hline MSCA & Marie Sklodowska-Curie actions & 1,774 & 30 & $1.7 \%$ \\
\hline TWINING & Twinning of research institutions & 43 & 1 & $1.3 \%$ \\
\hline CAREER & $\begin{array}{l}\text { Make scientific and technological careers attractive for } \\
\text { young people }\end{array}$ & 6 & 0.1 & $1.3 \%$ \\
\hline CROSST & Cross-theme & 74 & 1 & $0.9 \%$ \\
\hline GOV & $\begin{array}{l}\text { Develop the governance for the advancement of } \\
\text { responsible research and innovation }\end{array}$ & 15 & 0.1 & $0.8 \%$ \\
\hline TPT & Smart, green and integrated transport & 357 & 2 & $0.6 \%$ \\
\hline WIDESPREAD & $\begin{array}{l}\text { Teaming of excellent research institutions and low } \\
\text { performing RDI regions }\end{array}$ & 76 & 0.4 & $0.6 \%$ \\
\hline NMP & Nanotechnologies, Advanced Materials and Production & 240 & 1 & $0.5 \%$ \\
\hline SPACE & Space & 35 & 0.1 & $0.3 \%$ \\
\hline SME & Innovation in SMEs & 37 & 0.1 & $0.2 \%$ \\
\hline ERA & ERA chairs & 24 & & $0.0 \%$ \\
\hline GENDEREQ & Promote gender equality in research and innovation & 5 & & $0.0 \%$ \\
\hline INEGSOC & Integrate society in science and innovation & 14 & & $0.0 \%$ \\
\hline SEAWP-CROSST & $\begin{array}{l}\text { Spreading excellence and widening participation - Cross- } \\
\text { theme }\end{array}$ & 1 & & $0.0 \%$ \\
\hline Total & & 11,678 & 234 & $2.0 \%$ \\
\hline
\end{tabular}




\section{Finnish participation in the area of Cleantech, Bioeconomy and Circular economy within FP7 and H2020}

The following analysis is based on our screening and tagging of action lines and proposals as relevant to the field of Cleantech, Bioeconomy and Circular economy (hence-forth referred to as "CBC"), as described in the end of this appendix.

Finnish actors have contributed to the submission of 3,798 CBC proposals in H2O20 (as of May 2017). This equates to $5.6 \%$ of all such proposals submitted to the programme during this period. This is slightly lower than the proportion of FP7 CBC proposals involving Finland (6.1\%).

As is shown in the table below, all but two of the comparator countries (IE and NO) have participated in a greater proportion of CBC proposals than Finland, in both FP7 and H2020. Even when taking into account the relative number of $R \& D$ personnel in each country, the number of proposals involving Finland is lower than all comparator countries in FP7 and lower than three comparators in $\mathrm{H} 2020$.

Table 51 FP7/H2020 CBC proposals involving Finland and comparator countries

\begin{tabular}{|c|c|c|c|c|c|c|c|c|}
\hline $\mathrm{H} 2020$ & All & FI & AT & DK & IE & NL & NO & SE \\
\hline Number of proposals involving... & 67,806 & 3,798 & 4,431 & 4,597 & 2,918 & 9,536 & 2,861 & 5,508 \\
\hline Proportion of all proposals involving... & & $5.6 \%$ & $6.5 \%$ & $6.8 \%$ & $4.3 \%$ & $14.1 \%$ & $4.2 \%$ & $8.1 \%$ \\
\hline $\begin{array}{l}\text { Number of proposals per } 1,000 \text { researchers } \\
\text { in... }\end{array}$ & & 74.1 & 64.9 & 77.4 & 100.9 & 75.9 & 68.9 & 65.6 \\
\hline FP7 & All & $\mathrm{FI}$ & AT & DK & IE & NL & NO & SE \\
\hline Number of proposals involving... & 82,125 & 5,044 & 6,082 & 5,399 & 3,753 & 12,455 & 3,874 & 8,456 \\
\hline Proportion of all proposals involving... & & $6.1 \%$ & $7.4 \%$ & $6.6 \%$ & $4.6 \%$ & $15.2 \%$ & $4.7 \%$ & $10.3 \%$ \\
\hline $\begin{array}{l}\text { Number of proposals per } 1,000 \text { researchers } \\
\text { in... }\end{array}$ & & 91.4 & 101.5 & 96.5 & 180.0 & 118.1 & 106.5 & 107.6 \\
\hline
\end{tabular}

In $42 \%$ of $\mathrm{H} 2020 \mathrm{CBC}$ proposals involving Finland, a Finnish actor held the role of coordinator. This is high than in FP7, where $34 \%$ of Finnish CBC proposals were led by a Finnish coordinator. Most comparator countries had a lower or similar rate of coordination in H2020, while two countries had a slightly higher rate of coordination in FP7 (IE \& NL).

If we take account of the relative size of the researcher base in each country, the number of CBC proposal coordinators from Finland (31.2) in H2020 is below the rate for all comparator countries except DK \& IE. In FP7, the Finnish rate (31.4 coordinators per 1,000 personnel) was below that of all comparators except FI.

Table 52 FP7/H2020 CBC proposals with a 'domestic' coordinator

\begin{tabular}{|c|c|c|c|c|c|c|c|c|}
\hline $\mathrm{H} 2020$ & All & $\mathrm{FI}$ & AT & DK & IE & $\mathbf{N L}$ & NO & SE \\
\hline Number of proposals with domestic coordinator & 67,806 & 1,598 & 1,254 & 1,951 & 1,232 & 3,814 & 1,131 & 2,143 \\
\hline $\begin{array}{l}\% \text { of country's proposals with domestic } \\
\text { coordinator }\end{array}$ & & $42 \%$ & $28 \%$ & $42 \%$ & $42 \%$ & $40 \%$ & $40 \%$ & $38.9 \%$ \\
\hline Coordinators per 1,000 researchers & & 31.2 & 18.4 & 32.9 & 42.6 & 30.3 & 27.3 & 25.5 \\
\hline FP7 & All & $\mathrm{FI}$ & AT & DK & IE & NL & NO & SE \\
\hline Number of proposals with domestic coordinator & 82,125 & 1,735 & 1,797 & 1,794 & 1,355 & 4,578 & 1,269 & 3,052 \\
\hline $\begin{array}{l}\% \text { of country's proposals with domestic } \\
\text { coordinator }\end{array}$ & & $34 \%$ & $30 \%$ & $33 \%$ & $36 \%$ & $37 \%$ & $33 \%$ & $36 \%$ \\
\hline Coordinators per 1,000 researchers & & 31.4 & 30.0 & 32.1 & 65.0 & 43.4 & 34.9 & 38.8 \\
\hline
\end{tabular}

Finland has participated in 2,732 multi-partner H2020 CBC proposals, of which it has served as the coordinator in $532(19 \%)$. This puts it in the middle of the comparator countries. The Finnish rate of $\mathrm{CBC}$ proposal coordination in $\mathrm{H} 2020$, relative to the FTE 
researcher population, is lower than all the comparator countries except Norway and Sweden.

Table 53 FP7/H2020 'multi-partner' (MP) CBC proposals with a 'domestic' coordinator

\begin{tabular}{|c|c|c|c|c|c|c|c|c|}
\hline $\mathrm{H} 2020$ & All & $\mathrm{FI}$ & AT & DK & IE & NL & NO & SE \\
\hline Number of MP proposals involving... & 23,747 & 2,732 & 3,698 & 3,265 & 2,169 & 7,186 & 2,158 & 3,939 \\
\hline $\begin{array}{l}\text { Number of MP proposals with domestic } \\
\text { coordinator }\end{array}$ & 23,747 & 532 & 521 & 619 & 483 & 1,464 & 428 & 574 \\
\hline $\begin{array}{l}\text { \% of country's MP proposals with domestic } \\
\text { coordinator }\end{array}$ & & $19 \%$ & $14 \%$ & $19 \%$ & $22 \%$ & $20 \%$ & $20 \%$ & $15 \%$ \\
\hline $\begin{array}{l}\text { Coordinators of MP proposals per } 1,000 \\
\text { researchers }\end{array}$ & & 53.3 & 54.2 & 55.0 & 75.0 & 57.2 & 52.0 & 46.9 \\
\hline FP7 & All & $\mathrm{FI}$ & AT & DK & IE & NL & NO & SE \\
\hline Number of MP proposals involving... & 35,642 & 4,038 & 5,189 & 4,326 & 3,052 & 9,793 & 3,272 & 6,512 \\
\hline $\begin{array}{l}\text { Number of MP proposals with domestic } \\
\text { coordinator }\end{array}$ & 35,642 & 729 & 904 & 721 & 654 & 1,916 & 667 & 1,108 \\
\hline $\begin{array}{l}\text { \% of country's MP proposals with domestic } \\
\text { coordinator }\end{array}$ & & $18 \%$ & $17 \%$ & $17 \%$ & $21 \%$ & $20 \%$ & $20 \%$ & $17 \%$ \\
\hline $\begin{array}{l}\text { Coordinators of MP proposals per } 1,000 \\
\text { researchers }\end{array}$ & & 13.2 & 15.1 & 12.9 & 31.4 & 18.2 & 18.3 & 14.1 \\
\hline
\end{tabular}

Because of multiple Finnish participations in some proposals, the total number of Finnish participations in $\mathrm{H} 2020 \mathrm{CBC}$ proposals $(5,290)$ is higher than the number of unique CBC proposals in which Finland is involved $(3,798)$. These Finnish participations represent just $2.2 \%$ of all participations in $\mathrm{H} 2020 \mathrm{CBC}$ proposals, which is lower than for each of the comparator countries, except Norway. When taking account of the size of the respective researcher populations, Finland performs comparably better with a higher number of participations in $\mathrm{H} 2020 \mathrm{CBC}$ proposals (103 per 1,000 R\&D personnel) than all other comparators except Ireland and the Netherlands.

Finland accounted for a similar proportion (2.0\%) of all FP7 participations in CBC proposals. However, because of the longer time period covered, its participation rate (128 per 1,000 $\mathrm{R} \& \mathrm{D}$ personnel) was higher than in $\mathrm{H} 2020$. However, this was lower than all comparator countries except Denmark.

Table 54 Participations in FP7/H2020 CBC proposals from Finland and comparator countries

\begin{tabular}{|c|c|c|c|c|c|c|c|c|}
\hline H2020 & All & $\mathrm{FI}$ & AT & DK & IE & NL & NO & SE \\
\hline Number of participations in proposals & 241,851 & 5,290 & 5,865 & 5,963 & 3,764 & 14,025 & 3,821 & 7,328 \\
\hline Proportion of all participations in proposals & & $2.2 \%$ & $2.4 \%$ & $2.5 \%$ & $1.6 \%$ & $5.8 \%$ & $1.6 \%$ & $3.0 \%$ \\
\hline $\begin{array}{l}\text { Number of participations in proposals per } 1,000 \\
\text { researchers in... }\end{array}$ & & 103 & 86 & 100 & 130 & 112 & 92 & 87 \\
\hline FP7 & All & $\mathrm{FI}$ & $\overline{\text { AT }}$ & DK & IE & NL & NO & SE \\
\hline Number of participations in proposals & 345,607 & 7,056 & 8,431 & 7,179 & 4,927 & 18,510 & 5,453 & 11,502 \\
\hline Proportion of all participations in proposals & & $2.0 \%$ & $2.4 \%$ & $2.1 \%$ & $1.4 \%$ & $5.4 \%$ & $1.6 \%$ & $3.3 \%$ \\
\hline $\begin{array}{l}\text { Number of participations in proposals per } 1,000 \\
\text { researchers in... }\end{array}$ & & 128 & 141 & 128 & 236 & 175 & 150 & 146 \\
\hline
\end{tabular}

The table below shows the distribution of $\mathrm{H} 2020 \mathrm{CBC}$ proposal participations between different types of actor (categorisations as used in eCORDA). For Finland, it shows that two organisation types (HES and PRC combined) accounts for the majority $(76 \%)$ of participations in CBC proposals, with REC organisations accounting for a further $19 \%$.

The table also shows the proportion of PRC participations that are SMEs. ${ }^{173}$ For Finland, the rate is $86 \%$, which is higher than the overall average, and also higher than all of the comparator countries.

${ }^{173}$ Across all countries, information on whether a PRC participation is from an SME or not is only available in $78 \%$ of cases. For the percentages shown in the table, the denominator is the total population of PRCs where the status is known (i.e. SME or not). 


\begin{tabular}{|c|c|c|c|c|c|c|c|c|}
\hline $\mathrm{H} 2020$ & All & $\mathrm{FI}$ & AT & DK & IE & NL & NO & SE \\
\hline HES - Higher or secondary education & $38 \%$ & $43 \%$ & $38 \%$ & $52 \%$ & $54 \%$ & $45 \%$ & $38 \%$ & $56 \%$ \\
\hline OTH - Others & $4 \%$ & $3 \%$ & $5 \%$ & $2 \%$ & $3 \%$ & $4 \%$ & $2 \%$ & $2 \%$ \\
\hline $\begin{array}{l}\text { PRC - Private for profit (excl. } \\
\text { education) }\end{array}$ & $35 \%$ & $33 \%$ & $34 \%$ & $32 \%$ & $35 \%$ & $35 \%$ & $31 \%$ & $30 \%$ \\
\hline PUB - Public body (excl. REC/HES) & $3 \%$ & $3 \%$ & $2 \%$ & $6 \%$ & $3 \%$ & $2 \%$ & $3 \%$ & $4 \%$ \\
\hline REC - Research organisations & $19 \%$ & $19 \%$ & $21 \%$ & $8 \%$ & $5 \%$ & $14 \%$ & $26 \%$ & $8 \%$ \\
\hline Total & 241,851 & 5,290 & 5,865 & 5,963 & 3,764 & 14,025 & 3,821 & 7,328 \\
\hline SMEs as a $\%$ of PRC & $79 \%$ & $86 \%$ & $76 \%$ & $81 \%$ & $80 \%$ & $80 \%$ & $80 \%$ & $76 \%$ \\
\hline
\end{tabular}

The average EC funding request per Finnish participation in H2020 CBC proposals was around $€ 672$ thousand, which is higher than in most of the comparator countries, but slightly lower than the overall average.

Table 56 EC contributions requested in H2020 CBC proposals

\begin{tabular}{|c|c|c|c|c|c|c|c|c|}
\hline $\mathrm{H} 2020$ & All & $\mathrm{FI}$ & AT & DK & IE & NL & NO & SE \\
\hline $\begin{array}{l}\text { Selected participations in } \\
\text { proposals (those with } \\
\text { financial data) }\end{array}$ & 241,851 & 5,290 & 5,865 & 5,963 & 3,764 & 14,025 & 3,821 & 7,328 \\
\hline $\begin{array}{l}\text { Total EC contribution } \\
\text { requested }(€ \mathrm{~m})\end{array}$ & 138,862 & 3,557 & 3,237 & 3,873 & 2,385 & 9,288 & 2,651 & 5,050 \\
\hline $\begin{array}{l}\text { Average EC contribution }(€) \\
\text { requested per participation }\end{array}$ & 574,163 & 672,370 & 551,992 & 649,566 & 633,760 & 662,235 & 693,727 & 689,191 \\
\hline
\end{tabular}

Below we compare the distribution of $\mathrm{CBC}$ proposal participations at the sub-programme level. Overall, Finland accounts for $2.2 \%$ of all participations in H2020 CBC proposals.

It is more active (relatively) in 13 sub-programmes, and the Euratom, ICT, and ERC subprogrammes in particular, where it accounts for at least $3 \%$ of all CBC proposal participations in each case. Only in the RISKFINANCE sub-programme is Finland more active than all of the comparator countries.

Table 57 H2020 sub-programmes with a relatively high participation rate of Finland in CBC proposals

\begin{tabular}{|c|c|c|c|c|c|c|c|c|}
\hline & Overall & $\mathrm{FI}$ & AT & DK & IE & NL & NO & SE \\
\hline EURATOM & 1,020 & $3.3 \%$ & $0.7 \%$ & $0.5 \%$ & $0.1 \%$ & $2.5 \%$ & $0.4 \%$ & $7.1 \%$ \\
\hline ICT & 1,7535 & $3.1 \%$ & $2.7 \%$ & $1.6 \%$ & $1.9 \%$ & $4.7 \%$ & $1.5 \%$ & $2.3 \%$ \\
\hline ERC & 13,705 & $3.0 \%$ & $1.8 \%$ & $2.5 \%$ & $1.4 \%$ & $6.3 \%$ & $1.3 \%$ & $4.1 \%$ \\
\hline ENV & 15,828 & $2.9 \%$ & $2.2 \%$ & $2.0 \%$ & $1.3 \%$ & $5.9 \%$ & $1.6 \%$ & $3.2 \%$ \\
\hline CAREER & 1,135 & $2.8 \%$ & $3.3 \%$ & $1.3 \%$ & $2.2 \%$ & $3.3 \%$ & $1.7 \%$ & $2.9 \%$ \\
\hline ADVMANU & 8,554 & $2.8 \%$ & $2.9 \%$ & $1.4 \%$ & $1.2 \%$ & $4.4 \%$ & $1.4 \%$ & $2.7 \%$ \\
\hline RISKFINANCE & 110 & $2.7 \%$ & $0.9 \%$ & $1.8 \%$ & $0.9 \%$ & $1.8 \%$ & $0.9 \%$ & $0.9 \%$ \\
\hline INFRA & 3,529 & $2.6 \%$ & $2.6 \%$ & $2.0 \%$ & $1.7 \%$ & $7.7 \%$ & $2.4 \%$ & $3.4 \%$ \\
\hline SOCIETY & 7,540 & $2.6 \%$ & $2.8 \%$ & $2.0 \%$ & $1.7 \%$ & $3.7 \%$ & $1.5 \%$ & $2.0 \%$ \\
\hline NMP & 5,810 & $2.4 \%$ & $1.9 \%$ & $2.3 \%$ & $1.8 \%$ & $4.1 \%$ & $1.3 \%$ & $2.6 \%$ \\
\hline HEALTH & 27,949 & $2.4 \%$ & $2.3 \%$ & $2.5 \%$ & $1.6 \%$ & $7.8 \%$ & $1.4 \%$ & $3.4 \%$ \\
\hline ADVMAT & 3,244 & $2.2 \%$ & $2.2 \%$ & $2.0 \%$ & $1.7 \%$ & $3.2 \%$ & $1.6 \%$ & $2.8 \%$ \\
\hline SME & 1,237 & $2.2 \%$ & $2.7 \%$ & $2.4 \%$ & $1.6 \%$ & $3.6 \%$ & $1.6 \%$ & $3.1 \%$ \\
\hline Total & 241,851 & $2.2 \%$ & $2.4 \%$ & $2.5 \%$ & $1.6 \%$ & $5.8 \%$ & $1.6 \%$ & $3.0 \%$ \\
\hline
\end{tabular}

Finland is relatively less active in CBC proposals in the remaining 19 sub-programmes (shown below). In particular, there have been no Finnish participations in relevant proposals in two of the cross-theme sub-programmes or the ERA or RESACCESS subprogrammes. Finland also only accounts for less than $1 \%$ of participations in relevant H2020 proposals in the GENDEREQ sub-programme.

Table 58 H2020 sub-programmes with a relatively low participation rate of Finland in CBC proposals

\begin{tabular}{ccccccccc}
\hline & Overall & FI & AT & DK & IE & NL & NO & SE \\
\hline ENERGY & 24,609 & $2.2 \%$ & $3.0 \%$ & $3.0 \%$ & $1.5 \%$ & $4.7 \%$ & $1.8 \%$ & $2.8 \%$ \\
\hline
\end{tabular}




\begin{tabular}{|c|c|c|c|c|c|c|c|c|}
\hline FOOD & 19,920 & $2.1 \%$ & $1.9 \%$ & $2.8 \%$ & $1.6 \%$ & $6.0 \%$ & $2.1 \%$ & $2.1 \%$ \\
\hline TWINING & 1,100 & $2.0 \%$ & $3.2 \%$ & $2.5 \%$ & $1.2 \%$ & $5.2 \%$ & $1.4 \%$ & $4.0 \%$ \\
\hline FET & 11,254 & $1.8 \%$ & $2.6 \%$ & $2.0 \%$ & $1.2 \%$ & $5.7 \%$ & $1.2 \%$ & $3.1 \%$ \\
\hline SPACE & 2,174 & $1.8 \%$ & $3.1 \%$ & $1.1 \%$ & $1.1 \%$ & $4.2 \%$ & $1.4 \%$ & $1.7 \%$ \\
\hline SECURITY & 4,101 & $1.7 \%$ & $3.0 \%$ & $1.3 \%$ & $2.0 \%$ & $4.3 \%$ & $1.6 \%$ & $2.0 \%$ \\
\hline WIDESPREAD & 1,148 & $1.7 \%$ & $3.0 \%$ & $0.8 \%$ & $0.9 \%$ & $3.6 \%$ & $0.3 \%$ & $2.0 \%$ \\
\hline TPT & 9,525 & $1.6 \%$ & $2.9 \%$ & $1.5 \%$ & $0.8 \%$ & $4.9 \%$ & $1.6 \%$ & $3.6 \%$ \\
\hline SCIENCE & 374 & $1.6 \%$ & $2.7 \%$ & $2.4 \%$ & $2.7 \%$ & $4.5 \%$ & $1.3 \%$ & $2.9 \%$ \\
\hline CROSST & 4,669 & $1.6 \%$ & $2.5 \%$ & $2.7 \%$ & $2.1 \%$ & $6.3 \%$ & $1.8 \%$ & $2.6 \%$ \\
\hline MSCA & 51,765 & $1.5 \%$ & $2.1 \%$ & $3.3 \%$ & $1.7 \%$ & $6.7 \%$ & $1.6 \%$ & $3.4 \%$ \\
\hline INEGSOC & 943 & $1.5 \%$ & $4.3 \%$ & $1.5 \%$ & $1.3 \%$ & $4.1 \%$ & $1.0 \%$ & $1.2 \%$ \\
\hline GOV & 377 & $1.3 \%$ & $4.8 \%$ & $2.1 \%$ & $1.9 \%$ & $8.5 \%$ & $2.9 \%$ & $1.6 \%$ \\
\hline BIOTECH & 2,256 & $1.2 \%$ & $2.7 \%$ & $3.0 \%$ & $1.8 \%$ & $6.4 \%$ & $2.4 \%$ & $3.7 \%$ \\
\hline GENDEREQ & 339 & $0.9 \%$ & $2.4 \%$ & $0.3 \%$ & $2.1 \%$ & $4.1 \%$ & $0.3 \%$ & $1.5 \%$ \\
\hline ERA & 58 & $0.0 \%$ & $0.0 \%$ & $0.0 \%$ & $0.0 \%$ & $0.0 \%$ & $0.0 \%$ & $0.0 \%$ \\
\hline RESACCESS & 24 & $0.0 \%$ & $0.0 \%$ & $4.2 \%$ & $0.0 \%$ & $16.7 \%$ & $0.0 \%$ & $0.0 \%$ \\
\hline SEAWP-CROSST & 17 & $0.0 \%$ & $11.8 \%$ & $0.0 \%$ & $0.0 \%$ & $17.6 \%$ & $0.0 \%$ & $5.9 \%$ \\
\hline SWAFS-CROSST & 2 & $0.0 \%$ & $0.0 \%$ & $0.0 \%$ & $0.0 \%$ & $0.0 \%$ & $0.0 \%$ & $0.0 \%$ \\
\hline Total & 241,851 & $2.2 \%$ & $2.4 \%$ & $2.5 \%$ & $1.6 \%$ & $5.8 \%$ & $1.6 \%$ & $3.0 \%$ \\
\hline
\end{tabular}

\section{Success rates and participation in CBC projects}

To May 2017, 508 H2020 grants had been awarded to CBC projects involving Finland. This represents $6.5 \%$ of all $\mathrm{H} 2020 \mathrm{CBC}$ projects, which is lower than all of the comparator countries except Ireland and Norway. Finland compares little better when one adjusts for the size of the research base in each country. Finland has been awarded $9.9 \mathrm{H} 2020 \mathrm{CBC}$ projects for every 1,000 R\&D personnel in the country, which is lower than all of the comparator countries except Norway and Sweden. This is an improvement on FP7, where the Finnish rate (18 per 1,000$)$ was lower than all comparators.

Table 59 CBC Projects (per 1,000 R\&D personnel) - Finland and comparator countries

\begin{tabular}{|c|c|c|c|c|c|c|c|c|}
\hline H2020 & All & FI & AT & DK & IE & NL & NO & SE \\
\hline Projects & 7,863 & 508 & 702 & 680 & 429 & 1450 & 410 & 821 \\
\hline Projects per 1,000 researchers & & 9.9 & 10.3 & 11.5 & 14.8 & 11.5 & 9.9 & 9.8 \\
\hline FP7 & All & $\mathrm{FI}$ & AT & DK & IE & NL & NO & SE \\
\hline Projects & 13,417 & 997 & 1,325 & 1,238 & 794 & 2,840 & 1,097 & 1776 \\
\hline Projects per 1,000 researchers & & 18.1 & 22.1 & 22.1 & 38.1 & 26.9 & 30.2 & 22.6 \\
\hline
\end{tabular}

The $508 \mathrm{H} 2020 \mathrm{CBC}$ projects involving Finland came from 3,798 proposals. This equates to a proposal success rate of $13.4 \%$ - which is above the overall success rate of $\mathrm{H} 2020$ CBC proposals (11.6\%), but below the rate achieved in all of the comparator countries. Finnish success rates in FP7 CBC proposals were higher (19.8\%) than in $\mathrm{H} 2020$, but this partly reflects higher success rates seen in FP7 overall (16.3\%), and as a result the Finnish success rate was also lower than all comparators in this programme.

Table 60 Success rate of CBC proposals - Finland and comparator countries

\begin{tabular}{lcccccccc}
\hline H2020 & All & FI & AT & DK & IE & NL & NO & SE \\
\hline Proposals & 67,806 & 3,798 & 4,431 & 4,597 & 2,918 & 9,536 & 2,861 & 5,508 \\
\hline Projects & 7,863 & 508 & 702 & 680 & 429 & 1450 & 410 & 821 \\
\hline Success rate & $11.6 \%$ & $13.4 \%$ & $15.8 \%$ & $14.8 \%$ & $14.7 \%$ & $15.2 \%$ & $14.3 \%$ & $14.9 \%$ \\
\hline FP7 & All & FI & AT & DK & IE & NL & NO & SE \\
\hline Proposals & 82,125 & 5,044 & 6,082 & 5,399 & 3,753 & 12,455 & 3,874 & 8,456 \\
\hline Projects & 13,417 & 997 & 1,325 & 1,238 & 794 & 2,840 & 1,097 & 1776 \\
\hline Success rate & $16.3 \%$ & $19.8 \%$ & $21.8 \%$ & $22.9 \%$ & $21.2 \%$ & $22.8 \%$ & $28.3 \%$ & $21.0 \%$ \\
\hline
\end{tabular}


H2020 grants have been awarded to $143 \mathrm{CBC}$ projects with a Finnish coordinator. This equates to 2.8 projects for every 1,000 R\&D personnel in the country. This rate is below that of all comparator countries except SE. The rate (3.3 coordinators per 1,000 personnel) for Finland in FP7 also compared poorly with all comparators.

Table 61 Coordinators of CBC projects (per 1,000 R\&D personnel) - Finland and comparator countries

\begin{tabular}{lcccccccc}
\hline H2020 & All & FI & AT & DK & IE & NL & NO & SE \\
\hline Coordinators & 7,863 & 143 & 202 & 268 & 173 & 577 & 129 & 239 \\
\hline Coordinators per 1,000 researchers & & 2.8 & 3.0 & 4.5 & 6.0 & 4.6 & 3.1 & 2.8 \\
\hline FP7 & All & FI & AT & DK & IE & NL & NO & SE \\
\hline Coordinators & 13,288 & 182 & 362 & 310 & 235 & 910 & 188 & 439 \\
\hline Coordinators per 1,000 researchers & & 3.3 & 6.0 & 5.5 & 11.3 & 8.6 & 5.2 & 5.6 \\
\hline
\end{tabular}

The success rate of Finnish-coordinated CBC proposals is $8.9 \%$ in $\mathrm{H} 2020$ - which is lower than the overall average (11.6\%), and below the rates of coordinator success achieved in all comparator countries. In FP7, Finland's success rate for coordinators was slightly better (10.5\%), but this was still lower than all comparator countries.

Table 62 Success rate of CBC proposals with/without domestic coordinator - Finland and comparator countries

\begin{tabular}{lcccccccc}
\hline H2020 success rates & All & FI & AT & DK & IE & NL & NO & SE \\
\hline Proposal with domestic coordinator & $11.6 \%$ & $8.9 \%$ & $16.1 \%$ & $13.7 \%$ & $14.0 \%$ & $15.1 \%$ & $11.4 \%$ & $11.2 \%$ \\
\hline Proposal without domestic coordinator & & $16.6 \%$ & $15.7 \%$ & $15.6 \%$ & $15.2 \%$ & $15.3 \%$ & $16.2 \%$ & $17.3 \%$ \\
\hline FP7 success rates & All & FI & AT & DK & IE & NL & NO & SE \\
\hline Proposal with domestic coordinator & $16.2 \%$ & $\mathbf{1 0 . 5} \%$ & $20.1 \%$ & $17.3 \%$ & $17.3 \%$ & $19.9 \%$ & $14.8 \%$ & $14.4 \%$ \\
\hline Proposal without domestic coordinator & & $\mathbf{2 4 . 6} \%$ & $22.5 \%$ & $25.7 \%$ & $23.3 \%$ & $24.5 \%$ & $34.9 \%$ & $24.7 \%$ \\
\hline
\end{tabular}

If we look only at those $\mathrm{H} 2020 \mathrm{CBC}$ proposals/projects with multiple participants (i.e. excluding those where the coordinator is the only partner), the success rate for $\mathrm{FI}$ coordinators increases from $8.9 \%$ to $9.4 \%$. However, this still compares unfavourably with the overall average and with all comparator countries.

Table 63 Success rate of multi-partner CBC proposals with domestic coordinator

\begin{tabular}{lcccccccc}
\hline H2020 - multi partner & All & FI & AT & DK & IE & NL & NO & SE \\
\hline Proposals & 23,747 & 532 & 521 & 619 & 483 & 1,464 & 428 & 574 \\
\hline Projects & 2877 & 50 & 90 & 71 & 71 & 236 & 59 & 75 \\
\hline Success rate & $12.1 \%$ & $9.4 \%$ & $17.3 \%$ & $11.5 \%$ & $14.7 \%$ & $16.1 \%$ & $13.8 \%$ & $13.1 \%$ \\
\hline
\end{tabular}

The 508 CBC grants awarded to Finland in H2020 involve 729 individual Finnish participations. This represents $2.1 \%$ of all participations in $\mathrm{H} 2020$ projects, which is lower than any of the comparator countries, except Ireland and Norway. Even taking account of the size of the researcher base, Finland does not compare favourably with these countries. The 14.2 CBC participations per 1,000 R\&D personnel in Finland is below that achieved elsewhere expect in Norway and Sweden.

Table 64 Participations in CBC projects (per 1,000 R\&D personnel) - Finland and comparator countries

\begin{tabular}{lcccccccc}
\hline H2020 & All & FI & AT & DK & IE & NL & NO & SE \\
\hline Participations in projects & 35,035 & 729 & 982 & 904 & 566 & 2349 & 577 & 1185 \\
\hline Participations per 1,000 researchers & & 14.2 & 14.4 & 15.2 & 19.6 & 18.7 & 13.9 & 14.1 \\
\hline FP7 & All & FI & AT & DK & IE & NL & NO & SE \\
\hline Participations in projects & 75,084 & $\mathbf{1 , 6 4 2}$ & 1,993 & 1,786 & 1,111 & 4,790 & 1,285 & 2,679 \\
\hline Participations per 1,000 researchers & & 29.7 & 33.3 & 31.9 & 53.3 & 45.4 & 30.2 & 34.1 \\
\hline
\end{tabular}


The 729 Finnish participations in successful H2020 CBC projects, from an original 5,290 participations in proposals, represents a participation success rate of $13.8 \%$ in $\mathrm{H} 2020$ so far. This is below the overall rate of success for all participations in CBC proposals (14.5\%), as well as below that achieved in all of the comparator countries.

Table 65 Success rate of CBC participations - Finland and comparator countries

\begin{tabular}{lcccccccc}
\hline Participation success rate & All & FI & AT & DK & IE & NL & NO & SE \\
\hline H2020 & $14.5 \%$ & $13.8 \%$ & $16.7 \%$ & $15.2 \%$ & $15.0 \%$ & $16.7 \%$ & $15.1 \%$ & $16.2 \%$ \\
\hline FP7 & $21.7 \%$ & $23.3 \%$ & $23.6 \%$ & $24.9 \%$ & $22.5 \%$ & $25.9 \%$ & $20.1 \%$ & $23.3 \%$ \\
\hline
\end{tabular}

Comparing across different organisation types, Finnish success rates for CBC participations were highest amongst public bodies (29\%). Rates here were higher than the overall average $(26 \%)$, but lower than most comparator countries. The success rates of Finnish participations from other organisation types also tend not to compare well with other countries.

The table also shows the success rate of SME-PRC participations in CBC proposals. ${ }^{174}$ For Finland, the rate is $12 \%$, which is below the $\mathrm{H} 2020$ average (13\%), as well as below that achieved in all comparator countries except Norway.

Table 66 Success rate of CBC participations, by organisation type - Finland and comparator countries (H2020)

\begin{tabular}{lcccccccc}
\hline Participation success rate & All & FI & AT & DK & IE & NL & NO & SE \\
\hline HES - Higher or secondary education & $12 \%$ & $11 \%$ & $13 \%$ & $15 \%$ & $14 \%$ & $15 \%$ & $12 \%$ & $14 \%$ \\
\hline PRC - Private for profit (excl. education) & $13 \%$ & $13 \%$ & $18 \%$ & $14 \%$ & $14 \%$ & $16 \%$ & $12 \%$ & $18 \%$ \\
\hline PUB - Public body (excl. research and education) & $26 \%$ & $\mathbf{2 9} \%$ & $33 \%$ & $22 \%$ & $31 \%$ & $27 \%$ & $42 \%$ & $33 \%$ \\
\hline REC - Research organisations & $17 \%$ & $18 \%$ & $19 \%$ & $16 \%$ & $22 \%$ & $23 \%$ & $19 \%$ & $19 \%$ \\
\hline OTH - Others & $20 \%$ & $20 \%$ & $19 \%$ & $20 \%$ & $20 \%$ & $19 \%$ & $18 \%$ & $19 \%$ \\
\hline PRC-SMEs & $13 \%$ & $12 \%$ & $15 \%$ & $14 \%$ & $15 \%$ & $16 \%$ & $10 \%$ & $15 \%$ \\
\hline
\end{tabular}

EC contributions to Finnish participations in $\mathrm{H} 2020 \mathrm{CBC}$ projects totalled $€ 335$ million, which equates to $2.3 \%$ of all funding to $\mathrm{CBC}$ participations to date. This is below the proportion realised by each of the other comparator countries except Ireland and Norway. The average contribution to each Finnish CBC participation (at €460 thousand) is also below that achieved by all comparator countries, although slightly above the all country average.

Table 67 EC contributions to CBC participations as a proportion of requested funding - Finland and comparator countries

\begin{tabular}{lcccccccc}
\hline H2020 & All & FI & AT & DK & IE & NL & NO & SE \\
\hline $\begin{array}{l}\text { Selected participations } \\
\text { in projects (those with } \\
\text { financial data) }\end{array}$ & $\begin{array}{c}35,03 \\
5\end{array}$ & 729 & 982 & 904 & 566 & 2349 & 577 & 1184 \\
\hline $\begin{array}{l}\text { Total EC contribution } \\
(€ \text { million) }\end{array}$ & $\begin{array}{c}14,80 \\
7\end{array}$ & 335 & 422 & 404 & 257 & 1,211 & 306 & 571 \\
\hline $\begin{array}{l}\% \text { of total EC } \\
\text { contributions }\end{array}$ & $2.3 \%$ & $2.9 \%$ & $2.7 \%$ & $1.7 \%$ & $8.2 \%$ & $2.1 \%$ & $3.9 \%$ \\
\hline $\begin{array}{l}\text { Average EC contribution } \\
(€) \text { per participation }\end{array}$ & $\begin{array}{c}422,6 \\
35\end{array}$ & 459,534 & 429,735 & 446,903 & 454,064 & 515,539 & 530,329 & 482,264 \\
\hline
\end{tabular}

There were 10 sub-programmes of $\mathrm{H} 2020$ where Finnish participation success rates in $\mathrm{CBC}$ proposals were above the overall average. These are shown at the top of the table

\footnotetext{
${ }^{174}$ As mentioned previously, information on whether a PRC participant is an SME or not is only available for $78 \%$ of proposal participations and $80 \%$ of project participations. Success rates are calculated based only on those that are known.
} 
below and include CAREER, INFRA, SECURITY and EURATOM, where Finnish success rates were $20 \%$ or more higher than overall in these sub-programmes. Elsewhere Finnish success rates were below average, or Finland has not yet participated in relevant proposals. The total number of participations in relevant proposals is also shown to give a sense of the scale of opportunity for $\mathrm{CBC}$ activity within each sub-programme.

Table 68 Finnish success rates in H2020 CBC proposals by sub-programme

\begin{tabular}{|c|c|c|c|c|c|}
\hline Sub-programme & & $\begin{array}{l}\text { All participations } \\
\text { in proposals }\end{array}$ & $\begin{array}{c}\text { Overall } \\
\text { success } \\
\text { rate }\end{array}$ & $\begin{array}{l}\text { FI } \\
\text { success } \\
\text { rate }\end{array}$ & $\begin{array}{c}\% \\
\text { differe } \\
\text { nce }\end{array}$ \\
\hline CAREER & $\begin{array}{l}\text { Make scientific and technological careers } \\
\text { attractive for young people }\end{array}$ & 1,135 & $2.2 \%$ & $6.3 \%$ & $183.8 \%$ \\
\hline INFRA & Research infrastructures & 3,529 & $44.9 \%$ & $61.3 \%$ & $36.6 \%$ \\
\hline SECURITY & $\begin{array}{l}\text { Secure societies - Protecting freedom and } \\
\text { security of Europe and its citizens }\end{array}$ & 4,101 & $16.1 \%$ & $20.0 \%$ & $24.5 \%$ \\
\hline EURATOM & Euratom & 1,020 & $48.9 \%$ & $58.8 \%$ & $20.2 \%$ \\
\hline ADVMANU & Advanced manufacturing and processing & 8,554 & $15.6 \%$ & $17.1 \%$ & $9.7 \%$ \\
\hline ADVMAT & Advanced materials & 3,244 & $16.6 \%$ & $18.1 \%$ & $8.7 \%$ \\
\hline WIDESPREAD & $\begin{array}{l}\text { Teaming of excellent research institutions } \\
\text { and low performing RDI regions }\end{array}$ & 1,148 & $19.7 \%$ & $21.1 \%$ & $6.9 \%$ \\
\hline GOV & $\begin{array}{l}\text { Develop the governance for the } \\
\text { advancement of responsible research and } \\
\text { innovation }\end{array}$ & 377 & $18.8 \%$ & $20.0 \%$ & $6.2 \%$ \\
\hline BIOTECH & Biotechnology & 2,256 & $10.9 \%$ & $11.5 \%$ & $5.8 \%$ \\
\hline FOOD & $\begin{array}{l}\text { Food security, sustainable agriculture and } \\
\text { forestry, marine and maritime and inland } \\
\text { water research }\end{array}$ & 19,920 & $18.4 \%$ & $19.4 \%$ & $5.3 \%$ \\
\hline SCIENCE & Encourage citizens to engage in science & 374 & $0.0 \%$ & $0.0 \%$ & $0 \%$ \\
\hline HEALTH & Health, demographic change and wellbeing & 27,949 & $11.2 \%$ & $11.1 \%$ & $-0.9 \%$ \\
\hline ENV & $\begin{array}{l}\text { Climate action, environment, resource } \\
\text { efficiency and raw materials }\end{array}$ & 15,828 & $18.5 \%$ & $18.2 \%$ & $-1.8 \%$ \\
\hline ICT & $\begin{array}{l}\text { Information and Communication } \\
\text { Technologies }\end{array}$ & 17,535 & $13.0 \%$ & $12.1 \%$ & $-7.0 \%$ \\
\hline CROSST & Cross-theme & 4,669 & $6.2 \%$ & $5.5 \%$ & $-11.8 \%$ \\
\hline ENERGY & Secure, clean and efficient energy & 24,609 & $16.4 \%$ & $14.2 \%$ & $-13.6 \%$ \\
\hline MSCA & Marie Sklodowska-Curie actions & 51,765 & $11.9 \%$ & $10.1 \%$ & $-14.7 \%$ \\
\hline TPT & Smart, green and integrated transport & 9,525 & $27.6 \%$ & $22.3 \%$ & $-19.1 \%$ \\
\hline NMP & $\begin{array}{l}\text { Nanotechnologies, Advanced Materials and } \\
\text { Production }\end{array}$ & 5,810 & $10.6 \%$ & $8.5 \%$ & $-20.4 \%$ \\
\hline SPACE & Space & 2,174 & $19.6 \%$ & $15.0 \%$ & $-23.6 \%$ \\
\hline SOCIETY & $\begin{array}{l}\text { Europe in a changing world - inclusive, } \\
\text { innovative and reflective Societies }\end{array}$ & 7,540 & $9.0 \%$ & $6.7 \%$ & $-25.8 \%$ \\
\hline FET & Future and Emerging Technologies & 11,254 & $3.9 \%$ & $2.9 \%$ & $-26.2 \%$ \\
\hline TWINING & Twinning of research institutions & 1,100 & $12.5 \%$ & $9.1 \%$ & $-27.0 \%$ \\
\hline INEGSOC & Integrate society in science and innovation & 943 & $11.1 \%$ & $7.1 \%$ & $-35.9 \%$ \\
\hline ERC & European Research Council & 13,705 & $13.7 \%$ & $8.6 \%$ & $-37.2 \%$ \\
\hline SME & Innovation in SMEs & 1,237 & $29.8 \%$ & $3.7 \%$ & $-87.6 \%$ \\
\hline GENDEREQ & $\begin{array}{l}\text { Promote gender equality in research and } \\
\text { innovation }\end{array}$ & 339 & $11.2 \%$ & $0.0 \%$ & $100.0 \%$ \\
\hline RISKFINANCE & Access to risk finance & 110 & $7.3 \%$ & $0.0 \%$ & $100.0 \%$ \\
\hline ERA & ERA chairs & 58 & $13.8 \%$ & $\mathrm{n} / \mathrm{a}$ & $\mathrm{n} / \mathrm{a}$ \\
\hline RESACCESS & $\begin{array}{l}\text { Develop the accessibility and the use of the } \\
\text { results of publicly-funded research }\end{array}$ & 24 & $45.8 \%$ & $\mathrm{n} / \mathrm{a}$ & $\mathrm{n} / \mathrm{a}$ \\
\hline SEAWP-CROSST & $\begin{array}{l}\text { Spreading excellence and widening } \\
\text { participation - Cross-theme }\end{array}$ & 17 & $100.0 \%$ & $\mathrm{n} / \mathrm{a}$ & $\mathrm{n} / \mathrm{a}$ \\
\hline SWAFS-CROSST & Science with and for Society - Cross-theme & 2 & $100.0 \%$ & $\mathrm{n} / \mathrm{a}$ & $\mathrm{n} / \mathrm{a}$ \\
\hline Total & & 241,851 & $14.5 \%$ & $13.8 \%$ & $-4.9 \%$ \\
\hline
\end{tabular}

Overall, EC contributions to Finnish participations in H2020 CBC projects accounted for $2.3 \%$ of total EC contributions to relevant projects. However, there are 11 sub-programmes where Finland achieved a higher proportion of the total - and in particular the CAREER, EURATOM and ADVMANU programmes, where Finland secured over $4 \%$ of the funding awarded to $\mathrm{CBC}$ projects in each case. Elsewhere the proportion of funding awarded to Finland was below $2.3 \%$. In the three sub-programmes awarding most funding to $\mathrm{CBC}$ projects (ERC, ENERGY and MSCA), Finland's share of contributions was $2.2 \%, 2.4 \%$ and $1.4 \%$ respectively. 
Table 69 EC contributions to Finnish participations in H2020 CBC projects, by subprogramme

\begin{tabular}{|c|c|c|c|c|}
\hline Sub-programme & & $\begin{array}{c}\text { Total EC } \\
\text { contributions } \\
\text { (€Mio.) }\end{array}$ & $\begin{array}{c}\text { EC } \\
\text { contributions } \\
\text { to } \mathrm{FI}(€ M i o .) \\
\end{array}$ & $\%$ \\
\hline CAREER & $\begin{array}{l}\text { Make scientific and technological careers } \\
\text { attractive for young people }\end{array}$ & 7 & 1 & $7.0 \%$ \\
\hline EURATOM & Euratom & 111 & 5 & $4.5 \%$ \\
\hline ADVMANU & Advanced manufacturing and processing & 555 & 22 & $4.0 \%$ \\
\hline INFRA & Research infrastructures & 545 & 20 & $3.7 \%$ \\
\hline ENV & $\begin{array}{l}\text { Climate action, environment, resource efficiency } \\
\text { and raw materials }\end{array}$ & 954 & 35 & $3.7 \%$ \\
\hline ADVMAT & Advanced materials & 248 & 8 & $3.3 \%$ \\
\hline ENERGY & Secure, clean and efficient energy & 1,855 & 45 & $2.4 \%$ \\
\hline BIOTECH & Biotechnology & 143 & 3 & $2.4 \%$ \\
\hline ICT & Information and Communication Technologies & 868 & 21 & $2.4 \%$ \\
\hline SECURITY & $\begin{array}{l}\text { Secure societies - Protecting freedom and } \\
\text { security of Europe and its citizens }\end{array}$ & 227 & 5 & $2.4 \%$ \\
\hline FOOD & $\begin{array}{l}\text { Food security, sustainable agriculture and } \\
\text { forestry, marine and maritime and inland water } \\
\text { research }\end{array}$ & 1,196 & 28 & $2.3 \%$ \\
\hline ERC & European Research Council & 2,779 & 62 & $2.2 \%$ \\
\hline SOCIETY & $\begin{array}{l}\text { Europe in a changing world - inclusive, innovative } \\
\text { and reflective Societies }\end{array}$ & 161 & 3 & $2.0 \%$ \\
\hline HEALTH & Health, demographic change and wellbeing & 1,453 & 27 & $1.8 \%$ \\
\hline CROSST & Cross-theme & 131 & 2 & $1.7 \%$ \\
\hline NMP & $\begin{array}{l}\text { Nanotechnologies, Advanced Materials and } \\
\text { Production }\end{array}$ & 250 & 4 & $1.5 \%$ \\
\hline TPT & Smart, green and integrated transport & 958 & 14 & $1.5 \%$ \\
\hline MSCA & Marie Sklodowska-Curie actions & 1,713 & 25 & $1.4 \%$ \\
\hline TWINING & Twinning of research institutions & 35 & 0.4 & $1.2 \%$ \\
\hline SPACE & Space & 109 & 1 & $1.0 \%$ \\
\hline GOV & $\begin{array}{l}\text { Develop the governance for the advancement of } \\
\text { responsible research and innovation }\end{array}$ & 19 & 0.2 & $1.0 \%$ \\
\hline FET & Future and Emerging Technologies & 234 & 2 & $0.9 \%$ \\
\hline INEGSOC & Integrate society in science and innovation & 20 & 0.1 & $0.5 \%$ \\
\hline WIDESPREAD & $\begin{array}{l}\text { Teaming of excellent research institutions and low } \\
\text { performing RDI regions }\end{array}$ & 142 & 1 & $0.4 \%$ \\
\hline SME & Innovation in SMEs & 60 & 0 & $0.0 \%$ \\
\hline ERA & ERA chairs & 19 & 0 & $0.0 \%$ \\
\hline GENDEREQ & $\begin{array}{l}\text { Promote gender equality in research and } \\
\text { innovation }\end{array}$ & 9 & 0 & $0.0 \%$ \\
\hline RISKFINANCE & Access to risk finance & 3 & 0 & $0.0 \%$ \\
\hline $\begin{array}{l}\text { SEAWP- } \\
\text { CROSST }\end{array}$ & $\begin{array}{l}\text { Spreading excellence and widening participation - } \\
\text { Cross-theme }\end{array}$ & 2 & 0 & $0.0 \%$ \\
\hline RESACCESS & $\begin{array}{l}\text { Develop the accessibility and the use of the } \\
\text { results of publicly-funded research }\end{array}$ & 1 & 0 & $0.0 \%$ \\
\hline $\begin{array}{l}\text { SWAFS- } \\
\text { CROSST }\end{array}$ & Science with and for Society - Cross-theme & 1 & 0 & $0.0 \%$ \\
\hline Total & & 14,807 & 335 & $2.3 \%$ \\
\hline
\end{tabular}

\section{Finnish participation in area of Digitalisation within FP7 and H2020}

The following analysis is based on our screening and tagging of action lines and proposals as relevant to Digitalisation, as described in the end of the appendix.

Finnish actors have contributed to the submission of 3,647 Digitalisation proposals in H2020 (as of May 2017). This equates to $6.1 \%$ of all such proposals submitted to the programme during this period. This is only slightly lower than the proportion of Digitalisation proposals involving Finland in FP7 (6.8\%).

As is shown in the table below, half of the comparator countries (AT, NL, and SE) have participated in a greater number and proportion of Digitalisation proposals than Finland, in both FP7 and H2020. However, when taking into account the relative number of R\&D personnel in each country, the number of proposals involving Finland in $\mathrm{H} 2020$ is higher than all comparator countries except Ireland. This is an improvement on FP7, where the Finnish rate of involvement was below that of most comparators. 
Table 70 FP7/H2020 Digitalisation proposals involving Finland and comparator countries

\begin{tabular}{lcccccccc}
\hline H2020 & All & FI & AT & DK & IE & NL & NO & SE \\
\hline Number of proposals involving $\ldots$ & 60,054 & 3,647 & 4,177 & 3,368 & 2,909 & 7,728 & 2,191 & 4,663 \\
\hline Proportion of all proposals involving... & & $6.1 \%$ & $7.0 \%$ & $5.6 \%$ & $4.8 \%$ & $12.9 \%$ & $3.6 \%$ & $7.8 \%$ \\
\hline $\begin{array}{l}\text { Number of proposals per 1,000 researchers } \\
\text { in... }\end{array}$ & & 71 & 61 & 57 & 101 & 61 & 53 & 56 \\
\hline FP7 & All & FI & AT & DK & IE & NL & NO & SE \\
\hline Number of proposals involving... & 66,324 & 4,533 & 5,811 & 3,716 & 3,653 & 9,733 & 2,787 & 6,781 \\
\hline Proportion of all proposals involving... & & $6.8 \%$ & $8.8 \%$ & $5.6 \%$ & $5.5 \%$ & $14.7 \%$ & $4.2 \%$ & $10.2 \%$ \\
\hline $\begin{array}{l}\text { Number of proposals per 1,000 researchers } \\
\text { in... }\end{array}$ & 82 & 97 & 66 & 175 & 92 & 77 & 86 \\
\hline
\end{tabular}

In $43 \%$ of $\mathrm{H} 2020$ Digitalisation proposals involving Finland, a Finnish actor held the role of coordinator. This is much higher than in FP7, where $30 \%$ of Finnish Digitalisation proposals were led by a Finnish coordinator. All comparator countries had a lower rate of coordination than Finland in H2020, but not in FP7 where IE, NL and SE had a higher rate.

If we take account of the relative size of the researcher base in each country, the number of Digitalisation proposal coordinators from Finland (31) in H2020 is above the rate for all comparator countries except IE. In FP7, the Finnish rate (25 coordinators per 1,000 personnel) was below most of the comparators.

Table 71 FP7/H2020 Digitalisation proposals with a 'domestic' coordinator

\begin{tabular}{|c|c|c|c|c|c|c|c|c|}
\hline $\mathrm{H} 2020$ & All & FI & AT & DK & IE & NL & NO & SE \\
\hline Number of proposals with domestic coordinator & 60,054 & 1,578 & 1,178 & 1,362 & 1,160 & 2,712 & 795 & 1,555 \\
\hline$\%$ of country's proposals with domestic coordinator & & $43 \%$ & $28 \%$ & $40 \%$ & $40 \%$ & $35 \%$ & $36 \%$ & $33 \%$ \\
\hline Coordinators per 1,000 researchers & & 31 & 17 & 23 & 40 & 22 & 19 & 19 \\
\hline FP7 & All & FI & AT & DK & IE & NL & NO & SE \\
\hline Number of proposals with domestic coordinator & 66,324 & 1,360 & 1,594 & 1,072 & 1,189 & 2,940 & 766 & 2,050 \\
\hline$\%$ of country's proposals with domestic coordinator & & $30 \%$ & $27 \%$ & $29 \%$ & $33 \%$ & $30 \%$ & $27 \%$ & $30 \%$ \\
\hline Coordinators per 1,000 researchers & & 25 & 27 & 19 & 57 & 28 & 21 & 26 \\
\hline
\end{tabular}

Finland has participated in 2,614 multi-partner H2020 Digitalisation proposals, of which it has served as the coordinator in $545(21 \%)$. This is a higher rate than all comparator countries except Ireland (22\%). The Finnish rate of Digitalisation proposal coordination in $\mathrm{H} 2020$ relative to the FTE researcher population (10.6), is again higher than all comparator countries expect Ireland. This is a higher rate of activity than in FP7, where Finland had a lower rate of MP coordinators per researcher than nearly all comparators.

Table 72 FP7/H2020 'multi-partner' (MP) Digitalisation proposals with a 'domestic' coordinator

\begin{tabular}{|c|c|c|c|c|c|c|c|c|}
\hline $\mathrm{H} 2020$ & All & $\mathrm{FI}$ & AT & DK & IE & NL & NO & SE \\
\hline Number of MP proposals involving... & 23,305 & 2,614 & 3,565 & 2,503 & 2,233 & 6,107 & 1,724 & 3,606 \\
\hline $\begin{array}{l}\text { Number of MP proposals with domestic } \\
\text { coordinator }\end{array}$ & 23,305 & 545 & 566 & 497 & 484 & 1,091 & 328 & 498 \\
\hline $\begin{array}{l}\text { \% of country's MP proposals with domestic } \\
\text { coordinator }\end{array}$ & & $21 \%$ & $16 \%$ & $20 \%$ & $22 \%$ & $18 \%$ & $19 \%$ & $14 \%$ \\
\hline $\begin{array}{l}\text { Coordinators of MP proposals per } 1,000 \\
\text { researchers }\end{array}$ & & 10.6 & 8.3 & 8.4 & 16.7 & 8.7 & 7.9 & 5.9 \\
\hline FP7 & All & FI & AT & DK & IE & NL & NO & SE \\
\hline Number of MP proposals involving... & 34,335 & 3,846 & 5,103 & 3,168 & 3,139 & 8,153 & 2,480 & 5,721 \\
\hline $\begin{array}{l}\text { Number of MP proposals with domestic } \\
\text { coordinator }\end{array}$ & 34,335 & 673 & 886 & 524 & 675 & 1,360 & 459 & 990 \\
\hline $\begin{array}{l}\text { \% of country's MP proposals with domestic } \\
\text { coordinator }\end{array}$ & & $17 \%$ & $17 \%$ & $17 \%$ & $22 \%$ & $17 \%$ & $19 \%$ & $17 \%$ \\
\hline $\begin{array}{l}\text { Coordinators of MP proposals per 1,000 } \\
\text { researchers }\end{array}$ & & 12.2 & 14.8 & 9.4 & 32.4 & 12.9 & 12.6 & 12.6 \\
\hline
\end{tabular}


Because of multiple participations in some proposals, the total number of Finnish participations in H2020 Digitalisation proposals $(5,126)$ is higher than the number of unique Digitalisation proposals in which Finland is involved $(3,647)$. These Finnish participations represent just $2.3 \%$ of all participations in H2020 Digitalisation proposals, which is a lower proportion than AT, NL, and SE. However, when taking account of the size of the respective researcher populations, Finland has a higher number of participations in H2020 Digitalisation proposals (100 per 1,000 R\&D personnel) than all of the comparator countries except Ireland.

Finland accounted for a similar proportion (2.1\%) of all participations in Digitalisation proposals in FP7. However, because of the longer time period covered, its participation rate (131 per 1,000 R\&D personnel) was higher than in H2020.

Table 73 Participations in FP7/H2020 Digitalisation proposals from Finland and comparator countries

\begin{tabular}{|c|c|c|c|c|c|c|c|c|}
\hline H2020 & All & $\mathrm{FI}$ & AT & DK & IE & NL & NO & SE \\
\hline Number of participations in proposals & 225,108 & 5,126 & 5,719 & 4,427 & 3,822 & 11,256 & 2,931 & 6,277 \\
\hline Proportion of all participations in proposals & & $2.3 \%$ & $2.5 \%$ & $2.0 \%$ & $1.7 \%$ & $5.0 \%$ & $1.3 \%$ & $2.8 \%$ \\
\hline $\begin{array}{l}\text { Number of participations in proposals per } 1,000 \\
\text { researchers in... }\end{array}$ & & 100 & 84 & 75 & 132 & 90 & 71 & 75 \\
\hline FP7 & All & FI & AT & DK & IE & NL & NO & SE \\
\hline Number of participations in proposals & 307,680 & 6,382 & 7,861 & 4,869 & 4,694 & 14,160 & 3,792 & 9,410 \\
\hline Proportion of all participations in proposals & & $2.1 \%$ & $2.6 \%$ & $1.6 \%$ & $1.5 \%$ & $4.6 \%$ & $1.2 \%$ & $3.1 \%$ \\
\hline $\begin{array}{l}\text { Number of participations in proposals per } 1,000 \\
\text { researchers in... }\end{array}$ & & 116 & 131 & 87 & 225 & 134 & 104 & 120 \\
\hline
\end{tabular}

The table below shows the distribution of H2020 Digitalisation proposal participations between different types of actor (categorisations as used in eCORDA). For Finland, it shows that two organisation types (PRC and HES) account for the majority $(79 \%)$ of participations in Digitalisation proposals. Compared to the overall average, Finland's rate of PRC participation is slightly higher.

The table also shows the proportion of PRC participations that are SMEs ${ }^{175}$. For Finland, the rate is $88 \%$, which is higher than the overall average, and also higher than all of the comparator countries.

Table 74 Distribution of participations in H2020 Digitalisation proposals by organisational type

\begin{tabular}{|c|c|c|c|c|c|c|c|c|}
\hline $\mathrm{H} 2020$ & All & $\mathrm{FI}$ & AT & DK & IE & NL & NO & SE \\
\hline $\begin{array}{l}\text { PRC - Private for profit (excl. } \\
\text { education) }\end{array}$ & $36 \%$ & $41 \%$ & $35 \%$ & $49 \%$ & $51 \%$ & $43 \%$ & $33 \%$ & $52 \%$ \\
\hline REC - Research organisations & $3 \%$ & $2 \%$ & $3 \%$ & $2 \%$ & $2 \%$ & $4 \%$ & $2 \%$ & $1 \%$ \\
\hline HES - Higher or secondary education & $41 \%$ & $38 \%$ & $39 \%$ & $37 \%$ & $42 \%$ & $39 \%$ & $38 \%$ & $34 \%$ \\
\hline PUB - Public body (excl. REC/HES) & $3 \%$ & $2 \%$ & $1 \%$ & $5 \%$ & $3 \%$ & $2 \%$ & $3 \%$ & $4 \%$ \\
\hline OTH - Others & $18 \%$ & $16 \%$ & $21 \%$ & $8 \%$ & $2 \%$ & $12 \%$ & $25 \%$ & $8 \%$ \\
\hline Total & 225,108 & 5,126 & 5,719 & 4,427 & 3,822 & 11,256 & 2,931 & 6,277 \\
\hline SMEs as a $\%$ of $P R C$ & $77 \%$ & $88 \%$ & $72 \%$ & $85 \%$ & $75 \%$ & $78 \%$ & $83 \%$ & $73 \%$ \\
\hline
\end{tabular}

The average EC funding request per Finnish participation in H2020 Digitalisation proposals was around $€ 629$ thousand, which is higher than in all of the comparator countries.

Table 75 EC contributions requested in H2020 Digitalisation proposals

\begin{tabular}{|c|c|c|c|c|c|c|c|}
\hline $\mathrm{H} 2020$ & All & $\mathrm{FI}$ & AT & DK & IE & NL & NO \\
\hline $\begin{array}{l}\text { Selected participations in proposals } \\
\text { (those with financial data) }\end{array}$ & 225,108 & 5,126 & 5,719 & 4,427 & 3,822 & 11,256 & 2,931 \\
\hline
\end{tabular}

${ }^{175}$ Across all countries, information on whether a PRC participation is from an SME or not is only available in $78 \%$ of cases. For the percentages shown in the table, the denominator is the total population of PRCs where the status is known (i.e. SME or not). 


\begin{tabular}{lcccccc}
\hline $\begin{array}{l}\text { Total EC contribution requested } \\
(€ \text { million) }\end{array}$ & 117,938 & 3,225 & 2,845 & 2,667 & 2,208 & 6,588 \\
\hline $\begin{array}{l}\text { Average EC contribution }(€) \\
\text { requested per participation }\end{array}$ & 523,915 & 629,218 & 497,490 & 602,446 & 577,795 & 585,308 \\
\hline
\end{tabular}

Below we compare the distribution of Digitalisation proposal participations at the subprogramme level (a full list of sub-programme acronyms and titles is provided at the end of the appendix).

Overall, Finland accounts for $2.3 \%$ of all participations in H2020 Digitalisation proposals.

It is more active (relatively) in 14 sub-programmes, and the RISKFINANCE, EURATOM and ERC sub-programmes in particular, where it accounts for at least $3 \%$ of all Digitalisation proposal participations in each case.

Table 76 H2020 sub-programmes with a relatively high participation rate of Finland in Digitalisation proposals

\begin{tabular}{|c|c|c|c|c|c|c|c|c|}
\hline & Overall & $\mathrm{FI}$ & AT & DK & IE & NL & NO & SE \\
\hline RISKFINANCE & 98 & $4.1 \%$ & $2.0 \%$ & $5.1 \%$ & $2.0 \%$ & $6.1 \%$ & $0.0 \%$ & $1.0 \%$ \\
\hline EURATOM & 704 & $3.4 \%$ & $0.1 \%$ & $0.1 \%$ & $0.0 \%$ & $2.8 \%$ & $0.6 \%$ & $7.4 \%$ \\
\hline ERC & 10,730 & $3.0 \%$ & $2.2 \%$ & $2.2 \%$ & $1.5 \%$ & $5.6 \%$ & $0.8 \%$ & $3.3 \%$ \\
\hline WIDESPREAD & 692 & $2.9 \%$ & $2.5 \%$ & $0.4 \%$ & $0.4 \%$ & $1.9 \%$ & $0.3 \%$ & $3.3 \%$ \\
\hline ICT & 48,333 & $2.9 \%$ & $2.8 \%$ & $1.4 \%$ & $2.0 \%$ & $4.7 \%$ & $1.4 \%$ & $2.4 \%$ \\
\hline ENV & 6,406 & $2.7 \%$ & $2.4 \%$ & $1.3 \%$ & $1.1 \%$ & $4.9 \%$ & $1.4 \%$ & $2.5 \%$ \\
\hline HEALTH & 18,264 & $2.7 \%$ & $2.3 \%$ & $2.2 \%$ & $1.9 \%$ & $6.7 \%$ & $1.5 \%$ & $3.2 \%$ \\
\hline SCIENCE & 186 & $2.7 \%$ & $3.8 \%$ & $1.6 \%$ & $2.7 \%$ & $2.7 \%$ & $2.7 \%$ & $4.3 \%$ \\
\hline NMP & 8,629 & $2.7 \%$ & $2.1 \%$ & $2.4 \%$ & $1.8 \%$ & $4.5 \%$ & $1.1 \%$ & $2.9 \%$ \\
\hline CAREER & 1,211 & $2.6 \%$ & $3.3 \%$ & $1.2 \%$ & $2.0 \%$ & $3.1 \%$ & $1.4 \%$ & $2.6 \%$ \\
\hline ENERGY & 12,274 & $2.6 \%$ & $2.8 \%$ & $3.1 \%$ & $1.7 \%$ & $4.1 \%$ & $1.6 \%$ & $2.7 \%$ \\
\hline ADVMANU & 9,349 & $2.4 \%$ & $3.0 \%$ & $1.6 \%$ & $1.4 \%$ & $3.4 \%$ & $1.1 \%$ & $2.7 \%$ \\
\hline FOOD & 6,115 & $2.3 \%$ & $2.5 \%$ & $2.5 \%$ & $1.6 \%$ & $5.3 \%$ & $2.1 \%$ & $2.4 \%$ \\
\hline ADVMAT & 3,454 & $2.3 \%$ & $2.3 \%$ & $1.9 \%$ & $1.4 \%$ & $3.1 \%$ & $1.5 \%$ & $2.8 \%$ \\
\hline SME & 1,237 & $2.2 \%$ & $2.7 \%$ & $2.4 \%$ & $1.6 \%$ & $3.6 \%$ & $1.6 \%$ & $3.1 \%$ \\
\hline Total & 225,108 & $2.3 \%$ & $2.5 \%$ & $2.0 \%$ & $1.7 \%$ & $5.0 \%$ & $1.3 \%$ & $2.8 \%$ \\
\hline
\end{tabular}

Finland is relatively less active in Digitalisation proposals in the remaining 17 subprogrammes (shown below). In particular, there have been no Finnish participations in relevant proposals GENDEREQ, RESACCESS, ERA or SWAFS-CROSST subprogrammes. Finland also only accounts for less than $1 \%$ of participations in relevant H2020 proposals in the BIOTECH sub-programme.

Table 77 H2020 sub-programmes with a relatively low participation rate of Finland in Digitalisation proposals

\begin{tabular}{|c|c|c|c|c|c|c|c|c|}
\hline & Overall & $\mathrm{FI}$ & AT & DK & IE & NL & NO & SE \\
\hline SPACE & 3,807 & $2.2 \%$ & $2.9 \%$ & $1.0 \%$ & $1.0 \%$ & $3.9 \%$ & $1.2 \%$ & $1.9 \%$ \\
\hline SME & 980 & $2.0 \%$ & $3.3 \%$ & $2.1 \%$ & $1.2 \%$ & $3.1 \%$ & $1.5 \%$ & $2.9 \%$ \\
\hline FET & 16,561 & $2.0 \%$ & $2.7 \%$ & $1.9 \%$ & $1.3 \%$ & $5.3 \%$ & $0.9 \%$ & $3.2 \%$ \\
\hline GOV & 300 & $2.0 \%$ & $4.3 \%$ & $1.7 \%$ & $1.7 \%$ & $11.0 \%$ & $2.3 \%$ & $1.3 \%$ \\
\hline TWINING & 957 & $2.0 \%$ & $3.8 \%$ & $1.7 \%$ & $1.0 \%$ & $4.6 \%$ & $0.9 \%$ & $2.7 \%$ \\
\hline SOCIETY & 8,070 & $1.9 \%$ & $2.5 \%$ & $1.6 \%$ & $1.8 \%$ & $3.9 \%$ & $0.8 \%$ & $1.9 \%$ \\
\hline INFRA & 3,233 & $1.9 \%$ & $2.5 \%$ & $1.9 \%$ & $2.1 \%$ & $7.5 \%$ & $1.5 \%$ & $3.0 \%$ \\
\hline CROSST & 4,719 & $1.7 \%$ & $2.7 \%$ & $2.0 \%$ & $2.1 \%$ & $5.5 \%$ & $1.4 \%$ & $2.5 \%$ \\
\hline SECURITY & 9,974 & $1.6 \%$ & $2.8 \%$ & $0.9 \%$ & $2.2 \%$ & $4.0 \%$ & $1.6 \%$ & $1.7 \%$ \\
\hline TPT & 11,419 & $1.6 \%$ & $2.9 \%$ & $1.5 \%$ & $1.3 \%$ & $4.8 \%$ & $1.4 \%$ & $3.3 \%$ \\
\hline MSCA & 37,052 & $1.5 \%$ & $2.1 \%$ & $2.9 \%$ & $1.7 \%$ & $5.8 \%$ & $1.3 \%$ & $3.2 \%$ \\
\hline INEGSOC & 567 & $1.2 \%$ & $4.2 \%$ & $1.6 \%$ & $1.2 \%$ & $5.8 \%$ & $0.9 \%$ & $0.2 \%$ \\
\hline BIOTECH & 840 & $0.8 \%$ & $2.3 \%$ & $2.4 \%$ & $1.8 \%$ & $4.5 \%$ & $1.4 \%$ & $3.5 \%$ \\
\hline GENDEREQ & 124 & $0.0 \%$ & $5.6 \%$ & $0.0 \%$ & $2.4 \%$ & $0.0 \%$ & $0.0 \%$ & $2.4 \%$ \\
\hline
\end{tabular}




\begin{tabular}{lcccccccc}
\hline RESACCESS & 26 & $0.0 \%$ & $0.0 \%$ & $3.8 \%$ & $0.0 \%$ & $15.4 \%$ & $0.0 \%$ & $0.0 \%$ \\
\hline ERA & 32 & $0.0 \%$ & $0.0 \%$ & $0.0 \%$ & $0.0 \%$ & $0.0 \%$ & $0.0 \%$ & $0.0 \%$ \\
\hline SWAFS-CROSST & 2 & $0.0 \%$ & $0.0 \%$ & $0.0 \%$ & $0.0 \%$ & $0.0 \%$ & $0.0 \%$ & $0.0 \%$ \\
\hline \multicolumn{2}{l}{} & & & & & & & \\
\hline Total & $\mathbf{2 2 5 , 1 0 8}$ & $2.3 \%$ & $\mathbf{2 . 5} \%$ & $\mathbf{2 . 0} \%$ & $\mathbf{1 . 7} \%$ & $\mathbf{5 . 0} \%$ & $\mathbf{1 . 3} \%$ & $\mathbf{2 . 8} \%$ \\
\hline
\end{tabular}

\section{Success rates and participation in Digitalisation projects}

To May 2017, 427 H2020 grants had been awarded to Digitalisation projects involving Finland. This represents $6.5 \%$ of all H2020 Digitalisation projects, which is lower than AT, $\mathrm{NL}$ and SE. When one adjusts for the size of the research base in each country, Finland (with $8.3 \mathrm{H} 2020$ Digitalisation projects for every 1,000 R\&D personnel) sits in the middle of the comparator countries.

Table 78 Digitalisation Projects (per 1,000 R\&D personnel) - Finland and comparator countries

\begin{tabular}{|c|c|c|c|c|c|c|c|c|}
\hline $\mathrm{H} 2020$ & All & $\mathrm{FI}$ & AT & DK & IE & NL & NO & SE \\
\hline Projects & 6,573 & 427 & 606 & 424 & 376 & 1121 & 306 & 645 \\
\hline Projects per 1,000 researchers & & 8.3 & 8.9 & 7.1 & 13.0 & 8.9 & 7.4 & 7.7 \\
\hline FP7 & All & FI & AT & DK & IE & NL & NO & SE \\
\hline Projects & 10,309 & 819 & 1142 & 807 & 706 & 2134 & 509 & 1354 \\
\hline Projects per 1,000 researchers & & 14.8 & 19.1 & 14.4 & 33.9 & 20.2 & 14.0 & 17.2 \\
\hline
\end{tabular}

The $427 \mathrm{H} 2020$ Digitalisation projects involving Finland came from 4,533 proposals. This equates to a proposal success rate of $9.4 \%$ - which is lower than the overall success rate of H2020 Digitalisation proposals (9.9\%), as well as below the rate achieved in all comparator countries. Finnish success rates in FP7 Digitalisation proposals were even higher (18.1\%) than in $\mathrm{H} 2020$, but this partly reflects higher success rates seen in FP7 overall. Proposal success rates were still below all comparator countries.

Table 79 Success rate of Digitalisation proposals - Finland and comparator countries

\begin{tabular}{lcccccccc}
\hline H2020 & All & FI & AT & DK & IE & NL & NO & SE \\
\hline Proposals & 66,324 & 4,533 & 5,811 & 3,716 & 3,653 & 9,733 & 2,787 & 6,781 \\
\hline Projects & 6,573 & 427 & 606 & 424 & 376 & 1121 & 306 & 645 \\
\hline Success rate & $9.9 \%$ & $9.4 \%$ & $10.4 \%$ & $11.4 \%$ & $10.3 \%$ & $11.5 \%$ & $11.0 \%$ & $9.5 \%$ \\
\hline FP7 & All & FI & AT & DK & IE & NL & NO & SE \\
\hline Proposals & 66,324 & 4,533 & 5,811 & 3,716 & 3,653 & 9,733 & 2,787 & 6,781 \\
\hline Projects & 10,309 & 819 & 1142 & 807 & 706 & 2134 & 509 & 1354 \\
\hline Success rate & $15.6 \%$ & $18.1 \%$ & $19.7 \%$ & $21.7 \%$ & $19.3 \%$ & $21.9 \%$ & $18.3 \%$ & $20.0 \%$ \\
\hline
\end{tabular}

H2020 grants have been awarded to 128 Digitalisation projects with a Finnish coordinator. The equates to 2.5 projects for every 1,000 R\&D personnel in the country. This rate is below that of all comparator countries apart from Norway and Sweden. The rate (2.7 coordinators per 1,000 personnel) for Finland in FP7 was lower than all comparators except Denmark.

Table 80 Coordinators of Digitalisation projects (per 1,000 R\&D personnel) - Finland and comparator countries

\begin{tabular}{|c|c|c|c|c|c|c|c|c|}
\hline $\mathrm{H} 2020$ & All & FI & AT & DK & IE & NL & NO & SE \\
\hline Coordinators & 6,573 & 128 & 180 & 160 & 135 & 409 & 88 & 166 \\
\hline Coordinators per 1,000 researchers & & 2.5 & 2.6 & 2.7 & 4.7 & 3.3 & 2.1 & 2.0 \\
\hline FP7 & All & $\mathrm{FI}$ & AT & DK & IE & NL & NO & SE \\
\hline Coordinators & 10,309 & 149 & 299 & 167 & 197 & 588 & 128 & 273 \\
\hline Coordinators per 1,000 researchers & & 2.7 & 5.0 & 3.0 & 9.4 & 5.6 & 3.5 & 3.5 \\
\hline
\end{tabular}


The success rate of Finnish-coordinated Digitalisation proposals in $\mathrm{H} 2020$ is $8.1 \%$. This rate is both lower than the overall H2020 figure (10.9\%), and lower than the rates of coordinator success achieved in all comparator countries. In FP7, Finland's success rate for coordinators (16.6\%), was above average and greater than in half of the comparator countries.

Table 81 Success rate of Digitalisation proposals with/without domestic coordinator - Finland and comparator countries

\begin{tabular}{|c|c|c|c|c|c|c|c|c|}
\hline H2020 success rates & All & $\mathrm{FI}$ & AT & DK & IE & NL & NO & SE \\
\hline Proposal with domestic coordinator & $10.9 \%$ & $8.1 \%$ & $15.3 \%$ & $11.7 \%$ & $11.6 \%$ & $15.1 \%$ & $11.1 \%$ & $10.7 \%$ \\
\hline Proposal without domestic coordinator & & $14.5 \%$ & $14.2 \%$ & $13.2 \%$ & $13.8 \%$ & $14.2 \%$ & $15.6 \%$ & $15.4 \%$ \\
\hline FP7 success rates & All & FI & AT & DK & IE & NL & NO & SE \\
\hline Proposal with domestic coordinator & $15.5 \%$ & $16.6 \%$ & $20.0 \%$ & $15.6 \%$ & $13.3 \%$ & $16.7 \%$ & $11.0 \%$ & $18.8 \%$ \\
\hline Proposal without domestic coordinator & & $20.7 \%$ & $22.8 \%$ & $24.2 \%$ & $22.8 \%$ & $18.9 \%$ & $21.1 \%$ & $20.0 \%$ \\
\hline
\end{tabular}

If we look only at those H2020 Digitalisation proposals/projects with multiple participants (i.e. excluding those where the coordinator is the only partner), the success rate for $\mathrm{FI}$ coordinators increases from $14.5 \%$ to $19 \%$. However, this is still lower than in all of the comparator countries.

Table 82 Success rate of multi-partner Digitalisation proposals with domestic coordinator

\begin{tabular}{|c|c|c|c|c|c|c|c|c|}
\hline H2020 - multi partner & All & $\mathrm{FI}$ & AT & DK & IE & NL & NO & SE \\
\hline Proposals & 23,305 & 545 & 566 & 497 & 484 & 1,091 & 328 & 498 \\
\hline Projects & & 104 & 182 & 103 & 135 & 324 & 97 & 161 \\
\hline Success rate & & $19 \%$ & $32 \%$ & $21 \%$ & $28 \%$ & $30 \%$ & $30 \%$ & $32 \%$ \\
\hline
\end{tabular}

The 427 Digitalisation grants awarded to Finland in H2020 involve 607 individual Finnish participations. This represents $2 \%$ of all participations in $\mathrm{H} 2020$ Digitalisation projects. When taking account of the size of the researcher base, Finland sits in the middle of the comparator countries. The 11.8 Digitalisation participations per 1,000 R\&D personnel in Finland is below that achieved in $\mathrm{FI}, \mathrm{AT}$ or NL, but above that of DK, NO and SE. A similar pattern can be seen in FP7.

Table 83 Participations in Digitalisation projects (per 1,000 R\&D personnel) - Finland and comparator countries

\begin{tabular}{lcccccccc}
\hline H2020 & All & FI & AT & DK & IE & NL & NO & SE \\
\hline Participations in projects & 30,009 & 607 & 923 & 572 & 497 & 1,783 & 423 & 949 \\
\hline Participations per 1,000 researchers & & 11.8 & 13.5 & 9.6 & 17.2 & 14.2 & 10.2 & 11.3 \\
\hline FP7 & All & FI & AT & DK & IE & NL & NO & SE \\
\hline Participations in projects & 62,327 & 1,412 & 1,701 & 1,148 & 951 & 3,509 & 718 & 2,018 \\
\hline Participations per 1,000 researchers & & 25.6 & 28.4 & 20.5 & 45.6 & 33.3 & 19.7 & 25.7 \\
\hline
\end{tabular}

The 607 Finnish participations in successful H2020 Digitalisation projects, from an original 5,126 participations in proposals, represents a participation success rate of $11.8 \%$ in $\mathrm{H} 2020$ so far. This is below the overall rate of success for all participations in Digitalisation proposals (13.3\%), and below that achieved in all of the comparator countries. The Finnish success rate in FP7 compared more favourably.

Table 84 Success rate of Digitalisation participations - Finland and comparator countries

\begin{tabular}{lcccccccc}
\hline Participation success rate & All & FI & AT & DK & IE & NL & NO & SE \\
\hline H2020 & $13.3 \%$ & $11.8 \%$ & $16.1 \%$ & $12.9 \%$ & $13.0 \%$ & $15.8 \%$ & $14.4 \%$ & $15.1 \%$ \\
\hline FP7 & $20.3 \%$ & $22.1 \%$ & $21.6 \%$ & $23.6 \%$ & $20.3 \%$ & $24.8 \%$ & $18.9 \%$ & $21.4 \%$ \\
\hline
\end{tabular}


Comparing across different organisation types, Finnish success rates for Digitalisation participations were highest amongst PUB and PRC organisations (both 18\%). The PRC success rate was above average and above most comparator countries. Success rates for HES and REC were below average and below all comparators.

The table also shows the success rate of SME-PRC participations in Digitalisation proposals ${ }^{176}$. For Finland, the rate is $11 \%$, which is the same as the $\mathrm{H} 2020$ average, but below that achieved in most comparator countries.

Table 85 Success rate of Digitalisation participations, by organisation type - Finland and comparator countries (H2020)

\begin{tabular}{lccccccc}
\hline Participation success rate & All & FI & AT & DK & IE & NL & NO \\
\hline HES - Higher or secondary education & $12 \%$ & $9 \%$ & $13 \%$ & $13 \%$ & $12 \%$ & $14 \%$ & $11 \%$ \\
\hline PRC - Private for profit (excl. education) & $17 \%$ & $18 \%$ & $16 \%$ & $21 \%$ & $9 \%$ & $17 \%$ & $17 \%$ \\
\hline REC - Research organisations & $13 \%$ & $12 \%$ & $18 \%$ & $13 \%$ & $14 \%$ & $16 \%$ & $15 \%$ \\
\hline PUB - Public body (excl. research and education) & $20 \%$ & $18 \%$ & $30 \%$ & $15 \%$ & $17 \%$ & $22 \%$ & $30 \%$ \\
\hline OTH - Others & $16 \%$ & $16 \%$ & $18 \%$ & $13 \%$ & $9 \%$ & $20 \%$ & $15 \%$ \\
\hline PRC-SMEs & $11 \%$ & $11 \%$ & $12 \%$ & $11 \%$ & $13 \%$ & $13 \%$ & $14 \%$ \\
\hline
\end{tabular}

EC contributions to Finnish participations in H2020 Digitalisation projects totalled €294 million, which equates to $2.3 \%$ of all funding to Digitalisation participations to date. This is below the proportion realised by Austria, the Netherlands, and Sweden. The average contribution to each Finnish Digitalisation participation (at $€ 484$ thousand) is however above that achieved by all comparator countries apart from the Netherlands.

Table 86 EC contributions to Digitalisation participations as a proportion of requested funding - Finland and comparator countries

\begin{tabular}{|c|c|c|c|c|c|c|c|c|}
\hline $\mathrm{H} 2020$ & All & $\mathrm{FI}$ & AT & DK & IE & NL & NO & SE \\
\hline $\begin{array}{l}\text { Selected participations in } \\
\text { projects (those with financial } \\
\text { data) }\end{array}$ & 30,009 & 607 & 923 & 572 & 497 & 1783 & 423 & 949 \\
\hline Total EC contribution (€million) & 12,881 & 294 & 370 & 272 & 226 & 910 & 195 & 431 \\
\hline$\%$ of total EC contributions & & $2.3 \%$ & $2.9 \%$ & $2.1 \%$ & $1.8 \%$ & $7.1 \%$ & $1.5 \%$ & $3.3 \%$ \\
\hline $\begin{array}{l}\text { Average EC contribution per } \\
\text { participation }\end{array}$ & 429,238 & 484,349 & 400,867 & 475,524 & 454,728 & 510,376 & 460,993 & 454,162 \\
\hline
\end{tabular}

There were 10 sub-programmes of $\mathrm{H} 2020$ where Finnish participation success rates in Digitalisation proposals were above the overall average. These are shown at the top of the table below and include RISKFINANCE, INEGSOC, CAREER and FOOD, where Finnish success rates were a third or more higher than overall in these sub-programmes. Elsewhere Finnish success rates were below average, or Finland has not yet participated in relevant proposals. The total number of participations in relevant proposals is also shown to give a sense of the scale of opportunity for Digitalisation activity within each subprogramme.

Table 87 Finnish success rates in H2020 Digitalisation proposals by sub-programme

\begin{tabular}{llcccc}
\hline Sub-programme & & $\begin{array}{c}\text { All } \\
\text { participations in } \\
\text { proposals }\end{array}$ & $\begin{array}{c}\text { Overall } \\
\text { success rate }\end{array}$ & $\begin{array}{c}\text { FI } \\
\text { success } \\
\text { rate }\end{array}$ & $\begin{array}{c}\% \\
\text { differen } \\
\text { ce }\end{array}$ \\
\hline RISKFINANCE & Access to risk finance & 98 & $9.2 \%$ & $25.0 \%$ & $172.2 \%$ \\
\hline INEGSOC & $\begin{array}{l}\text { Integrate society in science and } \\
\text { innovation }\end{array}$ & 567 & $11.8 \%$ & $28.6 \%$ & $141.8 \%$ \\
\hline CAREER & $\begin{array}{l}\text { Make scientific and technological careers } \\
\text { attractive for young people }\end{array}$ & 1,211 & $4.4 \%$ & $6.3 \%$ & $42.8 \%$ \\
\hline
\end{tabular}

${ }^{176}$ As mentioned previously, information on whether a PRC participant is an SME or not is only available for $78 \%$ of proposal participations and $80 \%$ of project participations. Success rates are calculated based only on those that are known. 


\begin{tabular}{|c|c|c|c|c|c|}
\hline FOOD & $\begin{array}{l}\text { Food security, sustainable agriculture } \\
\text { and forestry, marine and maritime and } \\
\text { inland water research }\end{array}$ & 6,115 & $16.3 \%$ & $22.4 \%$ & $37.3 \%$ \\
\hline TWINING & Twinning of research institutions & 957 & $12.6 \%$ & $15.8 \%$ & $24.9 \%$ \\
\hline EURATOM & Euratom & 704 & $48.4 \%$ & $58.3 \%$ & $20.4 \%$ \\
\hline ENERGY & Secure, clean and efficient energy & 12,274 & $14.5 \%$ & $16.2 \%$ & $11.9 \%$ \\
\hline ENV & $\begin{array}{l}\text { Climate action, environment, resource } \\
\text { efficiency and raw materials }\end{array}$ & 6,406 & $19.7 \%$ & $21.8 \%$ & $11.0 \%$ \\
\hline WIDESPREAD & $\begin{array}{l}\text { Teaming of excellent research } \\
\text { institutions and low performing RDI } \\
\text { regions }\end{array}$ & 692 & $24.6 \%$ & $25.0 \%$ & $1.8 \%$ \\
\hline SECURITY & $\begin{array}{l}\text { Secure societies - Protecting freedom } \\
\text { and security of Europe and its citizens }\end{array}$ & 9,974 & $11.9 \%$ & $11.9 \%$ & $0.2 \%$ \\
\hline SCIENCE & Encourage citizens to engage in science & 186 & $0.0 \%$ & $0.0 \%$ & $0 \%$ \\
\hline ADVMANU & Advanced manufacturing and processing & 9,349 & $15.8 \%$ & $14.9 \%$ & $-5.4 \%$ \\
\hline ICT & $\begin{array}{l}\text { Information and Communication } \\
\text { Technologies }\end{array}$ & 48,333 & $14.5 \%$ & $13.1 \%$ & $-9.5 \%$ \\
\hline INFRA & Research infrastructures & 3,233 & $36.1 \%$ & $30.6 \%$ & $-15.1 \%$ \\
\hline MSCA & Marie Sklodowska-Curie actions & 37,052 & $11.7 \%$ & $9.4 \%$ & $-19.6 \%$ \\
\hline SME & Innovation in SMEs & 980 & $13.0 \%$ & $10.0 \%$ & $-22.8 \%$ \\
\hline SOCIETY & $\begin{array}{l}\text { Europe in a changing world - inclusive, } \\
\text { innovative and reflective Societies }\end{array}$ & 8,070 & $7.7 \%$ & $5.8 \%$ & $-24.8 \%$ \\
\hline TPT & Smart, green and integrated transport & 11,419 & $23.4 \%$ & $17.0 \%$ & $-27.3 \%$ \\
\hline HEALTH & $\begin{array}{l}\text { Health, demographic change and } \\
\text { wellbeing }\end{array}$ & 18,264 & $8.7 \%$ & $6.3 \%$ & $-28.4 \%$ \\
\hline GOV & $\begin{array}{l}\text { Develop the governance for the } \\
\text { advancement of responsible research } \\
\text { and innovation }\end{array}$ & 300 & $23.3 \%$ & $16.7 \%$ & $-28.6 \%$ \\
\hline FET & Future and Emerging Technologies & 16,561 & $5.4 \%$ & $3.9 \%$ & $-28.8 \%$ \\
\hline ADVMAT & Advanced materials & 3,454 & $18.0 \%$ & $12.7 \%$ & $-29.5 \%$ \\
\hline NMP & $\begin{array}{l}\text { Nanotechnologies, Advanced Materials } \\
\text { and Production }\end{array}$ & 8,629 & $10.2 \%$ & $7.0 \%$ & $-31.8 \%$ \\
\hline SPACE & Space & 3,807 & $17.0 \%$ & $10.7 \%$ & $-37.2 \%$ \\
\hline ERC & European Research Council & 10,730 & $14.6 \%$ & $9.1 \%$ & $-38.0 \%$ \\
\hline CROSST & Cross-theme & 4,719 & $4.0 \%$ & $2.5 \%$ & $-38.0 \%$ \\
\hline BIOTECH & Biotechnology & 840 & $12.9 \%$ & $0.0 \%$ & $-100.0 \%$ \\
\hline GENDEREQ & $\begin{array}{l}\text { Promote gender equality in research and } \\
\text { innovation }\end{array}$ & 124 & $7.3 \%$ & $\mathrm{n} / \mathrm{a}$ & $n / a$ \\
\hline ERA & ERA chairs & 32 & $18.8 \%$ & $\mathrm{n} / \mathrm{a}$ & $\mathrm{n} / \mathrm{a}$ \\
\hline RESACCESS & $\begin{array}{l}\text { Develop the accessibility and the use of } \\
\text { the results of publicly-funded research }\end{array}$ & 26 & $42.3 \%$ & $\mathrm{n} / \mathrm{a}$ & $\mathrm{n} / \mathrm{a}$ \\
\hline $\begin{array}{l}\text { SWAFS- } \\
\text { CROSST }\end{array}$ & $\begin{array}{l}\begin{array}{l}\text { Science with and for Society - Cross- } \\
\text { theme }\end{array} \\
\text { them }\end{array}$ & 2 & $100.0 \%$ & $\mathrm{n} / \mathrm{a}$ & $\mathrm{n} / \mathrm{a}$ \\
\hline Total & & 225,108 & $13.3 \%$ & $11.8 \%$ & $-11.2 \%$ \\
\hline
\end{tabular}

Overall, EC contributions to Finnish participations in H2020 Digitalisation projects accounted for $2.3 \%$ of total EC contributions to relevant projects. However, there are 9 subprogrammes where Finland achieved a higher proportion of the total - and in particular the INEGSOC, ENV, ENERGY and RISK FINANCE programmes, where Finland secured over $4 \%$ of the funding awarded to Digitalisation projects in each case. Elsewhere the proportion of funding awarded to Finland was below $2.3 \%$. In the three sub-programmes awarding most funding to $\mathrm{CBC}$ projects (ICT, ERC and MSCA), Finland's share of contributions was $2.7 \%, 2.0 \%$ and $1.3 \%$ respectively.

Table 88 EC contributions to Finnish participations in H2020 Digitalisation projects, by sub-programme

\begin{tabular}{|c|c|c|c|c|}
\hline Sub-programme & & $\begin{array}{c}\text { Total EC } \\
\text { contributions } \\
\text { (€Mio.) }\end{array}$ & $\begin{array}{l}\text { EC contributions to } \\
\text { FI (€Mio.) }\end{array}$ & $\%$ \\
\hline INEGSOC & Integrate society in science and innovation & 14 & 1 & $5.1 \%$ \\
\hline ENV & $\begin{array}{l}\text { Climate action, environment, resource } \\
\text { efficiency and raw materials }\end{array}$ & 457 & 20 & $4.4 \%$ \\
\hline ENERGY & Secure, clean and efficient energy & 863 & 36 & $4.2 \%$ \\
\hline RISKFINANCE & Access to risk finance & 2 & 0.1 & $4.0 \%$ \\
\hline CAREER & $\begin{array}{l}\text { Make scientific and technological careers } \\
\text { attractive for young people }\end{array}$ & 13 & 1 & $3.9 \%$ \\
\hline EURATOM & Euratom & 86 & 3 & $3.5 \%$ \\
\hline ADVMANU & Advanced manufacturing and processing & 586 & 16 & $2.8 \%$ \\
\hline ICT & $\begin{array}{l}\text { Information and Communication } \\
\text { Technologies }\end{array}$ & 2,762 & 73 & $2.7 \%$ \\
\hline SECURITY & $\begin{array}{l}\text { Secure societies - Protecting freedom and } \\
\text { security of Europe and its citizens }\end{array}$ & 398 & 10 & $2.5 \%$ \\
\hline ADVMAT & Advanced materials & 275 & 6 & $2.2 \%$ \\
\hline
\end{tabular}




\begin{tabular}{|c|c|c|c|c|}
\hline FOOD & $\begin{array}{l}\text { Food security, sustainable agriculture and } \\
\text { forestry, marine and maritime and inland water } \\
\text { research }\end{array}$ & 360 & 8 & $2.2 \%$ \\
\hline TPT & Smart, green and integrated transport & 940 & 20 & $2.1 \%$ \\
\hline ERC & European Research Council & 2,202 & 43 & $2.0 \%$ \\
\hline INFRA & Research infrastructures & 523 & 10 & $1.9 \%$ \\
\hline HEALTH & Health, demographic change and wellbeing & 686 & 13 & $1.9 \%$ \\
\hline SOCIETY & $\begin{array}{l}\text { Europe in a changing world - inclusive, } \\
\text { innovative and reflective Societies }\end{array}$ & 163 & 3 & $1.9 \%$ \\
\hline TWINING & Twinning of research institutions & 30 & 0.5 & $1.7 \%$ \\
\hline CROSST & Cross-theme & 87 & 1 & $1.7 \%$ \\
\hline NMP & $\begin{array}{l}\text { Nanotechnologies, Advanced Materials and } \\
\text { Production }\end{array}$ & 356 & 5 & $1.4 \%$ \\
\hline MSCA & Marie Sklodowska-Curie actions & 1,225 & 16 & $1.3 \%$ \\
\hline FET & Future and Emerging Technologies & 469 & 5 & $1.1 \%$ \\
\hline WIDESPREAD & $\begin{array}{l}\text { Teaming of excellent research institutions and } \\
\text { low performing RDI regions }\end{array}$ & 55 & 1 & $1.1 \%$ \\
\hline GOV & $\begin{array}{l}\text { Develop the governance for the advancement } \\
\text { of responsible research and innovation }\end{array}$ & 19 & 0.2 & $1.0 \%$ \\
\hline SME & Innovation in SMEs & 24 & 0.2 & $0.9 \%$ \\
\hline SPACE & Space & 209 & 2 & $0.9 \%$ \\
\hline BIOTECH & Biotechnology & 60 & 0 & $0.0 \%$ \\
\hline ERA & ERA chairs & 15 & 0 & $0.0 \%$ \\
\hline GENDEREQ & $\begin{array}{l}\text { Promote gender equality in research and } \\
\text { innovation }\end{array}$ & 2 & 0 & $0.0 \%$ \\
\hline RESACCESS & $\begin{array}{l}\text { Develop the accessibility and the use of the } \\
\text { results of publicly-funded research }\end{array}$ & 1 & 0 & $0.0 \%$ \\
\hline $\begin{array}{l}\text { SWAFS- } \\
\text { CROSST }\end{array}$ & Science with and for Society - Cross-theme & 1 & 0 & $0.0 \%$ \\
\hline Total & & 12,881 & 294 & $2.3 \%$ \\
\hline
\end{tabular}

\section{Longitudinal analysis of participation and success rates}

To explore the performance of Finland and its comparators in the Framework Programmes over time, we have assessed participation and success rates based on the year of the relevant call. Calls issued between 2007 and 2013 relate to FP7, while those issued between 2014 and 2017 relate to $\mathrm{H} 2020$.

\section{Rates of participation and success over time - overall}

Finland accounts for $2.0 \%$ of participations in all FP7 proposals and $2.2 \%$ of participations in all H2020 proposals. In both cases, this rate is below that of AT, NL and SE and above that of IE and NO (FI is higher than DK in FP7 and lower than DK in H2020). The following figure shows Finland's rate of participation in proposals each year (based on the year of the relevant call). For comparison, we also show a simple average of the participation rates across the six comparator countries each year.

As can be seen, Finland's rate of participation is below the six-country average through-out the period. Both the Finnish and comparator rates of participation in proposals appear to be increasing slightly over time (see the dotted linear trend lines, which show the 'best-fit' straight lines for each dataset), with the comparator rate seemingly rising a little more rapidly. 
Figure 1 Proportion of all participations in proposals, per year - Finland and comparator country average

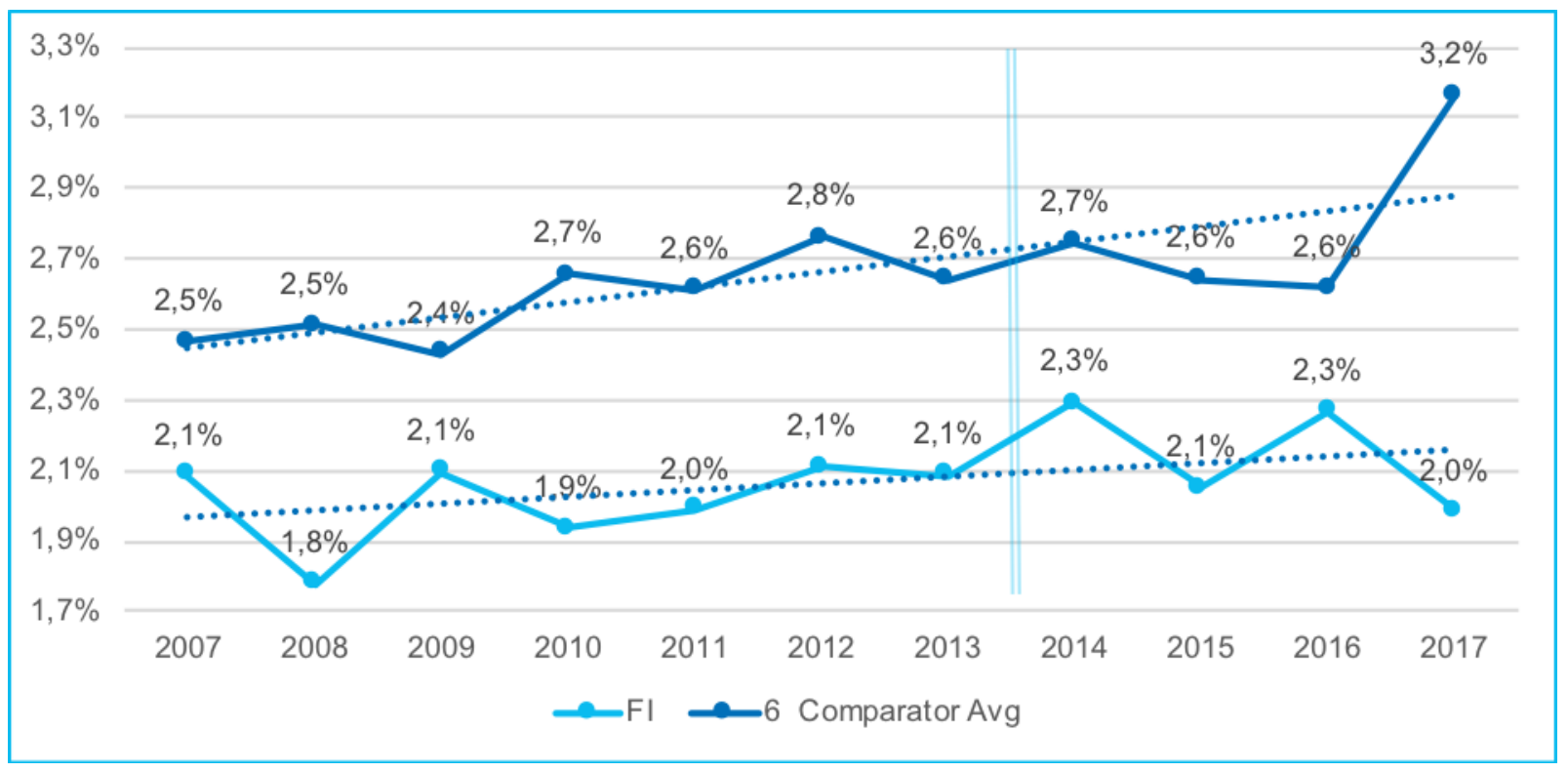

\section{$\underline{\text { Rates of project participation over time }}$}

Finland accounts for $2.1 \%$ of all participations in both FP7 and H2020 projects. In both cases, this rate is below that of $A T, N L$ and SE and above that of IE and NO ( $F I$ is higher than DK in FP7 and lower than DK in H2020). The following figure shows Finland's rate of participation in projects each year (based on the year of the relevant call, not the year of grant award). For comparison, we also show a simple average of the participation rates across the six comparator countries each year.

As can be seen, Finland's rate of participation in projects is below the six-country average throughout the period. More importantly, the two rates appear to diverge slightly over time, with the comparator country rate of project participation increasing slightly and the Finnish rate decreasing slightly.

Figure 2 Proportion of all participations in projects, per year - Finland and comparator country average

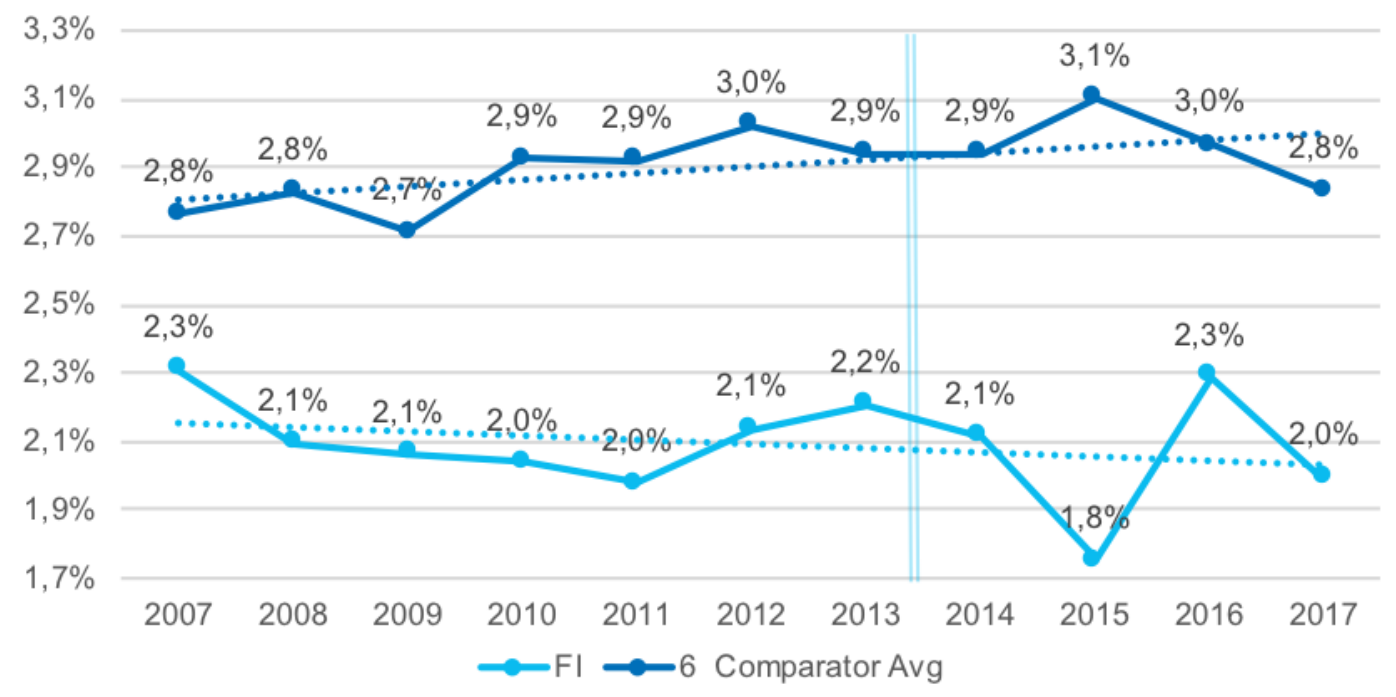




\section{Participation success rates over time}

The success rate of Finnish proposal participations was 21.8\% in FP7 (below all comparator countries, except for IE) and 13.5\% in H2020 (below all comparator countries).

The following figure shows Finland's participation success rate each year (line, left axis), based on the year of the relevant call. This shows a significant drop in Finnish success rates moving from 2013 (FP7) to 2014 (H2020). However, we should bear in mind that success rates in $\mathrm{H} 2020$ more generally are lower than they were in FP7. For comparison purposes, we therefore also show (bars, right axis) the percentage-point difference between the Finnish success rate and that of the six comparator countries (average of their respective rates) in each year. As can be seen, Finland's success rate was slightly above the six-country average in the first two years of FP7 and in the latest year of H2020, but has been lower throughout the rest of the period.

Figure 3 Proposal participations success rate, per year - Finland and difference from comparator average

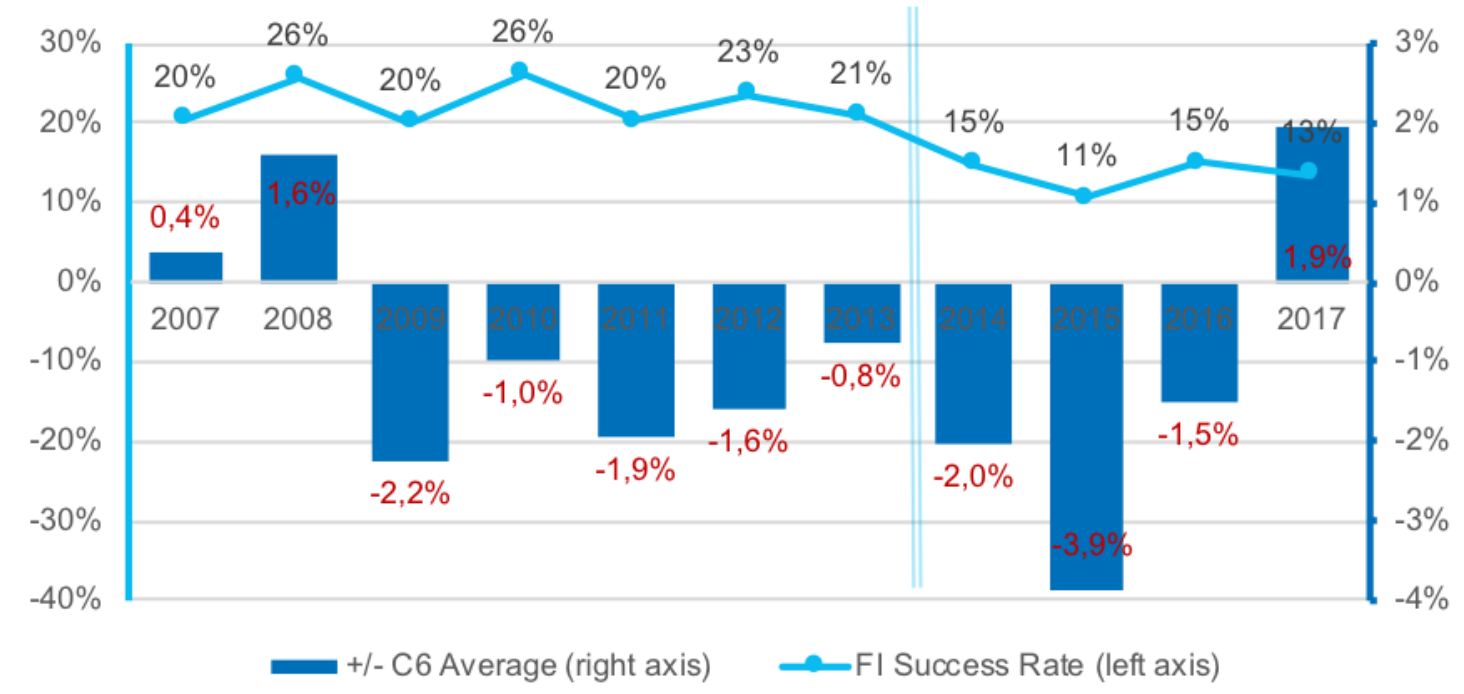

\section{Rates of participation and success over time - in the H\&W area}

Finland accounts for $2.0 \%$ of participations in all FP7 H\&W proposals and $2.1 \%$ of participations in all $\mathrm{H} 2020 \mathrm{H} \& W$ proposals. In both cases, this rate is below that of AT, DK, $\mathrm{NL}$ and SE and above that of IE and NO. The following figure shows Finland's rate of participation in proposals each year (based on the year of the relevant call). For comparison, we also show a simple average of the participation rates across the six comparator countries each year.

As can be seen, Finland's rate of participation is below the six-country average through-out the period. Both the Finnish and comparator rates of participation in proposals appear to be increasing slightly over time (see the dotted linear trend lines, which show the 'best-fit' straight lines for each dataset), with the comparator rate rising more rapidly. 


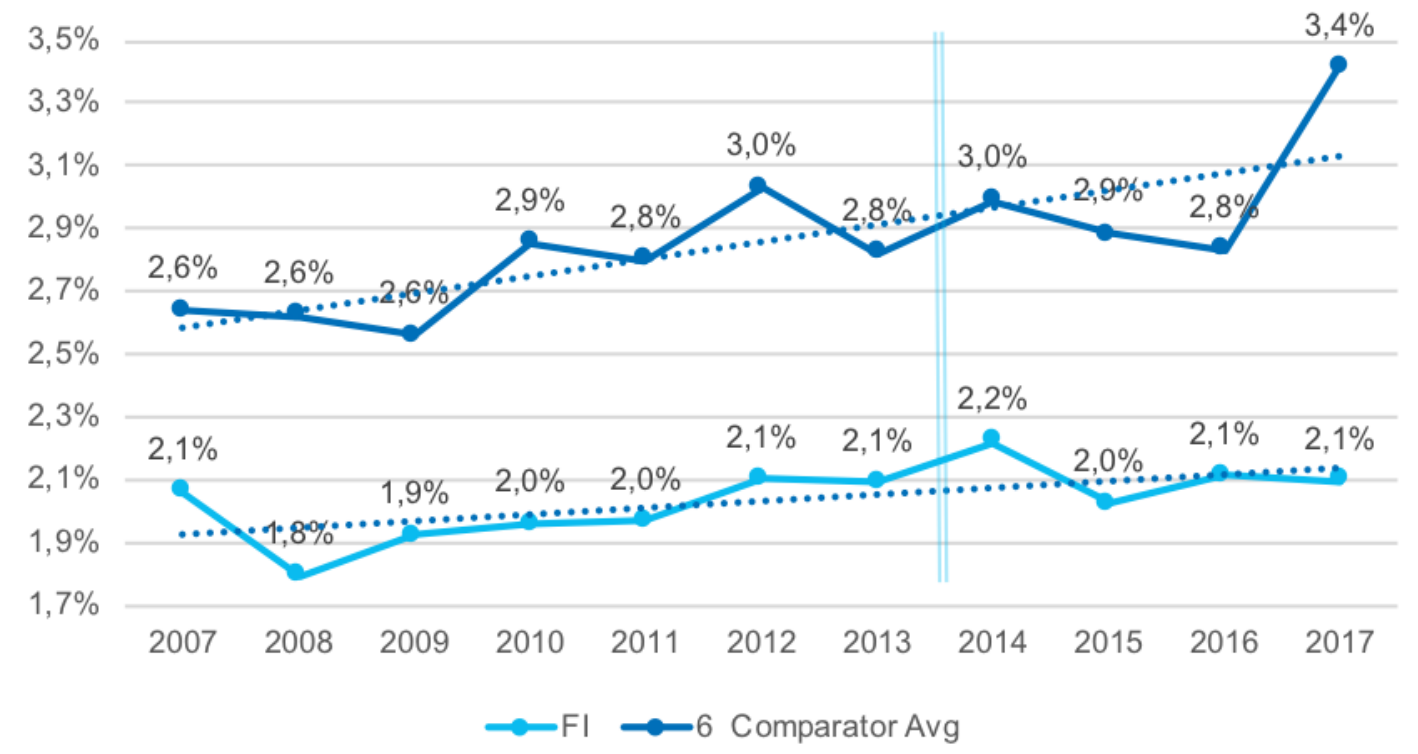

\section{$\underline{\text { Rates of project participation over time }}$}

Finland accounts for $2.1 \%$ of all participations in FP7 H\&W projects and $2.0 \%$ of all participations in $\mathrm{H} 2020 \mathrm{H} \& W$ projects. In both cases, this rate is below that of AT, DK, NL and SE and above that of IE and NO. The following figure shows Finland's rate of participation in projects each year (based on the year of the relevant call, not the year of grant award). For comparison, we also show a simple average of the participation rates across the six comparator countries each year.

As can be seen, Finland's rate of participation in projects is below the six-country average throughout the period. More importantly, the two rates appear to diverge over time, with the comparator country rate of project participation increasing and the Finnish rate decreasing.

Figure 5 Proportion of all participations in projects, per year - Finland and C6 average $-H \& W$ area

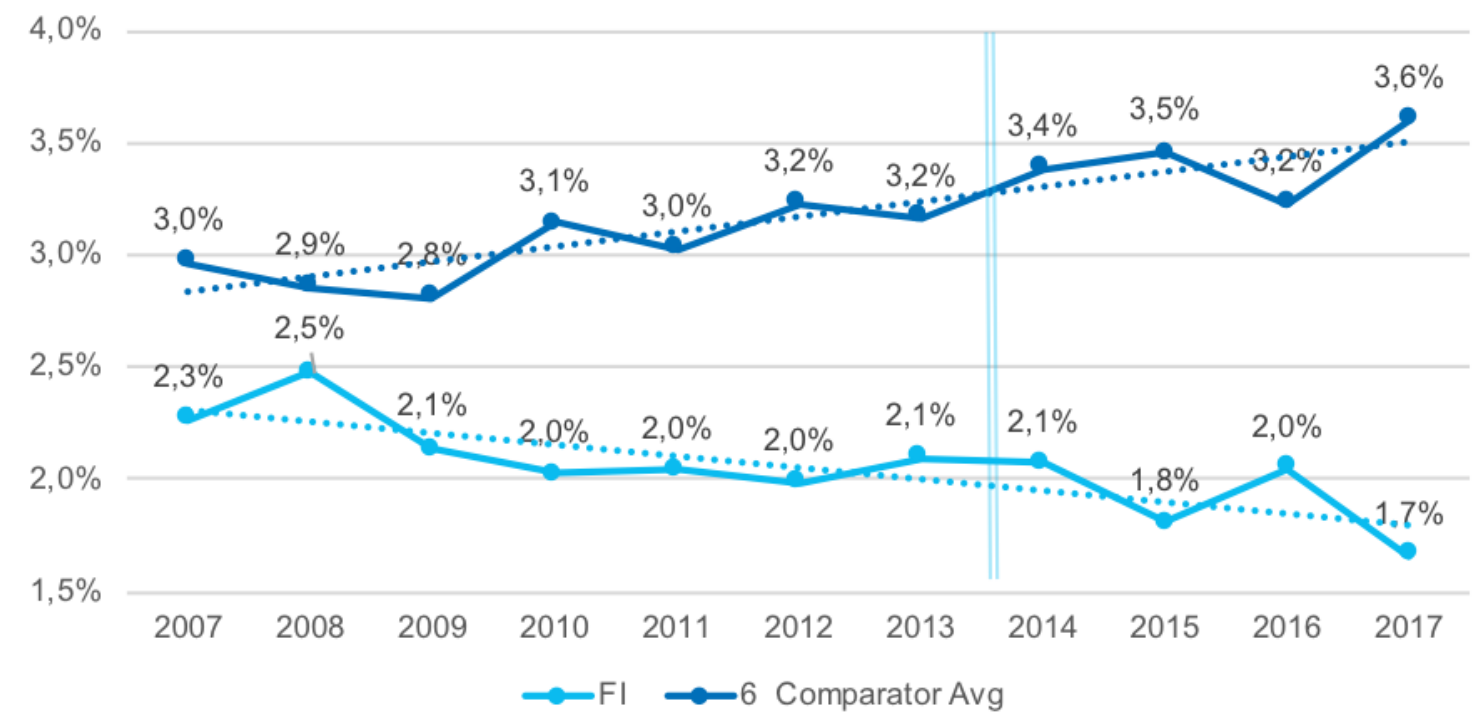




\section{$\underline{\text { Participation success rates over time }}$}

The success rate of Finnish proposal participations in the H\&W area was 19.2\% in FP7 and $12.3 \%$ in $\mathrm{H} 2020$. In both cases, these rates were below that seen in all of the comparator countries.

The following figure shows Finland's participation success rate each year (line, left axis), based on the year of the relevant call. This shows a significant drop in success rates moving from 2013 (FP7) to 2014 (H2020). However, we should bear in mind that success rates in $\mathrm{H} 2020$ are lower overall than they were in FP7. For comparison purposes, we therefore also show (bars, right axis) the percentage-point difference between the Finnish success rate and that of the six comparator countries (average of their respective rates) in each year. As can be seen, Finland's success rate was slightly above the six-country average in the first three years of FP7, but has been lower each year since.

Figure 6 Proposal participations success rate, per year - Finland and difference from C6 average - H\&W area

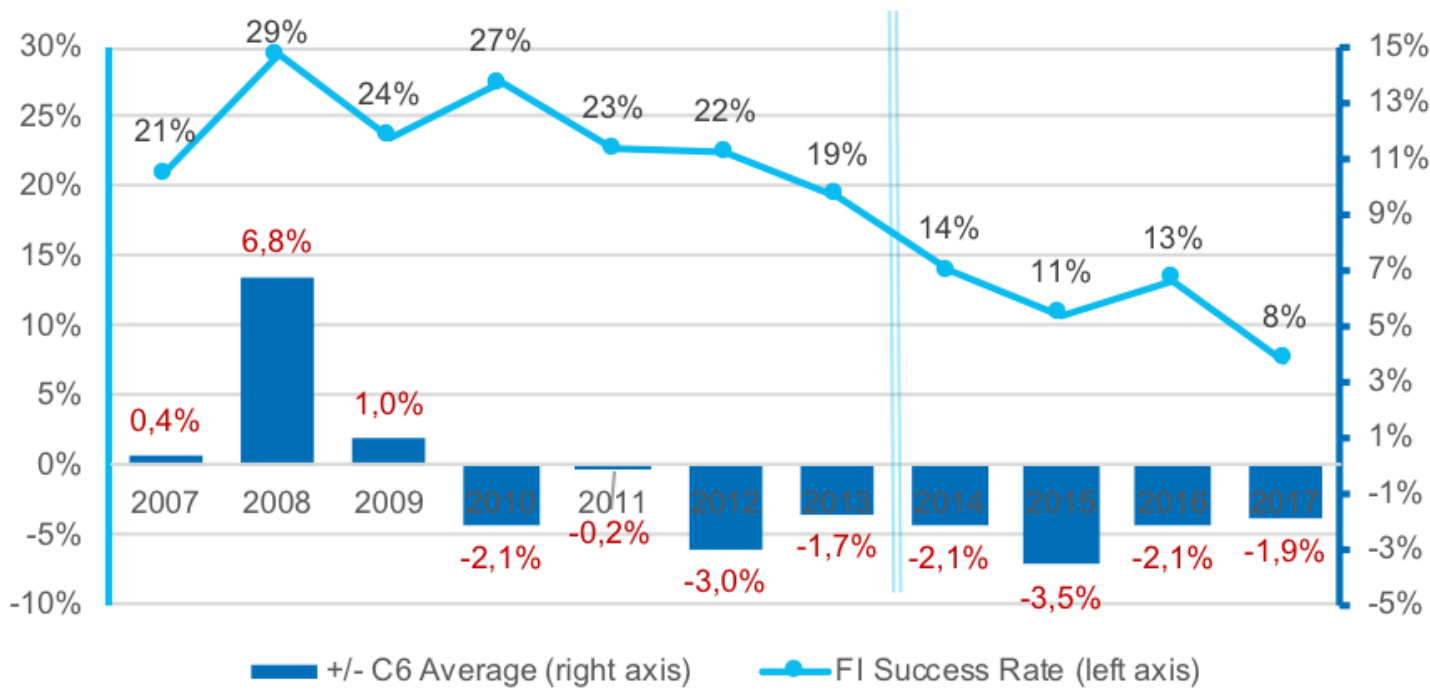

\section{Rates of participation and success over time - in the CBC area}

Finland accounts for $2.0 \%$ of participations in all FP7 CBC proposals and $2.2 \%$ of participations in all $\mathrm{H} 2020 \mathrm{CBC}$ proposals. In both cases, this rate is below that of AT, DK, $\mathrm{NL}$ and SE and above that of IE and NO. The following figure shows Finland's rate of participation in proposals each year (based on the year of the relevant call). For comparison, we also show a simple average of the participation rates across the six comparator countries each year.

As can be seen, Finland's rate of participation is below the six-country average through-out the period. Both the Finnish and comparator rates of participation in proposals appear to be increasing slightly over time (see the dotted linear trend lines, which show the 'best-fit' straight lines for each dataset), with the comparator rate seemingly rising a little more rapidly.

Figure 7 Proportion of all participations in proposals, per year - Finland and C6 average - CBC area 


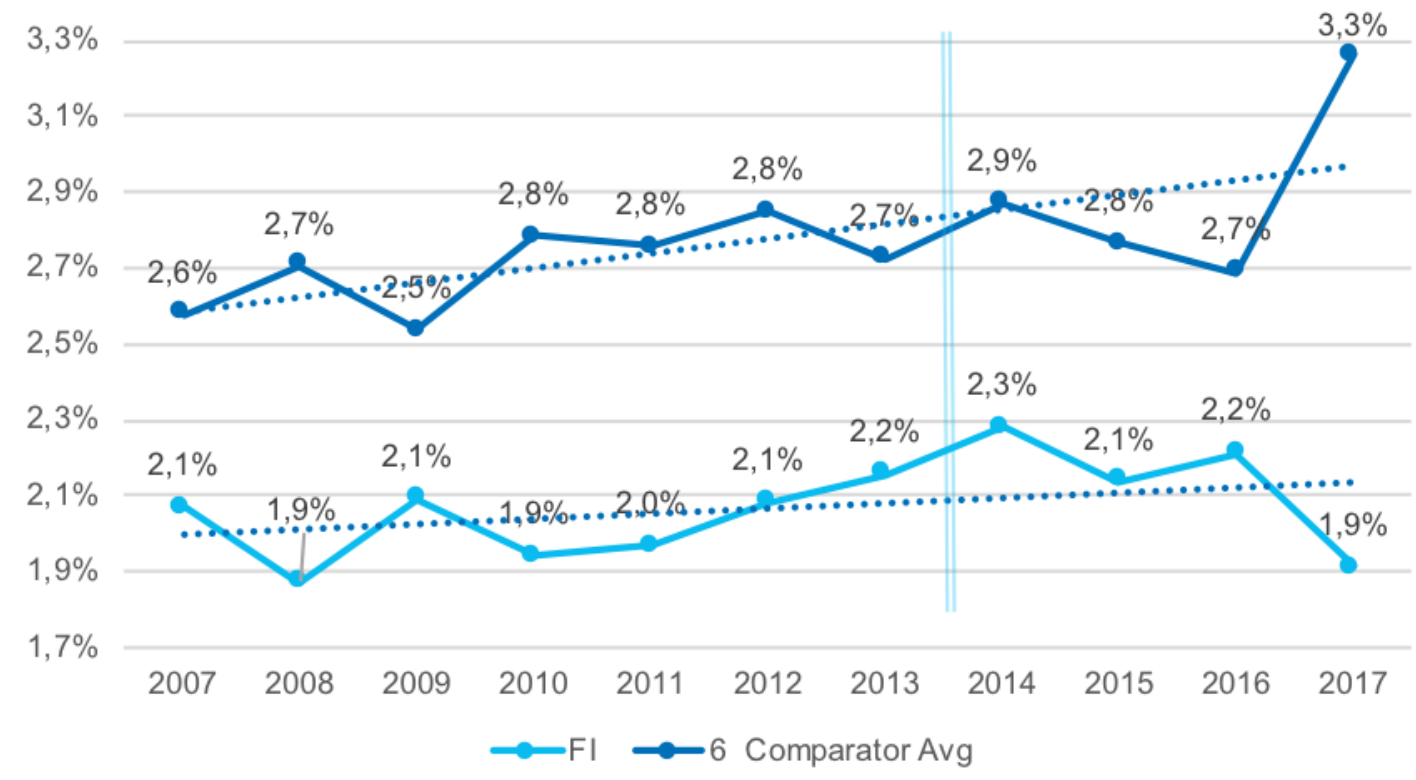

\section{$\underline{\text { Rates of project participation over time }}$}

Finland accounts for $2.2 \%$ of all participations in FP7 CBC projects and $2.1 \%$ of all participations in $\mathrm{H} 2020 \mathrm{CBC}$ projects. In both cases, this rate is below that of AT, DK, NL and SE and above that of IE and NO. The following figure shows Finland's rate of participation in projects each year (based on the year of the relevant call, not the year of grant award). For comparison, we also show a simple average of the participation rates across the six comparator countries each year.

As can be seen, Finland's rate of participation in projects is below the six-country average throughout the period. More importantly, the two rates appear to diverge slightly over time, with the comparator country rate of project participation increasing slightly and the Finnish rate decreasing.

Figure 8 Proportion of all participations in projects, per year - Finland and C6 average - CBC area

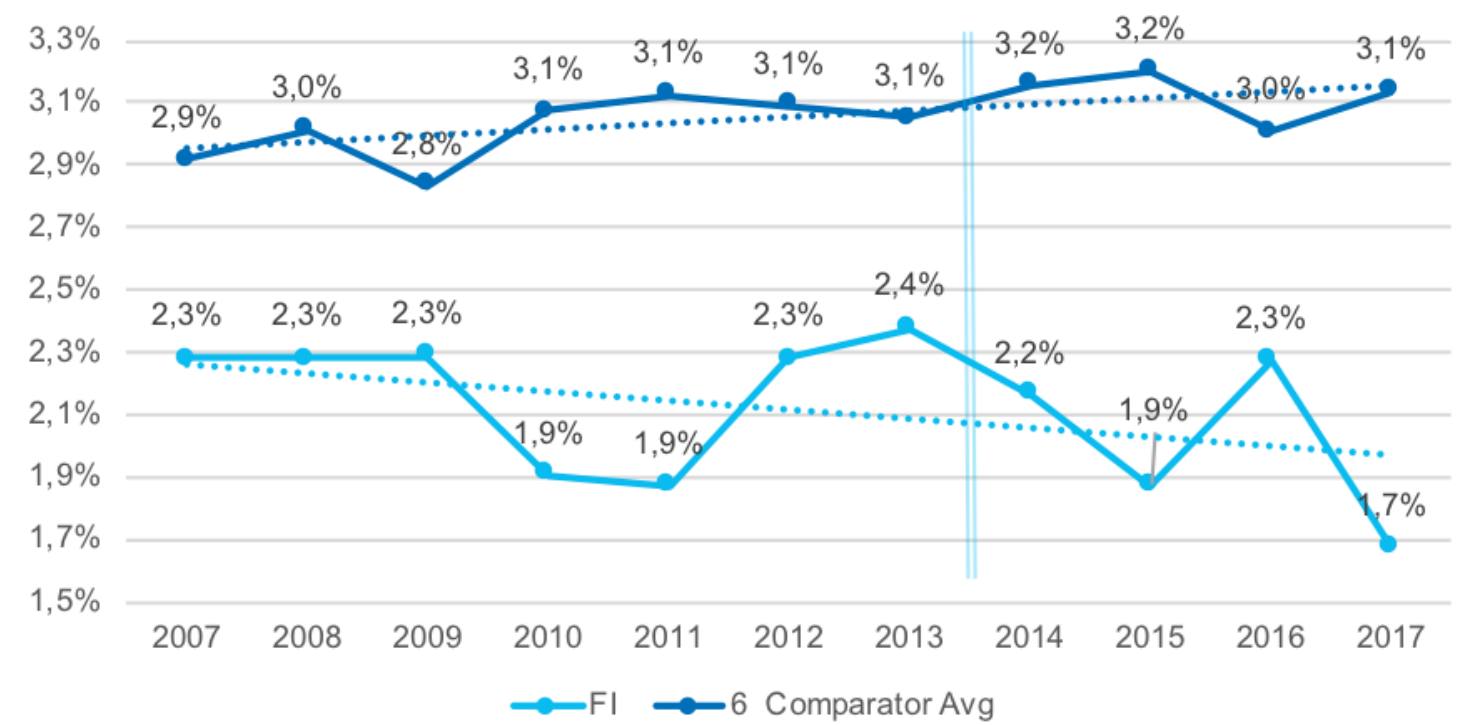




\section{Participation success rates over time}

The success rate of Finnish proposal participations in the CBC area was 23.3\% in FP7 (below half of the comparator countries) and 13.8\% in H2020 (below all comparator countries).

The following figure shows Finland's participation success rate each year (line, left axis), based on the year of the relevant call. This shows a significant drop in success rates moving from 2013 (FP7) to 2014 (H2020). However, we should bear in mind that success rates in $\mathrm{H} 2020$ are lower overall than they were in FP7. For comparison purposes, we therefore also show (bars, right axis) the percentage-point difference between the Finnish success rate and that of the six comparator countries (average of their respective rates) in each year. As can be seen, Finland's success rate was similar to or above the six-country average during the seven years of FP7. However, in each year of H2020 so far, the Finnish participation success rate has been below the six-country average.

Figure 9 Proposal participations success rate, per year - Finland and difference from C6 average - CBC area

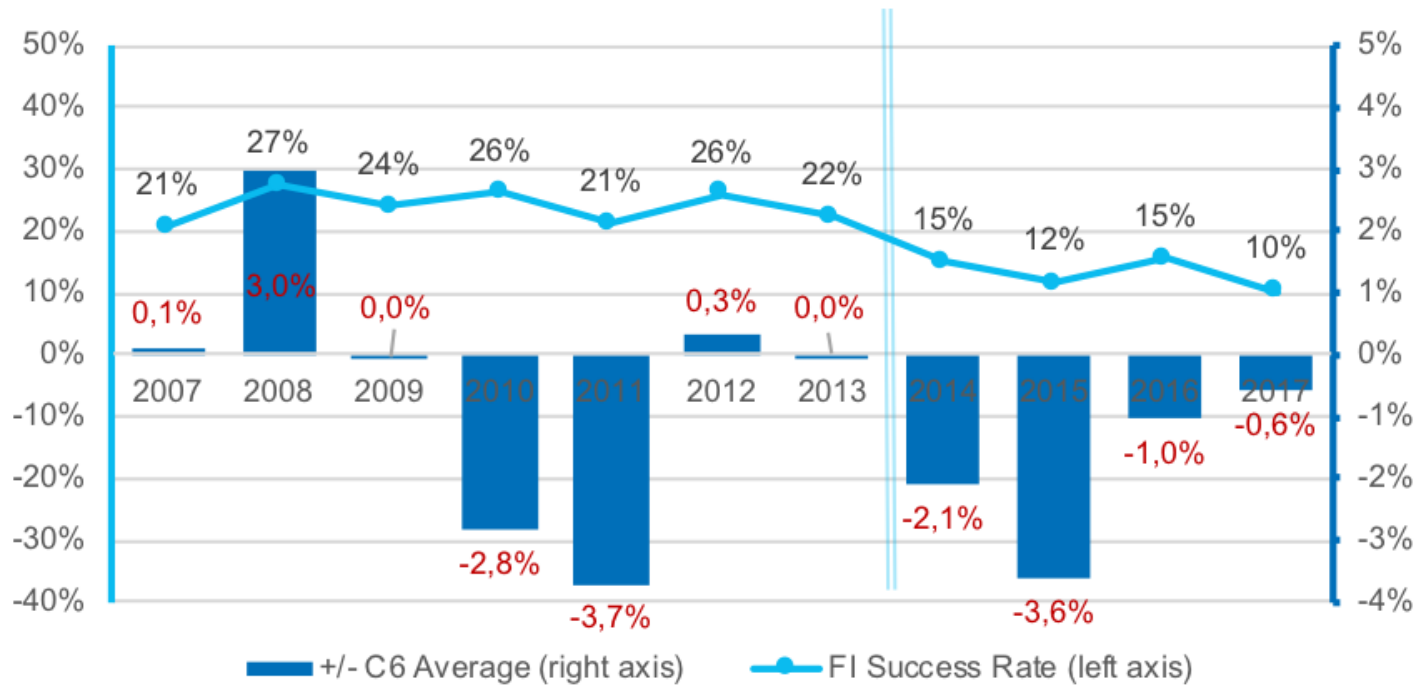

\section{Rates of participation and success over time - in the Digitalisation area}

Finland accounts for $2.1 \%$ of participations in all FP7 Digitalisation proposals and $2.3 \%$ of participations in all H2020 Digitalisation proposals. In both cases, this rate is below that of AT, NL and SE and above that of DK, IE and NO. The following figure shows Finland's rate of participation in proposals each year (based on the year of the relevant call). For comparison, we also show a simple average of the participation rates across the six comparator countries each year.

As can be seen, Finland's rate of participation is below the six-country average through-out the period. Both the Finnish and comparator rates of participation in proposals appear to be increasing over time (see the dotted linear trend lines, which show the 'best-fit' straight lines for each dataset), and at broadly the same rate. 


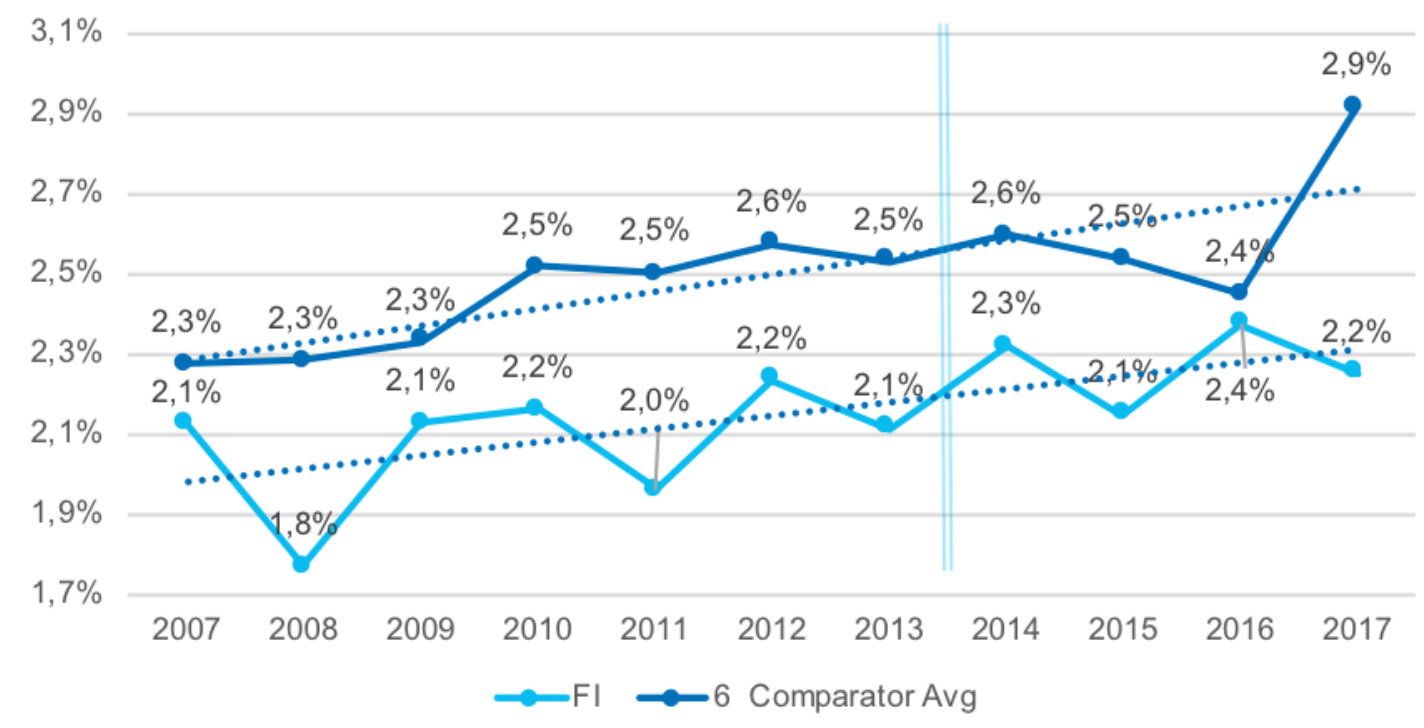

\section{$\underline{\text { Rates of project participation over time }}$}

Finland accounts for $2.3 \%$ of all participations in FP7 Digitalisation projects and $2.0 \%$ of all participations in H2020 Digitalisation projects. In both cases, this rate is below that of AT, $\mathrm{NL}$ and SE and above that of DK, IE and NO. The following figure shows Finland's rate of participation in projects each year (based on the year of the relevant call, not the year of grant award). For comparison, we also show a simple average of the participation rates across the six comparator countries each year.

As can be seen, Finland's rate of participation in projects is below the six-country average throughout most of the period (every year except for 2008). More importantly, the two rates appear to diverge slightly over time, with the comparator country rate of project participation increasing slightly and the Finnish rate decreasing slightly.

Figure 11 Proportion of all participations in projects, per year - Finland and C6 avg. - Digitalisation area

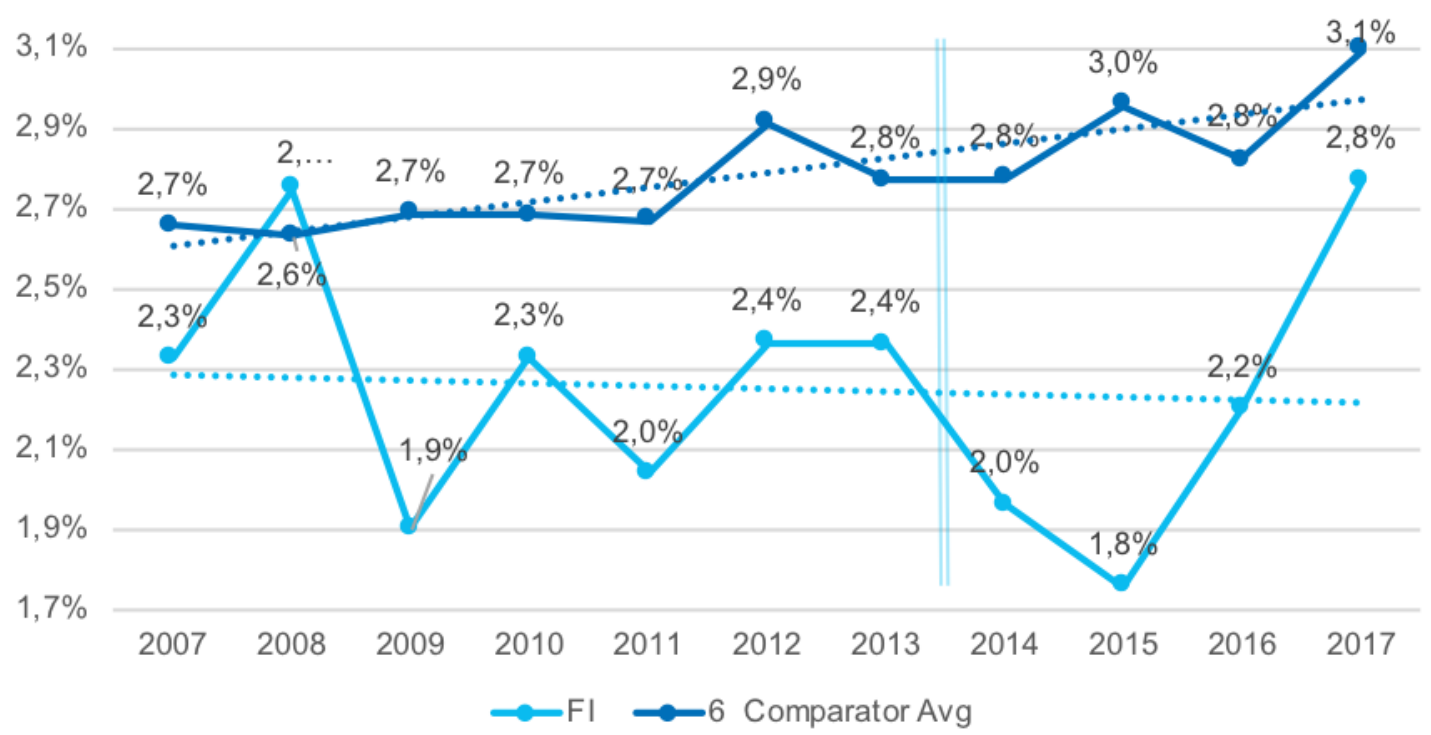




\section{Participation success rates over time}

The success rate of Finnish proposal participations in the Digitalisation area was $22.1 \%$ in FP7 (above all of the comparator countries except DK and NL) and $11.8 \%$ in H2020 (below all comparators.

The following figure shows Finland's participation success rate each year (line, left axis), based on the year of the relevant call. This shows a significant drop in success rates moving from 2013 (FP7) to 2014 (H2020). However, we should bear in mind that success rates in $\mathrm{H} 2020$ are lower overall than they were in FP7. For comparison purposes, we therefore also show (bars, right axis) the percentage-point difference between the Finnish success rate and that of the six comparator countries (average of their respective rates) in each year. As can be seen, Finland's success rate has been above the six-country average in some years, and below it in others. Most recently, Finland performed worse than these comparators in the first three years of $\mathrm{H} 2020$, but better than the six country average in the latest year (2017).

Figure 12 Proposal participations success rate, per year - Finland and difference from C6 avg. - Digitalisation

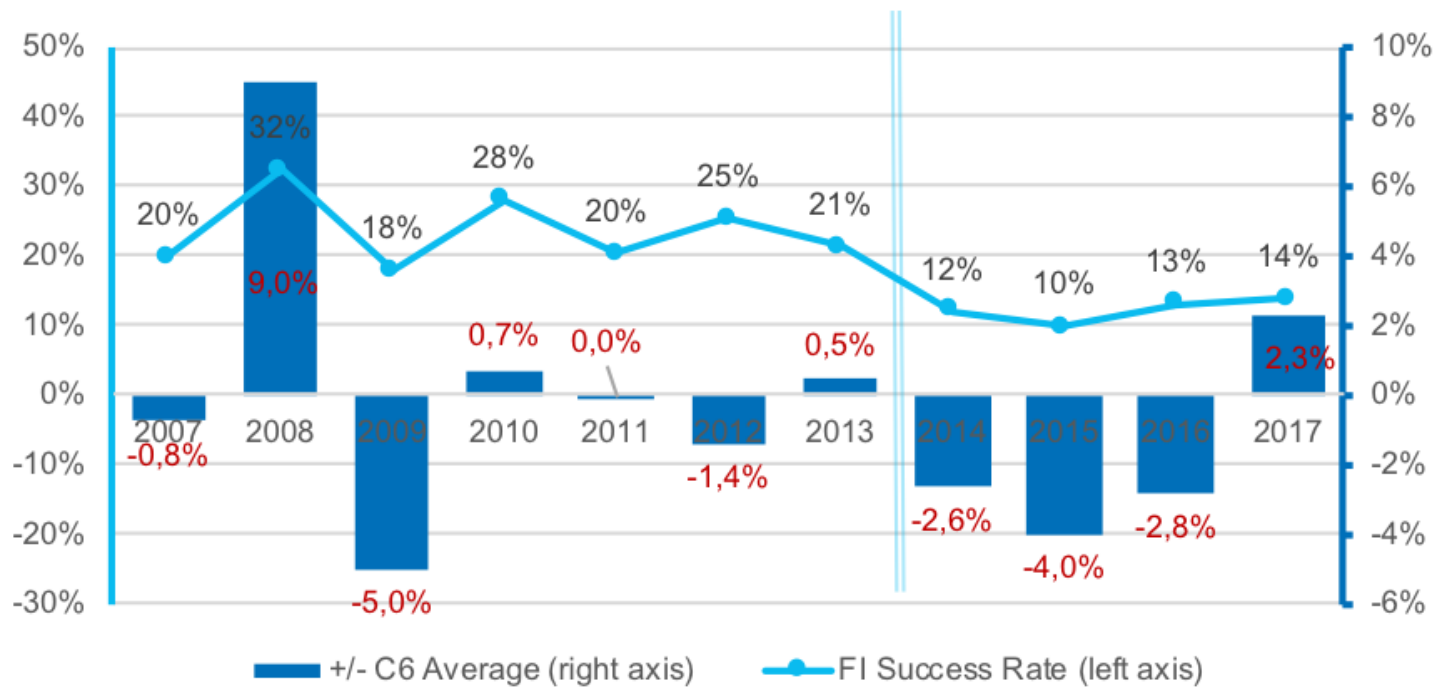

\section{Participation in the SME instrument}

\section{Introduction}

The SME Instrument (SMEI) is a new component introduced in Horizon 2020. It targets SMEs with the potential to grow and internationalise, offering SME-tailored support that is intended to stimulate all forms of innovation. It targets projects that have reached at least TRL6 (or the non-technological equivalent) and focuses on innovation and close-to-market activities.

The instrument has been designed with three un-sequential phases:

- $\quad$ Phase 1 (SMEI-1) - Investigation of technical and commercial feasibility of a business idea. H2020 provides business innovation grants of $€ 50,000$ for feasibility assessment purposes. 
Phase 2 (SMEI-2) - Development and demonstration. H2020 provides grants of up to $€ 2.5$ million to develop innovation and for demonstration purposes.

-

Phase 3 (SMEI-2) - Additional EU support to enter the market. H2020 offers no further funding for this phase. Instead it is a bundle of service offerings (support, training, mentorship, access to finance) are offered immediately after an SME becomes a beneficiary of SMEI phases 1 or 2 .

The SME Instrument targets SME innovation activity related to any of the seven Societal Challenges and the Key Enabling and Industrial Technologies under the Industrial Leadership pillar. At least $7 \%$ of the budgets of each of these specific objectives / societal challenges should be allocated to the SME Instrument over the duration of Horizon 2020.

\section{Overall participation in H2020 SME Instrument}

Finland's level of involvement in SME Instrument proposals compares favourably against nearly all comparator countries, for both phases of the instrument.

It has participated in 604 SME Instrument Phase 1 (SMEI-1) proposals, or $2.3 \%$ of all 26,447 participations so far. This is more than all comparator countries except for NL (3.3\%). Weighting proposal activity by taking account of the size of researcher populations, Finland's rate of participations in SMEI-1 proposals (11.8 per 1,000 R\&D personnel) is above all comparators except IE.

Finland has also participated in 573 SMEI-2 proposals, meaning it is relatively more active here (3.9\% of 14,575 participations) than in Phase 1 . However, it still ranks slightly below $\mathrm{NL}$ in terms of absolute levels of involvement. Compared with the size of the re-searcher population, however, Finland's rate of participations in SMEI-2 proposals (11.2 per 1,000 personnel) is above all comparator countries.

Table 89 Participations in H2020 SMEI proposals - Finland and comparators

\begin{tabular}{|c|c|c|c|c|c|c|c|c|}
\hline SMEI Phase 1 - Feasibility & All & FI & AT & DK & IE & NL & NO & SE \\
\hline Number of participations in proposals & 26,447 & 604 & 306 & 506 & 371 & 877 & 423 & 523 \\
\hline$\%$ of all participations in proposals & $100 \%$ & $2.3 \%$ & $1.2 \%$ & $1.9 \%$ & $1.4 \%$ & $3.3 \%$ & $1.6 \%$ & $2.0 \%$ \\
\hline Participations per 1,000 researchers & & 11.8 & 4.5 & 8.5 & 12.8 & 7.0 & 10.2 & 6.2 \\
\hline SMEI Phase 2 - Development \& Demo. & All & $\mathrm{FI}$ & AT & DK & IE & NL & NO & SE \\
\hline Number of participations in proposals & 14,575 & 573 & 200 & 451 & 247 & 636 & 219 & 555 \\
\hline$\%$ of all participations in proposals & $100 \%$ & $3.9 \%$ & $1.4 \%$ & $3.1 \%$ & $1.7 \%$ & $4.4 \%$ & $1.5 \%$ & $3.8 \%$ \\
\hline Participations per 1,000 researchers & & 11.2 & 2.9 & 7.6 & 8.5 & 5.1 & 5.3 & 6.6 \\
\hline
\end{tabular}

In total, $€ 1.2$ billion of EC funding has been requested through SMEI-1 proposals. Finland accounts for $2.4 \%$ ( $€ 28$ million) of this total- a higher amount than any of the comparator countries except for NL. On average, Finnish participations requested $€ 46$ thousand each. This is above the $\mathrm{H} 2020$ average ( $€ 45$ thousand) and places Finland in the middle of the comparators (below SE, DK and SE, but above AT, NL and NO).

The size of phase 2 grants can be much bigger (up to $€ 2.5$ million) than phase 1 ( $€ 50$ thousand). As such, EC funding requests to SMEI-2 total $€ 19.3$ billion. Finland accounts for $5.0 \%$ ( $€ 957$ million) of this total - a higher proportion than any of the comparators except for NL. On average, Finnish participations in SMEI-2 proposals requested $€ 1.7$ million in funding each. This is above the $\mathrm{H} 2020$ average (€1.3 million), as well as higher than the average in all of the comparator countries. 
Table 90 EC funding requests in SMEI proposals - Finland and comparators

\begin{tabular}{|c|c|c|c|c|c|c|c|c|}
\hline SMEI Phase 1 - Feasibility & All & FI & AT & DK & IE & $\mathbf{N L}$ & NO & SE \\
\hline EC funding requested in proposals $(€ m)$ & 1,180 & 28 & 13 & 24 & 18 & 38 & 20 & 25 \\
\hline $\begin{array}{l}\% \text { of all EC funding requested in } \\
\text { proposals }\end{array}$ & $100 \%$ & $2.4 \%$ & $1.1 \%$ & $2.0 \%$ & $1.5 \%$ & $3.2 \%$ & $1.7 \%$ & $2.1 \%$ \\
\hline Average request per participation (€k) & 44.6 & 46.2 & 43.3 & 47.3 & 47.7 & 43.4 & 46.1 & 47.2 \\
\hline SMEI Phase 2 - Development \& Demo. & All & $\mathrm{FI}$ & AT & DK & IE & $\mathrm{NL}$ & NO & SE \\
\hline EC funding requested in proposals $(€ \mathrm{~m})$ & 19,263 & 957 & 241 & 675 & 383 & 1,055 & 318 & 906 \\
\hline $\begin{array}{l}\% \text { of all EC funding requested in } \\
\text { proposals }\end{array}$ & $100 \%$ & $5.0 \%$ & $1.3 \%$ & $3.5 \%$ & $2.0 \%$ & $5.5 \%$ & $1.7 \%$ & $4.7 \%$ \\
\hline Average request per participation $(€ \mathrm{~m})$ & 1.3 & 1.7 & 1.2 & 1.5 & 1.6 & 1.7 & 1.5 & 1.6 \\
\hline
\end{tabular}

\section{$\underline{\text { Participation in SMEI projects }}$}

Finland's relatively high rate of SMEI proposal activity has not fed through entirely into levels of project activity, particularly for Phase 1.

Of the nearly 2,200 H2020 SMEI-1 grants awarded so far, just 51 have been to Finland. This $2.3 \%$ share of participations places Finland in the middle of the comparator countries (below DK, NL and SE, but above AT, IE and NO). Its rate of participations in SMEI-1 projects (1.0 per 1,000 R\&D personnel) is also below four of the comparator countries (DK, $\mathrm{IE}, \mathrm{NO}$ and SE).

The country has fared a little better with SMEI-2. Of the 724 grants awarded so far, 33 (or 4.6\%) have been awarded to Finnish participants. This is fewer than in DK or NL, but more than in the other comparator countries. Compared with the size of the researcher population Finland's rate of participations in SMEI-2 projects ( 0.6 per 1,000 personnel) compares even more favourably, being higher than all comparator countries except for IE (SE also has the same rate as $\mathrm{FI}$ ).

Table 91 Participations in SMEI projects - Finland and comparators

\begin{tabular}{|c|c|c|c|c|c|c|c|c|}
\hline SMEl Phase 1 - Feasibility & All & $\mathrm{FI}$ & AT & DK & IE & NL & NO & SE \\
\hline Number of participations in projects & 2,191 & 51 & 46 & 79 & 47 & 87 & 43 & 85 \\
\hline$\%$ of all participations in projects & $100 \%$ & $2.3 \%$ & $2.1 \%$ & $3.6 \%$ & $2.1 \%$ & $4.0 \%$ & $2.0 \%$ & $3.9 \%$ \\
\hline Participations per 1,000 researchers & & 1.0 & 0.7 & 1.3 & 1.6 & 0.7 & 1.0 & 1.0 \\
\hline SMEI Phase 2 - Development \& Demo. & All & $\mathrm{FI}$ & AT & DK & IE & NL & NO & SE \\
\hline Number of participations in projects & 724 & 33 & 15 & 35 & 29 & 34 & 20 & 33 \\
\hline$\%$ of all participations in projects & $100 \%$ & $4.6 \%$ & $2.1 \%$ & $4.8 \%$ & $4.0 \%$ & $4.7 \%$ & $2.8 \%$ & $4.6 \%$ \\
\hline Participations per 1,000 researchers & & 0.6 & 0.2 & 0.6 & 1.0 & 0.3 & 0.5 & 0.4 \\
\hline
\end{tabular}

In total, $€ 101 \mathrm{~m}$ of EC funding has been awarded through SMEI-1 projects. Finland accounts for $2.3 \%$ ( $€ 2.3$ million) of this total - a higher amount than in AT, IE or NO, but below the other three comparators. On average, Finnish participations in SMEI-1 projects have been awarded $€ 45$ thousand in EC funding contributions each. This is slightly below the $\mathrm{H} 2020$ average ( $€ 46$ thousand), as well as below the averages in all comparator countries except for NL.

Over $€ 988$ million in EC funding has been awarded to SMEI-2 projects. Finland accounts for $5.4 \%$ ( $€ 54$ million) of this total - a higher proportion than any of the comparators except for NL and SE. On average, Finnish participations were awarded $€ 1.6$ million each through SMEI-2, which is above the overall average rate and places Finland in the middle of the comparator countries (above AT, DK and NO).

Table 92 EC funding contributions to SMEI project participations - Finland and comparators

\begin{tabular}{lcccccccc}
\hline SMEl Phase 1 - Feasibility & All & FI & AT & DK & IE & NL & NO & SE \\
\hline EC funding contributions (€million) & 101.5 & 2.3 & 2.2 & 3.8 & 2.3 & 3.8 & 2.1 & 4.0 \\
\hline$\%$ of all EC funding contributions & $100 \%$ & $2.3 \%$ & $2.2 \%$ & $3.7 \%$ & $2.3 \%$ & $3.7 \%$ & $2.1 \%$ & $3.9 \%$ \\
\hline
\end{tabular}




\begin{tabular}{|c|c|c|c|c|c|c|c|c|}
\hline $\begin{array}{l}\text { Average contribution per participation } \\
\text { (€thousand) }\end{array}$ & 46.3 & 45.1 & 47.8 & 48.1 & 48.9 & 43.7 & 48.8 & 47.1 \\
\hline SMEI Phase 2 - Development \& Demo. & All & FI & AT & DK & IE & NL & NO & SE \\
\hline EC funding contributions $(€ \mathrm{~m})$ & 988.7 & 53.7 & 19.5 & 45.9 & 51.2 & 55.4 & 28.6 & 54.2 \\
\hline$\%$ of all EC funding contributions & $100 \%$ & $5.4 \%$ & $2.0 \%$ & $4.6 \%$ & $5.2 \%$ & $5.6 \%$ & $2.9 \%$ & $5.5 \%$ \\
\hline $\begin{array}{l}\text { Average contribution per participation } \\
(€ \text { million) }\end{array}$ & 1.4 & 1.6 & 1.3 & 1.3 & 1.8 & 1.6 & 1.4 & 1.6 \\
\hline
\end{tabular}

\section{SMEI Success rates}

Based on the data presented above, on participations and funding in proposals / projects, we can calculate success rates within the SME Instrument so far. Finland compares unfavourably with most/all comparators, both in terms of participation success rates and the proportion of requested funding that has been awarded. This explains why the relatively high levels of proposal activity have not fed through into similar levels of SMEI project activity.

For SMEI-1, just $8.4 \%$ of Finnish participations in proposals have been successful. While this is slightly above the overall average, it is lower than for all of the comparator countries. AT $(15.0 \%)$, DK (15.6\%) and SE (16.3\%) in particular achieved success rates that were around double those seen in Finland. The proportion of requested that was awarded follows a similar pattern, although the Finnish rate $(8.2 \%)$ is also slightly below the overall average.

For SMEI-2, Finland has only performed marginally better. Its participation success rate $(5.8 \%)$ is above average and higher than in NL, but still below all other comparators (particularly IE, which achieved a success rate of $11.7 \%$ ). Finland's funding success rate $(5.6 \%)$ is also slightly below average and slightly above the NL rate, but below all other comparator countries (again IE stands out among this group with a $13.3 \%$ return).

Table 93 Success rates (participations and funding) in the SMEI - Finland and comparators

\begin{tabular}{|c|c|c|c|c|c|c|c|c|}
\hline SMEI Phase 1 - Feasibility & All & $\mathrm{FI}$ & AT & DK & IE & $\mathbf{N L}$ & NO & SE \\
\hline Participation success rates & $8.3 \%$ & $8.4 \%$ & $15.0 \%$ & $15.6 \%$ & $12.7 \%$ & $9.9 \%$ & $10.2 \%$ & $16.3 \%$ \\
\hline$\%$ of requested funding awarded & $8.6 \%$ & $8.2 \%$ & $16.6 \%$ & $15.9 \%$ & $13.0 \%$ & $10.0 \%$ & $10.8 \%$ & $16.2 \%$ \\
\hline SMEI Phase 2 - Development \& Demo. & All & $\mathrm{FI}$ & AT & DK & IE & NL & NO & SE \\
\hline Participation success rates & $5.0 \%$ & $5.8 \%$ & $7.5 \%$ & $7.8 \%$ & $11.7 \%$ & $5.3 \%$ & $9.1 \%$ & $5.9 \%$ \\
\hline$\%$ of requested funding awarded & $5.1 \%$ & $5.6 \%$ & $8.1 \%$ & $6.8 \%$ & $13.3 \%$ & $5.3 \%$ & $9.0 \%$ & $6.0 \%$ \\
\hline
\end{tabular}

\section{Health \& Wellbeing}

Finland's level of involvement in SME Instrument proposals in the Health and Wellbeing area compares quite favourably against most comparator countries, particularly for Phase 1.

It has participated in 204 SME Instrument Phase 1 (SMEI-1) proposals, or $2.2 \%$ of all 9,166 participations so far. This is more than all comparator countries except for NL (3.7\%). Weighting proposal activity by taking account of the size of researcher populations, Finland's rate of participations in SMEI-1 proposals (4.0 per 1,000 R\&D personnel) is above all comparators.

Finland has also participated in $170 \mathrm{SMEI}-2$ proposals, meaning it is relatively more active here (3.3\% of 5,184 participations) than in Phase 1 . However, it ranks below DK, NL and $\mathrm{SE}$ in terms of absolute levels of involvement. Compared with the size of the researcher population, Finland's rate of participations in SMEI-2 proposals ( 0.8 per 1,000 personnel) is still below DK and IE. 


\begin{tabular}{|c|c|c|c|c|c|c|c|c|}
\hline SMEI Phase 1 - Feasibility & All & $\mathrm{FI}$ & AT & DK & IE & $\mathbf{N L}$ & NO & SE \\
\hline Number of participations in proposals & 9,166 & 204 & 115 & 202 & 113 & 339 & 158 & 194 \\
\hline$\%$ of all participations in proposals & $100 \%$ & $2.2 \%$ & $1.3 \%$ & $2.2 \%$ & $1.2 \%$ & $3.7 \%$ & $1.7 \%$ & $2.1 \%$ \\
\hline Participations per 1,000 researchers & & $\overline{4.0}$ & 1.7 & 3.4 & 3.9 & 2.7 & 3.8 & 2.3 \\
\hline SMEl Phase 2 - Development \& Demo. & All & $\mathrm{FI}$ & AT & DK & IE & $\mathbf{N L}$ & NO & SE \\
\hline Number of participations in proposals & 5,184 & 170 & 54 & 200 & 120 & 267 & 65 & 251 \\
\hline$\%$ of all participations in proposals & $100 \%$ & $3.3 \%$ & $1.0 \%$ & $3.9 \%$ & $2.3 \%$ & $5.2 \%$ & $1.3 \%$ & $4.8 \%$ \\
\hline Participations per 1,000 researchers & & 3.3 & 0.8 & 3.4 & 4.2 & 2.1 & 1.6 & 3.0 \\
\hline
\end{tabular}

In total, $€ 410 \mathrm{~m}$ of EC funding has been requested through SMEI-1 proposals. Finland accounts for $2.3 \%(€ 10 \mathrm{~m})$ of this total- placing it in the middle of the comparator countries. On average, Finnish participations requested $€ 47 \mathrm{k}$ each. This is above the $\mathrm{H} 2020$ average $(€ 45 \mathrm{k})$ and again places Finland in the middle of the comparators (below DK, IE and SE, but above AT, NL and NO).

Finland accounts for 3.9\% (€324m) of total requests for Phase 2 - placing it in the middle of comparators. On average, Finnish participations in SMEI-2 proposals requested $€ 1.9 \mathrm{~m}$ in funding each. This is above the $\mathrm{H} 2020$ average $(€ 1.6 \mathrm{~m})$, as well as higher than the average in all of the comparator countries except for NL and NO.

Table 95 EC funding requests in SMEI proposals - Finland and comparators - H\&W

\begin{tabular}{|c|c|c|c|c|c|c|c|c|}
\hline SMEI Phase 1 - Feasibility & All & $\mathrm{FI}$ & AT & DK & IE & NL & NO & SE \\
\hline $\begin{array}{l}\text { EC funding requested in proposals } \\
\text { (€million) }\end{array}$ & 410 & 10 & 5 & 10 & 5 & 15 & 7 & 9 \\
\hline$\%$ of all EC funding requested in proposals & $100 \%$ & $2.3 \%$ & $1.2 \%$ & $2.4 \%$ & $1.3 \%$ & $3.6 \%$ & $1.8 \%$ & $2.3 \%$ \\
\hline $\begin{array}{l}\text { Average request per participation } \\
\text { (€thousand) }\end{array}$ & 45 & 47 & 41 & 48 & 48 & 44 & 46 & 48 \\
\hline SMEI Phase 2 - Development \& Demo. & All & $\mathrm{FI}$ & AT & DK & IE & $\mathbf{N L}$ & NO & SE \\
\hline $\begin{array}{l}\text { EC funding requested in proposals } \\
\text { (€million) }\end{array}$ & 8,325 & 324 & 90 & 348 & 207 & 596 & 127 & 477 \\
\hline$\%$ of all EC funding requested in proposals & $100 \%$ & $3.9 \%$ & $1.1 \%$ & $4.2 \%$ & $2.5 \%$ & $7.2 \%$ & $1.5 \%$ & $5.7 \%$ \\
\hline Average request per participation (€million) & 1.6 & 1.9 & 1.7 & 1.7 & 1.7 & 2.2 & 2.0 & 1.9 \\
\hline
\end{tabular}

\section{Participation in SMEI H\&W projects}

Finland's relatively high rate of SMEI proposal activity has not fed through into similarly favourable levels of project activity.

Of the $856 \mathrm{H} 2020$ SMEl-1 grants awarded so far, just 19 have been to Finland. This $2.2 \%$ share of participations places Finland below all comparator countries except FI. Finland's rate of participations in SMEI-1 projects (0.4 per 1,000 R\&D personnel) is also below four of the comparator countries.

The country has fared little better with SMEI-2. Of the 232 grants awarded so far, 7 (or $3.0 \%$ ) have been awarded to Finnish participants. This is fewer than in DK, IE, NL or SE, but more than in the other two comparator countries. Compared with the size of the researcher population Finland's rate of participations in SMEI-2 projects (0.1 per 1,000 personnel) places it in the middle of the comparators.

Table 96 Participations in SMEI projects - Finland and comparators - H\&W

\begin{tabular}{|c|c|c|c|c|c|c|c|c|}
\hline SMEI Phase 1 - Feasibility & All & $\mathrm{FI}$ & AT & DK & IE & NL & NO & SE \\
\hline Number of participations in projects & 856 & 19 & 21 & 31 & 17 & 41 & 23 & 34 \\
\hline$\%$ of all participations in projects & $100 \%$ & $2.2 \%$ & $2.5 \%$ & $3.6 \%$ & $2.0 \%$ & $4.8 \%$ & $2.7 \%$ & $4.0 \%$ \\
\hline Participations per 1,000 researchers & & 0.37 & 0.31 & 0.52 & 0.59 & 0.33 & 0.55 & 0.40 \\
\hline SMEI Phase 2 - Development \& Demo. & All & $\mathrm{FI}$ & AT & DK & IE & NL & NO & SE \\
\hline Number of participations in projects & 232 & 7 & 3 & 9 & 16 & 12 & 4 & 13 \\
\hline$\%$ of all participations in projects & $100 \%$ & $3.0 \%$ & $1.3 \%$ & $3.9 \%$ & $6.9 \%$ & $5.2 \%$ & $1.7 \%$ & $5.6 \%$ \\
\hline Participations per 1,000 researchers & & 0.14 & 0.04 & 0.15 & 0.55 & 0.10 & 0.10 & 0.15 \\
\hline
\end{tabular}


In total, $€ 40$ million of EC funding has been awarded through SMEI-1 projects. Finland accounts for $2.2 \%$ ( $€ 0.9$ million) of this total - a lower amount than all comparators except for IE. On average, Finnish participations in SMEI-1 projects have been awarded $€ 47.4$ thousand in EC funding contributions each. This is slightly above the $\mathrm{H} 2020$ average (€47.1 thousand), but below the averages in four comparator countries.

Over $€ 385 \mathrm{~m}$ in EC funding has been awarded to SMEI-2 projects. Finland accounts for 2.6\% ( $€ 10$ million) of this total - less than all comparators except for AT and NO. On average, Finnish participations were awarded $€ 1.4$ million each through SMEI-2, which is below the overall average rate and below four of the comparator countries.

Table 97 EC funding contributions to SMEI project participations - Finland and comparators $-H \& W$

\begin{tabular}{|c|c|c|c|c|c|c|c|c|}
\hline SMEl Phase 1 - Feasibility & All & $\mathrm{FI}$ & AT & DK & IE & NL & NO & SE \\
\hline EC funding contributions (€million) & 40.3 & 0.9 & 1.0 & 1.5 & 0.8 & 2.0 & 1.1 & 1.6 \\
\hline$\%$ of all EC funding contributions & $100 \%$ & $2.2 \%$ & $2.5 \%$ & $3.7 \%$ & $2.0 \%$ & $4.8 \%$ & $2.7 \%$ & $4.0 \%$ \\
\hline $\begin{array}{l}\text { Average contribution per participation } \\
\text { ( } € \text { thousand) }\end{array}$ & 47.1 & 47.4 & 47.6 & 48.4 & 47.1 & 47.6 & 47.8 & 47.1 \\
\hline SMEI Phase 2 - Development \& Demo. & All & $\mathrm{FI}$ & AT & DK & IE & NL & NO & SE \\
\hline EC funding contributions (€million) & 384.5 & 9.9 & 5.2 & 12.5 & 32.5 & 26.4 & 5.5 & 28.0 \\
\hline$\%$ of all EC funding contributions & $100 \%$ & $2.6 \%$ & $1.3 \%$ & $3.2 \%$ & $8.4 \%$ & $6.9 \%$ & $1.4 \%$ & $7.3 \%$ \\
\hline $\begin{array}{l}\text { Average contribution per participation } \\
(€ \text { million) }\end{array}$ & 1.7 & 1.4 & 1.7 & 1.4 & 2.0 & 2.2 & 1.4 & 2.2 \\
\hline
\end{tabular}

\section{SMEI Success rates $-\mathrm{H} \& \mathrm{~W}$}

Finland compares unfavourably with all comparators (and the overall H2020 average) in the $\mathrm{H} \& \mathrm{~W}$ area, both in terms of participation success rates and the proportion of requested funding that has been awarded. This explains why the relatively good levels of proposal activity have not fed through into similar levels of SMEI project activity.

For SMEI-1, just $9.3 \%$ of Finnish participations in proposals have been successful. This is slightly below the overall average, as well as lower than for all of the comparator countries. The proportion of requested funding that was awarded follows a similar pattern.

For SMEI-2, Finland has performed no better. Its participation success rate $(4.1 \%)$ is below average and below that of all comparators. Finland's funding success rate $(3.0 \%)$ is also below average and below rates in all comparator countries.

Table 98 Success rates (participations and funding) in the SMEI - Finland and comparators - H\&W

\begin{tabular}{|c|c|c|c|c|c|c|c|c|}
\hline SMEI Phase 1 - Feasibility & All & $\mathrm{FI}$ & AT & DK & IE & NL & NO & SE \\
\hline Participation success rates & $9.3 \%$ & $9.3 \%$ & $18.3 \%$ & $15.3 \%$ & $15.0 \%$ & $12.1 \%$ & $14.6 \%$ & $17.5 \%$ \\
\hline$\%$ of requested funding awarded & $9.8 \%$ & $9.5 \%$ & $21.1 \%$ & $15.4 \%$ & $14.8 \%$ & $13.0 \%$ & $15.1 \%$ & $17.2 \%$ \\
\hline SMEI Phase 2 - Development \& Demo. & All & $\mathrm{FI}$ & AT & DK & IE & NL & NO & SE \\
\hline Participation success rates & $4.5 \%$ & $4.1 \%$ & $5.6 \%$ & $4.5 \%$ & $13.3 \%$ & $4.5 \%$ & $6.2 \%$ & $5.2 \%$ \\
\hline$\%$ of requested funding awarded & $4.6 \%$ & $3.0 \%$ & $5.7 \%$ & $3.6 \%$ & $15.7 \%$ & $4.4 \%$ & $4.4 \%$ & $5.9 \%$ \\
\hline
\end{tabular}

\section{Cleantech, Bioeconomy and Circular Economy}

Finland's level of involvement in SME Instrument proposals in the CBC area compares favourably against most comparator countries, in both of the instrument's phases.

It has participated in 272 SME Instrument Phase 1 (SMEI-1) proposals, or $2.2 \%$ of all 12,589 participations so far. This is more than all comparator countries except for NL (3.6\%). Weighting proposal activity by taking account of the size of researcher populations, 
Finland's rate of participations in SMEI-1 proposals (5.3 per 1,000 R\&D personnel) is above all comparators except IE.

Finland has also participated in 219 SMEI-2 proposals, meaning it is slightly more active here $(3.1 \%$ of 7,091 participations) than in Phase 1 . However, here it ranks below DK, NL and SE in terms of absolute levels of involvement. Compared with the size of the researcher population, however, Finland's rate of participations in SMEI-2 proposals (4.3 per 1,000 personnel) is above all comparator countries except for IE.

Table 99 Participations in H2020 SMEI proposals - Finland and comparators - CBC

\begin{tabular}{|c|c|c|c|c|c|c|c|c|}
\hline SMEI Phase 1 - Feasibility & All & $\mathrm{FI}$ & AT & DK & IE & NL & NO & SE \\
\hline Number of participations in proposals & 12,589 & 272 & 144 & 247 & 154 & 449 & 205 & 265 \\
\hline$\%$ of all participations in proposals & $100 \%$ & $2.2 \%$ & $1.1 \%$ & $2.0 \%$ & $1.2 \%$ & $3.6 \%$ & $1.6 \%$ & $2.1 \%$ \\
\hline Participations per 1,000 researchers & & 5.3 & 2.1 & 4.2 & 5.3 & 3.6 & 4.9 & 3.2 \\
\hline SMEI Phase 2 - Development \& Demo. & All & $\mathrm{FI}$ & AT & DK & IE & NL & NO & SE \\
\hline Number of participations in proposals & 7,091 & 219 & 95 & 244 & 135 & 330 & 132 & 269 \\
\hline$\%$ of all participations in proposals & $100 \%$ & $3.1 \%$ & $1.3 \%$ & $3.4 \%$ & $1.9 \%$ & $4.7 \%$ & $1.9 \%$ & $3.8 \%$ \\
\hline Participations per 1,000 researchers & & 4.3 & 1.4 & 4.1 & 4.7 & 2.6 & 3.2 & 3.2 \\
\hline
\end{tabular}

In total, $€ 550$ million of EC funding has been requested through SMEI-1 proposals. Finland accounts for $2.3 \%$ ( $€ 12$ million) of this total- a higher amount than any of the comparator countries except for NL. On average, Finnish participations requested $€ 46$ thousand each. This is above the $\mathrm{H} 2020$ average ( $€ 44$ thousand) and places Finland in the middle of the comparators (below DK, NO and SE, but above AT, IE and NL).

Finland accounts for $4.0 \%$ ( $€ 384$ million) of total requests for Phase 2 - placing it in the middle of the comparator countries. On average, Finnish participations in SMEI-2 proposals requested $€ 1.8$ million in funding each. This is above the $\mathrm{H} 2020$ average ( $€ 1.4$ million), as well as higher than the average in all of the comparator countries.

Table 100 EC funding requests in SMEI proposals - Finland and comparators - CBC

\begin{tabular}{|c|c|c|c|c|c|c|c|c|}
\hline SMEI Phase 1 - Feasibility & All & $\mathrm{FI}$ & AT & DK & IE & NL & NO & SE \\
\hline $\begin{array}{l}\text { EC funding requested in proposals } \\
\text { (€million) }\end{array}$ & 550 & 12 & 6 & 12 & 7 & 19 & 9 & 12 \\
\hline$\%$ of all EC funding requested in proposals & $100 \%$ & $2.3 \%$ & $1.1 \%$ & $2.1 \%$ & $1.3 \%$ & $3.5 \%$ & $1.7 \%$ & $2.2 \%$ \\
\hline $\begin{array}{l}\text { Average request per participation } \\
\text { (€thousand) }\end{array}$ & 44 & 46 & 41 & 48 & 46 & 42 & 46 & 47 \\
\hline SMEI Phase 2 - Development \& Demo. & All & $\mathrm{FI}$ & AT & DK & IE & NL & NO & SE \\
\hline $\begin{array}{l}\text { EC funding requested in proposals } \\
\text { (€million) }\end{array}$ & 9,616 & 384 & 116 & 389 & 213 & 555 & 190 & 427 \\
\hline$\%$ of all EC funding requested in proposals & $100 \%$ & $4.0 \%$ & $1.2 \%$ & $4.0 \%$ & $2.2 \%$ & $5.8 \%$ & $2.0 \%$ & $4.4 \%$ \\
\hline Average request per participation (€million) & 1.4 & 1.8 & 1.2 & 1.6 & 1.6 & 1.7 & 1.4 & 1.6 \\
\hline
\end{tabular}

\section{$\underline{\text { Participation in SMEI CBC projects }}$}

Finland's relatively high rate of SMEI proposal activity in the CBC area has not fed through entirely into levels of project activity.

Of the nearly 1,200 H2020 SMEI-1 grants awarded so far, just 33 have been to Finland. This $2.8 \%$ share of participations places Finland in the middle of the comparator countries. Its rate of participations in SMEI-1 projects ( 0.6 per 1,000 R\&D personnel) is also below two of the comparator countries (DK and IE).

The country has fared a little better with SMEI-2. Of the 399 grants awarded so far, 15 (or $3.8 \%$ ) have been awarded to Finnish participants. This is fewer than in four of the comparator countries. Compared with the size of the researcher population Finland's rate of participations in SMEI-2 projects (0.3 per 1,000 personnel) is below that of DK and IE. 
Table 101 Participations in SMEI projects - Finland and comparators - CBC

\begin{tabular}{|c|c|c|c|c|c|c|c|c|}
\hline SMEI Phase 1 - Feasibility & All & $\mathrm{FI}$ & AT & DK & IE & NL & NO & SE \\
\hline Number of participations in projects & 1,196 & 33 & 24 & 42 & 23 & 51 & 25 & 48 \\
\hline$\%$ of all participations in projects & $100 \%$ & $2.8 \%$ & $2.0 \%$ & $3.5 \%$ & $1.9 \%$ & $4.3 \%$ & $2.1 \%$ & $4.0 \%$ \\
\hline Participations per 1,000 researchers & & 0.64 & 0.35 & 0.71 & 0.80 & 0.41 & 0.60 & 0.57 \\
\hline SMEI Phase 2 - Development \& Demo. & All & FI & AT & DK & IE & NL & NO & SE \\
\hline Number of participations in projects & 399 & 15 & 5 & 19 & 17 & 24 & 11 & 20 \\
\hline$\%$ of all participations in projects & $100 \%$ & $3.8 \%$ & $1.3 \%$ & $4.8 \%$ & $4.3 \%$ & $6.0 \%$ & $2.8 \%$ & $5.0 \%$ \\
\hline Participations per 1,000 researchers & & 0.29 & 0.07 & 0.32 & 0.59 & 0.19 & 0.27 & 0.24 \\
\hline
\end{tabular}

In total, $€ 55$ million of EC funding has been awarded through SMEI-1 projects. Finland accounts for $2.7 \%$ ( $€ 1.5$ million) of this total - placing it in the middle of the comparator countries. On average, Finnish participations in SMEI-1 projects have been awarded $€ 44$ thousand in EC funding contributions each. This is slightly below the H2020 average (€46 thousand), as well as below the averages in all comparator countries.

Over $€ 544$ million in EC funding has been awarded to SMEI-2 projects. Finland accounts for $4.5 \%$ (€24 million) of this total - a lower proportion than any of the comparators except for AT and NO. On average, Finnish participations were awarded $€ 1.6$ million each through SMEI-2, which is above the overall average rate and above that of most comparator countries.

Table 102 EC funding contributions to SMEI project participations - Finland and comparators - CBC

\begin{tabular}{|c|c|c|c|c|c|c|c|c|}
\hline SMEl Phase 1 - Feasibility & All & FI & AT & DK & IE & NL & NO & SE \\
\hline EC funding contributions ( $€$ million) & 54.6 & 1.5 & 1.1 & 2.0 & 1.1 & 2.3 & 1.2 & 2.2 \\
\hline$\%$ of all EC funding contributions & $100 \%$ & $2.7 \%$ & $2.0 \%$ & $3.7 \%$ & $2.0 \%$ & $4.1 \%$ & $2.2 \%$ & $4.0 \%$ \\
\hline $\begin{array}{l}\text { Average contribution per participation } \\
\text { (€thousand) }\end{array}$ & 45.7 & 43.9 & 45.8 & 47.6 & 47.8 & 44.1 & 48.0 & 45.8 \\
\hline SMEI Phase 2 - Development \& Demo. & All & $\mathrm{FI}$ & AT & DK & IE & NL & NO & SE \\
\hline EC funding contributions (€million) & 544.7 & 24.3 & 7.5 & 30.1 & 30.0 & 40.5 & 14.7 & 29.4 \\
\hline$\%$ of all EC funding contributions & $100 \%$ & $4.5 \%$ & $1.4 \%$ & $5.5 \%$ & $5.5 \%$ & $7.4 \%$ & $2.7 \%$ & $5.4 \%$ \\
\hline $\begin{array}{l}\text { Average contribution per participation } \\
\text { (€million) }\end{array}$ & 1.4 & 1.6 & 1.5 & 1.6 & 1.8 & 1.7 & 1.3 & 1.5 \\
\hline
\end{tabular}

\section{$\underline{\text { SMEI Success rates - CBC }}$}

Finland compares unfavourably with comparators, both in terms of participation success rates and the proportion of requested funding that has been awarded. This explains why the relatively high levels of proposal activity have not fed through into similar levels of SMEI project activity.

For SMEI-1, 12.1\% of Finnish participations in proposals have been successful. While this is above the overall average $(9.5 \%)$, it is lower than for all of the comparator countries except NL. The proportion of requested funding that was awarded follows a similar pattern, although the Finnish rate (11.6\%) is below all comparator countries.

For SMEI-2, Finland has only performed no better. Its participation success rate (6.8\%) is again above average, but below all comparator countries except one (AT). Its funding success rate $(6.3 \%)$ is also below that of all comparator countries.

Table 103 Success rates (participations and funding) in the SMEI - Finland and comparators - CBC

\begin{tabular}{|c|c|c|c|c|c|c|c|c|}
\hline SMEl Phase 1 - Feasibility & All & $\mathrm{FI}$ & AT & DK & IE & NL & NO & SE \\
\hline Participation success rates & $9.5 \%$ & $12.1 \%$ & $16.7 \%$ & $17.0 \%$ & $14.9 \%$ & $11.4 \%$ & $12.2 \%$ & $18.1 \%$ \\
\hline$\%$ of requested funding awarded & $9.9 \%$ & $11.6 \%$ & $18.5 \%$ & $16.9 \%$ & $15.6 \%$ & $11.8 \%$ & $12.7 \%$ & $17.8 \%$ \\
\hline SMEI Phase 2 - Development \& Demo. & All & $\mathrm{FI}$ & AT & DK & IE & NL & NO & SE \\
\hline Participation success rates & $5.6 \%$ & $6.8 \%$ & $5.3 \%$ & $7.8 \%$ & $12.6 \%$ & $7.3 \%$ & $8.3 \%$ & $7.4 \%$ \\
\hline$\%$ of requested funding awarded & $5.7 \%$ & $6.3 \%$ & $6.4 \%$ & $7.7 \%$ & $14.1 \%$ & $7.3 \%$ & $7.7 \%$ & $6.9 \%$ \\
\hline
\end{tabular}




\section{Digitalisation}

Finland's level of involvement in SME Instrument proposals in the Digitalisation area compares favourably against nearly all comparator countries, in both of the instrument's phases.

It has participated in 304 SME Instrument Phase 1 (SMEI-1) proposals, or $2.3 \%$ of all 13,316 participations so far. This is more than all comparator countries except for NL (3.1\%). Weighting proposal activity by taking account of the size of researcher populations, Finland's rate of participations in SMEI-1 proposals (5.9 per 1,000 R\&D personnel) is above all comparators except IE.

Finland has also participated in 340 SMEI-2 proposals, meaning it is relatively more active here (4.5\% of 7,574 participations) than in Phase 1 . Indeed, it ranks above all comparator countries in terms of absolute levels of involvement. Compared with the size of the researcher population, Finland's rate of participations in SMEI-2 proposals (6.6 per 1,000 personnel) is also above all comparators.

Table 104 Participations in H2020 SMEI proposals - Finland and comparators - Digitalisation

\begin{tabular}{|c|c|c|c|c|c|c|c|c|}
\hline SMEl Phase 1 - Feasibility & All & $\mathrm{FI}$ & AT & DK & IE & $\mathrm{NL}$ & NO & SE \\
\hline Number of participations in proposals & 13,316 & 304 & 160 & 225 & 212 & 408 & 207 & 227 \\
\hline$\%$ of all participations in proposals & $100 \%$ & $2.3 \%$ & $1.2 \%$ & $1.7 \%$ & $1.6 \%$ & $3.1 \%$ & $1.6 \%$ & $1.7 \%$ \\
\hline Participations per 1,000 researchers & & 5.9 & 2.3 & 3.8 & 7.3 & 3.2 & 5.0 & 2.7 \\
\hline SMEI Phase 2 - Development \& Demo. & All & $\mathrm{FI}$ & AT & DK & IE & $\mathrm{NL}$ & NO & SE \\
\hline Number of participations in proposals & 7,574 & 340 & 85 & 233 & 110 & 293 & 113 & 281 \\
\hline$\%$ of all participations in proposals & $100 \%$ & $4.5 \%$ & $1.1 \%$ & $3.1 \%$ & $1.5 \%$ & $3.9 \%$ & $1.5 \%$ & $3.7 \%$ \\
\hline Participations per 1,000 researchers & & 6.6 & 1.2 & 3.9 & 3.8 & 2.3 & 2.7 & 3.3 \\
\hline
\end{tabular}

In total, $€ 596$ million of EC funding has been requested through SMEI-1 proposals. Finland accounts for $2.4 \%$ ( $€ 15$ million) of this total- a higher amount than any of the comparator countries except for NL. On average, Finnish participations requested $€ 48$ thousand each. This is above the $\mathrm{H} 2020$ average ( $€ 45$ thousand) and places Finland above all comparators except IE and SE.

Finland accounts for $5.6 \%$ ( $€ 537$ million) of all funding requests in SMEI-2 proposals, more than any of the comparators. On average, Finnish participations in SMEI-2 proposals requested $€ 1.6$ million in funding each. This is above the $\mathrm{H} 2020$ average ( $€ 1.3$ million), as well as higher than the average in all of the comparator countries.

Table 105 EC funding requests in SMEI proposals - Finland and comparators - Digitalisation

\begin{tabular}{|c|c|c|c|c|c|c|c|c|}
\hline SMEI Phase 1 - Feasibility & All & $\mathrm{FI}$ & AT & DK & IE & NL & NO & SE \\
\hline $\begin{array}{l}\text { EC funding requested in proposals } \\
\text { (€million) }\end{array}$ & 596 & 15 & 7 & 11 & 10 & 18 & 9 & 11 \\
\hline $\begin{array}{l}\% \text { of all EC funding requested in } \\
\text { proposals }\end{array}$ & $100 \%$ & $2.4 \%$ & $1.2 \%$ & $1.8 \%$ & $1.7 \%$ & $2.9 \%$ & $1.5 \%$ & $1.9 \%$ \\
\hline $\begin{array}{l}\text { Average request per participation } \\
\text { (€thousand) }\end{array}$ & 45 & 48 & 44 & 47 & 48 & 43 & 44 & 49 \\
\hline SMEI Phase 2 - Development \& Demo. & All & $\mathrm{FI}$ & AT & DK & IE & NL & NO & SE \\
\hline $\begin{array}{l}\text { EC funding requested in proposals } \\
(€ \text { million })\end{array}$ & 9,568 & 534 & 94 & 310 & 157 & 437 & 168 & 419 \\
\hline $\begin{array}{l}\% \text { of all EC funding requested in } \\
\text { proposals }\end{array}$ & $100 \%$ & $5.6 \%$ & $1.0 \%$ & $3.2 \%$ & $1.6 \%$ & $4.6 \%$ & $1.8 \%$ & $4.4 \%$ \\
\hline $\begin{array}{l}\text { Average request per participation } \\
(€ \text { million) }\end{array}$ & 1.3 & 1.6 & 1.1 & 1.3 & 1.4 & 1.5 & 1.5 & 1.5 \\
\hline
\end{tabular}


Finland's relatively high rate of SMEI proposal activity (for both phases of the instrument has only fed through into relatively high levels of project activity for Phase 2.

Of the $1,060 \mathrm{H} 2020$ SMEl-1 grants awarded so far, just 27 have been to Finland. This $2.5 \%$ share of participations is lower than four of the six comparators and only slightly above AT and NO. Its rate of participations in SMEI-1 projects ( 0.5 per 1,000 R\&D personnel) is also mid-ranking amongst the comparators.

The country has fared much better with SMEI-2. Of the 359 grants awarded so far, 19 (or $5.3 \%$ ) have been awarded to Finnish participants. This is more than any of the comparator countries. Compared with the size of the researcher population Finland's rate of participations in SMEI-2 projects (0.4 per 1,000 personnel) also compares favourably with most comparators (except IE).

Table 106 Participations in SMEI projects - Finland and comparators - Digitalisation

\begin{tabular}{lcccccccc}
\hline SMEl Phase 1 - Feasibility & All & FI & AT & DK & IE & NL & NO & SE \\
\hline Number of participations in projects & 1,060 & 27 & 24 & 32 & 28 & 33 & 25 & 33 \\
\hline$\%$ of all participations in projects & $100 \%$ & $2.5 \%$ & $2.3 \%$ & $3.0 \%$ & $2.6 \%$ & $3.1 \%$ & $2.4 \%$ & $3.1 \%$ \\
\hline Participations per 1,000 researchers & & 0.53 & 0.35 & 0.54 & 0.97 & 0.26 & 0.60 & 0.39 \\
\hline SMEl Phase 2 - Development \& Demo. & All & FI & AT & DK & IE & NL & NO & SE \\
\hline Number of participations in projects & 359 & 19 & 8 & 14 & 12 & 14 & 8 & 16 \\
\hline$\%$ of all participations in projects & $100 \%$ & $5.3 \%$ & $2.2 \%$ & $3.9 \%$ & $3.3 \%$ & $3.9 \%$ & $2.2 \%$ & $4.5 \%$ \\
\hline Participations per 1,000 researchers & & 0.37 & 0.12 & 0.24 & 0.42 & 0.11 & 0.19 & 0.19 \\
\hline
\end{tabular}

In total, $€ 49$ million of EC funding has been awarded through SMEI-1 projects. Finland accounts for $2.5 \%$ ( $€ 1.3$ million) of this total - a lower amount than all comparator countries except for AT and NO. On average, Finnish participations in SMEI-1 projects have been awarded $€ 46$ thousand in EC funding contributions each. This is slightly below the H2020 average, as well as below the averages in all comparator countries except for AT and NL.

Over $€ 470$ million in EC funding has been awarded to SMEI-2 projects. Finland accounts for $6.5 \%$ ( $€ 31$ million) of this total - a higher proportion than any of the comparators. On average, Finnish participations were awarded $€ 1.6$ million each through SMEI-2, which is above the overall average and above that of all comparators except IE and NO.

Table 107 EC funding contributions to SMEI project participations - Finland and comparators - Digitalisation

\begin{tabular}{|c|c|c|c|c|c|c|c|c|}
\hline SMEI Phase 1 - Feasibility & All & $\mathrm{FI}$ & AT & DK & IE & NL & NO & SE \\
\hline EC funding contributions (€million) & 49.3 & 1.3 & 1.1 & 1.6 & 1.4 & 1.5 & 1.2 & 1.7 \\
\hline$\%$ of all EC funding contributions & $100 \%$ & $2.5 \%$ & $2.2 \%$ & $3.1 \%$ & $2.7 \%$ & $2.9 \%$ & $2.4 \%$ & $3.3 \%$ \\
\hline $\begin{array}{l}\text { Average contribution per participation } \\
\text { (€thousand) }\end{array}$ & 46.5 & 46.3 & 45.8 & 48.4 & 48.2 & 43.9 & 48.0 & 50.0 \\
\hline SMEI Phase 2 - Development \& Demo. & All & $\mathrm{FI}$ & AT & DK & IE & $\overline{\mathrm{NL}}$ & NO & SE \\
\hline EC funding contributions (€million) & 470.1 & 30.7 & 7.5 & 14.1 & 21.4 & 17.4 & 13.1 & 20.0 \\
\hline$\%$ of all EC funding contributions & $100 \%$ & $6.5 \%$ & $1.6 \%$ & $3.0 \%$ & $4.6 \%$ & $3.7 \%$ & $2.8 \%$ & $4.3 \%$ \\
\hline $\begin{array}{l}\text { Average contribution per participation } \\
\text { (€million) }\end{array}$ & 1.3 & 1.6 & 0.9 & 1.0 & 1.8 & 1.2 & 1.6 & 1.3 \\
\hline
\end{tabular}

\section{SMEI Success rates - Digitalisation}

While Finland's success across both phases of the SMEI is slightly above average, it compares unfavourably with most of the comparator countries, both in terms of participation success rates and the proportion of requested funding that has been awarded.

For SMEI-1, just $8.9 \%$ of Finnish participations in proposals have been successful. While this is slightly above the overall average, it is lower than for all the comparator countries except for NL. The proportion of requested funding that was awarded follows a similar 
pattern. As a result, Finland's relatively high levels of proposal activity in Phase 1 have not fed through into relatively high levels of SMEI-1 project activity.

For SMEI-2, Finland has only performed marginally better. Its participation success rate $(5.6 \%)$ is above average and higher than in $\mathrm{NL}$, but still below all other comparators. However, its funding success rate (5.7\%) places it in the middle of the six comparators.

Table 108 Success rates (participations and funding) in the SMEI - Finland and comparators - Digitalisation

\begin{tabular}{|c|c|c|c|c|c|c|c|c|}
\hline SMEl Phase 1 - Feasibility & All & $\mathrm{FI}$ & AT & DK & IE & $\mathbf{N L}$ & NO & SE \\
\hline Participation success rates & $8.0 \%$ & $8.9 \%$ & $15.0 \%$ & $14.2 \%$ & $13.2 \%$ & $8.1 \%$ & $12.1 \%$ & $14.5 \%$ \\
\hline$\%$ of requested funding awarded & $8.3 \%$ & $8.6 \%$ & $15.7 \%$ & $14.6 \%$ & $13.3 \%$ & $8.3 \%$ & $13.0 \%$ & $14.9 \%$ \\
\hline SMEI Phase 2 - Development \& Demo. & All & $\mathrm{FI}$ & AT & DK & IE & NL & NO & SE \\
\hline Participation success rates & $4.7 \%$ & $5.6 \%$ & $9.4 \%$ & $6.0 \%$ & $10.9 \%$ & $4.8 \%$ & $7.1 \%$ & $5.7 \%$ \\
\hline$\%$ of requested funding awarded & $4.9 \%$ & $5.7 \%$ & $8.0 \%$ & $4.6 \%$ & $13.6 \%$ & $4.0 \%$ & $7.8 \%$ & $4.8 \%$ \\
\hline
\end{tabular}

\section{Participation in European Research Council (ERC) activities}

\section{Introduction}

The European Research Council (ERC) - located within the Excellent Science pillar of $\mathrm{H} 2020$ - provides attractive and flexible funding to enable talented and creative individual researchers and their teams to pursue the most promising avenues at the frontiers of science, on the basis of EU-wide competition. The ERC's mission is to encourage the highest quality research in Europe through competitive funding, and to support investigatordriven frontier research across all fields of research, on the basis of scientific excellence.

A total budget of $€ 13,095$ million is available under $\mathrm{H} 2020$ for the implementation of the different ERC funding schemes (starting grants, consolidator grants, advanced grants, proof of concept grants and synergy grants), with between $€ 150 \mathrm{k}$ (for proof of concept) and $€ 10 \mathrm{~m}$ (for synergy) available for individual grants. In nearly all cases, ERC grants are awarded to one researcher at one host institution for a single project, with the single selection criteria being scientific excellence. The relatively small number of synergy grants are intended for ambitious research questions that can only be answered by the coordinated work of a small group of 2-4 principal investigators.

\section{Overall participation in H2020 ERC}

Finland's level of involvement in ERC proposals compares favourably against nearly all comparator countries. It has participated in $760 \mathrm{ERC}$ proposals, or $2.9 \%$ of all 26,407 participations in proposals so far. This is more than all comparator countries except for $\mathrm{NL}$ $(6.4 \%)$ and SE $(3.5 \%)$. Weighting proposal activity by taking account of the size of researcher populations, Finland's rate of participations in ERC proposals (14.8 per 1,000 $\mathrm{R} \& \mathrm{D}$ personnel) is above all comparators.

Table 109 Participations in H2020 ERC proposals - Finland and comparators

\begin{tabular}{|c|c|c|c|c|c|c|c|c|}
\hline & All & $\mathrm{FI}$ & AT & DK & IE & NL & NO & SE \\
\hline Number of participations in proposals & 26,407 & 760 & 519 & 622 & 369 & 1,687 & 361 & 926 \\
\hline$\%$ of all participations in proposals & $100 \%$ & $2.9 \%$ & $2.0 \%$ & $2.4 \%$ & $1.4 \%$ & $6.4 \%$ & $1.4 \%$ & $3.5 \%$ \\
\hline Participations per 1,000 researchers & & 14.8 & 7.6 & 10.5 & 12.8 & 13.4 & 8.7 & 11.0 \\
\hline
\end{tabular}

In total, €42.1 billion of EC funding has been requested through ERC proposals. Fin-land accounts for $3.2 \%$ (€1.3 billion) of this total - a higher amount than any of the comparator 
countries except for $\mathrm{NL}$ and $\mathrm{SE}$. On average, Finnish participations re-quested $€ 1.77$ million each. This is above the $\mathrm{H} 2020$ average ( $€ 1.59$ million) and higher than all of the comparator countries except NO.

Table 110 EC funding requests in ERC proposals - Finland and comparators

\begin{tabular}{|c|c|c|c|c|c|c|c|c|}
\hline & All & $\mathrm{FI}$ & AT & DK & IE & $\mathbf{N L}$ & NO & SE \\
\hline EC funding requested in proposals $(€ \mathrm{~m})$ & 42,085 & 1,345 & 881 & 1071 & 626 & 2877 & 660 & 1,582 \\
\hline$\%$ of all EC funding requested in proposals & $100 \%$ & $3.2 \%$ & $2.1 \%$ & $2.5 \%$ & $1.5 \%$ & $6.8 \%$ & $1.6 \%$ & $3.8 \%$ \\
\hline Average request per participation $(€ \mathrm{~m})$ & 1.59 & 1.77 & 1.70 & 1.72 & 1.70 & 1.71 & 1.83 & 1.71 \\
\hline
\end{tabular}

\section{$\underline{\text { Participation in ERC projects }}$}

Finland's relatively high rate of ERC proposal activity has not fed through entirely into levels of project activity. Of the nearly 3,700 H2020 ERC grants awarded so far, just 64 have been to Finland. This $1.7 \%$ share of participations places Finland below most comparator countries (except NO and IE). Its rate of participations in ERC projects (1.2 per 1,000 R\&D personnel) is below five of the comparator countries (and only higher than NO).

Table 111 Participations in ERC projects - Finland and comparators

\begin{tabular}{|c|c|c|c|c|c|c|c|c|}
\hline & All & $\mathrm{FI}$ & AT & DK & IE & NL & NO & SE \\
\hline Number of participations in projects & 3,687 & 64 & 100 & 76 & 44 & 337 & 29 & 112 \\
\hline$\%$ of all participations in projects & $100 \%$ & $1.7 \%$ & $2.7 \%$ & $2.1 \%$ & $1.2 \%$ & $9.1 \%$ & $0.8 \%$ & $3.0 \%$ \\
\hline Participations per 1,000 researchers & & 1.2 & 1.5 & 1.3 & 1.5 & 2.7 & 0.7 & 1.3 \\
\hline
\end{tabular}

In total, $€ 5$.3bn of EC funding has been awarded through ERC projects. Finland ac-counts for $2.0 \%$ ( $€ 104$ million) of this total - a higher amount than in IE or NO, but below the other comparators. On average, Finnish participations in ERC projects have been awarded $€ 1.62$ million in EC funding contributions each. This is above the $\mathrm{H} 2020$ aver-age ( $€ 1.43$ million), as well as above the averages in all comparator countries except for NO.

Table 112 EC funding contributions to ERC project participations - Finland and comparators

\begin{tabular}{|c|c|c|c|c|c|c|c|c|}
\hline & All & $\mathrm{FI}$ & AT & DK & IE & NL & NO & SE \\
\hline EC funding contributions ( $€$ million) & 5,269 & 104 & 150 & 117 & 57 & 495 & 53 & 165 \\
\hline$\%$ of all EC funding contributions & $100 \%$ & $2.0 \%$ & $2.9 \%$ & $2.2 \%$ & $1.1 \%$ & $9.4 \%$ & $1.0 \%$ & $3.1 \%$ \\
\hline Average contribution per participation $(€ M)$ & 1.43 & 1.62 & 1.50 & 1.54 & 1.30 & 1.47 & 1.81 & 1.47 \\
\hline
\end{tabular}

\section{ERC Success rates}

Based on the data presented above, on participations and funding in proposals / pro-jects, we can calculate success rates within ERC so far. Finland compares unfavourably with most/all comparators, both in terms of participation success rates and the proportion of requested funding that has been awarded. This explains why the relatively high levels of proposal activity have not fed through into similar levels of ERC project activity.

Just $8.4 \%$ of Finnish participations in ERC proposals have been successful. This is lower the overall average and lower than all of the comparator countries (except NO). AT (19.3\%) and $\mathrm{NL}(20.0 \%)$ in particular achieved success rates that were more than double those seen in Finland. The proportion of requested funding that was awarded follows a similar pattern, although the Finnish rate $(7.7 \%)$ is below that of all comparators, including NO.

Table 113 Success rates (participations and funding) in ERC - Finland and comparators

\begin{tabular}{|c|c|c|c|c|c|c|c|c|}
\hline & All & $\mathrm{FI}$ & AT & DK & IE & NL & NO & SE \\
\hline Participation success rates & $14.0 \%$ & $8.4 \%$ & $19.3 \%$ & $12.2 \%$ & $11.9 \%$ & $20.0 \%$ & $8.0 \%$ & $12.1 \%$ \\
\hline
\end{tabular}




\section{Health \& Wellbeing}

\section{Participation in ERC H\&W proposals}

Finland's level of involvement in ERC Instrument proposals in the Health and Wellbeing area compares quite favourably against most comparator countries. It has participated in 403 ERC proposals, or $3.0 \%$ of all 13,523 participations so far. This is more than all comparator countries except for NL (7.0\%). Weighting proposal activity by taking ac-count of the size of researcher populations, Finland's rate of participations in ERC proposals (7.9 per 1,000 R\&D personnel) is above all comparators.

Table 114 Participations in H2020 ERC proposals - Finland and comparators - H\&W

\begin{tabular}{|c|c|c|c|c|c|c|c|c|}
\hline & All & $\mathrm{FI}$ & AT & DK & IE & $\mathbf{N L}$ & NO & SE \\
\hline Number of participations in proposals & 13,523 & 403 & 253 & 308 & 191 & 943 & 149 & 550 \\
\hline$\%$ of all participations in proposals & $100 \%$ & $3.0 \%$ & $1.9 \%$ & $2.3 \%$ & $1.4 \%$ & $7.0 \%$ & $1.1 \%$ & $4.1 \%$ \\
\hline Participations per 1,000 researchers & & $\overline{7.9}$ & 3.7 & 5.2 & 6.6 & 7.5 & 3.6 & 6.5 \\
\hline
\end{tabular}

In total, $€ 22$ billion of EC funding has been requested through ERC proposals. Finland accounts for $3.3 \%$ ( $€ 735$ million) of this total- placing it above all countries except NL $(7.2 \%)$ and SE (4.5\%). On average, Finnish participations requested $€ 1.82$ million each. This is above the $\mathrm{H} 2020$ average ( $€ 1.62$ million) and places Finland above all comparators.

Table 115 EC funding requests in ERC proposals - Finland and comparators $-H \& W$

\begin{tabular}{|c|c|c|c|c|c|c|c|c|}
\hline & All & $\mathrm{FI}$ & AT & DK & IE & $\mathbf{N L}$ & NO & SE \\
\hline EC funding requested in proposals (€million) & 21,967 & 735 & 436 & 533 & 339 & 1,583 & 268 & 986 \\
\hline$\%$ of all EC funding requested in proposals & $100 \%$ & $3.3 \%$ & $2.0 \%$ & $2.4 \%$ & $1.5 \%$ & $7.2 \%$ & $1.2 \%$ & $4.5 \%$ \\
\hline Average request per participation (€million) & 1.62 & $\overline{1.82}$ & 1.72 & 1.73 & 1.78 & 1.68 & 1.80 & 1.79 \\
\hline
\end{tabular}

\section{Participation in ERC H\&W projects}

Finland's relatively high rate of ERC proposal activity has not fed through into similarly favourable levels of project activity. Of the 1,968 H2020 ERC grants awarded so far, just 30 have been to Finland. This $1.5 \%$ share of participations places Finland below all comparator countries except IE and NO. Finland's rate of participations in ERC projects ( 0.6 per 1,000 $R \& D$ personnel) is also below five of the comparator countries.

Table 116 Participations in ERC projects - Finland and comparators $-H \& W$

\begin{tabular}{|c|c|c|c|c|c|c|c|c|}
\hline & All & FI & AT & DK & IE & NL & NO & SE \\
\hline Number of participations in projects & 1,968 & 30 & 61 & 47 & 19 & 194 & 13 & 63 \\
\hline$\%$ of all participations in projects & $100 \%$ & $1.5 \%$ & $3.1 \%$ & $2.4 \%$ & $1.0 \%$ & $9.9 \%$ & $0.7 \%$ & $3.2 \%$ \\
\hline Participations per 1,000 researchers & & 0.6 & 0.9 & 0.8 & 0.7 & 1.5 & 0.3 & 0.8 \\
\hline
\end{tabular}

In total, $€ 2.8$ billion of EC funding has been awarded through ERC projects. Finland accounts for $1.9 \%$ ( $€ 52$ million) of this total - a lower amount than all comparators except for IE and NO. On average, Finnish participations in ERC projects have been awarded $€ 1.74$ million in EC funding contributions each. This is above the $\mathrm{H} 2020$ average ( $€ 1.43$ million), as well as above that of all comparator countries. 


\begin{tabular}{|c|c|c|c|c|c|c|c|c|}
\hline & All & FI & AT & DK & IE & $\mathbf{N L}$ & NO & SE \\
\hline EC funding contributions ( $€$ million) & 2,806 & 52 & 98 & 69 & 25 & 267 & 23 & 96 \\
\hline$\%$ of all EC funding contributions & $100 \%$ & $1.9 \%$ & $3.5 \%$ & $2.5 \%$ & $0.9 \%$ & $9.5 \%$ & $0.8 \%$ & $3.4 \%$ \\
\hline $\begin{array}{l}\text { Average contribution per participation } \\
\text { ( } \text { million) }\end{array}$ & 1.43 & 1.74 & 1.60 & 1.47 & 1.34 & 1.37 & 1.73 & 1.53 \\
\hline
\end{tabular}

\section{ERC Success rates $-\mathrm{H} \& W$}

Finland compares unfavourably with all comparators (and the overall $\mathrm{H} 2020$ average) in the $\mathrm{H} \& \mathrm{~W}$ area, both in terms of participation success rates and the proportion of re-quested funding that has been awarded. This explains why the relatively good levels of proposal activity have not fed through into similar levels of ERC project activity.

Table 118 Success rates (participations and funding) in ERC-Finland and comparators $-H \& W$

\begin{tabular}{|c|c|c|c|c|c|c|c|c|}
\hline & All & $\mathrm{FI}$ & AT & DK & IE & NL & NO & SE \\
\hline Participation success rates & $14.6 \%$ & $7.4 \%$ & $24.1 \%$ & $15.3 \%$ & $9.9 \%$ & $20.6 \%$ & $8.7 \%$ & $11.5 \%$ \\
\hline$\%$ of requested funding awarded & $12.8 \%$ & $7.1 \%$ & $22.4 \%$ & $13.0 \%$ & $7.5 \%$ & $16.8 \%$ & $8.4 \%$ & $9.8 \%$ \\
\hline
\end{tabular}

\section{Cleantech, Bioeconomy and Circular Economy}

\section{Participation in ERC CBC proposals}

Finland's level of involvement in ERC proposals in the CBC area compares favourably against most comparator countries. It has participated 418 times in ERC proposals, or $3.1 \%$ of all 13,690 participations so far. This is more than all comparator countries except for NL $(6.4 \%)$ and SE (4.1\%). Weighting proposal activity by taking account of the size of researcher populations, Finland's rate of participations in ERC proposals (8.2 per 1,000 $\mathrm{R} \& \mathrm{D}$ personnel) is above all comparators.

Table 119 Participations in H2020 ERC proposals - Finland and comparators - CBC

\begin{tabular}{|c|c|c|c|c|c|c|c|c|}
\hline & All & $\mathrm{FI}$ & AT & DK & IE & NL & NO & SE \\
\hline Number of participations in proposals & 13,690 & 418 & 249 & 347 & 194 & 870 & 178 & 558 \\
\hline$\%$ of all participations in proposals & $100 \%$ & $3.1 \%$ & $1.8 \%$ & $2.5 \%$ & $1.4 \%$ & $6.4 \%$ & $1.3 \%$ & $4.1 \%$ \\
\hline Participations per 1,000 researchers & & 8.2 & 3.6 & 5.8 & 6.7 & 6.9 & 4.3 & 6.6 \\
\hline
\end{tabular}

In total, $€ 22.4$ billion of EC funding has been requested through ERC proposals. Finland accounts for $3.4 \%$ ( $€ 761$ million) of this total; a higher amount than any of the comparator countries except for NL and SE. On average, Finnish participations requested $€ 1.82$ million each. This is above the $\mathrm{H} 2020$ average ( $€ 1.64$ million) and all comparators except NO.

Table 120 EC funding requests in ERC proposals - Finland and comparators - CBC

\begin{tabular}{|c|c|c|c|c|c|c|c|c|}
\hline & All & FI & AT & DK & IE & $\mathbf{N L}$ & NO & SE \\
\hline $\begin{array}{l}\text { EC funding requested in proposals } \\
(€ \text { million) }\end{array}$ & 22,422 & 761 & 425 & 603 & 333 & 1,508 & 332 & 984 \\
\hline$\%$ of all EC funding requested in proposals & $100 \%$ & $3.4 \%$ & $1.9 \%$ & $2.7 \%$ & $1.5 \%$ & $6.7 \%$ & $1.5 \%$ & $4.4 \%$ \\
\hline Average request per participation (€million) & 1.64 & 1.82 & 1.71 & 1.74 & 1.72 & 1.73 & 1.87 & 1.76 \\
\hline
\end{tabular}

\section{Participation in ERC CBC projects}

Finland's relatively high rate of ERC proposal activity in the CBC area has not fed through entirely into levels of project activity. Of the nearly 1,900 H2020 ERC grants awarded so 
far, just 36 have been to Finland. This $1.9 \%$ share of participations places Finland below all comparator countries except IE (1.2\%) and NO (0.6\%). Its rate of participations in ERC projects ( 0.7 per $1,000 \mathrm{R} \& \mathrm{D}$ personnel) is also below all comparator countries except NO.

Table 121 Participations in ERC projects - Finland and comparators - CBC

\begin{tabular}{|c|c|c|c|c|c|c|c|c|}
\hline & All & FI & AT & DK & IE & $\mathbf{N L}$ & NO & SE \\
\hline Number of participations in projects & 1,880 & 36 & 63 & 43 & 23 & 163 & 12 & 63 \\
\hline$\%$ of all participations in projects & $100 \%$ & $1.9 \%$ & $3.4 \%$ & $2.3 \%$ & $1.2 \%$ & $8.7 \%$ & $0.6 \%$ & $3.4 \%$ \\
\hline Participations per 1,000 researchers & & 0.70 & 0.92 & 0.72 & 0.80 & 1.30 & 0.29 & 0.75 \\
\hline
\end{tabular}

In total, $€ 2.8$ billion of EC funding has been awarded through ERC projects. Finland accounts for $2.2 \%$ ( $€ 62$ million) of this total - placing it below most of the comparator countries (except IE and NO). On average, Finnish participations in ERC projects have been awarded $€ 1.72$ million in EC funding contributions each. This is above the $\mathrm{H} 2020$ average ( $€ 1.48$ million), as well as above the averages in all comparator countries except NO.

Table 122 EC funding contributions to ERC project participations - Finland and comparators - CBC

\begin{tabular}{|c|c|c|c|c|c|c|c|c|}
\hline & All & $\mathrm{FI}$ & AT & DK & IE & NL & NO & SE \\
\hline EC funding contributions ( $€$ million) & 2,779 & 62 & 98 & 65 & 31 & 237 & 21 & 97 \\
\hline$\%$ of all EC funding contributions & $100 \%$ & $2.2 \%$ & $3.5 \%$ & $2.3 \%$ & $1.1 \%$ & $8.5 \%$ & $0.8 \%$ & $3.5 \%$ \\
\hline $\begin{array}{l}\text { Average contribution per participation } \\
\text { (€million) }\end{array}$ & 1.48 & 1.72 & 1.55 & 1.51 & 1.36 & 1.45 & 1.78 & 1.54 \\
\hline
\end{tabular}

\section{ERC Success rates - CBC}

Finland compares unfavourably with most comparators, both in terms of participation success rates and the proportion of requested funding that has been awarded. Only Norway has lower success rates amongst the comparator countries. This explains why the relatively high levels of proposal activity have not fed through into similar levels of ERC project activity.

Table 123 Success rates (participations and funding) in ERC-Finland and comparators - CBC

\begin{tabular}{|c|c|c|c|c|c|c|c|c|}
\hline & All & $\mathrm{FI}$ & AT & DK & IE & NL & NO & SE \\
\hline Participation success rates & $13.7 \%$ & $8.6 \%$ & $25.3 \%$ & $12.4 \%$ & $11.9 \%$ & $18.7 \%$ & $6.7 \%$ & $11.3 \%$ \\
\hline$\%$ of requested funding awarded & $12.4 \%$ & $8.1 \%$ & $23.0 \%$ & $10.8 \%$ & $9.4 \%$ & $15.7 \%$ & $6.4 \%$ & $9.9 \%$ \\
\hline
\end{tabular}

\section{Digitalisation}

\section{Participation in ERC Digitalisation proposals}

Finland's level of involvement in ERC Instrument proposals in the Digitalisation area compares favourably against nearly all comparator countries.

It has participated in $320 \mathrm{ERC}$ proposals, or $3.0 \%$ of all 10,712 participations so far. This is more than all comparator countries except for NL (5.6\%) and SE (3.3\%). Weighting proposal activity by taking account of the size of researcher populations, Fin-land's rate of participations in ERC proposals ( 6.2 per 1,000 R\&D personnel) is above all comparators.

Table 124 Participations in H2020 ERC proposals - Finland and comparators - Digitalisation

\begin{tabular}{|c|c|c|c|c|c|c|c|c|}
\hline & All & FI & AT & DK & IE & $\overline{\mathrm{NL}}$ & NO & SE \\
\hline Number of participations in proposals & 10,712 & 320 & 231 & 233 & 164 & 600 & 85 & 355 \\
\hline$\%$ of all participations in proposals & $100 \%$ & $3.0 \%$ & $2.2 \%$ & $2.2 \%$ & $1.5 \%$ & $5.6 \%$ & $0.8 \%$ & $3.3 \%$ \\
\hline Participations per 1,000 researchers & & $\overline{6.2}$ & 3.4 & 3.9 & 5.7 & 4.8 & 2.0 & 4.2 \\
\hline
\end{tabular}


In total, $€ 17.4$ billion of EC funding has been requested through ERC proposals. Finland accounts for $3.2 \%$ ( $€ 564$ million) of this total- a higher amount than any of the comparator countries except for NL (6.0\%) and SE (3.5\%). On average, Finnish participations requested $€ 1.8$ million each. This is above the $\mathrm{H} 2020$ average ( $€ 1.6$ million) and above all comparators except NO.

Table 125 EC funding requests in ERC proposals - Finland and comparators - Digitalisation

\begin{tabular}{|c|c|c|c|c|c|c|c|c|}
\hline & All & $\mathrm{FI}$ & AT & DK & IE & NL & NO & SE \\
\hline $\begin{array}{l}\text { EC funding requested in proposals } \\
(€ \text { million) }\end{array}$ & 17,430 & 564 & 377 & 395 & 272 & 1,043 & 166 & 608 \\
\hline $\begin{array}{l}\% \text { of all EC funding requested in } \\
\text { proposals }\end{array}$ & $100 \%$ & $3.2 \%$ & $2.2 \%$ & $2.3 \%$ & $1.6 \%$ & $6.0 \%$ & $1.0 \%$ & $3.5 \%$ \\
\hline $\begin{array}{l}\text { Average request per participation } \\
\text { (€million) }\end{array}$ & 1.63 & 1.76 & 1.63 & 1.69 & 1.66 & 1.74 & 1.95 & 1.71 \\
\hline
\end{tabular}

\section{Participation in ERC Digitalisation projects}

Finland's relatively high rate of ERC proposal activity has not entirely fed through into relatively high levels of project activity. Of the 1,560 H2020 ERC grants awarded so far, just 29 have been to Finland. This $1.9 \%$ share of participations is lower than four of the six comparators and only above IE and NO. Its rate of participations in ERC projects $(0.57$ per $1,000 R \& D$ personnel) is also below most comparators.

Table 126 Participations in ERC projects - Finland and comparators - Digitalisation

\begin{tabular}{|c|c|c|c|c|c|c|c|c|}
\hline & All & $\mathrm{FI}$ & AT & DK & IE & NL & NO & SE \\
\hline Number of participations in projects & 1,560 & 29 & 40 & 30 & 22 & 144 & 6 & 46 \\
\hline$\%$ of all participations in projects & $100 \%$ & $1.9 \%$ & $2.6 \%$ & $1.9 \%$ & $1.4 \%$ & $9.2 \%$ & $0.4 \%$ & $2.9 \%$ \\
\hline Participations per 1,000 researchers & & 0.57 & 0.59 & 0.51 & 0.76 & 1.15 & 0.14 & 0.55 \\
\hline
\end{tabular}

In total, $€ 2.2$ billion of EC funding has been awarded through ERC projects. Finland accounts for $2.0 \%$ ( $€ 43$ million) of this total - a lower amount than all comparator countries except for IE and NO. On average, Finnish participations in ERC projects have been awarded $€ 1.5$ million in EC funding contributions each. This is slightly above the $\mathrm{H} 2020$ average, but slightly below the averages in three of the comparator countries (DK, NL, NO).

Table 127 EC funding contributions to ERC project participations - Finland and comparators - Digitalisation

\begin{tabular}{|c|c|c|c|c|c|c|c|c|}
\hline & All & $\mathrm{FI}$ & AT & DK & IE & NL & NO & SE \\
\hline EC funding contributions (€million) & 2,201 & 43 & 52 & 46 & 24 & 218 & 12 & 63 \\
\hline$\%$ of all EC funding contributions & $100 \%$ & $2.0 \%$ & $2.4 \%$ & $2.1 \%$ & $1.1 \%$ & $9.9 \%$ & $0.6 \%$ & $2.9 \%$ \\
\hline $\begin{array}{l}\text { Average contribution per participation } \\
\text { (€million) }\end{array}$ & 1.41 & 1.49 & 1.29 & 1.52 & 1.11 & 1.51 & 2.02 & 1.38 \\
\hline
\end{tabular}

\section{ERC Success rates - Digitalisation}

Finland's success in ERC is below average, and below most comparator countries (except Norway), both in terms of participation success rates and the proportion of requested funding that has been awarded.

Table 128 Success rates (participations and funding) in ERC - Finland and comparators - Digitalisation

\begin{tabular}{|c|c|c|c|c|c|c|c|c|}
\hline & All & $\mathrm{FI}$ & AT & DK & IE & $\overline{N L}$ & NO & SE \\
\hline Participation success rates & $14.6 \%$ & $9.1 \%$ & $17.3 \%$ & $12.9 \%$ & $13.4 \%$ & $24.0 \%$ & $7.1 \%$ & $13.0 \%$ \\
\hline$\%$ of requested funding awarded & $12.6 \%$ & $7.7 \%$ & $13.7 \%$ & $11.5 \%$ & $9.0 \%$ & $20.9 \%$ & $7.3 \%$ & $10.4 \%$ \\
\hline
\end{tabular}




\section{Details of the semantic analysis}

The study has used semantic analysis to identify areas of FP7 and H2020 that are of relevance to the three selected priority areas: Health \& Wellbeing; Cleantech, Bioeconomy and Circular economy (CBC); and Digitalisation. Below, we explain the methodology for this analysis and provide summary tables that profile the locations within FP7/H2020 where we have identified relevant activity.

The aim was to identify and tag all FP7/H2020 projects and proposals that fall with each the three priority areas, regardless of where these are located within the FP7/H2020

programme structure. This sub-set of proposals and projects could then serve as the basis for analysis of Finnish (and comparator country) participation in each of the priority areas.

Cutting such large data sources thematically, at a level that is relevant to the topics of interest (and where these topics are only partially covered by standard classifications) is increasingly only possible with the use of more advanced data classification techniques. We have therefore built a tool that allows us to analyse the unstructured text from framework programme databases, to identify and tag key concepts and categories, and to select those of relevance to a given topic. The use of this semantic analysis approach is more powerful and sophisticated than a simple keyword search, allowing for more accurate identification of relevant parts of large datasets.

The identification and tagging was based on a semantic analysis of concepts contained within the titles and abstracts of proposals. We used proposal titles and abstracts rather than call titles and descriptions, as the latter can be too broad/imprecise and are also missing for certain parts of the programme (e.g. H2020 priority 1). The process was as follows:

- $\quad$ The title and abstract of all proposals submitted to FP7 and H2020 was extracted from the latest release of E-Corda and tagged using a semantic text analysis solution ('Dandelion').

- $\quad$ This tool 'reads' each title and abstract, analysing the words and their context, to identify a list of 5-20 key 'concepts' for each proposal (and tagging the proposal as such). These concepts are similar to keywords within the title and abstract, but also reflect the context in which each is mentioned.

- Having run this semantic analysis across all titles and abstracts, the tool then uses ontologies to organise these concepts into a smaller number of 'categories'. Most categories will relate to a number of related concepts, while individual concepts may be covered by one or more categories.

- $\quad$ The results are used to construct a database of concepts and categories identified across proposals.

- $\quad$ Based on the study team's understanding of the priority areas of interest, we built queries that search through this database and select categories of relevance to each priority area. (The associated concepts can help determine the relevance of a given category. Specific concepts can also be excluded from a selected category if irrelevant.). Lists of categories selected for each priority area are provided in the three tables below. 
The tool then produced a list of all proposals relevant to each priority area (i.e. those that were tagged against the selected categories and concepts). These results were then imported back into the full E-Corda databases (projects and proposals), as the basis for the profiling/analysis of participation in the three priority areas of interest.

Once the relevant proposals and projects within the eCORDA database were tagged against each of the three priority areas, some basic checks were undertaken to test the robustness of the semantic analysis and selection process. For instance, the distribution of identified projects across the sub-programmes of $\mathrm{H} 2020$ provided a quick visual check against broad a priori assumptions.

Table 129 Semantic analysis categories selected for the Health \& Wellbeing thematic area

\begin{tabular}{|c|c|}
\hline $\begin{array}{l}\text { Categories relating to general health and wellbeing, with a focus } \\
\text { on technology and devices }\end{array}$ & Categories relating to Digital Health \\
\hline $\begin{array}{ll}\text { - } & \text { Medical research } \\
\text { - } & \text { Medical technology } \\
\text { - } & \text { Biomedical engineering } \\
\text { - } & \text { Medical equipment } \\
\text { - } & \text { Medical monitoring } \\
\text { - } & \text { Medical robotics } \\
\text { - } & \text { Medical technology } \\
\text { - } & \text { Quality of life } \\
\text { - } \text { Biotechnology }\end{array}$ & $\begin{array}{l}\text { - Electronic health record software } \\
\text { - } \text { Electronic health records } \\
\text { - Health informatics } \\
\text { - Health informatics and eHealth associations } \\
\text { - Health information technology companies } \\
\text { - Health standards } \\
\text { - Healthcare software } \\
\text { - } \text { Telehealth } \\
\text { - } \text { Cardiac imaging } \\
\text { - } \text { Migestive system imaging } \\
\text { - Magnetic resonance imaging } \\
\text { - } \text { Redical imaging } \\
\text { - Urologic imaging } \\
\text { - } \text { Biotechnology databases } \\
\text { - Cancer genome databases } \\
\text { - } \text { Clinical data management } \\
\text { - Medical databases } \\
\text { Metabolomic databases }\end{array}$ \\
\hline
\end{tabular}

Table 130 Semantic analysis categories selected for the Cleantech, Bioeconomy and Circular economy (CBC) thematic area

\begin{tabular}{|c|c|c|}
\hline \multicolumn{2}{|l|}{ Categories relating to Bioeconomy } & \multirow{2}{*}{$\begin{array}{ll}\text { Categories relating to } \\
\text { Renewable energy } \\
\text { - Renewable energy } \\
\text { - Renewable energy } \\
\text { commercialisation } \\
\text { Renewable energy } \\
\text { technology } \\
\text { - Renewable energy policy } \\
\text { - Renewable fuels } \\
\text { - Renewable resources } \\
\text { - Recycling } \\
\text { - Recycling by material }\end{array}$} \\
\hline $\begin{array}{l}\text { - Agricultural economics } \\
\text { - Animal cells } \\
\text { - Animal disease control } \\
\text { - Animal diseases } \\
\text { - Animal fats } \\
\text { - Animal feed } \\
\text { - Animal fungal diseases } \\
\text { - Animal genes } \\
\text { - Animal glandular products } \\
\text { - Animal husbandry } \\
\text { - Animal reproductive system } \\
\text { - Animal welfare } \\
\text { - Anthrozoology } \\
\text { - Applied and interdisciplinary physics } \\
\text { - } \text { Appropriate technology } \\
\text { - Biochemical engineering } \\
\text { - Biochemistry } \\
\text { - Biocybernetics } \\
\text { - Bioenergy } \\
\text { - Biofuels } \\
\text { - Biologicormatics } \\
\text { - Biomass } \\
\text { - Biomaterials } \\
\text { - Biomineralisation } \\
\text { - Biophysics } \\
\text { Bioreactors }\end{array}$ & 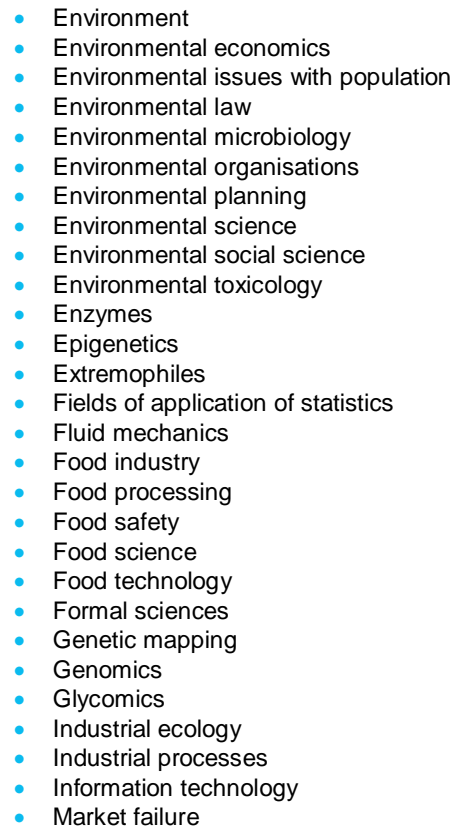 & \\
\hline
\end{tabular}




\begin{tabular}{|c|c|}
\hline $\begin{array}{l}\text { - } \text { Biostatistics } \\
\text { - } \text { Biotechnology } \\
\text { - } \text { Branches of biology of botany } \\
\text { - Carbohydrate chemistry } \\
\text { - Carbohydrates } \\
\text { - Catalysts } \\
\text { - Chemical biology } \\
\text { - Chemical engineering } \\
\text { - Chemical structures } \\
\text { - Chemical synthesis } \\
\text { - Chemistry } \\
\text { - Community ecology } \\
\text { - Computational biology } \\
\text { - } \text { Demography } \\
\text { - Ecological experiments } \\
\text { - Emerging technologies }\end{array}$ & $\begin{array}{l}\text { - Mathematical and theoretical biology } \\
\text { - } \text { Microbiology } \\
\text { - } \text { Molecular biology } \\
\text { - } \text { Molecular genetics } \\
\text { - } \text { Omics } \\
\text { - Plant physiology } \\
\text { - Population } \\
\text { - Population ecology } \\
\text { - Production and manufacturing } \\
\text { - Protein engineering } \\
\text { - Protein structure } \\
\text { - Proteins } \\
\text { - Proteomics } \\
\text { - Soil science } \\
\text { - Structural biology } \\
\text { - Subfields of ecology } \\
\text { - Sugar } \\
\text { - Synthetic biology }\end{array}$ \\
\hline
\end{tabular}

Table 131 Semantic analysis categories selected for the Digitalisation thematic area

\begin{tabular}{|c|c|}
\hline Categories relating to Robotics & Categories relating to $\mathrm{Al} /$ data science \\
\hline $\begin{array}{ll}\text { - } & \text { Healthcare robotics } \\
\text { - } & \text { Redical robotics } \\
\text { - } & \text { Robotic sensing } \\
\text { - } & \text { Robot control } \\
\text { - } & \text { Robot kinematics } \\
\text { - } & \text { Robot navigation } \\
\text { - } & \text { Robot locomotion } \\
\text { - } & \text { Robotic manipulation } \\
\text { - Robotics }\end{array}$ & $\begin{array}{l}\text { - } \text { Machine learning } \\
\text { - } \text { Artificial intelligence } \\
\text { - } \text { Big data } \\
\text { - } \text { Data mining } \\
\text { - } \text { Automatic identification and data capture } \\
\text { - } \text { Classification algorithms } \\
\text { - } \text { Predictive modelling [concept] } \\
\text { - } \text { Business intelligence } \\
\text { - Cloud computing }\end{array}$ \\
\hline Categories relating to Other areas of computing & Categories relating to ICT in society / learning \\
\hline $\begin{array}{l}\text { - } \text { Cluster computing } \\
\text { - } \text { Concurrent computing } \\
\text { - } \text { Distributed computing architecture } \\
\text { - } \text { Grid computing } \\
\text { - Parallel computing } \\
\text { - Reconfigurable computing } \\
\text { - Supercomputing } \\
\text { - Quantum computing }\end{array}$ & 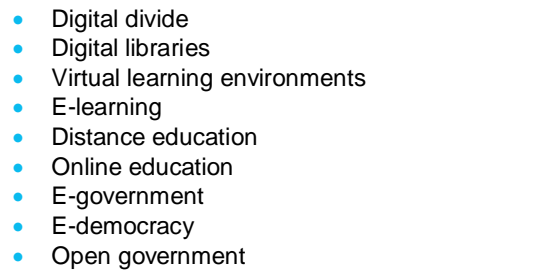 \\
\hline Categories relating to ICT in media & Categories relating to Cybersecurity \\
\hline $\begin{array}{l}\text { - Digital media } \\
\text { - Augmented reality } \\
\text { - Augmented reality applications }\end{array}$ & $\begin{array}{l}\text { - } \text { Computer security } \\
\text { - Information privacy } \\
\text { - Hacking (computer security) } \\
\text { - } \text { Cyberwarfare } \\
\text { - } \text { Cybercrime } \\
\text { - Information privacy }\end{array}$ \\
\hline \multicolumn{2}{|l|}{ Categories relating to Industry 4.0} \\
\hline $\begin{array}{l}\text { - Photonics } \\
\text { - Sensors } \\
\text { - Electronics }\end{array}$ & $\begin{array}{l}\text { - Industrial automation } \\
\text { - Advanced manufacturing } \\
\text { - Internet of Things }\end{array}$ \\
\hline
\end{tabular}

In the tables below we profile the locations within $\mathrm{FP} 7 / \mathrm{H} 2020$ where we have identified areas of relevance to the three priority topics. These tables show the overall funding provided to each sub-programme of FP7/H2020, as well as the amount and proportion of this accounted for by projects tagged within each of the three priority areas. This provides an overview of both the distribution and scale of relevant activity (i.e. where across FP programmes has relevant activity taken place and how significant is this within the wider portfolio of projects). Shading has been used to highlight the main concentrations of relevant activity - either in absolute terms, or relative to the overall size of each subprogramme. 


\section{List of programmes and sub-programmes}

Figure 13 FP7 programmes and sub-programmes

\begin{tabular}{lll}
\hline Programme & $\begin{array}{l}\text { Sub-programme } \\
\text { Acronym }\end{array}$ & Sub-programme Title \\
\hline & HEALTH & Health \\
\cline { 2 - 3 } & KBBE & Food, Agriculture, and Biotechnology \\
\cline { 2 - 3 } & ICT & Information and Communication Technologies \\
\cline { 2 - 3 } & NMP & Nanosciences, Nanotechnologies, Materials and new Production Technologies \\
\cline { 2 - 3 } ENEPERATION & ENERG & Energy \\
\cline { 2 - 3 } & ENV & Environment (including Climate Change) \\
\cline { 2 - 3 } & TPT & Transport (including Aeronautics) \\
\cline { 2 - 3 } & SSH & Socio-economic sciences and Humanities \\
\cline { 2 - 3 } & SPA & Space \\
\cline { 2 - 3 } & SEC & Security \\
\cline { 2 - 3 } & GA & General Activities (Annex IV) \\
\hline IDEAS & ERC & Joint Technology Initiatives (Annex IV-SP1) \\
\hline PEOPLE & PEOPLE & European Research Council \\
\hline \multirow{3}{*}{ CAPACITIES } & Marie-Curie Actions \\
\cline { 2 - 3 } & INFRA & Research Infrastructures \\
\cline { 2 - 3 } & SME & Research for the benefit of SMEs \\
\cline { 2 - 3 } & REGIONS & Regions of Knowledge \\
\cline { 2 - 3 } & REGPOT & Research Potential \\
\cline { 2 - 3 } & SiS & Science in Society \\
\cline { 2 - 3 } & COH & Coherent development of research policies \\
\hline \multirow{2}{*}{ Euratom } & INCO & Activities of International Cooperation \\
\cline { 2 - 3 } & Fusion & Fusion Energy \\
\hline & Fission & Nuclear Fission and Radiation Protection \\
\hline & & \\
\hline
\end{tabular}

Figure 14 H2020 programmes and sub-programmes

\begin{tabular}{|c|c|c|}
\hline Programme & $\begin{array}{l}\text { Sub-programme } \\
\text { Acronym }\end{array}$ & Sub-programme Title \\
\hline \multirow{5}{*}{$\begin{array}{l}\text { Excellent } \\
\text { Science }\end{array}$} & EXCSCI-CROSST & Excellent Science - Cross-theme \\
\hline & ERC & European Research Council \\
\hline & FET & Future and Emerging Technologies \\
\hline & MSCA & Marie Sklodowska-Curie actions \\
\hline & INFRA & Research infrastructures \\
\hline \multirow{10}{*}{$\begin{array}{l}\text { Industrial } \\
\text { Leadership }\end{array}$} & INDLEAD-CROSST & Industrial Leadership - Cross-theme \\
\hline & LEIT & Leadership in enabling and industrial technologies (LEIT) \\
\hline & ICT & Information and Communication Technologies \\
\hline & NMP & Nanotechnologies, Advanced Materials and Production \\
\hline & ADVMAT & Advanced materials \\
\hline & BIOTECH & Biotechnology \\
\hline & ADVMANU & Advanced manufacturing and processing \\
\hline & SPACE & Space \\
\hline & RISKFINANCE & Access to risk finance \\
\hline & SME & Innovation in SMEs \\
\hline \multirow{8}{*}{$\begin{array}{l}\text { Societal } \\
\text { Challenges }\end{array}$} & SOCCHAL-CROSST & Societal Challenges - Cross-theme \\
\hline & HEALTH & Health, demographic change and wellbeing \\
\hline & FOOD & $\begin{array}{l}\text { Food security, sustainable agriculture and forestry, marine and maritime and inland } \\
\text { water research }\end{array}$ \\
\hline & ENERGY & Secure, clean and efficient energy \\
\hline & TPT & Smart, green and integrated transport \\
\hline & ENV & Climate action, environment, resource efficiency and raw materials \\
\hline & SOCIETY & Europe in a changing world - inclusive, innovative and reflective Societies \\
\hline & SECURITY & Secure societies - Protecting freedom and security of Europe and its citizens \\
\hline \multirow{7}{*}{$\begin{array}{l}\text { Spreading } \\
\text { excellence and } \\
\text { widening } \\
\text { participation }\end{array}$} & SEAWP-CROSST & Spreading excellence and widening participation - Cross-theme \\
\hline & WIDESPREAD & Teaming of excellent research institutions and low performing RDI regions \\
\hline & TWINING & Twinning of research institutions \\
\hline & ERA & ERA chairs \\
\hline & PSF & Policy Support Facility (PSF) \\
\hline & INTNET & Supporting access to international networks \\
\hline & NCPNET & Transnational networks of National Contact Points \\
\hline \multirow{9}{*}{$\begin{array}{l}\text { Science with } \\
\text { and for Society }\end{array}$} & SWAFS-CROSST & Science with and for Society - Cross-theme \\
\hline & CAREER & Make scientific and technological careers attractive for young people \\
\hline & GENDEREQ & Promote gender equality in research and innovation \\
\hline & INEGSOC & Integrate society in science and innovation \\
\hline & SCIENCE & Encourage citizens to engage in science \\
\hline & RESACCESS & Develop the accessibility and the use of the results of publicly-funded research \\
\hline & GOV & $\begin{array}{l}\text { Develop the governance for the advancement of responsible research and } \\
\text { innovation }\end{array}$ \\
\hline & IMPACT & Anticipating and assessing potential environmental, health and safety impacts \\
\hline & KNOWLEDGE & Improve knowledge on science communication \\
\hline Euratom & EURATOM & Euratom \\
\hline EC & CROSST & Cross-theme \\
\hline
\end{tabular}




\section{APPENDIX B: STAKEHOLDER INTERVIEWS}

Summary of the stakeholder interviews

\begin{tabular}{|c|c|c|}
\hline Question/Theme & Summarized statements & Quotes/Notes \\
\hline $\begin{array}{l}\text { How important is EU RDI to } \\
\text { Finnish competitiveness in } \\
\text { general? }\end{array}$ & $\begin{array}{l}\text { EU funding is important enabler of international } \\
\text { collaboration and networking } \\
\text { EU FPs set a standard for both business and } \\
\text { research performance } \\
\text { Participation raises the visibility and reputation } \\
\text { of Finnish industry and research in Europe } \\
\text { FP creates opportunities for innovation through } \\
\text { opening new networks and markets } \\
\text { As national RDI is waning, EU FPs are } \\
\text { becoming more important especially for } \\
\text { research organisations }\end{array}$ & $\begin{array}{l}\text { Vs. the voice from the industry: } \\
\text { "Not the most important factor in the wide } \\
\text { view, TEKES funding is better in everything, } \\
\text { with more flexibility, less competition, shorter } \\
\text { lead times, favourable funding terms." }\end{array}$ \\
\hline $\begin{array}{l}\text { What are the main benefits } \\
\text { of EU Framework } \\
\text { Programmes? Do you have } \\
\text { specific examples? }\end{array}$ & $\begin{array}{l}\text { Specific benefits are institutional and personal } \\
\text { contacts and networks, that can be leveraged } \\
\text { in future collaboration } \\
\text { - enables PPPP type collaboration } \\
\text { - Developing existing contacts to deeper } \\
\text { collaborations } \\
\text { - EU funding is of especially beneficial for } \\
\text { researchers' career (Pillar I/ERC specifically) } \\
\text { Participation in FPs and surrounding } \\
\text { collaboration networks enables influencing } \\
\text { direction of research and technology } \\
\text { development } \\
\text { - networks that work in and around FP also } \\
\text { often work on standards and are consulted in } \\
\text { regulation matters } \\
\text { Participation in EU FPs develops strategic } \\
\text { thinking } \\
\text { - The application process that forces setting } \\
\text { specific long-term goals and thinking about the } \\
\text { impact is beneficial for the applicants } \\
\text { Pillar I/ERC funding has enabled research that } \\
\text { is not possible with national funding } \\
\text { - critical mass of resources } \\
\text { - long-term and strategic and/or risky research } \\
\text { - Specifically, for researchers, high-quality } \\
\text { publications and the prestige of attaining } \\
\text { EU/ERC funding } \\
\text { Effect to aligning RDI policies between } \\
\text { Member States is more an objective than } \\
\text { reality } \\
\text { - too little resources to proactively plan and } \\
\text { prepare proposals }\end{array}$ & \\
\hline $\begin{array}{l}\text { Do EU FPs have negative } \\
\text { effects? }\end{array}$ & $\begin{array}{l}\text { Massive consortia and partnership can form } \\
\text { inefficiency and in fact hinder innovation } \\
\text { - undertakings where incumbent MNEs are in } \\
\text { charge can be used to sandbag and steer } \\
\text { innovation to stay in the comfort zone of the } \\
\text { incumbents } \\
\text { - Very large projects and consortia (up } 10 \\
\text { million and } 40 \text { participants) tend to be } \\
\text { inefficient and too broad for concrete RDI. } \\
\text { Too strong concern in relatively short term } \\
\text { 'impact' risks overt focus on short terms } \\
\text { fashionable RDI topics } \\
\text { Bureaucracy and complex application } \\
\text { procedure } \\
\text { - complex and lengthy technical reports eat up } \\
\text { resources from the actual substantive work } \\
\text { - Very low success rate in many of the } \\
\text { programs wastes resources and raises } \\
\text { threshold for applying }\end{array}$ & $\begin{array}{l}\text { "FP funding has a greater benefit than the } \\
\text { nominal output, because the formation of } \\
\text { networks and the merit value" } \\
\text { Of application consultants: "have we really } \\
\text { had the best ideas [in the programme] or } \\
\text { wrote something to humour the funders?" }\end{array}$ \\
\hline
\end{tabular}




\begin{tabular}{|c|c|c|}
\hline Question/Theme & Summarized statements & Quotes/Notes \\
\hline & $\begin{array}{l}\text { Entry of EU consultants into the application } \\
\text { arena is a concern } \\
\text { Specifically, in research ERC grant has gained } \\
\text { slightly too much weight as recruitment criteria } \\
\text { Pitting "research" and "innovation" against } \\
\text { each other } \\
\text { - false dichotomy that leads into squabbling } \\
\text { over budget } \\
\text { - signals lack of vision and long term thinking }\end{array}$ & \\
\hline $\begin{array}{l}\text { What are the main impact } \\
\text { mechanisms of EU FPs? }\end{array}$ & $\begin{array}{l}\text { Internationalisation } \\
\text { Network formation } \\
\text { - enables further collaboration } \\
\text { - collaborative projects bring new actor } \\
\text { combinations; new value chains (SMEs and } \\
\text { large enterprises), solving technological } \\
\text { problems and setting directions (large } \\
\text { enterprises and research institutions), } \\
\text { spreading solutions and finding new markets } \\
\text { (international networks) } \\
\text { Modest- moderate effect to themes in national } \\
\text { RDI policy } \\
\text { Developing critical mass around specific topics } \\
\text { to create significant advancements } \\
\text { - pooling of interests, skills, knowledge and } \\
\text { infrastructure together (4) } \\
\text { Direct career advancement for researchers } \\
\text { - merit badge/cache/halo effect from receiving } \\
\text { ERC grant } \\
\text { - enables access to networks and } \\
\text { infrastructures } \\
\text { - international visibility (2) }\end{array}$ & $\begin{array}{l}\text { People are driven by their own incentives, not } \\
\text { only EU programming }\end{array}$ \\
\hline $\begin{array}{l}\text { What is the relationship } \\
\text { between EU and national } \\
\text { RDI funding? }\end{array}$ & $\begin{array}{l}\text { Generally national and EU funding complement } \\
\text { each other } \\
\text { - national funding enables addressing issues in } \\
\text { specific national context } \\
\text { - EU funding brings EU level added value and } \\
\text { internationalisation (3) } \\
\text { - Larger problem is competition between } \\
\text { Finnish actors within programs } \\
\text { - No harmful overlaps, rather national } \\
\text { programs have in the past been helpful in } \\
\text { building the competence necessary to be a } \\
\text { serious partner in the EU } \\
\text { - While in principle there is a continuum, in } \\
\text { practice researchers apply money from every } \\
\text { outlet that somehow fits the programme } \\
\text { Influence between programs is more incidental } \\
\text { and happens through higher level policy } \\
\text { making than purposive coordinated } \\
\text { programming } \\
\text { - there are incidental gaps and mismatches } \\
\text { Potential top applicants are reluctant to apply } \\
\text { for EU funding (both industry and academia) } \\
\text { - Is national funding too convenient and easy? } \\
\text { - individual and organisational incentives } \\
\text { - Earlier SHOKs contributed to developing } \\
\text { projects towards FP7/Horizon } 2020 \text { vs. SHOKs } \\
\text { took attention away from FP7 and capacity } \\
\text { building for Horizon } 2020 \text { was lost } \\
\text { - AKA has the process figured, they identify } \\
\text { potential applicants and coach them from the } \\
\text { start towards ERC } \\
\text { In Pillar I, there is a clear continuum from } \\
\text { national to EU funding } \\
\text { - in research "98\%" of fundees have previously } \\
\text { been raised on national money }\end{array}$ & $\begin{array}{l}\text { "MEE/TEKES has woken up half way through } \\
\text { Horizon } 2020 \text { to think about the relationship } \\
\text { between their own instruments and FP" } \\
\text { "At some point the thinking was that we do } \\
\text { some things nationally and some in the EU, } \\
\text { but the error is that unless you have built the } \\
\text { base in national programs, you can't get into } \\
\text { the projects. You can just walk into the EU, } \\
\text { the RDI is on a different level." }\end{array}$ \\
\hline $\begin{array}{l}\text { How should the EU FPs be } \\
\text { developed in the future }\end{array}$ & $\begin{array}{l}\text { The 3-Pillar structure is functional and familiar } \\
\text { - development should follow stable and } \\
\text { predictable trajectory } \\
\text { Further simplification and streamlining }\end{array}$ & $\begin{array}{l}\text { "All the time there has been talk of } \\
\text { simplification. When one thing has been } \\
\text { streamlined, something else has become } \\
\text { more complex" }\end{array}$ \\
\hline
\end{tabular}




\begin{tabular}{|c|c|c|}
\hline Question/Theme & Summarized statements & Quotes/Notes \\
\hline & 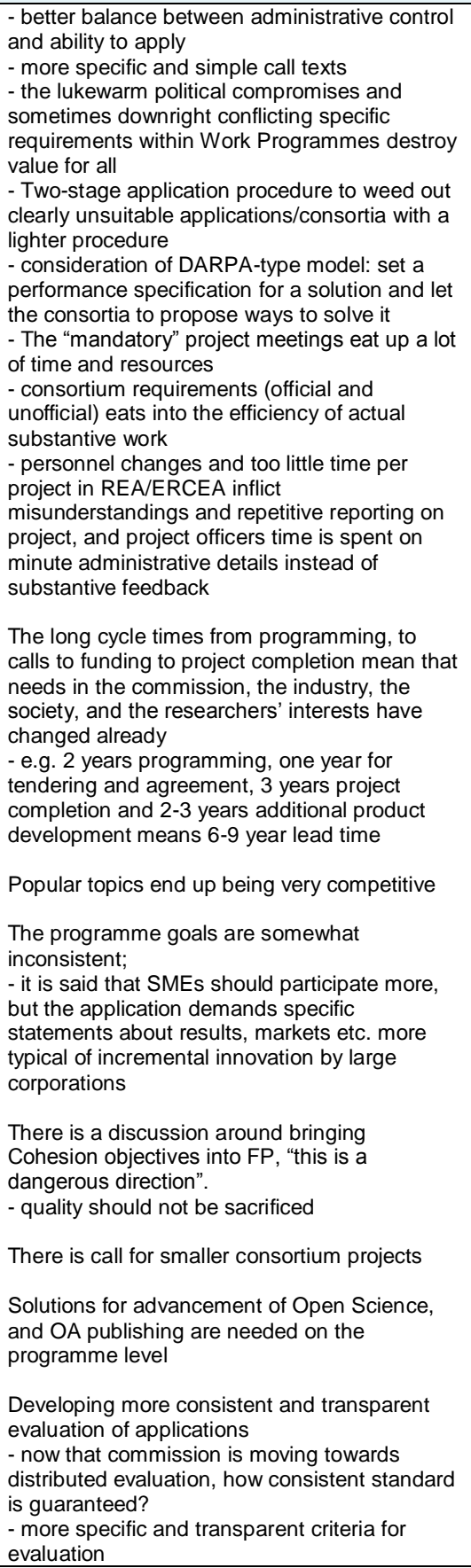 & $\begin{array}{l}\text { - Rather blacklist applicants than increase } \\
\text { financial control? } \\
\text { "There are too many last ditch applications in } \\
\text { the process (both nationally and at EU level)" } \\
\text { Ability to use time and resources on } \\
\text { preparation of application and related travel is } \\
\text { in short order in present efficiency focus }\end{array}$ \\
\hline $\begin{array}{l}\text { How should the national } \\
\text { procedures for } \\
\text { preparing/supporting EU } \\
\text { RDI }\end{array}$ & $\begin{array}{l}\text { NCP activities should be built-up } \\
\text { - NCPs handle their duties on the side with } \\
\text { very small resources, all other obligations are } \\
\text { prioritized } \\
\text { - more active and targeted hands-on } \\
\text { information and application support is called for } \\
\text { - other countries' NCPs produce actual } \\
\text { programme and application guides and other } \\
\text { materials } \\
\text { - Culture of openness has much improved, e.g. } \\
\text { Working Programme drafts are openly shared } \\
\text { - There is need for more information and } \\
\text { opportunity recognition in the field } \\
\text { - "One stop shop is needed for RDI funding" } \\
\text { - Also, other agency employees than NCPs } \\
\text { should be able to recognise possibilities for } \\
\text { Complementary funding is problematic and } \\
\text { there's little evidence of effectiveness } \\
\text { - TEKES "encouragement funding" for } \\
\text { applications that have above threshold score in } \\
\text { REA evaluation is well-liked, as is AKA/SRC } \\
\text { overhead subsidy by the applicants }\end{array}$ & $\begin{array}{l}\text { "Finnish success would be much greater if } \\
\text { pre-award investment would be systematic } \\
\text { and sufficient. Even the most successful } \\
\text { organisations lack strategic view to funding } \\
\text { instruments and clear goals. Pressure for } \\
\text { application should be considerably increased } \\
\text { with incentives" } \\
\text { On pre-award funding and support: } \\
\text { "When funding the application process the } \\
\text { only guarantee is that the funds will be used" } \\
\text { "We have quit our internal application funding } \\
\text { because the observation that only those } \\
\text { applied who were not going to get funded by } \\
\text { the EU in the first place" } \\
\text { vs. } \\
\text { "preparation could be so much more than just } \\
\text { writing applications, but we don't have } \\
\text { resources for proactive partnering and } \\
\text { preparation" }\end{array}$ \\
\hline
\end{tabular}




\begin{tabular}{|c|c|c|}
\hline Question/Theme & Summarized statements & Quotes/Notes \\
\hline & $\begin{array}{l}\text { - Subsidies for application process seem to } \\
\text { have little effect on application success } \\
\text { National level strategy is needed } \\
\text { - There is a call for an umbrella strategy to } \\
\text { enable relevant actors to see where everyone } \\
\text { else stands and enable concerted lobbying } \\
\text { - An overarching and stable Finnish strategy is } \\
\text { needed so actors can position themselves, and } \\
\text { for effective proactive lobbying } \\
\text { - Finnish positions are prepared by individual } \\
\text { civil servants or by committee members on an } \\
\text { ad hoc basis besides their other jobs, there } \\
\text { seems to be very little process looking from the } \\
\text { outside } \\
\text { - The process and results are detached from } \\
\text { the field, EU20 stakeholder and expert } \\
\text { consultations are limited and PC members rely } \\
\text { on their own networks } \\
\text { - Finland is well represented in different } \\
\text { decision-making bodies, but there's a lack of } \\
\text { coherent message } \\
\text { - There should be a structured process to } \\
\text { identify the best national competence and } \\
\text { focus the national strategy around those } \\
\text { - Lack of basic trust and informal cooperation } \\
\text { that creates it in between ministries and } \\
\text { agencies, as well as other actors } \\
\text { - The preparation for FPs and individual Work } \\
\text { Programmes should adopt a more proactive } \\
\text { stance, based on national policy goals and } \\
\text { honest recognition of strengths } \\
\text { - Good basics, for example motivated, and } \\
\text { well-educated and networked people, are the } \\
\text { best investment into success in the long run. } \\
\text { Low acceptance rates are a serious frustration } \\
\text { and disincentive for applicants } \\
\text { The synergy between ERDF/ESF funding and } \\
\text { FP should be explored further } \\
\text { - could be used better to develop ecosystems } \\
\text { in regions } \\
\text { The role of application consultants is } \\
\text { somewhat problematic } \\
\text { - adds to system level inefficiency } \\
\text { - however, they help in communicating ideas } \\
\text { - possible role as a network builder }\end{array}$ & $\begin{array}{l}\text { "It would be ideal that TEKES programme } \\
\text { personnel could coach applicant directly" } \\
\text { Developing common goals is very difficult, for } \\
\text { individual organisations and individual actors, } \\
\text { it sometimes makes sense to compete on the } \\
\text { same calls, as Finnish contribution effectively } \\
\text { is fixed and thus individuals want to risk } \\
\text { getting all or nothing. } \\
\text { "a national strategy is a good idea, BUT, if it's } \\
\text { a top down effort it'll take forever and if it's a } \\
\text { bottom up effort it'll be not accepted in the } \\
\text { top. Involving RIC is a good idea, but the } \\
\text { process needs an owner, if people are } \\
\text { preparing it on the side, it just doesn't work" } \\
\text { National level services tend to become } \\
\text { inflexible and bureaucratic. } \\
\text { How deep is the bench, do the national } \\
\text { mechanisms produce applicants? "when } \\
\text { every qualified applicant is funded, do we } \\
\text { have more" } \\
\text { "Not all potential top applicant use time for } \\
\text { applying to EU funding, since national funding } \\
\text { is easier" } \\
\text { There is a need for job circulation between } \\
\text { ME create understanding of procedures and } \\
\text { create mutual trust } \\
\text { "Finnish position in EU has been weakened } \\
\text { because of lack of national strategy" } \\
\text { haven't seen the possibilities" } \\
\text { board, many good project proposals have } \\
\text { "It is a problem if two of the largest national } \\
\text { RDI funders can't stand behind the national } \\
\text { position paper"' } \\
\text { "EU20 should prepare positions ... but it } \\
\text { doesn't, they just accept drafts presented to } \\
\text { them" } \\
\text { The field is lacking a big picture of various } \\
\text { instruments and funding schemes, and the } \\
\text { application schedules } \\
\text { RDI subsidies are used to supplement lacking } \\
\text { basic funding, not as a leverage to create } \\
\text { something bigger } \\
\end{array}$ \\
\hline Other & $\begin{array}{l}\text { Enterprises lack vision and strategic thinking } \\
\text { and knowledge/understanding of the } \\
\text { possibilities } \\
\text { - pervasive lack in long term thinking and } \\
\text { commitment to innovation } \\
\text { - there is a lack of capacity to operate } \\
\text { internationally } \\
\text { - old incumbents invest little in innovation, } \\
\text { while } \\
\text { - SMEs have a limited role in employment and } \\
\text { economy, barring some isolated examples } \\
\text { Multidisciplinary applications fall through the } \\
\text { cracks in evaluation }\end{array}$ & \\
\hline
\end{tabular}

The table is a summary of the interviews, coded into statements using a bottom-up content analysis approach. 


\section{APPENDIX C: STAKEHOLDER SURVEYS}

\section{Expert survey}

A Finnish language survey was sent on 18 May 2017 to 210 experts. All together 60 responses were received giving a response rate of $29 \%$.

Highest numbers of responses are from agency representatives (18) and from higher education institutes (HEIs) (18, combined of respondents from universities and universities of applied sciences (UAS)). Of all respondents, 43 are in an expert position (17 of them in programme committees) and 21 have a liaison role within the organisation they represent, couple of respondents have both of the roles. On average respondents assessed their knowledge of framework programmes fairly well, a median value being 4 on a scale of 1 to 5 for both $\mathrm{H} 2020$ and previous FPs.

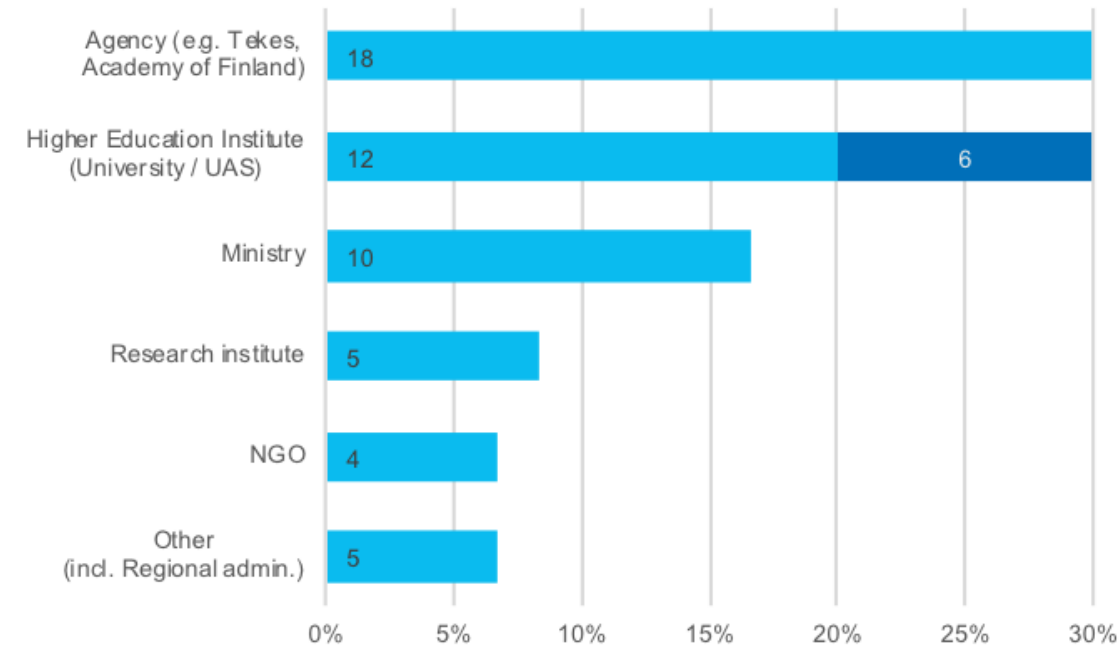

Figure 15 Breakdown of the expert survey respondents. $N=60$

\section{The added value of framework programmes}

As Figure 16 shows, respondents mainly agree with the proposed suggestions on the overall added value of FPs. On the scale from 1 (strongly disagree) to 5 (strongly agree), 20 out of 59 strongly agree and 25 agree that FPs have enabled larger and higher volume of implementation of RDI-activities (giving and average value of 4.1 out of 5). Respondents also consider FPs to have a high additionality for their projects. Out of 59 respondents 15 strongly agree, 27 agree that FPs have led to the RDI-activities that would not have been possible without FP funding. On the other hand, respondents least agree with the claim that FPs have enabled faster implementation of RDI-activities, together only 18 either agree or strongly agree. 


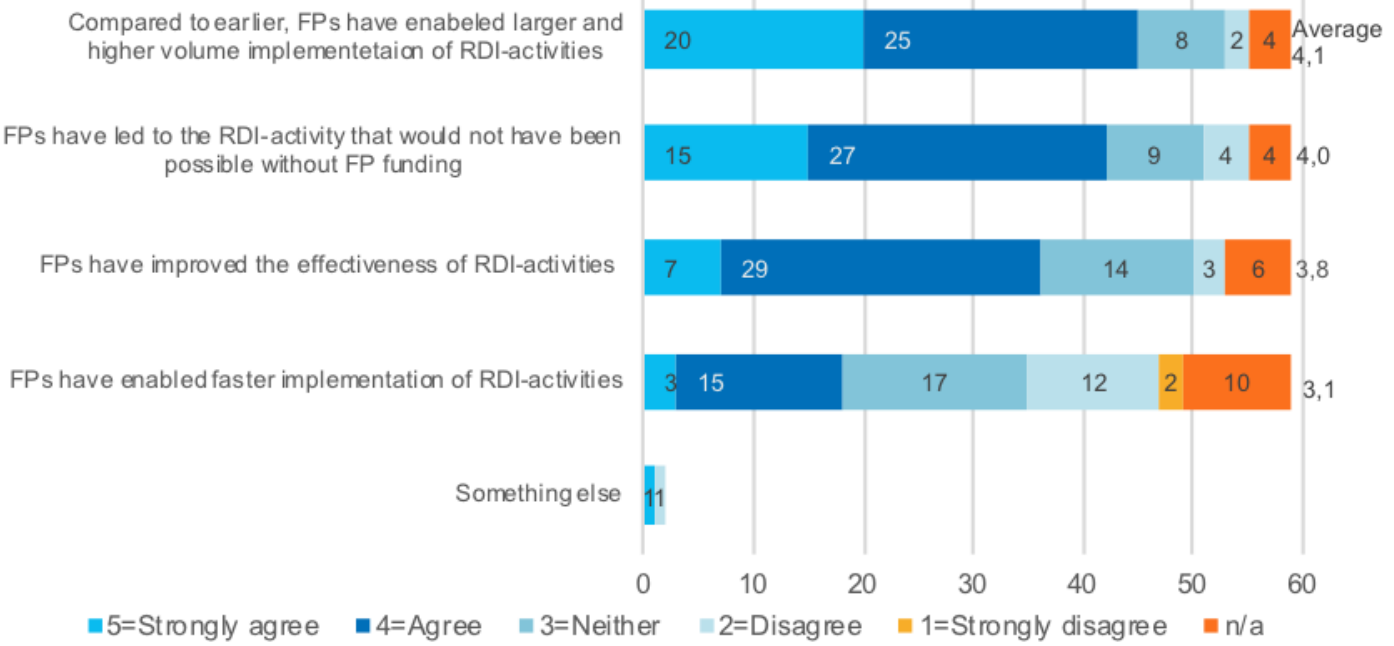

Figure 16 Do you agree with the following overall added value of FPs? N=59

Respondents were also asked to assess the added value of FPs on thematically. As the Figure 17 below shows, respondents consider the FPs to have fairly significant added value on a number of proposed themes. The main added value lies on strengthening international networks. Most of the respondents consider FPs to have either highly significant (44) or significant (13) added value in strengthening international networks, with a lowest significance in strengthening national networks ( 3 and 22 respectively). The second highest added value lies on the availability of funding and third, on identification of common challenges.

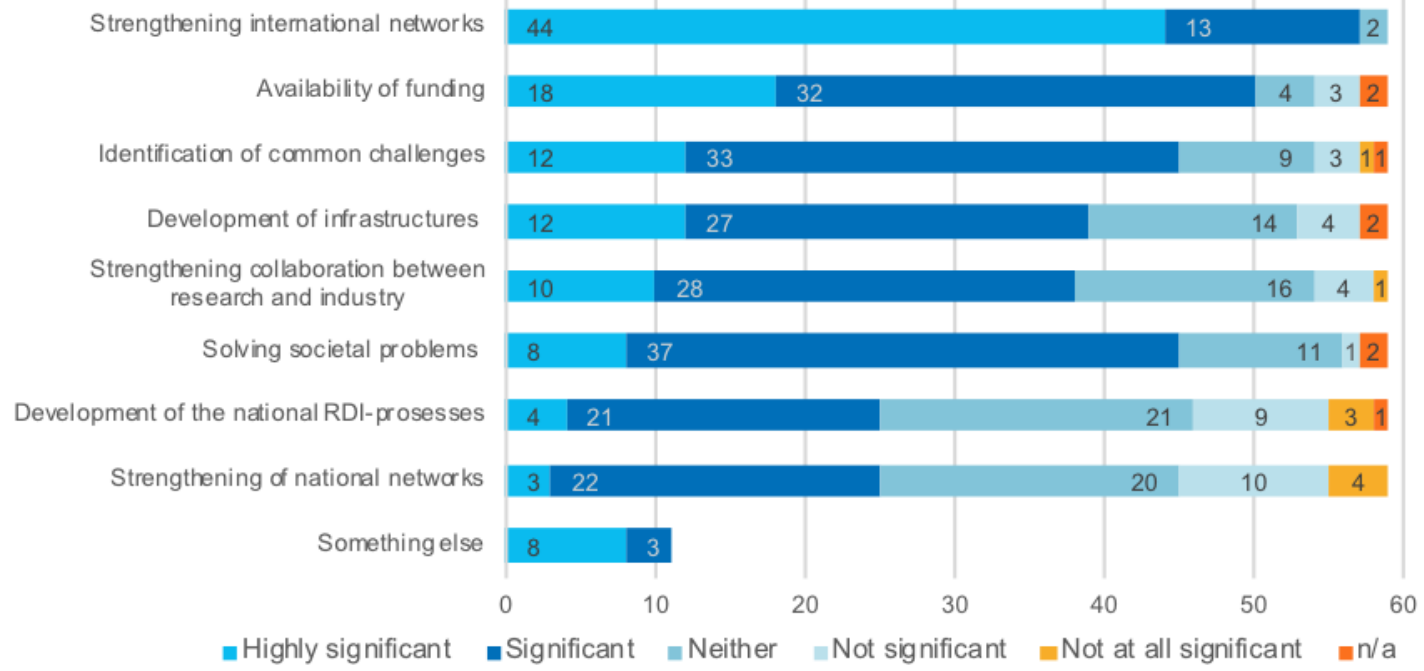

Figure 17 How significant you consider the added value created by the EU Research and Innovation Framework Programme to the following themes? $N=59$

\section{The impact of framework programmes}

Respondents were asked to take a stand on FPs impact on specific issues and thematically on the private sector and their international competitiveness as well as on research.

As the Figure 18 shows, a relatively high number of respondents do not consider FPs to have any type of impact on listed overall results. The greatest impact, however, the respondents either strongly agree (7) or agree (23) is on advancing the development of PPP models and on bringing new themes into the Finnish RDI-policy ( 3 and 27 respectively). On 
the other hand, FPs have least impact on harmonising RDI-policies of different national actors.

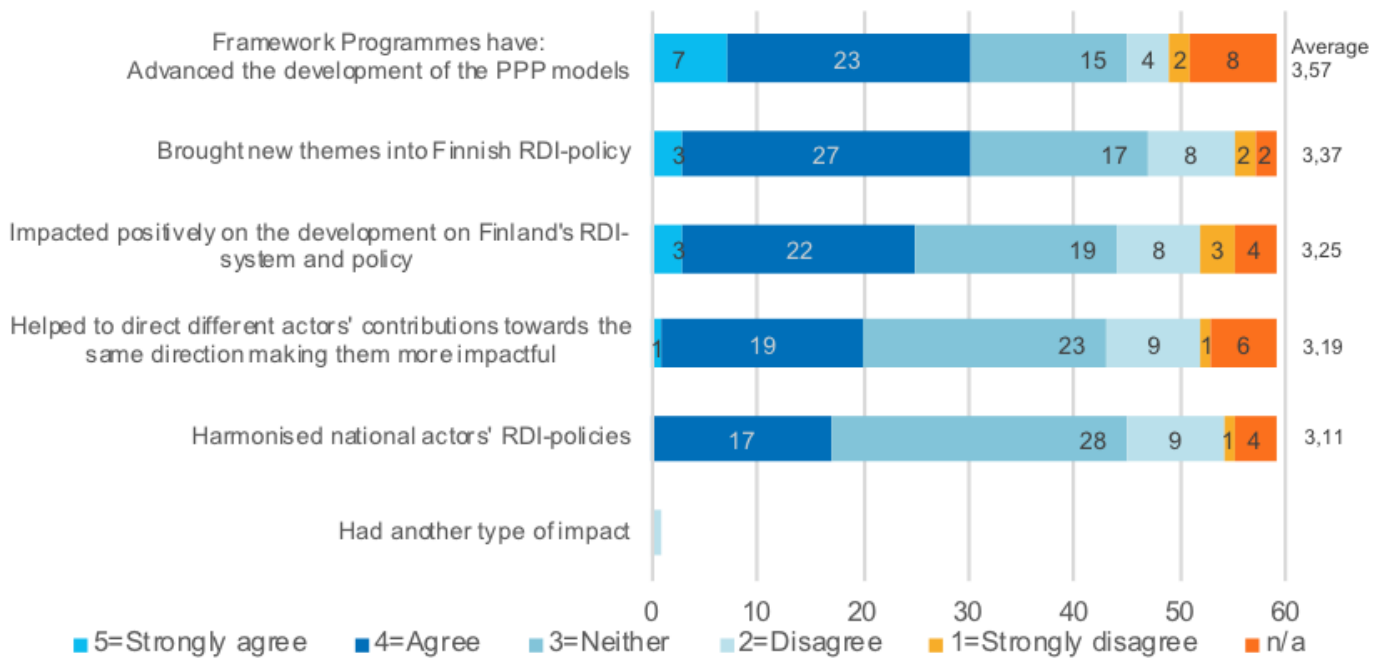

Figure 18 Do you agree with the following positions on FPs impact? N=59

In line with the considered added value of the FPs, the respondents agree most with the stated impact on the creation of new international partnerships for both private sector competitiveness and research. From among 60 respondents 31 strongly agree and 22 agree with the FPs' impact on creating new international research partnerships. Out of 60 respondents 25 strongly agree and 21 agree with FPs' impact also on creating international company partnerships.

\section{Impact on research}

In addition to creating international partnerships (average 4.4 / 5), respondents agree on FPs' role in advancing researchers international mobility (average 4.3) and that they have brought international visibility to the Finnish research. None of the suggested impacts were strongly opposed, but a relatively high number of respondents neither agree or disagree, especially on FPs' impact on collaboration between either research and industry (15) or between different research domains (17), as Figure 19 below shows.

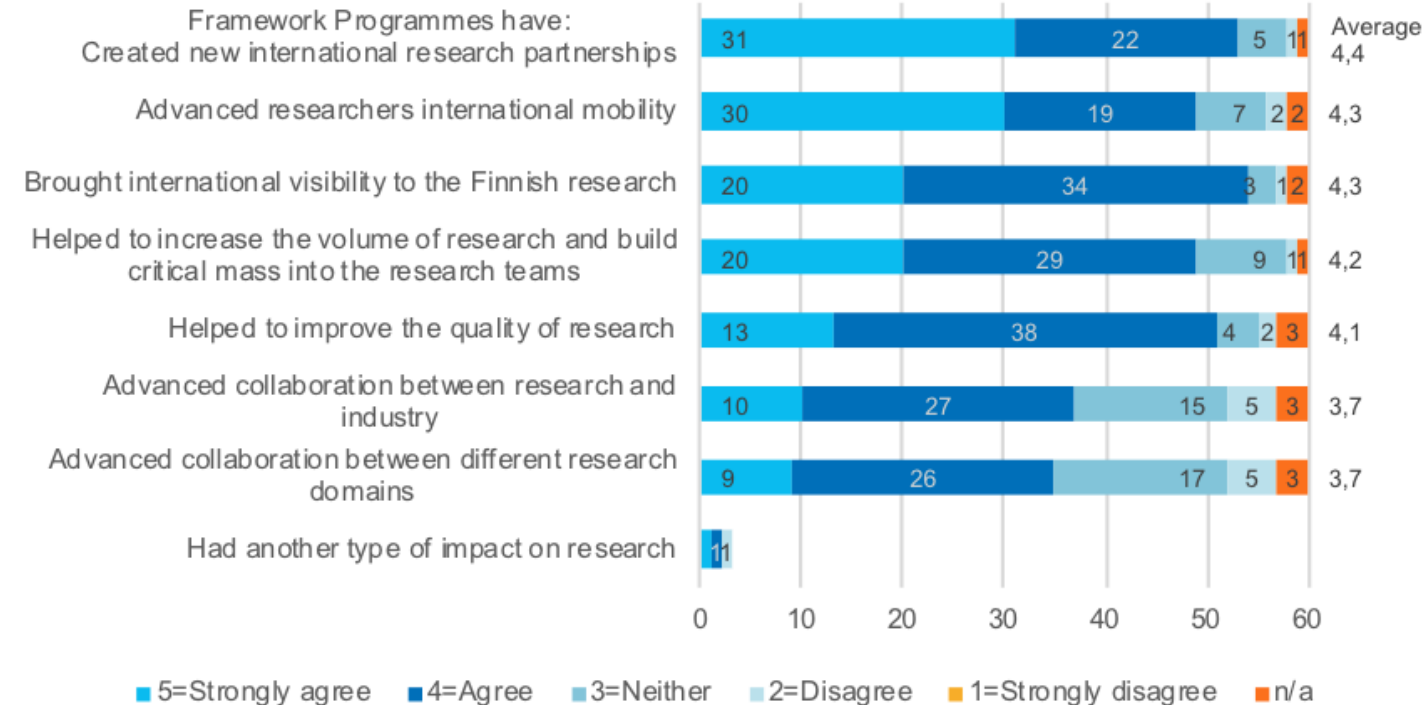

Figure 19 Do you agree with the following positions on FPs impact on research? N=60 
Respondent group -specific responses related to FPs' impact on research are illustrated below in Figure 20, which shows respondent group specific averages on a scale from 1 (strongly disagree) to 5 (strongly agree). In general, all respondent groups are more or less in an agreement with stated positions on FPs impact on research. Because of small totals for respondent groups other than agency, HEls and ministry, no actual comparative analyses can be made between all groups and comparisons therefore are more indicative.

It can be observed that both HEls and research institutes are slightly less in an agreement with FPs' alleged impact on collaboration between research and industry than other respondent groups. Similarly, ministry and research institute respondents seem to agree less than NGOs on FPs' alleged impact on helping to increase the volume of research and to build critical mass into the research teams.

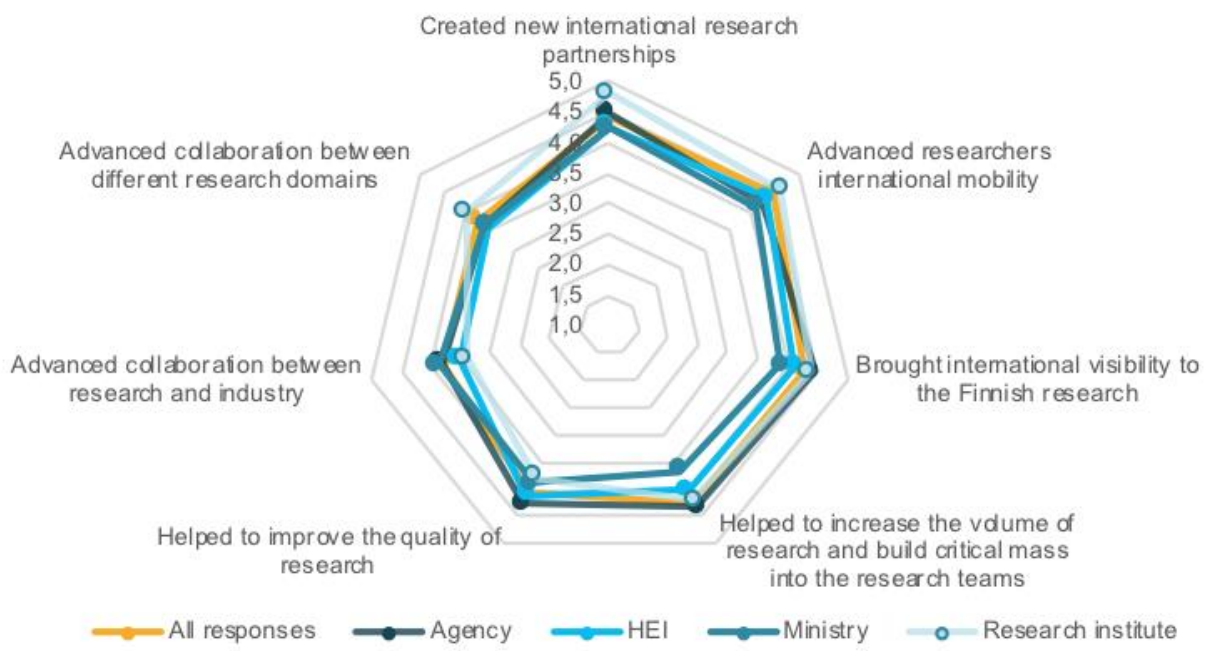

Figure 20 Do you agree with the following positions on FPs impact on research? Comparison between respondent groups. $N=60$

\section{Impact on private sector and international competitiveness}

As Figure 21 shows, in addition to creating international partnerships, the respondents strongly agree (17) and agree (27) on FPs' impact on advancing companies access to international scientific knowledge and research infrastructure. The statement on FPs' impact on advancing companies' access to international distribution, production and other material resources is least agreed, with only 4 strongly agreeing and 15 agreeing with the argument. 


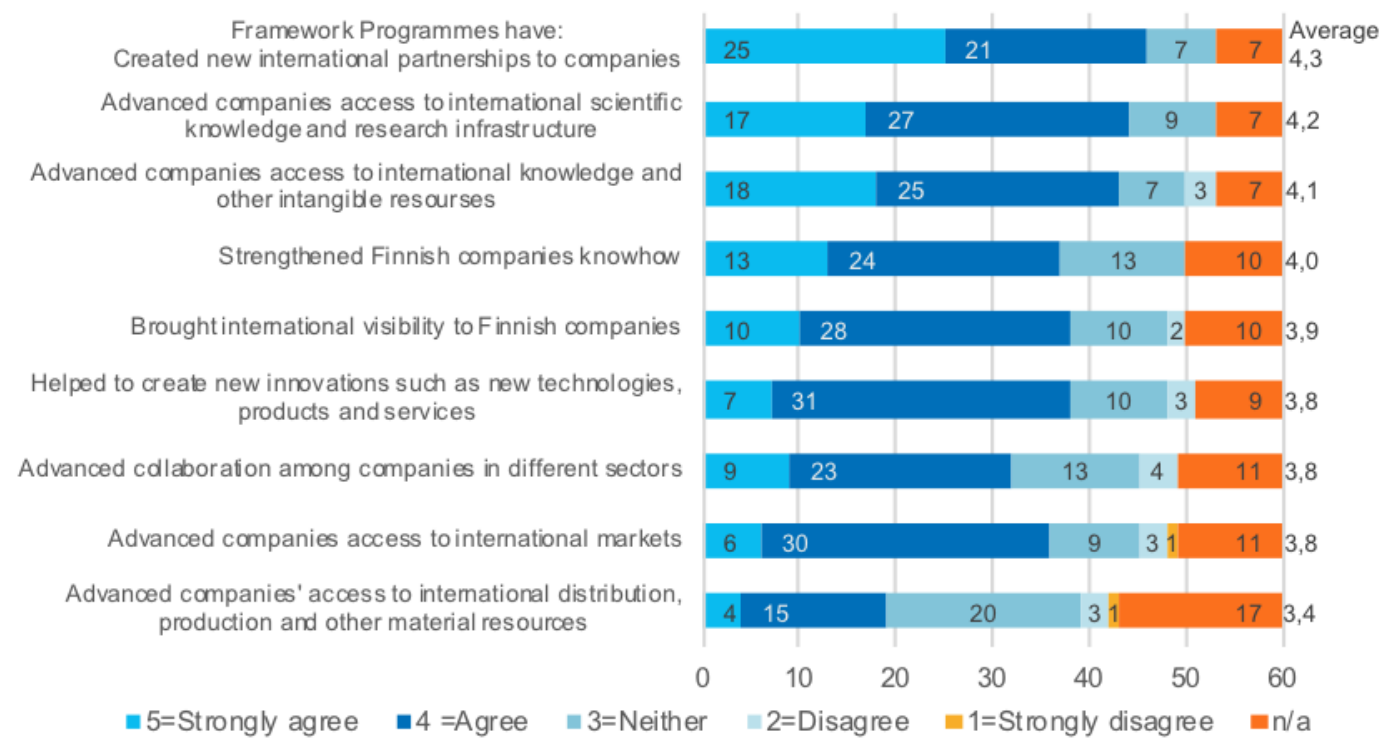

Figure 21 Do you agree with the following positions on FPs impact on companies and their international competitiveness? $N=60$

Slight variation in responses can again be observed when comparing responses between respondent groups, as the following Figure 22 shows.

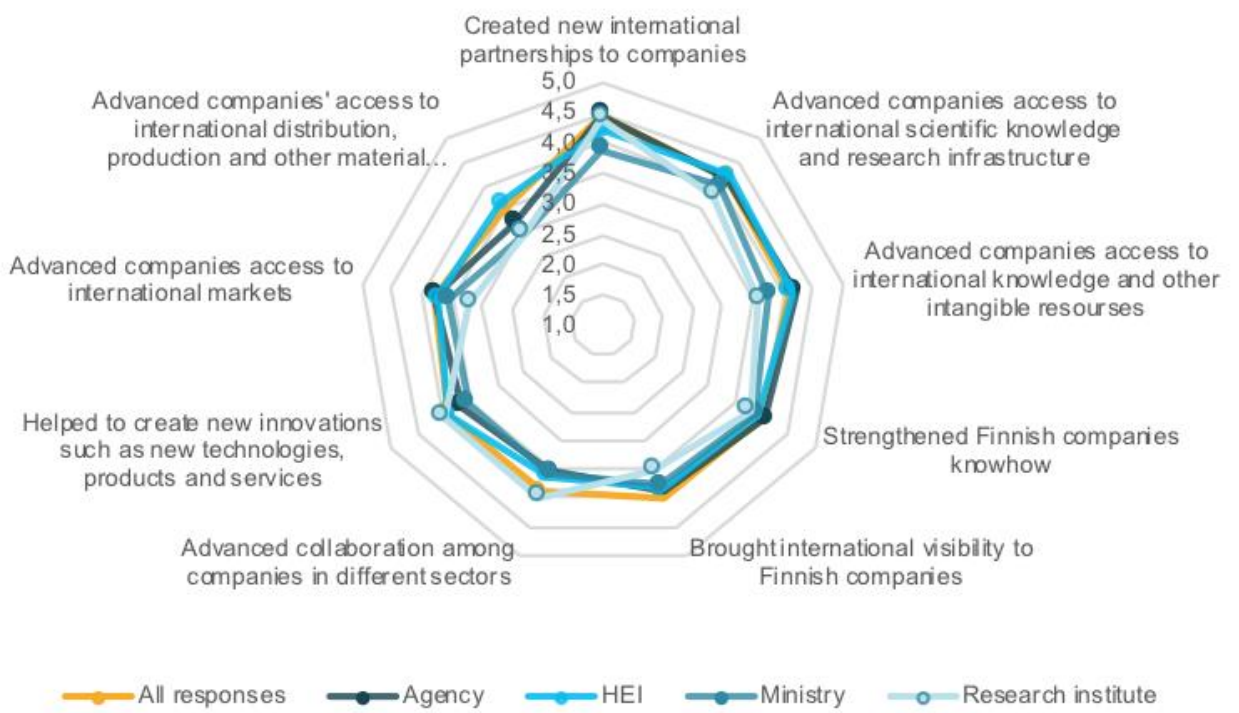

Figure 22 Do you agree with the following positions on FPs impact on companies and their international competitiveness? Comparison between respondent groups. $N=60$ (Scale 1-5)

\section{Improving the FPs for the future}

Related to further development of FPs, their respondents were asked to rate the importance of a number of suggested development measures on a scale from 1 (no importance at all) to 4 (highly important). The list of suggested measures was created based on previously suggested measures to support participation in FPs.

As the following Figure 23 shows, none of the suggested actions received unanimous support. Making the application process faster was, however, considered as the most important way to improve FPs for the future with 20 out of 59 considering it highly important 
and 27 important (average 3.1/4). This development measure is supported by all main respondent groups. The least favourable suggestion is to decrease the number of themes with 31 finding it either unimportant or not important at all.

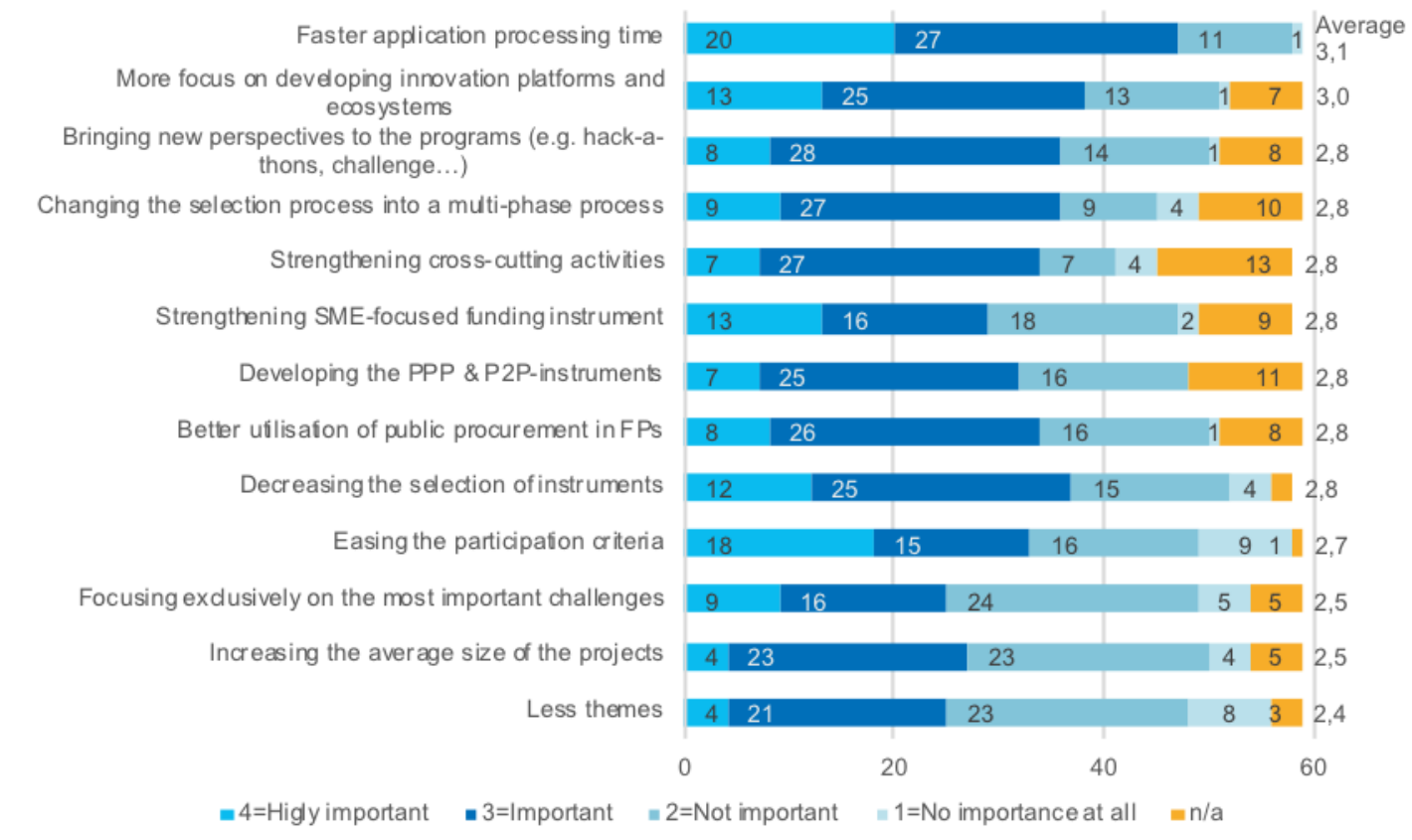

Figure 23 How important you consider the following suggestion on how to improve the FPs? All respondent groups. $N=58-59$

Comparison between the main respondent groups in Figure 24 shows that there are partly clear variations in considerations towards different suggestions. Compared to other respondent groups, agencies find some of the suggested actions more important than others do. For example, 13 out of 18 agency representatives consider easing the participation criteria important or highly important (an average for agency being 3.2 / 4 whereas the total average is $2.7 / 4$ ).

For HEls, the least favourable (average 1.9) way to improve FPs would be to focus exclusively on the most important challenges. The same suggestion is considered among the most important ones by agency respondents (with an average of 3.1). Ministry respondents consider strengthening the cross-cutting themes and changing the selection process into a multi-phase process as the most important ways (average 3.1 for both). Changing the selection process is among the agencies' least supported suggestions (average 2.8). Due to the total number of responses from research institutes, the comparative result is only indicative. It is however interesting to see how low average importance (2.0) the research institute respondents give to the strengthening of the SME instrument. 


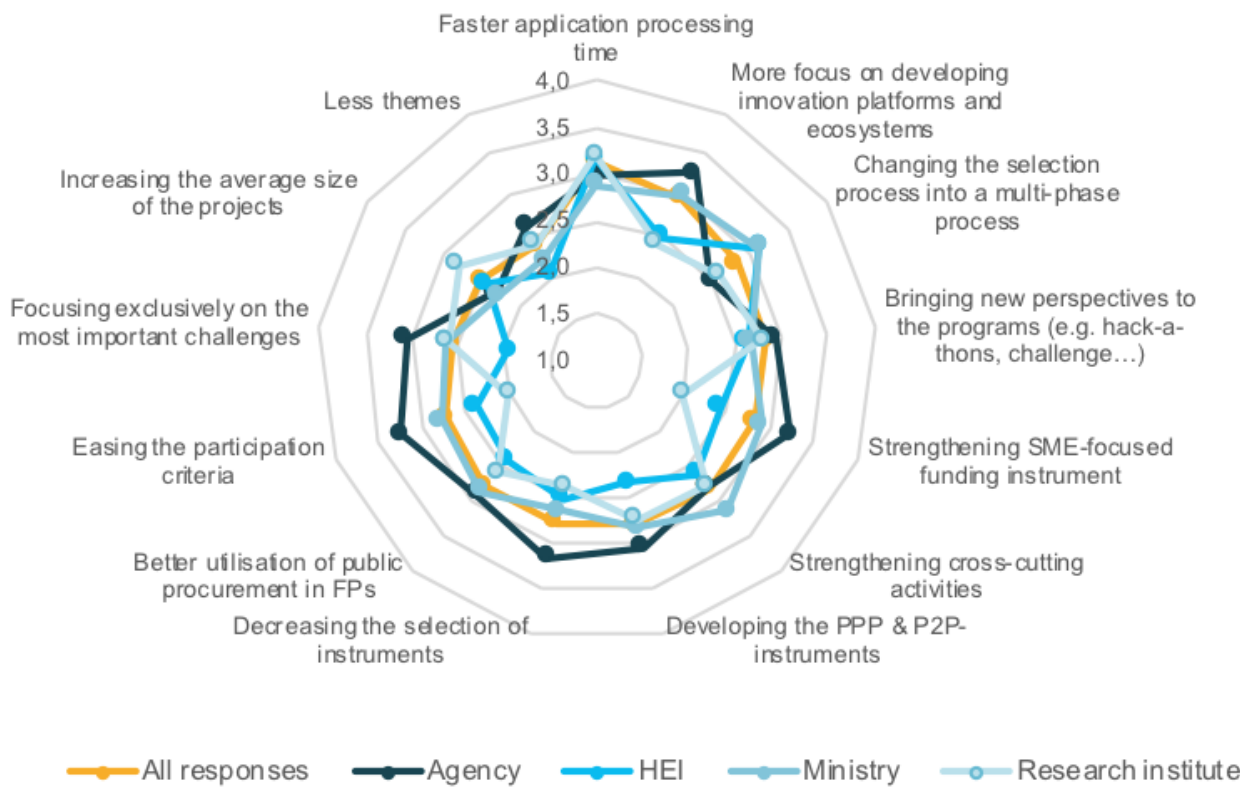

Figure 24 How important you consider the following suggestion on how to improve the FPs? Comparison between respondent groups. $N=58-59$ (Scale 1-4)

\section{Participant survey}

Participant survey was conducted in English. The invitation was sent on 22 May 2017 to 2013 FP-participants. Altogether 146 responses were received (response rate 7.3\%).

The main respondent groups were higher education institutes (HEIs) (47 from universities and 3 from universities of applied sciences (UAS)), private companies (33 responses from companies less than 50 employees, 6 from companies with 50-250 employees, 8 from companies over 250 employees), and 39 responses from research institutes.

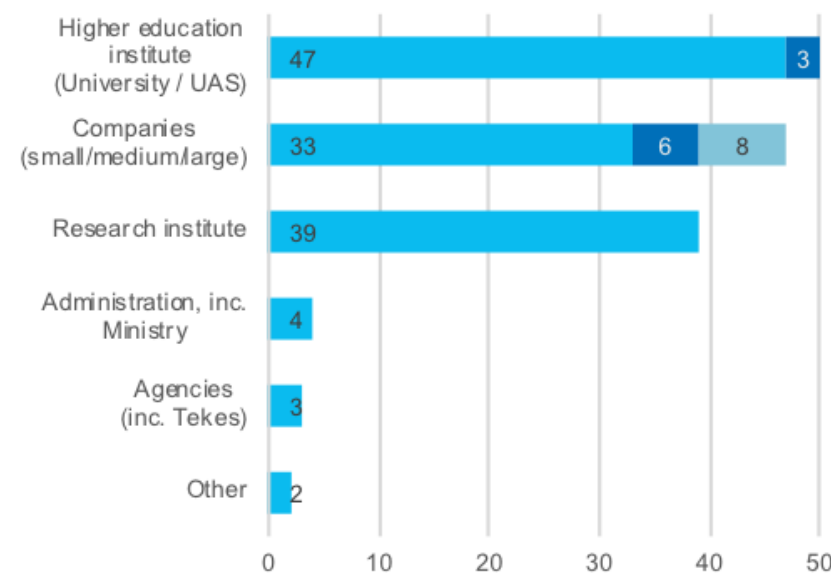

Figure 25 Organisation type. $N=145$

As Figures 26 and 27 show, among the respondents, a large part of the respondents have participated in the current H2020 (104) and the previous FP7 framework programme (110), and many have also participated in the FP6 (55) or even earlier (36). Approximately equally many respondents from HEls (31), companies (35) and research institutions (33) are participating or have participated the current $\mathrm{H} 2020$ programme. 

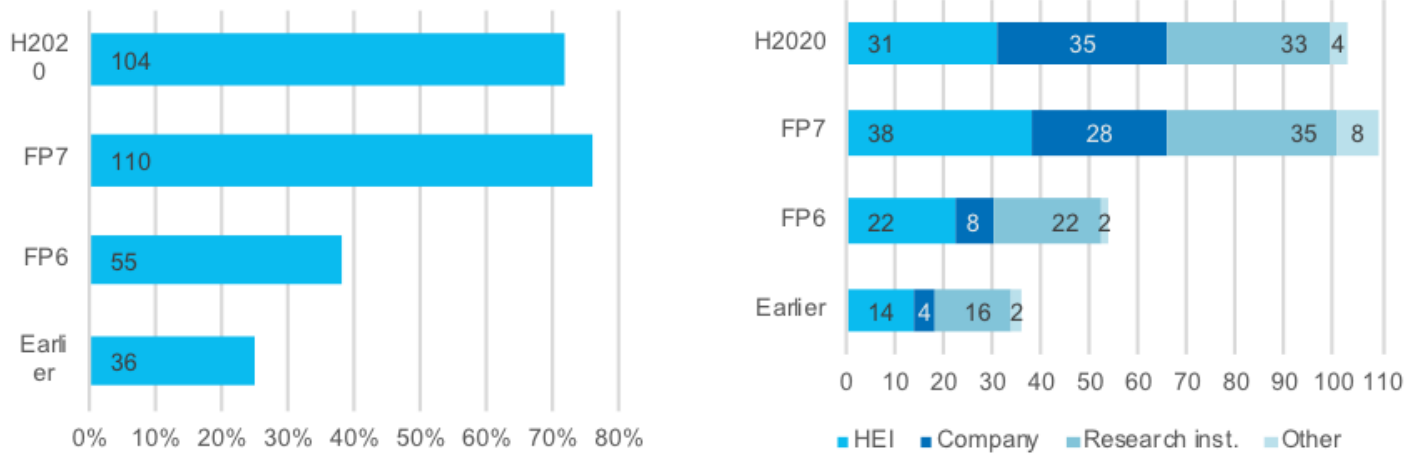

Figure 26 Which FPs have you participated in? Select all that apply. $N=146$

Figure 27 Which FPs have you participated in? Select all that apply. Comparison between respondent groups. $N=146$

About one fourth (27\%) of the respondents have participated in only one FP projects, but almost as many have been part of six or more projects, as Figures 13 and 14 below show. As many had participated in multiple projects, they also had had different roles within them. The primary role of a researcher / participant was selected 82 times, and the task manager WP manager 65 times. Respondents had also held a role as a project coordinator (34 times), principal investigator (33) and administrator / funding coordinator / EU or FP liaison officer (13).
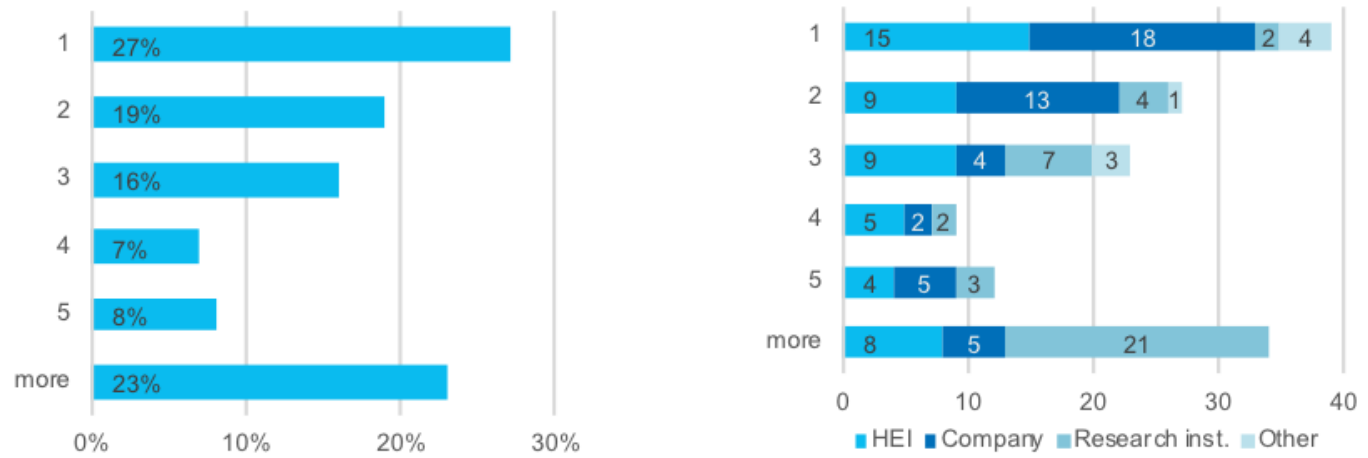

Figure 28 How many individual FP projects have you participated in? N=146

Figure 29 How many individual FP projects have you participated in? Comparison between respondent groups. $N=146$

\section{FPs added value}

The following Figure 30 shows that all main respondent groups consider FPs to have a high additionality for their projects. In total, 92 respondents $(65 \%)$ consider that their project would not have been carried out at all without FP funding, and 28 respondents (20\%) consider that their projects were carried out on a larger scale that what it would have been without the FP funding. 


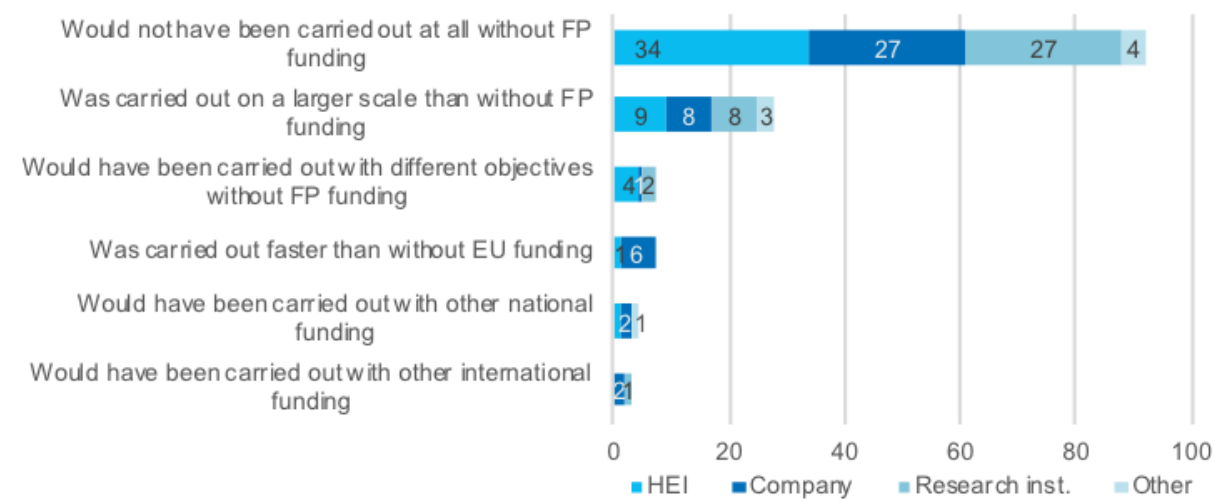

Figure 30 Was the project something you would have done anyway in some way or form? The project ... N=142

According to the respondents, much of the research and innovation activities would not have been implemented without FP funding, as the Figure 31 below shows. The standard deviation of the proportion of research and innovation activities that respondents estimate to have been able to implement without FP funding is $22 \%$ (average 29\%). This is despite the projects' evidently strong linkage to respondents' organisational strategies, as Figure 32 shows.

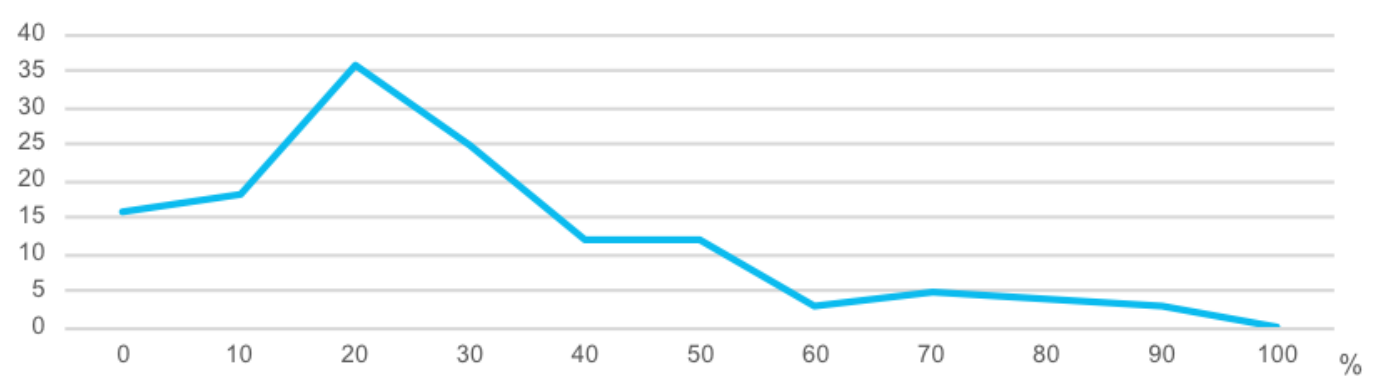

Figure 31 What estimated percentage of these research and innovation activities done under FP you would have done anyway in some way, shape, or form without funding from FP? N=133

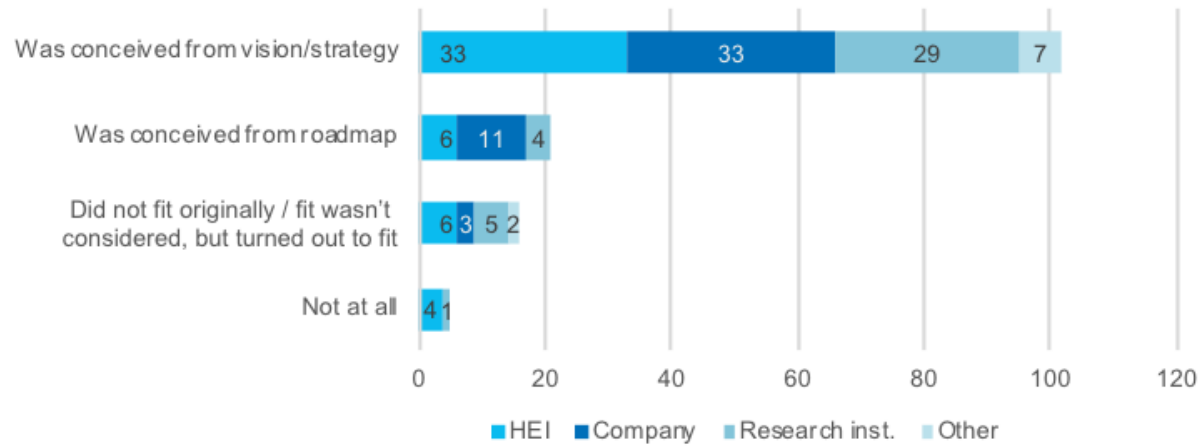

Figure 32 How did the project fit to organisational strategy? N=144

Respondents were also asked to rate the importance of selected aspects against the FPs and rate how well the FP fares on these aspects against the baseline of a relevant national funding from Tekes and the Academy of Finland. Figure 33 shows, that respondents consider access to new knowledge, capabilities and partner networks as well as access to funding and the financial boost given by the programme as the most important aspects. These are closely followed by contribution to shaping strategy and access to infrastructures. 


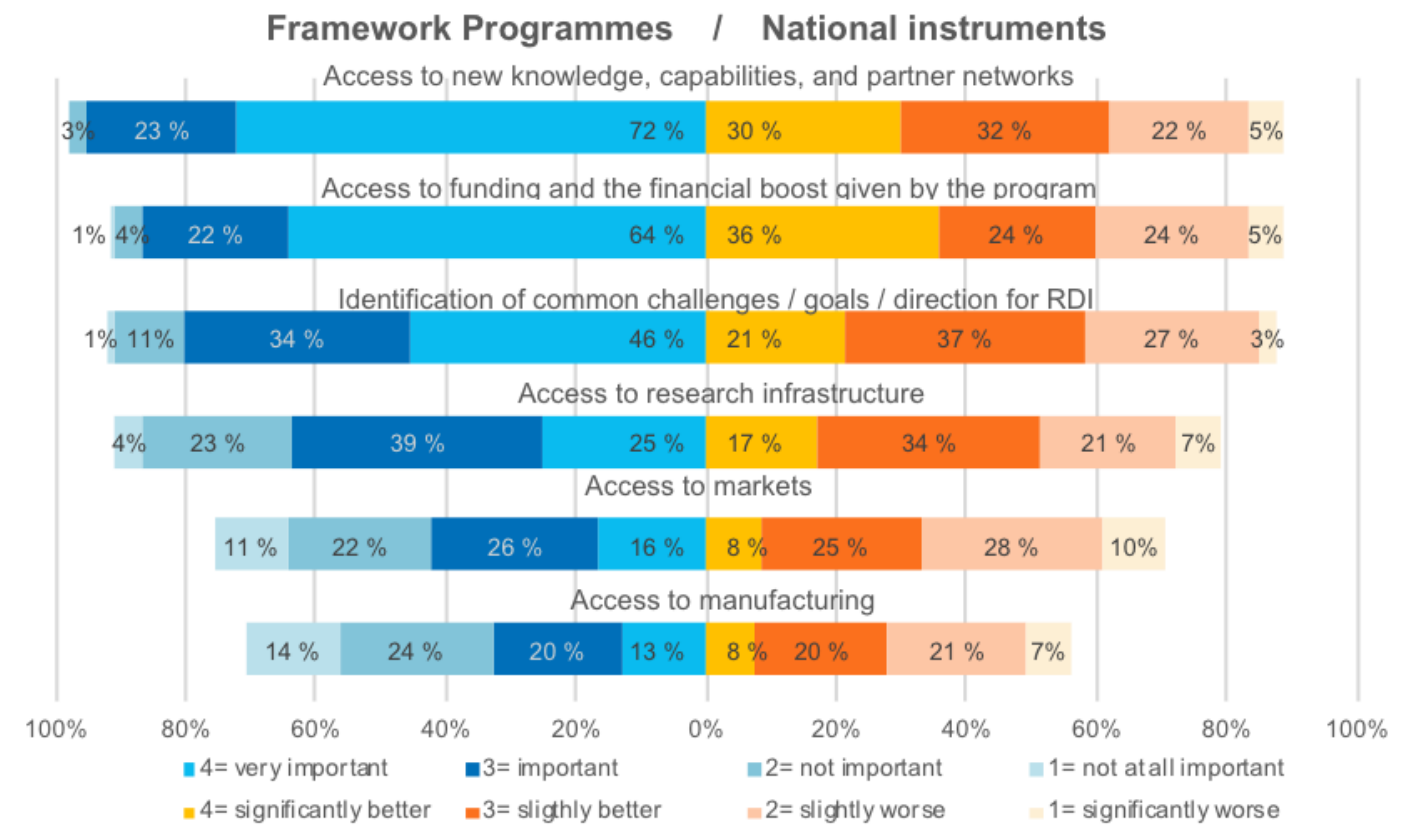

Figure 33 How important are the following aspects of the programs for reaching the goals set for participation?

\section{Implementation of projects}

Respondents were asked to select three most relevant objectives for participating in the FPs. Similar to experts, participants also consider the formation of international networks important and as the primary goal in participating the FPs (altogether 87 respondents selected this option, see Figure 34 below).

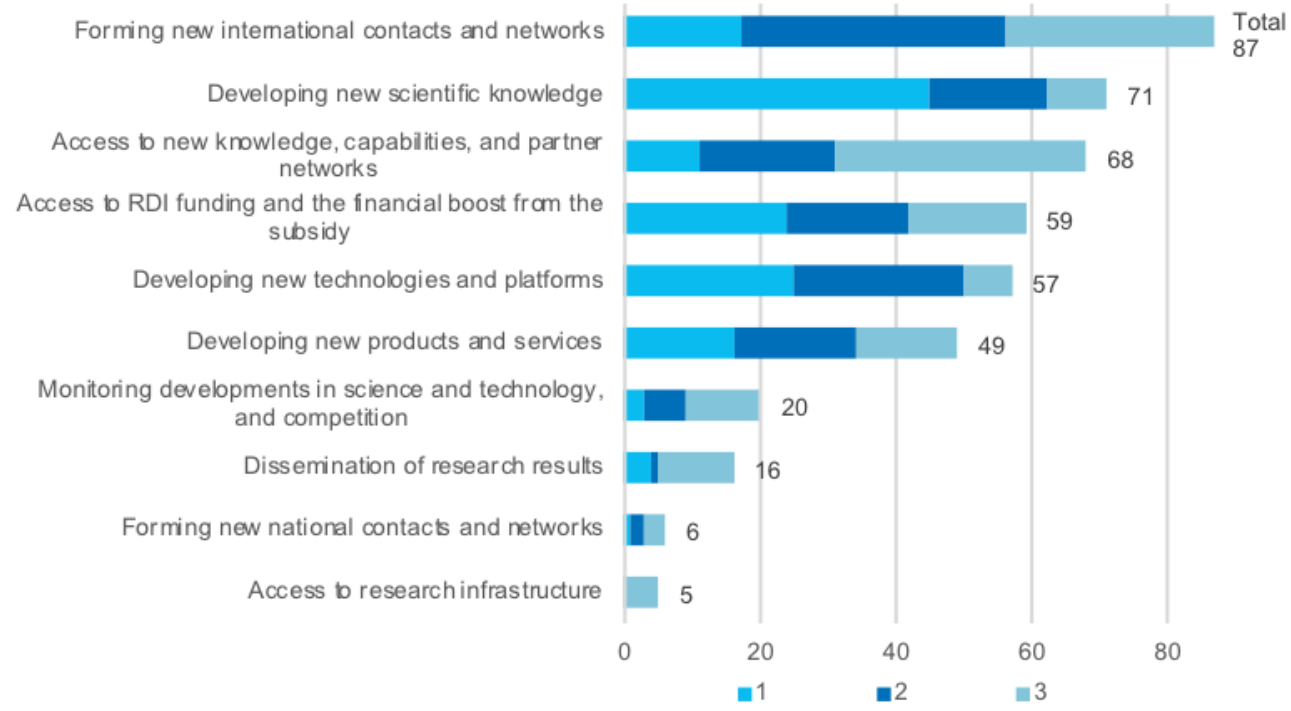

Figure 34 What were your primary goals for participating in the FPs? Please select three most relevant goals? Respondents $N=146$, responses $N=438$

Differences between respondent groups can be observed below. Although all main respondent groups value the formation of international networks as one of their primary goals within FPs (HEls $34 / 50$, companies $23 / 47$, research institutions 22/39), the main goal for companies is still the development of new products and services (28) as well as technologies and platforms (26), and for research institutes the development of new scientific knowledge (27), which is just about the highest for HEls as well (35). Interestingly 
the access to research infrastructure and dissemination of research results are among the lowest on the list, also for the research institutions.

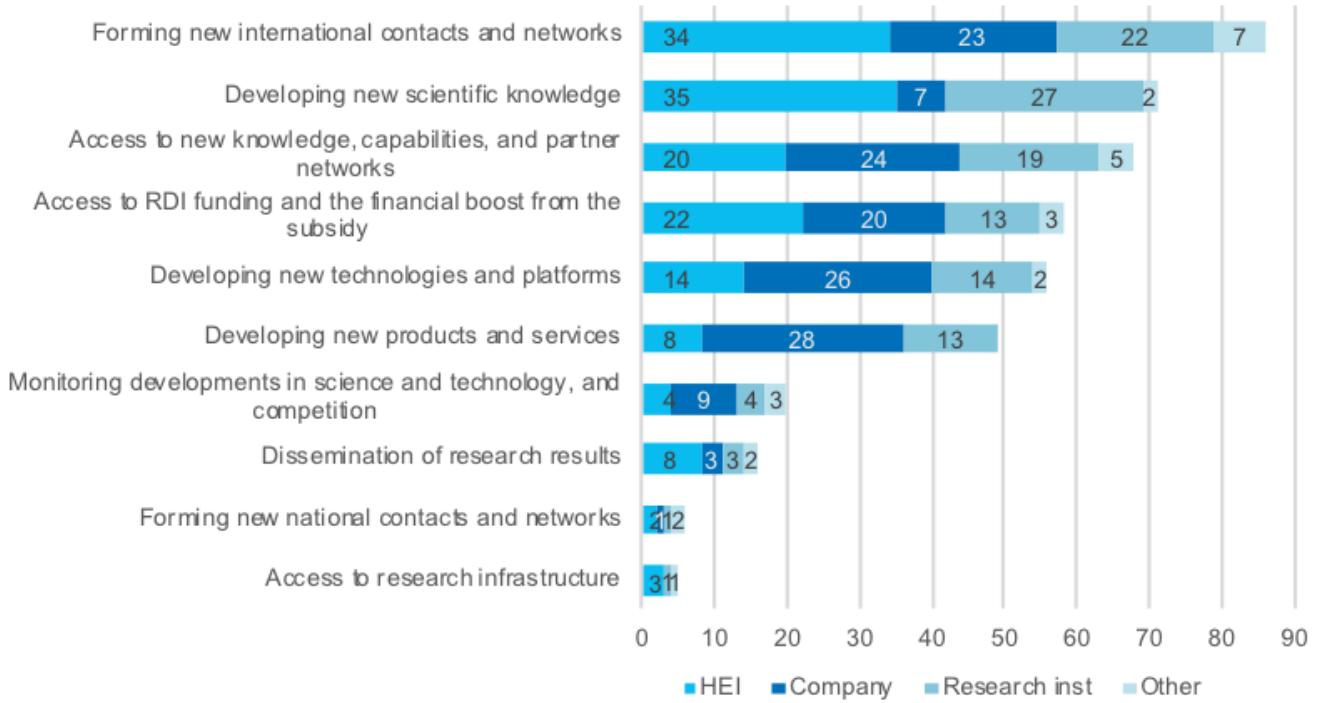

Figure 35 What were your primary goals for participating in the FPs? Please select three most relevant goals? Comparison between the respondent groups. Respondents $N=145$, responses $N=435$

The respondents were asked to assess how well their projects had achieved the goals set for them in a scale from 1 (not at all, the resources spent by the project were wasted) to 7 (the project met and / or exceeded all goals and expectations. As Figure 36 shows, altogether $71(49 \%)$ respondents selected the figure 6 indicating a high level of goals being achieved in the implemented projects, but some room being left for further improvement. Research companies, especially assess their projects' goals being achieved well, with number 5 being the lowest response. Not all projects however have achieved their goals, but none of the respondents consider money being totally wasted. In average company representatives assess weaker achievement of the goals. However, almost equally many company representatives responded with the highest number 7 (7 responses) and with midvalue number 4 (8 responses).

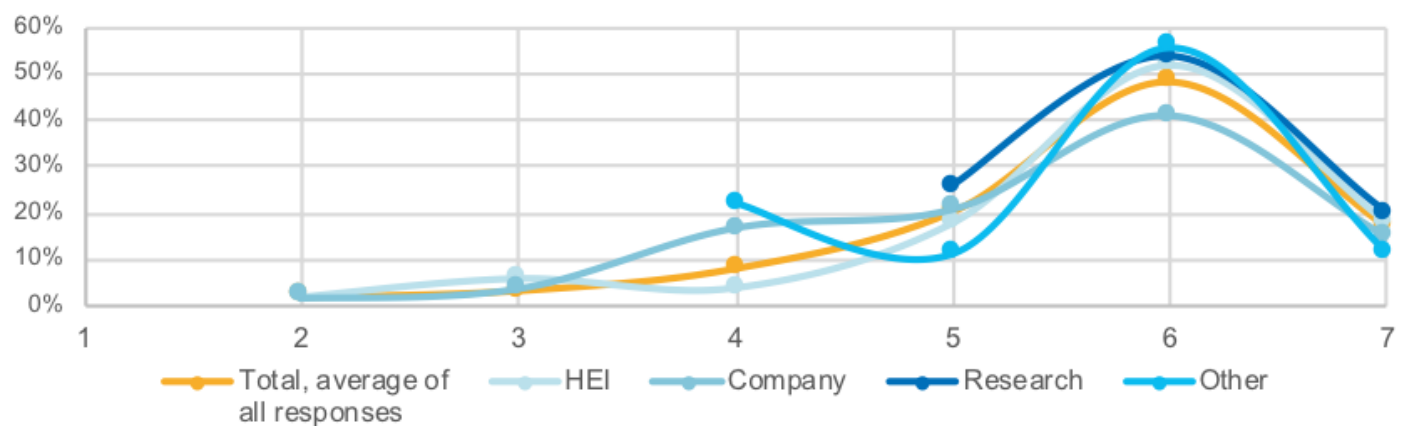

Figure 36 Did you achieve the goals set for the project/participation? N=145. Scale 1-7;

$1=$ Not at all, the resources spent by the project were wasted, $7=$ The project met and $/$ or exceeded all goals and expectations.

According to the respondents their main difficulty had concerned partners who have had problems delivering on time and quality ( 45 out of 111 respondents). The next Figure 38 below shows that this is the challenge especially according to the respondents from research institutions (34\% of research institute respondents selected this option). Secondly, the data availability and / quality cause challenges according to 35 respondents, and 30 respondents consider it as a challenge that project partners have their own agendas for the 
common project. Among the respondents representing HEls and other respondent groups (incl. ministries and agencies) selected this option more often, $19 \%$ and $25 \%$ respectively within the respondent group. The choice of partners per se was still not considered as the success impeding factor more than by 10 respondents, which tells that the difficulty may lay in the cooperation and communication between the partners.

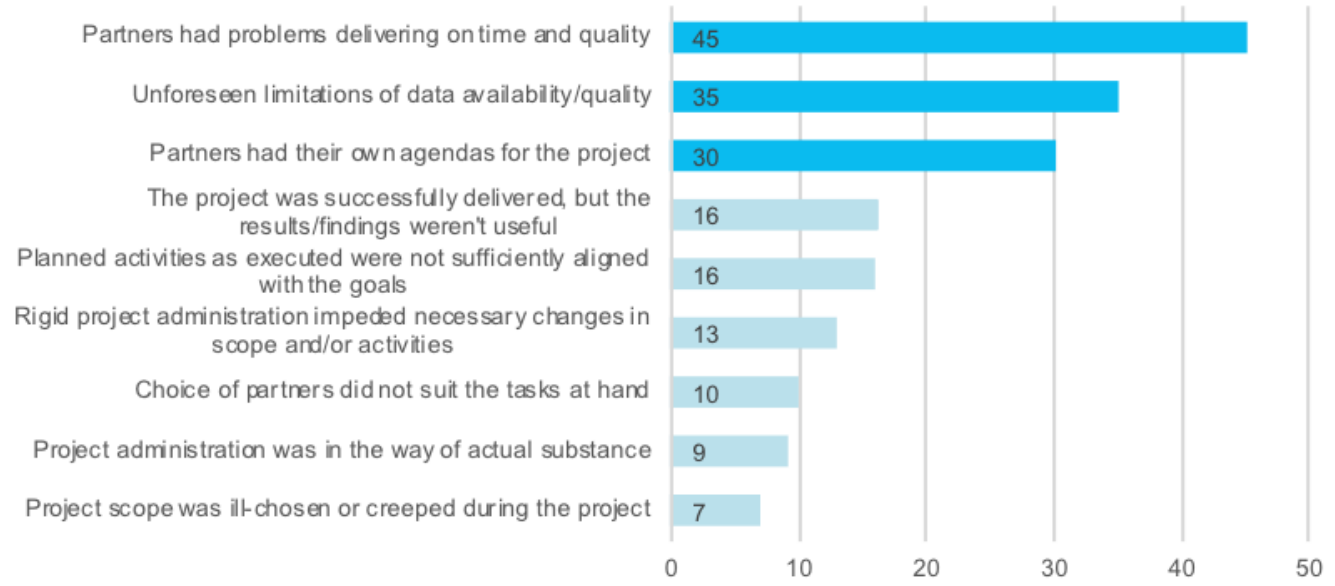

Figure 37 What were the main challenges / factors impeding success? All responses. Respondents $N=111$, responses $N=181$

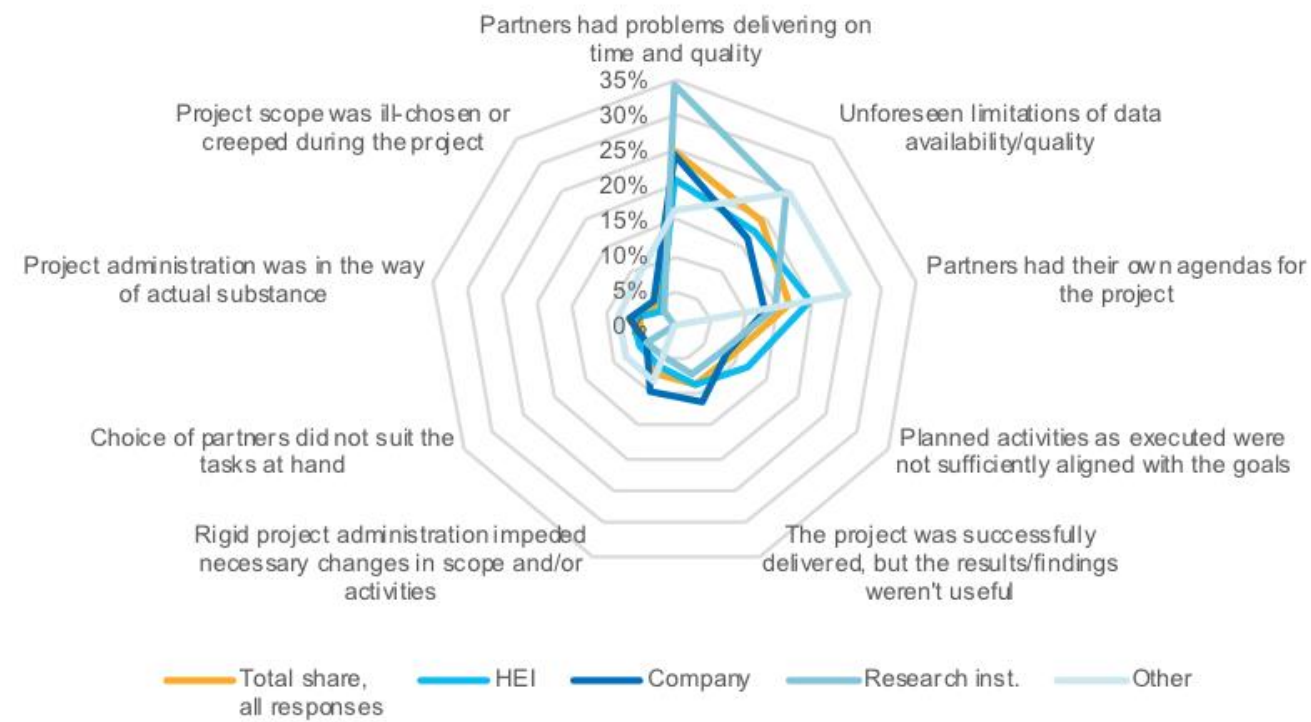

Figure 38 What were the main challenges / factors impeding success? Comparison between respondent groups. Respondents $N=111$, responses $N=181$

Regarding the success factors, three are again above the other suggestions, as the Figure 39 shows. Functioning partnership seems equally much as the success factor as the nonfunctioning is the success impeding one. Altogether 91 respondents consider the partners' commitment to the project goals and plan being as the main success factor, which is just about as many as those (92) who considered the well-chosen project scope as the success factor. The third success factor is that the planned activities were well-aligned with the goals, which was selected by 71 respondents. Slight variations among respondent groups can also be observed in Figure 40. 
Project scope was well-chosen and stable throughout

The partners were committed to the project goals and plan

Planned activities were well-aligned with the goals

Project administration supported achieving the goals Choice of partners were ideally suited to execute the tasks towards the goals

Project administration enabled necessary changes in scope and/or activities

Data availability/quality were not a problem

Partners delivered on fme and quality

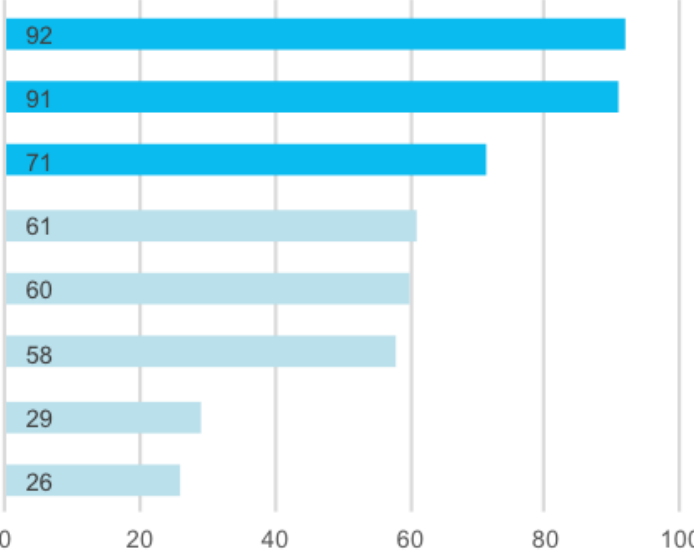

Figure 39 What were the main factors that contributed to the success of the project? Respondents $N=144$, responses $N=488$

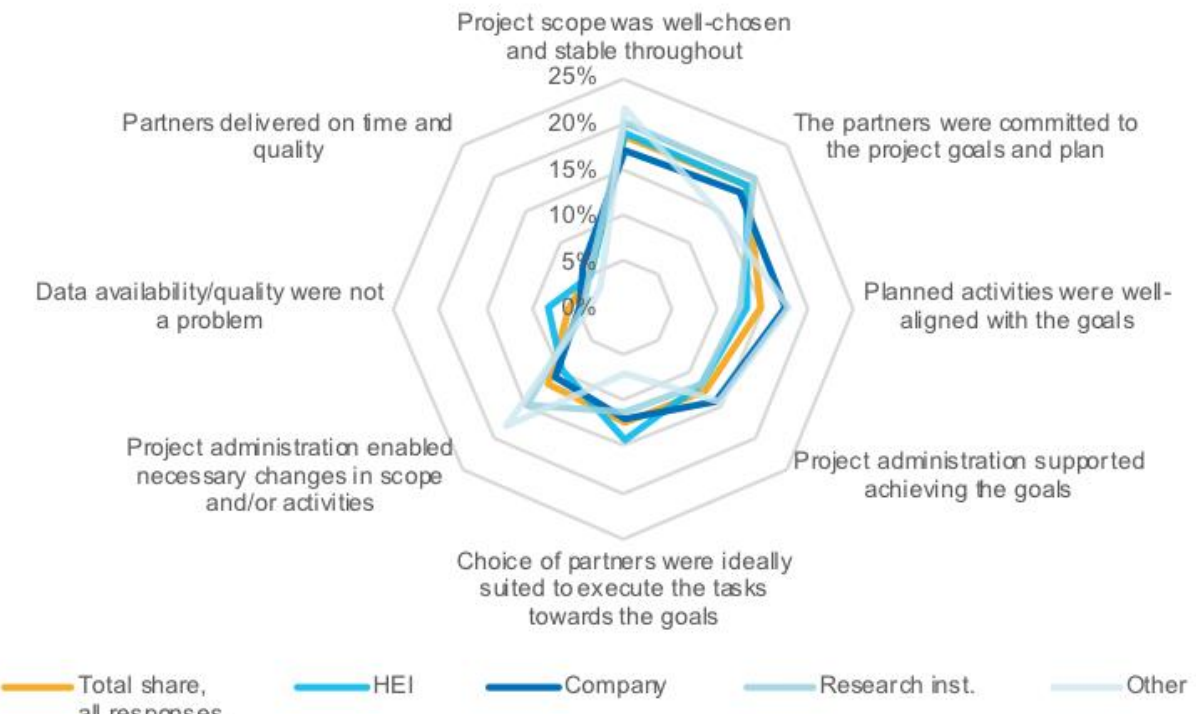

Figure 40 What were the main factors that contributed to the success of the project? Comparison between respondent groups. Respondents $N=144$, responses $N=488$

\section{Improving the FPs for the future}

Similar to experts, participants would improve the future FPs by making the application process faster (altogether 103 agree), as the Figure 41 shows. Increasing bottom-up nonthemed calls and funding is also supported (76 agree). On the contrary, participants wish not to see the focus becoming exclusively on Grand Challenges (85 disagree). 

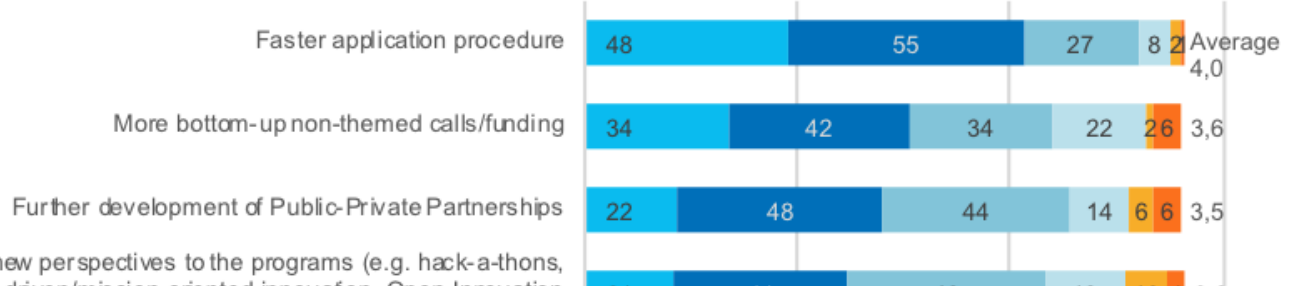

Bringing new perspectives to the programs (e.g. hack-a-thons, challenge driven/mission oriented innovation, Open Innovation processes)

Strengthening SME-focused funding instruments

Multi-phase application procedure

Strengthening cross-cutting activities (presently Circular Economy, Internet of Things, and Smart and Sustainable Cities)

Bringing/linking innovative public procurement into FPs

More mission-oriented/top-down calls/funding

Fewer types of funding programs/forms of participation

More focus on developing innovation platforms and ecosystems

Loosening the criteria for participation
Less themes
Increase in average projectsize

Focus exclusively on the most important challenges (Grand Challenges)

\begin{tabular}{|c|c|c|c|c|c|}
\hline 21 & 41 & & & \multicolumn{2}{|c|}{1} \\
\hline 26 & 26 & 48 & 22 & 10 & 9 \\
\hline 21 & 40 & 32 & 33 & & 1 \\
\hline
\end{tabular}

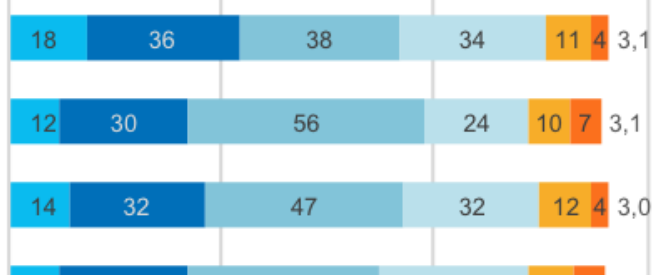

\begin{tabular}{|c|c|c|c|c|}
\hline 12 & 30 & 45 & 35 & 117 \\
\hline
\end{tabular}

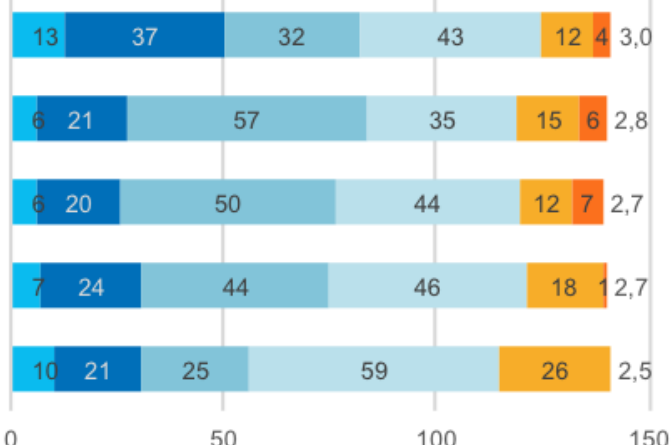

50

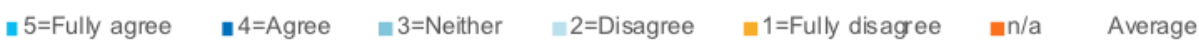

Figure 41 Indicate your agreement with the following proposal to improve FP structure for better impact? Scale 1 (fully disagree) -5 (fully agree). $N=139-141$

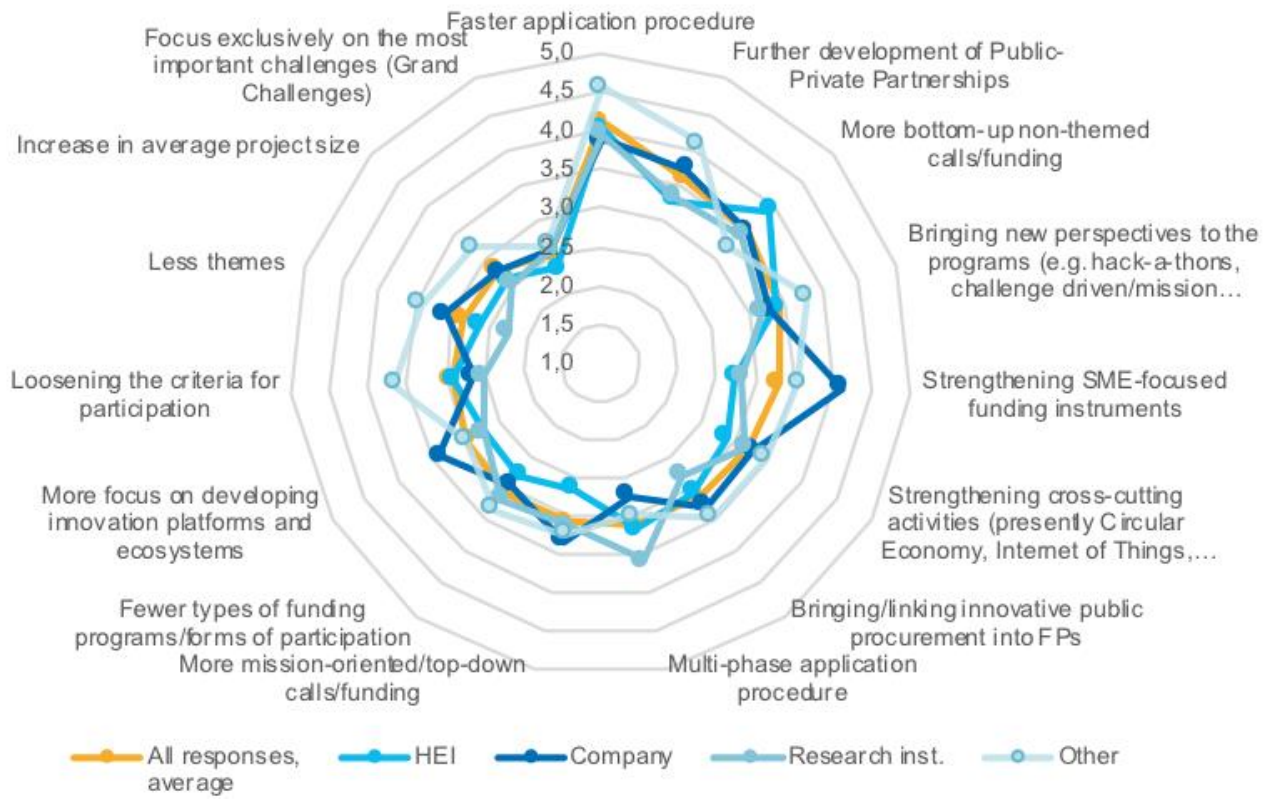

Figure 42 Indicate your agreement with the following proposal to improve FP structure for better impact? Scale 1 (fully disagree) -5 (fully agree). $N=139-141$ Comparison between respondent groups 


\section{Outcomes and impact}

According to respondents, the most significant outcomes are associated with new skills and knowledge, followed by new partnerships or networks. These are closely followed by scientific publications and new strategic directions. These outcomes are very stable across participant groups, the largest difference is in commercial outcomes where research organisations typically have seen less of those.

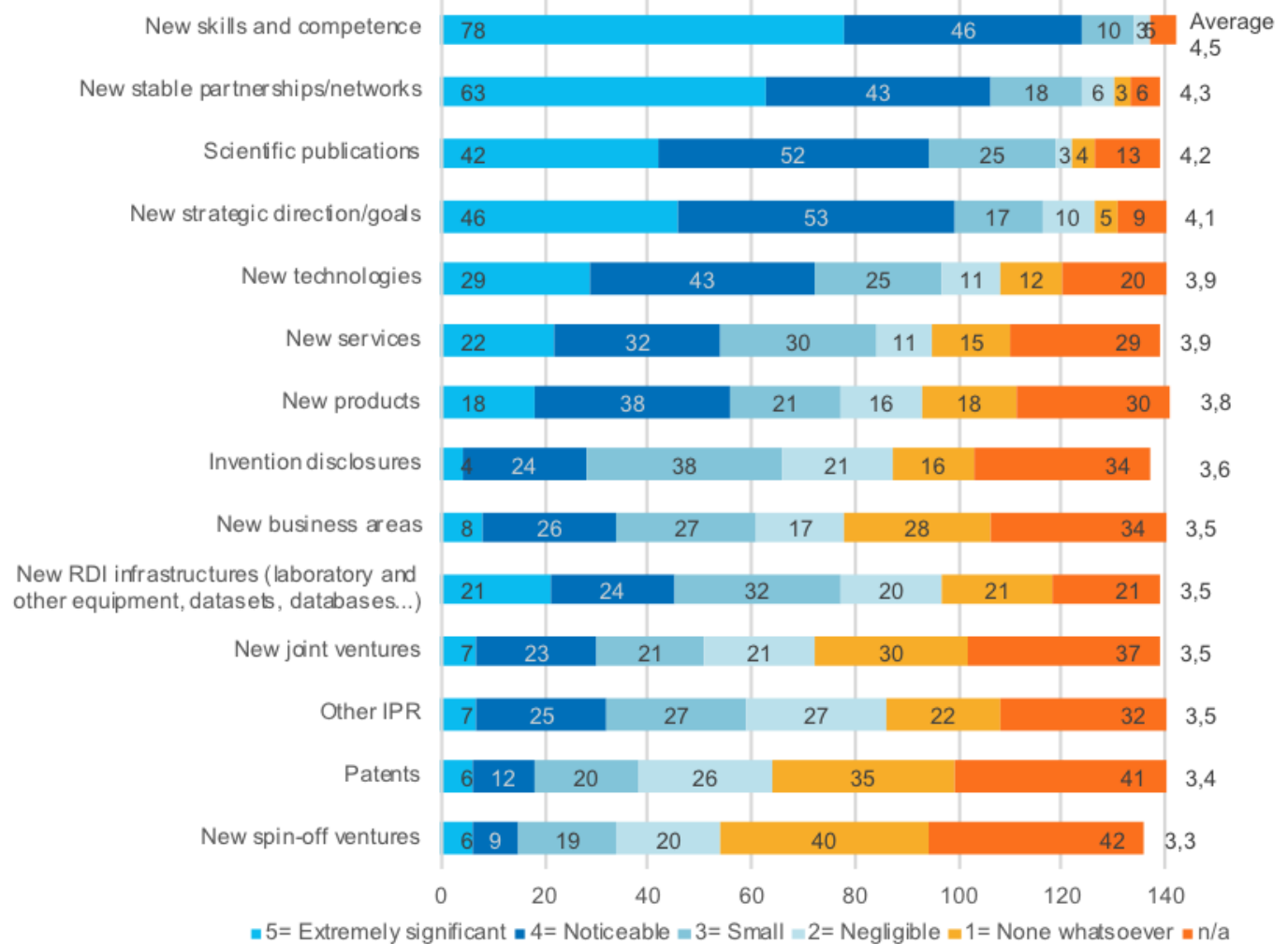

Figure 43 Outcomes that can be attributed to projects funded by EU FPs during and after the funding period. $N=136-142$

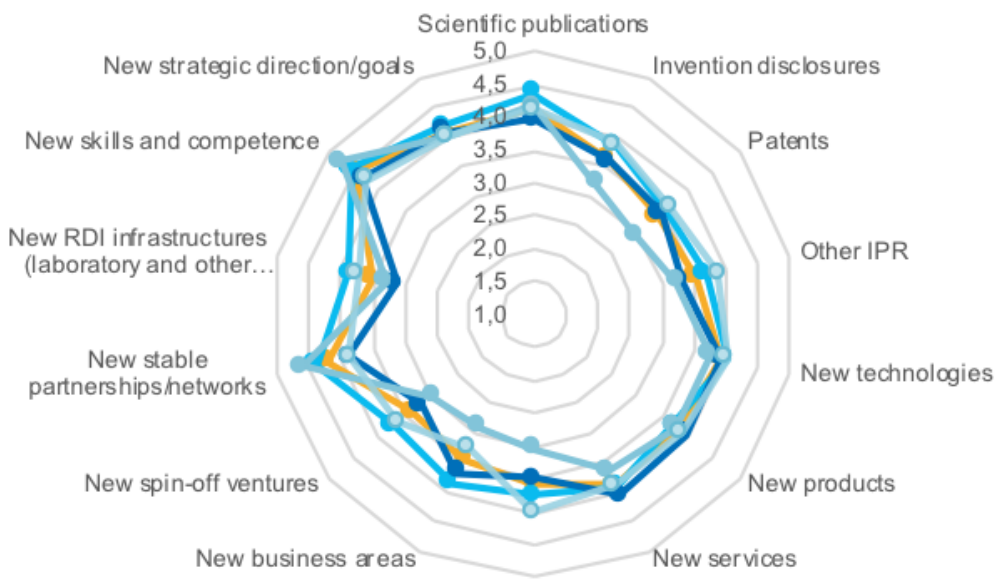

New jaint ventures -All responses, $\longrightarrow \mathrm{HEI} \longrightarrow$ Company $\longrightarrow$ Research inst. $\quad$ Other

Figure 44 Outcomes that can be attributed to projects funded by EU FPs during and after the funding period. Comparison between respondent groups.

In the longer view, the self-reported impact is rather heavily academic, as three out of the top five are related to increase in high-quality publications and citations, see Figure 42. 
However, employment and contribution to solving European societal challenges are number 3 and 4 , which indicates a relatively significant social impact as well. The respondent groups are in relatively close agreement except in terms of employment and revenue.

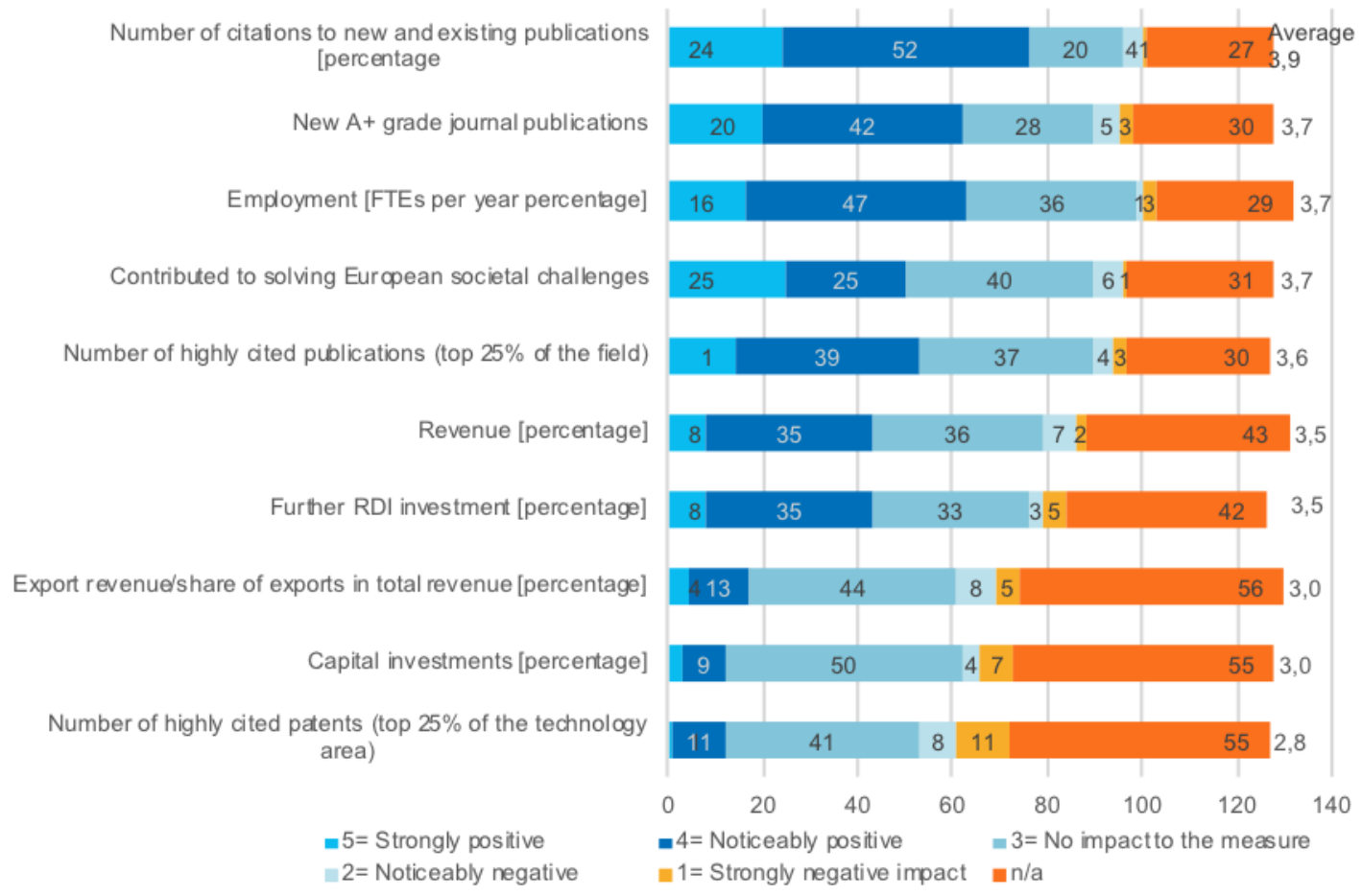

Figure 45 Impact of FP participation. Please give your best estimate of the net effect of FP participation, increase (or decrease) in the following measures. $N=126-132$

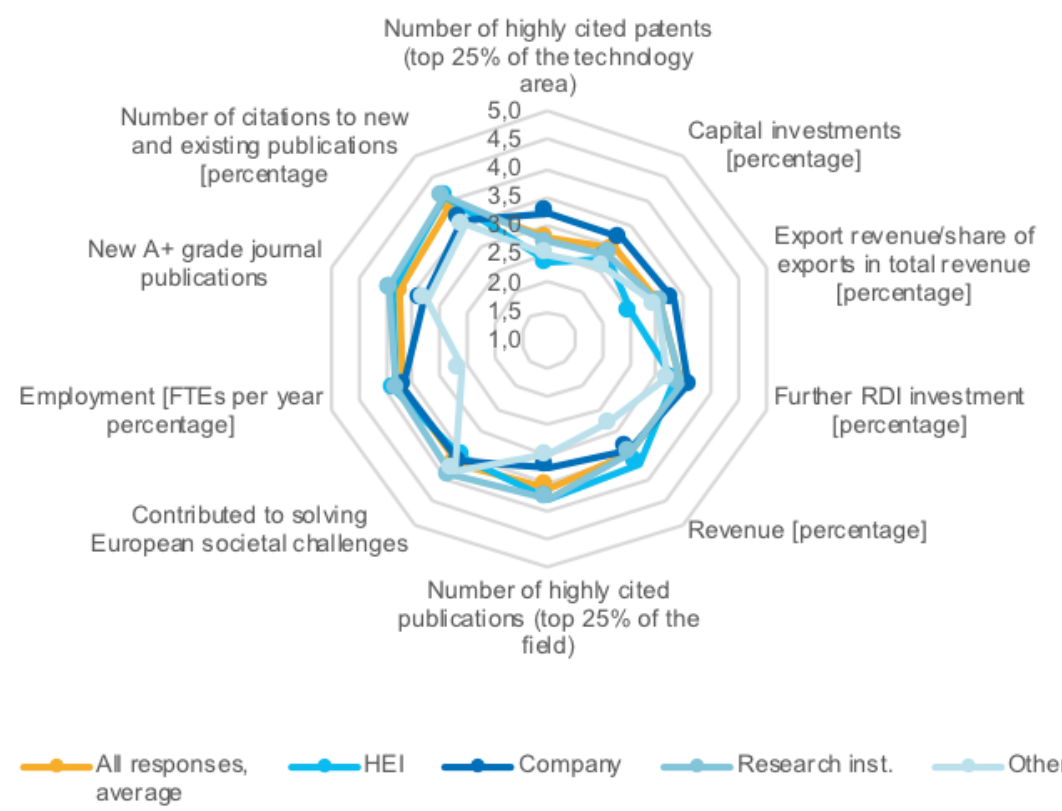

Figure 46Impact of participation, comparison between respondent groups. 


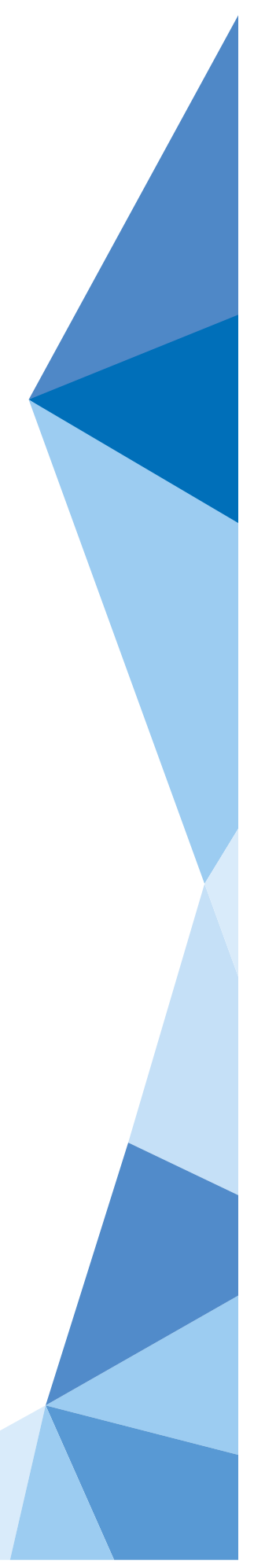

VALTIONEUVOSTON

SELVITYS- JA TUTKIMUSTOIMINTA

tietokayttoon.fi

technopolis sroupl $_{\text {rat }}$

4FRONT

ISSN 2342-6799 (pdf)

ISBN 978-952-287-511-2 (pdf) 